

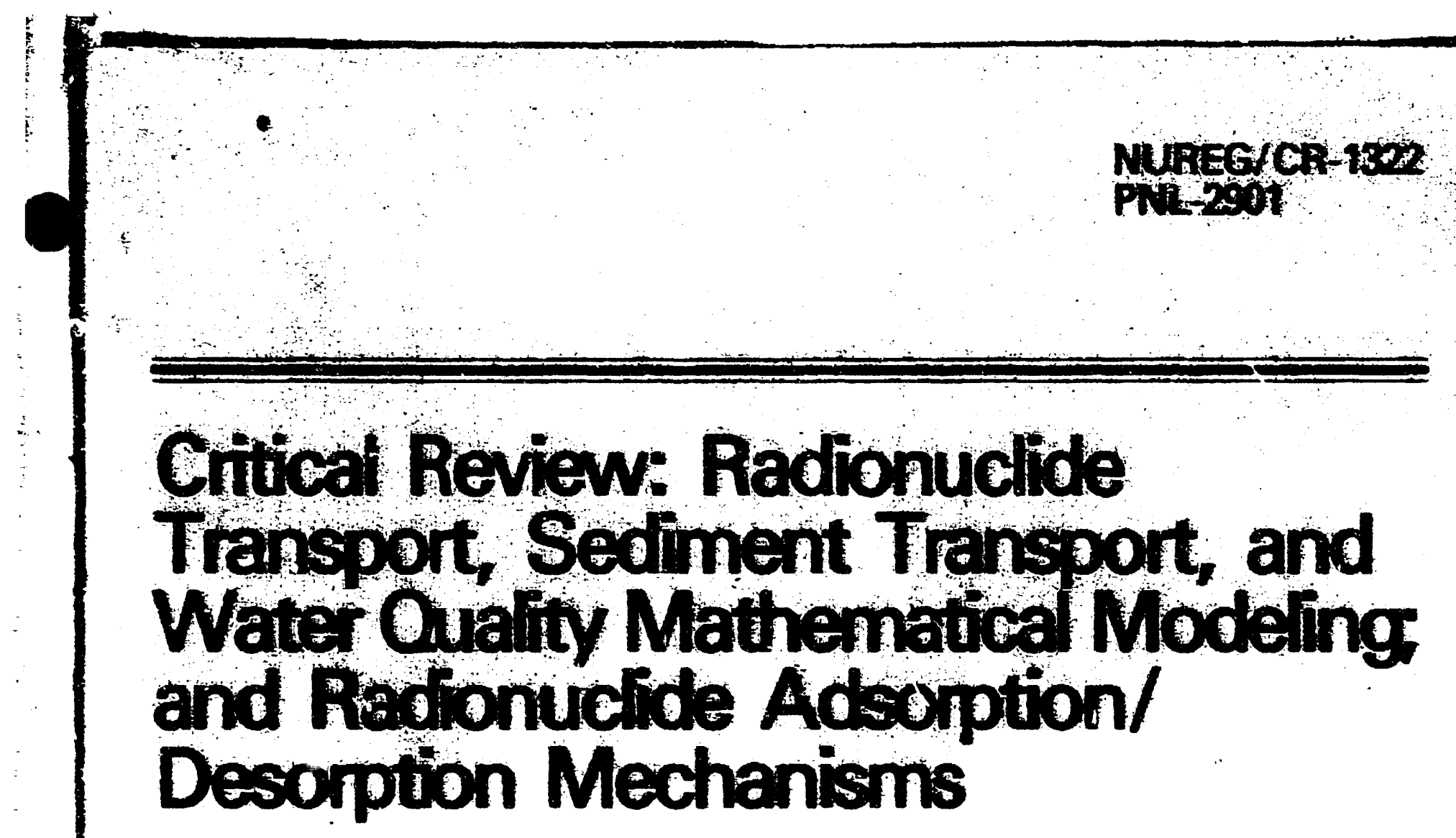

Propered by Y. Oriati, R. J. Some, E. M. Anold, C. E. Comen, D. L. Thompeon

Pectile northweet Lboretery

Operead by

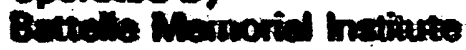

Preporod ter

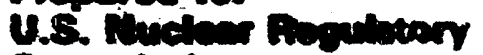

Cocuniserten

nomerar

NATIONUL TECHNICAL

INFORMATION SERVICE

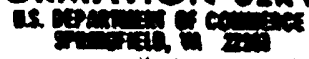

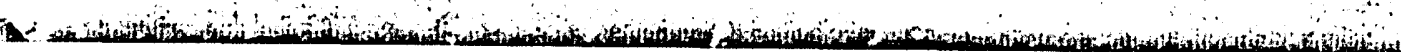



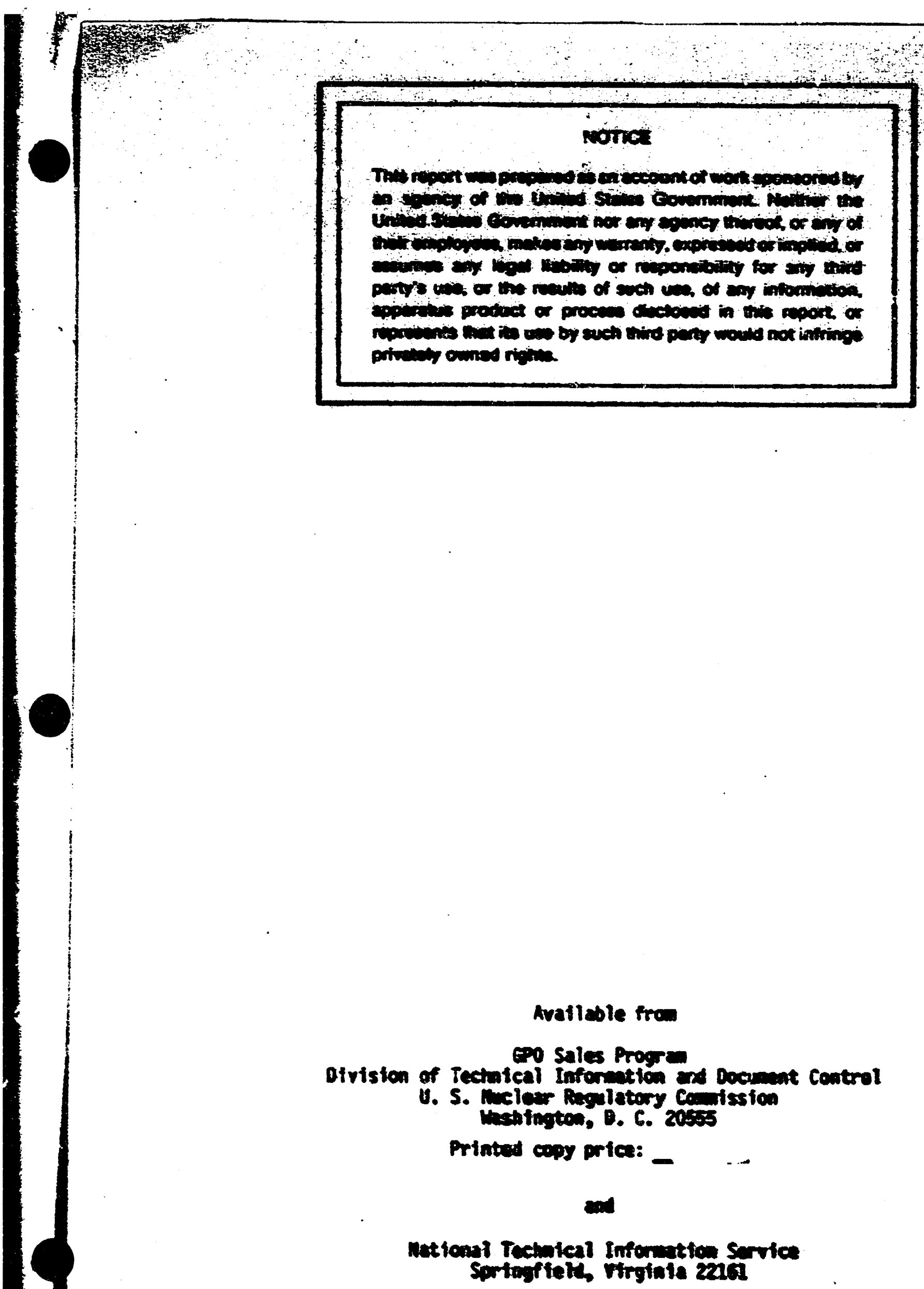


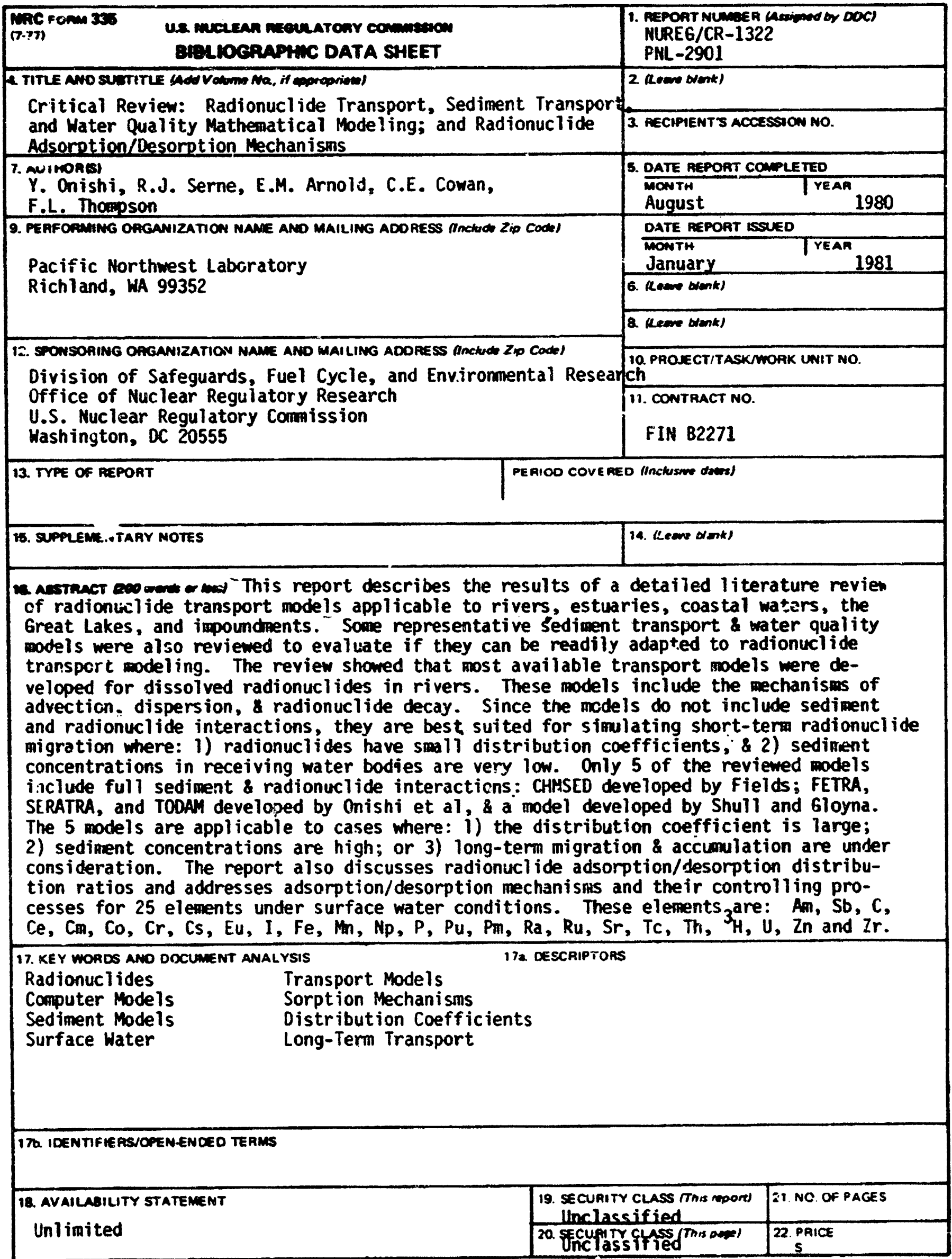

4ne fonven 235 (7.27) 
NUREG/CR-1322

PNL-2O01

RE

\section{Critical Review: Radionuclide Transport, Sediment Transport, and Water Quality Mathematical Modeling; and Radionuclide Adsorption/ Desorption Mechanisms}

Manuscript Complecedt August 1980

Date Publiched: Jamiary 1981

Prepared by

Y. Onishi, R. J. Serne, E. M. Amold, C. E. Cowen, F. L. Thompson

Pacific Northwest Laboratory

Richland, WA 9852

Prepared for

Divinion of Safoguards, Fuel Cycle and Emvironmental Research

Office of Nuctear Regulatory Research

U.S. Nuclaar Rogulatory Commiasion

Washington, D.C. 2055

NRC FN No. Be201 


\section{ABSTRACT}

This report describes the results of a detailed literature review of radionuclide transport models applicable to rivers, estuaries, coastal waters, the Great Lakes, and impoundments. Some representative sediment transport and water quality modeis were also reviewed to evaluate if they can be readily adapted to radionuclide transport modeling.

The review showed that wost available transport nodels mere developed for dissolved radionuclides in rivers. These nodels include the mechanisus of advection, dispersion, and radionuclide decay. Since the nodels do not include sediment and radicnuclide interactions, they are best suited for simulating short-tera radionuclide migration there: 1) radionuclides have sall distribution coefficients, and 2) sediment concentrations in receiving water bodies are very law. Only five of the reviewed nodels include full sediment and radionuclide interactions: CuiSED developed by Fields; FETRA, SERATRA, and ToON developed by Onishi et al., and a model developed by Shull and 6loyma. The five nodels are applicable to cases where: 1) the distribution coefficient is large; 2) sediment concentrations are high; or 3) long-term uigration and accumlation are under consideration.

This report also discusses radionuclide adsorption/desorption distribution ratios and addresses adsorption/desorption mechanisas and their controlling processes for 25 elements under surface water conditions. These elements are: $\mathrm{Am}, \mathrm{Sb}, \mathrm{C}, \mathrm{Ce}, \mathrm{Cm}, \mathrm{Co}, \mathrm{Cr}, \mathrm{Cs}, \mathrm{Eu}, \mathrm{I}, \mathrm{Fe}, \mathrm{m}, \mathrm{Mp}, \mathrm{P}, \mathrm{Pu}, \mathrm{Pm}, \mathrm{Ra}, \mathrm{Ru}, \mathrm{Sr}$, Tc, Th, $H, U$, Zn and $2 r$. 


\section{SUMARY}

A comprehensive literature survey was conducted to assess radionuclide transport models that are applicable to surface waters. Twenty-eight models were examined for their inclusion of transport and fate mechanisms (and their formlations), applicability, limitations, and past application results for different types of water bodies, i.e., rivers, estuaries, coastal waters, the Great Lakes, and impoundments. Eighteen representative sediment transport and twenty-six conventional water quality models mere also reviewed to determine if these types of models can be easily adapted to radionuclide migration phenomena in surface waters.

Most radionuclide transport models are based on the adrection/diffusion equation. These models range from simple analytical solutions to sophisticated numerical models. For some siaplified cases, analytical solutions provide useful information on radionuclide distributions with very minor efforts. Mumerical models, however, can accomnodate a wide variation of channel geametry, flow distribution, and sediment and radionuclide distributions.

The study ,evealed that the important mechanisas of radionuclide transport and fate are: 1) advection and dispersion of radionuclides by current, surface waves, and turbulent mixing; 2) radionuclide decay; 3) radionuclide contributions from outsife xurces and subsequent mixing; and 4) interaction between radiomuclides and sediment and soluble constituents such as complexing ligands.

Most available radionuclide transport models mere developed for dissolved radiomuciides in rivers and include the first three mechanisas. These models are best suited to short-term radionuclide migration where: 1) radionuclides have small distribution coefficients, $\mathrm{Kd}$, and 2) sediment concentrations in receiving mater bodies are very low. Most water quality models can also simulate dissolved radionuclide transport with minimal modifications (if any) to the models. When only dissolved radionuclide transport is concerned, the water quality models developed by Leendertse; Yotsukura and Sayre; and Dailey and Harleasen are some of the more sound models with good past application. 
Another table (see Table 8.95), based on solution thermodymamics, was constructed to predict what species of each element would predominate in environmental waters. Based upon the nature of the predominant solution species, qualitative predictions on adsorption and nobility of the radiomuclides can be made.

The review of radionuclide adsorption/desorption wechanisms indicated that additional research is neded for a better understanding of sediment and radionuclide interactions. In accordance, the following activities are recomended:

1. determination of radionuclide adsorption mechanisms

2. evaluation of factors that influence radionuclide/geologic media interactions

3. experimental consideration of the effects of resiox potential on radionuclide migration

4. characterization of organic ligands; evaluation of the influence of organic igands on radionuclide migration

5. detern. nation of thernodymanic data for several solution species

6. generation of $\mathrm{Kd}$ data that can be used in a comparative node

7. maintenance of a bank of such Kd data

8. determination of radionuclide adsorption and desorption reaction kinetics with sediments. 


\section{CONTENTS}

ABSTRACT •

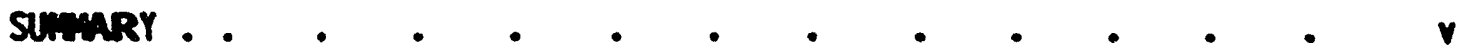

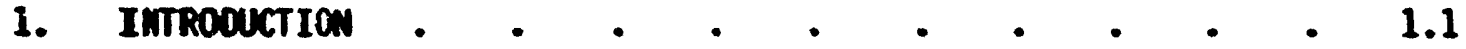

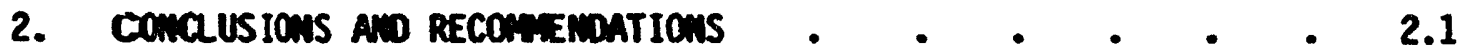

2. EEMERAL DESCRIPTION OF MATHEMTICAL MODELS • • • - 3.1

RADIOMECLIDE TRANSPORT MOOELS $\quad$ • $\quad$ •

HATER QUNITY AMD SEDIMENT TRANSPORT MOELS • • • 3.6

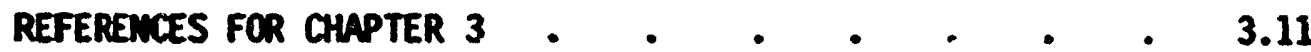

4. RADIOANCLIDE TRAHSPORT IN MON-TIDAL RIVERS • $\quad$ - $\quad . \quad 4.1$

PHYSICAL MECHANISUS OF RADIOMUCLIDE TRAMSPORT IM

MON-TIDNL RIVERS • • • • • • • • • • • 4.1

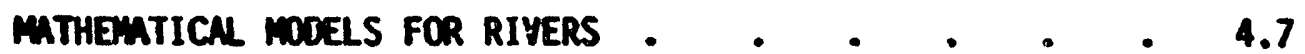

REFERENCES FOR CHAPTER 4 4 . . . . . . 4.55

5. RADIOUICLIOE TRAUSPORT IN ESTUARIES $\bullet \quad \cdot \quad \cdot \quad \cdot \quad \cdot 5.1$

PHYSICAL MECHANISIS OF RADIOUNCLIDE TRANSPORT

In ESTUARIES $\bullet$ •

MATKEMTICAL MODELS FOR ESTULRIES . • • • • 5.2

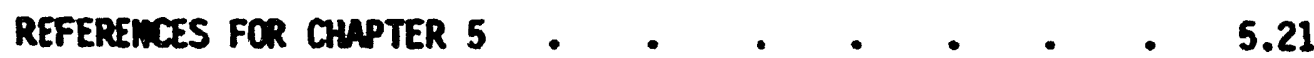

6. RADIOMUCLIDE TRAMSPORT IN OCEAMS AND EREAT LAKES • • - 6.1

PATSICA MECHAMISIS OF RADIOMUCL IDE TRAMSPORT

IN OCFANS AND EREAT LAKES •

MATHEMTICAL MODELS FOR OCEAN AMD THE EREAT LAKES • $\quad 6.8$

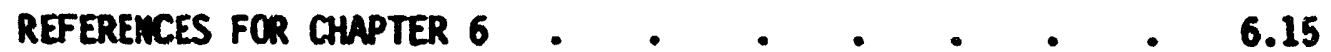

7. RADIOMUCLIDE TRAMSPORT IN LAKES MD RESERMIRS • • $\quad 7.1$

PHYSICA RECHAISUS OF RADIOUUCLIDE TRAMSPORT IN

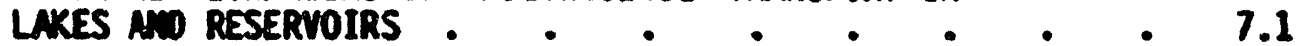


MATHEMATICAL MODELS FOR LAKES AMD RESERYOIRS

7.5

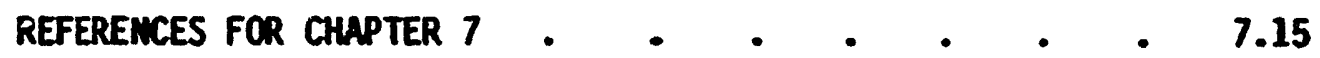

8. RADTONUCLIDE ADSORPTION/DESORPTION • • • • • • 8.1

MeCHAMISUS • • • • •

SELECTION CRITERIA AND SOURCES OF RADIONUCLIDES

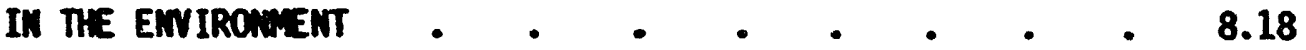

Element Literature REVIEM •

AERICIUM • • • • • • • • • • • • 8.25

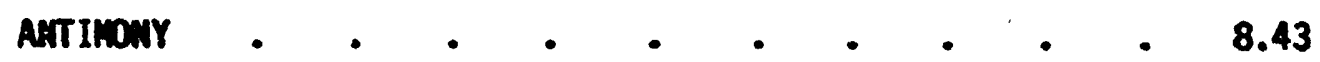

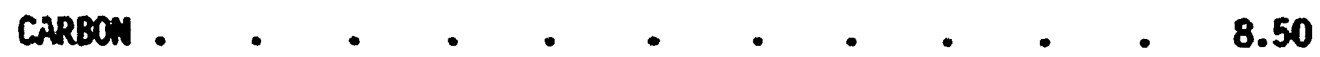

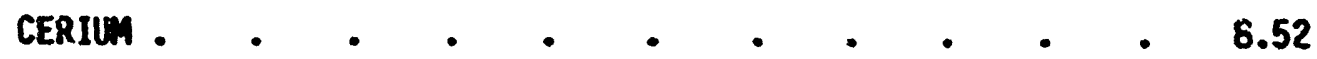

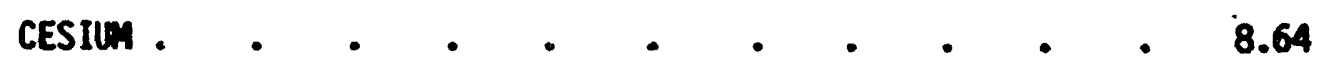

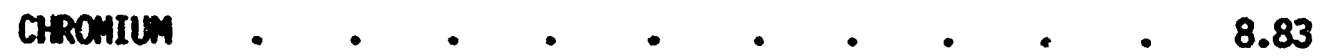

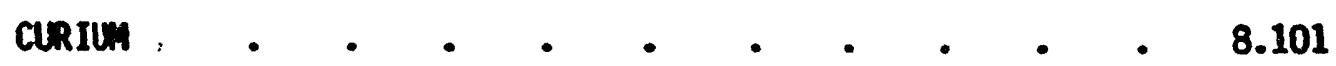

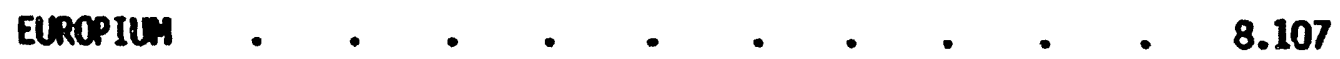

IRON • • • • • • •

MEPTUHIUN • • • • •

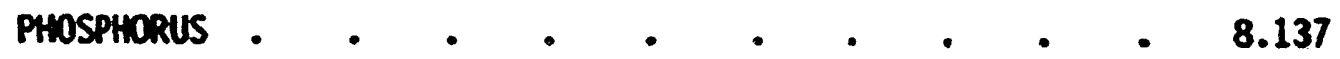

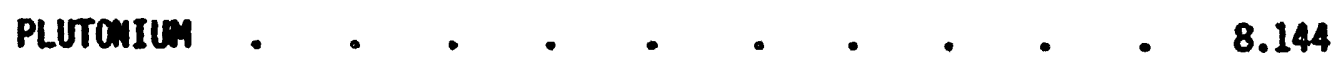

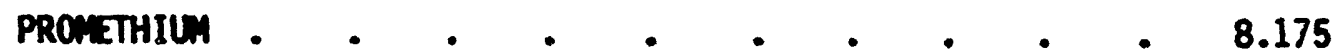

RADIUH . • • • • •

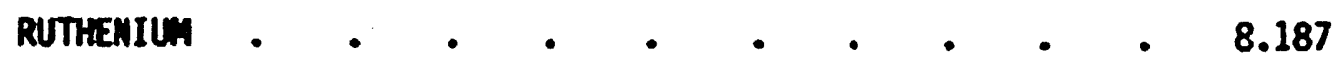

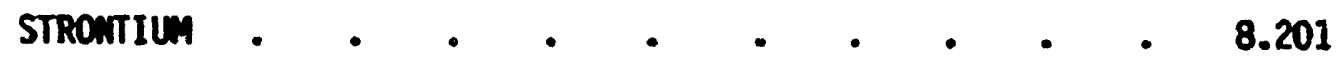

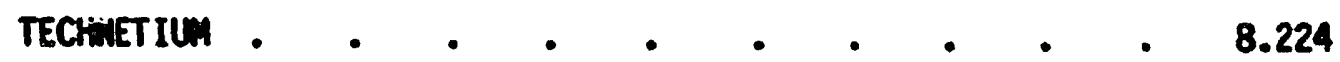

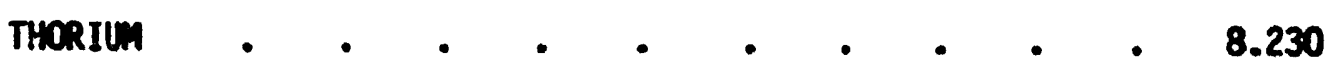

TRITIUN • • • • • • • • • • • • 8.239 


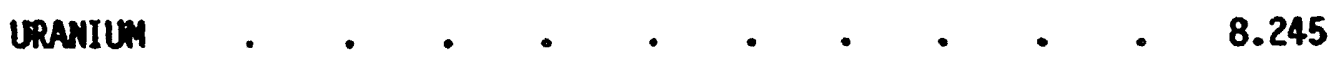

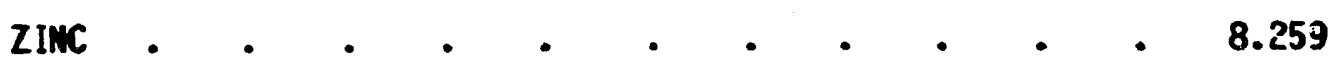

$$
\begin{aligned}
& \text { ZIRCONIU⿴囗十 • • • }
\end{aligned}
$$

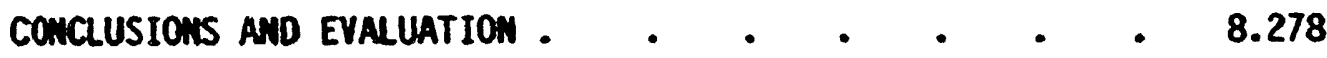

$$
\begin{aligned}
& \text { REFEREMCES FOR CHAPTER } 8 \text {. } 5 \text { • }
\end{aligned}
$$

J

I

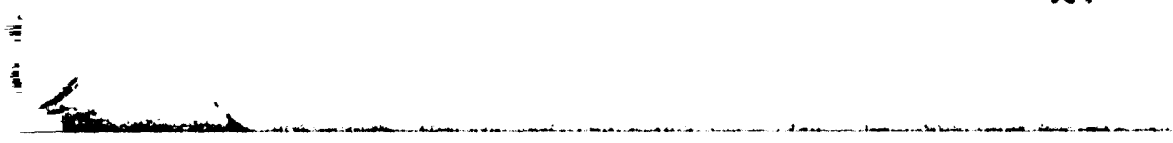




\section{FIGURES}

3.1 Particle movement . . . . . . . . . 3.10

4.1a Overall Model Structure • . . . . . . . . 4.13

4.1b Water Transport Model . . . . . . . . 4.13

4.2 Longitudinal Distributions of Dissolved, Particulate and Total Cesiv-137 Concentrations in the Clinch River, Tennessee . . . . . . . . . 4.26

4.3 Plug Flow River Model . . . . . . . . . 4.30

4.4 Mixed Tank Model . . . . . . . . . . 4.31

7.5 Comparison Between Simulated ard Measured Transverse Concentration Distributions, Transects 3 and 4 in the Missouri River

4.6 Dissolved Oxygen Calibration of PIOMEER Model . . 4.44

4.7 Dissolv :d Oxygen Verification of PIONEER Model . . . 4.44

4.8 Observed and Simulated Transport Rate Versus Measured FIon Velocity for Complete Set of Available Sapling Dates in the Rio Grande River Near Bernalililo, Mew Mexico 4.49

4.9 Measured and Simulated Values of Volumetric Sediment Discharge Rates in the Hudson River at a Cross Section 10 Miles Upstrean from the Battery . . . . . . . 4.50

4.10 Theoretical and Observed Longitudinal Distribution of Tracer Particles: North Load River Field Experiment . • 4.53

5.1 Tidally Averaged Sedinent Concentration of Each Sediment Iype for the Met Freshwater Input Discharge of $58.3 \mathrm{~m} / \mathrm{sec}$ in the James River Estuary . . . . 5.7

5.2 Tidally Averaged Sediment Concentration of Each Sedibent Type for the Met Freshwater Input Discharge of $247 \mathrm{~m} / \mathrm{sec}$ in the James River Estuary

5.3 Tidally Averaged Particulate Kepone Concentrations for the Net Freshwater Discharge of $58.3 \mathrm{~m}^{3} / \mathrm{sec}$ in the James River Estuary . . . . . . . . 5.8

5.4 MRC Estuary Model . . . . . . . . . . 5.10 
5.5 Compariso:l of Computed and reasured Values of Velocity and Salinity in the James River Estcary . . . 5.12

5.6 Channel-Junction Definition for Computational Mesh . 5.16

5.7 Suspended Sediment Concentrations During Spring Tide 4.18

6.1 Comparison of Computed and Measured Temperature Distributions in the Conowingo Reservoir in the

Vicinity of the Peach Botton Atomic Power Station - $\quad 6.11$

7.1 Comartments of the Lake Ecological Model of Vanderploeg, Booth and Clark . . . . . . . 7.6

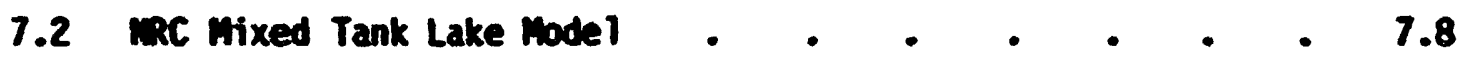

8.1 The Activity of Yarious Nericiu Species in Equilibrium with $\mathrm{NO}_{2}(\mathrm{~s})$ in an Oxidizing Soil Environment. . 8.26

8.2 Particulate Formation of $A(I I I)$ in Var River Hater as a Function of Changes in pH . . . . . 4.28

8.3 Particulate Formation of $\mathrm{Ma}$ (III) in Sea Water as a

8.4 Equilibriu Time for Particulate Formation and Mdsorption on Sediments of $\ln$ (III) in Var River Hater and Its Desorption from Sediments in the Sea later . . . 8.29

8.5 Mdsorption of $\mathrm{m}$ (III) on Sediments in Var River Mater at Different pH Values . . . . . . . . 8.29

8.6 Desorption of Mol(II) from Sediments in the Sea Mater

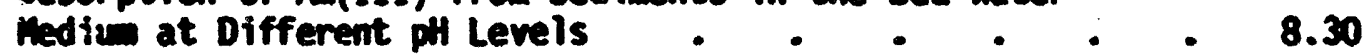

8.7 Distribution Coefficient for $241 \mathrm{~nm}$ as a Function of Sediment Concentration in Fresh Mater. . . . 8.31

8.8 Distribution Coefficient for $241_{\text {ha }}$ as a Function of ph

6.9 Distribution Coefficients for 241 n as a Function of pH in Marine Mater-Sediment Systed . . . . . 8.32

8.10 Effect of Varying EOTA Concentration on Kd Values
of $24, \ldots .38$

8.11 The Activity of Various Ant imny Species in Equilibrim
with $\mathrm{Sb}_{2} \mathrm{O}_{3}(\mathrm{~s})$ with punt4 $=3.0$ and of- = 4.5. . . . 8.45 
8.12 The Activity of Various Ceriu Species in Equilibriu with CePOA (s) in an Oxidizing Soil Environment . . . .

8.13 Distribution Coefficient of 244ce in Sediment . $\quad$ - 8.59

8.14 Distribution Coefficient of Several Minerals as a Function of Sodium Concentration - . . . $\quad$. 8.73

8.15 The Activity of Various Cobalt Ions in Equilibrium with $\mathrm{COCO}_{3}(\mathrm{~s})$ in an Oxidizing Soil Environment . . $\quad 8.90$

8.16 Variation of Adsorption of 60Co at Constant Carrier Concentration ans sediment Load with Varying pH • • 8.92

8.17 Variation of Desorption of Trace Elements at Constant Adsorbed Trace-Element Concentration and Sediment Load with Yarying if

8.18 The Activity of Various Curium Ion Species in Equilibriu with $\mathrm{Ca}(\mathrm{OH})_{3}(\mathrm{~s})$

8.19 The Mctivity of Various Europio Species in Equilibriun with $\mathrm{Eu}(\mathrm{OH})_{3}(\mathrm{~s})$

8.20 The Influence of pit on the Activity of Europiu in Solution

8.21 Sorption of $131_{1}$ cato Leitha Sediment as a Function of Grain Size.$\quad$. . . . . . 8.123

8.22 The Activity of Various Neptunion Species in Equilibriu with hpoz(s) in an Oxidizing Soil Environment

8.23 Rewoval of Phosphate by Roanoke River Solids as a Function of pit

8.24 The Effect of Prior Contact Time on the Desorption of Phosphorus from Solids

8.25 The Effect of Variations in Salinity on the Uptake of Phosphorus - • . • . . • • • 8.142

8.26 The Activity of Various Plutonion Species in Soit Solution in Equilibriu with PoOz(s) at ph 8

8.27 The Activity of Various Plutonio Species in Soil Solution in with PuOz(s) in a Hildiy Oxidizing Soil Enviroment 
8.28 Particulate Formation of Pu(III, IV, VI) in Var River Hater as a Function of Changes in PH . • • • • 8.150

8.29 Particulate Formation of Pu(III, IV, VI) in Sea Hater as a Function of Changes in pH . . . . . .

8.30 Equilibrive Time for Adsorption on Sediments of Pu(IV) in Var River Mater and Its Desorption from Sediments in the Seamater Medium. . . . . .

8.31 Desorption of Pu(III) and M(III) from Sediments in the Seamater Mediun at Different phl Levels. • • • • 8.151

8.32 Adsorption of Plutonion by Soil as a Function of pH $• \quad \mathbf{8 . 1 6 0}$

8.33 Effect of pH and Plutonium Oxidation State on the Adsorption of Plutonitu by Soil • • . . . 8.162

8.34 The Activity of Various Ruthen iun Species in Eqnilibrium with RuOz in Oxidizing and Other Conditions . - . 8.190

8.35 The Relative Stability of Various Strontiun Solids • $\quad 8.203$

8.36 The Activities of Various Strantiun Species in Equilibric with $\mathrm{SrCO}_{3}(\mathrm{~s})$ in the Soil . . . B.204

8.37 Activity of Various Thorium Species in Soil in

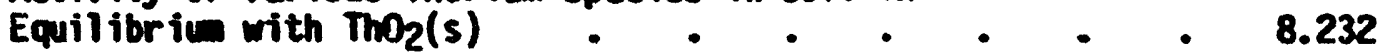

8.38 Activity of Various Uranium Species in Equilibrium with MazUOA in an Oxidizing Soil Environment . • • • 8.248

8.39 Adsorption of Zinc at Constant Carrier Concentration and Sediment Lead with Yarying pH . • . • • 8.262

8.40 Desorption of 2 inc at Constant Adsorted Trace Element
Concentration and Sediment Load with Varying pH • • $\quad 8.262$

8.41 Variation of Desorption of Zinc in Sea Mater of Different Salinities at Different pH • • • • • 8.263

8.42 The Activity of Various Zirconium Species in Equilibriu with Zircon and Soil Solution Silica . • $\quad 8.271$ 


\section{TABLES}

4.1 Radionuclide Data for Rivers . . . . . . . 4.8

4.2 Sumary of Radionuclide Transport Model . . . . 4.9

4.3 Stmary of Sediment Transport Models . . . . . 4.10

4.4 Sumary of Hater Quality Models . . . . . . 4.11

5.1 Estuary Data . . . . . . . • . 5.3

6.1 Physical-Chemical States of Radionuclides in Bikini
Atoll Lagoon in Percent.

6.2 Ocean and Great Lakes Data . . . . . . . 6.6

7.1 Lakes and Reservoirs Data . . . . . . . . 7.4

8.1 Composition of Burns, Mississippi Montmorillonite . $\quad 8.4$

8.2 Comparison of Experinental and Computed Strontium
Kd Values for Montmorillonite

8.3 Most Potentially Yazardous Elements . . • . $\quad 8.19$

8.4 1975 Sumary Liquid Release of Radionuclides from Commercial LLR and PIR Reactors in the

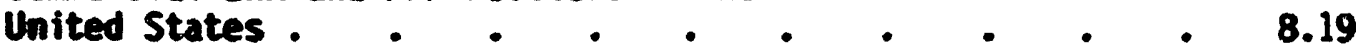

8.5 Anmual and Cumlated Releases and Production of Radiomuclides from Muclear Plants and Fuel Reprocessing Plants for the Horld from 1975 to $2000 . . \quad . \quad . \quad . \quad . \quad . \quad 8.20$

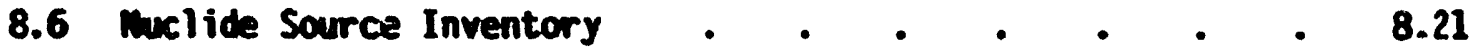

8.7 Average Activities of Solution Constituents . . . . 8.23

8.8 Sediment Characteristics and Average Kd/fa Particle

8.9 Percent Distribution of Radionuclides After 11 Days

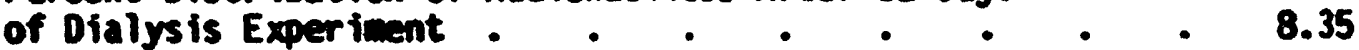

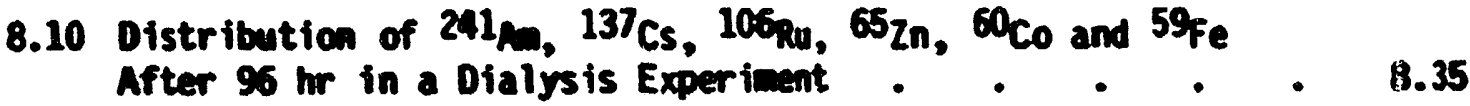


8.11 Sumary of Adsorption/Desorption Distribution Coefficients with Properties of the Sediment/Mater

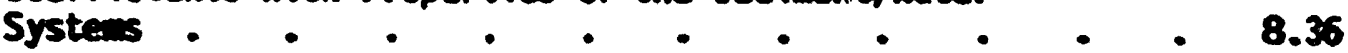

8.12 Sediment/later Kd Values for Lake Mashington Systen as a Function of Different Organic Compounds . • $\quad 8.37$

8.13 mericiun 50-Day Distribution . . . . • 8.39

8.14 Antimony Concentrations in Rocks and Sediments . - . 8.43

8.15 Activity and Percentages of Antinony Isotopes . - . 8.46

8.16 1255b Aralysis of Mater and Soil Saples from a

8.17 Cerivan Abrendance in Rocks . • . . . . 8.52

8.18 Stable Isotopes of Ceriz • • • . • . 8.53

8.19 Cerín Data . . . . . . . . • 8.55

8.20 Kdce ento Post-6lacial Clay from Distilled Mater - - 8.56

8.21 Adsorption of 144ce on Suspended Solids . . . 8.62

8.22 Cesium Content of Rocks and Sediments . . . . 8.64

8.23 Kdcs in Various Sediments from Durssa and Eisma - $\quad 8.68$

8.24 KdCs on Mitelva River Sediments • • • • - 8.68

8.25 Distribution of $137 \mathrm{Cs}$ Between Sea Hater and

8.26 Cs Sorption by Clinch River Sediment . . . . 8.75

8.27 Properties of Matural Hater Saples . . . . $\quad . \quad 8.81$

8.28 Adsorption of Radionuclides on Suspended Solids - $. \quad-8.81$

8.29 Chromiun Concentrations - • . . . . . 8.83

8.30 Cobalt Concentrations in Igneous and Sedimentary.
Rocks and Sedicents in pom

8.31 Kdco in Various Sediments from Dursm and Eism . . $\quad 8.91$

8.32 Curiun 50-day Distribution Computiod from
Sheppard et al. 
8.33 Kd Values for $242 \mathrm{Ca}$ in Untreated Aiken Clay Lo: $\quad$ 8.105

8.34 Europiu Content of Sediments and Igneous Rocks

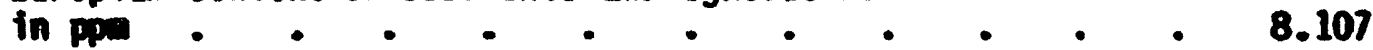

8.35 Variation of Trace europiu Kd Values on Mol Solls . . 8.110

8.36 Effect of pH and Europiten Concentration on Europium

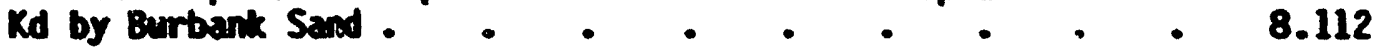

8.37 Iod ine Concentration in Sediments and Rocks . . . . 8.115

8.38 Range of Surface Soil Properties Used in the Mathyl lodide and Iodide Sorptions . • . • . . 8.119

8.39 Iron Contents of Sediments . . . . . . . 8.124

8.40 Kdfe Observed in Murine Sediments $\quad$. . . 8.125

8.41 Manganese Content of Various Sediments . . . . 8.127

$8.42 \mathrm{Kdm}$ Versus Particle Size . . . . . . . . 8.128

$8.43 \mathrm{Kd}$ man and $\mathrm{t} 1 / 2$ for Various Sediments $\quad$. $\quad$. 8.129

8.44 Properties of Soil Saples . . . . . . . . 8.134

8.45 Meptuniu Kd as a Function of Soil and Solution . . 8.134

8.46 Meptuniom 50-day Distribution Values Computed
fro Shepard et al.

8.47 Phosphorus Content of Rocks and Seciments - . . 8.137

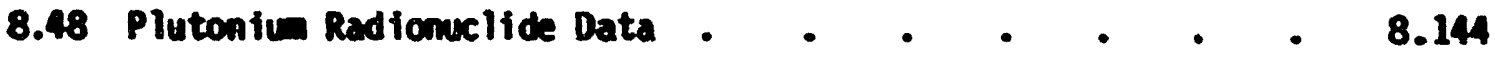

8.49 Sediment Characterization . - . . . . - 8.154

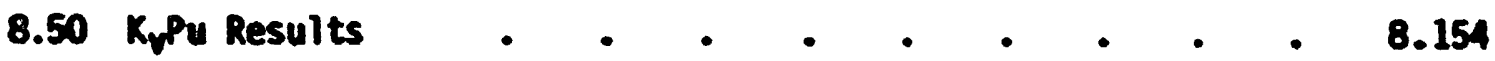

8.51 Percent Pu Rewoved by Extractants - . . . . . 8.157

8.52 Plutoniun Mdsorption Versus Particle Size . . . 8.158

8.53 Plutoniu kd Values for Quartz of Various Particle Sizes
from a $0.001 \mathrm{HWO}_{3}-$ Plutoniun Solution 
8.54 Plutonium Kd Values for Different Minerals of coarse Clay Size from $0.001 \mathrm{~N} \mathrm{Hu}_{3}$-Plutoniun Solution . . . . 8.159

8.55 Rhodes' Plutonium Kd Data as Reported by Evans . . $\quad 8.159$

8.56 Renoval of Plutoniu from ph 7 Mater by Several

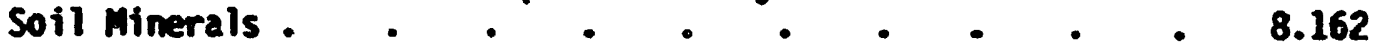

8.57 Plutoniun Kd as a Function of Oxidation State . . $\quad 8.164$

8.58 Kd Values of $238 \mathrm{pu}$ in Untreated Aiken Clay Loa $\quad$ - 8.164

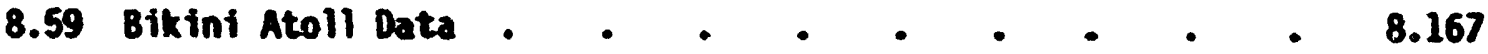

8.60 Kdpm and t 1/2 Values on Selected Sediments $\quad$ - . 8.177

8.61 Average Radiu Content of Various Geologic Media - . $\quad 8.179$

8.62 Radiu Kd Values from Lime-Meutralized Waste; $1.25 \mathrm{~g}$ Exchanger $/ \mathrm{l}$ of Waste . . . . . . 8.181

8.63 Simulated River Mater Composition - . . . . . 8.182

8.64 Radiun Distribution Coefficients with the
Solution of Table 8.63

8.65 Abundances of Rutheniu in Igneous Rocks and
Rock-forming Minera is in pin

8.66 Rutheniu Contents of Shales . . . . . . . 8.188

8.67 Atomic Percentages of Stable Rutheniu Isotopes . . - 8.188

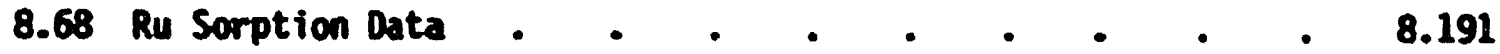

8.69 Ru Sorption in Fresh Mater . . . . . . 8.192

8.70 Properties of Natural Hater Saples . . . . . . . 8.194

\begin{tabular}{l}
8.71 Adsorption of 106 Ru on Suspended Solids in \\
Matural Haters \\
\hline
\end{tabular}

8.72 Rutheniu Distribution Coefficients on a Hanford Soll
as a Function of ph

8.73 Average Strontiu Contents of Igneous Rocks . . . B.201

8.74 Average Strontiu Content in Sedimentary Rocks
and Sediments in pon 


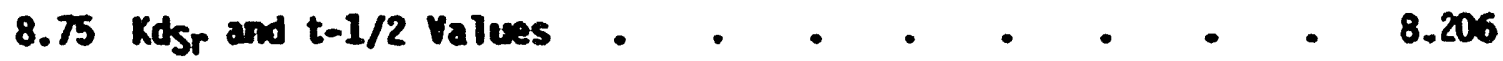

8.76 Technetiun Content of Some Matural Materials . . - 8.224

8.77 Range of Properties of 22 Surface Soils Used in the
Pertechnetate Adsorption Studies

\begin{tabular}{l} 
8.78 Properties of Soils Used in Technetiu Adsorption \\
Studies \\
\hline
\end{tabular}

8.79 Properties of Soil Saples . . . . . . - 8.227

8.80 Technetiun $\mathrm{Kd}$ as a Function of $\mathrm{mancO}_{3}$ Concentration for a South Carolina Soll Characterized in

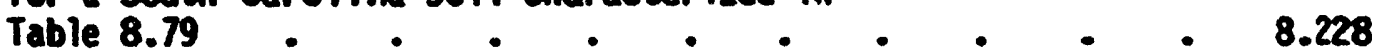

8.81 Thoriem Conte $t$ of Common Rocks and Sediments . - $\quad 8.230$

8.82 Abundances of Uraniun in Matural Materials . . - 8.245

8.83 Mrclear Properties of Ratural Uraniú Isotopes . • • 8.246

8.84 Desorption of Uraniu from Soils with Distilled
Mater and Carbonate Solutions $\quad . \quad$. $\quad$. 8.249

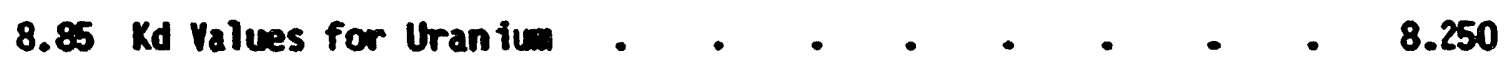

8.86 Zinc Concentration in Sediments . . . . . . 8.259

8.87 Zinc Sorption in Marine Environments . . . - . 8.261

8.88 Distribution of $65 \mathrm{Zn}$ in Columbia River Hater $\quad$ - $\quad$ - 8.266

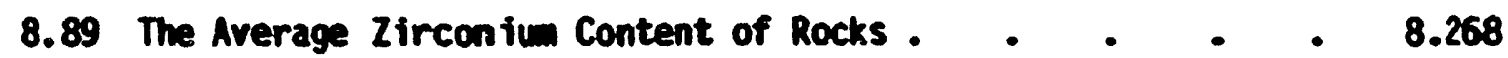

8.90 Matural Isotopes of Zirconiun and Their Abundances - 8.269

8.91 Zirconion Adscrption on Marine Sediments - • - • 8.272

8.92 Zircon-Niobiun Kd Values as a Function of pH. . • . 8.273

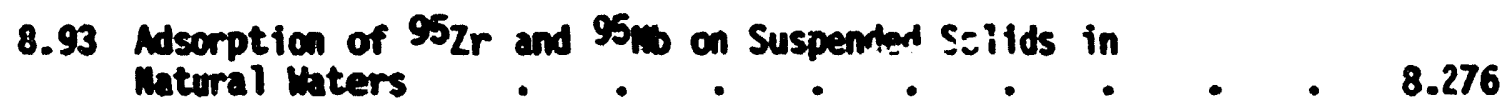

8.94 Fectors Report to affect Adsorption of Radicelements
Over the pil Range of 4 to 9 ..... 


\subsection{Predominant Solution Species of Elements in a pH 4 to 9 ,}

$\mathrm{PO}_{2} 0.68$ to $80, \mathrm{PCO}_{2}, 1.52$ to $3.52, \mathrm{PCl}-0.45$ to $3 / 0$, $\mathrm{PiN}_{3}=$ pSOZ- = 3.0, pht 4.5 and pitzPO4 5.0 Environment Hithout Organic Ligands . . . . . . . .

8.96 Eross Average $\mathrm{Kd} \mathbf{m l / g}$ for Studied Elements with Euphas is on Oxidizing Conditions 


\section{Intropuction}

The melear energy industry has grow considerably during the past decade, and muclear power is expected to become one of the major sources to neet the groving need for energy. Although considerable effort is being ade to winiaize the re sease of the radioactive wastes into the environient, it is fiportant to assess the potential environmental inpact of radionuclide releases. Various pathmays exist for exposure of hmans and biota to radioactive materials released from muclear facilities. Hydrologic transport (Iiquid pathay) is one element in the evaluation of the total radiation dose to man. Exposures can occur from routine or accidental releases of radionuclides in liquid effluents from muclear facilities. Wathematical wodels supported by coordinated data collection programs can be useful tools in assessing the hydrologic transport and ultimate fate of radionuclides. In order to assess migration, accumlation and fate of radionuclides in surface waters, mathenatical models must include major containant transport and fate mechanisus. These mechanisms include:

1. advection and dispersion of radionuclides by flow and surface waves

2. radionuclide decay

3. interaction between sedivent and radionuclides such as:

- radionuclide adsorption by sediment

- radionuclide desorption from sediment to water

- transport of particulate radionuclides (those adsorbed by sediment)

- deposition of particulate radionuclides to ocean and river beds

- scouring of particulate radionuclides from ocean and river beds

4. contaninant release and contributions from outside point and nonpoint sources and subsequent wixing.

This report gives the results of a comprehens ive literature survey conducted to assess radionuclide transport adels applicable to surface waters. Models were examined for their inclusion of transport and fate mechanisus, their formlations, applicability, linitations and past application results for each type of water body, i.e., rivers, esturaries, coastal maters, large 
lakes (e.g., the Great Lakes), and impoundments. Some representative sediment transport and general (conventional) water quality models were also reviewed to examine if these types of models can be easily adapted for radionuclide transport.

Before fundamental understanding and generalized predictive capability for radionuclide transport in rivers, estuaries, oceans and lakes can be obtained, radionuclide adsorption/desorption and controlling physical and chemical processes must be identified. This report also discusses in depth these mechanisms and processes, and contains a compilation of available knowledge on distribution coefficients obtained under expected ranges in environmental and water conditions. For this study, long half-life or biologically hazardous fission and activation products were evaluated. These elements include $\mathrm{N}, \mathrm{Sb}, \mathrm{C}, \mathrm{Ce}, \mathrm{Cm}, \mathrm{Co}, \mathrm{Cr}, \mathrm{Cs}, \mathrm{Eu}, \mathrm{I}, \mathrm{Fe}, \mathrm{M}, \mathrm{Np}, \mathrm{P}, \mathrm{Pu}, \mathrm{Pm}, \mathrm{Ra}, \mathrm{Ru}$,

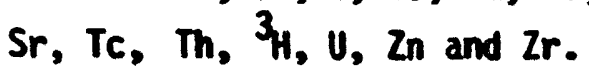

1.2 


\section{COMCLUSIONS AND RECOMENDATIONS}

The literature review on radionucl ide transport, water quality and sejiment transport models; and radionuclide adsorption/desorption mechanisus led to the following conclusions and recomiendations:

1. Host of the radionuclide transport and water quality models reviewed in this study can simulate dissolved-only radionuclide transport. Models developed by Leendertse; Yotsukura and Sayre; and Dailey and Harleaan have sound model formulation and have successful application history. However, the first two models do not include radionuclide decay in the analysis.

2. When: a) distribution coefficients of the radionuclides are large, b) sediment concentrations in a receiving water body are high, or c) long-tern radionuclide migration and accumulation are under consideration, dissolved and particulate forms of a radionuclide must be soived simultaneously by including full sediment-radiomuclide interactions. Sediment-radionuclide interactions involve radionuclide adsorption/ desorption, and transport, deposition and scouring of radionuclides sorbed by sediment. For these cases, the following five wodels can be used:

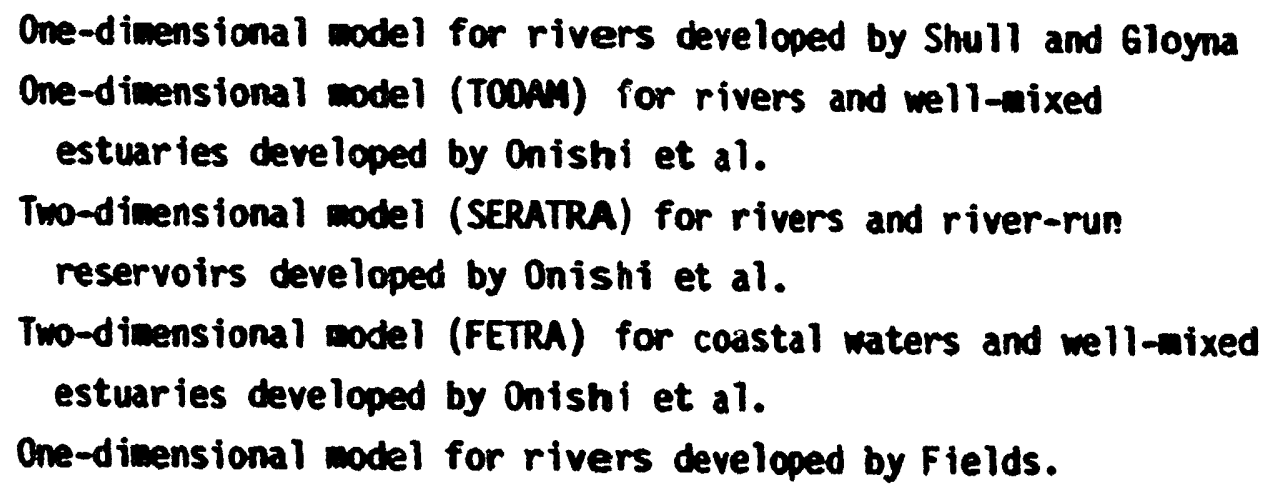

3. All of the above five models mave ween applied to actual sites and sane of then were partially verified with field data. However, wore complete codel verification is needed. 
4. Radionuclidas in solution exist in dynamic equilibrium with bed sediment and suspended sediment. Many factors that are inherent to the sediment and the solution can influence the concentration of the element and its species in solution. These factors include pH, Eh, CEC, type and amount of winerals, solubility of the element, complexing ligands, and competing ions. In order to deterwine the distribution of the element between solution and solid and its reactions with sediments, the identity and effect on sorption of each factor are needed. To date scientists have not identified the effects of important factors sufficiently.

5. This general lack of systematic evaluation of the effects of isportant factors is exacerbated by a lack of detailed sediment/water characterization for laboratory and field studies. It is extremely difficult to utilize existing literature to evaluate the effects of geochemical parameters on muclide sorption because of this lack of system characterization or control. Below is a list of sediment and solution parameters wich should be measured during sorption experiments to facilitate quantification of effects and delineation of sorption mechanisus.

\section{Suparting Information Necessary to Complete Kd}

There are mumerous characterizations that should be performed on geologic media and their pore waters to allow calculations of migration rates or Kds. The characterizations can be broken into two broad categories: physical or hydrologic and geochemical. The relative importance is based on the assumption that insufficient time and funds will be available to perform the complete characterization. If only partial geochemical characterization is possible, in general concentrate on the first seven.

\section{Important Geochenical Characterizations}

1. qualitative and quantitative wineralogy including prisary and secondary crystalline materials, amorphous coatings, etc. 
deterwined primarily by X-ray diffraction, cheaical treatment techniques, and petrographic exaination. Calciu carbonate content and hydrous oxide content (amorphous and crystalline) as well as aluminosilicate contents are nost important. Scaming electron microscopy and microprobes can be used to determine microstructural vianeralogy. These techniques can be very important in assessing the differeaces between mineralogy and weathering emvironments of cracks and fractures from the bulk rock material.

2. cation exchange capacity

3. pore water pH, Eh

4. pore water ajor cation content $(\mathrm{Ma}, \mathrm{Ca}, \mathrm{Mg}, \mathrm{K})$

5. pore water ajor anion content $\left(\mathrm{Cl}, \mathrm{HCO}_{3}, \mathrm{CO}_{3}, \mathrm{SO}_{4}, \mathrm{~m}_{3}\right)$

6. pore mater $\mathrm{SiO}_{2}$ content

7. organic content of genlogic material.

Less Ifportant Eechemical Characterizations

1. anion exchange capacity

2. distribution of mojor cations on exchange sites

3. pore water organic content, especially potential ligands (muic. fulvic acids)

4. pore water winor constituents, especially naturally occurring isotopes of important waste muclides $(S r, C s, I, U, R a)$ and cherically siailar elements (Ba, Bb, Br).

Important Physical or Hydrologic Characterizations

1. suspended sedinent content (solid/solution ratio)

2. permeability

3. water velocities

4. Surface area and particle size distribution

5. in situ te-perature

6. time of contact. 
6. The probable principal adsorption echanisus my be deduced frem an examination of the factors reported to be important for each elenent. For exaple, colloid formation is a good indication of precipitation, as pil also may be. An adsorption sensitivity to cation exchange capacity, competing ions and system ph usually indicates an ion exchange adsorption mechantsm. A sensitivity to the redox potential, Eh, usually indicates that the element has changed valence states mich typically leads to enhanced sorption via solubility constraints. Chromiu, neptuaite, phosphorus, plutoniun, technetion, and uraniom are wach more soluble conder oxidizing conditions than reducing. Iron and manganese if general exhibit the cpposite solubility trends.

7. Based upon the mature of the predominant solution specfes, qualitative predictions regarding the adsorption and novewent of vorious elenents can be made. Bed and suspeaded sedinents minly show cation exchange capacities (since they carry a large net negative charge) and to a Itwited extent, anion exchange capacities. Mus, wost cations would react with sedinents. Relative to each other, the trivalent cations are gearally nost easily adsorbed, the divalent cations are intermediate and the nonovalent cations are adsorbed least. Trition is unique in that it readily substitutes for hydrogen in water and nigrates, therefore, at the same velocity as ater. Complicating factors include a higher selectivity of a sedivent component for a given cation or a more successful hydrogen ion competition with one cation relative to another. The adsorption of strontion and cesion at low ph is a good example of the latter effect. Strontiu is wech ware easily adsorbed by sedilent at low pit than is cesion.

8. The highly charged metal ioas tead to polymerize or form colloidal size, charged precipitates. The trivalent metal tons $(n, C n, S b, R v)$ and pasdrivalent or higher charged natal ions (Pu, Th, U, Zr) are known to for polywers. Initially, at lawer ph, the polymers are positively charged and at of 9 become increasingly pesutively charged. The result is good adsorption at acidic to wentral in, and lessened adsorption from pit 9 uporard. 
9. The behavior of organic complexed species of elements is difficult to predict because of the lack of knowledge regarding the exact anture of the organic ligands, a wide variation in acounts and types of organic ligands, and the size and solubility of these organics. These orgaic aterials can efther retain the element or complex it. Many laboratory studies at inflated organic concentrations have show sigaificant changes in Kots for way elements, but the results for expertants at realistic organic concentrations are less dramatic.

10. At best, the available data suggest trends for the influence of some of the factors that centrol solution concentrations and interaction with solid antrices. This type of information weild not be very useful for quantitatively predicting the general fate of radionuclides in the enviroament. Niditional research and wore considered characterization of sedinent/mater systems are required for general understanding of the behavior of radioneclides.

11. Ceneral recomendations to further the pursuit of quantitative understanding of radionclide adsorption/desorption include:

a. wore detailed characterization and control of inportant geochemical parameters

b. Eore concern bout proper experimentation, such as studying adsorption coly at tracer concentrations below solubility constraints, care in solid/liquid phase separations

c. more reliance on thernodsnivic principles such as solution speciation and solubility to gaide experimeatal design and data interpretation

d. detennimation of adsorption/desorption kinetics.

12. Exper imenters are dunonished to atteupt to: a) provide data on sorption under controlled Eh, ph and dissolved solids conditions; b) differentiate adsorption from precipitation; c) evaluate. inorganic and organic complexation of cationic maclides; and d) utilize proper scientific design 
and statie-of-the-art instrumentation and procedures intle perforeing experiments. Critical areas ixclude concentration and techaignes of ading redionoclides to mters, solid/iquid phase sepmetion, and length of contact time exployed. 


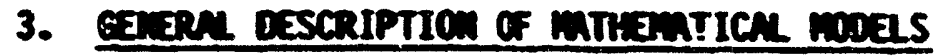

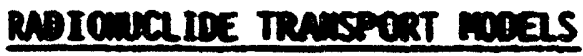

Trasport and fate of radiomelides can be predicted with vorions degrees of sophistication, ranging from a stiple algebraic, ass-balance approach to a mitt-dimensional minerical solution to the probleus. For exaple, a simple algebraic approch to the hydrologic transport of radionuclides considers caly adrection and wixing processes. These processes are represented in a spatially averaged form, using the wixing ratio and average travel time factors. The 1977 Regulatory Euide (US Mx 1977) describes more sopmisticated methodologies to solve the radionuclide transport, using the adrection-diffusion equation for various categories and classifications of problems, such as initial diletion, nontidal rivers, open coasts, estanaries, and impoundments.

The basic equation of anss conservation of a contaniant expressed in terms of the atrection-diffesion equation in Cortesian coordinates is:

$$
\begin{aligned}
& \frac{\partial C}{\partial t}+\frac{\partial}{\partial x_{i}}\left(u_{i} r\right)=\frac{\partial}{\partial x_{i}}\left(\varepsilon_{i} \frac{\partial C}{\partial x_{i}}\right)+\sum_{j=1}^{n} k_{j} c+\sum_{i=1}^{n} s_{j} \\
& \begin{array}{c}
\text { drmenic dvection diffusion or } \\
\text { term derm decay sink/source } \\
\text { term term }
\end{array}
\end{aligned}
$$

were:

$C=$ concentration of the contaminant

$t=t$ tine

$u_{i}=$ velocity term

$x_{i}=$ Cartesian coordinates

$\varepsilon_{i}=$ diffusion/dispersion coefficient

$\sum K_{j}=$ sin of decay rates for a contaninant

$\Sigma S_{j}=\sin$ of sink and/or source.

The above equation must be solved simaltmeousily for all phases of cootarinants (e.g., dissolved radicomclides, perticulate radionelides adsorbed 
by sed fiment, biota, etc.). Since it is mossible to solve the coupled equation analytically for a general case, mumical tectiqiques must be used. However, there are some simplified cases when the above equation can be solved malytically. These cases are mostly handling only dissolved radiomalides . some of the know analjtical solutions are discussed belon (USuac 1977).

1. Advection - Diffusi in Equation (vith only Longitudinal Velocity Compneats without Decay and Sink/Source Terns)

The governing equation for this case is:

$$
\frac{\partial c}{\partial t}+\frac{\partial}{\partial x}(u C)=\varepsilon_{x} \frac{\partial^{2} c}{\partial x^{2}}+\varepsilon_{y} \frac{\partial^{2} c}{\partial y^{2}}+\varepsilon_{z} \frac{\partial^{2} c}{\partial z^{2}}
$$

where:

$$
\begin{aligned}
U= & \text { longitudinal velocity } \\
x, y, z= & \text { longitudinal, lateral and vertical coordinates in } \\
& \text { Cartesian coordinates. } \\
\varepsilon_{x}, \varepsilon_{y}, \varepsilon_{z}= & \begin{array}{l}
\text { longitudimal, lateral and vertical dispersion } \\
\text { coefficients. }
\end{array}
\end{aligned}
$$

a. For an instantaneous point source with the constant velocity and diffusion coefficients the solution to this equation becomes:

$$
C(x, y, z ; t)=N f_{x}\left(x ; t ; f_{j}(y ; t) f_{z}(z ; t)\right.
$$

where:

$$
\begin{aligned}
& f_{x}(x ; t)=\frac{1}{2 \sqrt{\pi \varepsilon_{x} t}} \exp -\frac{(x-u t)^{2}}{\sqrt{\varepsilon} t} \\
& f_{y}(y ; t)=\frac{1}{2 \sqrt{\pi \varepsilon_{y} t}} \exp -\frac{y^{2}}{\sqrt{\varepsilon_{y} t}} \\
& f_{2}(2 ; t)=\frac{1}{2 \sqrt{\sqrt{\varepsilon} t}} \exp -\frac{z^{2}}{\sqrt{\varepsilon_{2}} t} \\
& M=\text { anout of activity released (say, in curies). }
\end{aligned}
$$


$C(x, y, z ; t)=\frac{n}{8(t)^{3 / 2} \sqrt{\varepsilon_{x}^{\varepsilon} y^{\varepsilon} z}} \exp \left\{-\frac{1}{4 t}\left[\frac{(x-u t)^{2}}{\varepsilon_{x}}+\frac{y^{2}}{\varepsilon_{y}}+\frac{z^{2}}{\varepsilon_{z}}\right]\right\}$

b. For coatimous point source with time dependeat-solution, the unsteady solution to Equation (3.2) becomes:

$C(x, y, z, t)=q_{0} C_{0} \int_{0}^{t} f_{x}(x ; \tau) f_{y}(y ; \tau) f_{z}(z ; \tau) d$

$c_{0}$ and $q_{0}$ are initial concentration and discharge of effluent. Equation (3.5) must still be solved by some integral tectmique with a computer.

c. For a contimous point source with a steady-state solution assuning the vertical concentration to be uniform:

$f_{z}(z, t)=\frac{1}{d}$

where $d$ = the flow depth, the steady-state solution of Equation (3.5) becomes:

$C(x, y)=\frac{q_{0} C_{0}}{2 \pi \cdot \sqrt{\varepsilon_{x} \varepsilon_{y}}} \exp \left|\frac{U_{x}}{2 \varepsilon_{x}}\right| K_{0}\left[\frac{U}{2 \varepsilon_{x}} \sqrt{x_{z}^{2}+\frac{\varepsilon_{x}}{\varepsilon_{y}} y^{2}}\right]$

where $K_{0}[]=$ the nodified Bessel function of the second kind of Oth order.

The solutions described above can only be applied to transport of conservative substances in an inf inite doma in without boundary conditions. Hence, the applicability of these types is rather Ifinited. Solutions more applicable to radionuclide transport are described later. 


\section{Mrection-Biffusion Eguation with a Decar Tern}

a. Continous release with the stedy-state solution.

A stuple diffusion model for steady-state dischurge into a water body (e.g., a lake or a coastal area) with a steady flow has the following governing equation:

$v \frac{x}{\partial x}=\varepsilon_{y} \frac{\partial^{2} c}{\partial y^{2}}+\varepsilon_{z} \frac{\partial^{2} c}{\partial z^{2}}-\lambda c$

where $\lambda$ is the radionuclide decay rate.

It is assined that the discharge is located at the point $\left(0, y_{s}, z_{s}\right)$, i.e., at the origin of the $x$-axis and a distance $y_{s}$ from the shoreline and $z_{s}$ beneath the meter surface. It is also assumed that water depth $d$ is constant. The steady-state solution to Equation (3.7) with no lateral boundary conditions is:

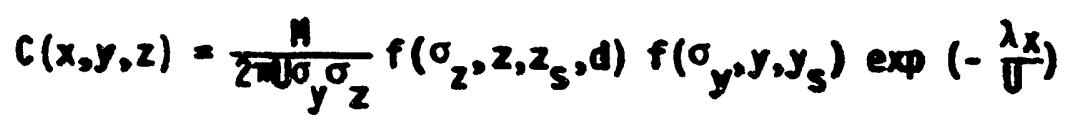

were:

$$
\begin{aligned}
& \left.f\left(\sigma_{z}, z, z_{s}, d\right)=\sum_{i=\infty}^{\infty} \mid \exp \left[-\frac{\left(2 \pi d+z_{s}-z\right)^{2}}{2 \sigma_{z}^{2}}\right]+\exp \left[-\frac{\left(2 \pi d-z_{s}-z\right)^{2}}{2 \sigma_{z}^{2}}\right]\right) \\
& f\left(\sigma_{y}, y, y_{s}\right)=\exp \left[-\frac{\left(y_{s}-y\right)^{2}}{2 \sigma_{y}^{2}}\right]+\exp \left[-\frac{\left(y_{s}+y\right)^{2}}{2 \sigma_{y}^{2}}\right] \\
& \sigma_{y}=\sqrt{\frac{2 \varepsilon_{y} x}{U}, \sigma_{z}}=\sqrt{\frac{2 \varepsilon_{z} x}{U}}
\end{aligned}
$$


For further information on wore general uses of this model, the usinG Regulatory Guide 1.113 an be consulted.

b. Instantaneous release with time dependent solution.

For a instantaneous release of a finite quantity of material from a line source at $x=0, y=y_{s}$, the governing equation becomes:

$$
\frac{\partial c}{\partial t}+U \frac{\partial c}{\partial x}=\varepsilon_{x} \frac{\partial^{2} c}{\partial x^{2}}+\varepsilon_{y} \frac{\partial^{2} c}{\partial y^{2}}-\lambda c
$$

The solution to this equation is:

$$
\begin{aligned}
C & =\frac{n}{\sqrt{\varepsilon_{x}^{\varepsilon} \varepsilon_{y} t} \exp }\left\{-\frac{(x-u t)^{2}}{4 \varepsilon_{x} t}-\lambda t\right)\left\{\exp \left(\frac{-y-y_{s}^{2}}{\sqrt{\varepsilon} y^{t}}\right)\right. \\
& +\exp \left(\frac{-\left(y+y_{s}\right)^{2}}{\sqrt{\varepsilon_{y} t}}\right)
\end{aligned}
$$

c. Continuous release with time dependent solution.

The general transient release ma be considered as a superposition of instantaneous releases and can therefore be simulated by integrating the instantaneous solution Equation (3.10):

$$
\begin{aligned}
& C=\int_{0}^{t} \frac{u f()}{\pi \sqrt{x^{2} y} d(t-\tau)} \exp \left\{-\frac{(x-u(t-\tau))^{2}}{t \varepsilon_{x}(t-\tau)}-\lambda(t-\tau)\right\} \\
& \left\{\exp \left(\frac{-\left(y-y_{s}\right)^{2}}{\tau \varepsilon_{y}(t-\tau)}\right)+\exp \left(\frac{-\left(y+y_{s}\right)^{2}}{\tau \varepsilon_{y}(t-\tau)}\right)\right\} d \tau
\end{aligned}
$$

where the release rate $\mathrm{Mf}(\tau)$ is say, in curies/sec. In general, this equation most be solved using numerical quadrature.

3.5 
The bove solutions (Equations 3.4, 3.5, 3.6, 3.8, 3.10 and 3.11) can be used to solve radionaclide transport in various mater bodies (oceans, estuaries, rivers, lakes and reserwirs) menever the assuptions tipposed during derivation of these equations are satisfied. A nore detalled description of radionuclide transport models is presented in Chapters 4 through 7. As show in these chapters, many radionuclide trasport models are available; however, most of thea solve only dissolved radionuclides without fully including adsorption/desorption mechenisms. For radioneclides with sall distribution coefficients, $\mathrm{Kd},\left(\right.$ (e.9., ${ }^{90} \mathrm{Sr},{ }^{51} \mathrm{Cr},{ }^{124} \mathrm{Sb}$, etc.) wich are mostly tremsported in a dissolved form, these nodels can adequately stmulate transport for both routine and accidental releases especially over the short term, provided there is sufficient information to simulate the flow field during the initial convective period. For radionuclides with large $\mathrm{Kd}$ values $\left(\mathrm{e.9.},{ }^{137} \mathrm{Cs},{ }^{54} \mathrm{~m}\right.$, ${ }^{65} \mathrm{Zn},{ }^{60} \mathrm{CO}_{0}{ }^{46} \mathrm{SC}, 238,239,240 \mathrm{Pu}$, etc.) wich are easily adsorbed by suspended and bottom sediment and aquatic biota, only a fen models are available to solve the migration of these radionuclides (ORin 1978).

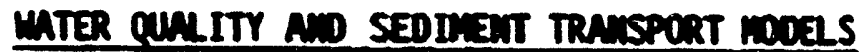

Water quality and sediment-only transport codels mere also reviened to exaine the feasibility of modifying these nodels for application to radionuclice transport. Mater quality models were divided into six groups. Representative models for each group are discussed. The six groups of water quality rodels are as follows:

Iype I. General advection-diffusion equations with (or without) decay and sink/source terms:

$$
\frac{\partial C}{\partial t}+v_{i} \frac{\partial C}{\partial x_{i}}=\frac{\partial}{\partial x_{i}}\left(\varepsilon_{i} \frac{\partial C}{\partial x}\right)+\sum_{j=1}^{m} k_{j} c+\sum_{j=1}^{n} s_{j}
$$


This type of model includes the besic transport mechanisas of advection and diffusion for both conservative and nonconservative substancess, and is the nost conlete for of water pality model. However, the application of this type of model to radionclice transport with winor modification is valid only for dissolved radionaclides with docay and source (or sink) terms representing radionaclide decay and reduction of dissoived concentration by non-moveble sed tanent or bict: . This type of model cannot, hovever, handle dissolved radiomaclide transport, coupled with particalate radionuclide trasport, e.g., adsorption andor desorption of radiomuclides by sedtaent and biota; transport, deposition, and resuspension of contaninanted sediment. Mecessary modification of these models to convert to transport mode's for both dissolved and particulate radionuclides, coupled with transport of sorbants (e.g., sediment, biota, etc.) is very extensive.

Iype II. Ndrection equation with (or without) decay and sink/source terms:

$$
\frac{\partial c}{\partial t}+u_{i} \frac{\partial c}{\partial x_{i}}=\sum_{j=1}^{n} k_{j} c+\sum_{j=1}^{n} s_{j}
$$

Type II nodels do not have a dispersion tern. Hence, the application of this type to both water quality and radionuclide transport (with some modification) is more linited than Type I nodel. This type of model can be applicable to fast-woving rivers.

Iype III. Lagrangian routing models with decay and sink/source term:

$$
\frac{\partial c}{\partial t}=\sum_{j=1}^{n} k_{j} c+\sum_{j=1}^{n} s_{j}
$$

This tspe of model calculates the concentration of a water quality paraneter in a Lagrangion system; i.e., the longitudinal coordinate system is moving with the flow velocity. Although the governing equation does not have any spatial coordinates, the solution is an unsteady, one-dinensional solution 
with decay and sink/sowrce occurring dring the travel time from ons location to the naxt. One enjor advantage of this type, as compared to Type II, is that the governing equation is much strpler. The najor shortconing for this type is that the solution must be one dimensional. This type of model is suitable for application to fairly uniform, now-tidal rivers. The application of this model with wimor modffication to the radionuclide transport is linited to the transport of dissolved radionuclides with decay and adsorption by other substances with constant adsorption rates, or with particulate radionelide concentrations preass igned.

Ire IV. Complete-rix model:

$$
\frac{\partial c}{\partial t}=\sum_{j=1}^{n} k_{j} c+\sum_{j=1}^{n} s_{j}
$$

Complete-mix wodels to not have spatial coordinates, and the concentration of a water quility paraneter is based on the linear reaction; i.e., change of concentration is proportional to the concentration itself. This type of nodel $c a$ be applied to certain lakes in mich concentration changes with the but does not change with locatica. The applicability of this type of radionuclide transport is very liafted. Havever, application can be made to dissolved radionuclides in well-wixed lakes and purticulate radionuclides adsorbed by non-wovable bed sedinent from know dissolved concentration.

Irpe V. Diffusion equation with (or without) decay and sink/source terms:

$$
\frac{\partial C}{\partial t}=\frac{\partial}{\partial x_{i}}\left(\varepsilon_{i} \frac{\partial c}{\partial x_{i}}\right)+\sum_{j=1}^{n} k_{j} c+\sum_{j=1}^{n} s_{j}
$$

These models do not contain the adrection term and consequently can be applied only to quiescent mater bodies. The aplication of this type of eodel for both water quality and radionuclides is accordingly very itwited. 


\section{Irpe VI. Monte irlo Model:}

This type of model is not based on a solution to atheantical equation but, rather, describes transport of constituents phenomenologically using a large computer memory benk to store information on movenent of constituents at each $t$ tive step. The procedure can be described as follows (Figure 3.1):

1. A large muber of particles with a given weight will be discharged from a source.

2. Each particle discharged into a water body woves domstrean from locations $A$ to $B$ with a given flow velocity dring one time step.

3. This particle also woves randoaly during the same time step from $A$ to $C$. The distance between $A$ and $C$ is random as is the direction, but the distance has a man value pre-assigned. This step represents a dispersion phenomenon.

4. By combining the movements that occurred in steps 2 and 3, the particle from the original location A will actually be noved to $D$ at the end of one tiace step.

5. Height of the particle will be changed during the one time step due to decay and sink/source.

6. Procedures 2 to 5 will be repeated on all particles discharged into the water body. Th: distribution of the particle might in the study area is then used to deternine the migration pattern of the constituent.

This method is computationally very stable and has no muerical dispersion problems. This is an attractive alternative to the advection-diffusion equation for the transport phencmenon. This type of model can be applied to either dissolved or particulate radionuclide transport with very minor adification. However, extensive nodification is required to couple dissolved and particulate radiomuclides with sediment and biota transport phenomena. 


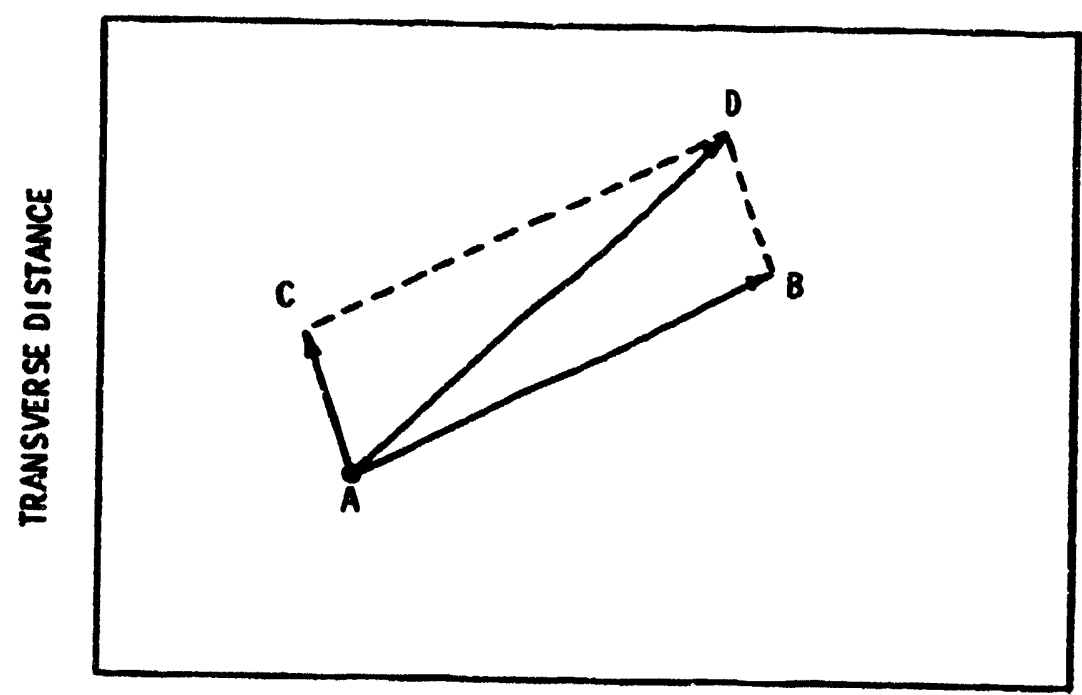

LONGITUDINAL DISTANCE

FIGRE 3.1. Particle Novement

As discussed above, all water quality nodels of Types I through VI can be applied to dissolved radionuclide transport with minor modification. However, extensive wodel codifications would be needed to simulate the transport of dis- solved and particulate radionuclides coupled with sediment transport. frong water quality codels, Types $I$ and VI are best suited to solve radionuclide transport problems in general.

Sediment transport models as discussed in Chapters 4 through 7 are of two basic types. One is based on a deterninistic approach (e.g., the advectiondiffusion of suspended sediment), and the other consists of stochastic models (mainly bed load sediment transport) based on the transport of bed materials as a sequance of alternating steps and rest periods with appropriate distribution functions. If sediment-only transport models predict suspended sediment concentration, then they can be used to predict particulate radionuclide transport with fairly minor modification. However, simulating the transport of dissolved and particulate radionuclides coupled with the transport of sediment and/or aquatic biota requires extensive modification to these sedinent models. 


\section{Referanes for CuMTER 3}

U.S. melem Regulatory Comission. 1977. Regulatory Cuide 1.113 -

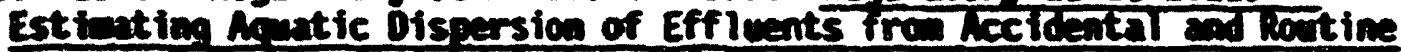

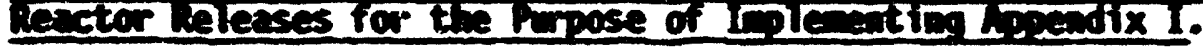

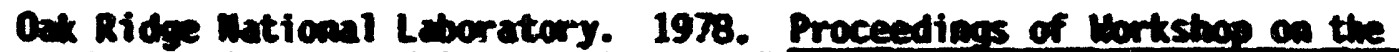

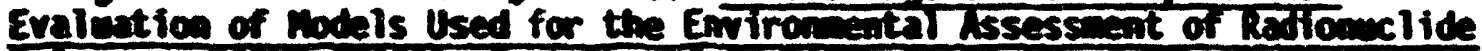

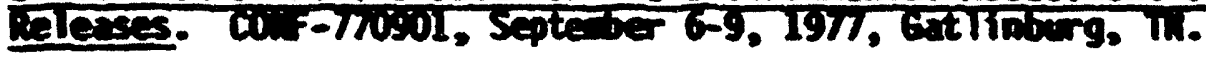




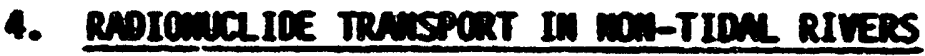

The codels reviened in this chapter, as well as in Chapters 5 through 7. fall into three categories:

1. odels Lesigned to sfmlate radionclide transport in particulate andor dissolved form

2. water quitity modeis mich can be used to simalate the fate of dissolved or particulate radiomulides. These mter quility models are discussed in several sebcategories as identified in Chapter 3.

3. sedinent transport models wich can be nodified to stulate particulate radionuclide movenent. Some of these models also could be used for dissolved radicouclides.

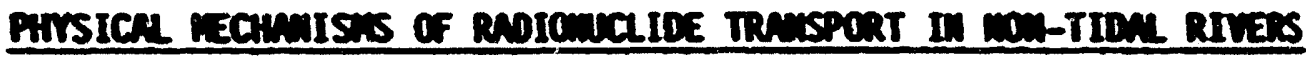

Radionuclides discharged to rivers are dispersed by currents and turbulent aixing. These radionclides are also adsorbed from solution cuto sedinants and biota. This results in a reduction of concentrations of dissolved radiomelides mich way be more easily assimilated by aquatic biota tha sorbed radionuclides. However, contaninated sediments way be deposited on the river bed, becowing a long-tern source of pollution through desorption and resuspeasion. This process may also create a significant pattmay to man. Most of the available nethods for evaluating rodiomuclide transport in surfece mters of not account for radionuclide uptake or desorption into water. Furthernore, these nethods do not account for transpont, deposition ad resuspension of contaminated sedinents. Models that do not compre sorption effects predict that radionuclides will be flustied from surface waters at the same rate at wich water is exchunged (USinc 1977). In actuality, sorption effects would cause sone redionuclides to flust ench wore slowly, at epproximately the rate at wich the strea components are exchnoged in the meter systen (Usux 1978 a,b: uszi 1978). Heace, in sane cases meglection such detention effects precludes accurate prediction of redicunclide distributions in tive and spece. This 
section presents results of field and laboratory studies mich illestrate the importance of the above-mentioned physical and chemical nechansins affecting radionuclide transport in rivers. Mctual adsorption and desorption mechanisms and distribution coefficients for various radionuclides are discussed in length in Chapter 8. The following two exaples suffice to indicate the inportance of sedinent on radiomelide migration:

1. Field measurewents taken in the early $19 c 0$ s indicated that approximately 753 of the dissolved radiomiclide, ${ }^{6} \mathrm{Zn}$, released at the Hanford site in unshington was adsorbed by river sedinent within 200 af les domstrean (Haushild et al., 1973).

2. Radiomuclide field measurenents obtained from the Clinch River near oax Ridge Mational Laboratory in Tennessee in the early 1960s indicated that approximately $90 x$ of ${ }^{137}$ Cs released was adsorbed by the river's suspended sediwent within a 10-eile reach downstrea of the effluent discharge (Churchill et al. 1965). At the same time, only about 58 of the $\mathrm{SO}_{\mathrm{Sr}}$ was associated with river sediment.

Moreover, in experimental studies conducted in a 200 -ft long hydraulic flum, E. F. 6loym and his associates (6losm et al. 1963-1972) found that interactions with the above-nentioned strean components could have a significant detention effect on the transport of various radionuclides. In instantaneous release experiments in a hydraulic flowe, wore than 906 of the dye passed through the flume within 1 day under a mean flow with a travel time of $10 \mathrm{hr}$, wereas only 24\%, 18\%, 11\%, and 28\%, respectively, of injected ${ }^{85} \mathrm{sr}$, ${ }^{137} \mathrm{Cs},{ }^{58} \mathrm{Co}$, and ${ }^{6} \mathrm{Zn}_{\mathrm{n}}$ were recovered at the domastreen end of the flume within 1 day (Shih and 6loym 1967). Rowe and Gloym (1964), Yousef and 6losma (1964), and Shith and Gloym (1967) have show that ${ }^{137}$ Cs and ${ }^{85} \mathrm{Sr}$ can be detected in meter, sedinents, and plants several conths after a single release of these radiounclides. These results reveal the cccurrence of adsorption and desorption of these muclides, which become a loager-tern somrce of pollution lifited by redionuclide decay. 
thitrodranic Treasport

Hytrodynaric transport is the principi transport mechanisa for radionmclides. The primary hydrodymanic mechanisas are advection and diffusionl dispersion. In the Clinch River system, Parker et al. (1966) found from field studies and mass-balance analyses that wost of the radionuclides being discharged from operations at the Oak Ridge Mational Laboratory passed through in the mater phase as dissolved radionuclides, with the exception of ${ }^{137} \mathrm{Cs}$, which has a large distribution coefficient.

Suspended Sediment

As indicated carlier, sediment plays an finportant role in radionuclide transport in rivers. One of the earliest investigations to deternine the ieportance of uptake of radiomuclides by sediment mas conducted by Carritt and Goodga1, wio studied the uptake of various radionuclides in solution by suspensions of Roanoke River and Chesapeake Bay sediments, bentonite, fuller's earth, and powdered pyrex glass (Sayre et al. 1963). The percentage of radionuclides sorbed by sediments ranged between $10 \%$ and $90 \%$. In addition, one of their tests showed that sorption by the sediment particles resulted in particulate radionuclide concentrations of more than 10,000 times those in the surrounding solution.

Tritremel et al. (1966) conducted tests to examine the uptake of various fission products by typical suspended sediment loads. They found that ${ }^{90} \mathrm{Sr}$, 131 I, ${ }^{140}$ La and other fission products tested were adsorbed fairly rapidly on the suspensions but were not permanently fixed. Results indicated that $50 \%$ of the radionuclides may have redissolved prior to equilibriu conditions. Fron their data they estimated that sorption by suspended sediment my eifect a 258 to $30 \%$ reduction of radionuclides in the maste eff luents of the reactor discharge into the Leithatihl Canal in Mustria.

Existing data indicate that some radionuclides are adsorbed to river sediment rather quirkly and then wigrate with the sediment movements. Deposition of suspended sediment with adsorbed radionuclides can result in a buildep of radioactivity if the rate of accumlation through deposition exceeds the 
rate of matural radionctive decay. Moreover, some of the contanimated sedinent could be resuspended, particularly uring periods of high flow, and thea be redeposited farther downstrean. Thus, an understanding of sedinent transport echanisus is essential to the prediction of radioneclide concentrations.

Brisbin et al. (1974) estimated that $7.2 \%$ of the ${ }^{137}$ Cs released to Steel Creek fro the Savanah River Laboratory at Aiken, South Carolim, was contained in the bed sediment, thus preventing the wovenent of a significant anount of ${ }^{137}$ Cs domistrean into the Savamah River. The amthors state that the situation under imrestigation is one of the highest knom concentrations of a predomimantly single isotope contamination of a natural systea.

In field studies conducted on the Clinch and Tenmessee Rivers, Pickering et al. (1956) found that botton sedinent in the vifinch River contained 218 of the ${ }^{137} \mathrm{CS}, 98$ of the ${ }^{60} \mathrm{Co}, 0.48$ of the ${ }^{106_{\mathrm{Pu}}}$ and 0.22 of the ${ }^{90} \mathrm{Sr}$ released to the river during nearly 20 years of operation at the 0ak Ridge Mational Laboratory. Noreover, based on vertical distributions of radionuclide concentrations in the bed sediment, they concluded that the ${ }^{137}$ CS and ${ }^{60}$ Co were incorporated in: ine botton sediment through adsorption by suspended sediment and subseprent deposition of suspended sediment.

As can be seen, the inportance of the adsorption of radionuclides by suspended particles and sedfments is well denonstrated from field and laboratory data. However, the mechanisus involved in the sorption processes are not yet clearly understood. Factors which influence sorption include the type of radionuclide, its cheafical form and oxidation state, particle size, concentration and mineralogic content of the suspended sediment, and various emvironmental conditions such as teaperature, dissolved oxygen, concentration, pH, oxidation-reduction potential, salinity, presence of competing ions, wixing characteristics, and pollutional stresses. The effects of these various factors have been illuaimated to a certain extent by the work of Glosma et al. (1953-1972).

Particle size is particularly important in sorption processes. It has been daterrined that sorption capacity of strean sediments is roughly proportional to the available surface area (Sayre et al. 1963). As pointed out by 
Sayre et a1.. the total surface area of 1- clay is 1,000 thes that for 1-m sand for a given weight. Welson et al. (1966) showed that sall silt and claysized particles contain a much greater concentration of radionuclides than do coarser particles.

\section{Bottom Sedtent}

Direct sorption by bed sedinent appears to have a much smaller effect on radionuclide transport than does sorption by suspended sediment. In hydraulic flume experiments, Bhagat and 6loym (1965) found that suspended atter subsequently deposited on the bed significantly increased the concentration of $103_{\mathrm{Ru}}$ in the botton sedfinent. Oaly less than $5 \%$ of the total ${ }^{103_{\mathrm{Ru}}}$ in the form of $103_{\text {Rum }}$ as adsorbed directly by bottom sedinent. When kaolinite clay suspeasions were added, as auch as $50 x$ of the 103 Rum in the water was adsorbed by the suspended natter. As a result of deposition, the anount of $103_{\text {Rum }}$ in the botton sedineat increased from $1 \%$ to $15 \%$ of the total $103_{\text {Ru }}$ discharged into the flume.

6loyna and his associates (Reymolds and 6loym 1963; Rowe and 6loyna 1964; Clanton and Glojma 1964, Yousef and Gloyma 1964) deterwined from additional studies that sorption by bed sediment is dependent on contact time, the mineralogical and chemical composition of the sediment, and on physical characteristics. They also found that uptake by bed sediment is only partially or siouly reversible.

Yousef et a1. (1970) pointed out that radionuclide migration is rather I inited to near the bed surface, mile activity in deeper layers results from physical processes such as sediment deposition and erosion. Studies were conducted by Gloym and his associates (Rome and Gloyma 1964; Yousef and Gloma 1964; Bhagat and 6loyna 1974; Shih and 6loyma 1966) to imrestigate the migration of radionuclioes to deeper layers of the bed sediment without deposition or resuspension of sediment. Results showed that the specific activity of the bed sedtent decreased exponentially with depth. After 15 to 30 days of contact tine, the depth at wich the specific activity of the sediment was less than 0.18 of that rear the surface was about $2 \mathrm{~cm}$ for ${ }^{65} \mathrm{Zn}$ and $14 \mathrm{~cm}$ for 
${ }^{137}$ CS (Gromiec and Gloyma 1973). Radionuclide concentration data from the Columbia River also indicated a penetration of bed sedinent by the radionemclides (6loyma and Ledbetter 1969).

Results of analyses performed by Brisbin et al. (1974) showed that over $68 \%$ of the total ${ }^{137} \mathrm{CS}$ was located in the upper $20 \mathrm{~cm}(7.9 \mathrm{in.})$ of bed sediment in Steel Creek near Savanah River Laboratory during 9 jears of plant operation (1961 to 1970). Experimental data collected by Mahnoud et al. (1973) using bottion sedinent from the Ismailia Canal in Egypt indicated that for both flowing and nonflowing ecosystems the ${ }^{60}$ co incorporated in the bottom sediment was detected minily in the upper layer, mile ${ }^{134}$ Cs and ${ }^{89}$ Sr migrated to deeper layers.

Biota

Hanoud et al. (1973) found through laboratory investigations that the maximu uptake of ${ }^{89} \mathrm{Sr},{ }^{60} \mathrm{Co}$, and ${ }^{134} \mathrm{Cs}$ by various aquatic plants was reached after 1 to 4 days. A major portion, ranging from $45 \%$ to $85 \%$ of the sorbed radionuclides, was released after 2 to 4 days.

6loyna and his associates (Armstrong and 6loyna 1967; Bhagat and Gloyma 1964; Rove and 6loyma 1964) found that sorption by plant surfaces is rapid and ahost completely reversible. They concluded from their experimental results that plants play an insignificant role in radionuclide transport, except perhaps in slow-moving and enriched streans and impoundments. Gloyna notes that radionuclide concentration data from the Clinch River indicate that effects of plant uptake may be neglected in a mass-balance analysis of radiomuclides (6loyma and Ledbetter 1969).

Thus, the data cited above indicate that sedinent effects on radionuclide transport are important: 1) if the sediment concentration is high, 2) if radionuclides have high distribution coefficients, and 3) if long-term transport and accumlation of radionuclides are of concern. Under these conditions, if sediment effects are not considered, there is significant potential for erroneous evaluations of radionuclide distributions in surface water. 
Sources of dissolved and particulate radionuclide concentration data are listed in Table 4.1. There have been many such studies (Fisher 1970; helson et al. 1966; Osterberg et al. 1966; Haushild et al. 1971; etc.). However, only a sall saple is given here. The Colubia River in Mashington and the Clinch and Tennessee Rivers in Tennessee have been extensively sapled because of the early reactor operations. Cood information sources for the Clinch and Tennessee Rivers include Robertson et al. (1973). A sumary of Hanford Reservation related work (Colubia River) can be found in U.S. Atonic Energy Comission (1973). In addition, several excellent articles may be found in Pruter and AIrerson (1972) and the IAEA Proceedings on "Disposal of Radioactive Mastes into Seas, Oceans, and Surface Haters" (1966). Excellent sources of radionclide data on the Clinch River are Jenne and Mahiberg (1965) and cottrell (1959).

\section{MTHEMTICAL MORELS FOR RIVERS}

The greatest nuber of nodels surveyed mere those developed for rivers. These wodels included radionclide and sedicent transport nodels, and water quality wodels. The radionuclide transport models range from those specifically developed to predict the radionuclide concentrations in the river to those developed as a part of a man-dose model. The rater quality models include various types as described in Chapter 3. The sediment models are of two principal types: 1) deterministic models based on the advectiondiffusion equation or a simpler equation of continuity, and 2) stochastic or probabilistic adels.

Sumaries of radionuclide transport, water quality, and sediment transport models for all four types of water bodies (non-tidal rivers, estuaries, oceans and the Great Lakes, and impoundwents) are show in Tables 4.2, 4.3, and 4.4, respectively.

Radionuclic Transport rodels for Rivers

The radionuclide transport nodels for rivers cover a wide range of complexity and use. One set of codels includes those that are a part of a larger man-dose wodel. These codels generally incorporate dilution of the aterial 
IAPLE 4.1. Radionclide Data for Rivers

\begin{tabular}{|c|c|}
\hline Dereses & River \\
\hline nurteon, 1520 & Clibch and Tenmesses \\
\hline Wirten, $18=2$ & Clituch an Temesen \\
\hline net et., Ist & 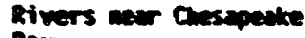 \\
\hline Amatill $*$ al., Les & 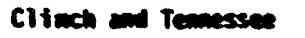 \\
\hline nurcen. Iess & Clituch en Temesses \\
\hline Curtes et al.s 19ss & Andsen \\
\hline Hensintid et al., ISs5 & Colmbia, Late ballula \\
\hline Parker et al.. 196s & Clinct \\
\hline Perkins at al.. 1965 & colembla \\
\hline Pickerity et al.. 195s & Clinch ad Teumesen \\
\hline Crrigu a al.. 1557 & Clind an Tenmeses \\
\hline Corigin al Pictering, 1557 & Clind $\leadsto$ Temesser \\
\hline Struamess at al, 1557 & Clinct and Temessee \\
\hline $\operatorname{sen}$ et: al.. 19as & Creste, \\
\hline Pieker ing. Ino & Clinch tentesses \\
\hline mall alem, $19 n$ & Columbia \\
\hline mete a $1 . .19 n$ & Hedsen \\
\hline 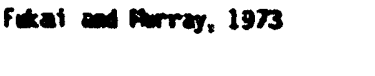 & $\begin{array}{l}\text { Data revien for } \\
\text { semul riwers }\end{array}$ \\
\hline mbetson et al.. 1973 & colemala \\
\hline Crisbia et al., 1994 & $\begin{array}{l}\text { Steel Cract aner } \\
\text { Savemin fiver }\end{array}$ \\
\hline Sime and enteschalt. 1975 & $\begin{array}{l}\text { The Ri hers creat. } \\
\text { Sevalen hiver }\end{array}$ \\
\hline Ecter anishl, ISTS & crect. \\
\hline
\end{tabular}

Ire of Rodionctite tore

Perticulate form of $2060,137 \mathrm{ts}$, soss

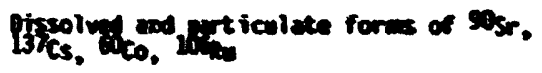

porticulate 65 and se

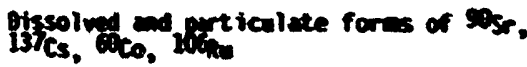

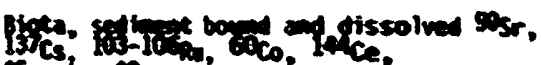
sotrit, 90

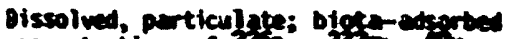

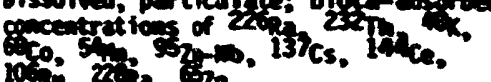

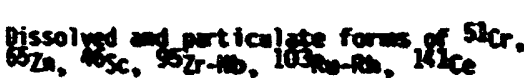

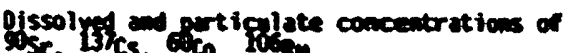

Dissolved perticulate refionaclide concentrations

Perticalys comcentrations of $137 \mathrm{Cs}$,

Purticulate form of 137Cs, CAco, Sise, wein

Prticalge fors of $137 \mathrm{Cs}, 105 \mathrm{ks}$, soss.

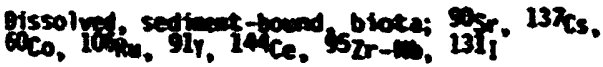

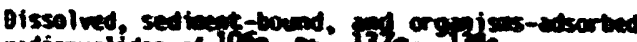

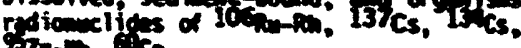

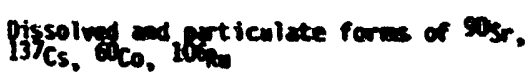

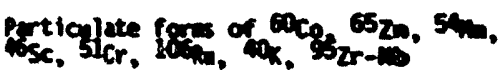

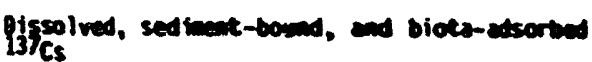

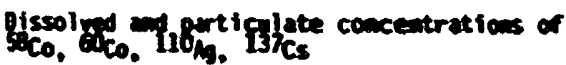
pissoly d purtigulate gonce-prations of

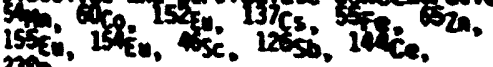
23s.

Purticalate concentrations of $137 \mathrm{Cs}$

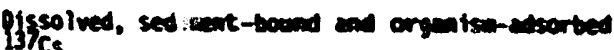

Oissolved prticalate fors of 134cs.

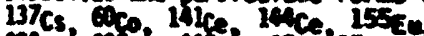

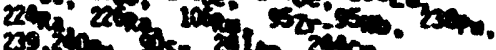




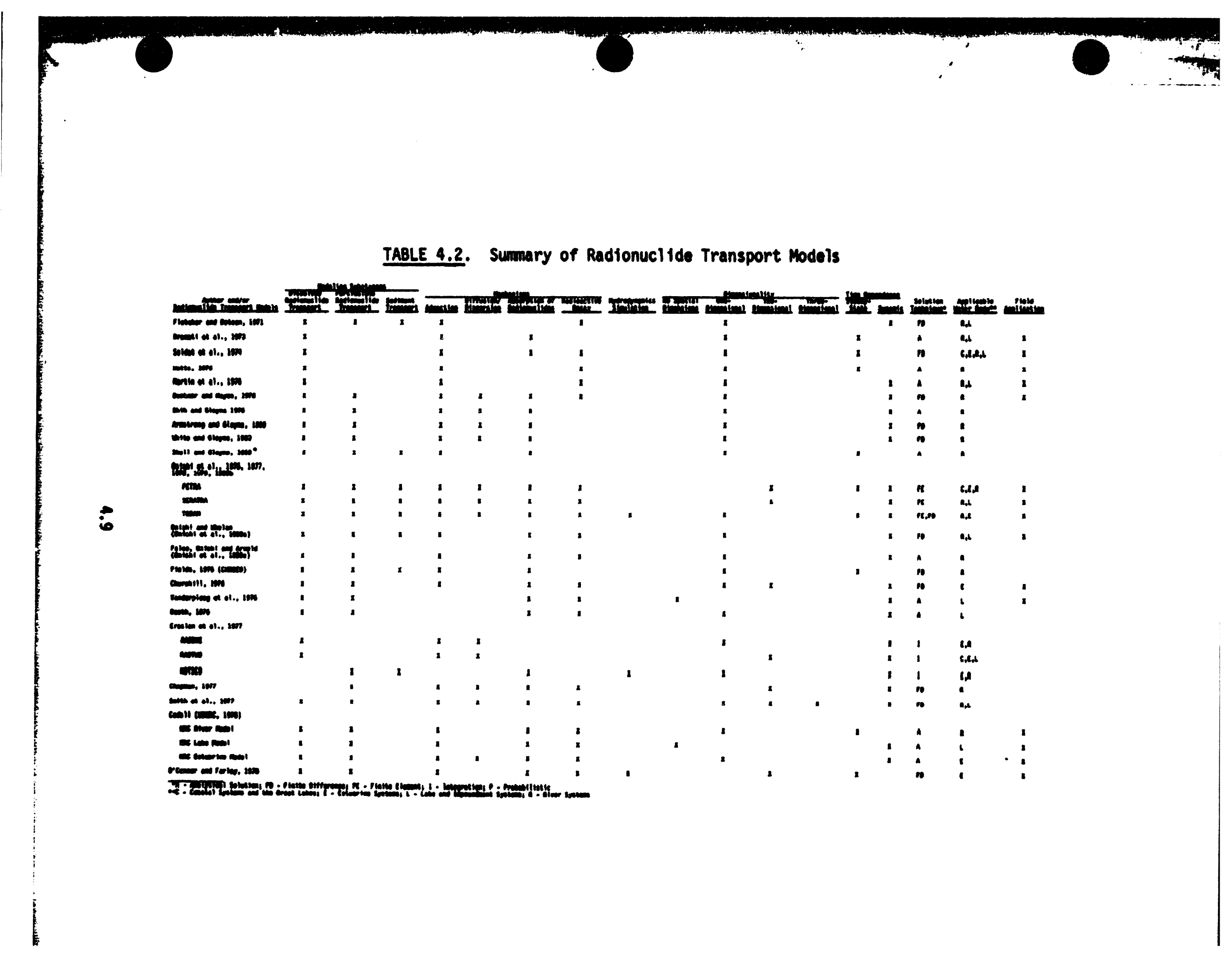


TABLE 4.3. Summary of Sediment Transport Models

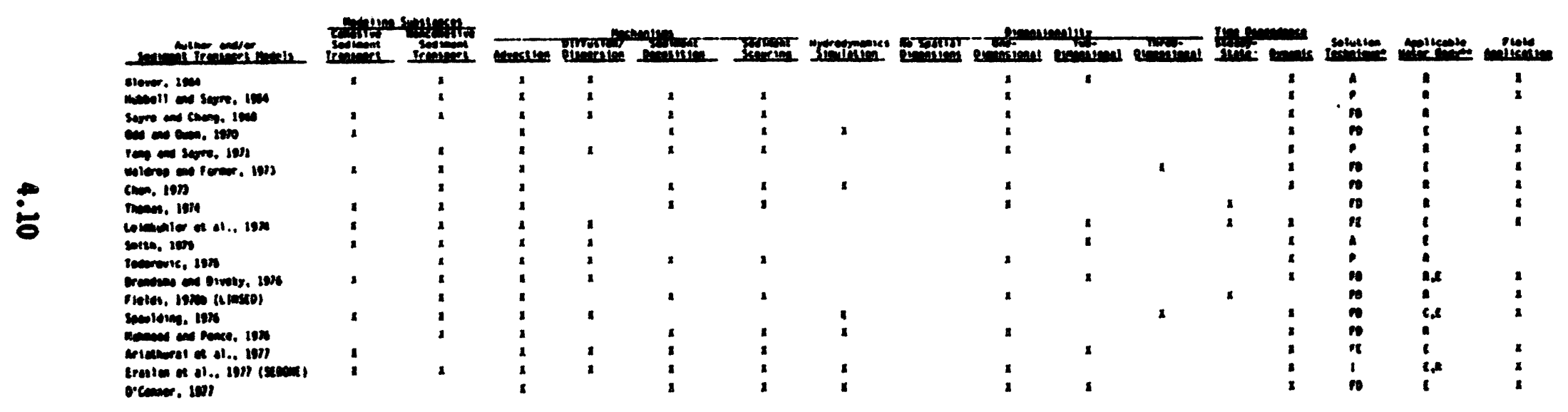

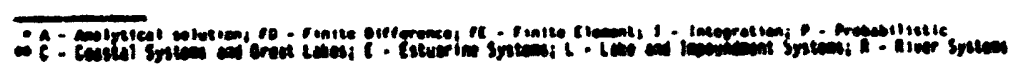




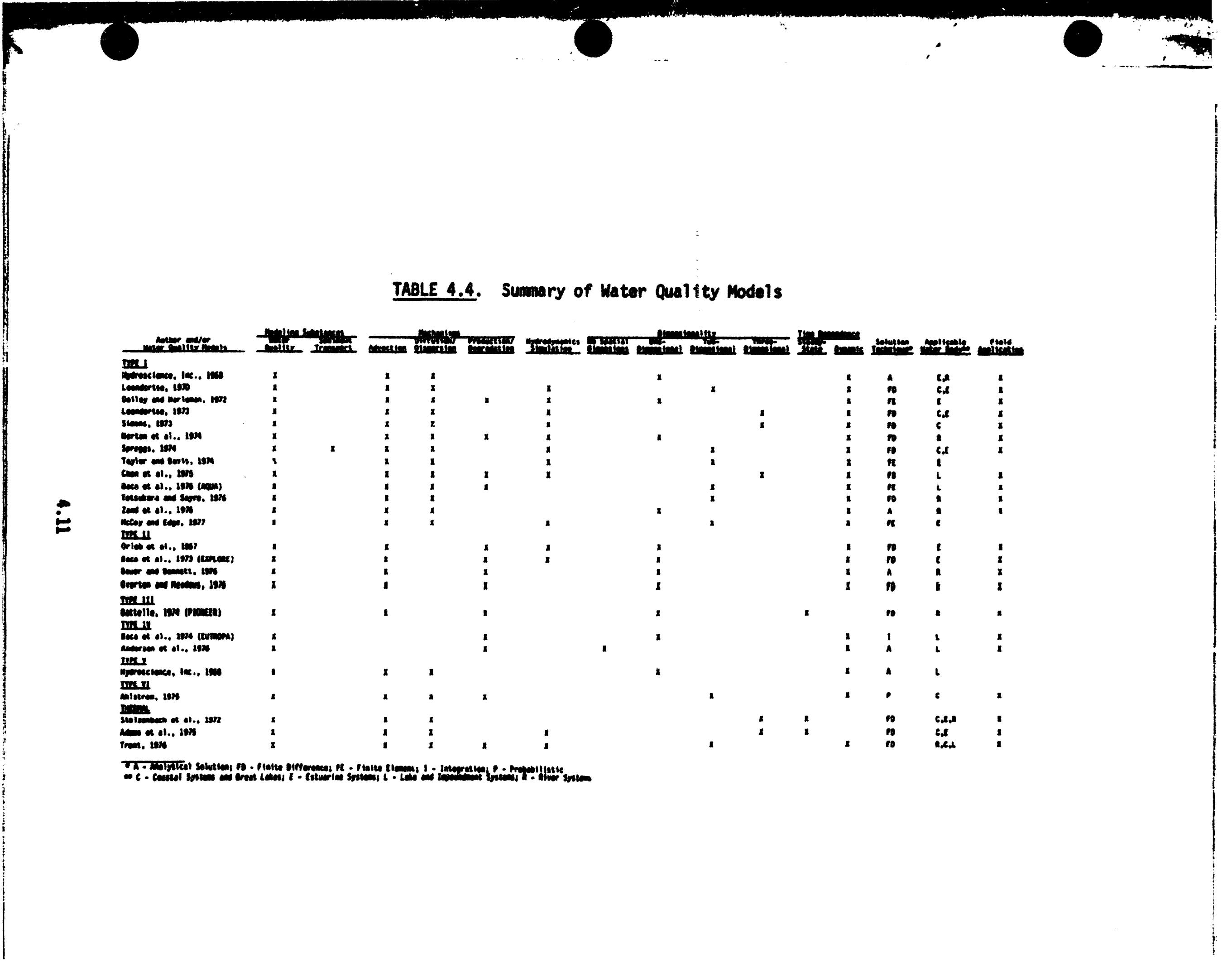


by the flow volum of the river and include decay of the radionuclide according to the travel time to a specified domstrean point. A few of the sodels include prediction of sediment concentrations, al though the reduction in dissolved radionuclide concentration by adsorption is not accountep for. Most of the other models predict the dissolved radiomaclide concentration in the river by solution of the advection-dispersion equation. Source/sink terms in some models are used to simulate uptake by sedinent. Very few models solve both dissolved and particulate radionuclide transport by considering dymanic transport of sediment.

The following first five models are man-dose models mitch contain radiomuclide transport in water as submodels.

F letcher and Dotson (1971); Fletcher, Dotson, Peterson, and Betson (1973)

The model developed by Fletcher et al. (1973) is one of the earliest models to compute the radionuclide dose to man through liquid and gaseous pathmays. components included in this study are show in Figure 4.1. As shom in this figure, the liquid pathway model includes dissolved and particulate radionuclide transport and sediment transport. Various options include inputs from muerous point sources, input from air deposition and overland flow, flood deposition and groundwater transport. The liquid pathmay model is an unsteady, one-dimensional code and calculates the temporal and spatial (longitudinal) distributions of dissolved radionuclide concentration as well as the concentration of radionuclides attached to suspended and bottom sediments of various sizes. The transport wodel can also account for the effects of flow stratification and sediment trapping in reservoirs. The dissolved radionuclide concentration at a given location is found by applying the mass conservation equation with radioactive decay as follows:

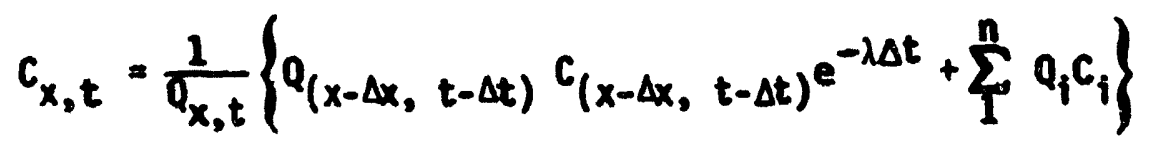




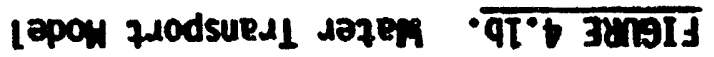

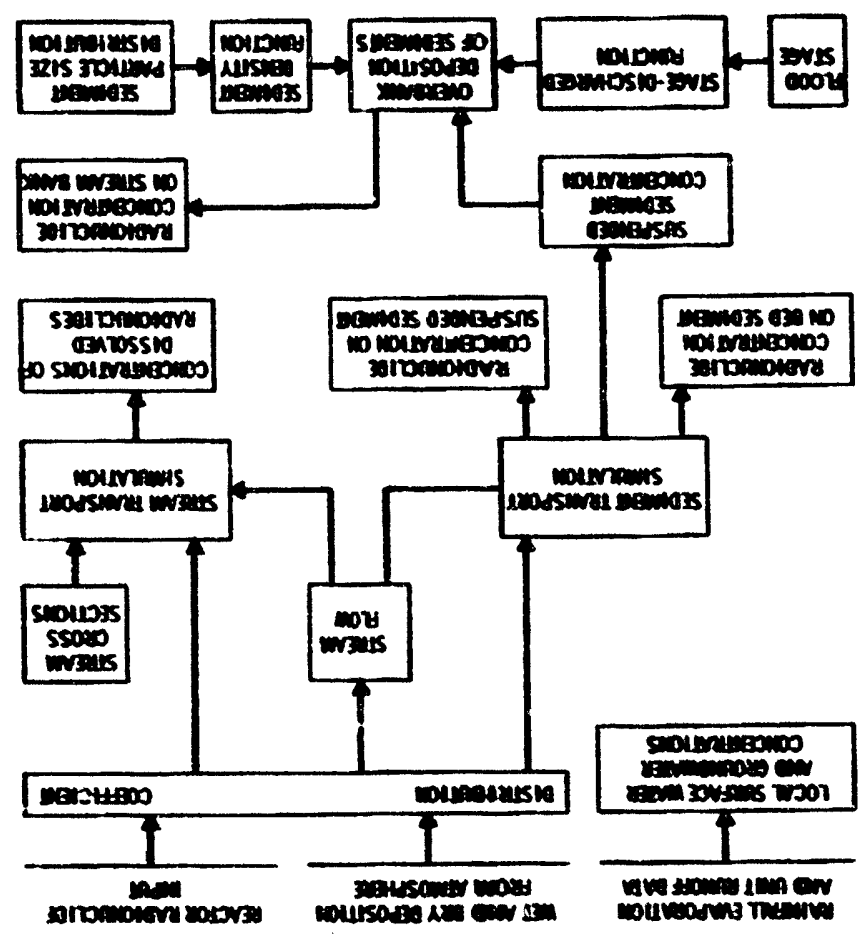

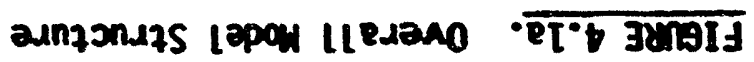

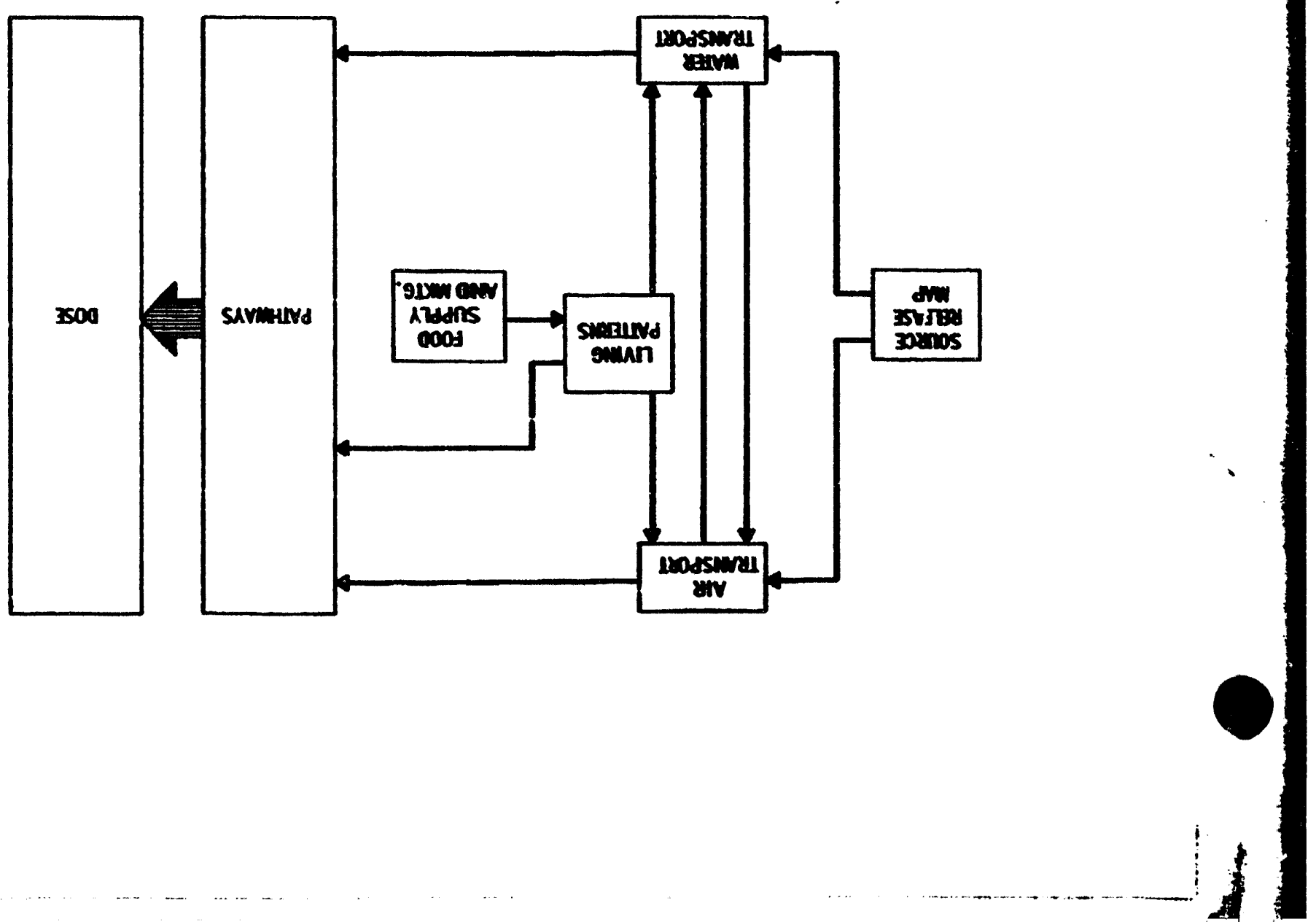


mere

$$
\begin{aligned}
C_{x_{0}} & =\text { dissolved radionuclide concentration at the location } x \text { and time } t \\
\mathbf{C}_{\mathbf{i}} & =\text { dissolved radionuclide concentration of tributary } \\
\mathbf{Q}_{x_{0} t} & =\text { flow rate at the location } x \text { and tive } t \\
\mathbf{Q}_{\mathbf{i}} & =\text { tributary flow rate } \\
\boldsymbol{\lambda} & =\text { radionuclide decay }
\end{aligned}
$$

The sediment transport rate, $S$, is found analytically from the following equation:

$$
S=a \mathbf{a}^{b}
$$

where $Q$ is the flow rate and $a$ and $b$ are constants that must be estinated for each sediment size range. The concentration of radionuclides attached to sediment is calculated from the know dissolved radionuclide concentration and the distribution coefficient value, $K d$. Since the anount of radionuclide adsorbed to the sediment is not subtracted from the dissolved concentration, strictly speaking the ass conservation in a strean reach is not satisfied.

This model, as well as man-dose models in the following sections, expresses the very complicated liquid pathay transport with extremely simplified formulations. Consequently, it is very easy to apply this model, but the results may either be overestimated or underestimated. These nerits and shortcowings are shared by other man-dose codels, as discussed below.

$$
\text { Branati, Harzul10, Rosa and Zara (1973) }
$$

Branati et al. (1973) developed a simple man-dose model, VNDOSA, with two parts; one for gaseous release and the other for liquid discharges. This nodel incorporates the transfer parameters of 24 radionuclides for 1 iquid releases and 20 radionuclides for gaseous re leases in order to calculate anmul doses for five critical organs for various critical groups of population. Formulations for the calculation of radiomeclide transport are very similar to thuse of Fletcher et al. (1973) discussed above. 


\section{Soldat, Robinson and Baker (1974); Soldat (1976)}

These papers discuss a set of models which predict the radionuclide dose to $\mathrm{man}$ and other organisas through air, water, soil and food. As a part of the liquid pathway, time-dependent, one-dimensional distributions of conceatrations of the radionuclides in the meter and those attached to shoreline sed twent are calculated. Dissolved radionuclide concentration at a selected location is calculated as in the nodel of fletcher et al. (1973) (i.e., by dividing the effluent radionaclide concentration at the point of discharge by a dilution factor and by decaying the radionuclide over the travel time to the selected location; the dilution factor is the ratio of the discharge of the receiving water and the effluent flow). An order of magnitude estimate of the radionclide concentration dsorbed to shoreline sedinent was obtained from the rate of radionuclide transfer fro the ater to the sedinent, the concenuration of dissolved radionclide in the adjacent waters, decay rate and lifetime of the muclear facility by using the following equation:

$$
s_{i}=k_{j} c_{i} \frac{\left(1-e^{-\lambda_{j} t_{s}}\right)}{\lambda_{i}}
$$

where

$S_{i}=$ the concentration of muclide $i$ in the sediment

$C_{i}=$ the concentration of muclide $i$ in the adjacent water

$K_{j}=$ mass transfer rate

$\lambda_{1}=$ the decay rate

$t_{s}=$ time of exposure or operating tine of the facility.

The accumblation of radionuclides in the aquatic biota is calculated from the dissolved concentration, biaccumlation factor, and decay rate.

\section{Watts (1976)}

This is another man-dose model, via aquatic pathways, for chromic radioacclide releases. It was developed by nodifying the aqueous phase portion of the Soldat et al. (1974) model discussed above. The unsteady, one-dinensional distribution of dissolved radionuclide concentration is calculated by the following equation: 


$$
C_{i}=\frac{R_{i}}{D}\left(1-E_{i}\right) \operatorname{esp}\left(-\lambda_{i} D\right)
$$

miene

$R_{i}=$ rediomclide i release rate

$U$ - average strein flow rate

$E_{i}=$ fraction of aterial i rewaned from the strea

$\lambda_{i}=$ decas constant of redioneclide $i$

$D=$ travel the from release point to saple point.

The adel was eplied to chronic tritio releases to the Savanalh River, near Stramen River Leboratory, South Carolina.

Mutin, Roibins, Melson, Cousins and Cullitan (1976)

Martin et al. (1976) developed an unsteady, adel, RMoOS, to assess the consequences to man from radiosctive liquid effluents through the cunsumption of drinking mater. Rivers and inpoundents can be modeled, although the frpoundments mist be miformly aixed and the effect of retention time included. The aquatic dispersion wodel predicts only dissolved radionuclide concentrations by solving for conservation of ass and using the routing technique. The radionuclide concentration at a given location is calculated siply by considering the difution of the radionclide effluent by the receiving water and the decrease in radioactivity caused by radicauclide decay. Radionuclide decay is computed using the travel tive from the effluent discharge location to the location under consideration. One unique aspect of this nodel is the fact that pareats and danghters of rediomelides can be solved by taking into account the growth rate of dusgter radionuclides. In the river sibulation, the flow rate downstrean cansot be decreased so that diversion of river weter cannot be accounted for. The codel ans developed for and applied to the Mississippi River Basia. Honever, because of the lack of field data, model verification was not attenpted.

The following models are not man-dose models but were developed to predict radionclide aigration in rivers. 


\section{Buckener en Hoves (1975); Buckner, thaves and latts (1975)}

The custexty, ane-dineasional radiomalide transport nodel developed by Buckier et al. (1975) at Saranath River Laboratory uses the advectiondiffusion equation with a source/sink tern used to calculate dissolved and sedinent-bound redionaclide concentrations. The river is divided into two regions: the min chansel and a deaduater zome. The deadiater 200 represents backwaters and slow-moving sections of the river, as well as adsorptiondesorption with sedinent. The source/sink tern expressing the diffusion of contanimat between deadwater zone and min chanol is represented as:

$$
s_{i}=\frac{P}{h_{s}}\left[u_{i}-c\right]
$$

where

$M=$ the mass transfer coefficient

$P$ = the wetted perineter between deadmater zome and minstrean

$A_{s}=$ cross-sectional area of the deactwater zone

$W_{i}=$ concentration of rediomaclide in the deadinater 20 ne

$C=$ concentration of radiomuclide in the minstrean.

Adsorption and desorption of redioneclides by sedinent and plants are also represeated by the source/siak term given as:

$$
s_{j}=T_{s j}\left[u_{j}-K_{j} c\right]
$$

mere

$T_{s j}=$ mass transfer coefficient between minstrean and compartinent j (sed iment or plants)

$W_{j}$ a radionuclide concentration edsorbed by compartient $j$

$K_{j}=$ distribution coefficient.

The bove formlations of dissolved and particulate rediomalide trasport are the same as those developed by Gloyma and his associates (Shith and Gloyma 1957, 1959, 1970; Anmitrong and Clogna 1938; Mite and Gloym 1959), as discussed in detail later. Although the concentration of redionuclides attiched 
to bed sedineat and plants is calculated for a particular section of the river, the effisets of sediment transportaticn are not included.

The adrection-diffusion equation was solved by a finite difference method. One of the attractive features of the model is that the selection of the best set of parameters for nodel calibration is ade by using a least square approximation and ainimizing the error between wodel prediction and measured data.

The model was aplied to the Savannah River for instantancous releases of be and trition mich are both in a dissolved form only. Computed and measured results for both cases agreed very well indicating the nodel can predict dissolved radionuclide migration very well. However, the meed to use tho different dispersion coefficients (a one onder of magnitude difference) for these two cases in the same river suggests either a problem in the accuracy of mensured data to be used for nodel calibration, or the need for the further wodel improvenent. Since the rodel was applied to dissolved substances only without adsorption/desorption effects, the model must be further tested for its validity for the prediction of dissolved and particulate radiconclide transport with the ir interactions.

Awother paper by Thacketon and Sctwelle (1970) discusses the original dead zone nodel developed by Hayes (1966) in his Ph.0. thesis. The relative nerits of the model are discussed, but particular emphasis is placed an the method for deternining six paraneters used in the model.

\section{Glorm et al. (1963-1972)}

Several unsteady, one-dimensional, mathematical uodels resulted from a series of studies - Radioactivity Transport in Iater" - undertaken by E. F. Gloym and his associates at the University of Texas at Mustin. Imvestigations were ade of the trasport and dispersion of strontiv, cesilu, rutheniun, cobalt, and chrovium with adsorption-desorption mechanises included. In addition to codel development, a series of experinents were conductual in a oodel river consisting of a dual-chanael flue and varions other components. Each chamel of the metal flume as 200 ft long. 1.25 ft wide, and 2 ft deep with a slope wich could be varied betmeen 0 and 0.006. 
Thee of the resulting nodels discussed below are based on the unsteady, one-dimensional, advection-diffusion equation with a source/sint tera added to include the effect of sorption and desorption by aquatic plants and/or nonnovable botton sediment. The governing equations for dissolved radionuclides and particulate radionuclides adsorbed by plants and/or bed sediment are as follows:

$$
\begin{aligned}
& \frac{\partial c}{\partial t}+v \frac{\partial c}{\partial x}=\varepsilon_{x} \frac{\partial^{2} c}{\partial x^{2}}+m_{j} k_{j}\left[c_{j}-k_{d} c\right] \\
& \frac{\partial c_{j}}{\partial t}=k_{j}\left[k d c-c_{j}\right]
\end{aligned}
$$

where

$C=$ dissolved radionuclide concentration

$C_{j}=$ concentration of particulate radionuclide attached to $j^{\text {th }}$ sorbent such as plants and bed sediment

Kd = distribution coefficient

$K_{j}=$ mass transfer coefficient for $j^{\text {th }}$ sorbent

$\omega_{j}=$ mass of $h^{\text {th }}$ sorbent

$\mathcal{U}=$ mean velocity in $\mathrm{x}$ direction.

As show above, the last term in Equation (4.6) expresses the adsorptiondesorption mechanisas. The primary differences anong the three models discussed belon are in the selection of the particulate sorbent (e.g., plants and bed sediment) and the solution technique.

Shin and 6loyn $(1967,1969,1970)$. The model developed by Shih and 6loyn (1967) is capable of describing the transport of radionuclides injected instantaneously into a strean. The wodel takes into acccunt effects of nonnovable bed sediment for adsorption-desorption mechanisms in order to solve dissolved radiomaclide concentration in a stream.

Assumtions interent in the nodel include a constant average velocity and an initial radionuclice concentration in both water and bed sediment of zero. 
Although the solutions are alytical, they contain complicated integrals which ast be solved mmerically. The anthors" wethod for obtaining analytical solution from their initial formation is not clear. Shith and 6losinalso present wore general governing equations wich incorporate the interaction of dissolved radionclides with water in the deadwater 20ne, with plants, and with bed sediment. However, these equations mere not solved.

Shith and Gloym conducted a series of experiments in the river model flume to identify dispersion processes of ${ }^{85} \mathrm{Sr}$ for both contimuaus and instantaneous releases. The value of the dispersion coefficient was deterwined through instantaneous releases of dye. A cont inuous release experiment conducted in the hutraulic flune by using ${ }^{85} \mathrm{Sr}$ ms used to deterwine the value of the mass transfer coefficient. Using these values, Shih and Glosm comared both their sorption-desorption odel and Taylor's dispersed flow nodel (onedimensional, advection-diffusion wodel with mo sink/source term) with observed data from model river experiments using instantaneous releases of ${ }^{85}$ Sr. Values predicted by the dispersed flow nodel without sorption effects deviated significantly from the observed data, wille the sorption-desorption nodel showed better agreement. These experimental results demonstrate the ifportance of sorption mechanisms. Shull and 6loym (1968) note that the solutions developed by Shih and Gloym work well for low velocity nodel rivers but produce errors iben applied to natural rivers.

Armstron and Glome (1968). Armstrong and Gloyma obtained a wore general wodel by solving the above described equations muerically by an explicit finite difference nethod. Their nodel includes the effects of adsorptiondesorption by plants. In order to verify the nodel, they conducted radiomuclide dispersion tests in the river model flume for both instantaneous and continuous releases of ${ }^{85} \mathrm{Sr}$. Agreement of the computer results with the measured data for instantaneous and contimuous releases was very good and reasonabie, respectively. Since this model is a murical simalation codel, the nodel applicability is wider than the analytical wodel developed by Shith and 6loyma. However, their muerical solution requires further iaprovenent because of the instability caused by an initial zero radionuclise concentration on tha: bed. 
Experiments conducted by Armstrong and 6loyn (1967) also revealed the following interesting aspects of adsorption-desorption phenomena: Adsorption of ${ }^{85} \mathrm{Sr}$ by plants is much quicker than desorption from the plants. Rapid sorption of ${ }^{85} \mathrm{Sr}$ by plants is followed by mch slower sorption by bed sediment. These findings agree well with those of mittacker $(1951,1961)$ who studied ${ }^{32} p$ sorption phenomena in a lake. Wnittacker reported that $32_{p}$ followed three steps: 1) initial rapid movement to plankton followed by rapid release, 2) a slower movement to attached algae, and 3) an even slower wovenent to lake sediment. These studies ieply that the ecological system of the lake wa be one of the hoortant factors in the assessment of radionuclide migration in lakes and reservoirs (Chapter 7). However, Arnstrong and Gloyma reported that, within their experimental ranges, aquatic plants played a negligible role in ${ }^{85} \mathrm{Sr}$ transport.

White and 6loma (1969). The one-dimensional mathematical model developed by thite and Gloym includes the mechanisms of sorption and desorption by both plants and botton sediment and uses an inplicit finite difference solution method. It is capable of treating instantaneous, continuous, or time-varying releases of radionuclide activity. The nodel showed good agreement when conpared with data from experiments in the nodel river using both continuous and instantareous releases of ${ }^{85} \mathrm{Sr}$. The model is the basis for the radionuclide block of the Qual-II model (Morton et al. 1974) discussed later.

All three aforementioned models simulate unsteady, one-dimensional radiomuclide transport by accounting for radionuclide adsorption-desorption with bed sediaent and aquatic plants. Foundations and formilations of these models are sound. The analytical solution obtained by Shih and 6loyma (1967) is especially useful because it is sifiple to apply. However, a shortconing of these models is that these sorbents (sediment and plants) are assumed to be stationary. The models include neither transport, deposition and resuspension of sediment, nor sorption-desorption with suspended sediment. Because direct adsorption by bed sediment has in many cases a much swaller effect on radionuclice transport than does sorption by suspended sediment (Bhagat and 6loyma, 1965), these models are rather limited to rivers and certain lakes where almost no suspended sed iment exists. 
Sull and 6loma (1968). A somemat different type of nodel from the previously discussed models of Gloyma and his associates was developed by Shull and 6loym (1968). This wodel is an unsteady, one-dimensional wathematical model with a 1000-aile computation range capable of simulating both dissolved and particulate radionuclide transport in large rivers with contimuous low concentration waste discharges. This routing model, which uses a Lagrangian system, incorporates the effects of adrective-mass transport but does not include the dispersion mechanism. An analytical solution technique is used. The wodel includes stochastic, temporal flow variation; flooding; channel geonetry variation with tive and distance; generalized boundary sorption; and scour and deposition. A brief description of assuptions inherent in each of these nodel capabilities follows.

The simlation period for streanflow synthesis was chosen to be 1 enth except during a flood period. Chamel geometry (i.e., the width and depth of the assuned rectangalar cross section) and travel time are functions of the flow rate. Radionuclide sorption includes the combined effects of sorption by bed sediment, iptake by attached plants, and sorption by the fluid dead zone and is expressed by the same formulation as that of the three previous floyma codels. Sorption occurring in a flood plain is siailar to channel sorption except that the initial concentration of radionuclides on the surface is assumed to be zero. For flood plain deposition it was assuned that $1 \mathrm{x}$ of the total particulate concentration is dropped in the fiood plain. Scour, transport, and deposition of particulate radionuclides in the nodel are based on the following assumtions:

1. All sorbed radionuclides are near the surface of the benthal system and subject to scour or loosening.

2. All sorbed radionuclides are associated with particles that are sall enough to be present in the suspended load, at least nalf of the tive, when they are scoured.

3. A single critical velocity determines the occurrence or nonoccurrence of suspension of this size of particle. 
4. During scour, the strean is assuned to be in equilibrien with respect to sedinent transport; i.e., it is transporting exactly its capacity at every station so that no net deposition or scour of the benthal system cocurs in the river.

Standard output includes monthly transport and storage data for stations at 10, 100, and 1000 ailes belon the miste source and total storage on the flood plain above the 1000-mile station.

This codel was not intended to be used for direct muerical application since the duta required for its verification are not enpirically available. Rather, it was meant to be used as a guide to understanding system behavior. The authors determined from the nodel reswlts that some large reservoirs have the potential for accumlating long-lived radionuclides at a rate as high as half the waste release rate. Benthal sorption and desorption, flow variability, and flood plain deposition were deternined to be insignificant on a hazard basis for long-lived radionuclides on a long-tern basis.

This model is useful, as Sholl and Gloyma pointed out, to understanding the system qualitatively. However, there are many assuptions in the nodel which are abitrary and wich may rot be justified (e.g., the flood plain sediwent deposition abount) when wodel results are considered quantitatively.

Onishi et al. (1976, 1980a), Onishi (1977) Onishi and Wise (1979a,b)

Models SERATRA and TOONM

Onishi et al. (1976) developed an unsteady, two-dinensional (longitudinal and vertical) wodel, SERATRA (Sediment-Radionuclide Transport,) as a means of more realistic prediction of radionuclide migration by coupling it with sediment transport. SERATRA is a finite element wodel wich predicts transport of sediment and radionuclides (and other toxic contaminants). It uses general advection-diffusion equations with decay and sink/source terns and appropriate boundary conditions. The wodel consists of the following three subadels coupled to describe sedinent-contaminant (radionuclide) interaction and migration: 1) a sediment transport submodel, 2) a dissolved contaminant transport submodel. and 3) a particulate contaminant (contaminant adsorbed by sediment) transport submodel. 
Since the wovenents and adsorption capacities of sedimeat vary significantly with sedinent sizes or sedtaent types, the sedinent transport subodal simalates transport, deposition and erosion of three sediment size fractions (or sediment types) of cohesive and noncohesive sedineates. The dissoived contavinant transport submodel includes mechanisus of contanimant adsorption and desorption, as well as radionuclide decay and contaninant degradation resulting frow hytrolysis, oxidation, photolysis, wlatilization and blological activity, where applicable. The particulate contarinant transport subodel simlates transport, deposition and erosion of contaminants associated with each sedinent size fraction.

Adsorption-desorption mechanisis were assuned to have occurred between dissolved contaminants and sedinents (both suspended and bed sedinents). The mechanisus are expressed by a distribution coeffictent and a transfer rate which describes how quickly dissolved and particulate contaninant concentrations reach the ir equilibriu condition, similar to the right hand side of Equation (4.7) (Onishi and Wise 1979b) These formulations assume that adsorption-desorption mechanisms are completely reversible. However, as shown in Chapter 8 in length, these nechanisms are not fully reversible in wany instances.

SERATRA also predicts changes of bed conditions for sediment and particulate contaminants, including: 1) riverbed elevation changes de to sediment deposition and scour, 2) longitudinal and vertical distributions of ratio of each bed sed tment component, and 3) longitudinal and rertical distributions of particulate contauinants in the river bed. One of the shortconings of the nodel is that it has a vertical dispersion coefficient but does not have a longitudinal dispersion term. The model uses a nomuniform vertical distribution of longitudimal velocity to produce sediment and contminant distributions dispersed from those obtained in cross-sectionally averaged flow cases. However, lack of a longitudinal dispersion term in the molel akes it difficult to excomodate an effect of transwerse variation of longitudinal velocity, mich ay become important in large rivers, to spread the sediment and radiomaclide cloud longitudinally. 
The model was applied to a large river, the Colubbia River (approximately 100-k reach), near the Hanford Site, Mashington (Onishi 1977) to an intermediate size river, the Clinch River (approximately 37-kw reach) near Oak Ridge Mational Laboratory, Tennessee (Onishi et al., 19790) and to very small streass, Four Wile and tholf Creeks (approximately 68-kn reach) in central loma (Onishi and Wise 19790), to simlate migration of sedinents, radiomoclides and pesticides. For the Colubia River, simulation was conducted for the noveinent of ${ }^{65} \mathrm{Zn}$ with and without the adsorption mechanisan to identify effects of $65 \mathrm{Zn}$ adsorption by sediment.

For the Clinch River, simulation mas also conducted for both continoous and instantaneous releases of ${ }^{137} \mathrm{CS}$ and ${ }^{90} \mathrm{Sr}$. These radionaclides were selected not only on the availability of field data but also for their extreme adsorption characteristic (cost of the ${ }^{137}$ Cs is transported with sediment, wile the majority of the ${ }^{9 O_{S r}}$ is transported in a dissolved form). Comparison of computed results with measured data for both Columbia and Clinch Rivers indicates good agreement for both sediment and radionuclide distributions, as shom in Figure 4.2 (Onishi et al. 1980a). However, because of very limited data to be compared, the model is mi fully tested for its validity. Currently, SERATRA is being applied to the Cattaraugus and Butternilk Creeks mear the West Valley radioactive maste burial site in Mew York to conduct a comprehensive verification test. Examination of simlation results for the Colubia and Clinch Rivers clearly indicates that suspended sediment has significant effects on radiomuclide transport through radionuclide adsorption and desorption, and desorption and resuspension of contaninated sediment.

Additionally, the two-dimensional model, SERATRA, was simplified to a onedimensional (longitudinal) code Iransient One-Dimensional Degradation and Migration Model (TOOM) including the longitudinal dispersion tern. This one-dimensional, sediment-contaminant program was then coupled to an unsteady, hytrodymanic node1, anoper (Freed 1973), to form a new nodel suitable to many rivers mere vertical distributions of Ediment and radionuclides are not a mor concern. In the special case of the intermittent flow of Mortandad Can-

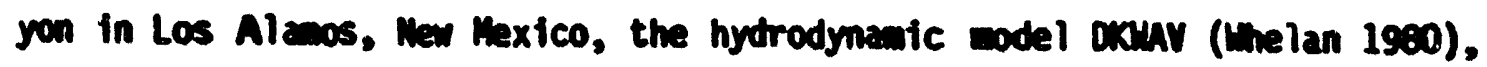
rather than OMOPER, was Eaployed to estimate movements of flow, sedicent and rediomuclides (Onishi et al. 1980). 


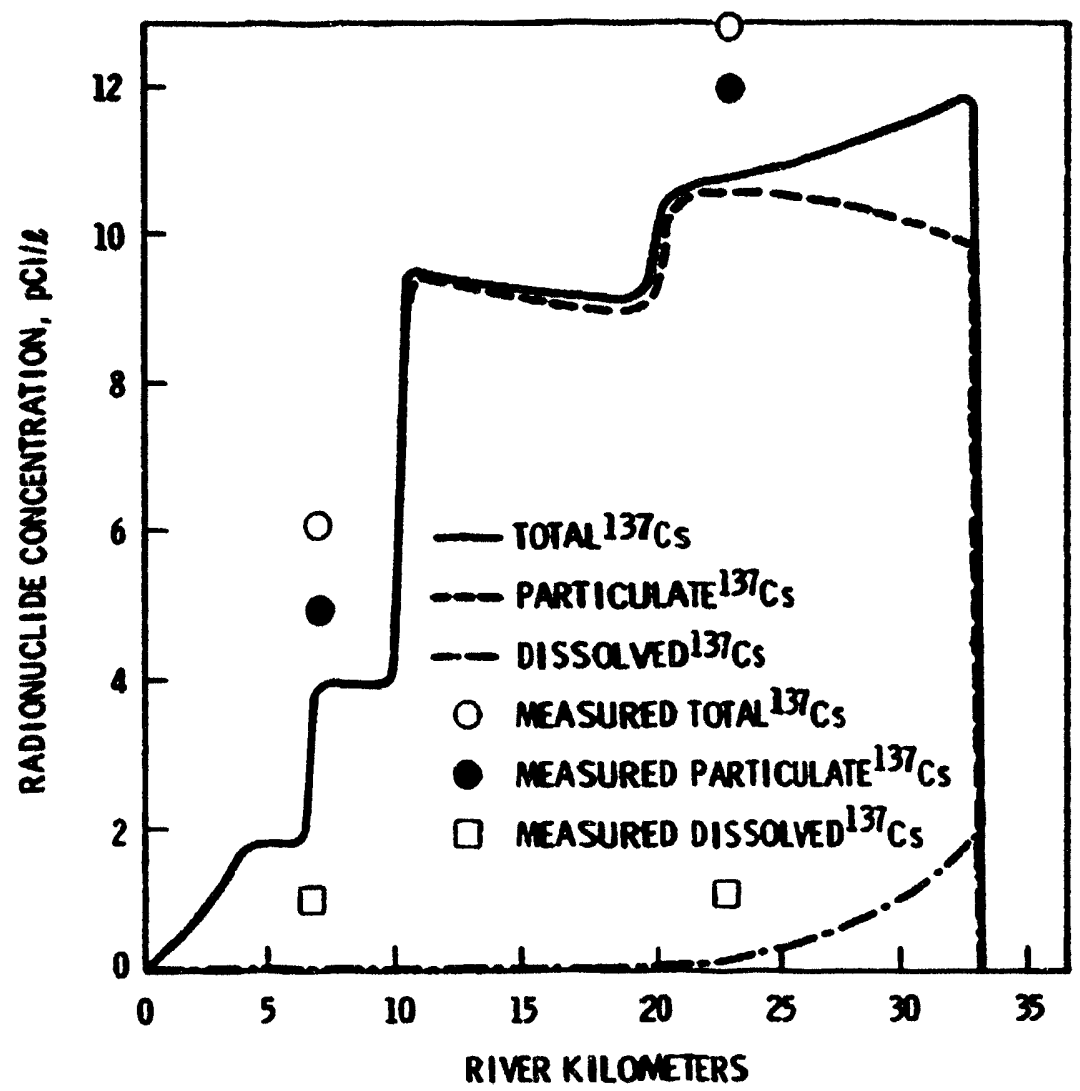

FIGURE 4.2. Longitudinal Distributions of Dissolved, Particulate and Total Cesium-137 Concentrations in the Clinch River, Tennesst?

Onishi et al. (1976, 1979); Onishi and Ecker (1977); Onishi and Wise (1978a,b) Hodel FETRA

Onishi et a1. (1976) also developed another unsteady (as well as steady) sediment-contaminant transport model, FETRA. This model solves longitudinal and lateral distribution of sediment and contaminant transport by including sediment-contaminant interaction and wave-sediment interaction mechanisas. FETRA is applicable to relatively wide and shallow water bodies, such as wide estuaries, coastal waters, the Great Lakes, as well as wide rivers. Detailed descriptions of FETRA are given in Chapter 5. 


\section{Fields (1976a)}

Fields' model, ChusED, is capable of simulating the transport of trace contaninants in the dissolved form and the particulate form (adsorbed to sediment) as runoff from the land surface or as flow in a chanmel. CHuSED is a composite model combining the Wisconsin Hytrologic Transport Model (HIM) with a sedisent transport model for a rectangular strean channel (SEDTRM). Both the IMTM and the SEDTRM models are components of the Unified Transport Model wich simulates the transport of a trace contaminant through a watershed ecosystem. In the chamel, the dissolved contaninant transport is governed by the hydrologic flow routing of the $\mathrm{Wm}$, while the adsorbed contaninants are routed according to the sediment transport dynamics of SEDTRM, described below.

Fields uses the distribution coefficient, Kd, to allow for simulation of first-order chemical exchange between the water and the sediment in the channel system. Such exchange is assumed to occur at both input and output of each reach. The Kd value for the pollutant of interest is assumed to be the same for each of the 12 sediment size classes included in SEDTRM and for each river reach. However, in reality $\mathrm{Kd}$ values do change significantly with sediment sizes and types due to large variations in exchange capacities and surface areas of sediments with sediment sizes and types (Kennedy 1965; Jenne and Mahlberg 1968). Commonly, the finest sediment clay has a larger Kd value than silt, wich in turn has a greater Kd value than sand (Pruter and Alverson, 1972). A! though ChusEd does not allow for a variable $K d$ value, it does include a parameter wich must be specified by the user for each sediment size class to indicate whether the size c?ass is to be included in sediment-contaminant interactions. Because CHuSED is not compatible with the other one-dimensional mode is of the Unified Transport Approach (UTA) progran deveioped by Oak Ridge Wational Laboratory, another sediment transport model (SEDOWE) has been deve 1oped (Eraslan et al. 1977; Hetrick et al. 1979). SEDowe will be further discussed in this chapter. Radionuclide transport models applicable to rivers which are also part of the UTA program include RADOHE, a one-dimensional, dissolved radionuclide model and HOTSED, a model for the transport of particulate radionuclides (Eraslan et al. 1977), both of which are discussed in Chapter 5. 


\section{Chapm (1977)}

In the dissolved and particulate contaninant transport adel developed by Chopan (1977), the basic equation for dissolved contaninants is a twodimensional, unsteady, advection-diffusion equation with a sink/source term containing the Freund ich formulation of adsorption-desorption mechanisa. In this equation, the longitudinal velocity component was deleted by assuring the flow is uniforn and the coordinate system moves with the flow. However, loomgitudinal velocity varies vertically according to the logarithric velocity distribution with Von Karmin comstant equal to 0.4. The vertical diffusion coefficient was estimated from the vertical velocity distribution and stratification. The longitudinal dispersion coefficient was also calculated from the vertical distributions of the flow. The suspended sedinent profiie is assumed to be one wich is independent of time and longitudinal direction. A particulate contaminant equation is formulated as: the rate of change of particulate concentration is equal to the anount adsorbed by or desorbed froa sediment. This type of expression is the same as those obtained by Shih and 6loym (1967) and Buckmer and Hayes (1975). The dissolved and particulate contaminants were then solved merically by an explicit finite difference scheme.

In general, the model can be applicable to cases with steady flows in uniform thannels. However, it has several inherent linitations which preclude its wide application. First, the assumtion that flow and sediment concentration are independent of longitudinal distance is not generally valid. Especially, since sediment transport rate is in general proportion to the third to fifth power of velocity, the model assumption of constant sediment concentration with longitudinal distance and time greatly linit its applicablity. Secandly, the method to calculate the longitudinal dispersion by using the vertical distribution of flow will underestimate the dispersion in large natural streams. In large natural strews, nomuniformity of transverse distribution of flow dominates the longitudinal dispersion (Fisher 1967) but not by the vertical distribition of flow as Chapanan used it to obtain longitudinal distribution coefficient, as shared by SERATRA for its shortcomings. Finally, the wodel must assume that there is no initial concentration of contaminants in a study region. 


\section{Srith et al. (1977)}

Smith et al. (1977) reported a compartment wode 1, Exurs, to predict tressport and transforma' ion of potentially harnful chemicals in a freshnater environent. Although the model mas developed for toxic chemicals, it is applicable to radionaclides as mell. The model, Exum, calculates both dissolved and purticulate chemicals including the mechanisas of adsorption and desorption and chearical and biological degradation. The nodel handles each cherical degradation mechanism separately. Chemical degradation results from hydrolysis, oxidation, photolysis, and volatilization. Although the effects of particulate chemical deposition and resuspension are included in the codel, the acounts of sedinent transport, deposition and scouring must be supplied to the codel as input data at each computation point. Exns is limited to transport and transformation processes that might occur under steady-state environmental exposure, such as continuous releases of chearicals to steady-state flow and sediment conditions.

Since the model divides the modeling area into a muber of completely mixed compartments, it can be applied to streans and lakes as one-, two- or three-dimensional cases. Exars uses the predictor-convector method to integrate governing equations. The nodel was used to study various chewicals including p-cresol, benz(a)anthracene, benzo(a)pyrase, quinoline, benzo(f)quinoline, 9H-carbazole, M-dibenzo(c,g)carbazole, enzo(b)thiophene, dibenzothiophene, methyl parathion, and mirex.

Codell (LeC Plog-flou Hodel) (usinc 1978)

Codell at MaC developed a Plug-flow Model by assuming that the radioactivity from the source was considered tc de moving as a plug in a uniform channel domstrean to the mouth, as illustrated in Figure 4.3.

In a steady, unifornly flowing, plug-flow channel, concentrations of dissolved and particulate radionuclides, $C$ and $C_{P}$, can be described by the following equations: 


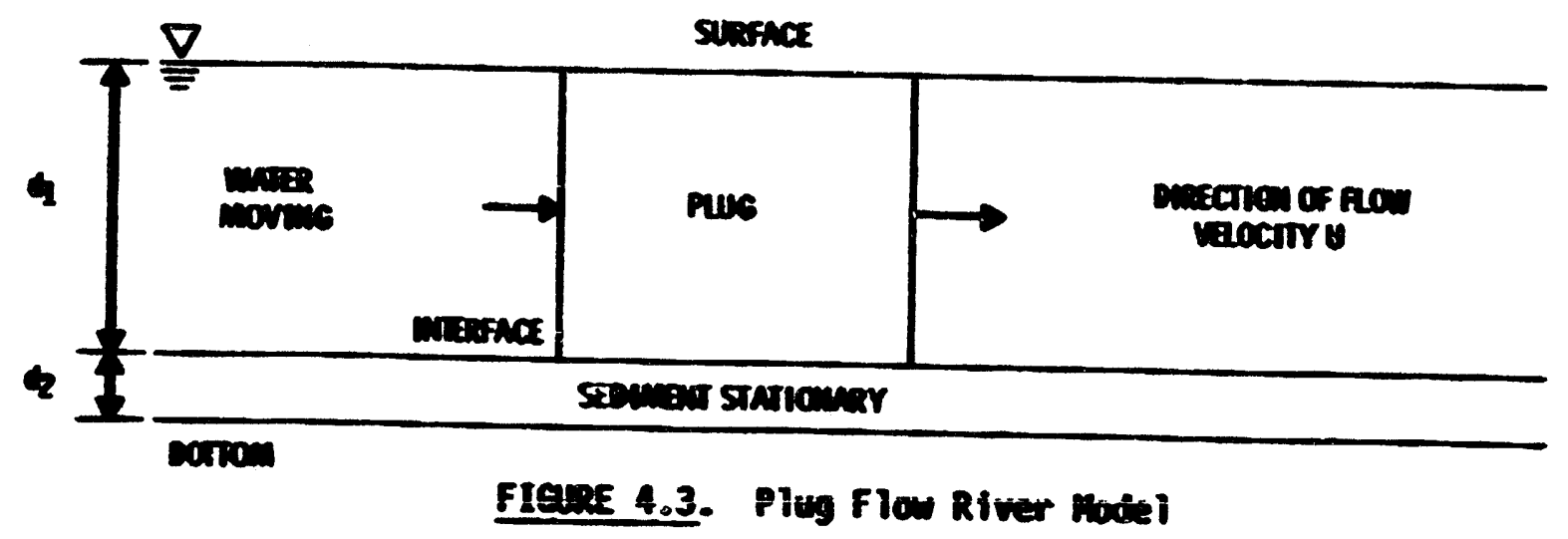

$$
\begin{aligned}
& v \frac{d}{d x}=\lambda_{1} c_{i}-\lambda_{2} c \\
& c_{p}=\frac{\lambda_{3}}{\lambda_{4}} c
\end{aligned}
$$

where

$$
\begin{aligned}
& \lambda_{1}=\frac{K_{f}}{d_{1} R_{d}} \\
& \lambda_{2}=\lambda+\frac{\varepsilon v K_{d}}{d_{1}}+\frac{K_{f}}{d_{1}} \\
& \lambda_{3}=\lambda+\frac{E v K_{d}}{d_{2}}+\frac{K_{f}}{d_{2}} \\
& \lambda_{4}=\lambda+\frac{\varepsilon r}{d_{2}}+\frac{K_{f}}{d_{2} K_{d}} \\
& K_{f}=\text { the coefficient for direct transfer from the mater to bottom } \\
& K_{d}=\text { the equilibriun sorption coefficient } \\
& \varepsilon=\text { the sed iment effectiveness factor }
\end{aligned}
$$


$d_{1}=$ the everage depth of the meter layer

$d_{2}=$ the merage depth of the effective sedinent layer

$\varepsilon=$ the rediological decay coofficient $=1 \mathrm{~h} 2 / \mathrm{malf}$ life

$U=$ averase velocity in the chamel

$v=$ the sedinentation rate

Equations (4.8) an (4.9) way be solved to give an expression for the mater-phase concentration

$$
C=\frac{\mu(t)}{q} \exp \left\{\left(\frac{\lambda_{1} \lambda_{3}}{\lambda_{4}}-\lambda_{2}\right) \times N\right\}
$$

where

$x=$ the distance from the source

$M(t)$ = the rate of release of : adioactive material at the source

$q$ = the flow-rate past the source

Particulate radionuclide concentrations can then be obtained by Equation (4.9).

anishi ad Melan (Hixim Tank Model with Sedinent Transport) (Onishi 19006)

A wixing tank transport mode1, similar to the one used for the pesticide transport in strems (Onishi et al. 1900b), will be described here (Figure 4.4).

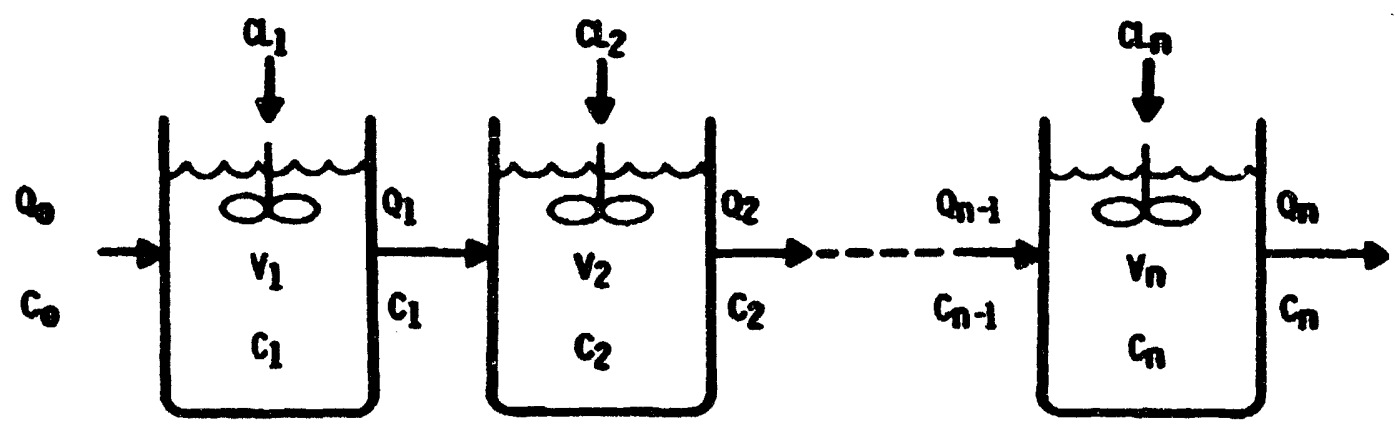

FIERE 4.4. Mixed Tank Model 
The following assumptions are te:

1. River reaches are divided as a series of tanks with wich sedicent and radionuclide concentrations are completely mixed.

2. Radionuclide and sediment contributions from point and nonpoint sources are treated as lateral influx uniformly distributed along the river reach for each segnent.

3. Dissolved and particulate radionuclides are linearly related by a distribution coefficient.

4. Dissolved and particulate radionuclides reach their equilibrium conditions with in one tive step.

5. There is no particulate radionuclide deposition to the river bed nor resuspension from the bed.

The mass conservation of sediment in the $n$-th tank leads to the following sedient transport equation;

$$
\left.\frac{\partial(S V)}{\partial t}\right|_{n}=a_{n-1} S_{n-1}+s_{n}-Q_{n} S_{n}
$$

were

$Q_{n}=$ flow discharge from $n$-th tank

$S_{n}=$ sedirent concentration in the $n$-th tank

$S_{n}=$ lateral influx of sed iment

$V=$ water volune of the $n$-th tank

$t=$ tive

Rearranging Equation (4.11), the following sediment transport equation was cbtained:

$$
\frac{\partial S}{\partial t}=-S_{n}\left[\frac{1}{V}\left(\frac{\partial v}{\partial t}+Q\right)\right]_{n}+\frac{Q_{n-1} S_{n-1}+S L_{n}}{V_{n}}
$$


The mas balances of the dissolved and particulate radionuclides in the n-th tank are:

$$
\begin{aligned}
&\left.\frac{\partial(C V)}{\partial t}\right|_{n}=C_{n-1} C_{n-1}+C_{n}-C_{n} C_{n}-C_{n} V_{n}-S_{n} Y_{n} K_{1}\left(K_{d} C_{n}-C_{P n}\right) \\
&\left.\frac{\partial\left(C_{p} S V\right)}{\partial t}\right|_{n}= S_{n-1} C_{P n-1} C_{n-1}+C_{p} L_{n}-S_{n} C_{P_{n}} C_{n} \\
&-\lambda C_{P n} S_{n} Y_{n}+S_{n} Y_{n} K_{1}\left(K_{d} C_{n}-C_{P n}\right)
\end{aligned}
$$

where

$c_{n}=$ dissolved radiomalide concentration in the $n$-th tank

$C_{P_{n}}=$ particulate radionuclide concentration in the $n$-th tank

$a_{n}=$ lateral influx of dissolved radionuclide

$C_{p} t_{n}=$ lateral influx of particulate radionuclide

$k_{d}=$ distribution coefficient of radionuclide

$K_{1}=$ transfer rate at wich dissolved and particulate radionuclides reach their equilibrim conditions

The total radionuclide wass balance can be obtained by adding Equations (4.13) and (4.14):

$$
\begin{aligned}
\left.\frac{\partial(C V)}{\partial t}\right|_{n}+\frac{\partial\left(C_{p} S V\right)}{\partial t}{ }_{n} & =Q_{n-1} C_{n-1}+C_{n}-Q_{n} C_{n}-\lambda\left(C_{n}+C_{P n} S_{n}\right) \nu_{n} \\
& +S_{n-1} C_{P n-1} Q_{n-1}+C_{p} L_{n}-S_{n} C_{P n} C_{n}
\end{aligned}
$$

Note that

$$
C_{P n}=K_{d} C_{n}
$$


Substituting Equation (4.16) into Equation (4.15) yields the following equation:

$$
\begin{aligned}
\frac{\partial \operatorname{cv}\left(1+S K_{d}\right)}{\partial t}{ }_{n} & =\left(1+s_{n-1} K_{d}\right) Q_{n-1} c_{n-1}+\left(a_{n}+c_{P n}\right) \\
& -\left(1+S_{n} K_{d}\right) Q_{n} C_{n}-\lambda V_{n} C_{n}\left(1+s_{n} K_{d}\right)
\end{aligned}
$$

Hence

$$
\begin{aligned}
\frac{\partial C_{n}}{\partial t} & =\frac{1}{V_{n}\left(1+S_{n} K_{d}\right)}\left[\left(1+S_{n-1} K_{d}\right) Q_{n-1} C_{n-1}+\left(C_{n}+C_{p} L_{n}\right)\right. \\
& \left.-\left(1+S_{n} K_{d}\right) Q_{n} C_{n}-V_{n} C_{n}\left(1+S_{n} K_{d}\right)-C_{n} \frac{\partial}{\partial t}\left\{v_{n}\left(1+S_{n} K_{d}\right)\right)\right]
\end{aligned}
$$

Equations (4.13) and (4.16) are then solved to obtain sediment and dissolved radionuclide concentrations, $S_{n}, C_{n}$, in the nth tank. In general, Equatrons (4.13) and (4.16) aust be solved numerically. However, for the following simplified case, an analytical solution can be obtained:

$$
\begin{aligned}
& c_{0}=0 \\
& a_{n}=0 \quad \text { for all i ? } \\
& s_{n}=s_{n-1}=\ldots=s_{i}=\text { constant for all } n \text {. } \\
& Q_{n}, V_{n} \text { are not functions of time for all } n \text {. }
\end{aligned}
$$

With these conditions, Equation (4.17) may be simplified to

$$
\begin{aligned}
\frac{\partial c_{n}}{\partial t} & =\frac{a_{n-1} c_{n-1}}{V_{n}}+\frac{a_{n}+c_{p} L_{n}}{V_{n}\left(1+S_{n} K_{d}\right)}-\left\{\frac{a_{n}}{V_{n}}-\lambda\right\} c_{n} \\
& =\frac{c_{n}}{V_{n}}\left\{a_{n-1}+\frac{a_{n}+c_{p} L_{n}}{\left(1+S_{n} r_{d}\right) C_{n}}\right\}-\left\{\frac{a_{n}}{V_{n}}+\lambda\right\} c_{n}
\end{aligned}
$$

4.34 
For an instantaneous release of $a_{1}+C_{p} L_{1}$ (wnit of say curies), the concentration of dissolved radionuclide in the n-th river reach (tank) is:

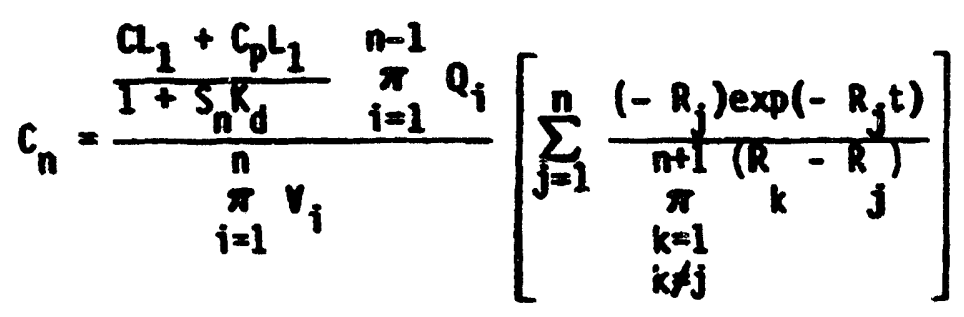

where

$$
\begin{aligned}
R_{j} & =\frac{Q_{n}}{V_{n}}+\lambda \\
R_{n+1} & =0
\end{aligned}
$$

A particulate radionuclide concentration is then obtained by Equation (4.16). Total radionuclide concentration $\mathrm{CT}_{n}$ is then calculated by:

$$
C T_{n}=C_{n}+S_{n} C_{P_{n}}
$$

Falco, Onishi, and Arnold (Plug flow Model with Sediment Interaction) (Onishi 1980)

The following analytical solution was derived here for radionuclide transport in rivers by generalizing an original approach taken by J. W. Falco at EPA Environmental Research Laboratory, Athens, Georgia. The following assumtions are made:

1. The flow is steady and uniform in a uniforn channel.

2. Sediment concentration is constant.

3. Radionuclides are released instantaneously along river reaches.

4. Dissolved and particulate radionuclides are linearly related by the distribution coefficient.

5. Dissolved and particulate radionuclides reach their equilibrium conditions within ore tine step.

6. There is no deposition of particulate radionuclide to the river bed nor resuspension from the bed. 
The governing equation and the initial condition of dissolved radiomuclide transport are:

$$
\begin{array}{ll}
\frac{\partial C}{\partial t}+U \frac{\partial C}{\partial x}=-\lambda C-S x_{1}\left(x_{d} C-C_{p}\right) & \\
C=f(x) & \text { at } t=0
\end{array}
$$

where

$C=$ dissolved radionuclide concentration per unit volume of mater $c_{p}=$ particulate radionuclide concentration per unit weight of sediment $k_{1}=$ radionuclice transfer rate at wich dissolved and particulate radionuclides reach their equilibriu conditions

$K_{d}=$ radionuclide distribution coefficient

$S=$ sediment concentration

$U=$ velocity

$t=t$ ime

$x=$ longitudinal distance

$\lambda=$ radionuclide decay rate

For particulate radionuclides, the governing equation and the initial condition are:

$$
\begin{gathered}
\frac{\partial C_{p}}{\partial t}+U \frac{\partial C_{p}}{\partial x}=-\lambda C_{p}+K_{i}\left(K_{d} C-C_{p}\right) \\
C_{p}=g(x) \quad \text { at } \quad t=0
\end{gathered}
$$

Mote that:

$$
C_{p}=K_{d} C
$$

Total radionuclide concentration, $c_{t}$, is:

$$
C_{t}=C+S C_{p}=\left(1+S K_{d}\right) C
$$


Hence, ihe total radionuclide transport equation can be obtained by suming Equation (4.21) and a product of sediment concentration and Equation (4.23):

$$
\frac{\partial C}{\partial t}+U \frac{\partial C}{\partial x}+S \frac{\partial C_{p}}{\partial t}+u \frac{\partial C_{p}}{\partial x}=-\lambda C-\lambda S C_{p}
$$

Substituting Equation (4.25) into Equation (4.27) and rearranging a resulting equation yields:

$$
\frac{\partial C}{\partial t}+U \frac{\partial C}{\partial x}=-\lambda C
$$

The initial condition for total radionuclide transport is:

$$
C_{T}=C+S C_{p}=f(x)+S g(x)
$$

or

$$
C=\frac{f(x)+\sin (x)}{1+\sin _{d}}=f(x)
$$

Equation (4.28) with the initial condition, Equation (4.29) can be solved by the method of characteristics. The solution to Equation (4.28) (i.e., the dissolved radiomuclide concentration) then becomes:

$$
C=F(x-u t) e^{-\lambda t}
$$

Concentrations of particulate and total (sum of dissolved and particulate) radionuclides are then computed by Equations (4.25) and (4.26).

If computations for core general radionuclide releases are desired, the following convolution integral athod will produce the desired solution: 


$$
c(t)=\int_{0}^{t} c_{i}(t-\tau) 6(\tau) d
$$

where

$$
\begin{aligned}
& C(t)=\text { dissolved concentration at time } t \\
& C_{i}(t-\tau)=\text { analytical solution for concentration at time } t-\tau \text { for an } \\
& \text { instantaneous release wich occurred at time } t=0 \\
& \mathbf{G}(\tau)=\text { a function defining a noninstantaneous rate of radionuclide } \\
& \text { release }
\end{aligned}
$$

Particulate and total radiomuclide concentrations for this case are also obtained by Equations (4.25) and (4.26).

Mater Quality Models in Rivers

All of the river mater quality models except for the model developed by Yotsukura and Sayre (1976) were one-dimensional afvection-dispersion models. The models included general source/sink terms which represented a large number of different factors including decay, inflow, various biochemical and chemical transforations as well as hydrodymamic effects.

Water Ruality Hodels of Type I

Morton, Roesner, Evenson, and Monser (1974). Models Qual I and II developed by Morton et al. (1974) are general water quality models including dissolved radionuclide as one of the mater quality parameters. The win equation is the unsteady, one-dimensional advection-diffusion equation with decay (Mater Quality Model of Type I). The decay term expresses various reactions of water quality parameters. Hence, for radionuclides, the radioactive decay is considered, but full sediment and biotic interactions (e.g., adsorption/ desorption; and transport, deposition and erosion of contaminated sediment) was not included in the models. The hydrodymamics can be computed through a subroutine or supplied by a model user. The hydrodynamic subroutine calculates the velocity by assuning steady flow. Solution of the advectiondiffusion equation is obtained by an implicit finite difference formulation. 
These models are good examples of how the general water quality models can be used to predict the dissolved radionuclide concentration and the limitations of these codels for their application to radionuclides with high $\mathrm{Kd}$ values.

The codel qual II was utilized by Willis, Anderson, and Dracup (1976) to simulate $\mathrm{BOO}, \mathrm{DO}$ and total nitrogen in the Truckee River in northern California and Mevada. Agreement between field data and the computer simulation was reasonably good.

Zand, Kennedy, Zellweger and Avanzeno (1976). This river water quality codel was developed to predict the water quality based on unsteady, onedimensional adrection and diffusion with decay of the substances (Hater Quality Model of Type I). The transport equation is solved analytically by assuming the constant velocity. The model as applied to solve migration of chloride, sodium ard stable strontium in the Uvas Creek, California.

The field study conducted by Zand et al. indicates that chloride and sodiu are not adsorbed by suspended sediment but that a significant amount of stable strontion is attached to the sedibent. Interestingly, the agreenents between computed and measured results for chloride and sodium are very good, buic comparison for the stable strontium indicates poor agreenent. This study again demonstrates the importance of radionuclide adsorption-desorption by sediment and the limitation of applicability of water quality models to radionuclide transport.

Yotsukura and Sayre (1976). The model equation is a two-diwensional, advection-diffusion equation without decay and sink-source terns (Water Quality Model of Type I). This water quality mode 1 predicts the steady-state, dissolved constituent distribution in a meandering, nonuniform, natural stream. Two features of the equation derived in this paper are that it employs the transverse cumlative discharge (su of equal-discharged strean tubes) as an independent variable replacing the transverse distance and that it is deve1oped in an orthogonal curvilinear (natural) coordinate system which follows the general direction of the channel flow. With the help of the continuity equation of flow, the transverse advection term, which is one of the very 
difficult quantities to measure in a river and wich also cannot be neglected in a strea, is elininated from the advection-diffusion equation by a transformation where in cumlative discharge replaces transverse distance.

The final equation to be solved is a classic Fickian diffusion equation. This equation can be solved either analytically or by an explicit finite difference method. The model was applied to the Missouri and Potonoc Rivers and the Atrisco Feeder Canal in Mew Mexico. The agreenents between field and predicted results are very good to confirm the validity of the mode1, as shown in Figure 4.5 (Sayre and Yeh 1973).

\section{Nater Quality Models of Type II}

Hydroscience (1968). This report described a series of water quality models developed for the Hudson River - Lake Champlain Area. These nodels include those that calculte water quality parameters in either rivers or estuaries. The lake models are discussed in Chapter 7. Models applicable to rivers and estuaries are discussed below.

The river model is a steady, one-dimensional, convection equation with decay and source/sink terms. The diffusion term is not considered (Water Quality Model of Type II, See Chapter 2). To aid in solving the equation, the cross-sectional area of the river is considered constant along the whole length. The equations are then solved analytically by assuming a steady state and mass balance of aterial entering or leaving the element through advective transport in each geometric element along the river. These analytical solutions have been obtained for transport of conservative and nonconservative substances, including dissolved oxygen.

The estuary model is the same as that developed for rivers except that diffusion is included to predict transport (Mater Quality Model of Type I). ceometry of the estuary can be constant or vary as a function of longitudinal distance. Mass balance of material entering or leaving an element through advective transport and diffusive transport is given for each element. Tidally averaged velocity is used for advection. Analytical solutions are given for four options to express channel geometry as a function of distance including the constant channel geometry. 
These adels have been appliad to the Hudson River estuary. The river nodel has also been applieo to the upper Hudson River.

Baver and Bemett (1976). An unsteady, one-dinensional, water quality nodel was developed by Baver and Remett to simulate the behavios of 00 and BOO in streass. The adel includes convection, decay and sink/source terms but does not have a diffusion ter (Hater Quality hodel of Type II).

Both nitrogenous and carbonaceous biochemical oxygen demands are caiculated by taking into account the settling of aterial, reaeration and decay. The odel equations are solved by a merical integration technique called the convolution approach. Hence the model can be applied to both steady and unsteady flow fields. In the ir paper it was stated that the model was verified but the results are not presented in the report.

Overton and Meadous (1976). Overton and Meadows developed a nodel to predict effects of urban runoff on river water quality. The basic nodel equation is a one-dimensional, unsteady, advection equation with decay am sink/source terms. However, no diffusion term is included in the nodel (Water Quality Madel of Type (I). Cow ination of decay and sink/source terms can represent effects of general nonpoint source runoff, point source pollution, rearation, nitrogenous oxygen deaand, photosynthesis, respiration and sedimentation on water quality. The equations are solved by an explicit finite difference method. The odel was applied to solve the distribution of dissolved oxygen in Third Fork Crzek, Morth Carolina. Some unsteady cases had very good agree. ment. However, the steady-state solution underpredicted the oxygen deficit at each station.

Mater Quality Models of Type III

Haddel et al. (1974), Battelle (1974), Brandstetter and Brown (1977) Model PIONEER. PIONEER is a steady-state, water qliality model soived in Lagrangian coordinates and belonging to Water Quality Models of Type III. As discussec in Chapter 3, a Type III nodel solves water quality parameters by the first order reaction formula. The resulting set of differential equations is solved by a fourth order Runge-Kutta procedure. The solution is then 
assigned to an appropriate longitudinal location by the routine eathod with a knom travel time. Velocity and depth are assumed to be functions of the flow rate, and the travel time through the river reach is calculated from the flow velocity. The following water quality paraneters can be calculated by this node 1:

- total nitrogan

- total dissolved solids

- phosphorus

- coliform bacteria

- amonia

- nitrite

- nitrate

- biocherical oxygen demand

- chlorophyir a

- dissolved oxygen

- toxic compound.

The nodel was applied to the South Platte River Basin in Mebraska and Colorado (Haddel et al. 1974), the Chehal is River in Mashington (Battelle 1974), and the Cheming River in Mew York (Brandstetter and Brom 1977). Comparison of computed and measured values for wodel calibration and verification on dissolved oxygen in the Chemung River shows reasonable agreenent (Figures 4.6 and 4.7 ).

Sedizent Transport Models in Rivers

There are two basic methods (deterministic and stochastic approaches) for describing sediment transport in rivers. The deterainistic approach is to use the advection-diffusion equation of continuity for sediment, or a routine method similar to that exployed for water quality models. This method is represented by the papers by Sayre (1971), Fie.ds (1976a, b), Thomas (1974), Chen (1973) and Mahood (1976). Glover (1964) discusses practical application of this method to field situations. The remaining models are stochastic models for sediment transport. All of these models are for instantaneous release of sediment except for the very general method of Todorovic (1975) for extension of the general instantaneous solution to a contimous release. 


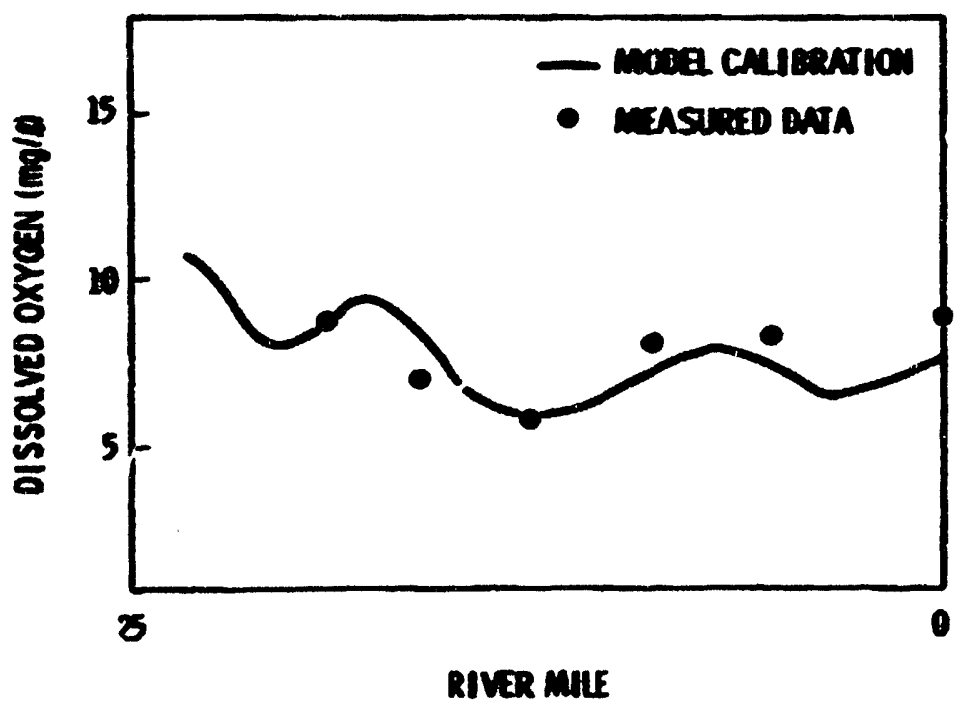

FIERE 4.6. Dis iolved Oxygen Calibration of PIOWEER Model (Bram and Brandstetter 1978)

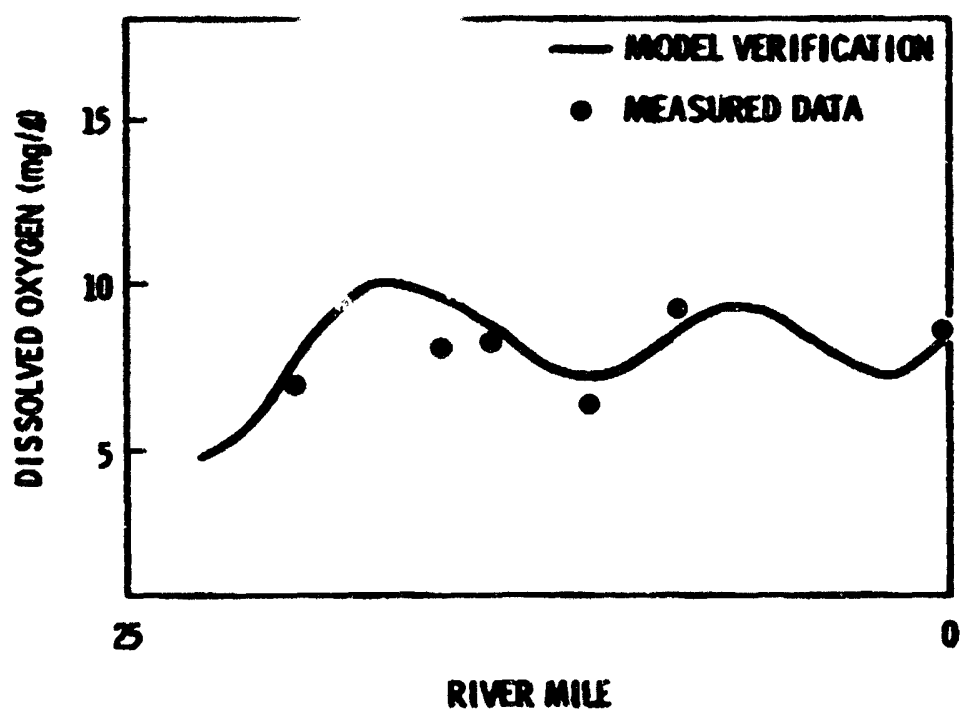

FIQRE 4.7. Dissolved Oxygen Verification of PIOuEER Mode1 (Brom and Brandstetter 1978) 


\section{Glower (19SA)}

Glover (1954) describes the application of andytical solutions to usteady, one and two-dinensional, advection-diffusion equations without decay and source/sick terms to the nuvenent of dissolved aterials or small suspeaded particles. The solutions are for instantaneous line and plane sources, and continuons line sources in streans of uniform cross section. Because of the inportance of longitudinal and lateral dispersion in determining the woveneat of constituents in mter, various formlations to estimate these dispersion coefficieats are listed, along with longitudinal and lateral dispersion coefficteats for may streas and flumes. Computed dispersion coefficients were compared with laboratory and field measurenent. Agreenent of computed dispersions calculated by the Taylor or the Elder formulas with those obtained fro laboratory flumes was very good but differed by several orders of magnitude for streas, wainly due to the nominiforwity of transverse distribution of velocity mich occurs in a natural strean. Taylor and Eldar derived epirical formlations of both longitudinal and lateral dispersion coefficients based on data obtained from natural streas. Analytical solutions were applied to the South Platte River (Mebraska) by using these longitudinal dispersion coefficients, and to the Colubia River by using the lateral coefficient. Comparison of computed concentrations of salinity to field data indicates reasonable agreement for the South Platte River and very good agreenent for the Colubia River.

\section{Sarre and Chan (1958) and Sarre (1971)}

Sayre and Chang developed an unsteady, two-dimensional, suspended sedinent transport adel. The model consists of the advection-diffusion equation and the equation of contimuity for sediment. The tur equations are:

$$
\frac{\partial C}{\partial t}+v \frac{\partial C}{\partial x}-V_{s} \frac{\partial C}{\partial y}=\frac{\partial}{\partial y}\left(\varepsilon_{y} \frac{\partial C}{\partial y}\right)+\varepsilon_{x} \frac{\partial^{2} C}{\partial x^{2}}
$$

and

$$
\frac{d y}{d t}=a y_{s} C\left(x, 0^{+}, t\right)-r w
$$


where

$C$ = sediment concentration

$U=$ the local velocity

$\varepsilon_{y}, \varepsilon_{x}=$ the local turbulent diffusion coefficients for longitudinal and vertical direction, $x$ and $y$, respectively

$W=$ the wight of tracer particles stored per unit area of bed surface

$V_{s}=$ the settling velocity of the particles

$a=a$ bed absorbency coefficient

$\gamma=$ an entrainment rate coefficient

$c\left(x, 0^{+}, t\right)=$ the local concentration inmediately above the bed

These are in turn coupled with boundary conditions at the river bed and weter surface. The bed surface boundary condition states that a lass balance must exist between the flow and the bed, and the water surface boundary condition indicates that $n 0$ ass transfer occurs across the water surface. Instead of solving these equations analytically for some simplified cases, Sayre (1971) adapted an inmovative approach. This alternative nethod eaployed by Sayre is to use Aris oment transformation for $c(X, Y, t)$ and $u(X, t)$ to elivinate the variable $X$, and to obtain a new set of equations which can be solved for the $p^{\text {th }}$ mament of the longitudinal distribution (e.9., 1st woment is the mean of the concentration distribution). The el imination of $X$ cakes the transformed equations easier to solve; however, some detail is sacrificed because the solutions are for anents of longitudinal distribution of substances rather than the concentrations thenselves. The exact muerical wethod re uses to solve the equation for $p=0,1,2$ and 3 is not given but was probably a finite difference method. Using these moments he can calculate the area under the distribution area $(p=0)$ and the mean $(p=1)$, variance $(p=2)$ and skemess $(p=3)$ of the distribution function.

No verification or application was given by the authors. Instead, they offered an explanation of difficulties in verifying the codel. These difficulties include: 1) difficulties due to differences between spatial representation of experinental results and time variation of couputed results, 2) difficulties dre to lack of agreement on how to evaluate $\varepsilon_{y}$, and 3) difficuities 
we to controversy over whether average settling velocity, $V_{s}$, is the sane in turbulent flow as in still water. Also due to inadequate knowledge of the dymanics of fluid-particle interaction, particulariy close to the bed, sone of the parameters cannot be predicted from knom flow and sedisent properties.

The nodel is particularly useful because it yields characteristics of the relevent flow. One of the ipportant advantages of using this model is that it is applicable not only to the Taylor (or diffusive) period but also to the convective (or initial) period of mass transport. Most of conventional advectiondiffusion equations atilizing Fick's first law of diffusion, strictly speaking, cannot be applied to the convective period.

Sayre and Chang discussed laboratory flume results and compared the results with Fickian diffusion. They also discussed the various diffusion coefficients and how they wight be estimated.

Fields (1976a, b)

Fields developed a one-dimensional, sediment transport code, SEDTR, to calculate sediment load in a single region of a rectangular strean channel. This model uses a sediment transport capacity equation developed by Bagnold (1966) wich is based on energy and momentu conservation. Migrating sediwent is separated into two components: bed load and suspended load. Bagnold's approach to the calculaticn of sediment transport rates assumes that the sediment is cohesionless, that sediment aggregation or flocculation does not occur, and that the sediment is uniform and thus can be described by a single density, diameter, wolume concentration, and angle of repose (Fields 1976a). However, SEDTRM divides the sediment into 12 different size fractions comprising the full size range of both cohesive and cohesionless sediment: clay (dianeter $<4 \mu$ ), silt ( $4 \mu<d i a m e t e r<62 \mu)$, and sand $(62 \mu<$ diameter $<2000 \mu$ ).

SEOTR predicts the mass transport rate for suspended sedinent as a function of volue flow rate, channel properties, and the fall velocity of the suspended sedicent. Manning's equation is used to calculate the flow velocity and volue flow rate from channel parameters. SEDTRN , rovides for computation of both viscous and inertial particle settling through adifications to Stokes' Iaw. 
In addition, the model includes a parameter to indicate the tendency for a particulate class to remain in suspension. This tendency parameter is defined as:

the ratio of the time required for particles of size Class I $(1=1, \ldots, 12)$ in still water to settle out of suspension to the average time required for particles from all size classes. It is the relative contribution of a sediment size class to the suspended load, assuaing equal anounts of each sediment size class on the bed and unlimited availability of resident bed sediment (Fields 1976a).

To compute the bedload transport rate, the model requires a deternination of an effective particle diameter for the bed sediment in order to provide a more accurate determination of bedload flux at low flow rates. Fields notes that his effective diameter reflects the degree of coupling of bedload particles to the faster woving water above. It should be noted that Bagnold was unable to test the bedload term in his final transport rate relationship because of a lack of data.

SEOTRI is designed to be combined with a driver code. The composite model resulting from the merging of SEDTRM with the Wisconsin Hytrologic Transport Model ms called Caustid (Channel Sediment Transport Model) (Fields 1976a). A description of its capabilities can be found in an earlier section. To allow for the computation of sediment transport in a witi-reach rectangular strean chamel, fields combined SEDTRM with a driver code which reads input data and contains bookkeeping to account for and route transported sediment between reaches. The resulting model, LIUSED (Fields 1976b), does not require extens ive specifications of matershed characteristics as does ChusED.

LIISED was applied to the Rio Grande River near Bernalillo, Mew Mexico, to calculate sed iment concentrations in the river for model verirication (Fie lds 1976a,b). Agreement between the field data and computer results was good (Figure 4.8). It should be noted, however, that almost all bed sediment in the 'io Grande River consists of sand; in addition, the suspended sediment is primarily sand (Mordin 1964; Mordin and Beverage 1965).

The "Strean Power" concept (Bagnold 1966; Simons and Sentusk 1977), deve loped by Bagnold, wich forms the basis for SEDTRN, has been criticized 


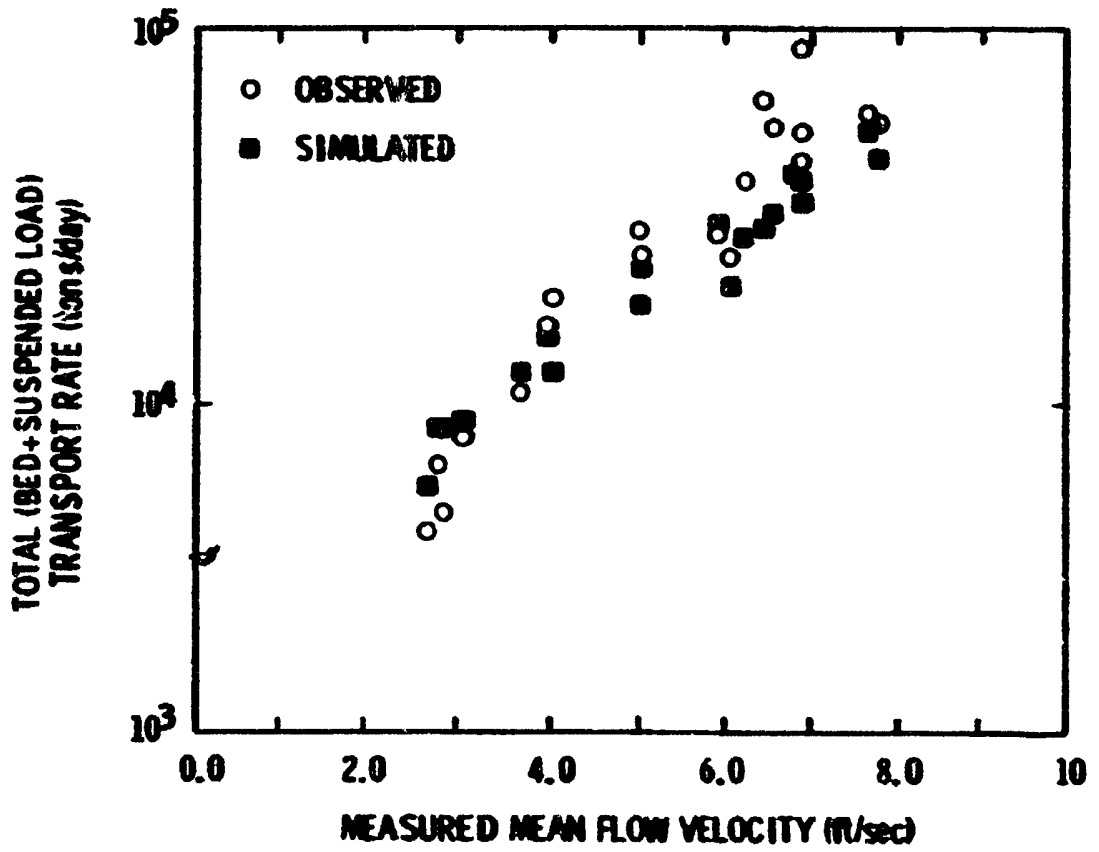

FIEURE 4.8. Observed and Simulated Transport Rate (Bedload Plus Suspended Load) Versus Measured flow Velocity for Coeplete Set of Available Sapling Dates in the Rio Grande River near Bermalillo, Mew Mexico (Fields 1976)

both as a concept and for its applicability to real streans (Graf 1971; Yanoni 1975; Yalin 1972). For examle, Bagnold's method is applicable only to cases with high sediment concentrations and cannot be applied to rivers having sediment diameters below 15\% (fine silts and clays) (Graf 1971; Yanoni 1975; Yalin 1972). As stated earlier, cost of the particulate radionuclides are associated with finer silt and clay, wich have dianeters below 154 .

Upon its development, SEDTRM was one of the components of the Unified Transport Model developed by Oak Ridge Mational Laboratory (ORNL) to simulate the transport of a trace contaminant through a matershed ecosystea (fields, 1974). A wore recent progra at CRou involves the development of mathematical code is for assessment of thermal, chemical, radiological and biological inpacts on mater bodies from power plants. Because the mathematical formulation and computer code structure of SEDTPW were not compatible with other onedimensional codels of the progran, a new one-dimensional, sediment transport mode 1, SEDowe, has been developed by CRm (Eraslan et ai. 1977; Hetrick et al. 
1979). The codel is a discrete-element formulation based on the sediment mass conservation principles; the formalation includes a layer for suspended sediment, a layer for creeping-bed sediment, and a layer for the stationary resident-bed sediment, with each layer being comprised of particles of different sizes. SEDOME is applicable to both uniformly flowing rivers and tidal-transient estuaries. It has been used to simulate sediment concentration along the Hudson River with reasonable agreement as showen in Figure 4.9 (Eraslan et al. 1977).

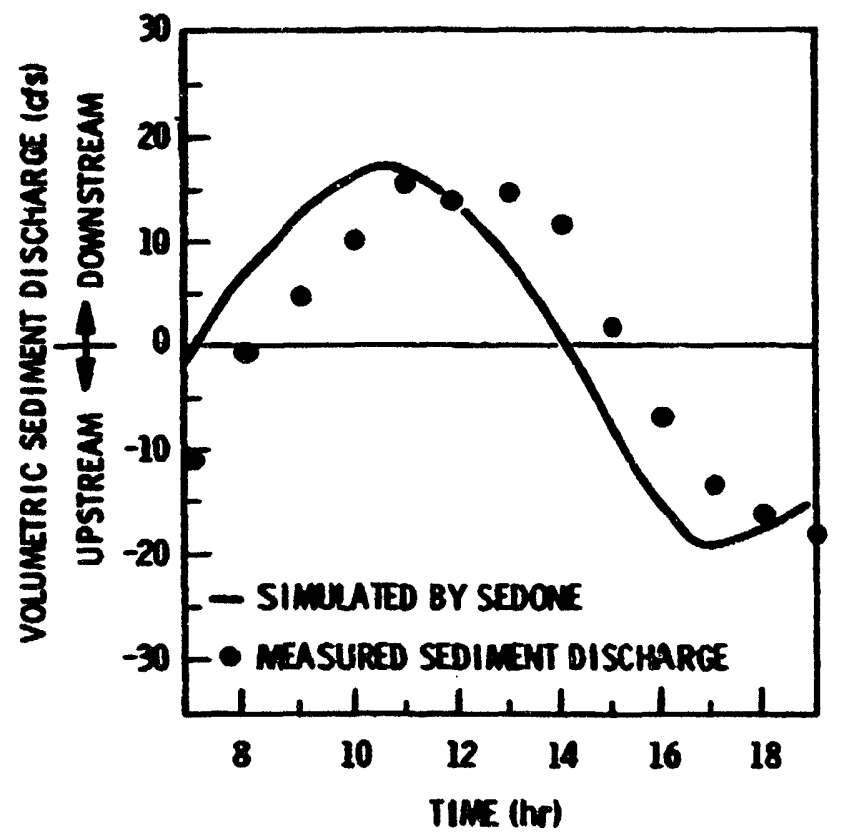

FIQRE 4.9. Measured and Simulated Values of Yolunetric Sediment Discharge Rates in the Hudson River at a Cross Section 10 Mi Tes Upstrean from the Battery (Erasian et al. 1977)

Thomas (1974)

Thomas has developed one of the wost widely used one-dimensional, steadystate, computer codes at the U.S. Corps of Engineers Hydrologic Engineering Center to simulate sediment transport, scour, and deposition in rivers. The flow is assuned to be steady and one-dimensional. In simulating the ability of the strean to transport sediment, the wodel considers the full range of conditions embodied in Einstein's Bed Load function plus silt and clay 
transport and deposition, armoring, and destruction of the arwor layer. The cross section is subdivided into two parts--that part which has a movable bed, and that wich does not; and the boundary between these parts remains fixed for the study. The entire novable bed part of the cross section is woved vertically up and dow depending on bed scour or deposition. The solution is accomlished by using a finite difference scheme. This model is best suited to predict aigration of sand in rivers whose flows do not change with tive or change very slowly. Its applicability to the migration of cohesive sediments is improved by replacing an originally used exirical formulation on cohesive sediment erosion and deposition by Partheniades (1962) and Krone (1962) formulations, wich are also used by sediment-contaminant models, SERATRA and FETRA.

Chen (1973)

As Ph.D. Thesis work, Chen derived the basic partial differential equations of a gradually varied, unsteady flow in natural alluvial channels and developed an unsteady, one-dimensional model. The codel simulates water and sediment routing processes in natural streans, and the degradation and aggradation at the site of hydraulic structures by solving the equations of contimuity and wotion for sediment-laden flow and the equation of continuity for sediment simultaneously. The equation of continuity of sediment was derived simply from the conservation theory; the sediment inflow wimus the sediment outflow is equal to the change of storage of sediment in the control volume. The sediment routing process of the model uses Einstein's Bed Laad Function (1950) or Toffaleti's model (1969). He reported that these equations mere solved by the linear-implicit finite difference ethod. Unlike Sayre (1971) and Fields $(1976 a, b)$ discussed earlier, his wodel does not directly provide sediment concentrations but provides river bed elevation changes due to sediment deposition and scouring. The model was applied to lower Mississippi and Missouri Rivers and yields reasonably good agreement with field data. The model applicability is liaited to sand-bed rivers.

\section{Mahmord and Ponce (1976)}

A one-dimensional, unsteads, mathematical model for simulation of bed elevation changes in sand-bed chamel due to transport, erosion and deposition 
of sand was developed by hubood and Ponce (1976). The governing equations for the model comprise the momentum equation for the water-sediment wixture, and the continuity equations for the mater and sediment, a concept similar to that used by Chen (1973) described above. By assuning a steady-state flow and empirical formula on velocity distribucions, friction factor, sediment and bed load functions, Mahwood and Ponce reduced these equations to an equation of a local flow depth alone wich was then solved by a linearized inplicit. The model was applied to hypothetical cases.

\section{Hubbell and Sarre (1964): Sarre and thbbell (1965)}

In alluvial channels with ripple or dune beds, the sediment particles along the bed are transported by surface creep. They wove with discrete steps of variable length, between wich they are buried for periods of variable duration. Lagrangian probabilistic models (as is the case here) express the transport of bed aterial particles as a sequence of alternating steps and rest periods. In order to solve this problem, the following steps were taken: It was assuned that step lengths and rest period duration are sets of identically distributed random variables. The length of any particular step and the duration of any particular rest period of a given particle are independent of location and time (homogeneous probability field), which inplies that the bed must be flat or nearly flat. The distance traveled by a particle in $n$ steps is gand distributed and the muber of witing periods, $i$, in a given time intervil is Poisson distributed. However, it is not practical to know the number of steps and rest periods; instead, a function that describes the probability that a particle will have gone a certain distance $x$ in time $t$ regardless of the number of steps is desired.

By using the ideas of joint and conditional probability, a probability density function for longitudinal position of a particle at time $t$ is developed. This ore-dimensional, time-dependent function allows calculation of the concentration of trace particles in weight per unit volume of bed material at any point in the river. These same equations were derived independently by Einstein (1937) and Todorovic (1967) not by the stochastical approach but by analytical and experimental approach. Results of the model show good agreement with field and laboratory data (Figure 4.10). 

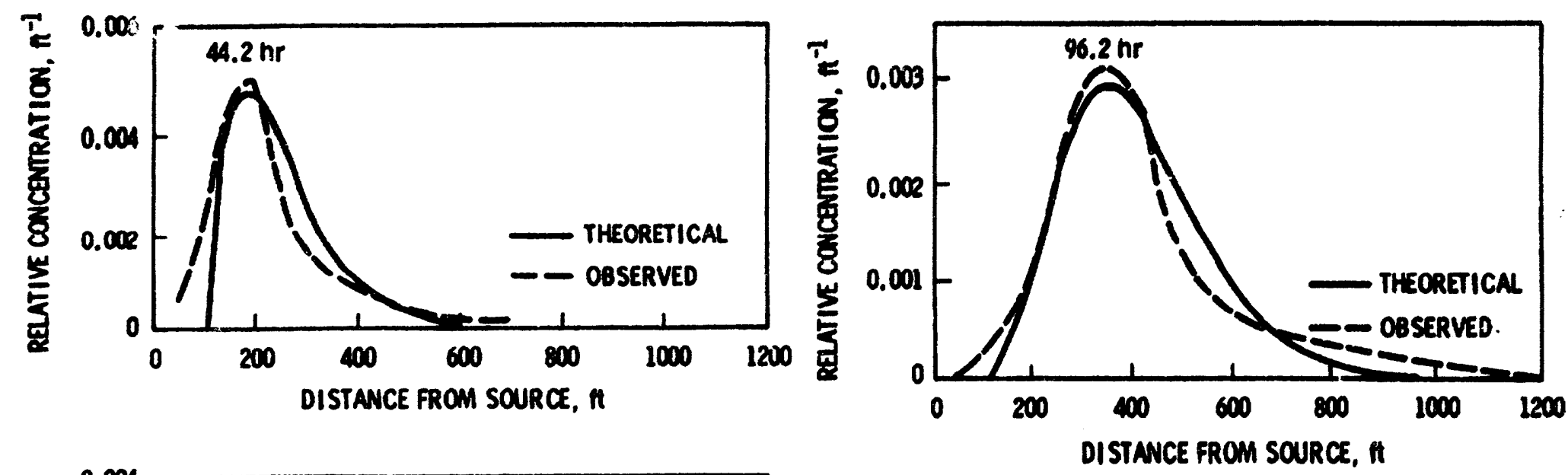

in
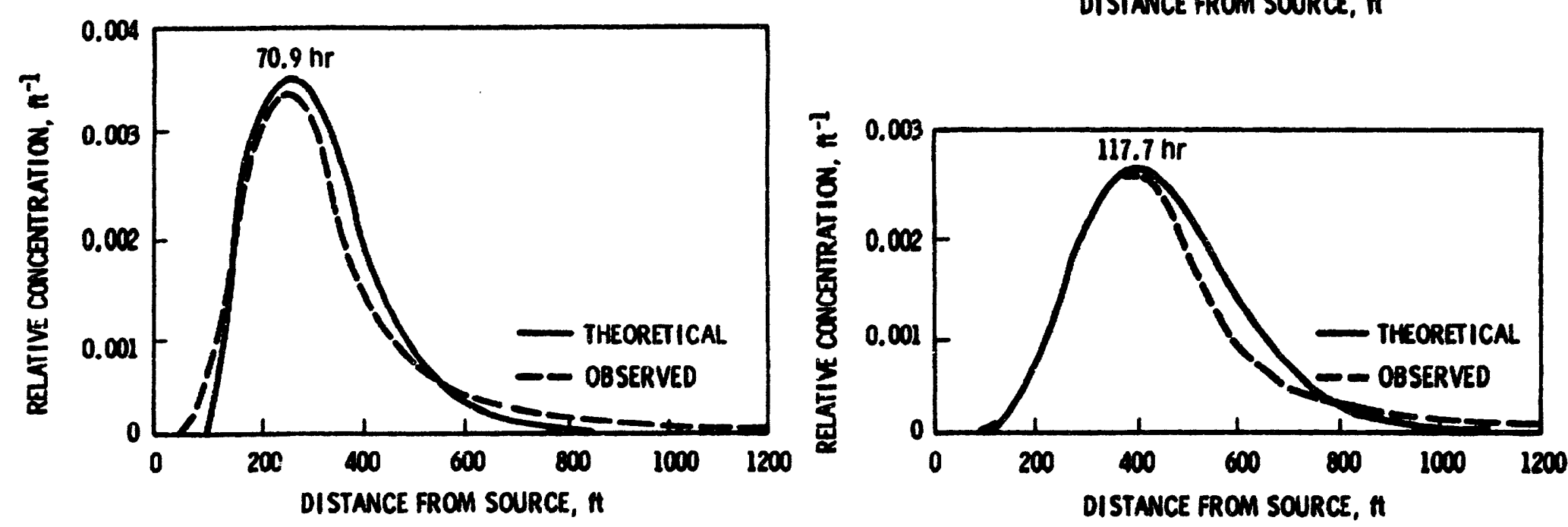

FIGURE 4.10. Theoretical and Observed Longitudinal Distribution of Tracer Particles: North Loud River Fleld Experiment (Hubbell and Sayre 1964) 


\section{Yang and Sayre (1971)}

The unsteady, one-dimensional model developed by Yang and Sayre (1971) is a refinement of the model developed by Hubbell and Sayre (1964). The assumcions and methodology are the s as reported by Hubbell and Sayre except that the distribution of waiting periods is expressed by an exponential distribution function instead of a Poisson function. The results on comparisons with field data had better agreement.

Shen and Cheong (1973, 1977) and Cheong and Shen (1976) discuss extensions of the model presented by Yang and Sayre (1971). They exanined the behavior of the wodel under various conditions, constructed envelopes of concentration distributions, and calculated the wean concentration of sediment in transport at any time. One important conclusion was that the concentration distribution function is initially highly skewed but becomes progressively symetrical with time. Therefore, after a long period of time the distribution function can be approximated by a Gaussian curve.

\section{Todorovic (1975)}

All previously discussed stochastic models mere developed for instantaneous release of sediment. Todorovic discusses how any density function for instantaneous release can be used to give a density function of a contimuous release with almost all conceivable (nonrandom) release modes. The unsteady, one-dimensional, stochastic model for longitudinal dispersion, developed by Todorovic, is obtained by means of a simple integral transformation from distribution functions of instantaneous release cases. Simple case studias were conducted by applying the model. However, no field appiicaition or verification of the model was presented.

\subsection{4}


Buckner, M. R., and D. M. Hayes. 1975. "1975 Pollutant Transport in Matural Streams." Presented at the Topical Meeting on Computational Methods in Muclear Engineering, Merican Muclear Society, Charleston, SC.

Buckner, M. R., D. H. Hayes axd J. R. Hatts. 1975. Energency Response Capability fer Pollutant Release to Streans and Rivers. Tip-15-75-73, OuPont de hewours (E.I.) and Co., Savannah River Laboratory, Aiken, SC.

Carrigan, P. H., Jr.. R. J. Pickering, T. Tamura, and R. Forbes. 1967a. Radioactive Materials in Botto Sedinents of Clinch River: Part $A_{2}$ Investigations of Radionuclides in Upper Portion of Sedinents. Supp lement 2A to Status Report 10.5 on Cifinch kiver Study, ORNL-3721 Supp 1. 2A, Oak Ridge National Laboratory, Oak Ridge, TH.

Carrigan, P. H., Jr. and R. J. Pickering. 1967b. Radioactive Materials in Botton Sediment of Clinch River: Part B, Inventory and :... tical Distribution of Radionuclides in Undisturbed Core. Supplement 28 to Status Report 10.5 on Clinch River Study. CikL-3721, Suppl. 2B. Oak Ridge Mational Laboratory, Oak Ridge, Ti.

Chapman, R. S. 1977. A Podel to Investigate the Influence of Suspended Sediment on the Mass Transport of Pollution Cpen Channel Flow. Wish-II-X9.601 .

Chen, Y. H. 1973. Mathematical Modeling of Nater and Sediment Routing in Matural Channels. Ph.J. Thesis, Departinent of Civil Engineering, Colorado State University, fort Collins, co.

Cheong, H. F. and H. H. Shen. 1976. "Stochastic Characteristics of Sediment Motion," ASCE 102(HY7):1035-1049.

Churchill, M. A., J. A. Cragwall, R. H. Andrews and S. L. Jones. 1965. Concentrations Total Sediment Loads and Mass Transport of Radionuclides in

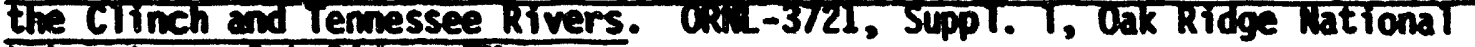
Laboratory, Oak Ridge, in.

Clanton, V. S. and E. F. Gloyna. 1964. Radioactivity Transport in Hater-Sorption and Release of RadionucTices by Sedinents of the Euadalupe River. Eli:-10-6104, Technical Report 10. 6 to the U.S. Atanic Energy Comission, University of Texas, Austin, TX.

Sottrell, W. D. 1959. Radioactivity in Silt of the Clinch and Tennessee Rivers. USAEC ORnL-2847, Oak Ridge hational Laboratory, Oak Ridge, III.

Divies, S., F. Costito and M. Eisenbud 1966. Mradioactivity in the hudson River.- Proceedinos of the First Syposiu on Hudson River Ecoloay. Hudson River Va Tley conission of hew Tork. 
Ecker, R. M., and Y. Onishi. 1979. Sediment and Radionuclide Transport in Rivers. Phase 1. Field Sam ling Procre uuring hean Flow Cattaraugus and Butter ilk creeks, hew rork. Mlies/ck-1030, PiL-3I17, Pacific horthest Laboratory, Richland, Wh.*

Einstein, H. 1937. Der Geschiebetreibals Mahscheinlichkeitsproblem. Ver lag Raschen and Co., Zurich, Switzerland.

Eraslan, A. H., E. J. Akin, J. M. Barton, J. L. Bledsoe, K. E. Cross, H. Dianent, D. E. Fields, S. K. Fischer, J. L. Harris, D. M. Hetrick, J. T. Holdewan, K. K. Kin, M. H. Lietzke, J. E. Park, M. R. Patterson, R. D. Sharp, and B. Thomas, Jr. 1977. Development of a Unified Transport

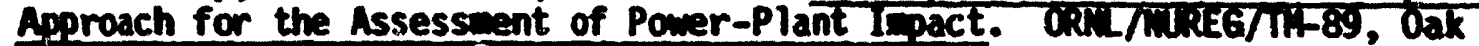
Ridge kational Laboratory, Oak Ridge Ti.

Fields, D. E. 1974. Modification of the Unified Transport Model to Allow for Sedicent Transport and Chemical Exchange." Trace Contaninants in the Emvironment. LBL-3217. Available from the Mational Technical Information Service, Springfield, VA, pp. 205-209.

Fields, D. E. 1976a. CunSED: Simulation of Sediment and Trace Contaminant Transport with Sediment/Conteminant Interaction. CRWLIRF/EATC-19, Cak RToge hational Laboratory, oak Ridge, Ti.

Fields, 0. E. 1\$76b. LIUSED: A One-Dimensional Multireach Sediment Transport model. ORn//CSU-15, bak Ridge Laboratory, Oak Ridge, Ti.

Fisher, W. L. 1970. Evaluation of Radiologicai Conditions in the Vicinity of Hanford for 1968. BimL-T3T, Pacific Vorthwest Laboratory, RTchland, Wh.

Fisher, H. B. 1967. "The Mechanics of Dispersion in Matural Streans," Journal of Hytraulic Division. 93(HY,6, ASCE):187-216.

Fletcher, J. F., M. L. Dotson, D. E. Peterson and R. P. Betson. 1973. Thodeling the Regional Transport of Radionuclide in a Major United States River Basin," Enviror ental Behavior of Radionuclide Released in the Muclear Industry. InEN Viena.

Fletcher, J. F. and H. L. Potson (eds). 1971. Hermes-A Digital Computer Code for Estinating Reqional Radiological Effects from the Mrclear Power Indistry. Ustec kep. Heul-Tik-71-1968.

Freed, D. L. 1973. "Technique for Implicit Oynamic Rciting in Rivers with Major Tributaries." Mater Resources Research. $9(4): 918-926$.

Fukaf, R. and C. M. Murray. 1973. "Environmental Behavior of Radiocobalt and Radiosilver Released from Muclear Power Stations into Aquatic Systews," Emvironental Behavior of Radionuclides Released in The Muclear Industry. hustria. International Atowic Energy Agency, Vienna, pp. 217-24I. 
6lover, R. E. 1964. Dispersion of Dissolved or Suspended Materials in Flowing Streas - Transport of Redonuclides by Strexs. Usts Protessional Paper 433-6.

6loyma, E. F. et al. 1963-1972. "Radioactivity Transport in Hater." Technical Reports 1 thround 23. U.S. AEC Contract No. AT(11-1)-490, The University of Texas, hustin, ix.

Gloyma, E. F. and J. O. Ledbetter. 1969. Principles of Radiological Health. Marcel Dekker, Inc., New York, WY.

Graf, H. H. 1971. Hydraulics of Sediment Transport. McGraw-Hill Book Company.

Gromiec, M. J. and E. F. Gloyma. 1973. Radioactivity Transrort in Mater -Final Report. EHE-73-01, Technical Report 10.23 to the U.S. Atosic Energy Conission, Center for Research in Mater Resources, University of Texas, Aust in, TX.

Haushild, H. L., R. H. Perkins, H. H. Stevens, G. R. Dempster and J. L. Glenn. 1966. Progress Report: Radionuclide Transport in the Pasco to Vancouver, Mashington Reach of the Colo bia River Jily 19.22 to septe-ber 1963 for the Project: The occurrence, Transport and visposition of kadionuclides as Solutes and Associated with Fluvial sedients in the Lower Collobia River. Geological survey. Cpen-file Report. U.S. Departient of Interior.

Haushild, H. L., H. H. Stevens, Jr., J. L. Melson and 6. R. Deipster, Jr. 1971. Radionuclides in Transport in the Colubia River from Pasco to Vancouver, Lashin.ton. Geological survey. Open-fite Report. U.S. Departwent of Interior, Hestern Resources Division, Portland, OR.

Haushild, H. L., H. H. Stevens, Jr., J. L. Melson and G. R. Dempster, Jr. 1973. Radionuclides in Transport in the Columia River fram Pasco to Vancouver, Lashington. Eeological Survey Protessional Paper 433-n, U.S. Eeological Survey, U.S. Departinent of Interior, Portland, OR.

Hayes, J. R. 1963. Mass Transport Mechanisms in Open Channel Flow. Doctoral Thesis. Vanderbilt University. Mashville, in.

Hetrick, D. M., A. H. Erz'slan, and M. R. Patterson. 1979. SEDOME: A Computer Code for Siculating Tidal-Transient, One-Dimensional Hydrodynalc Conditions and inree-Layer, Variable-Size Sedicent Concentrations in controlled Rivers

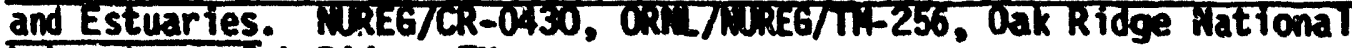
Laboratory, Oak Ridge, TH.

Hubbell, D. H. and H. H. Sayre. 1964. "Sand Transport Studies with Radioactive Tracers." ASCE. 90(HY3):39-68. 
Hubbell, D. H. and J. L. Glenn. 1971. Distribution of Radionuclides in Botto Sedients of the Coluobia River Estuary. Open-file Report. Departient of Interior, Portiand CR. Hater Resources Division, Geological Survey.

Hytroscience, Inc. 1978. Mathenatical Models for Mater Quality for the Hudson-Chamlain and Metropolitan Coastal hater Pol:ution Control Project.

Jenne, E. A. and J. S. Hahlberg. 1965. Management and Iron Oxide Scavenging of Cobalt 60 in White Oak Creek Sediment, Oak Ridge, Tem." A. Geophys. Union Trans. 46(1):70 (Abstract).

Jenne, E. A. and J. S. Wahlberg. 1968. Role of Certain Strean-Sediment Coconents in Radioion Sartion. Ceological Survey Professional Paper 433-F, J.S. Eeological Survey.

Kennedy, Y. C. 1365. Mineralogy and Cation-Exchange Capacity of Sediments from Selected Strears. Geological Survey Professional Paper 433-0, U.S. Departiment of Interior.

Krone, R. 1962. Flume Studies of the Transport of the Sediment in Estuari, Shoaling Processes. Hydraulic Engineering Laboratory and Sanitary Engineer ing Research Laboratory, University of California At Berkeley.

Mahnoud, K. A., Y. A. Yousef, M. M. Ishak, H. E. Y. Adbel-Malik, S. R. Khalil, A. Shafik, R. M. K. El-Shinawy. 1973. "Transfer Mechanisa and Concentrating Processes of Certain Radionuclides in the Aquatic Ecology of the Ismailia Canal," Environmental Behavior of Radionuclides Released in the Muclaar Industry. International Atoic Energy Agency, Vienna, hustria. pp. 205-215.

Mahmood, K., and V. M. Ponce. 1976. Mathematical Modeling of Sedicentation Transients in Sand-Bed Channels. CER75-76K/-Vip28, Eng Treering Research Center, Colorado State University, Fort Collins, Co.

Martin, J. A., Jr., C. Robbins, C. B. Melson, R. D. Cousins, Ir., M. A. Culliton. 1976. A Coputer Code (RLRDOS) to Calculate Population Doses from Radioactive LTouid Eff luents and on Apolication to huclear Power Reactors $\sigma_{\text {. }}$ the Mississ ippi River basin. U.S. EPh, Office of Radiation Prograss, Environental Analysis uivision.

Morton, R. J. (ed). 1962a. Status Report Mo. 2 on Clinch River Study. Clinch River Study Steering Comittee. CRKL-320Z, Oak Ridge National Laboratory, Oak Ridge, TH.

Morton, R. J. (ed). 1962b Status Report No. 3 on Clinch River Study. Clinch River Study Steering Comittee. Cil -33\%, Dak Ridge kational Laboratory, Oak Ridge, TH. 
Norton, R. J. (ed). 1965. Status Report Ho. 5 on Clinch River Study. Clinch River Study Steering Comittee. ORTL-3721, Oak Ridge hational Laboratory, Oak Ridge, TH.

Nelson, J. L., R. M. Perkins, J. P. Mielsen, and W. L. Haushild. 1966. Reactions of Radionuclides from the Hanford Reactors with Columia River Sed iments." Disposal of Radioactive lastes into Seas, Oceans, and Surface Waters. International Atomic Energy Agency, Vienna, Austria. Pp. 139-161.

Mordin, C. F., Jr. 1964. Aspects of F1um Resistance and Sediment Transport: Rio Grande Mear Bernalilito, hew Texico. Water-Supply Paper 1498-H, U.5. Eeological Survey, Washington, D.C.

Mord in, C. F., Jr., and J. P. Beverage. 1965. Sediment Transport in the Rio Grande, Mei Mexico. US6S Professional Paper 462-F, U.S. Geological Survey, Thashington, U.C.

Morton, H. R., L. A. Roesner, D. E. Evenson, and J. R. Monser. 1974. Computer Progras Documentation for the Strean Quality Model, Qual-II. Water Resource Enginears, Inc., kaimut Creek, Ch.

Onishi, Y. 1977. Matheatical Simulatior of Sediment and Radionuclide Transport in the Colvibia River. Bin-2228, Pacific horthest Laboratory, Richland, W.

Onishi, Y. 1980. "Section 4. Sediment Effects" of Aquatic Disposal of Radionuclides. Prepared by P. J. Ryan, M. Leonard, G. Segal and Y. Onishi for the Suwimer Schoo! of Health Physics Society.

Onishi, Y. and R. M. Ecker. 1977. "Mathematical Simulation of Transport of Kepone and Kepone-Laden Sediments in the James River Estuary." Proceedings of Kepone Senimar II.

Onishi, Y. and S. E. Hise. 1978a. Mathematical Modeling of Sedinent and Contaninant Transport in the danes River Estuary." Proceedings of the 26th Annual ASCE Hydraulic Division Speciality Conference on Verification of Whenatica: and Phrsical hodels in Hytraulic Emolneering. College Park, iv. hegust g-11, pp. 303-310.

Onishi, Y. and S. E. Wise. 1978b. Mathematical Similation of Transport of Sediment and Kepone in the lanes RTver Estuary. Phi-2731, Pacific Northest Laboratory, RThiand. 14 .

Onishi, Y., and S. E. Wise. 1979a. "Finite Element Model for Sediment and Toxic Conteninant Transport in Streams." Proceedinos of Hydraulics and Eneray Divisions Specialty Conference of ASCE on Conservation and Utivization of Water and Energy Resources." San Francisco, $W$, PP. 144-150. 
Onishi, Y., and S. E. Wise. 1979b. Mathematical Mode1, SERAiRA, for Sediment-Containant Transport in Rivers and Its Application to Pesticide Transport in Four Mile and Wolf Creeks in Iowa." Submitted to U.S. Environmental Protection Agency, Environental Research Laboratory at Athens, EA by Battelle, Pacific Nortmest Laboratories: Richland, WA.

Onishi, Y., P. A. Johanson, R. G. Baca and E. L. Hilty. 1976. Studies of Colubia River Hater Quality--Developent: of Mathematical Models of Sediment and Radionuclice Transport Amalysis. Bim-8-452, Pacific Northwest Laboratory, Richland, wh.

Onishi, Y., E. M. Arnold, and D. H. Mayer. 1979. Modified Finite Element Transport Model, FETRA, for Sediment and Radionuc Tide Higration in Cpen

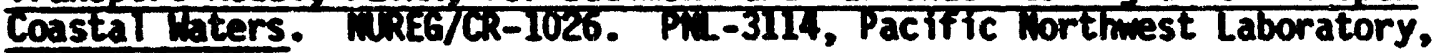
Richland, W. *

Onishi, Y., D. L. Schreiber, and R. B. Codell. 1980a. Mathematical Simulation of Sediment and Radionuclide Transport in the Clinch River, Tennessee," Chapter 18 of Processes Imvolving Contaminants and Sediment. R. A. Baker (ed.), Ann Arbor science Publisher, Inc. Pp. 393-406.

Onishi, Y., 6. Whelan, M. A. Parkhurst, A. R. Olsen, and P. J. Gutknecht. 19806. Prel iminary Assessment of Toxaphene Migration and Risk in the Yazoo River Basin, dississipi. Subnitted to the U.S. Environental Protection Agency by Battelle, Pacific Morthiest Laboratories, Richland, WA.

Onishi, Y., S. M. Brown, 6. Whelan, R. L. Skaggs, K. T. Key, C. T. Kincaid, A. E. Reisenaver, and T. H. Horst. 1980C. Development of a Multimedia Radionuclide Exposure Model for Low-Level Maste Managenent. PIL-3370, Pacific Northmest Laboratory, Richland, W.

Osterberg, C. L, M. Cutshall, V. Johnson, J. Cronin, D. Jennings, L. Frederick. 1966. "Some Monbiological Aspects of Colubia River Radioactivity." Disposal of Radioactive lastes into Seas, Oceans and Surface Maters. Syposion, 321, IAL, Viema Austria.

Overton, D. E. and M. E. Meadows. 1976. Mathematical Podeling for Mater Quality Management in Streans Under Unsteady Hydraulic Conditions. Research Report Ko. 55. Hater Resources kesearch Center, University of Tennessee.

Parker, F. L., M. A. Churchill, R. H. Andrew, B. J. Frederick, P. H. Carrigan, J:., J. S. Cragwali, Jr., S. A. Jones, E. G. Struxness, and R. J. Morton. 1966. "Dilution, Dispersion and Mass Transport of Radionuclides in the Clinch and Temessee Rivers." Proceedings of the Srmosiu on the Disposal of Radiactive lastes into Seas, uceans and Surtace hters. International Atomic Energy hgency, Vtema, hustria, p. 33-54. 
Partheniades, E. 1962. A Study of Erosion and Deposition of Cohesive Soils in Salt Hater. Ph.0. Thesis, University of California at Berkeley.

Perkins, R. H., J. L. Melson, H. L. Haushild. 1966. "Behavior and Transport of Radionuclides in the Columia River Between Hanford and Vancouver, Mashington." Limnol. Oceanogr. 11(2):235.

Pickering, R. J. 1970. Composition of Hater in Clinch River, Tennessee River, and witeoak Creek as Related to bisposal of Low-Level Radioactive Liquid Wastes. Geological Survey Professional Paper 433-J, bepartient of Interior.

Pickering, R. J., P. H. Carrigan, Jr., T. Tamura, H. H. Abee, J. H. Beverage, and R. W. Andrew, Jr. 1966. Radioactivity in Botton Sediment of the Clinch and Tennessee Rivers." Disposal of Radioactive Mastes into Seas, Oceans, and Surface Haters. International Atomic Energy Agency, Vienna, Tustria, pp. 57-85.

Pruter, A. T. and D. L. Alverson. 1972. The Columbia River Estuary and Adjacent Ocean Maters--Bioenviromental Studies. University of Tashington Press, Seattle, Wh.

Renn, C. E., J. T. O'Connor and I. Hintner. 1964. Adsorption of Radioactive Zinc and Iron on River Silts. MY0-10544.

Reynolds, T. D. and E. F. Gloyna. 1963. Radioactivity Transport in Hater--Transport of Strontiu and Cesiu by Strean and Estuarine Sediments. rechnical Report No. I to the U.S. Atomic Energy Comission, Jniversity of Texas, Austin, TX.

Robertson, D. E., H. B. Silker, J. C. Langford, M. R. Petersen, and R. W. Perkins. 1973. "Fr-nsport and Depletion of Radionuclides in the Columia River." Radioa:-ve Contamination of the Marine Environment. International Ato Tc Energy Agency, Vienna, Austria. pp. 141-155.

Rowe, D. R. and E. F. Gloyma. 1964. Radioactivity Transport in Mater--The Transport of $65 \mathrm{Zn}$ in an Agieous Environent. ERt $-09-6403$, Technical Report 110. 5 to the U.S. Atomic Energy Comission, Center for Research in Hater Resources, University of Texas, Aust in TX.

Sax, N. I., P. C. Lewon, A. H. Benton and J. J. Gabay. 1969. Radioecological Surveillance of the Watemays Around a Huclear Fuel Processing Plant." Radioecological Health Dats and Reports. 10(7):289-296.

Sayre, M. H. 1971. "Transport and Dispersion of Fluvial Sediments: Some Mathematical Podels and Their Verification by Trace Methods." IAEA Panel on the Uses of Tracers in Sedimentology. 
Sayre, H. H. and T.-P. Yeh. 1973. Transverse Mixing Characteristics of the Missouri River Dounstrea from the Cooper Nuclear Station. IIHR Report ijo. 145, Iowa Institute of Hydraulic Research, University of Iowa, Iowa City, IA.

Sayre, H. H. and F. M. Chang. 1968. A Laboratory Investigation of Open-Channel Dispersion Processes for Dissolved, Suspended and FToating Dispersants. USES Professional Paper 433-E.

Sayre, H. H. and D. H. Hubbell. 1965. Transport and Dispersion of Labeled Bed Meterial. Morth Locys River, MB, U.S. Eeol. Surv. Paper, 433-C.

Sayre, H. H., H. P. Guy, and A. R. Chamberlain. 1963. Uptake and Transport of Radionuclides oy Stream Sediments. Geological Survey Professional Paper 433-A.

Shen, H. H. and H. F. Cheong. 1973. "Dispersion of Contaminated Sediment Bed Load." J. of the Hydraulics Division. ASCE, 99(HY11):1947-1965.

Shen, H. W. and H. F. Cheong. 1977. "Statistical Properties of Sediment Bed Profiles." J. of the Hydraulics Division. ASCE, 103 (HY11):1303-1321.

Shih, C. S. and E. F. 6loyna. 1967. Radioactivity Transport in Mater-Mathematical Model for the Transport of Radionuclices. EHE-04-6702, Technical Report 10. I2 to the U.S. Atomic Energy Comission, University of Texas, Austin, TX.

Shih, C. S. and E. F. Gloyma. 1969. "Influence of Sediments on Transport of Solutes." J. Hydraulics Div. ASCE 95(HY4):1348-1367.

Shih, C. S. and E. F. 6loyma. 1970. Mathematical Model for the Transport of Kadionuclides in Strean System." Environental Surveillance in the Vicinity of Muclear Facilities. Reinig, W. C. (ed.), Charles C. Thomas Publishing Co., Springfield, IL.

Shul1, R. D. and E. F. 6loyna. 1968. Radioactivity Transport in Mater-Simulation of Sustained Releases to Selected River Environiments. EHE-07-6801, Technical Report 10. 15 to the U.S. Atomic Energy Comiss ion, University of Texas, Austin, Tx.

Shure, D. J. and M. R. Eottschalk. 1975. "Cesium-137 Dymanics within a Reactor Effluent Strea in South Carolina." Radioecology and Energy Resources. C. E. Cushing, Jr. (ed.), pp. 234-241.

Simons, D. B. and Senturk, F. 1977. Sediment Transport Technology. Mater Resources Publications, Fort Collins, Co. 
Smith, J. H., H. R. Mabey, M. Bohonos, B. R. Holt, S. S. Lee, T.-H. Chou, D. C. Bomberger, and T. Mill. 1977. Environmental Pathways of Selected Cinemicals in Freshmater Systems. Part I: Background and Exper imental Procedures. EPA-600/7-7/-113, Subsitted to U.S. Environental Protection Agency by SRI International, Men lo Park, CA.

Soldat, J. K. 1976. Methodology for Calculation of Radiation Doses in the Environs from Muclear fuel Cycle Facitities. Biil-2075, Pacific horthmest Laboratory, Richland, WA.

Soldat, J. K., M. M. Robinson and D. A. Baker. 1974. Models and Computer Codes for Evaluating Radiation Doses. BMm-1754, Pacific Northmest Laboratory, Richland, Wh.

Struxness, E. G., P. H. Carrigan, Jr., M. A. Churchill, K. E. Cousin, R. J. Morton, D. J. Melson, F. L. Parker. 1967. Comprehensive Report of the Clinch River Study. CRR -4035, Clinch River Study Steering Comittee, Dak Ridge National Laboratory, Oak Ridge, TN.

Thackston, E. L. and K. B. Schne 11, Jr. 1970. "Predicting Effects of Dead Zone on Strean Mixing." ASCE Sanitary Engineering Division. 96(SA2): 319-331.

Thomas, M. A. 1974. Scour and Deposition in Rivers and Reservoirs. The Hydrologic Ergineering Center, U.S. Arny Corps of Engineers, Davis, CA.

Tritreme1, Ch., 6. Knollmayer, E. Handerer, H. 6. Heintschel, and P. Stipanits. 1966. "Behavior of Radioisotopes Released to a Strean." Proceedings of the Symposiu on the Disposal of Radioactive Mastes into Seas, Oceans, and surtace laters. International Atomic Energy hgency, Viema, pp. 89-105.

Todorovic, P. 1975. "A Stochastic Model Dispersion of Sediment Particles Released from a Contimuous Source." Nater Resources Research. 1166:919-925.

U.S. Atomic Energy Comission. 1973. Radioactive Maste Management, A Bibliography of Publicly Available Literature Pertaining to the US.IEC's Hanford, Washincton Production Site. Mo-33510.

U.S. Environmental Protection Agency. 1978. Kepone Mitigating Project Report, Standard and Criteria, Office of Hater and Hazardous Materials, Washington, D.C.

U.S. Muclear Regulatory Comission. 1976. Requlatory Euide 1.113 Estinating Aquatic Dispersion of Effluents from Accidental and Routine Reactor Releases for the Purpose of Inplementing hpeendix 1 . 
U.S. Muclear Regulatory Comission. 1978a. Liquid Pathay Generic Study. Inpacts of Accidental Radioactivity Releases to the Hydrosphere from Floating and Land-Based huclear Power Plants. MTRE6-0440. kt

U.S. Muclear Regulatory Comission. 1978b. Revised Draft Environentai Statement Related to the Proposed Manufacture of Floating linclear Poiver Plants. MEREG-0I27 (Revision 1)

Maddel, M. M., C. R. Cole, and R. G. Baca. 1974. A Hater Qual ity Model for the South Platte River Basin - Documentation Report. Prepared for the Environental Protection Agency, Battelle, Pacific Nortmest Laboratories, Richland, M.

Natts, J. R. 1976. Modeling of Radiation Doses from Chronic Aqueous Releases." Paper presented at the Health Physics Society Annual Meeting. San Franc is Co, CA.

Whelan, 6. 1980. Distributed Model for Sediment Yield. Master's Thesis, Mechanics and Hydraulics. University of Iowa, Iowa lity, Iowa.

White, A. and E. F. 6loyma. 1969. Radioactivity Transport in Nater-Mathematical Simulation. EHE-70-04, Technical Report Ro. I9 to the U.S. Atomic Energy Conission, University of Texas, Austin, TX.

Whittacker, R. H. 1951. Removal of Radiophosphorus Contaminant from the Mater in an Aquariu Co cunity. Document HW-28536, Atomic Energy Comission.

Whittacker, R. H. 1961. "Experiments with Radiophosphorus Tracer in Aquarium Microcosins." Ecol. Monogr. 31:157-188.

Hillis, R., D. R. Anderson and J. A. Dracup. 1976. "Transient Hater Quality Mode i ing in Streans." Mater Resource Bulletin. 12(1):157-174.

Hrenn, M. E., J. H. Lentsch, M. Eisenbad, G. L. Laver, and G. P. Howells. 1971. "Radiocesium Distribution in Hater Sediments and Biota of the Hudson River Estuary from 1964 through 1970." Radionuclides in Ecosystens. pp. 334-343, D. J. Melson (ed.).

Yalin, M. S. 1972. Mechanics of Sediment Transport. Pergamon Press.

Yang, C. T. and H. H. Sayre. 1971. "Stochastic Model of Sediment Dispersion." ASCE. 97(HY2):265-288.

Tainoni, Y. A. Sedimentation Engineering. Prepared by the ASCE Task Comittee for the Preparation of the Manual on sedimentation of the Sedimentation Comittee of the Hydraulics Division, ASCE. 
Yotsukura, M. and W. M. Sayre. 1976. "Transverse Mixing in Matural Channels." Hater Resources Research. 12(4):695-704.

Yousef, Y. A. and E. F. Gloyna. 1964. Radioactivity Transport in Mater--The Transport of $58 \mathrm{CO}_{0}$ in an Aqueuus Environent. EHE-12-6405, Technical Report ko. 7 to the U.S. Atomic Energy Comission, 121 pp.

Yousef, Y. A., Akira Kudo, and E. F. 610yma. 1970. Radioactivity Transport in Mater--Si ary Report. EHE-70-05, Technical Report 10. 20 to the U.S. Atomic Energy Comission, 80 pp.

Zand, S. M., V. C. Kennedy, 6. H. Zelliweger and R. J. Avanzeno. 1976. "Solute Transport and Modeling of Hater Quality in a Small Stream." J. Res. U.S. Geol. Surv. $4(2): 233-40$.

FAvailable for purchase from the NRC/GPO Sales Program, U.S. Nuclear Regulatory Comission, Washington, DC 20555, and the National Technical Information Service, Springfield, VA 22161.

**Available for purchase from the National Technical Information Service, Springfield, VA 22161.

**Available free upon written request to the Division of Technical Information and Document Contro1, U.S. Nuclear Regulatory Comission, Washington, DC 20555. 


\section{RADIOHUCLIDE TRAMSPORT IN ESTUARIES}

This chapter reviews models that simulate the transport of radionuclides, sediment and other water quality parameters in estuarine erivironments. A dominant characterizing feature of estuarine systems is that the flow is oscillatory rather than unifirectional as in rivers. Consequently, the models are dynamic (transient) and do not depend on steady-state conditions.

Included in this chapter are me11-known analytical models that solve various special cases determined by simplified versions of advection-diffusion equations.

\section{PHYSICAL NECHAMISNS OF RADIOHUCLIDE TRAMSPORT IN ESTUARIES}

Mathematical models for estuaries must simulate flow and transport through a body of water that has a tidal connection with the open sea and receives an influx of fresh water from rivers and other land drainage. The estuarine sea water is masurably diluted by this freshrater inflow. These conditions exist in the lower reaches of rivers, and a host of different kinds of sounds, bays, and inlets.

Pritchard (1967) has divided these possiblities into four classes based upon geomorphological criteria. These are 1) drowned river valleys - e.g. Chesapeake Bay, 2) Fjords - e.g. Norway, British Columbia, 3) bar built estuaries - e.g., Albemarle Sound, Morth Carolina, 4) estuaries provided by tectonic processes - e.g. San Francisco Bay. This classification indicates the variety of estuarine geomorphology, which together with the variability of estuarine flow, mixing conditions, and salinity distributions present a complex situation for mathematical simulation. In applications to a typical selection of estuaries stable salt medges, stratifications, or mell-mixed conditions might prevail. It of ten happens that there is a longitudinal division of these conditions in a given estuary so that one condition is not adequate to completely characterize the estuary (Officer 1976). 
A major course of differences in estuaries is the contrast in discharge of sediments from the land drainage (Guilcher 1967). Rivers which carry high concentrations of sedimerits fill the ir estuaries wore effectively with fluvial sediments than those with smaller sediment loads. The Colubia and Mississippi Rivers flush out some of their sediment loads onto the continental sheif bc cause of their high flow rates. Conversely, warine sediments can penetrate the estuary via the wedge of salt water flowing upstrean along the botton as in the Rhine estuary and Chesapeake Bay (Guilcher 1967).

Another complicating feature of sediment movement in estuaries is the effect of salinity variation in the estuary on the processes of sorption and flocculation. The electrolytic coagulation of charged colloidal particles is influenced by the electrolytic potential of the water holding the particles in suspension. The potential depends upon the total ion concentration in the water and thus it varies with salinity throughout the estuary (Postma 1967).

Mathematical models for estuaries must be able to simulate flow and transport under conditions of pronounced transience with reversing tides and density difference between fresh and saline water. In estuaries, suspended sediment concentrations are high because of high velocities at ebb and flood tide and an infinite supply of frash input sediment from the river inlets. Furthermore, sediments found in estuaries generally consist of finer particles (a notable exception is the sediment in the Colubia River estuary) wich adsorb more radionuclides than coarser sediments. This high concentration of fine suspended sediment supplied from the freshwater trainage makes sediment transport an important echanisa of radionuclide movement through the estuary (Schubel 1975). The importance of sediment transport on the migration of a contaninant is clearly demonstrated by the recent Kepone (pesticide) spill in the Janes River estuary in Virginia (EPA 1978; Dauson et al. 1978). Some of the radiomuclide field data are show in Table 5.1 .

\section{MATHEMATICA MOOELS FOR ESTURIES}

Mode is reviewed in this chapter include those that similate transport of radionuclide, sediment and water quality constituents. 
TABLE 5.1. Estuary Data

\begin{tabular}{|c|c|c|}
\hline Reference & Materbody & Type of Data \\
\hline $\begin{array}{l}\text { thebell and Glemn } \\
\text { (1971) }\end{array}$ & $\begin{array}{l}\text { Colubia River } \\
\text { Estuary }\end{array}$ & tion of ${ }^{51} \mathrm{cr}$, \\
\hline $\begin{array}{l}\text { Evans, D. H. and } \\
\text { M. H. Cutshal1 } \\
\text { (1972) }\end{array}$ & $\begin{array}{l}\text { Colubia River } \\
\text { Estuary }\end{array}$ & 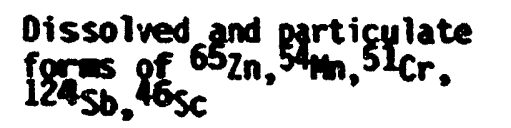 \\
\hline $\begin{array}{l}\text { Klingman and } \\
\text { Kaufan } 1965\end{array}$ & $\begin{array}{l}\text { San Francisco } \\
\text { Bay }\end{array}$ & $\begin{array}{l}\text { Particulate and dissolved } \\
\text { forms of } S_{2 n-95}\end{array}$ \\
\hline $\begin{array}{l}\text { Mishimaki, Y. } \\
\text { et al. } 1972\end{array}$ & Osaka Bay, Japan & $\begin{array}{l}\text { Partifulate forms } \\
\text { of Ifice and } 91 \%\end{array}$ \\
\hline $\begin{array}{l}\text { Water Resources } \\
\text { Data for Mew York } \\
\text { (The State of } \\
\text { Mew York) }\end{array}$ & $\begin{array}{l}\text { Hudson River } \\
\text { Estuary }\end{array}$ & $\begin{array}{l}\text { Dissolved and particulate } \\
\text { forms of gross alpha, gross } \\
\text { beta; dissolved 226Ra and } U\end{array}$ \\
\hline $\begin{array}{l}\text { Lentsch et al. } \\
\text { (1970) }\end{array}$ & $\begin{array}{l}\text { Hudson River } \\
\text { Estuary }\end{array}$ & $\begin{array}{l}144 \mathrm{Ce}, 58 \mathrm{co}, 60 \mathrm{co}, \\
134 \mathrm{Cs}, 137 \mathrm{Cs}, 54 \mathrm{mi}, \\
\text { 90sr in water and bed } \\
\text { sed fiment. }\end{array}$ \\
\hline $\begin{array}{l}\text { Lentsch et al. } \\
\text { (1971) }\end{array}$ & $\begin{array}{l}\text { Hudson River } \\
\text { Estuary }\end{array}$ & $\begin{array}{l}13 / \mathrm{Cs} \text { in } \mathrm{gter} \text { and bed } \\
\text { sed inent, } 5 \mathrm{~m} \text { in the } \\
\text { river bed }\end{array}$ \\
\hline $\begin{array}{l}\text { Urem et al. } \\
\text { (1971) }\end{array}$ & $\begin{array}{l}\text { Hedson River } \\
\text { Estuary }\end{array}$ & $\begin{array}{l}\text { Dissolved and particulate } \\
\text { forms of } 137 \mathrm{Cs}\end{array}$ \\
\hline $\begin{array}{l}\text { Trem } \\
\text { 1975) }\end{array}$ & $\begin{array}{l}\text { Hudson River } \\
\text { Estuary }\end{array}$ & $\begin{array}{l}58 \mathrm{Co}, 60 \mathrm{co}, 134 \mathrm{cs}, \\
137 \mathrm{Cs}, 5 \mathrm{hm} \text { in water. } \\
\text { and bed and suspended } \\
\text { sed iment }\end{array}$ \\
\hline $\begin{array}{l}\text { Urem et al. } \\
\text { (1973) }\end{array}$ & $\begin{array}{l}\text { Hudson River } \\
\text { Estipary }\end{array}$ & 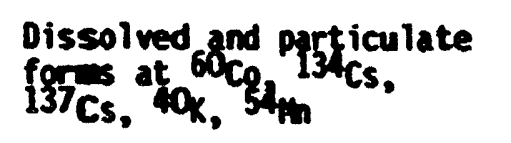 \\
\hline Proore (1974) & $\begin{array}{l}\text { Hudson River } \\
\text { Estuary }\end{array}$ & $\begin{array}{l}\text { Dissolved and particylate } \\
\text { forms of } 13^{n} C_{S s} \text { and }\left[37_{C s}\right.\end{array}$ \\
\hline $\begin{array}{l}\text { Jinks and trem } \\
\text { (1975) }\end{array}$ & $\begin{array}{l}\text { Hudson River } \\
\text { Estuary }\end{array}$ & Dissolved and pafticulate \\
\hline
\end{tabular}


TABLE 5.1 (contd)

Reference

limean and Jinks
(1975)
lmem et al.
$(1976)$
stipsos et al.
$(1976)$

Hamond et al.

Simoson and Wllias (1978)

0lsen et al.

(1978)

uren et al.

(1979)

Mine Yarkee Atomic

Powar Co. (1976,

1978, 1979)

Churchill (1976)

U.S. Emvironmental Protection Asency

(1976) laterbody

Hudson River

Estuary

Hedson River

Estuary

Hudson River

Estuary

Hudson River

Estuary

Hudson River

Estuary

Mudson River

Estuary

Indson River

Estuary

Montsweag Bay, Maine

montsweing 8ay, Haine

Montsweag Bay. Mine
Type of Data

137 Cs in wter and bed sediment

137 Cs in water and bed sedinent

60 co, 134cs, 137 cs, 239,240 py in bed core sediment

Particulate Ra

${ }_{40}^{60,}{ }^{134} \mathrm{Cs}_{\mathrm{r}},{ }^{137} \mathrm{Cs}_{\mathrm{q}}$ in bed core sediment

60Co, 134Cs, 137cs, 40 $K$ in bed core sedimeni

$60 \mathrm{Co}, 134 \mathrm{Cs}, 137 \mathrm{Cs}$, 4. "5h, in wter, and bed and suspended sed timent

Dissolved,and particulate

foris of $7 \mathrm{Be}, 14 \mathrm{ce}$. 17 ce, ${ }^{20} \mathrm{Co}_{134 \mathrm{Cs}}$ 137 Cs, 3y, ar, $103 \mathrm{Ru}, 10 \mathrm{Rs}, 228 \mathrm{Th}$ $95 z$ rosim

58 co, 60co. 134cs, $137 \mathrm{Cs}, 58 \mathrm{~min}$, in bed sediment

228 Ac, 2148i, 58co,

$60 \mathrm{Co}, 134 \mathrm{Cs} 137 \mathrm{Cs}$.

Fin, 40x, 214pt and

20 iti in bed sedinent

Dissolved gross alpha, beta and gissolved ind ${ }^{34}{ }^{3} 7_{C s}$. 222n. 


\section{Radionuclide Transport Models}

Onishi et al. (1976, 1979); Onishi and Ecker (1977); Onishi and Mise $(1978, b)$

\section{ModeI FETRA}

The finite element model, FETRA (Finite Element Iransport), simulates transport of sediment and radiomuclides (and other contaminants, such as heavy metals, pesticides and other toxic substances) in estuaries and coastal maters. Since the model is an unsteady, depth-averaged, two-dinensional (longitudinal and lateral) model, its applicability to estuaries is limited to vertically well-mixed estuaries. The model is based upon general advection-diffusion equations with decay and sink/source terms with appropriate boundary conditions. Siailar to the sediment-contaminant transport model, SERATRA, developed by Onishi (1977), FETRA consists of three submodels coupled to include the merthenisens of sed iment-contaminant interaction. The submodels are: 1) a sediment transport model, 2) a dissolved contaninant transport model, and 3) a particulate contaminant (contaninants adsorbed by sediment) transport model. Transport of sediment and particulate contaninant is simulated for each sediment size fraction or sediment type. FETRA handles both linear and quadratic approximations to velocity and depth distributions in order to be compatible with various finite element hydrodymanic models [e.g., Ran II (Morton et al. 1974) and CAFE (Pagenkopf 1976)] which supply hydrodymaic input to FETRA.

The sediment suboodel includes mechanisas of: 1) advection and dispersion (longitudirsl and lateral) of sediments, 2) wave wotion to suspend sediments in both surf and offshore zones, 3) sediment cohesion, 4) sediment deposition on the ocean and river beds, 5) sediment resuspension from the ocean and riverbed (bed erosion and armoring), and 6) outside contributions of sediments and subsequent mixing. The dissolved and particulate contaninant subbodels include mechanisas of: 1) advection and dispersion of dissolved and particulate contarinants, 2) adsorption/desorption, 3) redionuclide decay and other chemical/ biological degradation, 4) deposition and erosion of particulate contaninants, and 5) contamimant contribut? $n$ from outside sources and subsequent mixing. FETRA also computes changes on bed conditions of sediaent and radionuclides. 
In the implementation of the finite elenent method, triangular elements are used with six nodes associated with each element. Quadratic approximations are made within each element. Onishi et al. (1976̈, 1979) reported good agreenent in comparisons of computed results by FETRA wi... knom analytical solutions of simple one- and turo-dimensional advection-diffusion equations.

The model was applied to the James River estuary to deternine the longitudinal morement of sedinent, and migration of the pesticide, Kepone, in both dissolved and particulate forms under unsteady estuary flow conditions (Onishi and Ecker 1977; Onishi and Wise 1978a,b). Sediment transport modeling was conducted for cohesive and noncohesive sediments, and for organic watter. In the dames River study, the wodel parameters and coefficients to be adjusted were dispersion coefficients and paranters used to calculate deposition and erosion rates of cohesive sediments based on Partheniades (1972) and Krone (1962) formulas. Although the paraneters of these two forinlas are physically measurable, those values are not usually available. Hence, these parameters were rather arbitrarily adjusted to fit measured sedibent concentration. The lack of rationale for selection of these paraneters is one of the problems FETRA faces. Other paraneters (e.g., Kepone distribution coefficients, sediment sizes, fall velocity, etc.) were deternined by theoretical and experimental analyses and field conditions prior to the wodel sinulation. Thus, the major calibration effort mas exercised to reproduce sediment distribution patterns similar to measured time-varying longitudimal distributions of sediment concentrations. Madel calibration for sediment transport was performed under one flow condition (freshmater input discharge of $58.3 \mathrm{~m}^{3} / \mathrm{sec}$ ). The calibration results are shom in Figure 5.1. For the verification of the node1, the freshwater input discharge of $247 \mathrm{~m}^{3} / \mathrm{sec}$ case ms tested. The comparison between measured sediment concentrations ard computed results for the verification run is shom in Figure 5.2, revealing that the nodel reproduced two-peaked distributions mell (Onishi and Wise 1978a). The good comparison of computed farticilate and masured Repone is show in Figure 5.3. The rodel also calculated the scour and deposition of sedicent and Kepone in the lanes River. 


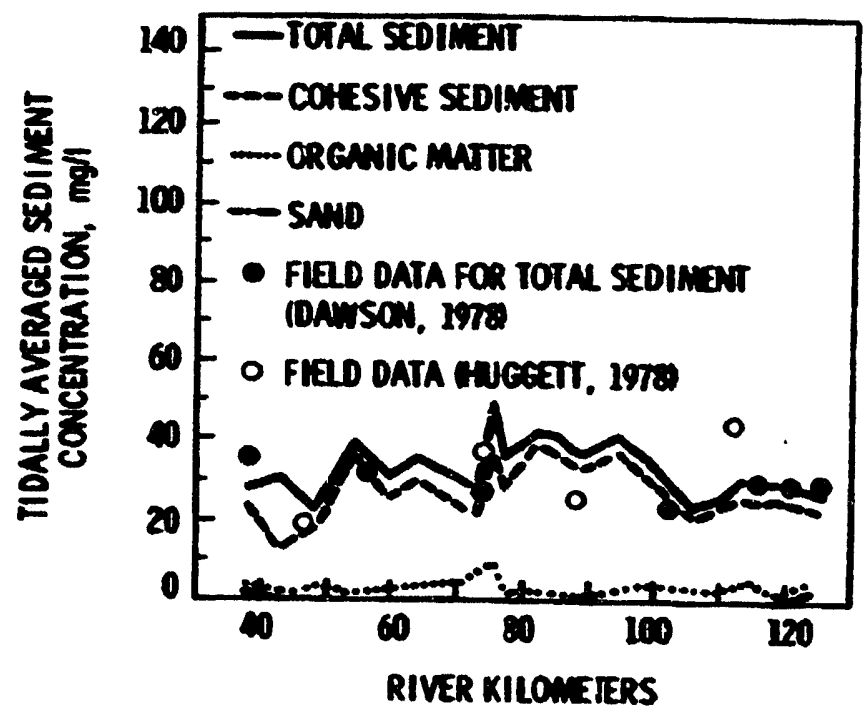

FIERE 5.1. Tidally Averaged Sediment Concentration of Each Sediment Type for the Met Freshwater Input Discharge of $58.3 \mathrm{~m}^{3} / \mathrm{sec}$ in the James River Estuary (Onishi and Wise 1978a)

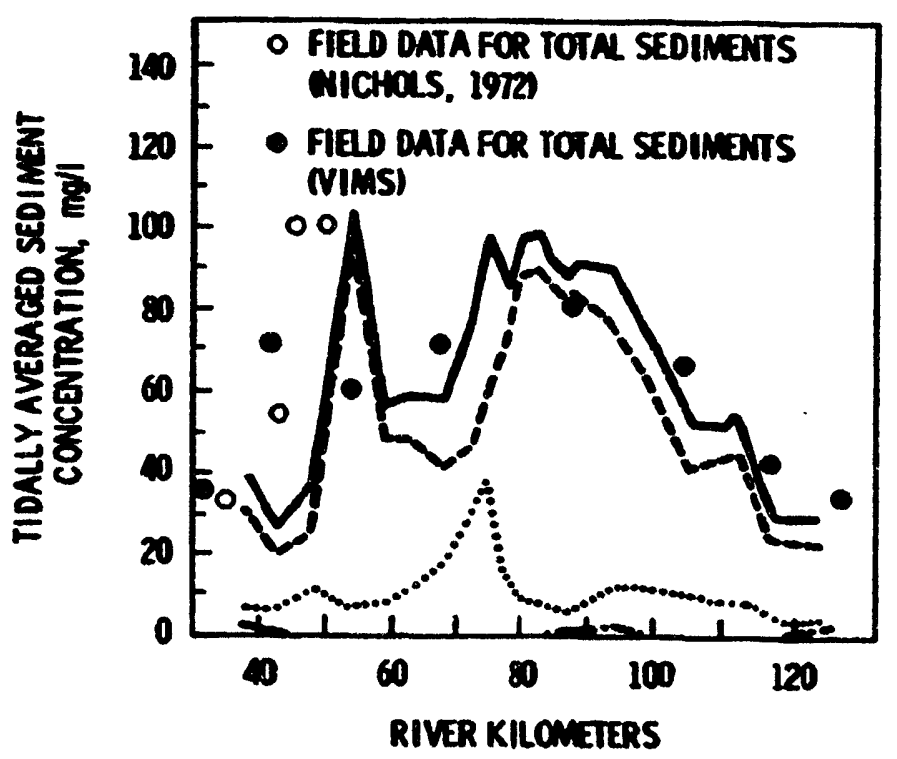

FIERE 5.2. Tidally Averaged Sediment Concentration of Each Sediwent Type for the Met Freshmater Input Discharge of $247 \mathrm{~m} / \mathrm{sec}$ in the Jaces River Estuary (Onishi and Wise 1978a) 


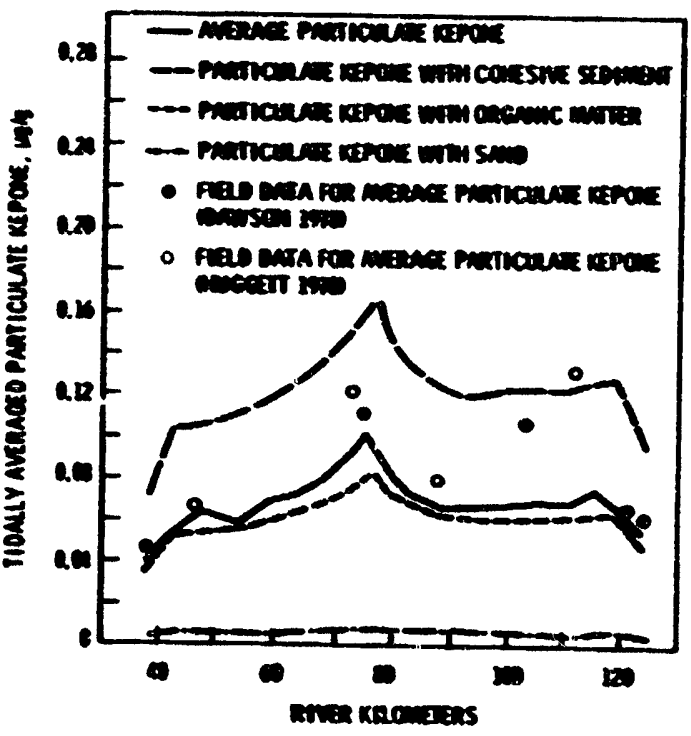

FIGRE 5.3. Tidally Averaged Particulate Kepone Concentrations for the Het FreshHater Discharge of $58.3 \mathrm{~m}^{3} / \mathrm{sec}$ in the danes River Estuary (Onishi and Hise 1978a)

Several limitations of FETRA are as follows: 1) the codel requires extensive input data which may linit its applicability; 2) it requires rather extensive computer tive that a long-term contincous simulation way be prohibitive; and 3) the wodel treats adsorption/desorption mechanisins as complete reversible mecharisus producing a possible error.

Churchill (1976). An adaptation of the schene of the Find Water Quality model (Orlob et al. 1957) is used by Cherchill (1976) with radionuclide sorption included at the bed sediment-water interface. (Description of the Finh model is given under "Hater Quality rodels" Section in this chapter.) Radionuclide sorption ws nodeled by the equation:

$$
C=C_{0}\left[1-K_{d}\left(1-e^{-\infty t}\right)\right]
$$


where

$C=$ radionuclide concentration

$C_{0}=$ radionuclide concentration at time $t=0$

$K_{d}=$ equilibrium constant

$\alpha=$ constant for exponential radionuclide sorption

In this formulation the channels are allowed to run dry, and resultant flows and velocities are calculated at junction points. The required input is:

- channel dimensions

- initial conditions

a) velocities

b) cross-sectional areas

c) junction heads

- channel orientations

- maming roughness coefficient

- discharges and withdramals from junctions

- boundary tidal conditions.

The dispersion progran requires input on:

- initial concentration at each junction

- rates and concentrations of discharges and withdramils

- boundary concentrations over the entire silulation period.

- diffusion and sorption constants.

The results of the calculations include water and sediment concentration factors of each radionuclide at each junction at specified tines. This nodel has been field tested in montsweag Bay and Bailey Cover, Maine, at the site of the Maine Yankee muclear power plant. The distributions and magnitudes of the sedibent bound radionuclide concentrations were compared with measured values.

Codell (Mic Estuary Model) (usinc 1978)

For the mic liquid pathmy generic study (USmiC 1978), R. B. Codell and mic staff described an analytic solution to simplified forms of the 
advection-diffusion equation for a core-welt accident transport model. The model is one dimensional with the tidally averaged net domstrea currents and with radicouclide-sediment interactions.

As illustrated in Figure 5.4, a water layer of thickness $d_{1}$ is in contact with a sediment layer of thickness $d_{2}$. The water layer is moving with a net downstream velocity (nontidal) of $U_{f}$, and the bed is moving with a net domstrean velocity $U_{b}$. Diffusive transport from tidal oscillations in the water and sediment layers is assumed to be with constant longitudinal dispersion coefficients $D_{x}$ and $D_{x b}$, respectively. Sedimentation and burial occur uniformly at a rate $v$.

SuRface
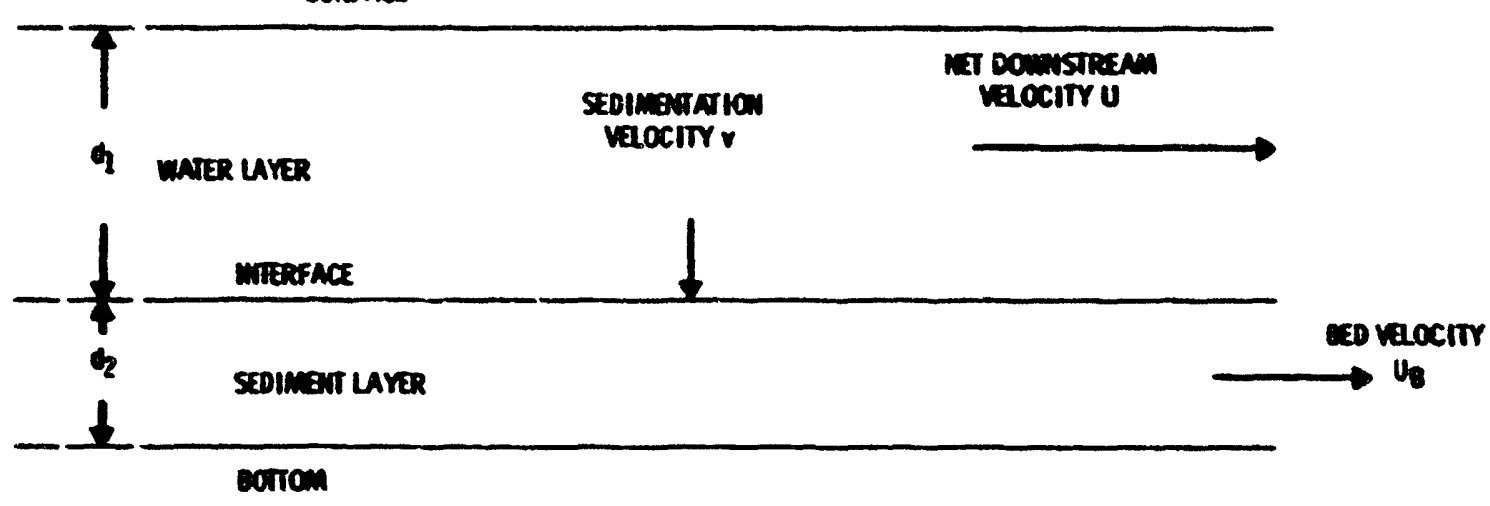

FIGURE 5.4. NRC Estuary Model

It is assumed that the sediment and water are in chemical equilibrium, and their concentrations are related by the equilibrium distribution coefficlient $K_{d}$ :

$$
C_{p}=R_{d} C
$$

where $C_{p}$ is the radionuclide concentration on the sediment, and $C$ is the radionuclide concentration in the water.

5.10 
The differential equation describing the concentration in the water phase becomes:

$$
\frac{\partial C}{\partial t}+U \cdot \frac{\partial C}{\partial x}=E_{L} \cdot \frac{\partial^{2} i}{\partial x^{2}}-C
$$

where

$$
\begin{aligned}
& U^{\prime}=\frac{f U+(1-f) U_{b} K_{d}}{f+(1-f) K_{d}} \\
& E^{\prime}=\frac{f D_{x}+(1-f) D_{x} K_{d}}{f+(1-f) K_{d}} \\
& f=\frac{d_{1}}{d_{x}+d_{2}},(1-f)=\frac{d_{2}}{d_{1}+d_{2}}
\end{aligned}
$$

The solution to Equation (5.3) for an instantaneous source of 1.0 curie at $x=0$ is:

$$
c=\frac{1}{a \sqrt{4 \pi E_{L}{ }^{\prime} t}} \exp -\left\{\frac{\left(x-U^{\prime} t^{2}\right.}{4 E_{L} \cdot t}-\lambda \cdot t\right\}
$$

where

$$
\begin{aligned}
a & =f+(1-f) K_{d} \\
\lambda^{\prime} & =\lambda+\left[\frac{U k d}{d_{2}}(1-f)\right] /\left[f+(1-f) k_{d}\right]
\end{aligned}
$$

The solution is generalized for arbitrary releases by using Equation (4.31). Particulate radionuclide concentrations can then be obtained by Equation (5.2). 


\section{O'Connor and Farley (1978)}

In a recent paper, 0 'Comor and Farley (1978) describe a hytrodynanic, pesticide-transport, ecological wodel wich was also applied to the James River estuary. The codel is quasi two-dimensional (longitudinal-vertically layered) and steady state (tidally averaged) with a capability for the simulation of both dissolved and particulate contaninants. The transport equations used are purely advective with no diffusion being similated. The momentum equat:on does not include a longitudinal inertia term resulting in some restriction on the applicability of the codel. Comparison of predicted and measured values for the James River case indicates good agreement (Figure 5.5). This model requires various coefficients and parameters requiring rather extensive field data needed to assign values of these parameters, including sediment concentrations at each reach as input data.

vaccir. is
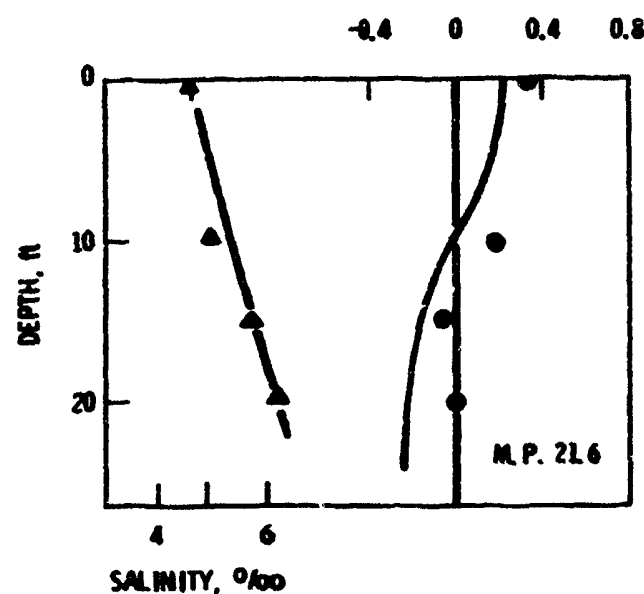

vacom. ins

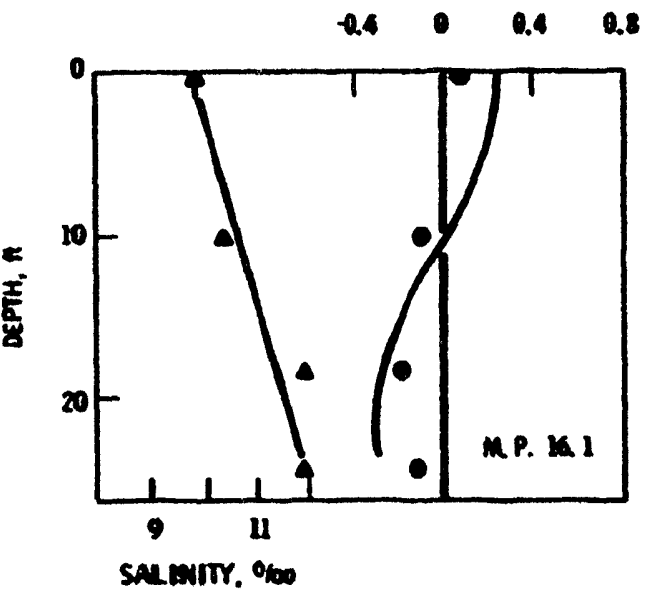

FIGURE 5.5. Comparison of Computed and Measured Values of Velocity and Salinity in the James River Estuary (O'Connor and Far ley 1978)

\section{Eraslan (1977)}

A project at Oak Ridge Mational Laboratory involves the development of transient, one- and two-dimensional, far-field athematical wodels for the assessment of the environmental impact of power plant operations in estuaries 
and rivers, lakes and cooling ponds, and coastal regions. The project, known as the "Unified Transport Approach (UTA) for the Assesswent of Power Plant Imacts," includes models for thermal, chemical, radiological and biological impacts (Eraslan et a1. 1977). Formulations of the UTA models will be fundamentally similar in theory, allowing the application of virtually identical mmerical solution methods and computational algoriths. All are discreteelement formulations with Runge-Kutta-6ill muerical solutions.

As part of the UTA progran (see Chapter 4), three radionuclide transport models have been developed for application to estuaries. According to Eraslan et a1. (1977), RuDWE is a transient, one-dimensional transport model for dissolved radionuclides applicable to controlled rivers and estuaries; RADTix was developed directly from the thermal code, FARTIP, and is a transient, twodimensional, dissolved-radionuclide transport model for lakes, estuaries, and coastal regions. Neither RADONE nor RADTIO has yet been verified (Eraslan et al. 1977). Technical reports describing these two nodels have yet to be published, thus precluding detailed model evaluations. A third radicmuclide model applicable to estuaries, HOTSET, is a one-dimensional model for the transport of radionuclides adsorbed on sediment (Fields 1976). This preliminary wodel was constructed by merging the hydrodynamic part of the tidal transient, one-dimensional thermal and salinity code, ESTONE, with the sediment and contaminant transport code, CHISED (F ields 1976), described in Chapter 4. However, since the mathematical formulation and computer code structure of CFISED were not compatible with the other one-dimensional UTA models, another one-dicensional sediment transport node1, SEDOnE, was developed, as discussed in Chapter 4.

Yater Quality models

The following models are applicable for the deterwination of the iehavior of estuarine water quality parameters.

Mater Quality Models of Type I

Leendertse (1970, 1973). The wodel of Leendertse (1970), considered the representative of this type, is a two-dimensional, transient and steady-state 
hydrodymanic and water quality model which uses a finite difference solution method. The advection-diffusion equation is solved for dissolved constituknts, wich could include dissolved radionuclides. There are, however, no such source or decay terms presently included in the formulation. Water levels and constituent concentrations are required on the open boundaries of the nodeled region for the entire simulation period. This model has been used successfully to calculate fecal coliform concentrations in Janaica Bay, Mew York.

Leendertse et al. (1973) also developed a quasi, three-dimensional (vertically layered), hydrodymanic wodel for estuaries and ccastal seas mich also simulates salinity conservation and transport. This model could be used with dissolved radionuclide concentration replacing salinity in the model equation. The computational schewe is a finite difference method. There are no source or sink terms in the model as it is presently written. This aodel was applied with success to the Chesapeake Bay for the calculation of circulation patterns. This application is described in Leendertse, Alexander and Liu (1973).

Spraggs (1974). A generalized version of Leendertse's model by Spraggs (1974) simulates dissolved contaminants and sedinent transport by using the velocity field to trace the trajectories of particles treated as Lagrangian variables. This nodel has been applied to San Francisco Bay with good results. It should be noted that this model does not include adsorption-desorption mechanics or resuspension of sediment.

McCoy and Edge (1977). A water quality model with essentially the same capabilities as that of Leendertse has been constructej by McCoy and Edge (i977). This model is, however, a finite eleaent wodel wich considers stratification in the estuary.

Taylor and Davis (1974). This is a finite element model with capabilities similar to the nodel of McCoy and Edge. Mo sediment transport is included in this model. Cubic isoparametric elements are used to represent the estuary. A brief description appears in Taylor and Davis (1974). 
Daily and Harleman (1972). Daily and Harleman (1972) have written onedimensional model capable of simulating dissolved radionuclide transport. This model incorporates a solution of the dynamic, one-dimensional momentum, and advection-diffusion equations. These governing equations are solved along a network of branched and looped one-dimensional channels using the finite e iement method. Four constituents--salinity, temperature, biochemical oxygen demand $(B 00)$ and dissolved oxygen (DO)--are included in the mathematical model. There are decay terms for $\mathrm{BOD}, \mathrm{DO}$, and temperature. The concentration distributions of these constituents are obtained by solring sequentially the appropriate conservation of mass equations which include transport, mixing, and reaction processes. Transport processes due to tidal motion are specified by a combined solution of the continuity and momentum equations including density effects. The reaction processes are characterized by first-order kinetics. It should be noted that no Coriolis or channel curvature effects are accounted for in this model. The model has given good results in applications at Cork Harbor, Ireland, and the James River in Virginia. The present model may be considered an improved version of earlier models of Lee and Harlemen (1971) and Thatcher and therleman (1972).

\section{Mater Quality Models of Type II}

Orlob et al. (1967) (Fima Model). The representative model of this type is the Find dynamic estuary model developed by orlob et al. (1967), and modified and applied by Feigner and Harris (1970). The Fina model can be used for the one-dimensional simulation of dissolved radionuclides in an estuary. This model was developed by Mater Resources Engineers, Inc. for the Federal Mater Quality Acministration, U.S. Department of the Interior. The FWOA dymamic estuary model will calculate transient tidal flows and tidally varying concentrations of constituents of both conservative and nonconservative substances. The model is applied to a network system of channels and junctions laid out in a pattern wich characterizes the geonetry of the water body. Thus, the dynamics of mater bodies with two-dimensional geometry are simlated with a one-dinensional model. An example of the layeut is shown in Figure 5.6. Each channel is treated as a prismatic conduit with a specified length and width. 
unctions are given the properties associated with mass storage, volume, and depth. The one-dimensional motion equations are solved along the channels and the constituent equations are solved at the junctions. The governing equations describe the transfer of mass between junctions and balance of mass at the junctions. The solution technique is a finite difference scheme wich will handle up to five dissolved constituents. The wodel has been applied and verified at San Francisco Bay and San Diego Bay.

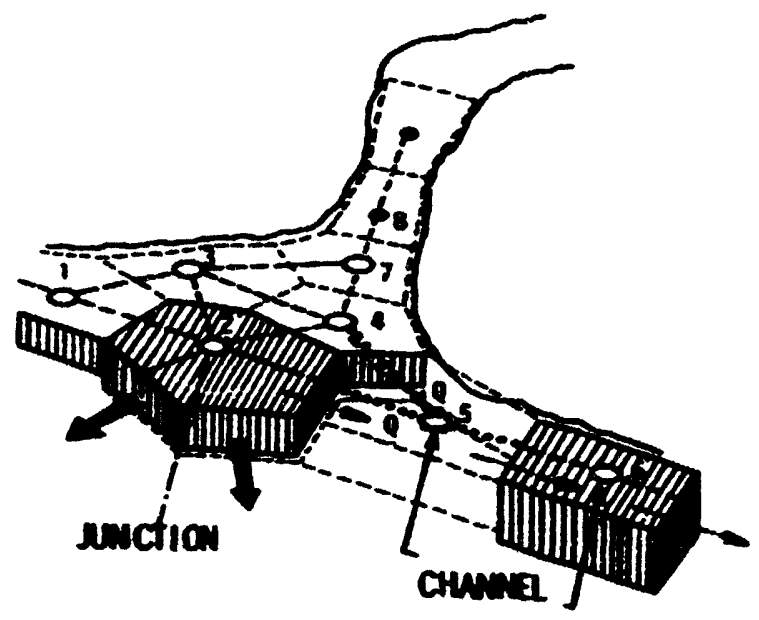

FIERE 5.6. Chamel-Junction Definition for Computational Mesh (Whan and Crlob 1972)

Baca et al. (1973) (EXPLCRE-1). The river basin mater quality nodel EXPLCRE-I of Bace et al. (1973) is a slightly nore general version of the fing model and is applicable to estuaries and tidally influenced rivers. The muerical features of this nodel are basically the sane as those of the fing codel except for the added generality of being able to treat up to 16 water quality parameters including 00,800 , plankton populations, phosphorus cycle dynamics, and nitrogen cycle dynawics.

Sedinent Transport models

odd and Owen (1972)

A hydrodymanic and sediment transport model for 60 wiles of the Thanes River estuary is reported in Odd and owen (1972). In determining the mater 
movement, the method mas to calculate, as a first approximation, the bulk flow, i.e., the flow over the complete depth; and then, as a second approximation, to apportion it between the upper and lower layers. The calculation of the total flow is based on the one-dinensional equations of montun and contimity, ignoring second order terms mich were considered to be insignificant. In the silt wovement portion of the model, empirical relations are used to simiate the processes of erosion (Partheniades 1962), transport in suspension, deposition (Krone 1962), bed consolidation, and re-erosion. This nodel could only be used to sinulate the advective transport of radiomuclides attached to suspended sediment particles. There are no source and sink terns or diffusion in the governing equation. Comparisons with measured data from the Thames River estuary show good agreement.

\section{Ariathurai, Machrthur and Krone (1977)}

The sediment-only transport model of Ariathurai, MacArthur and Krone (1977) could be used for particulate radionuclide transport in estuaries. However, only cohesive sediments are considered by the authors. This is a finite element, transient, cohesive sediment transport model wich simulates desposition and erosion in estuarine environents. Either depth-averaged or width-averaged equations may be solved. The bed is considered as layered composite with the physical properties of each sediment layer varying with overburden pressure. Suspended sediment concentrations and the bed profile are calculated at each time step. The solution scheme is to treat the time dependent ter $2 c / \partial t$ as an instantaneous constant and solve the resulting elliptic (advection-diffusion equation) equation for each discrete time. The transient problem is then handled by a finite difference method. The wodel was applied to the Savannah River estuary to calculate suspended sedinent transport. Comparison of computed results with field data indicates reasonable agreenent (Figure 5.7). 

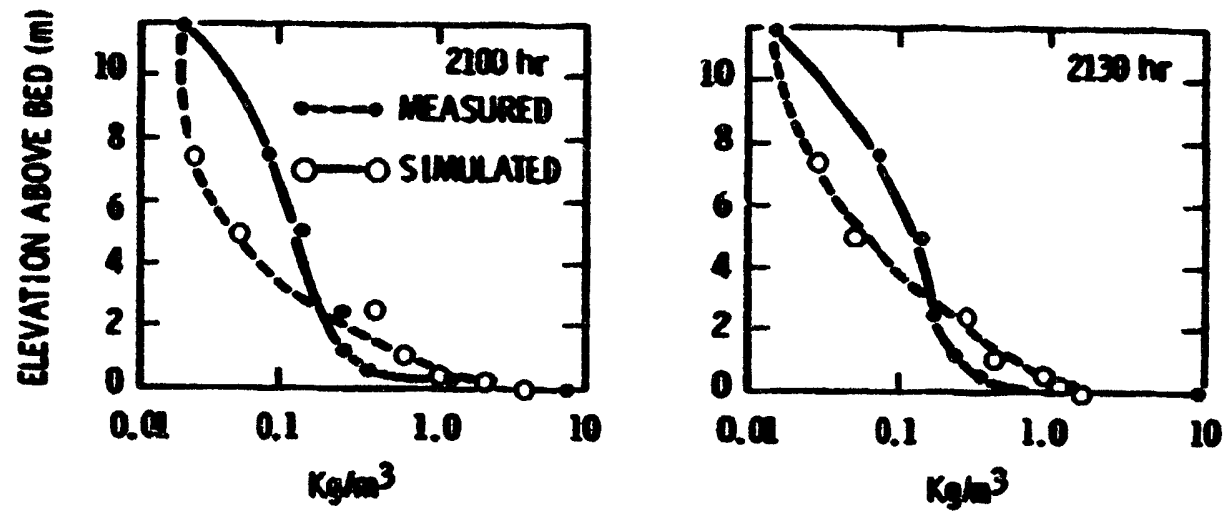

FIERE 5.7. Suspended Sediment Concentrations Ouring Spring Tide in the Savanath Estuary (Ariathurai, Fechrthur and Krone 1977)

Brandsra and Divoky (Dredoed Material Research Progra Models) (1976)

Two sediment-only models were designed at Tetra Tech for the U.S. Army Corps of Engineers Dredged Material Research Program (Brandsa and Divoky 1976). The first model is designed for a single instantaneous dup of dredged aterial. The processes of convective descent, dymamic collapse in the water colum and long-term passive diffusion are modeled. The initial cloud of material is assmed to be a hewisphere. The second model is for jet discharge from a fixed or noving ressel with the same descent, collapse and diffusion mechanisus wodeled as for the instantaneous dup nodel. In this case, however, the phenomenon being simlated is essentially that of a sinking jet rather than a shining clourd. In joth models the anbient current is assumed to be horizontal and variable in all three dimensions and time. When the nodels are used in cases of complex abient currents their performance will be very dependent on good velocity data. In the diffusion simulation, the twodimensional afvection-diffusion equation for a uniform flow field with no lateral boundaries is solved, and the solution is modified to account for nomm iform currents, lateral boundaries and unsteady flow. The modifications are intuitively reasonable but it would be interesting to see matheatical justification that the procecture always converges to a true solution. The approaches represented in these two sodels are based upon the work of koh and 
Chang (1973) and Fischer (1970, 1972). The mmerical solution methods employed are of the finite difference type. These codels could be used for radionclides associated with particulate material only.

Sith (1977)

A longitudinal-vertical sedinent transport model was developed by Saith (1977) for constal seas. This nodel is dynamic and includes specific (often empirical) sediment transport mechanisms. There are no hydrodymanics in the nodel formalation. Thus, velocity profiles for the transport nodel are required from extermal sources. The concentration field suspeaded sedinent is derived fron the advection-diffusion equation by asymiotic analytical techniques. There are no source or sink terms in the formulation. There is no verification documented in Saith's paper.

O'Comor (1971)

O'Comor (1971) describes one- and two-dimensional, unsteady, suspended sediment models mich were applied to the Potomac and nersey Estuaries. The cae-dimensional model is in the vertical direction only, including the sedinent fall velocity but no flow velocity. The boundary condition at the bedmater interface is specified in such a manner as to allow a net sediment flux across the interface. Thus, erosion and deposition may be simulated. The two-dimensional model has constituent concentrations varying in the longitudinal and vertical directions but no vertical velocities are included. Both mode is use finite difference solution schenes.

Maldrep and Farmer (1973)

Maldrop and farmer (1973) have developed a three-dimensional hydrodymaic and transport model intended for use in sediment transport codeling in a river deita. The effects of buoyancy caused by the difference in density of fresh and saline water are included. In addition, turbulence effects are considered via an eddy viscosity nodel. The adrection-diffusion equations are not solved in this model. Computed flow fields are ased to track a distribution of nomimal particles representing the suspendied load of the river as determined from 
field ata. The solution scheme enplosed is an assmptotic time-dependent finite difference techaique. The model has been applied to South Pass on the Hississippi River with satisfactory results.

\section{Snuldian (1976), Pavish and Spauldin (1977)}

Spulding (1976) used a hybrid Eulerian-Lagrangian particle-in-cell technique to develop a three-dimensional nodel capable of handling the long-term, transieat or steady-state transport of discrete sedinent particles in an estuary or constal zore. The work of Pavish and Spaulding (1977) is a contimution of this model. The solution algorith enploys a finite difference grid network wich horizontally translates with the mean particle wotion and expands with the dispersive growth of a marker particle cloud. The vertical cartesian coordinate is nondiansionalized by a transformation, wich casts the governing equations in $x-y-n$ space where $n$ is dimensionless. Through the use of the vertical transformation the code can treat complicated botton topography and the time varying free surfaces as uniform boundaries.

A relocity processor was developed for the interpolation of velocities from a vertically averaged two-dimensional velocity field of a tidally driven, finite difference, hydrodymanic mmerical model. The particle-in-cell algorith is then coupled to the hydrodsmavic velocity field by the velocity processor, and utilized to predict the long-tern diffusion and advection of dilute neutrally and negatively buoyant suspended sedinent clauds resulting from an instantaneous release of barged dredge spoil. The nodel has been applied to Brom's Ledge in Rhode Island Sound. This model could be used for particulate radionuclide transport in estuaries. However, there are no source, sink or decay terms in the governing equations, and deposition and resuspension mechanisus are not considered. 


\section{REFERENCSS FQR CHAPTER 5}

Ariatharal, R., R. C. Machrthur, and R. 8. Krone. 1977. Mathenatical Model of Esturial Sedteent Transport. U.S. Aruy Corps of Engineers, Whtenays Exper mant Station, Techicical Report 0-77-12, Vicksburg, is.

Buca, R. 6., M. W. Ladtel, C. R. isle, A. Brandstetter and D. B. Cearlock. 1973. Explore-1: A River Bas in vater Ouality Hodel. Battelle, Pacif ic Morthmest Levoratories, kichtand, tin.

Brandsm, M. G. and D. J. Divoky. 1976. Developent of Models for Prediction of Short Ten Fate of Dredoed material oischared Thto the Estuarine Emiroinent. U.S. corps of Eng ineer contract keport $1-76-5$ by Tetra Tech Inc., Pasadera, $C A$.

Chan, C. U. and 6. T. Orlob. 1972. Ecologic Simulation for Agutic Emvironents. Prepared for the office of hater kesources Research, U.S. Lepartinent of Interior by Hater Resources Engineers, Inc.

Churchill, J. H. 1976. Measurement and Computer Modeling of the Distribution of Muclear Reactor Discharred Radionuclides in the Estuarine Sedinent lear the hing lanke Atonic Power Plant in Uiscasset, Maine. N.S. Thesis, Entversity of haine, Orom, Te.

Committee on Tidal Hydraulics of the Hydraulics Division. 1970. Research lletds on Therml and Sedimentary Pollution in Tidal Mater." j. Hydraulic Division, ASCE. Pp. 1539-:548.

Daily, J. E. and D. R. F. Harlenan. 1972. Mumerical Model for the Prediction of Transient Hater Gulity in Estuary Metworks. Ralph in. Parsons Laboratory, h.T.T. Report io. 158.

Danson, 6. W., (Project Manager). 1978. The Feasibility of Mitioating Repone Contamination in the daes River Basia. Schitited to the U.S. Environmental Protection hency. Batelle, Pacific Worthmest Laboratories, Richland, In,

Eraslan, A. H. et al. 1977. Developent of a United Transport Approach for

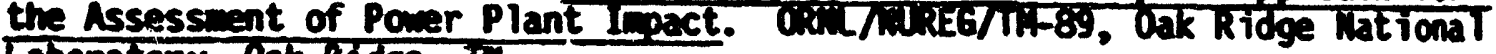
Laboratory, 0ak Ridge, in.

Evans, D. H. and M. H. Cutshall. 1972. "Effects of Ocean Hater on the Soluble-Suspended Distribution of Columbia River Radionuclides." Radioactive Contanination of the Marine Emironment. IAEA, Vienna, Austria, Pp. 125-140.

Feigner, K. D. and H. S. Harris. 1970. Docknentation Report-Fund Dymanic Estuary model. U.S. Departiment of Interior, Federal thater Quality Adinistration. 


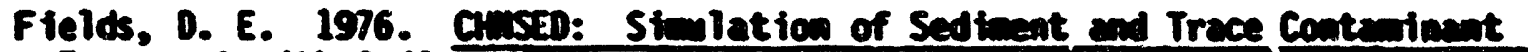

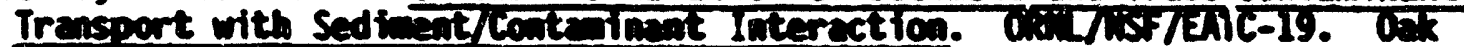

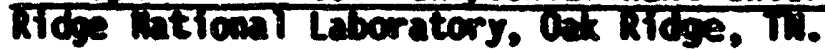

Fields, 0. E. 1977. WTSzD: A Che-Dimensiond, Tidal-Trasient, Discrete

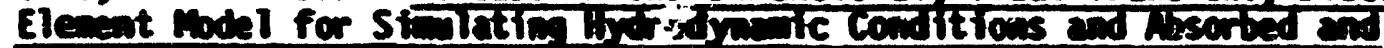

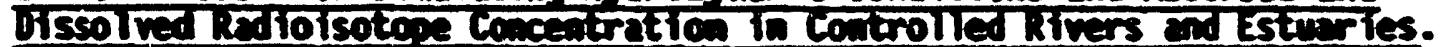

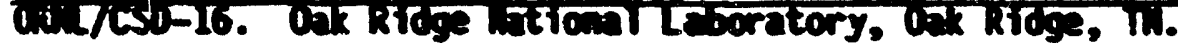

Fischer, H. B. 1970. A puthod for Predicting Pollutant Transport in Tidal Heter. Whter Resounces center contribution ho. I3k, college of Engireering, intrersity of California, Berkeley, Ca.

Fischer, H. B. 1972. "A Murical Model of Esturrine Pollutant Transport." Proceedines of the 13th Canstal Engineer ing Conference. Rerican Society of Civil engineers, hew York, hil. Pp. Zzus-zzih.

Euilcher, A. 1967. Origin of Sediments in Esturies." Mrican Association for the Adrancement of Science. Washington, D.C.

Hamond, D. E., H. J. Simpson, 6. Mathiew. 1977. Madon 222 Distribution and Transport Across the Sediment-Hater Interface in the Hudson River Estury. - Jourmal of Ceophrsical Research. 82(27):3913-3920.

Hebbell, D. W. and J. L. Glem. 1971. Distribution of Radionuclides in Botton Sedinents of the Colubia River Estury. U.S. Lapt. of Interior Eological survey upen file keport.

Huggett, R., D. Haven and M. Wichols. 1978. Kenone-Sediment Relationships in the dumes River, Virginia Institute of Mrine Science, Virginia, Seinitted

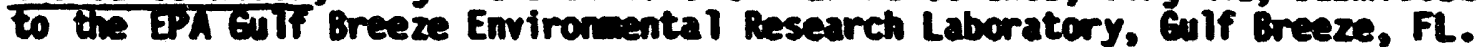

Jinks, S. M., and M. E. Urem. 1975. Radiocesiu Transport in the Hudson River Estuary." Chapter 11 of Emvironmental Toxicity of Anuatic Radionuclides: Models and Mechanisoms. H. M. ifilter end J. T. stamard (eds.), $1 \mathrm{~mm}$ froor Science Pobtisters, Inc., Am Artor, AI.

Klingan, P. C. and Kaufana, H. J. Transport of Radioneclides with Suspended Sedineat in Esturine Systes. Sanitary Em. Lab. College of Engineering, chiversity of California, Berkeley, CA. SEil Report no. 65-15.

Koh, 8. C. Y. and Y. C. Chang. 1973. Methentical Model for Barogd Ocean Disposal of Hater. Environental Protection rechnology.

Rrone, R. B. 1952. Flume Studies of the Transport of Sedinent in Estuarial Shaline Processes. University of Calformia, Hydraultc engineering Laboratory and Sanitury Engineering Research Laboratory.

Lee, C. H. and D. R. F. Harlewan. 1971. One-0rmenstonal, Real-Time model for

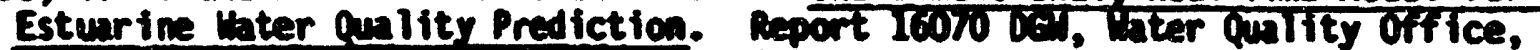
Emvironental Protection hesey, Tashington, D.C. 
Leendertse, J. J. 1970. H Hater Quality Sim lation Model for Hell Mixed Estuaries and Coastal Seas." Vo1. 1, Principles of Computation. Re-6230-RC.

Leendertse, J. J., R. C. Alexander and S. L. Liu. 1973. "A Three-Dimensional Modal for Estuaries and Coastal Seas." Volume 1, Principles of Computation. R-1417-OPR.

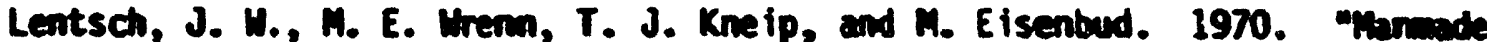
Radionuclides in the Hodson River Estuary." Proceedings of the Fifth Ameal Health Physics Society, Midyear Topical Sy posin on Heath Pinrsics Hspects

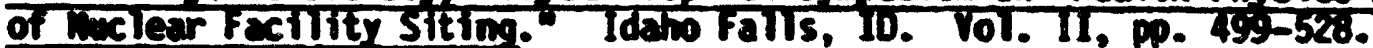

Lentsch, J. M., T. J. Kneip, M. E. Hrem, 6. P. Howells, and M. Eisenbud. 1971. "Stahle Maganese and Manganese-54 Distributions in the Physical and Biological Components of the Hadson River listury." Proceedings of the

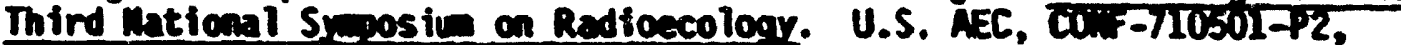
pp. is $3-i, 3$.

Maine Yankee Atomic Power Co. 1976. Mine Yankee Atomic Power Co. Ammal Report.

Mine Yankee Atomic Pourer Co. 1978. Mine Yaakee Atonic Pomer Co. Ammal Radiological Emvironental Surveillance teport 1 damary 1977 - 31 Lace-ber I971. Engineering office, Emvironnental Emgineering Uepartient.

Maine Yankee Atonic Power Co. 1979. Mine Yankee Atonic Power Co. Amual Radiological Emiron ental Surveill ance keport I Lamary 1978 - 31 Lece-ber 1978. Engimeering office, Emvironental engineering bepartient.

McCoy, J. E. and B. L. Edge. 1977. Mthodology for Apolyin the i inite Element Method to Partialiy Stratified Esturies. Report 10.66 , Water Resources Research institute, Cleison Dhiversity, Cleuson, SC.

Moore, H. L. 1974. "An Investigation of Factors Imfluencing Radiocesium Exciing in Estuarine Sediments of the Hudson River." Ph.0. Thesis, School of Engineering and Scifence, Mew York University.

Michols, M. M. 1972. "Sediments of the James River Estuary, Virginia," 6eo. Soc. Mer. Men. 133:169-212.

Mishimaki, Y., Y. Honda, Y. Kimura, H. Morishima, T. Koga, Y. Miyaguchi and H. Kani. 1972. "Behavior and Distribution of Radioactive Substances in Coastal and Estuarime Haters." Radioactive Contamination of the Marine Emvirorment. IAEA, Viema, Austria, PP. I7/-193.

Morton, H. R., L. A. Roesner, D. E. Evason, and J. R. Monser. 1974. Computer Progre Docuentation for the Strea Quality Model, OUL-11, Mater Rescurces Engineers, Inc., Wimit Creek, Ch. 
0'Connor, B. A. 1971. Whthentical Model for Sediment Oistribution." Proceedinos, Fourteenth Concress of the Intermational Association for Iridraulic kesearch. Pp. 195-zuk.

O'Comnor, D. J. and K. J. Farley. 1978. Preliminary Analys is of Kepone Distribution in the James River." Repone in the Marime Emvironment. U.S. EPA Research Laboratory, Sabine Island, EnIf Breeze, FL.

Odd, M. Y. M. and M. M. Owen. 1972. "A Two Layer Model of Mud Transport in the Thanes Estuary." Proc. Inst. Av. En. Supplenent 9, 175.

Officer, Charles B. 1976. Physical Oceanography of Estuaries. John Wiley and Sons, Hew York, NY. 45, pp.

Olsen, C. R., H. J. Simpson, R. F. Bopp, S. C. Millians, T. H. Peng and B. L. Deck. 1978. "A Eeochemical Amalysis of the Sediments and Sedinentation in the Hudson River Estuary." Jourmal of Sedimentary Petrology. 48(2):401-418.

Onishi, Y. and R. M. Ecker. 1977. Mnthenatical Simulation of Transport of Kepone and Kepone-Laden Sediments in the James River Estuary." Proceedings of the Conference, "Kepone Seminar 11." September 21-22, 1977, Easton, Tu.

Onishi, Y., P. A. Johanson, R. 6. Baca, and E. L. Hilty. 1976. Studies of Colubia River Mater Guality--Development of Mathemtical Models for Sed went and Radiomelide Iransport halysis. Bim-b-452, Prepared by Pacific hor thimest Laboratory, Richland, W, for U.S. Energy Research and Develo; zent Adwinistration.

Onishi, Y. and S. E. Mise. 1978a. Whathematical Modeling of Sedibent and Pesticice Transport in the James River Estuary." Proceedings of 26th Anmual Hydraulic Division Specialty Conference on Verification of Lthenatical and Physical hodels in Hydraulic Engineering. College Park, W, August 9-11, pp. 303-310.

Onishi, Y. and S. E. Hise. 1978b. Mathematical Simulation of Transport of Sedicent and Kepone in the lames River Estuary. PIL-2731. Pacific Rorthest Laboratory, Richland, Wh.

Onishi, Y., E. M. Amold, and D. H. Mayer. 1979. Modified Finite Element Transport Model, FETRA, for Sediment and Radionuc Tide Migration in Cpen Coastal haters, MiREs/CR-1026, PII-3114, Pacific Morthmest Laboratory, Richland, W..*

Orlob, 6. T., R. P. Shubinski and K. D. Feigner. 1967. Mathematical Modeling of Mater Quality in Estuarial Systems." Proceedinos of the Mational Symposium of Estuarine Pollution. Stanford University.

Pagenkopf, J. R., G. C. Christodonlou, B. R. Pearce and J. J. Connor. 1976. A User's Manual for Case I, A Two-Dimensional finite Element Circulation Mode1. Report Mo. 217, Massachusetts Institute of Technology. 
Partheniades, E. 1962. A Study of Erosion and Deposition of Cohesive Solis in Salt Mater. Ph.D. Thesis, Untrerity of California.

Pavish, D. L. and M. L. Spaulding. 1977. Developent and Application of a Three-Dimensional Morical Model for Predicting Pollutant and sedtent

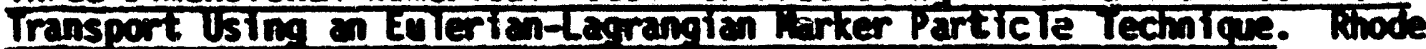
Istand Ucean Engineering Wept. Kinston. RI.

Pritchard, D. Y. 1967. What is an Estuary: Physical Viempoint. Estuaries, Edited by 6. H. Lauff. Anerican Association for the Advancement of Science, Iashington, D.C.

Postma, A. 1967. "Sediment Transport and Sedimentation in the Marine Environment." American Society of the Advancesent of Science. Mashington, D.C.

Schubel, J. R. 1975. Distribution and Transportation of Suspended Sedinent. Effects of Eneroy Related hetivites on the Atlantic Continent shelf. B. Vinowtiz (ed.). brockhiven hational Laboratory, Upton, il.

Simpson, H. J., C. R. Olsen, R. M. Trier, and S. C. Millians. 1976. minn-flade Radiomuclides and Sedinentation in the Hudson River Estuary." Science. 194:178-183.

Simpson, A. J. and S. C. Millians. 1978. "plutonium and Cesiun Radionuclides in the Hudson River Estuary-" Amual Technical Progress Report, Decenber 1, 1974 - November 30, 1975, Colubia University, Pal isades, New York, Lamont-Doherty Ceologicai Observatory.

Swith, J. D. 1977. "Modeling of Sediment Transport on Continental Shelves." The Sea. 6. E. D. Coldberg et al. (ed.), Johm Miley and Sons, Mew York, MY.

Spwilding, M. 1976. Mumercial Modeling of Pollutant Transport Using a Lagranian Marker Particle Technion. IISh Langley Research Center, Hopton, Vh. TISIVHif-73538.

Spraggs, L. D. 1974. Mrerical Simlation of Dredged Material Dispersion San Pablo Bay, San Francisco. Vol. I, hodel Levelonent. Report EEIJ-27/4 San Francisco isistrict, U.S. Corps of Engineers.

Taylor, C and J. M. Davis. 1974. Mmerical Model of Dispersion in Estuaries." Finite Element Methods in Flow Problems. J. T. Oden et al. (ed.), Wh Press.

Thanes Estuary Flood Prevention Investigation. 1970. Mathenatical Silt Model Studies. Report Ho. Ex. 479, Hydraulics Research Station, Mallingtord, Berksitire, England. 
Thatcher, M. L. and D. R. F. Harleman. 1972. A mathematical Model for the Prediction of Unsteady Salinity Intrusion in Estuartes. Tech. Rep. Wo. If, Ralph i. Parsons Laboratory, bepartient of CTVil Engtreering, Massachuetts Institute of Technology.

The State of New York, "Periodic Report of the Hater Quality Survelllance Metwork 1965 Through 1967, Mater Years."

The State of New York. 1976. Water Resources Data for New York, Water Year 1975."

The State of New York. 1977. Mater Resources Data for New York, Mater Year 1976."

The State of New York. 1978. Mater Resources Data for New York, Mater Year 1977."

U.S. Emvironmental Protection Agency. 1976. Radioactive Isotopic Characterization of the Environent Mear Viscassett, Wine Usimg Pre- and Post-uperationa Survers in the Vicinity of the hitine Vankee huclear Reactor. Emironental halysis Uivision, Offlice of Radiation Prograns, Washington, D.C.

U.S. Environmental Protection Agency. 1978. Kepone Mitigatim Project Report. Standard and Criteria Office of Hater and hazarcous ititerials, Tashington, D.C.

U.S. Muclear Regulatory Comission. 1978. Liquid Pathay Ceneric Study. Impacts of Accidental Radioactivity Releases to the Hydrosphere from Floating and Lan-based nuclear Power plants. "Thise-0740.

Haldrop, H. R. and R. C. Farmer. 1973. Three-Dimensional Flow and Sediment Transport at River Mouths. Tech. Rept. 10. 150. Coastal Studies Institute, Louisiana State Univerity, Baton Rouge, LA.

Urenn, M. E. and S. M. Jinks. 1975. "The Dosimetric Inplications of Releases to the Aquatic Emvirorment from the Muclear Power Industry." Enviromental Toxicity of Aouatic Radionuclides: Models and Mechanisms. H. T. Fither and J. N. Stannard (eds.), Ann Arbor Science Poblishers, Inc., Am Arbor, MI.

Hrenn, M. E., J. M. Lentsch, M. Eisenbud, 6. J. Laver, and 6. P. Howells. 1971. "Radjocesiu Distribution in Hater, Sediment and Biota in the Hudson River Estuary from 1965 through 1970." Third Mational Symposiva on Radioecology, Oak Ridge, Tennessee.

Urenn, M. E. et al. 1972. Radioecological Studies of the Hudson River. Progress Report to Con. Edison Company of Vew York. 
Mrenn, M. E., S. M. Jinks, M. Cohen, and L. M. Hairr. 1973. $-137 \mathrm{Cs}$ and 134Cs Distribution in Sediment, Mater and Biota of the Lower Hudson River and Their Dosimetric Implications for Man." Proceedings of the Third International congress of the International Radiation Protection Association weting. Washington, O.C.

Urenn, M. E. 1975. Radioecological Studies of the Hudson River. Mew York University Medical Center, Progress Report prepared for the Consolidated Edison Company of New York.

Urenn, M. E., et al. 1976. "A Mathematical Model Describing Radiocesiun Transport in the Hudson River Estuary." Proceedings of the Pourth Symposiu on Hudson River Ecology. Bear Mountain, WT, Paper Wo. 10.

Urenn, M. E., M. P. Singh, M. Cohen, M. Eisenbud, P. Linsalata, S. Schaffer, C. T. Cook and D. Mohigemuth. 1979. Radioecological Studies of the Hudson River: The Distribution of Beta-6ama-Enitting Radionuclides--Progress Report 1976 and 1971. Institute of Environmental Redicine, New York University dical Center, prepared for the Consolidated Edison Company of new York.

\#hvailable for Purchase from the MRC/GPO Sales Program, U.S. Muclear Regulatory Comission, Mashington, $D C$ 20555, and the Mational Technical Information Service, Springfield, VA 22161.

* Avallable for purchase from the Mational Technical Information Service, Springfield, VA 22161. 


\section{RADIOWUCLIDE TRMUSPORT IN OCEAUS AD THE GREAT LAKES}

This chapter discusses models for oceans and the Great Lakes that simulate migration of contaminants through a mumerical solution of the advectiondiffusion equations. Radionuclide concentration data were obtained and evaluated as to the ir suitability for model input and verification.

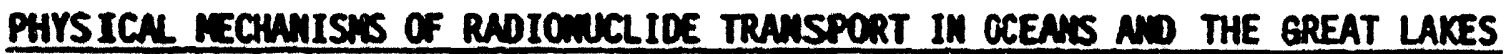

Cceans

Radionuclides discharged to coastal waters are dispersed by coastal currents, surface waves and turbulent mixing and are also adsorbed from solution onto marine sediment. The major driving forces to migrate radionuclide in coastal waters are advection and dispersion. As discussed in earlier chapters, the sediment-radionuclide interactions become important if: 1) radionuclides have large distribution coefficients; 2) receiving water bodies iddve large sediment concentrations of espectally fine sediment; and/or 3) long-term migration, accumulation and fate of radionuclides are concerned. In general, radionucl ides tend to have saller distribution coefficients and there are less sediment concentrations (except mearshore zone) in coastal waters than other surface waters (USIRC 1978a; Schubel 1975). Hence, effects of sedinent on radionuciide migration in coastal waters tend to be less important than those appearing in other surface waters. However, long-tern aigration, accumlation and fate of radionuclides with large half lives are still subject to sedimentradionuclide interactions. Considerable data exist to suggest that adsorption to and subsequent transport of marine sediment is an important radionuclide transport process. Some examples are:

1. Studies of radionuclide concentration in the vicinity of the Windscale Muclear Reprocessing Plant on the English Coast of the Ir ish Sea (Hetherington 1976; Livingston and Bowen 1976)

2. Studies of fallout radiomuclide concentrations at Bikini and Enimetok atolls in the Cental Pacific Ocean (Mevissi and Schell 1974, 1975a,b; Schell 1973, 1974, 1976) 
3. radionuclide concentration measurewents in the coastal waters of Mashington State (Schell 1977)

4. Open ocean sediment core samples from the Horth and South Atlantic Oceans and the Mediterranean Sea (Moshk in and Bowen 1973).

Data from the Irish Sea near the Hindscale Fuel Reprocessing Plant show that $95 \%$ of the plutoniu and $20 \%$ of the cesiu discharged to the Irish Sea frow the plant have been adsorbed onto warine sedicent and have reamined in the Irish Sea. The remaining percentages of plutonium and cesiun are in the dissolved form (Hetherington 1976) which is subject to be flushed from the sea. Hetherington concludes that, on the basis of ${ }^{239} \mathrm{Pu}$ and ${ }^{137} \mathrm{Cs}$ in core samples from the Windscale vicinity, sedimentation of waterial wich has been contaninated mille in suspension is the primary mechanisa by wich both of these radionuclides are deposited in marine sedinent.

Mrerous reports were reviewed wich contained data on the physicalcheanical states of radionuclides and their concentrations obtained from field studies confucted at Bikini and Eniwetok atolls. As an exaple of this information, Table 6.1 shows percentages of particulate, colloidal and soluble forms of various radionuclides. This table was taken from S:hell (1974).

As indicated in the table, biswuth was found to be $90 x$ colloidal, wille europiu and anericiu exhibited great variability in their forms with high percentages in particulate form for some measurenents. Plutoniu exhibited the greatest range of variability and was found to exist in particulate, colloidal, and soluble forms. Schell (1977) states that in the near coastal waters of Mashington State more than $75 \%$ of the ${ }^{210} \mathrm{~Pb}$ present is associated with particulate material $(0.3 \mathrm{~m})$. Furtherwore, Schell mentions that ${ }^{210_{\text {Po }}}$ is generally found in the particulate form in Mashington State waters.

The distribution of radionuclides in the cotton sediment of the Columia River estuary is discussed by Hubbell and 6lem (1971). Livingston and Bowen (1976) have studied fallout radionuclide concentrations at Buzzards Bay, Massachusetts, and have found that ${ }^{241} \mathrm{Pu}$ and $240 \mathrm{Pu}$ are largely bound to marine sediment. The data reviewed have shom that a relatively large nuber 
TAbeE 6.1. Physical-Chesical States of Radiomuclides in Bikini Atoll Lagoon in Percent (Schell 1974)

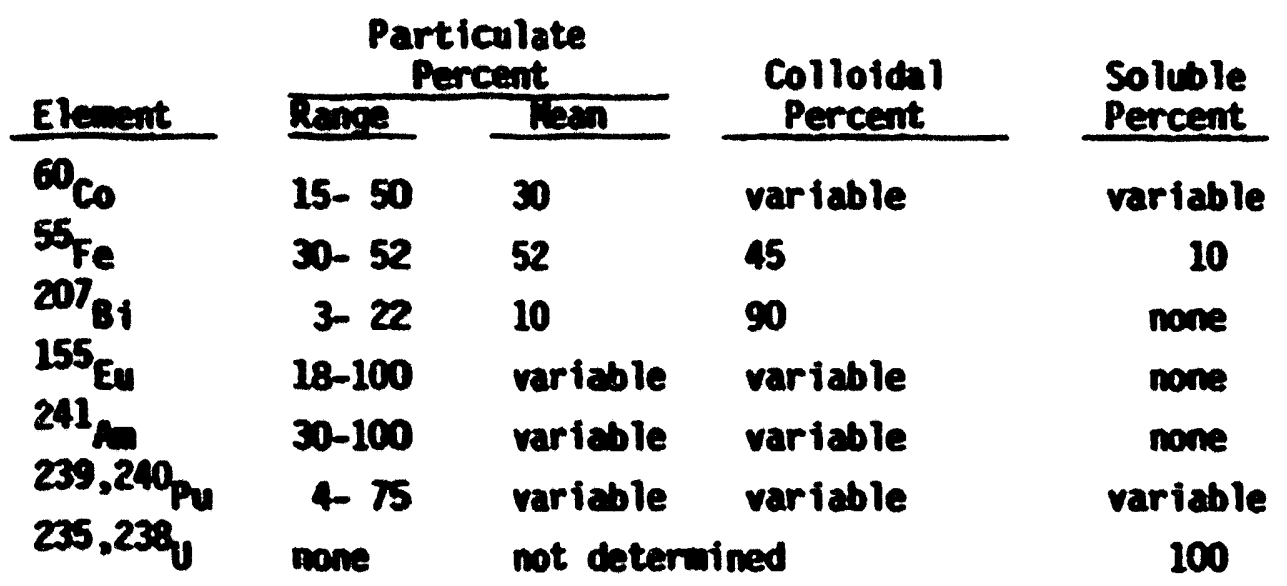

of radionuclides can exist in particulate and colloidal forms. Those radiomaclides in this group with high $k d$ values can be transported by marine sediwent and should be considered via aribe sedinent wovement in an oceanic radionuclide trassport codel. Thus, even though the suspended sediment load over much of the middle and outer continental shelf can be as much as several orders of agnitude less than the corresponding load in lakes and rivers, ocean transport of marine radionuclides with higher Kd values via suspended sediment cannot be neglected.

For radionuclides with saller $\mathrm{kd}$ values (say, less than $10^{4}$ ), the suspended sedinent concentration in most of the continental sheif is too sall to adsorb significant anounts of dissolved radionuclides especially for short-tern transport (Schubel 1975). However, as reported by Schubel (1975) in the long tern (over a period of years) suspended sediment ay still play an ieportant role in the ultiate rewoval of radionuclides. Furthenwore, he reported that the periodic resuspension of fine-grained botton sediment in estuaries, other canstal basins, and tidal reaches of rivers constitutes a very effective scavenging ecchanisa for radionuclides because of ansentially infinite supply of new sedinent. 
Additional factors can be considered for examining the sedimentradionuclide interaction. For example, severe stons and floods typically increase the suspended sediment load on the continental shelf by as unch as one order of magnitude. This higher sediment concentration increases the interaction between radionuclides and sediment during the storm and flood period, and thereafter patterns of radionuclide transport will be changed with a higher percentage of radionuclides being bound by marine sedinent. Secondly. ach of the botton deposits of the outer shelf are comprised of fine sedinent and organic atter subject to resuspension by surface wave stresses. In many cases this sediment shows a residual landward flow in the imner third of the shelf. Release of radioactive material and scavenging by this sedinent would tend to transport radionuclides shoreward. In the nearshore zone, particularly in areas influenced by the discharge of rivers, the suspended sediment load is very high and the transport of radionuclides by this sediment would be ieportant.

In the event that discharges of lon-level redioactive effluents to coastal waters continue (as well as some accidental spills), the need for a quantitative understanding of coastal radionuclide transport will be wore conpelling. Consequently, it is inportant to obtain a general capability of radionuclide transport wodeling by including wechanisus of advection, dispersion, surface waves, sedinent-radionuclide interactions and radionuclide decay.

The Ereat Lakes

The radionuclide transport in the Ereat Lakes is in general much more complex than those in the coastal waters. This comlexity is a product of the comlex behavior of currents, waves, wind, sediment transport and thernocline (usinc 1978a,b).

Field studies in the Ereat Lakes have revealed that coastal currents are predominantly parallel to shore and have typical speeds of $10 \mathrm{~cm} / \mathrm{sec}$ to $20 \mathrm{ca} / \mathrm{sec}(0.33$ to $0.66 \mathrm{ft} / \mathrm{sec})$. Currents generally persist for several days; then, in direct response to wind shifts, they quickly reverse and persist in the opposite direction for several days (Csanady 1970, 1972). Each reversal 
of the current is usully accomanied by large-scale wass exchange with offshore waters that effectively rewoves contaminants from the nearshore zone (Csanady 1970). Contaminants flushed from the mearshore zone are dispersed in the large-scale turbulence offshore, uniepeded until effects of the other shorelines are felt.

Meny of the contaminants are adsorbed by lake sediment minly due to fairly high suspended sediment concentration and a wore pronounced tendency for contaminants (radionuclides) to be adsorbed onto particulate matarials in fresh werer (Haigren and Melson 1973). It has been observed that areas of heavy sedimentation in the Ereat Lakes are also areas of high radjonuclise concentration.

Resuspension of radionuclides from the sediment to the water colum is will docanented in the Great Lakes. Malgren and Melson (1973) have conducted studies in Lake Hichigan wich show that due to sorption and desorption by sediments, ${ }^{239} \mathrm{pu}$ and ${ }^{137} \mathrm{Cs}$ (to a lesser extent) are depleted from the surface waters during sumer and are returned dur ing the winter wixing period to nearly the concentration of the previous spring.

Mixing of dissolved radionuclides can be linited by a therwocline. Eventially, however, dissolved radionuclides are nearly uniformly mixed in the lakes dre to several seasonal overturns in the lakes wixing the dissolved radicnuclides with deep maters. The characteristic mixing time for an instantaneous release is estinated to be from several weeks to several wonths, depending upon lake size and prevailing hydrologic conditions (Csanady 1970; Murthy et al. 1974). Some radionuclides are eventually flushed out of the lakes by the flow-through of fresh water. Others remin largely attached to sediments. The flushing $t$ ine for the Greak Lakes is on the order of years to tens of years, depending upon the particular lake volume and flow-through rate. Some of the existing radionuclide data sources for oceans and the Great Lakes are !isted in Table 6.2 . 
TaviF 6.2. Ocean and Great Lakes Data

efenences
Heft et al. (1973)
Wostitis et al. (1976)
Horrisen et al. (1976)

Blanchand et al. (1976) nersey const of At lantic nar the Osster Creat Pouner piant

veter sods

Humbolet Bay, California

Huboldt 8ay. California

Humboldt Bay, California

Irish Sea

Irish See

numbition (1953)

Longley and Templeton (195)

Tenoleton and Preston (19.5)

Perkins ad intlies (15s6)

defferies (1958, 1970)

Mitchall (1959, 1971a,b, Irish Sea 1973. 1975)

Prestom et al. (1971)

defferies et al. (1973)

defferies (1974)

hetherington et al. (1975)

Anctherington (1976a,b)

Aftchell (1977a,b)
Irish Ses

Irish Sea

Irish Sea

Irish Sea

Irish Sea

Irish Sea

Irish Sea

Irish $S=0$

Irish Se

Irish sea
Tre of Radiamelide Date

or $137 \mathrm{Cs}$ and $65 \mathrm{zn}$ in whr and bed sedinemt

Oaco, 134Cs, 137cs and 5Am in miter and bed sedinent

60co, 137Cs. 54m and 65za in witer and bed sedtrent for a dischurge canal of the Mintolot Bay power plant

Dissol ${ }^{137}$ Co $50 \mathrm{sr}$. Qto, Ibucs, I37cs, ot: 54, 2260, 12550, 252in in bed sedineat

Dissolved 106ipu

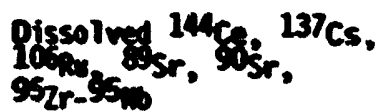

144ce, 137 Cs and 105ire in the shore silt

106 in in mter and bed sediment sosr in enfiltered sea werer

$144 c$, 137Cs 4h, 106in, Sozrosim in the bed core sediment

$14 \mathrm{cs}, 137 \mathrm{Cs}, 106 \mathrm{ime}$. 952r-9s in the bed sed tment.

144ce, ${ }^{237} \mathrm{Cs}, 4 \mathrm{~K}, 106 \mathrm{ide}$, 2411. gozr-sin in sea inter and bed sedinant

144ce, $137 \mathrm{Cs}, 106 \mathrm{im}, 95 \mathrm{zr}-$ som in sea inter and bed sediment

Dissolved 137Cs

14hes, 106in, $95 z r-95 m$ in bed sed timent

Pigsolved Es anticulate form of

otssolyed 137 Cs. 235\%m, 241/m and 2s.pu. 25:-240p in sea weter and bed sed trient

144ce, 134Cs, 137Cs, $10 \mathrm{cin}_{\mathrm{in}}$ Sozrasim in bed sedinent 
THBLE 6.2. (contd)

\begin{tabular}{|c|c|c|}
\hline Aferenex & Wter Bods & Tre of Radionelide Deta \\
\hline fint (1999) & Irish Sez & \\
\hline Peatureath at a1. (19:0) & Irish Sea & in \\
\hline Schell (1973) & $\begin{array}{l}\text { Bikini and Enimetck } \\
\text { atolls }\end{array}$ & Qifsoived and particulate forms of \\
\hline mevisst and Schell (1974) & $\begin{array}{l}\text { Bikini and Enimetok } \\
\text { atollis }\end{array}$ & iculate forms of \\
\hline Schell (1974) & $\begin{array}{l}\text { Bikini and Enimetck } \\
\text { atollis }\end{array}$ & iflate forms of \\
\hline $\begin{array}{l}\text { nevissi and Schell } \\
\text { (1975) }\end{array}$ & $\begin{array}{l}\text { Bikini and Enimetck } \\
\text { atollis }\end{array}$ & 2ulate forms of \\
\hline Schell (1976) & $\begin{array}{l}\text { Bikini and Enimetck } \\
\text { atollts }\end{array}$ & $\begin{array}{l}\text { icolote forms of } \\
\text { atsi. }\end{array}$ \\
\hline Dursine and $\operatorname{cosch}(1970)$ & At lantic & $\begin{array}{l}\text { Mdsorption-desorption gener ic } \\
\text { study }\end{array}$ \\
\hline Dumea (1972) & $\begin{array}{l}\text { Atlantic and } \\
\text { Mediterramean }\end{array}$ & Wigulate fors of \\
\hline rescratin (1972) & Atrantic & \\
\hline Stilker (1972) & Worth Pecific: & $\begin{array}{l}\text { ticulate forms of } \\
\text { Sem. }\end{array}$ \\
\hline $\begin{array}{l}\text { mosimin in and Bowean } \\
\text { (1973) }\end{array}$ & $\begin{array}{l}\text { Atlentic and } \\
\text { Mediterraneas }\end{array}$ & Qjpsolved and garticulate forms of \\
\hline $\begin{array}{l}\text { Livingston and Bowen } \\
\text { (1970) }\end{array}$ & At Jantic & $\begin{array}{l}\text { Dissolved and particulate forms of } \\
241 \text { m, 23sive, } 240 \text { p }\end{array}$ \\
\hline $\begin{array}{l}\text { Lermat and Tantgucht } \\
\text { (1972) }\end{array}$ & ereat Letres & Purticulate SPsr \\
\hline 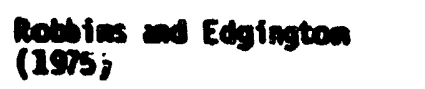 & ereat lates & \\
\hline
\end{tabular}


MTHEMTICN MONES FOR OCEAM AM THE EREAT LAKES

As in previous chapters, these nodels include those that simlate radiomuclide transport, water qulity, and sediment transport. Thermal plune codels are included in addition.

Radionuclide Transport Models

The models described in this section are analytical and mmerical wodels designed to simulate radionuclide transport. The following analytical radiomuclide transport wodels are described in the RRC report (USARC 1976).

A simple diffusion wodel for steady-state discharge into a lake or coastal area with a known steady shoreline current has governing equations expressed in Equation (3.7). As discussed in Chapter 3, it is assuned that the discharge is located at the point $\left(0, y_{s}, z_{s}\right)$, i.e., at the origin of the $x$-axis and a distance $y_{s}$ from the shore line and $z_{s}$ beneath the water surface. For a large lake of constant depth, $d$, and straight shoreline, the solution is given in Equation (3.8). For further information on wor a general uses of this model, the USinC Regulatory Guide 1.113 (USinC 1976) may be consulted.

For instantaneous and general transient releases of a firite quantity of material from a line source of $x=0, y=y_{s}$, solutions are given by Equations (3.10) and (3.11), respectively.

Of the mmerical models, there are two wodels wich can be applied to oceans and the Great Lakes.

Onishi et al. (1976, 1979), Onishi and Ecker (1977), Onishi and Wise $(1978 a, b)$

Onishi et a1. (1976) developed an unsteady, two-dimensional (lateral ar.J longitudinal), sediment-contaminant transport wodel which utilizes the finite element computation method with the Galerkin weighted resicual technique. This node1, FETRA (Finite Element Transport Mode1), has general advection-diffusion equations with decay and sink/source terms and consists of a sediement transport submodel, a dissolved contaminant transport submodel, and a particulate contaminant transport subuodel coupled together as discussed in Chapter 5. 
In most environments in coastal areas and large lakes (e.g., the Great Lakes), marine and lake sediments are mostly suspended by waves which themselves can transport only smil anounts of suspended sediment. The sedinent suspended by wave action is then transported mostly by a current wich, in most cases, is too small to suspend sediment by itself. Hence, the original FETRA code was adified to include sediment-wave interactions in both offshore and surf zones to extend its applicability to coastal waters and to a lesser extent large lakes (e.g., the Great Lakes) where wave action is one of the mechanisins of sediment and radionuclide transport.

FETRA uses the follaring concept to compute the erosion and deposition rates of sand: if the amount of sand being transported is less than what the flow and wave can carry, the current and waves wi!l scour sedicent from the ocean bed until an actual sediment load is equal to the carrying capacity or until the available bed sediments are all scoured, wichever occurs first. Conversely, sand will be deposited if tiug actual sediment load is above the flow and wave capacity to ca:ry sediments. For an offshore zone, sediment capacity was computed by formulations developed by Liang and lang (1973). For surf zone, Komar's formula (1977) is used to calculate the sediment transport capacity. For cohesive sediments, Parthenzides' (1962) and Krone's (1962) formulas for erosion and deposition rates are used. The applicability of the last two formulas in wave-doninated coastal waters is somewhat questionable. However, there are no alternative formulations rurrently available.

In order to compute offshore and littoral transport of sediment, thus particulate radionuclide, by these formulas, wave characteristics are needed. This was accomplished with: 1) inclusion of wind-induced wave mechan isms built in FETRA, and 2) a wave refraction progran (Bodson 1967; Ecker and Degraca 1974) wich is used in conjunction with FETRA.

FETRA is a depth-averaged, two-dimensional model and cannot include effects of therwocline and seasonal overturns appearing in the Great Lakes. Hence, the applicability of FETRA to the Great Lakes is very linited. The migration of radionuclides in the Ereat Lakes can be similated by: 1) a three-dinensional model wich can run very fast to be able to cover both 
short- and long-tern migration, 2) a combination of a three-dimensional nodel for a short term and a wixing tank model for a long term, or 3) a set of nearshore, offshore and wixing tank wodels (USmiC 1978a,b) to cover both short- and long-tern radionuclide migration and accumlation.

Erasian et al. (1977)

As discussed in Chapter 5, one- and two-dimensional dissolved radionuclide transport codels, RADONE and RADTW, respectively, were developed for estuaries and cceans (Eraslan et al., 1977). RADTw was developed from the thermal code FARTP, a tidal-transient, two-dinensional codel applicable to lakes, estuaries, and coastal regions. Technical reports have not been published for either RADTW or FARTW, thus precluding detailed nodel evaluations for the purposes of this study. However, an unsteady, two-dimensional model reported by Eraslan (1975) appears to have a formulation similar to these wodels antioned above. According to Eraslan et al. (1977), FARTip includes a hydrodymanic simulation, for wich the user must specify the two velocity components of the flow field in order to obtain the flow depth at a given location and time. Results from a sifulation of the Peach Bottom Atomic Power Station on the Conowingo Reservoir in the Hudson River showed excellent agreement with field-measured data for the temperature distributions as show in Figure 6.1. Mater Mality Models

The following are water quality mathematical wodels suitable for ocean and Great Lakes application. These models could be used only to simulate the movenent of dissolved radionuclides. The models described in the following section are divided into types of models based upon their governing equations (see Chapter 3 ).

\section{Mater Quality Models of Tye I}

Leendertse $(1970,1973)$. The nodel of Leendertse (1970), described in Chapter 5, is also applicable to oceans and the Great Lakes. This model, the representative of Type I node1s, is based on a rigorous treatuent of the governing differential equations. The model would be suitable only for dissolved radionuclides. 


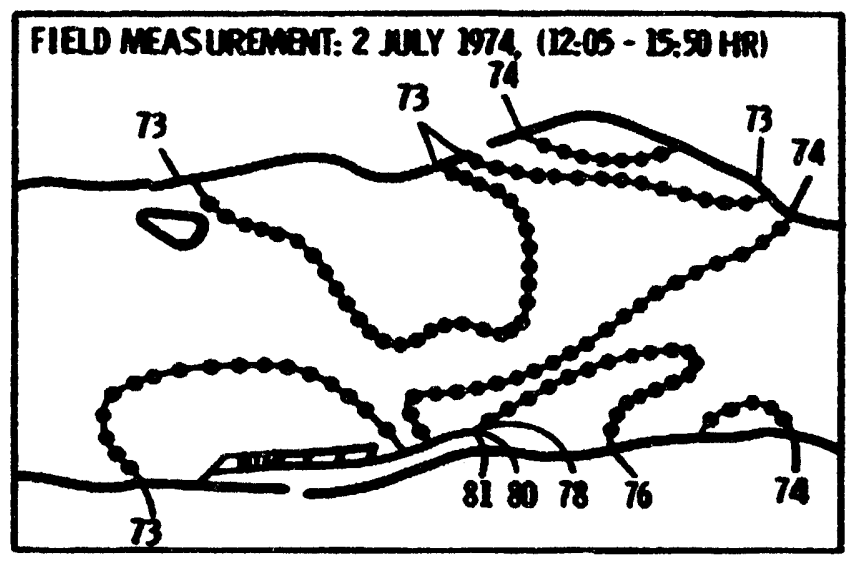

COMPUTER SIMULATIONE 2 NULY WT4, 15:00 HR SIMULATION STARTED: 1 JUY 1974, Q.OO HR

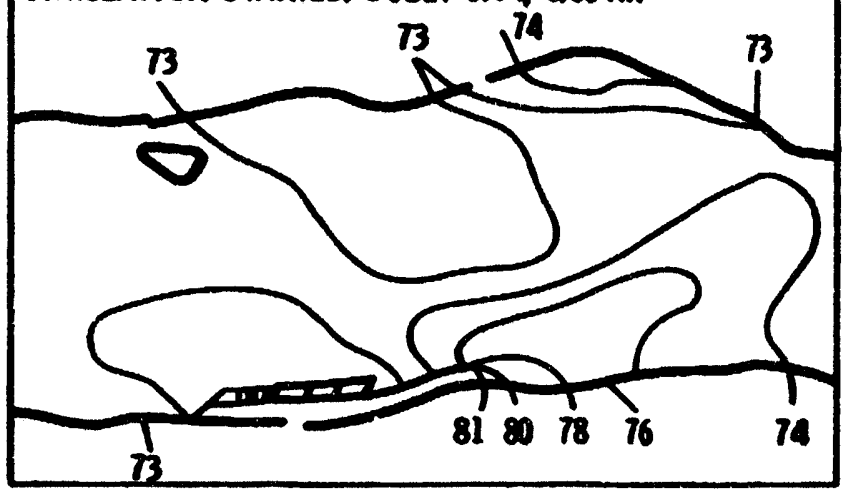

FIGRE 6.1. Comparison of Computed and Measured Temperature Distributions in the Conowingo Reservoir in the Vicinity of the Peach Botton Atomic Porer Station (Erasian et al. 1977)

Other water quality models of this class wich can be used for oceans and the Great Lakes include that of Spraggs (1974) which was discussed in detail in Chapter 5.

Simons (1973). Simons (1973) has designed a hydrodymamic and thermal structure for the 6reat Lakes. Both a homogeneous and a miltilayered model are described. The transfort equation is shown below:

$$
\frac{\partial(\theta)}{\partial t}+\frac{\partial\left(w_{\theta}\right)}{\partial x}+\frac{\partial\left(V_{\theta}\right)}{\partial y}+\frac{\partial\left(w_{\theta}\right)}{\partial z}+\frac{\partial^{\varepsilon} \theta}{\partial x} \frac{\partial \theta}{\partial x}+\frac{\partial}{\partial y}\left(\frac{\varepsilon_{\theta} \partial \theta}{\partial y}\right) \frac{\partial}{\partial z}\left(\frac{\varepsilon_{z} \partial \theta}{\partial z}\right)=0
$$


where

$$
\begin{aligned}
\theta & =T-T_{0}=\text { the temperature anomaly } \\
(U, Y, U) & =\text { local velocity vector } \\
\varepsilon_{\theta} & =\text { horizontal eddy diffusivity } \\
\varepsilon_{2} & =\text { rertical eddy diffusivity }
\end{aligned}
$$

For both models, the equations are solved in a vertically integrated form.

The nonlinear vertical acceleration is included and approximated with special assumtions about the vertical profiles of horizontal motions and the relation of botton stresses to volume transport. There are no source, sink, or decay terms included in the odel formlation. Both of these nodels could be made suitable for simulating dissolved radionuclide transport if a dissolved radionuclide is assumed to be a conservative substance. The governing equations are solved with a finite difference mumical scheme. Some one- and twodimensional test calculations have been performed and are reported in Simons (1973). Preliminary computations with a homogeneous model and a four-layered stratified model are reported in Simons (1971) and Sicons (1972).

Chen et al. (1975) (The Lake Ontario Model). This is a water quality ecological wodel wich solves a form of the advection-diffusion equation with source or sink terms. Thus, dissolved radionuclide transport can be simulated with this node 1. The model was developed at Tetra Tech, Inc. by Chen, Lorenzen and Smith (1975). Phosphorus and nitrogen cycle dymamics and plankton and fish population dymanics are also included in the model. The flow is calculated in the $x-2$ (longitudinal-vertical) plane by a finite difference method. The calculations are performed for the transient and/or steady-state cases. The model has been applied to Lake Ontario and the verification status is reported in Chen, Lorenzen and Swith (1975).

\section{Fonte Carlo models (Type VI)}

Battelle Oil Slick Model (Ahlstrom et al., 1975). The oil slick model is a two-dimensional, steady-state and/or transient transport wodel intended to simlate the movewent of oil slicks in marine maters. The oil slick model can be used for dissolved radionuclide transport modeling in marine or Great Lakes 
regions. The hydrodymamic equations are not incluced in the model formulation. so the velocity field must be supplied by external means. Adsorption mechanics are considered in the oil slick wodel. The solution scheme is known in the literature as the discrete parcel random walk method (see Chapter 3, Model Type VI). This athod is similar in some mas to Monte Carlo transport analysis and is based on the movement of a hypothetical entity referred to as a discrete parce 1. A Lagrangian approach is used for sim lating the parcel advection and a homogeneous Markov random walk process is used to model the dispersive component. If thousands of such parcels are released in a passive flow field and their discrete paths are followed and recorded as a function of tice, then the density of the ensemble may be interpreted as the concentration of a particular constituent, in this case crude oil or some chemical fraction of the oil.

\section{Sedinent Transport Podel}

\section{H. Leickuhter (1974)}

This model solves a to-dimensional, vertically integrated form of the adrection-diffusion equation. It is capable of hand ling both the transient and steady-state cases. The solution technique employed is a finite element (Galerkin) method wich uses a linear wighting function. The velocity field used in the code ast be externally supplied. Source and sink terms as well as decay terms are included in the formulation. A continuous source of sediment load with no deposition or resuspension is assumed. Prelininary verification against simple analytical solutions of one- and two-dimensional cases has been completed. In addition, the model was applied to predict suspended sediment dispersion in Massachusetts Bay. Certain stability criteria to be used in computer implementation of the model should be noted.

\section{Theral Plue Model}

Adass, Stolzenbach and Mar leman (1975)

Adams et al. (1975) have developed two wodels intended for use in simulating buoyant thermal plumes. One is an integral jet thermal plume nodel for predicting the near-field teaperatures due to buoyant surface discharges. The 
other is a far-field nodel in which the three-dimensional excess teaperatures are calculated by superifiposing the temperature distributions resulting from discrete, vertically-distributed line sources mich are treated by the method of moments. Ambient currents, wich can vary in the vertical direction and in time, surface heat loss, and turbulent diffusion in all directions are considered.

The models could be modified, with some effort, for use in modeling dissolved radionuclide transport. Comparison of model predictions with field data can be found in Adans et al. (1975). These comparisons show satisfactory agreement considering all of the assumptions which must be made to run integral models. 


\section{REFERENCES FOR CHAPTER 6}

Adans, E. E., K. D. Stolzenbach and D. R. F. Harlewan. 1975. Hear and Far Field Amalysis of Buovant Surface Discharges into Large Bodies of Later. Report ho. 205. Ralph h. Parson Laboratory, Departinent of Civil Engineering, MI.

Ah1strom, S. H. 1975. A Mathenatical Model for Predicting the Transport of 0il Slicks in Marine vaters. Battelle, Pactfic Northmest Laboratories, RTकाand, W.

Blanchard, R. L., H. L. Brinck, H. E. Kolde, H. L. Frieger, O. M. Montgowery, S. Cold, A. Martin, and B. Kahn. 1976. Radiological Survillance Studies at the Orster Creek Bun Muclear Ceneratin Station. EPh-52075-76-003, U.S. Environmental Protection Agency, Office of Radiation Programs, Eastern Environental Radiation Facility, Cincinnati, OH.

Csanady, 6. T. 1970. "Dispersal of Effluents in the Great Lakes." Hater Research. 4:78-114.

Csanady, 6. T. 1972. "Response of Large Stratified Lakes to Wind." Journal of Physical Oceanography. 2(1):3-13.

Chen, C. H., M. Lorenzen, and D. J. Snith. 1975. A Comprehensive Hater Quality Ecological Hodel for Lake Ontario. TETRA TECH Inc., Layfayette, CA.

Dunster, H. J. 1958. "The Disposal of Radioactive Liquid Hastes into Coastal Maters." Proceedings of the 2nd United Mations International Conference on the Peaceful Uses of Atonic Eheray. 18:350-399. United hations, hew York.

Duursma, E. K., and M. 6. Gross. 1971. Marine Seciments and Rad foactivity." Radioactivity in the Marine Environent. PP. 147-161. National Acadany of Sciences.

Dursima, E. K., and C. J. Bosch. 1970. "Theoretical, Experimental, and Field Studies Concerning Diffusion of Radioisotopes in Sediments and Suspended Particles of the Sea - Part B Methods and Experiments." Metherland J. of Sea Research. 4:395-469.

Duursma, E. K. 1972. "Specific Activity of Radionuclides Sorbed by Marine Sediments in Relation to the Stable Element Composition." AEA Proceedings.

Eugington, D. N. and J. A. Robbins. 19\%. "Patterns of Deposition of Radjonuclides in Sediments." Monbiological Transport and Transportation of Pollutants and Land and Hater: Processes and Critical uata Recuired for Predictive Lesorption. National Bureau of Standards. Gaithersburg, iv. 
Eraslan, A. H. 1975. A Transient, Two-Dimensional, Discrete - Element, Far-field Model for thermal lnact Analysis of Power Plant vischarges in Coastal and ut shore Reqions. Part 1: Eeneral bescription of the Thematical hods and the Results of an Apolication. ONL $-49 \%$, Oak Ridge Thtional Laboratory, Oak Ridge, Ti.

Eraslan, A. H. 1977. Development of a Unified Transport Approach for the

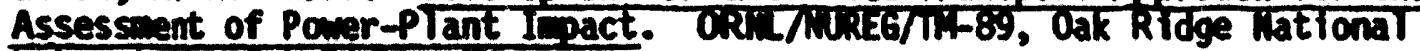
Laboratory, oak kidge, Ti.

Harrison, F. L., K. M. Hong and R. E. Heft. 1976. Interactions of Radionuclides in Hater, Particulates, and Oysters in the Discharge Canal of a Welear Power Planc. Ucil-51974. Lawrence Liverwore Laboratory, Univers ity of Californta, Livermore, CA.

Heft, R. E., H. A. Phillips, H. R. Ralston, and H. A. Steele. 1973. "Radionuclide Transport Studies in the Hiboldt Bay Marine Environent." Symosiu on the Interaction of Radioactive Contaninants with the Constituents of the Larine Environ ent. IAE, Vtenia, pp. 595-614.

Heft, R. E., M. A. Phi'lips, H. R. Ralston, and H. A. Steele. 1972. Radionuclide Transport Studies in the Huboldt Bay Marine Environent. UCiLL-73745, Lawrence Livermore Laboratory, Liverwore, CA.

Hetherington, J. A. 1976a. Behavior of Plutoniun Muclides in the Irish Sea, Environmental Toxicity of Aguatic Radionuclides: Models and Mechanisms. Forton and itiller, Eds, Amn Arbor Science, 1976.

Hetherington, J. A. 1976b. Radioactivity in Surface and Coastal Haters of the British Isles, 1974. Ministry of Agriculture, Fisheries and Fond. DTrectorate of Fisheries Research. Fisheries Radiobiological Laboratory, Technical Report FRL 11, Lomestoft.

Hetherington, J. A. and D. F. Jefferies. 1974. "The Distribution of Some Fission Product Radionuclides in Sea and Estuarine Sediments." Metherlands Journal of Sea Research. 8(4):319-338.

Hetherington, J. A., D. F. Jefferies, and M. B. Lovett. 1975. "Some Investigations into the Behavior of Plutonium in the Marine Environment." Impact of Nuclear Releases into the Aquatic Environment. International Atomic Energy Agency, Vienna, pp. 193-210.

Hubbe 11, D. H. and J. L. Glenn. 1971. Distribution of Radionuclides in Botton Sediments of the Columbia River Esteary. U.S. Dept. of the Interior. Geological Survey. Open File Report.

Hunt, G. J. 1979. Radioactivity in Surface and Coastal Maters of the British Isles, 1977. Aquatic Environment ionttoring Report Wo. 3. Winistry of Agriculture, Fisheries and Food. Directorate of Fisheries Research, Lowestoft. ISSN 0142-2499. 
lefferies, D. F. 1968. OFission-Product Radionuclises in Sediments from the Mortheast Irish Sea." Heloolander Niss. Meeresunters. 17:280-290.

Jefferies, D. F. 1970. "Exposure to Radiation from Gama-fioitting FissionProduct Radionuclides in Estuarine Sedinents from the Mortheast Irish Sea." H. C. Reinig (Ed.). Emvironmental Sumeillance in the Vicinity of Muclear Facilities, Charles C. Vhomas, Spring tetd, IL, Pp. zib-2ilo.

deffries, D. F., et al. 1973. "Distribution of Cesiu-137 in British Coastal Hater." Marine Pollution Bull. Pp. 118-122.

Koh, B. C. Y. and Y. C. Chang. 1973. Matheatical Model for Barged Ocean Disposal of Hater. Environeatal Protection Technology Series EPh

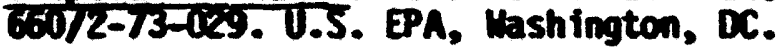

Leendertse, J. J. 1970. "A Mater Quality Simulation Model for Mell Mixed Estuaries and Coastal Seas." Principles of Computation. Vol. I. Pr-6230-RC.

Leendertse, J. J., R. C. Alexander, and S. L. Liu. 1973. "A ThreeDimensional Model for Estuaries and Coastal Seas." The Rand Corp. Principles of Computation. Yol. I, The Rand Corporation, R-147-OipR.

Leidkuhler, H., J. Comnor, J. Mang, G. Christodoulou and S. Sundgren. 1974. "Two-Dimens ional Finite Elewent Dispersion Model." Symosium on Modeling Technigues. ASCE San Francisco, California.

Lerman, A. and H. Taniguichi. 1972. "Strontium-90 - Diffision Transport in Sediments of the Great Lakes." J. of Geophysical Research 27:474-481.

Livingston, H. D. and V. T. Bowen. 1976. Contrasts Between Marime and Freshmater Biological Interactions of Plutoniv and hericive. U.S. Energy Research and Development Adinistration, heath and Safety Laboratory Environental Quarterly, MSL-315.

Livingston, H. D. and V. T. Bowen. 1976. "Anericium in the Marine Environent Relationships to Plutoniu." Emvironmental Toxicity of Aguatic Radionuclides: Models and Mechanisus. Morton and ifiller Eds., Amn Arbor science.

Longley, H. and W. L. Teapleton. 1965. Marine Environmental Monitoring in The Vicinity of Mindscale." In B.C. Godbold and J. K. Jones (eds). Radiological Monitoring of the Environent, Pergamon Press, Oxford, p. 219-247.

Mavchline, J. 1963. The Biographical and Ceographical Distribution in the Irish Sea of Radioactive Eft twent rro lindscale Works, 1959 to 19:0. UxheA Report MS: (Li) R2T. 
Mitchell, M. T. 1969. Radioactivity in Surface and Coastal Maters of the

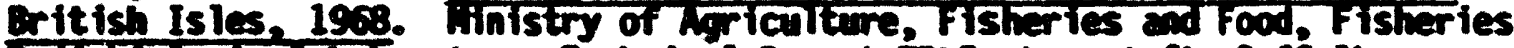
infobiological Laworatory, Technical Report FRL5, Lomestoft, Suffolk.

Mitchell, M. T. 1971a. Radioctivity in Surface and Constal laters of the Eritish Isles, 1969. Ministry of hriculture, fisheries and food, fisherfes REdiobiological Laboratory, Techical Beport FRT, Lowestoft, Suffolk.

Mitche11, M. T. 1971b. Radiactivity in Surface and Constal Mters of the British Isles, 1969. Hilistry of horiculture, Fisheries and Food, Fisheries Radiobtological Laboratory, Techaical Report FPL8, Lowestoft, Suffolk.

Mitchell, M. T. 1973. Rodioactivity in Surface and Coastal Haters of the

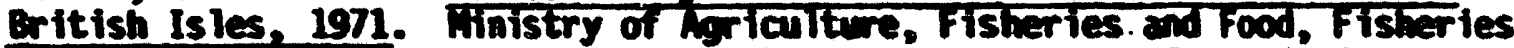
kedtobtological Laboratory, Tectnical Report FRL9, Lomestoft, Suffolk.

Mitche11. M. T. 1975. Radiactivity in Surface and Coastal liaters of the British Isles, 1972-1973. Tinistry of hriculture, ftsheries and food, Fisheries kadobiological Laboratory, Technical Report FPL10, Lowstoft, Suffolk.

Mitche11, M. T. 1977a. Radioactivity in Surface and Coastal Maters of the British Isles, 1375. Ministry of Ariculture, Fisheries and Food, Fisheries REdiobiological Laboratory, Technical Report FRL12, Lowestoft, Suffolk.

Mitchell, M. T. 1977b. Radioactivity in Surface and Coastal Maters of the British Isles, 1976. Part 1: The Irish Sea and its Emirons. Finistry of hricultire, fisheries and food, fisheries kadiobiological Laboratory, Techaical Report FRLII, Lanestoft, Suffolk.

Murthy, C. R., 6. Rullenberg, H. Uesterbery, and K. C. Miner. 1974. "LargeScale Diffusion Studies." IfYa Project $89 \mathrm{~m}$, Paper No. 14, Canada Centre for Inland laters.

Devissi, A. and U. R. Schell. 1974. Poloniu-210 and Plutonic-239, 210 in Biolonical Saples of Bikini and Enintak htoll beters. Laboratory of Rediation Ecology, Lniversity of thshington, Seatte, in.

Mevissi, A. and H. R. Schell. 1975. EEfficiency of a Large Yolue Mater Sapler for Some Radionuclides in Salt and Fresh Hater." Proc. 4th Mat. Sy_p. On Radiation Ecology. Oregon State University, Corvallis, OR.

Nevissi, A. and H. R. Schell. 1975a. "Distribution of Plutoniun and Americiu in Bikini Atoll Lagoon." Health Phrsics. 28:539-547.

Noshin, Y. E. 1972. Ecological Aspects of Plutoniu Dissemination in Aquatic Environments." Health Phrsics. 22:537-549. 
Mostrin, Y. E. and Y. T. Bonen. 1973. Concentrations and Distributions of Lang-Lived fallout Radionuclides in Open Ocean Sediments." Radioactive Contaniation of the Mrine Emiroiment. INEA, Viena, Austria, pp. 6/1-686.

Mosinkin, V. E., H. L. Robison and F. L. Harrison. 1976. Radiolonical Dose to

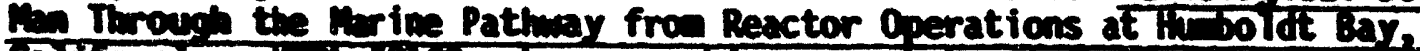

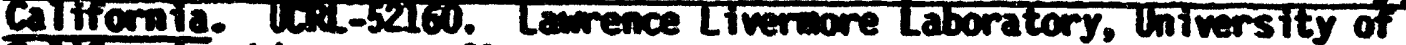
CAtfrornia, Livermore, $C_{\text {. }}$

Caishi, Y. and R. M. Ecker. 1977. Tathematical Simlation of Transport of Repome and Repone-Laden Sedtments in the James River Estuary." Proceedians of the Conference, Repone Seminar II. September 21-22, 1977. Easton, iu.

Onishi, Y.o P. A. Johanson, R. 6. Baca, and E. L. Hilty. 1976. Studies of

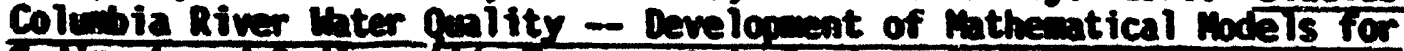

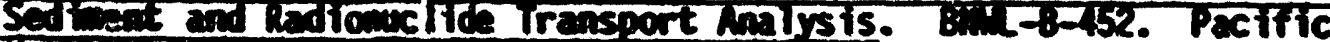
Worthest Laboratory, Kichland, W. Prepared for U.S. Energy Research and Development Adrinistration.

Onishi, Y. and S. E. Hise. 1978a. Ththematical Podeling of Sedinent and Pesticide Transport in the dames River Estuary." Proceedines of 26th Ammal Hytralic Division Specialty Conference on Verification of thentical and

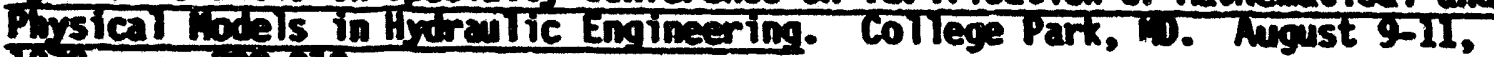
I978. P. 3lid-310.

Coishi, Y. and S. E. Hise. 1978b. Mthematical Simlation of Transport of Sedtent and Repone in the danes River Estuary. Pil-2731. Pacific iorthest Laboratory, Richland, "'k.

Pentreath, R. J., D. F. Jefferies, M. B. Lovett, and D. M. Melson. 1980. The Behavior of Transuranic and Other Loag-Lived Radionuclides in the Ir ish Sea and its Relevance to the Deep Sea Disposal of Radioactive Hastes." is OECD (unclear Eneroy Arency of the Organization of Ecomonir. Coordination and

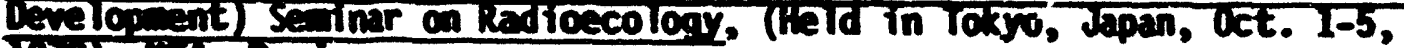
I979), Tin, Paris.

Perkins, E. J. and B. R. H. Millians. 1966. The Biolony of the Snleivy Firth in Relation to the forement and Acculation of Redroctime Riterials. IT. Iie vistribution of sed tents and benthos. P. 6. keport 587 (ci), lnited Kingarom Atomic Energy hithor ity Production Group.

Preston, A., D. F. Jefferies, and M. T. Mitchell. 1971. Experience Eained from the Controlled Introduction of Liquid Radiouctive Maste to Coastal Maters." Aclear Technigues in Emviron ental Pcllution. International

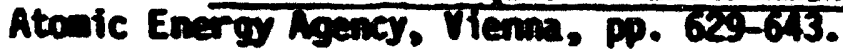

Robins, J. A. and D. M. Edgington. 1975. Metermination of Recent Sed ineatation Rates in Lake Michigan Using Pb-210 or Cs-137." Eeochin Cosuchin Reta. 39:205-304. 
Schell, H. R. 1973. Studies of Concentrations of Umeported Lonolived Radionclides in Biota and ucesn sedtents at Bikini and Entwetok htorts -

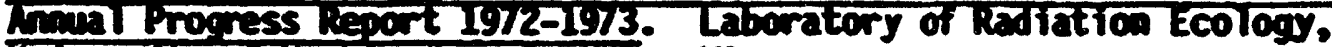
iniversity of Washingtion, Seatte, in.

Schell, H. R. 1974. Concentrations and Phrsical-Chenical States of Radionuclides in Bikini Atoll Lacon bater. Laboratory of Radiation Ecology, Latrersity of hashington, seatte, th.

Schell, M. R. 1976. "Biogechemistry of Transuranics," Bikini-Anmeal Prorress Repont (25) Feb. 1970, (26) Feb. 1976. Laboratory of kadtation Ecology, thiversity of hashingtion, Seattle, W.

Sche11, M. R. 1977. Concentration, Physico-Chemical States and Mean Residence tives of 210pt and 210 po in Marine and Estuarine laters." Geochinica et Geophrsica Acta. 41:1019-1031.

Schubel, J. 1975. Distribution and Transportation of Suspended Sedinent, "Effects of Energy Related Activities on the Atlantic Continental Shelf. Bermard lanowitz (ed.). Erochaven lational Laboratory, upton, if.

Silker, H. B. 1972. Horizontal and Vertical Distributions of Radionuclides

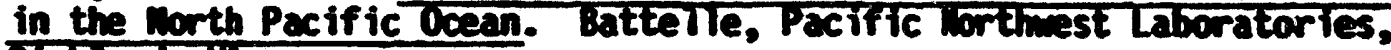
Richand, I..

Simons, T. J. 1973. Develogment of Three-0imensional Mmerical Podels of the Great Lakes. Scientific Series ho. 12. Inland hater Uirectorate, canada Centre for Inland laters, Burlington, Ontario.

Simons, T. J. 1971. "Development of Muerical Models of Lake Ontario." Proc. 14th Conf. Ereat Lakes Res., Mp. 654-659.

Simons. T. J. 1972. "Development of Mmerical Models of Lake Ontario, Part 2." Proc. 15th Conf. Ereat Lakes Res.-, pp. 655-672.

Spraggs, L. D. 1974. Mnerical Similation of Dredoed Mterial Dispersion San Pablo Bay, San Francisco, Vol. I, hodel Uevelonent. Report Eej-2irl. U.S. Corps of Engineers, $\operatorname{san}$ Francisco, $d$.

Teupleton, H. L. and A. Preston. 1966. "Transport and Distribution of Radioactive Effluents in Coastal and Estuarine Haters of the United Kingdon." Disposal of Radioactive lastes into Seas, Oceans, and Surface Haters. Intermational Atomic Energy hency, Viena, pp. 20t-28y.

U.S. Mclear Regulatory Comission. 1976. Regulatory Guide 1.113. Esthating Mrutic Dispersion of Effluents from Accidental and Routine

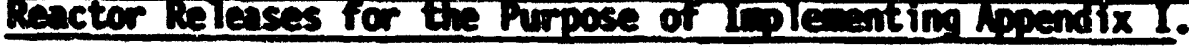


U.S. Muclear Regulatory Contssion. 1978a. Liguid Pathay Eeneric Study. Inacts of Rocidental Radioactivity Releases to the Hrodrosphere fro

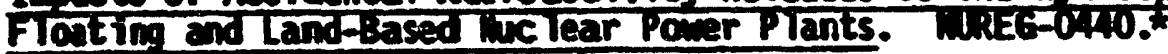

U.S. Mclear Regulatory Comission. 19780. Revised Oraft Environmental Statement Related to the Proposed Manufacture of Floatim hiclear Power

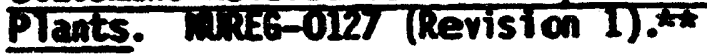

Maleren, M. A. and D. M. Melson. 1976. Residence Tifes for 239pu and 137 Cs is Lake Michioan thter. Argonne Ritional Laboratory Radiological and Emiro wental Research Division Amual Report, Part III, Ecology, Jamuary-Deceiber 1973, AL-8060, pp. 85-92.

\footnotetext{
Exvalisle for purchase frow the Mational Technical Information Service, Springfield, in 22161.

*Available free upon oritten request to the Division of Technical Information and Document Contro1, U.S. Muclear Regulatory Comission, Washington, DC 20555.
} 


\section{RADIOWUCLIDE TRUUSPORT III LAKES MO RESERMOIRS}

This chapter discusses models for lakes and reservoirs that can be used to simulate the migration of contaminants. The mechanisus wich result in transport of a contaminant are much different from the mechanisus in rivers or estivaries. In lakes and reservoir systems, biotic interactions become more inportant and physical wovenent of the water tends to be less inportant than for other types of water bodies. The various types of models discussed in this chapter include models for radionuclide transport, water quality, and thermal plume dispersion.

\section{PHTSICAL VECHNISIS OF RADIOMUCLIDE TRMSPORT IN LAKES. MD RESERVOIRS}

Because of the slower flow in relatively deep confined areas, unique processes to lakes and reservoirs are responsible for the distribution and novewent of the radionuclides in these impoundments. These major processes can be broken dow into three categories: 1) flow conditions, 2) sedinent interaction, and 3) biotic interaction. The relative importance of these three mechanisus depends on the nature of lakes and reservoirs, inflow characteristics, and the chemical characteristics of the radiomuclide.

In lakes with large inflows and outflows, the flow will be dominated by these currents. This is comonly seen in lakes which are expansions of river systems. In most lakes, however, the principal physical processes causing wovement of the water and associated substances are: 1) wind-induced currents, 2) turbulence and stratification and 3) seiches. Wind-induced currents result from the piling up of water on the leeward side of the lake. Equalization of head results in return flow currents. Since the magnitude and direction of the current is dependent on wind, they are time dependent. Seiches or periodic currents may result fra contimuous or persistent wind conditions (thutchinson 1957). Both of these currents may result in movement of botton material from shore areas to other shore areas or deeper sections.

Turbulence and stratification are ajor mechanisas for preventing or causing transport of radionuclides, mutrients, and other chemicals in lake ecosystems (Hutchinson 1957). Thernocline can effectively trap dissolved 
radionuclides in certa in parts of the lake. For example, Hasler and Likens (1963) reported that after introduction of radionuclides to a stratified lake, horizontal transport of the radionuclides occurred but little or no vertical transport was observed. Other research also reported by Hasler and Likens (1963) indicated that there is very little vertical wovement of radionuclides, especially through the thermocline. If the lake is stratified the radionuclide will remin in the layer it enters. In wost lakes, however, some wixing occurs each fall and spring due to seasonal overturns in lakes resulting in more vertically uniform distributions of dissolved radionuclides.

For many radionuclides wich become readily adsorbed to sediment, sedimentation from river inflows and sediment-water interaction become important processes in determining the radionuclide distribution in a lake or reservoir. once the radionuclide becomes attached to the sediment its fate will be essentially the same as that of the sediwent (Lomenick and Gardner, 1965; Lomenick and Tamara, 1965; Lerman and Taniguichi, 1971). Because of the decrease in velocity of the river inflow when entering lakes and reservoirs, extensive sedimentation occurs. Thus, the radionuclide can be trapped in the botton sediment. Because of radionuclide desorption from the bed sediment, it is possible to have a higher radionuclide concentration in the hypolimion (botton layer). This is mixed through the water colum at spring and fall turnover. Hence contaminated bed sediment is an important and continuous source of radionuclides to the water and organisus. Lerman and Lietzke (1975) and Hakonson and Whicker (1975) have discussed the ilportance of this mechanism in lakes. Hakonson and wicker (1975) estimated that $82 \%$ of the ${ }^{133} \mathrm{Cs}$ added to Twin Lakes in colorado was attached to the sediment. The importance of sediment as a sink for mutrients and as a continuous release source for these same mutrients is demonstrated in Uesterdahl (1973).

The rost complex component of the radionuclide distribution in lakes - and reservoirs is that the to biotic interaction. As with the sedimentradionuclide interaction, the importance of this mechanism is related to the chemical characteristics of the radionuclide, especially its biochenical affinity. Most studies on biological uptake of radionuclides have looked only 
at. the concentration of radionuclides in organisas and bioaccumlation factors but have not assessed the relative inportance of radionuclide uptake by aquatic biota to the overall migration of radionuclides in impoundments. Some measured concentrations and bioaccumulation factors suggest that the biotic compartments can store large quantities of some radionuclides (Emery and Klopfer 1974, 1976; Enery and Garland 1974; Enery and McShane 1978; Patzer 1976). This is especially true of photoplankton taking up certain radionuclides such as ${ }^{137}$ CS and ${ }^{90}$ Sr wich tend to act biochemically like potassium and calcium, respectively (Kahn et al. 1971 and Pendleton and Hanson, 1958).

Hakonson and Wicker (1975) measured the distribution of ${ }^{133} \mathrm{Cs}$ anong the various lake system components. Cesium-133 is readily adsorbed to sediment and is biologically active. Sediment accounted for $82 x$ of the radionuclide, water for 3x, and $15 \%$ was accounted for in the biotic components. The seston accounted for most of the biotic uptake. Similar results were observed by Ewery and Klopfer (1974, 1976), Emery and Garland (1974), and Emery and McShane (1978) for transuranics in a pond ecosysten.

The biota can also act as vectors to transport radionuclides horizontally or vertically through the stratified lakes. Although ${ }^{131}$ I has very little biological affinity, Hasler and Likens (1963) reported significant lateral movement of ${ }^{131}$ I in the bodies of aquatic insect larva. This movement would be even more significant for biologically active radionuclides. Hutchinson and Bowen (1947) also observed the dowmard movement of radionuclides in sinking plankton through the thermocline into the hypolimion. Vertical migration of zooplankton was also suggested as a possible means to distribute radionuclices vertically through the thermocline (McCarter et al. 1952). Although these data inply the possible importance of biotic uptake, presently there are not enough data to quantify its impact on the radionuclide migration in the impoundments.

Data sources for distribution of radionuclides in lakes and reservoirs are given in Table 7.1. 


\section{TABLE 7.1. Lakes and Reservoirs Data}

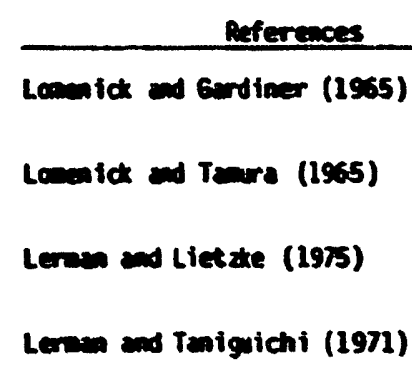

Kan et al. (19n)

Hutonsen and micker (1975)

Masler and Likens (1963)

Peadleton ad huson (1958)

Hetchinson and Bamen (1974)

nocirter et al. (1952)

Wolches

Volchot (1975)

Robertsen et al. (1973)

Heashtid et al. (19es)

Eury and Mestune (1970)

\section{.}

wite ouk Lake

Wite Oak Lake

Lake Erie Leke Onter io

leke Seperior

Lake Michign

Lake huras

Lake Ontario

Shermen Reser-

roir

Twin lake in

colorido

Rockies

Stenart's Durk

lake, To lake visconsin

Pond on Hinford

Reservation

Linsley Pond

Sin Lake inv Scotia

Great Milat

River Morth

Pond South

Pood, Mieni-

Erie Conal

Ereat mial

Rive. morth

Poad. South

Pond. Minei-

Erie Consl

Lake uallula in the Columia

atur

Lake vilula in the Columbia

200 uppond 2-19 Bitch, Heaford Reservation
Tre of Redionclioe Date

sedinet,bond 106in, 137cs,

Sediment-bound 137Cs, 106Rt,

Pigsolvg and sedineme bound

Dissolved and sediment-bound radionclides

Dissolved radionelides

Dissolved radionelides

Dissolved and sed twent-bound radionelides

Dissolved, sed inent-bound gits orginism-bound forms

Dissolyed and sedimentbound I33cs

Dissolyed and organisbound $\mathrm{ISI}_{1}$

Oissolved, sed in $x^{-1} t-b o u n d$, and organism-bound $137 \mathrm{Cs}$

Dissolved and organism-bound pissolved and sed inent-bound Qissolved and sedineat-bound gissolved and sediment-bound

Dissolved ird sedificents

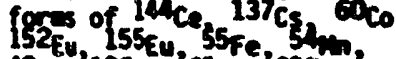
Osc, 126s, $652 \mathrm{n}, 23 \mathrm{~s}$, Otspolved fid sedfreat-boned forms

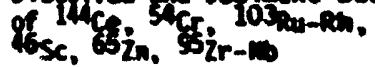

Dissolved, sedtentebonent ind cremisediond fors of $24 l_{h}$.

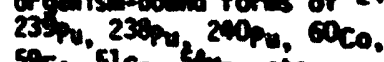

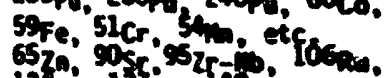

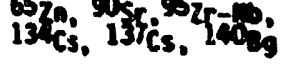




\section{MATHZMTICAL MODELS FOR LAKES AND RESERVOIRS}

The categories of lake nodels discussed here are radionuclide models, water quity models and thermal plume models. The water quality nodels were classified according to their governing equations, as described in Chapter 3. There are no sediment transport computer models specifically developed for impoundents.

Radionuclide Models for Lakes and Reservoirs

The first two models discussed below are very simple, compartmentalized wodels wich do not include any physical transport meciranisims that can influence the radionuclide distribution. These models would be wost applicable in systems where currents and stratification do not exist. The other three nodels are core applicable to reservoirs or lakes that are part of a river system.

\section{Vanderploeg, Booth and Clark (1976)}

This model is a lake ecological model designed to simulate radicnuclide transfer from the dissolved radionuclide concentration in a stagnant, nonstratified, shallow, eutrophic lake to fish throu'sh the food chains. Interactions among various constituents are shown in Figure 7.1. The interactions of the dissolved radionuclides with the bottom sediments and interstitial water are also included. A linear system-analysis model was developed to simulate time-dependent dynamics of specific activity and radionuclide concentration. However, the model does not solve spatial variations. Similar to the model developed by Booth (1975), all governing equations are expressed by the first order reaction form; i.e., the rate of change of the constituent concentration is directly proportional to the concentration of the constituent. The model equations are solved by an analytical method using matrix manipulations (Clark et ai. 1974).

The model was applied to thite Oak Lake near Oak Ridge Mational Laboratory, Oak Ridge, Tennessee. The time history of ${ }^{137} \mathrm{Cs}$ concentration in the water was used as an input condition to solve other constituent concentrations, and reasonably good agreewent was attained. The authors concluded from this 


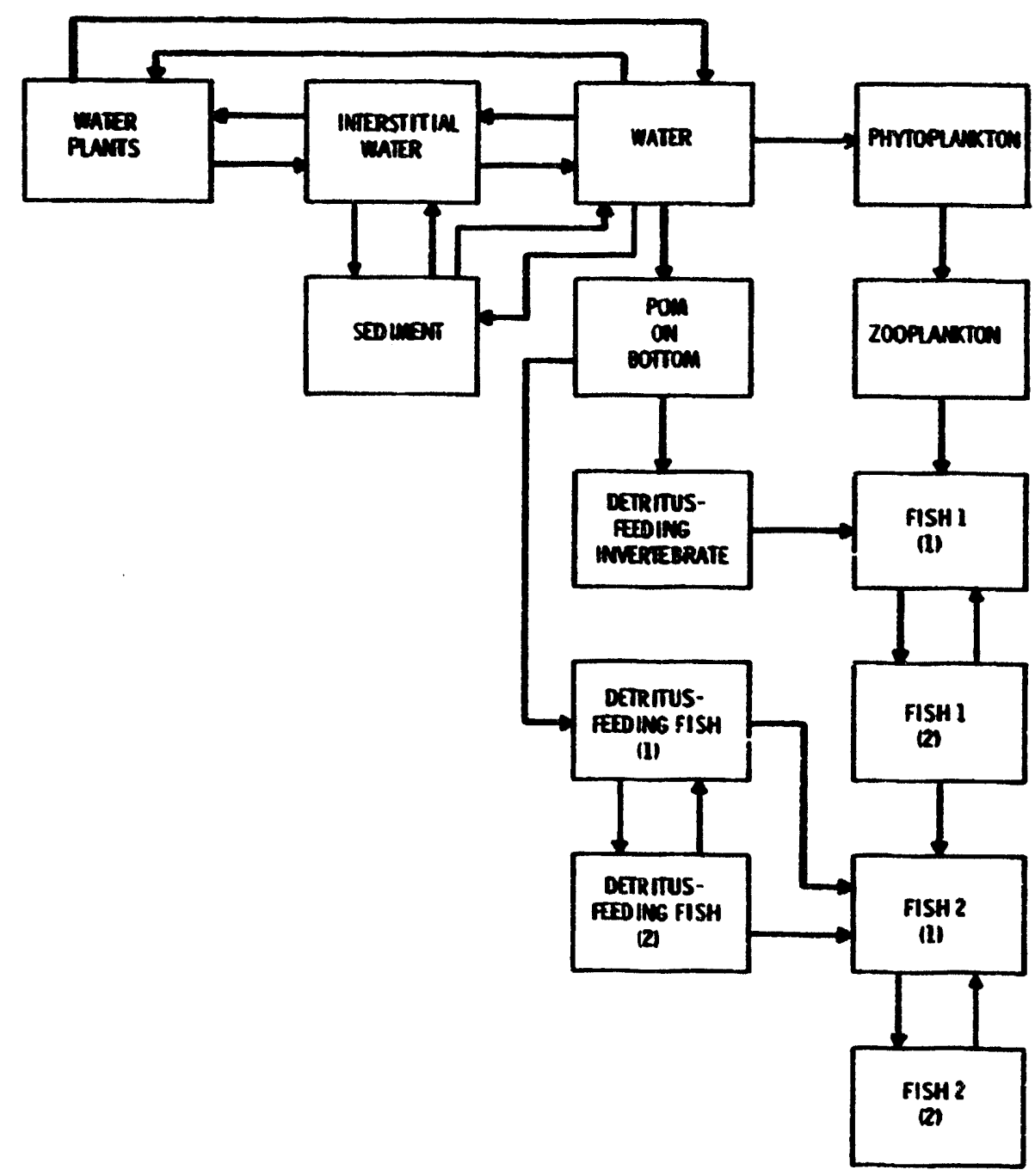

FIGRE 7.1. Compartments of the Lake Ecological Model of Vanderploeg, Booth and Clark (1976)

study that the bottom sediment was found not to be a major source of ${ }^{137}$ Cs to be taken up by the biota because reasonable agreement between the computed results and field data was obtained without taking into account the interactions of bottom sediment and biota. However, the good agreement does not necessarily inply that all model assumtions and nodel structure are correct. Full verification of this statement can only be made if the model results with all organism-sediment reactions included are found to be mearly identical to 
results without the ir interactions. Since this model is a comparticent ecosystem model and no dymanic movements of water and sediment are considered, the model applicability is linited to lakes with no measurable inflows and outflows.

\section{Booth (1975)}

This wodel is also a compartment wodel wich was developed to calculate the concentration of radionuclides in water, botton sediment and interstitial fluid. Interactions anong the sorbents are also accounted for. Botton sedients were divided into two parts, one wich interacts with overlying water and interstitial water, and the other wich is an uitinate sink adsorbing radionuclides from interstitial water. The governing equations of these four compartments are the first order reaction forms without spatial variations. The concentration of radionuclides attached to the sediment is then calculated from a known $k_{d}$ value and the concentration of known dissolved radionuclides. Radionuclide decay is also contained implicitly in the equation. The model does not include velocity components and suspended sediemt in the water. However, the rate of bed elevation change can be prescribed in the mode 1 to account for sedimentation rate in a lake. Hence, the best application of this oodel would be for large lakes and reservoirs where retention tive is large. No verification or application of the nodel was presented although the results of a sensitivity analysis were given.

Onishi et al. (1976) Onishi (1977a, b)

The unsteady, two-dimensional (longitudinal and vertical), sedimentcontaninant transport model, SERATRA, discussed in Chapter 4 is also applicable to impoundments. As discussed in Chapter 4, this model was applied to two rivers, the Colubia and Clinch Rivers, for river reaches including fast moving free-flow regions and slow woving regions (reservoirs) behind dans.

Eraslan et al. (1977)

As stated in Chapter 5, RADTnO is an unsteady, two-dimensional model for dissolved radionuclide transport in lakes, estuaries, and coastal regions. The wodel is one component of the UTA progran being developed at Oak Ridge National Laboratory (Eraslan et al. 1977). 


\section{Codell (MRC Mixed Tank Lake Model) (USKRC 1978)}

Codell at RiC developed a mixed tank model with sedimentation effects included for lakes and reservoirs (USHRC 1978). As show in Figure 7.2, this unsteady model divides a lake into water and bed sediment compartments through wich radionuclides are exchanged by direct adsorption/decorption mechanisins and sediment deposition. The following model assumptions were made:

- Hater inflow and outflow are constant but can be different.

- Sedinentation rate is constant.

- Sediments are not introduced to the lake nor renoved from the lake.

- The sediment layer thickness remains constant by assuming that if the sedimentation occurs, the portion of the original bed layer becomes inactive and is eliminated from the analysis.

- Dissolved and particulate radionuclides are in equilibrium conditions.

- Both dissolved and particulate radionuclides decay.

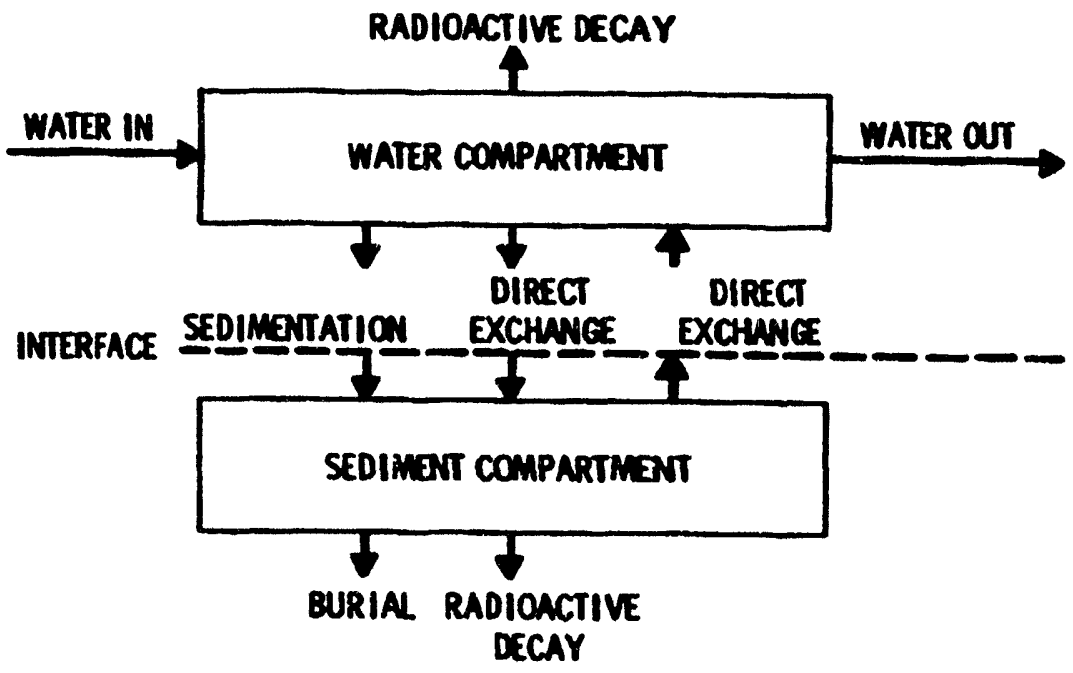

FIGURE 7.2. MRC Mixed Tank Lake Model 
Based on these assumtions, Codell derived analytical solutions of dissolved radionuclide concentration in the water compartment and of particulate radionuclide concentration in the bed sediment compartment for an instantaneous radionuclide release. His instantaneous solutions may be generalized using the convolution integral as shom in Figure 4.30. Detailed nodel derivation is described in USiRC (1978).

\section{Mater Quality Models in Lakes}

The water quality molels for lakes are of three basic types. The first type is based on the convection-diffusion equation with decay and source/sink terms (Water quality Models of Type I). This is the most general type of a nodel and would be most applicable when inflow and/or outflow conditions dcminated the hydrodynamics as in many reservoirs. The second type includes the effects of transfer of constituents between layers in stratified lakes as the result of diffusion or sinking of organisms but does not include the advection term (Nater Quality Models of Type V). This type of model can be used for lakes where water wovement is minimal. The third type of wodel contains ro hydrodymanic components (Hater Quality Models of Type IV) and can be used wostly for long-tern approximations to the lake system.

\section{Water Quality Models of Type I}

Baca $(1977 \mathrm{a}, \mathrm{b})$. The AquA model belongs in the Mater Quality Model Type I category and is an unsteady, two-dimensional, convection-diffision equation with decay and sink/source terms. It is a detailed limnological model based on the dynanics of heat and mass transport and cheaical and biological transformations.

The detailed limetic model is actually composed of two parts: 1) a hydrothermal model, and 2) a water quality model. The hydrothermal model uses five ajor processes to describe the thermal cycle and its effect on lake stratification and aixing to solve velocity and teperature distributions. These processes are: 1) internal heat transport, 2) advection and windinduced mixing, 3) atwospheric heat exchange, 4) formation and melting of ice 
cover, and 5) stratified fluid flow. The outputs from this nodel are used to describe the flow and teperature fields for the water quality nodel. This water qaility nodel takes into account the chemical and biochenical transformtious as well as the trophic interactions of phytopianiton and 200planixton to predict the values of: phytoplankton biomass, zooplankton biomass, nitrogen, phosphorus, dissolved oxygen, biochemical oxygen demand, teeperature, suspended sedinent and total dissolved solids. Model formulations are very siailar to those of the Lake Ontario model isivons 1971-1973) described in Chapter 6. The system of equations is solved by a finite elenent technique with the Galerkin weighted residual method. This nodel was also calibrated and verified with data from M. Bold Reserwoir (Gasperino et al. 1977; Baca et al. 1977a,b; Brandstetter 1977), and Long Lake Reservoir (Gasperino and Soltero 1977).

Hydroscieace - Mear-Field Steady Adrection-Diffusion Equation (1968). The first of the four Hydroscience nodels described here is a steady, twodinensional, adrection-diffusion equation with a decay term. This nodel also simlates water quality in the vicinity of streans or outfalls entering a lake. In this case, a proper evaluation is ade of the phenomena of advection, decay and dispersion to define profiles of substances influencing water quality. The governing equation consists of a longitudinal advection term, a vertical diffusion term and a decay term, and is solved analytically with constant velocity, diffusion coefficient and decay rate. This model is applicable to lakes where flow woves in the longitudiral direction with a uniform velocity.

\section{Hater Oanlity Models of Trpe $V$}

Hydroscience - Strat ified Lake Model (1968). An unsteady, one-dimensional, water quality codel was developed by Hydroscience (1968) to solve the vertical distribution of conservacive substances (primarily heat) in stratified lakes.

As a short-term nodel, a lake can be viewed as thermally stratified. It is assuned that advection and source terms are not important and the governing equation contains only two terms, unsteady and diffusion terms. By assuning that initial concentration (or vater temperature) is zero and that the concentration (or water temperature) is expressed by a cosine curve with tice at the 
water surface, the governing equation was analytically solved to obtain the diffusion of the substance (or transfer of heat) in the vertical water colum. The nodel has not yet been applied to an actual field case.

Hydroscience - Mearfield Steady Diffusion Hodel (1968). The near-field diffusion of monconservative substances is solved by this steady, turdimensional, diffusion nodel with a ciecay term. This nodel was developed to consider mater qaility in the vicinity of streans or sevage outfalls entering a lake. It assumes that the concentration of bacteria at any point beyond the initial wixing area is a function of turbulent diffusion and natural die-off of the bacteria. The governing equation as solved analytically in a polar coordiate systen, assuring that two diffusion coefficients and the decay rate are constant. However, because of the lack of a convection term, the nodel applicability is rather linited.

\section{Water Quality models of Tye IV}

Baca et al. (1974). The nodel developed by Baca et al. (1974) is a complete wixed tank wodel. The wodel solves a long-term lake eutrophication process based on a phosphorus balance by simulating inorganic, particulate and total phosphorus, chlorophyll a, and Secchi disk depth. In order to describe effects of a stratified and a well-mixed period on the phosphorus cycle, the codel solves the lake eutrophication process for two separate upper and lower layers.

The most important constituents of the model are the source/sink terms relating the various biochemical effects on phosphorus cycling. The analysis and formulation of the wodel is thus based on four basic limetic processes:

1. mutrient loading and effective flushing

2. nutrient uptake and regeneration

3. sediment-water interactions

4. formation and wigration of the therwocline. For convenience and expedience, these physical, chewical and biological processes are "luped" into simple mathematical characterizations expressed by decay and sink/source terms. The mathemtical formulation of the eutrophication wodel consists of two sets of linear ordinary differential equations 
wich were solved by the fourth-order Runge-futta techaique. The nodel was calibrated by using one year of field data and verified with the following year's data from it. Bold Reservoir near Mdelaide, Mustralia (Gasperino et al. 1977; Baca et al. 1977a,b,; Brandstetter et al. 1977) and Lake lashingtoa, Mashingtoa (Baca and Arnett, 1976).

Anderson, Dracup, Fogarty, and Willis (1976). This unsteady, wter quility nodel can only be applied to deep lakes were convection and dispersica wy not be important in deterwining water quality. The wodel equations are the first order reaction forms consisting of only decay and source/sink terms without any spatial dimensions considered. The source/sink terss include production of the nonconservative water quality paraneters. The nodel simslates may water qality paraneters including dissolved oxygen, biochenical oxygen demand, $\mathrm{PO}_{4}, \mathrm{~m}_{4}$, organic nitrogen, dissolved solids, $\mathrm{m}_{2}, \mathrm{~m}_{3}$, colifor bacteria and chlorophyll a. Layers representing the epilinion, thermocline and mpolivanion are modeled separately, except: 1) during spring turnower the three layers are mixed and the constituents are redistributed, and 2) during the sumer, organic nitrogen and some phosphorus are transferred frow one layer to another through settling of organisas. No information is given on how the codel equations are solved although most likely these equations were solved by some computer integration method. The nodel was applied to Deer Creek Reservoir in Utah to simlate distribution of 00,800 , organic nitrogen and $m_{3}$ during an 8-anth period. However, the field data were not sufficient to allow verification of the rodel.

Hydroscience - Long-Tern Lake Podel (1968). The last hydroscience codel is a long-tern, complete wixed tank, water quality wodel; thus it is an unsteady model which consists of three terms: unsteady, decay, and sink/source terns.

The long-tern lake wodel predicts the changes of lake mter quility over a geological tine scale. The mater body is considered completely wixed due to the year-to-sear spring turnover. The governing equations express the ass balance of nonconservative substances; the change in mass of a constituent over a time period is equal to the sum of: 1) the anount entering ainus the 
amunt leaving and 2) decay and sink/source (chemical decay, settling of aterials, reintroduction of material from lake bottom to mater, etc.). In its formalation, the difference between the amount entering and leaving is expressed as a sink/source tern. Lakes can be treated as one water body, or two stratified layers through wich constituents my interact. The concentrations of these substances were obtained by solving the governing equations anlytically.

\section{Thenal Plue Models in Lakes}

One inportant class of miter quality ectels is the thermal plune codels that predict the wovenent of heated water entering lakes. These nodeis are different from those described above because they include the heated mater's buyancy effects mich influence the movenent of flow. It is possible to adapt these codels to radionuclide transport, but the physical mechanisis in these tu types of transport are quite different. Care must be used when making application of a thermal plume nodel to radionuclide wodeling. Dissolved radionclide transport ma be sinulated by thenal plune nodels by assuring the radicinuclide plume to be a nonbuosant plume. Particulate radiomaclides wy be treated as a negative buyart plume. However, it is not feasible to use a thermal plue adel to solve the migration of both dissolved and particulate radiomaclides with their interaction. The two models discussed below are representative of the wo basic types of therial plune nodels: 1) "integration" codel and 2) full hydrothermal model.

Stolzenbach and Harlemen (1971, 1973); Stolzenbach et al. (1972); Stolzenbach (1972, 1975). The d -ivation of this integration nodel starts with the three-dimensional, steady hydrodymaic, and advection-diffusion equations to solve the temperature distributions of heated water discharged into the surface of a lake. The basic athodology was to reduce these equations to a first order, one-dimensional, ordinary differential equation which can then be solved muerically by the fourth order Runge-kutta method. The hated water is discharged from a rectangular open channel at the surface of an inf inite weter body wich way or my not have currents of its om. The following assuptions were ade to allow the equations to be reduced to first 
order ordinary differential equations: 1) steady-state flow, 2) hydrostatic pressure, 3) the Boussinesq appro: mation of the mater density gradient, 4) the boundary layer flow assuptions, 5) the heated mater to be treated as a jet, and 6) the velocity and temperature distributions around the centerline of the plume to be expressed by similarity functions. Thus, the first order, onedimensical, ordinary differential equation derived from the three-dimensional equations with these assuptions expresses the change in temperature along the centerline of the plume only. The temperature along the centerline is then used to estimate temperatures along two other coordinates by using a preassigned similarity function (e.g., normal distribution) to obtain threedimensional distributions of mater temperature.

Independent verifications of this codel and other thermal plume models were conducted by Dum et al. (1975) at Argonne Mational Laboratory. They reported that this nodel did not predict the temperature distribution very well except in the very near-field region. Particularly the computed plune width reveals poor agreenent with field data. In this verification study, the computed results were compared with field data of dispersion of heated plume discharged from power plants into the Great Lakes. Dum et al. (1975) also reported that the wodel cannot predict the teiperature distribution accurately if abient water velocities are greater than one-tenth of the initial heated jet velocity.

Trent (1975). In contrast to the abovementioned model of Stolzenbach et al. (1972), the second wodeling approach adopted by Trent (1975) uses few assuptions. The governing equations of the nodel, VECTRA, are the coupled steady/unsteady, two-dimensional equations for momentum, continuity, state, and advection-diffusion with a source term. These equations mere solved by converting the Mavier-Stokes equations and equations of continuity into strea function ant vorticity equations wich no longer contain a pressure term. These equations; together with the state and advection-diffusion equations, were then solved by an inplicit rinite difference schewe.

The wodel mas appijed to San Diego Bay to solve steady, two-dibensional velocity field, sediment corcentration, and water temperature distributions 
(Onishi 1976). It ms also applied to the cooling tomer plume dispersion process. Computer results and measured data obtained by laboratory physical codeling provide good agreenent (Onishi and Trent 1976). This andel is applicable to oceans, rivers, lakes, and reservoirs but not applicable to estuaries because it does not have a tidal notion mechanisa of hydrodynamics.

\section{REFEREMTES FOR CHAPTER 7}

Anderson, D. R., J. A. Oracup, T. J. Fogarty and $R=$ Mill is. 1975. Wuter Quality Modeling of Deep Reservoirs." J. Mater Poll. Control Ed. 48:134-146.

Baca, R. 6. and R. C. Amett. 1976. A Limplogical Model for Eutrophic Lakes and I poundents. Prepared for office of Research and Levelopment, U.S. EPh, Wishington, DC, by Battelle, Pacific Rorthmest Laboratories, Richland, II.

Baca, R. G., M. U. Lorenzen, R. D. Mudd, and L. Y. Kimel. 1974. A Eeneralized Hater Quality Model for Eutrophic Lakes and Reservoirs. Prepared for Uffice of kesearch and honitoring, U.S. EPh, Washington, OC, by Battelle, Pacific Morthmest Laboratories, Richiand, M.

Baca, R. 6., A. F. Gasperino, A. Brandstetter and A. S. Myhres. 1977a. Model formulation, Calibration and Verification Part 2 of Hater Quality podeIs for inicipal hater supply heservoirs. Prepared for the Engineering and Water supply bept. Adelaide, South hustral ia by Battelle, Pacif ic Northmest Laboratories, Richland, M.

Baca, R. 6., A. S. Mytres, A. Brandstetter and A. F. Gasperino. 1977b. Users Mamual Part 3 of Mater Ouality Models for Municipal Water Supoly Reservoirs. Prepared for the Engineering and Thter Supply Dept. Adelaide, South hustralia by Battelle, Pacific Morthest Laboratories, Richland, WA.

Booth, R. S. 1975. A System Analysis Model for Calculating Radionuclide iransport Between Receiving Laters and botton Sediment. Ciri-11;-4751, Stoudsberg, Ph.

Brandstetter, A., R. G. Baca, A. F. Gasperino and A. S. Myhres. 1977. Sumary Part 1 of Mater Quality Models for Municipal Mater Supply Reservoirs. Prepared for the Engineering and hater Supply Wept. Adelaide, South Awstralia by Battelle, Pacific Nortmest Laboratories, Richland, $M$.

Clark, F. H., R. S. Booth and H. A. Vanderploeg. 1974. User's Manual for moosoy, a Terminal Operated Progran Solving the Linear Matrix Equation $x=$

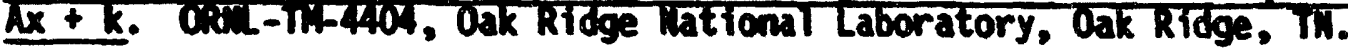


Dum, H. E., A. J. Policastro, and R. A. Paddock. 1975. Surface Thermal Plimes Evaluations. Argonne Mational Laboratory, Argonne, IL.

Enery, R. M. and D. C. Klopfer. 1974. The Ecological Behavior of Plutoniu and hericiu in a Freshmater Ecosyste: Phase I Limplonical characterization an Isotope Uistribution. Bin-185T. Paciric Morthuest Laboratory, Richan, w.

Enery, R. H. and D. C. Klopfer. 1976. "The Distribution of Transuranic Elements in A freshmater Pond Ecusysten." Environental Toxicity of Aguatic Radionuclides: Models and Mechanisms. M. D. Tithter and J. M. Stannard (eds). An trobor Science, Publishers Inc., Am Arbor, MI.

Enery, R. M. and T. R. Garland. 1974. The Ecological Behavior of Plutoniu and Rmericio in a Freshmater Ecosystem: Phase II Inplications of Differences in Transuranic Isotopic Ratios. Bim-1879, Pacific horthmest taboratory, Richland, W.

Enery, R. M. and M. C. MeShane. 1978. Radioecology of Muclear Maste Ponds and Streans on the Hanford Site. Pill $-249 \%$, Pac if ic Worthiest Laboratory, Richand, W.

Eraslan, A. H. et al. 1977. Developent of a Unified Transport Approach for the Assessent of Power-Plant I pact. CinL-Niliz6-Tik-89. dak Ridge hationat Laboratory, bak Ridge, iil.

Gasperino, A. F., A. Brandstetter, A. S. Myhres and R. 6. Baca. 1977. At. Bold Reservoir Data Acquisition and Evaluation Part 4 of Mater Quality hodels for Inicipal ther Supply Reservoirs. Prepared for the Engineering and Water Supply Dept. Acelaide, South Australia, by Battel le, Pacific Morthwest Laboratories, Richland, MA.

Gasperino, A. F. and R. A. Soltero. 1977. Phosphorus Reduction and its Effect on the Recovery of Long Lake Reservoir. Prepared for Washington State dept. of Ecology. Battelle, Pacific Northmest Laboratories, Richland, M.

Hakonson, T. E. and F. H. thicker. 1975. "Cesiun Kinetics in a Montane Lake Ecosystem." Health Physics. 28:699-706.

Hasler, A. D. and 6. E. Likens. 1963. "Biological and Physical Transport of Radionuclides i:: Stratified Lakes." Radioecology. PP. 463-470. U. Schultz and $A$. H. Klement (ed.).

Hutch inson, 6. E. 1957. A Treatise on Limnology. Vo1. 1. of Geology, Physics and Chemistry. John Wiley and Sons, New York. 1016 PD.

Hutch inson, G. E. and V. T. Bowen. 1947. "A Direct Dexoustration of the Phosphorus Cycle in a Small Lake". Proc. Mational Acadeay of Science (U.S.). $33(5): 148-153$. 
Hydrosciences, Inc. 1958. Mathematical Models for Hater Quality for the Hudson-Charolain and netropolitan Coastal hater Pollution coastal Project. Pi-2llo-9K2.

Kahn, B. et al. 1971. Radiological Survelllance Studies at a Pressurized Hater Muclear Power Reactor. EPh Report ho. Rilll-1.

Lerman, A. and T. A. Lietzke. 1975. Mptake and Migration of Tracers in Lake Sed inents." Limpol and Oceanography. 20(4):497-510.

Lerman, A. and H. Taniguichi. 1971. "Strontiu-90 and Cesiu-137 in Hater and Deep Sediments of the Great Lakes." Radionuclides in Ecosystens.

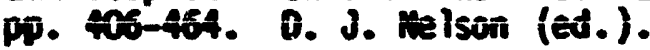

Lomenick, T. F. and D. A. Gardiner. 1965. "The Occurrence and Retention of Radionuclides in the Sediments of White Oak Lake." Health Physics. 11:567-577.

Lomenick, T. F. and T. Tamura. 1965. Mhaturally Occurring Fixation of Cestu-137 on Sediments of Locustrine Origin." Soil Science of America Proceedings. 29(4):383-387.

McCarter, J. A., F. R. Hayes, L. H. Jodray and M. L. Cameron. 1952. "Wovenent of Materials in the Hypolitinion of a Lake as Studied by the Addition of Radioactive Phosphorus." Can. J. 2001. 30:128-133.

Onishi, Y. 1976. Assessment of the Impact of the Proposed Mildlife Reserve Island in South San Uiego Bay on the South bay Pomer Plant. Prepared for San biego Gas and Electric Company, San Diego, $\alpha$ by battelle, Pacif ic Northmest Laboratories, Richland, in.

Onishi, Y., P. A. Johanson, R. 6. Baca and E. L. Hilty. 1976. Studies of Colubia River Hater Quality -- Development of Mathenatical Models for sedteent and Radiomelide Transport halysis. Bil-8-452. Pacific horthmest Laboratory, Rich Iand, Wh.

Onishi, Y. and D. S. Trent. 1976. Mathematical and Experinental Investigations on Dispersion and Recirculation of Ploces from Ory Cooling Towers at Wyodak Power Plant in Wyoming. Blim-1982, Pacific Northwest Laboratory, Richtand, $M$.

Onishi, Y. 1977a. Finite Element Models for Sediment and Contaninant Transport in Surface Taters -- Transport of Sediments and Radionuclides in

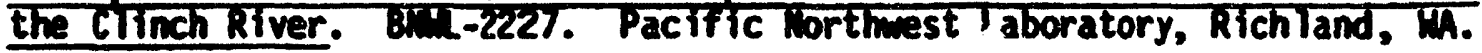

Onishi, Y. 97/0. Matheatical Simulation of Sedisent and Radionuclide Transport in the Colf bla kiver. Bi:L-2izi8. Pacific Worthest Laboratory, RTchland, Th. 
Patzer, R. 6. 1976. Concentration Factors and Transport Models for Radionclides in Aguatic Environents - ALiterature Revien. EPh-600/3-76-6oh.

Pendleton, R. C. and H. C. Hanson. 1958. "Adsorption of Cesiu-137 by Components of an Aquatic Commity". In Proceedims of the Second U.M. Intermational conference on Peaceful Uses of Ato.jic Eneray. 18: 19-433.

Stolzenbach, K. 1975. "Surface Discharges - Comparison of Alternative Schemes." Ennineerim Aspects of Heat Disposal from Poner Eeneration. D. R. F. Hartean (ed.). R. M. Parsons Laboratory for Hater kesouces and Hydrodynamics, Dept. of Civil Eng., MIT, Cabridge, M.

Stolzenbach, K. 1972. "Heated Surface Discharges." Engineering Aspects of Heat Disposal from Power Generation. D. R. F. Harlean (ed.). R. H. Parsons Laboratory for Hater Resources Hydrodynaics, Dept. of Civil Eng., MIT, Cadbridge, M.

Stolzenbach, K., E. Adaus and D. R. F. Marleman. 1972. A User's Manual for Three-Dimensional Heated Surface-Discharge Computations- Report 10. 156, $R_{\text {. }}$.. Parsons Laboratory for Hater Resources and Hydrodynamics, Dept. of Civil Eng., MIT, Cambridge, M.

Stolzenbach, K. and D. R. F. Har leman. 1971. An Analytical and Experimental Investigation of Surface Discharges of Heated Hater. Report No. 135, R. N. Parsons Laboratory for hater Resources and Hydrodynamics, Dept. of Civil Eng.., MIT, Cambridge, M.

Stolzenbach, K. and D. R. F. Har leman. 1973. "Three-Dimensional Heated Surface Jets." Mater Resour iss Research. $9(1)$.

Trent, D. S. 1976. Mathematical Modeling of Transport Processes in Aquatic Systems. BMil-SA-5374, Pacific Northest Laboratory, Richland, WA.

U.S. Muclear Regulatory Comission. 1978. Liquid Patmay Generic Study. Impact of Accidental Radioactivity Releases to the Hydrosphere from floating and Land-Based Huclear Power Plant. NiREG-0440.*

Vanderploeg, H. A., R. S. Booth and F. H. Clark. 1976. "A Specific Activity and Concentration Model Applied to Cesium-137 Movement in a Eutrophic Lake." Radioecology and Energy Resources. C. E. Cushing, Jr. (ed.) Dowden, Hutchenson 6 Sons, Inc.

Hesterdah1, H. E. 1973. A Study of Particulate Organic 32p in a Simulated Sediment Hater System. Ph.D. Thesis, University of OkTahoma.

Favailable for purchase from the National Technical Information Service, Springfield, VA 22161 . 


\section{RADIONLCLIDE ADSORPTION/OESORPTION}

\section{MECHANISUS}

Before a fundanental understanding and generalized predictive capability for radionuclide transport in oceans, rivers and lakes can be obtained, the physical and chemical processes wich control trace constituent adsorption/ desorption must be described. To become quantitative the knowledge of processes must be such that mathenatical relationships can be formulated. The mechanisms for which generalized mathematical relationships have been demonstrated are ion exchange, precipitation of pure mineral phases and complex formation.

\section{Ion Exchange}

Traditionally, most experimenters tho have studied the interaction of soluble trace constituents such as radionuclides have used ion-exchange concepts to express their results. Classically, ion exchange is described as the chenical interaction wich occurs when a charged solid matrix attracts oppositely charged solution species close enough to its surface to form electrostatic bonds. Because most geologic materials including soils, sediments and suspended solids have an inherent negative charge on their surface most interaction occurs with cations in solution. A measure of the geologic material's capacity to bind positively charged species is the cation-exchange capacity. Typical geologic aterials show a variation of from $0.01 \mathrm{meq} / \mathrm{g}$ to $1.3 \mathrm{meq} / \mathrm{g}$ of cation-exchange capacity depending upon the minera!ogy. There is a definite competition between soluble cations in solution for the exchange sites on the geo logic media's surface.

The degree of competition is a measurable quantity and can be expressed mathematically. A simple ion exchange reaction is shown below:

$$
\mathrm{Cs}^{+}+\mathrm{Na}-\mathrm{X} \stackrel{+}{\ddagger} \mathrm{Ss}-\mathrm{X}+\mathrm{Na}^{+}
$$

where:

$$
\begin{aligned}
& \mathrm{Cs}^{+}, \mathrm{Na}^{+} \text {represent the cation in solution } \\
& \mathrm{Na}-\mathrm{X}, \mathrm{Cs}-\mathrm{X} \text { represent the cation bound to the solid exchanger. }
\end{aligned}
$$


The competition between cesium and sodium can be determined quantitatively using thermodymamic constructs (mass-action)

$$
K=\frac{\left\{m a^{+}\right\}}{\left\{\operatorname{cs}^{+}\right\}} \frac{\{\operatorname{Cs}-x\}}{\operatorname{ma}-x\}}
$$

where:

$K=$ jon exchange constant

$f=$ the activities of the aforementioned species.

The ion-exchange constant $K$ can be determined from various experiments at variable cesium and sodium activities.

The ion-exchange equation for a general binary reaction is readily constructed from Equations (8.1) and (8.2).

$$
\begin{aligned}
& b A^{+a}+a[B-x] \neq b[A-x]+a B^{+b} \\
& K_{A B}=\frac{\left\{B^{+b}\right\}}{\left\{A^{+a}\right\}} \frac{\{A-x\}^{b}}{\{B-x\}^{a}}
\end{aligned}
$$

where:

$$
\begin{aligned}
A, B= & \text { cations in solution } \\
a, b= & \text { valence of the respective cations } \\
A-X, B-X= & \text { cations bound to solid exchanger } \\
K_{A-B}= & \text { selectivity constant, ion exchange constant or } \\
& \text { equilibrium constant for the completion of cation } A \\
& \text { versus cation } B .
\end{aligned}
$$

Equations (8.3) and (8.4) are general and thus of great value in predicting the reaction of cations in solution with negatively charged solid matrices such as geologic media if the necessary constant and activities are known or can be measured. There are several complications in the direct application of these generalized ion-exchange equations to radionuclide sorption in oceans, estuaries, rivers and lakes. 
In these environents there are many cations simultaneously competing for available exchange sites such that the binary exchange equation must be expanded greatly. The solid exchanger also now becones a mixture of winerals with different affinities for various cations such that a unique value of $K$ is not likely (a)though a weighted average, $k$, should be obtainable if the system is coupletely characterized). Finally, it is presently impossible to predict or measure the activities of solid phase components (i.e., A-X, B-X, etc.) and often difficult to predict or calculate solution species activities.

Several investigators have successfully quant if ied the adsorption of strontiv ass ing ion-exchange thermodynamic constructs. A Burns, Mississippi montworillonite, with the composition shown in Table 8.1, was used in macroion systems of potassiun, calciu and magnesium to obtain Kd values and calculated $K d$ values in mixed two and three ion systens (Baetsle et al., 1964). The selectivity coefficients given were

$K_{S r}^{K}=0.096\left(S r_{\text {mont. }}+2 K^{+} \rightarrow 2 K_{\text {mont. }}+S r^{+2}\right), K_{S r}^{M g}=1.08\left(S r_{\text {mont. }}+\mathrm{Mg}^{+2} \rightarrow\right.$ Mont. $\left.+\mathrm{Sr}^{+2}\right)$ and $\mathrm{K}_{\mathrm{Sr}}^{\mathrm{Ca}}=0.98\left(\mathrm{Sr}_{\text {mont. }}+\mathrm{Ca}^{+2} \rightarrow \mathrm{Ca}_{\text {mont. }}+\mathrm{Sr}^{+2}\right)$. The isotherms of the binary systems were obtained at several ionic strengths such as $0.1 N, 0.01 N$ and $0.001 \%$. Kd values for strontium, for example, in a Ca-hy system were then obtained by plotting the log of magnesium, calcium or some other macroion concentration versus the Kd to allow extrapolation of the resulting straight line relationship. Thus, the various binary system selectivity coefficients and Kd values determined for each macroion are used to determine a $K d$ in the binary macroion system.

Mercer $(1966,1967)$ has conducted similar studies on zeolite ion exchange from multicomponent systems and gave a table comparing his predicted strontium Kd results with those of Baetsle et al. (1964) on the Burns, Mississippi montmorillonite (Table 8.2). Clinoptilolite gave an experimental strontium $\mathrm{Kd}$ value of $733 \mathrm{ml} / \mathrm{g}$ from a macroion system 0.0104 meq $\mathrm{NH}_{4}^{+} / \mathrm{ml}+0.0891$ meq $\mathrm{Na}^{+} / \mathrm{ml}$, and a strontium $\mathrm{Kd}$ value of 160 from a macrosystem of 0.0170 meq $\mathrm{Na}^{+} / \mathrm{ml}+0.0830 \mathrm{meq} \mathrm{Ca}^{+2} / \mathrm{m} 1$. 
TABLE 8.1. Composition of Burns, Mississippi Montmorillonite. Capacity was $1.04 \mathrm{meq} / \mathrm{g}$ (Baets le et al., 1964).

\begin{tabular}{ccc} 
Camposition & & Percent \\
\cline { 1 - 1 } $\mathrm{SiO}_{2}$ & & 51.29 \\
$\mathrm{Al}_{2} \mathrm{O}_{3}$ & & 15.96 \\
$\mathrm{Fe}_{2} \mathrm{O}_{3}$ & & 2.46 \\
$\mathrm{FeO}^{2}$ & & 0.14 \\
$\mathrm{TiO}_{2}$ & & 0.18 \\
$\mathrm{CaO}^{2}$ & & 2.21 \\
$\mathrm{MgO}$ & 3.95 \\
$\mathrm{Na}_{2} \mathrm{O}$ & & 0.05 \\
$\mathrm{~K}_{2} \mathrm{O}^{-}$ & 0.13 \\
$\mathrm{H}_{2} \mathrm{O}^{-}$ & 18. \\
$\mathrm{H}_{2} \mathrm{O}^{+}$ & 5.37
\end{tabular}

TABLE 8.2. Comparison of Experimental and Computed Strontium Kd Values for Montworil lonite (Mercer 1966)

\begin{tabular}{|c|c|c|c|c|c|}
\hline Solution & $x+, n$ & $\mathrm{C}^{2+}, \mathrm{n}$ & $\mathrm{Cl}^{2+} \mathrm{H}$ & $\begin{array}{c}\text { Exper inentel } \\
x d(-1 / g)\end{array}$ & $\begin{array}{l}\text { Computed } \\
\text { Kd (DI/g) }\end{array}$ \\
\hline 1 & 0.0055 & 0.01382 & & 24.8 & 21 \\
\hline 2 & 0.0404 & 0.00962 & & 59.5 & 41 \\
\hline 3 & 0.0143 & 0.00504 & & 135.5 & 102 \\
\hline 4 & 0.00702 & 0.00412 & & 207.0 & 177 \\
\hline 5 & 0.00240 & 0.00282 & & 369.7 & 368 \\
\hline 6 & & 0.0180 & 0.0769 & 12.17 & 12.1 \\
\hline 7 & & 0.0146 & 0.0348 & 20.6 & 21.3 \\
\hline 8 & & 0.010 & 0.0005 & 56.9 & 53.2 \\
\hline 9 & & 0.0058 & 0.0032 & 114.3 & 105.8 \\
\hline 10 & & 0.0043 & 0.0009 & 193.5 & 221.8 \\
\hline 11 & 0.0085 & & 0.0124 & 18.0 & 22.0 \\
\hline 12 & 0.0411 & & 0.00050 & 50.0 & 48.0 \\
\hline 13 & 0.0155 & & 0.00520 & 116.0 & 111.0 \\
\hline 14 & 0.00612 & & 0.00360 & 193.0 & 203.0 \\
\hline 15 & 0.00582 & & 0.00248 & 336.0 & 300.0 \\
\hline 16 & & 0.0852 & 0.0128 & 12.3 & 14.5 \\
\hline 17 & & 0.0388 & 0.0114 & 25.8 & 24.5 \\
\hline 18 & & 0.0100 & 0.0074 & 58.6 & 55.0 \\
\hline 19 & & 0.0006 & 0.0056 & 100.6 & 107.0 \\
\hline 20 & & 0.0015 & 0.0036 & 244.1 & 209.0 \\
\hline
\end{tabular}


Wahlberg et al. (1965) studied the ion-exchange adsorption of strontium from calciun, magnesium, sodium and potassium solutions by kaol inite, montmorillonite and illite. The adsorption of strontium was described by the massaction equilibriu equation. Calcium provided the greatest competition for strontiun, and sodium the least. The data are presented in graphic form as $\mathrm{Sr}^{+2}$ normality (from $10^{-10_{N}}$ to $10^{-1} N$ ) versus strontium distribution coefficient (Kd). The clays used were American Petroleum Institute standards, well-characterized in the clay literature.

Hank ins and Short (1965) completed an experimental design to allow multiple regression analys is of the effects on strontium and cesiu $K d$ values of the following ions and their concentration ranges: $\mathrm{Ca}^{+2}, 5-500 \mathrm{ppm}$; $\mathrm{Na}^{+}, 6-650 \mathrm{ppm} ; \mathrm{K}^{+}, 1-100 \mathrm{ppm} ; \mathrm{NH}_{4}^{+}, 1-100 \mathrm{ppm} ; \mathrm{Mg}^{+2}, 1-125 \mathrm{ppm}^{+} \mathrm{Cs}^{+}$, 0.05-5 ppm; $\mathrm{PO}_{4}^{-3}, 0.1-10 \mathrm{ppm}$; and $\mathrm{pH}$ 4-9 The equation for strontium adsorption may be applicable to other soils besides IMEL, Idaho soils, if they do not contain abundant sesquioxides.

Wahlberg and Dewar (1965) studied ion-exchange adsorption of trace concentration strontium $\left(10^{-10}{ }^{85} \mathrm{Sr}\right)$ as affected by two competing cations. The $K d$ values calculated with the mass-action equation agreed most closely with high exchange montmorillonite than with lower capacity kaolinite.

Another article by Orcutt et al. (1957) includes experimental work on ion exchange in columns and its theoretical treatment. Several theories are presented that quantitatively describe hydraulic dispersion, ion-exchange equilibria and ion-exchange kinetics as they apply to the movement of radionuclides through natural porous media. In the opinion of the authors, the thecretical models, used in conjunction with field tests, served to reduce the uncertainties of ground disposal operations.

In general, enough scientists have found the ion exchange constructs useful to perpetuate their usage in the quantification of radionuclide sorption/ desorption.

Precipitation-Mineral Formation

The processes of mineral formation and precipitation are quantifiable using the themodynamic construct known as the solubility product rule (see 
Stum and Horgan, 1970, Chapter 6; Butler, 1964). then two or more species are present wich can interact to form an insoluble campound, one can determine whethir the compound should form by comparing the solubility equilibriu constant with the product of the solution species. An exanple follows:

$$
\mathrm{Sr}^{+2}+\mathrm{SO}_{4}^{-2}+\mathrm{SrSO}_{4}(t)
$$

where:

$$
\begin{aligned}
\mathrm{Sr} & +2, \mathrm{SO}_{4}^{-2}=\text { solution species } \\
\mathrm{SrSO}_{4} & =\text { an insoluble crystall ine material. }
\end{aligned}
$$

At equilibrium $\left\{\mathrm{SrSO}_{4}(t)\right\}=\{\mathrm{Sr}+2\}\left\{\mathrm{SO}_{4}^{-2}\right\}$ and using the convention that the activity of the solin phase is one:

$$
K_{S O}=\left\{\mathrm{Sr}^{+2}\right\}\left\{\mathrm{SO}_{4}^{-2}\right\}
$$

where:

$K_{S o}=$ the solubility product or equilibrium constant.

If the product of the strontiu and sulfate activities in solution is greater than $K_{S o}$ precipitation should occur. If the product is less than $K_{S_{0}}$ and the mineral $\mathrm{SrSO}_{4}$ is present in the system it should dissolve until the activity product in so?ution equals $K_{S_{0}}$. Equations $(8.5)$ and (8.6) can be generalized for any precipitate as follows:

$$
b A^{+a}+a B^{-b}+A_{b} B_{a}(t)
$$

and

$$
K_{S O}=\left\{A^{+a}\right\}^{b}\left\{B^{-b}\right\}^{a}
$$

If $K_{S o}$ is known or can be measured it is thus possible to predict che formation (precipitation) or dissolution of mineral phases. Traditionaily in the study of radionuclide sorption. precipitation was not considered iapcrtant because of the extremely low concentration of radionuclide usually wesent in solution. However, the formation of metal 
hydroxide precipitates of rare earths and actinides may occur at environental pH's due to the extremely lon $K_{S O}$. Such events are quite probable when acidic nuclear wastes contact geologic environments wich typically neutralize the waste strean, thus increasing the activity of the $\mathrm{OH}^{-}$ species. For rare earths, $\mathrm{H}^{3+}, \mathrm{K}_{\text {SO }}=\left[\mathrm{H}^{3+}\right\}\left[\mathrm{OH}^{3}\right]^{3}$ and swall increases in OF activity way allow $K_{S o}$ to be exceeded. Under rechicing conditions often found in the organic-laden sediments of certain lakes and estuaries, the precipitation of sulfide winerals is comon even for trace constituents.

Again, the direct application of precipitation-dissolution theories and quantification through the $K_{S_{0}}$ of pure minerals to the fate of trace anounts of radionuclides in rivers, lakes, estuaries and oceans is of ten obscured. Some of the complications are co-precipitation or scavenging of trace constituents during the fomation of precipitates of wajor components of the system (i.e., $\mathrm{CaCO}_{3}$, hydrous $\mathrm{Fe}, \mathrm{m}, \mathrm{Al}$ oxides), lattice substitution of trace constituents into existing mineral phases (i.e., a Sr atom replacing a $\mathrm{Ca}$ atom in an existing $\mathrm{CaCO}_{3}$ or $\mathrm{CaSO}_{4}$ mineral). These scavenging or substitution reactions are difficult to quantify (Stum and Morgan, 1970, Chapter 10), yet they have been proposed frequently as being a major mechanism of sorption of trace constituents. Articles pertinent to co-precipitation and lattice substitution of radionuclides include: Ames. 1959a; Anes, 1960a; Ames, 1960b; Ames, 1961a; Ames, 1961b; Ames, 1961c; Belousdva and Melikhov, 1972; and Bernovskaya and Bogdanov, 1971.

\section{Complexation-1ydrolysis}

The fundanental concept of chemical reactivity is based on the quest to improve stability in the configuration of the outer electron shells. Ionic species in solution, including trace radionuclides will react with other species in solution and form a complex if there is a large increase in stability. Typically, cations or metal ions combine with anions (also known as ligands). Preference for one ligand over another depends on the cations electronic structure and size and can become rather selective.

The stability of a complex can be measured and is represented by an equilibrium constant, $K$. For example: 


$$
\begin{aligned}
& \mathrm{CO}^{+2}+\mathrm{SO}_{4}^{-2}+\mathrm{COSO}_{4}^{0} \\
& K=\frac{\left\{\mathrm{CO} \mathrm{SO}_{4}\right\}}{\left\{\mathrm{CO}^{+2}\right\}\left\{\mathrm{SO}_{4}^{-2}\right\}}
\end{aligned}
$$

or in general:

$$
K_{i}-\frac{\left\{m_{i}\right\}}{\left\{m_{i-1}\right\}}[L\}
$$

where:

$$
\begin{aligned}
M & =\text { a metal or cation } \\
L & =\text { a ligand or an ion } \\
m_{i}, m_{i-1} & =\text { complexes. }
\end{aligned}
$$

Hytrolysis reactions are a specialized type of complex formation in which the $\mathrm{OH}^{-}$anion acts as the ligand. As the hydroxyl anion is ubiquitous in waters, hytrolysis reactions with sationic radionuclides are quite common. Hyctolysis reactions are also quite sensitive to $\mathrm{pH}$ changes. Besides being canan the hydrolys is of metallic radionuclides is important because hyctrolysis species are readily absorbed by solid surfaces. No thorough explanation for the enhanced sorption is available, but it is hypothesized that changes in the hyoration-sphere size and charge allow more covalent bonding between solid surfaces and the complex. Sone data pertinent to hydrolys is of radionur.lides can be found in the following references: Baes and Meswer, 1976; Davydor and Bogatyreva, 1972; Grebenshchikova et al., 1972; Grebenshchikova et al., 1975.

In most instances the formation of complexes increases solubility and would thus be expected th retard incorporation of radionuclides into sediments. On the other hand, as just mentioned, hydrolys is of ten increases adsorption by ill-defined processes. Therefore, it is difficult to a priori state what the effect of complexation will be on radionuclide sorption. The inorganic 
ligands, $\mathrm{SO}_{4}^{-2}, \mathrm{HCO}_{3}^{-}, \mathrm{CO}_{3}^{-2}$ and $\mathrm{Cl}^{-}$are present in high concentrations in sea water compared with fresh waters and may retard the sorption of radionuclides through soluble complex formation.

The complexation of metals with soluble organic ligands in natural waters is frequently postulated to explain the occurrence of metal ions at concentrations higher than those calculated fro existing solubility product constants. Analytical extraction schenes also often lend credence to the importance of such natural organic complexes but direct evidence is scarce. There are very few thernodynaic values available for organic ligand-netal complex stability constants such that quantification at present is impossible. A pertinent article on the importance of organic matter in radionuclide movenent is faure et al., 1972.

\section{Oxidation-Reduction}

This mechanisa is conceptually analogous to acid-base reactions. Just as acids and bases nay be interpreted as proton $\left(\mathrm{H}^{+}\right)$donors and acceptors, respectively, reductants and oxidants are defined as electron donors and acceptors. respe The measure of electron activity analogous to pH is De $=-\log \left\{\mathrm{e}^{-}\right\}$or $\quad \leq$ common $E$ which is proportional to pe. The oxidation-reduction potential is important in that it may control the valence state and ultimately the species present in solution for many radionuclides and aajor constituents such as $\mathrm{Fe}, \mathrm{m}, \mathrm{S}$ and $\mathrm{C}$. The stability fields of the various valence states pu:sible for eleaents as a function of pH are often portrayed in Eh-pH diagrans. Some pertinent references explaining the usage and construction of Eh-pH diagrans include: Baes and Mesmer, 1976; Garrels and Christ, 1965; Lindsay, 1972; Pourbaix, 1966; Rai and Serne, 1977; and Rai and Serne, 1978.

Such diagrans show how electrons and protons can sinultaneously shift the predominant soluble species or stable mineral from one moiety to another for an element. The oxidation-reduct ion reactions used to construct diagrans can be expressed quantitatively in the form of mass action equations as expressed earlier for precipitation and ion exchange with the resultant equilibriu constant, $R$, related to stability. In natural systews the use of thermodynanically derived oxidation-reduction reactions is not straightforward. Because 
many redox reactions are slow. the concentrations of some species may be far from those predicted thermodynaically. Also, warked differences in redox potential may occur over simall spatial areas near the sedinent-water interface. Therefore, the use of theoretical redox constructs to predict the fate of sensitive constituents including radionuclides will depend upon kinetic hindrances and systeas approach to equilibria. The fate of $\mathrm{Sb}, \mathrm{Wb}, \mathrm{Pu}, \mathrm{U}$ and $\mathrm{Tc}$ in aqueous environments and the important scavenging eechanisa of hydrous iron and anganese oxides for trace metals are directly affected by redox conditions. Colloid and Polyer Formation

A final sorption mechanisa on wich there is scant quantitative data is the formation of colloids and polywers. This process involves the combination of atoms of trace constituents with thenselves until a large entity (sub micron) with possible surface charge is formed. Colloids behave intermediately betureen sall soluble and larger suspended particulates. Oftentimes the radionuclide will be bound to a very fine particle of clay or other geologic material and is often designated as a "pseudo colloid." The colloid usually exhibits a saaller charge/surface area ratio and is thus less chemicaily reactive. Its movement, especially if neutrally charged, is most dictated by physical laws (gravity settling, filtration, etc.) wuch like suspended sediwents. Although quantitative mathenatical expressions of this phenomenon are not readily available, highly charged metal ions such as Pu, Th, U, Zr and to a lesser extent $m, C m, S b$ and $R u$ are believed to comonly migrate as colloids or polymers under certain conditions. Several articles pertinent to rajiocolloid formation. adsorption properties and transport properties were identified during this literature review: Benes, 1969; Betenekov et al., 1973; Eichholz et al., 1967; Feldwan, 1976; Folsom and Hodge, 1975; Kaufiman and Klingerman, 1963; Kepak, 1974; Kuznetsov et al., 1973; Lindenbau and Westfall, 1965.

\section{Existing Copputer Codes}

A quantitative description of nuclide transport requires development of models of the above mechanisas and potential mechanisas not identified, or a 
generalized wodel which describes the combined effects of such mechanisus. Travis (1978) reviews numerous equilibriu and kinetic wathematical wodels wich describe solute transport in porous media. These models are based on empirical observations and can be considered as functional relationships which describe the net effect of sorption-retardation mechanisas described above such as ion exchange, pure mineral precipitation, complexation, etc. These eapirical wathenatical relationships do not rely on descriptions on the physico-chenical processes controlling sorption; instead they describe the relationships between the amount of solute observed in solution and the amount of solute adsorbed on the solid natrix. Comonly used equilibriun eapirical nodels include linear adsorption isotherms $(S=k C)$, freundlich isotherms $\left(S=k C^{n}\right)$ and Languir isotherms $\left(S=\frac{k b C}{1+k C}\right)$ where $S=$ amount of solute sorbed on solid phase, $C=$ acount of solute in solution and $k, b$ and $n$ are constants. Again it should be stressed that such equilibrium models are based on eapirical observations on the dist-ibution of solute between solid and liquid as opposed to physico-chemical description of mechanisms and processes. Kinetic adsorption models are also reviewed by Travis (1978). Most of the $k$ inetic wodels have been constructed from first order $k$ inetic constructs, i.e.

$$
\frac{d S}{d t}=k_{1} C-k_{2} S
$$

Chemical models of mineral precipitation, complexation, oxidation-reduction and ion exchange based on physico-chemical lans, usually thenmodynanics and mass action relationships, do exist. The models' strengths lie in description of the major elements such as Si, Al, Ca, $\mathrm{Hg}, \mathrm{K}$, etc. as opposed to trace constituents such as nuclides. Also most of these models do not include transsport (hydrodynamics, advection, dispersion, etc). These models mich combine the chesistry with transport typically rely on siaplified one-dimensional flow algorithas. An excellent recent review of chemical models can be found in Jenne, 1979. Several other references to chenical codes are: Ahlstrom and Foote, 1976; Cameron and Klute, 1977; Dutt et al., 1972; Frissel and Reiniger, 
1974; Helgeson, 1968; Helgeson et al., 1970; Helgeson, 1969; Morel and Morgan, 1972; Fai and Franklin, 1973; Routson and Serne, 1972a, b; Tanji and Doneen, 1966; Tanji et a1., 1967a; Tanji et al., 1967b; van Genuchten and Wierenga, 1974; and Wolery, 1978.

In the next section the most common way of quantifying the chemical interaction of trace radionuclides with geologic media is addressed. The distribution coefficient, $\mathrm{Kd}$, concept is identical to a linear adsorption isotherm model.

\section{DEFI MITION OF Kd AMO RATE DEPENDEMCY}

The quantification of radionuclide adsorption is usually expressed in terms of a distribution coefficient, $K d$. There is some confusion and difficulty in the use of the Kd concept because to strict chemists it has a rigorous definition and can only be used properly when certain assuptions are met. To the engineer and waste management technician, $K d$ is often used in a broader sense and is defined as:

$$
\text { Kd }=\frac{\text { acount of radionuclide sorbed on solid phase }}{\text { anount of radionuclide left in solution }}
$$

Typically Kd has the SI units length ${ }^{3} /$ mass (i.e., $m l / g$ ) as it is convenient to measure the ratio anount/g of sediment/anount/ml of solution. Some users measure the anount of radionuclide on the solid phase in terms of volume of solid phase and thus calculate a unitless ratio of ten designated, $K$. If one can determine the bulk density of the solid phase, a conversion fram $k$ to Kd is possible.

In the strictest sense the concept of $K d$ was developed from ion-exchange theory to represent the equilibriu distribution of a trace constituent between the solid exchanger and solution. Referring to Equation (8.3), the generalized binary ion-exchange expression, and maling the following assumptions:

(a) the component $A^{+a}$ is present in very trace amounts and thus cannot displace a significant (measurable) anount of $B^{\text {tb }}$ from the sol id exchanger, and 
(b) the ratio of the activity coefficients of $A^{+a}$ on the exchanger and in solution is constant (oftentimes assuned to equal 1)

then the terms $\left\{B^{+b}\right\}$ and $\{B-X\}$ are essentially constant. Thus the ionexchange equation becones:

$$
K_{A B} \frac{\{B-x\}^{a}}{\left\{B^{+b}\right\}^{a}} \frac{\left\{Y A^{+a}\right\}^{b}}{\{r A-X\}^{b}}=\frac{(A-X)}{\left(A^{+a}\right)}
$$

where:

$Y=$ activity coefficients

()$=$ concentrations.

The left-hand side of Equation (8.13) with the aforementioned assumptions is a constant, therefore:

$$
K d=\frac{A-X}{A^{+a}} \text { wich is equivalent to Equation (8.12). }
$$

Key points to the correct usage of $\mathrm{Kd}$ include:

(a) the necessity of trace concentrations of component $A$

(b) the constancy of the activity coefficient ratio of component $A$

(c) the satisfaction of system equilibrium.

The third point is often treated lightly in the popular usage of $\mathrm{Kd}$ for radionuclide wigration calculations. Also as described in the previous section, reactions such as precipitation, mineral formation, and non-ideality of ion exchance in natural systems make the correct usage of Kd difficult.

To avoid confusion it would have been nice if engineers and scient ists involved in nuclear waste manageaent had chosen another symbol for the distribution of radionuclides between the solid and liquid phase. It ight be difficult and just as confusing to suggest a new symbol after 20 years of familiarity. At any rate the $K d$ concept has proved invaluable to the prediction of radionuclide migration as long as the qualifying assuptions are met and an 
understanding of the studied system is available. The Kd is typically inserted into a retardation term in the transport equation and the wovement of the radiomuclide is expressed in terms of the bulk vater:

$$
v_{\text {water }}=\left(1+\frac{B d}{Q} K d\right) v_{\text {nuclide }}
$$

where:

$$
\begin{aligned}
v & =\text { velocity } \\
B_{d} & =\text { bulk density of solid }\left(\frac{B d}{\theta}\right. \text { also equals solids/solution ratio) } \\
0 & =\text { porosity }
\end{aligned}
$$

As $K d$ increases, the water moves faster than the nuclide, thus indicating nuclide retardation. The assuaption of system equilibrium is often tacitly assumed. In the systems understudy the rapid movement of water and suspended sediments in rivers, estuaries and coastal waters may not satisfy the assumption of system equilibrium at all times and over all space. The low solids to solution ratio present in natural environments of interest as compared to laboratory systens usually studied may also complicate the interpretation of the applicability of Kd time-dependent data wich are available. On the other hand, the high surface area and exchange capacity commonly found for suspended sediments might allow more rapid attaiment of equilibriu sorption.

The few references wich included Kd determinations as a function of $t$ ime are addressed in the following sections on individual elements. Again it must be stressed that usage of laboratory time-dependent sorption results to predict sorption at field conditions cannot be readily performed. There is no data on sorption dependence on time under actual field conditions.

Another factor, until recently not given adequate study, was the area of reversibility. In the correct derivation of $\mathrm{Kd}$ from ion-exchange principles, $K d$ is equivalent to the ratio of the rate of adsorption to rate of desorption at steady state. For ideal ion exchange the binding of a charsed ion and replacement with another requires equal energy. This leads to an equal rate of adsorption and desorption or the derived $\mathrm{kd}$ value being correct for loading 
or leaching. In natural systems it is becoming apparent that many radionuclijes appear to desorb at slower rates and at steady state show a stronger affinity for the solid phase. This results in Kd's measured in the desorption direction to be greater than when measured in the adsorption direction (i.e., some degree of irreversibility is apparent). It thus looks, besides incorporating a time dependency for Kd into the transport equation, as though the direction of approach must also be considered. A transport equation, including both a time-dependent adsorption Kd and a time-dependent desorption Kd, way be necessary.

\section{FUMCTIOML RELATIONSHIPS}

To the uninitiated the Kd for a given radioisotope is commonly thought to be a constant value for all environmental conditions. Thus, it is comon to see tables listing the radioelements and one $\mathrm{Kd}$ value for each. Others with somewhat more sophistication realize the dependency of $\mathrm{Kd}$ on geologic media type or water composition and will list Kds for each element for a civen media such as western U.S. desert soil (Lester et al., 1975), or for fresh and seawater (Booth, 1975).

In reality the Kd may be dependent on many factors. Some investigators, Routson and Serne (1972a,b), Serne (1978), and Hawkins and Short (1965), have attempted to express $K d s$ as a function pertinent to geochemical variables such as water composition, $\mathrm{pH}$ and Eh.

Fram discussions in the previous two sections on mechanisms and rates, it is apparent that a comriete description of the depencency of $\mathrm{Kd}$ on geologic media, water consumption, hydrologic variables, time and direction (adsorption/ desorption) would be immensely complicated. This author feels that a statistical approach such as regression or adaptive learning networks could be used to empirically derive functional relationships for $K d$ to be used in transport equations. Simple attempts Routson and Serne (1972a,b) and Hawkins and Short (1965), have proven useful and current efforts, Serne (1978), are under way to increase the parameters included. 
The incorporation of a statistical approach requires the characterization of many system parameters to allow the important variables to be identified. The added cost in characterization in the author's view is warranted because:

- It allows much more detailed predictor equations for $K d$ to be evolved.

- It adds data and insight wich should allow scientists to hypothesize probable controlling echanisms which ultimately would allow fundamental understanding of nucl jde sorption/desorption.

- It forces good scientific methods to be employed.

A list of paraneters which should be considered when describing the experimental or field enviroment present wile determining $\mathrm{Kd}$ is found below. With this supporting information a systematic study of the correlation of the Kd for each valence state or species of each element can be performed. The type of function emanating from such a study would be a nonlinear multinominal such as:

$$
\begin{aligned}
& K d_{\text {nuclide species }}=f(\text { geologic parameters, water parameters, time) } \\
& K d=a(\text { Montmorillonite })+b(Q u a r t z)+c\left(\mathrm{Ca}^{+2}\right)+d\left(\mathrm{Na}^{+}\right)+e(p H) \ldots \\
& \quad+x(\mathrm{Ca})(\mathrm{pH})(\mathrm{Eh})+\text { etc. }
\end{aligned}
$$

where $a, b, c, \ldots x$ are statistically derived coefficients. Such complexlooking functions are readily incorporated into numerical computer transport models without increasing cost or complexity significantly. The use of these complex variable functions, however, are not amenable to many simple analytical ccomputer transport models.

The degree of complexity can be reduced to any level by dropping out the lesser significant terms in Equation (8 15), once the user has a clear objective or understanding of the accuracy needed in his whole transport systems model.

Each mechanisn previously discussed would te more sensitive to certain of the parameters listed than others. Thus, a study of the strength of correlation of certain parameters to a nuclide's $\mathrm{Kd}$ can provide insight as to which sorption mechanism may predominate. 


\section{SUPPORTIMG IMFORAATIOM MECESSARY TO EVALLATE}

FUNCTIOMAL DEPEMDENCY OF $\mathrm{Kd}$

Geological Media Parameters

1. Qualitative and Quantitative mineralogy in-luding primary and secondary crystalline materials

2. Amorphous Coat ings including hydrous $\mathrm{Fe}, \mathrm{Mn}, \mathrm{Al}$ oxides

3. Carbonate content ( $\mathrm{Ca}, \mathrm{Mg})$

4. Sulfide-Sulfate content, especially for reduced sediments

5. Organic Content

6 Cation-Exchange Capacity

7. Anion-Exchange Capacity

8. Nitrogen and Phosphorous Content (Mutrients)

9. Particle size distribution

10. Surface Area

11. Distribution of major cations on exchange sites

12. Bacterial Status

Water/6eologic Media Slurry

1. PH

2. Eh

3. Dissolved $\mathrm{O}_{2}$ content

4. Temperature

Water Parameters

1. Major cations ( $\mathrm{Ca}, \mathrm{Mg}, \mathrm{Na}, \mathrm{K}$ )

2. Major anions $\left(\mathrm{Cl}, \mathrm{HCO}_{3}, \mathrm{CO}_{3}, \mathrm{SO}_{4}\right)$

3. PH

4. Eh

5. Dissolved $\mathrm{O}_{2}$

6. Uissolved organic content (fractionated into types)

7. Dissolved nutrients $(N, P)$

8. Dissolved $\mathrm{SiO}_{2}$

9. Minor constituents, especially natural occurring stable isotopes of $\mathrm{Sr}$, CS, I, and other important radionucl ides

Nuclide Properties

1. Tracer Concentration (at start and at each measurement time)

2. Tracer Valence State or Species distribution (at start and at each measurement $t$ ime) 
Experimental or Hydrologic Parameters

1. Contact Time

2. Solids/Solution ratio

3. Degree of agitation

4. Water velocities

5. Suspended load concentration

6. Eddy diffusivities, bed shear stress (description of hydrologic system in field or exper imental methodology)

7. Desorption or Adsorption

\section{SELECTION CRITERIA AND SOLRCES OF RADIONUCLIOES IN THE ENVIROMMENT}

For this study the fission and activation products that are present in wastes (including cooling water and atmospheric emissions) rewaining after nuclear power generation and potential nuclear fuel reprocessing exhibiting long half-lives or biological hazards were selected. Using an approach similar to trenn and Jinks (1976) one finds the elements listed in Table 8.3 present the largest potential hazards for the entire nuclear fuel cycle. Sources of the projected inventory of nuclear materials being produced and/or discharged from existing or planned reactors and waste processing plants which were used to prepare Tables $\mathbf{8 . 3}$ to $\mathbf{8 . 6}$ are: Dames and Moore, 1976; Haury and Schikorski, 1977; Joseph et al., 1971; Magno et al., 1970; ORNL, 1970; Phillips et al., 1977; Schneider and Platt, 1974; USEPA, 1973; U.S. MRC, 1976; and Wrenn and Jinks, 1976

From the references cited the following putentially biologically hazardous elements were chosen for further study: $\mathrm{Am}, \mathrm{Sb}, \mathrm{Ce}, \mathrm{Co}, \mathrm{Cm}, \mathrm{Eu}, \mathrm{I}, \mathrm{Fe}, \mathrm{Mn}$, $\mathrm{Np}$, $\mathrm{Pu}, \mathrm{Pm}, \mathrm{Ra}, \mathrm{Ru}, \mathrm{Sr}, \mathrm{TC}, \mathrm{Th},{ }^{3} \mathrm{H}, \mathrm{U}$ and $\mathrm{Zr}$. Carbon-14, $\mathrm{Cr}, \mathrm{P}$ and $\mathrm{Zn}$ were also added for study.

It would have been interesting but beyond the scope of this study to include the amount of radionuclides present now and in the future from sources such as medical wastes. nuclear bomb testing and fossil fuel consumption in the selection process. Several elements which were more difficult to exclude from consideration include ${ }^{79} \mathrm{Se}$ and ${ }^{151} \mathrm{Sm}$. ${ }^{85} \mathrm{Kr}$ was excluded because it is an inert gas and would not interact with sediments by adsorption/desorption reactions. 
TABLE 8.3. Most Potentially Hazardous Elements

\begin{tabular}{|c|c|}
\hline Operation & Elements \\
\hline Mining & $R \mathbf{a}>\mathbf{U}>\mathrm{Th}$ \\
\hline Milling & $R \mathbf{a}>\mathbf{U}>\mathrm{Th}$ \\
\hline Fuel Fabrication & $\mathbf{u}$ \\
\hline Reactor Effluents & $\begin{array}{l}{ }^{3} \mathrm{H}, \mathrm{I}, \mathrm{Cs}, \mathrm{Co}, \mathrm{Fe}, \mathrm{m}>\mathrm{SO}, \\
\mathrm{Tc}, \mathrm{Ce}, \mathrm{Zr},{ }^{14} \mathrm{C}\end{array}$ \\
\hline Reprocessing & $\mathrm{Sr},{ }^{3} \mathrm{H}, \mathrm{Cs}, \mathrm{Co}$, transuranics \\
\hline Waste Storage & $\mathrm{I}, \mathrm{TC}$, transuranics, $\mathrm{Ra},{ }^{14} \mathrm{C}$ \\
\hline
\end{tabular}

TABLE 8.4. 1975 Sumary Liquid Release of Radionuclides from Comercial LLR and PLR Reactors in the United States

\begin{tabular}{cc} 
Isotope & Curies \\
\cline { 2 - 2 }${ }^{137} \mathrm{Cs}$ & 120 \\
${ }^{134} \mathrm{Cs}$ & 81 \\
${ }^{131} 1_{\mathrm{I}}$ & 23 \\
${ }^{58} \mathrm{Co}$ & 23 \\
${ }^{60} \mathrm{Co}$ & 22 \\
${ }^{90} \mathrm{Sr}$ & 0.5
\end{tabular}


TABLE 8.5. Annual and Cumulated Releases and Production of Radionuclides from Nuclear Plants and Fuel Reprocessing Plants for the World from 1975 to 2000

$\infty$
$\vdots$

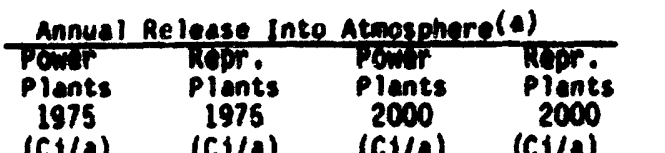

uclide

3H

$85 \mathrm{kr}$

inc

$129_{1}$

$905 r$

60co

106 Ru

134Cs

137 Cs

24lpu

orther Pu

Oether

Trens-

$2.1 \times 10^{2}$

84

42

1.1

$1.7 \times 10^{-1}$

$-\quad 7.2 \times 10^{-4}$

$1.5 \times 10^{-1}$

6.3

$2.6 \times 10-2$
$5.1 \times 10^{4} \quad 1.9 \times 10^{6}$

(1) Power plants in operation in the world, 1975: 57 GWe (2.27): equivalent reprocessing capacity: 1.4 stendard plants (1500 t per yearl): planned power plants in the world in the year 2000: $2100 \mathrm{GW}$ (see text); cquivolent raprocessing capacity: 42 stendard plants (1500 t per year).

(b) Includes rediouctive dacay, 1975-2000.

(c) increase of production rates slower than radtoact ive dacay.

(d) Total production including pu for recycling.

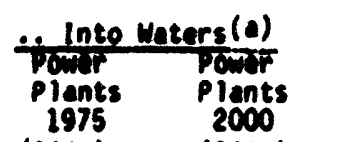

Plents Plents
1975

(cile) (cile)

-

$-$

$-$

$1.6 \times 10^{-1}$

5.7 rowir

Plents Plests

Plents, Plants
Ateosph. Ateosph.

(ci)

plents

Hater

$1.3 \times 10^{5} \quad 8.8 \times 10^{7}$

$3.9 \times 106$

$-$

- $\quad 1.6 \times 10^{5} \quad 2.4 \times 10^{5}$

$-$

$-$

$1.2 \times 10^{4}$

48

22

cumilated Production $197,-2000$ (ci)

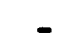

-

$-$

$3.4 \times 10^{10}$ -

$.1 \times 10^{2}$

$-$

$-$

$2.1 \times 10^{2}(c)$

$84(c)$

$1.7 \times 10^{2}$

16

$-$

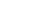

-

$1.8 \times 10^{-1}$

$4.4 \times 10^{8}(d)$

38

$8.0 \times 10^{7}$
Cuenuleted Releases, 1975-2000(b)

(C1) 
TABLE 8.6. Mucl ide Source Inventory(a)

\begin{tabular}{|c|c|c|c|c|c|c|c|}
\hline $\begin{array}{l}50 \\
60 \\
70 \\
80 \\
90 \\
00 \\
10 \\
20 \\
30 \\
0 \\
50 \\
50 \\
70 \\
0 \\
0 \\
0\end{array}$ & 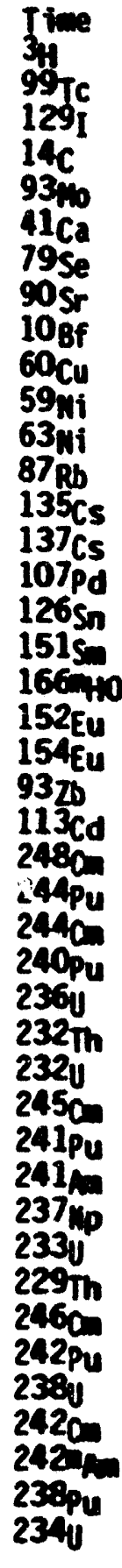 & $\begin{array}{l}0.00 E+00 \\
7.23 E+02 \\
2.86 E+06 \\
8.04 E+03 \\
1.03 E+06 \\
5.22 E+03 \\
6.85 E+02 \\
9.72 E+04 \\
1.29 E+10 \\
4.04 E+02 \\
7.70 E+07 \\
2.07 E+0 E \\
6.67 E+06 \\
4.67 E+00 \\
8.59 E+04 \\
1.85 E+10 \\
2.28 E+04 \\
1.28 E+05 \\
3.10 E+08 \\
1.00 E+02\end{array}$ & 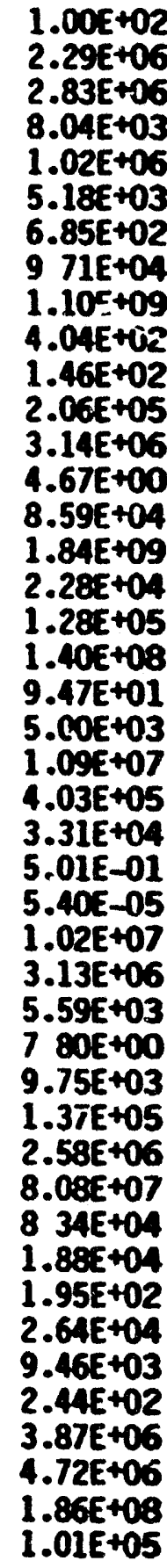 & 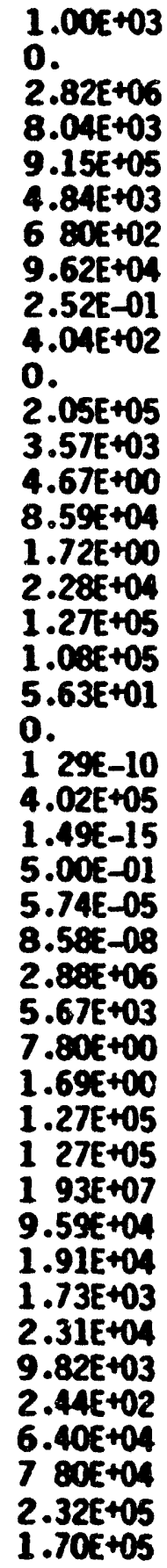 & $\begin{array}{l}1.00 E+04 \\
0 . \\
2.74 E+06 \\
8.04 E+03 \\
3.08 E+05 \\
2.42 E+03 \\
6.29 E+02 \\
8.74 E+04 \\
0 . \\
4.03 E+02 \\
0 . \\
1.89 E+05 \\
0 . \\
4.67 E+00 \\
8.57 E+04 \\
0 . \\
2.28 E+04 \\
1.19 E+05 \\
0 . \\
3.11 E-01 \\
0 . \\
0 . \\
4.00 E+05 \\
0 . \\
4.91 E-01 \\
9.16 E-05 \\
1.19 E-07 \\
1.15 E+06 \\
6.16 E+03 \\
7.30 E+00 \\
1.9 \\
5.97 E+04 \\
5.98 E+04 \\
5.98 E+04 \\
9.98 E+04 \\
2.21 E+04 \\
1.27 E+04 \\
6.15 E+03 \\
987 E+03 \\
2.44 E+02 \\
971 E-14\end{array}$ & $\begin{array}{l}1.00 E+05 \\
0 . \\
2.04 E+06 \\
8.01 E+03 \\
5.77 E+00 \\
2.37 E+00 \\
2.88 E+02 \\
3.35 E+04 \\
0 . \\
3.93 E+02 \\
0 . \\
8.69 E+04 \\
0 . \\
4.67 E+00 \\
8.40 E+04 \\
0 . \\
2.26 E+04 \\
6.39 E+04 \\
0 . \\
0 . \\
0 . \\
0 . \\
3.84 E+05 \\
0 . \\
4.11 E-01 \\
4.02 E-04 \\
5.23 E-07 \\
1.13 E+02 \\
6.47 E+03\end{array}$ & $\begin{array}{l}8.11 E+C \\
0 . \\
0 . \\
0 . \\
0 . \\
7.26 E+C \\
7.73 E+C \\
7.73 E+c \\
3.84 E- \\
1.63 E+C \\
2.45 E+C\end{array}$ \\
\hline
\end{tabular}


TABLE 8.6. (contd)

$\begin{array}{llllllll}540 & 230 \mathrm{Th} & 5.50 E+00 & 6.33 E+01 & 1.38 E+03 & 1.38 E+04 & 8.43 E+04 & 1.55 E+04 \\ 550 & 226 R \mathrm{a} & 3.47 E-01 & 1.56 E+00 & 2.47 E+02 & 1.08 E+04 & 8.44 E+04 & 1.55 E+04 \\ 560 & 247 \mathrm{Cm} & 1.29 E-01 & 1.29 E-01 & 129 E-01 & 1.29 E-01 & 1.29 E-01 & 1.24 E-01 \\ 570 & 242 \mathrm{Am} & 5.12 E+06 & 5.07 E-06 & 4.67 E+06 & 2.07 E+06 & 5.95 E+02 & 1.24 E-01 \\ 580 & 243 \mathrm{~cm} & 4.03 E+06 & 4.63 E+05 & 1.59 E-03 & 0 . & 0.0 & 0.0 \\ 590 & 239 P u & 9.69 E+05 & 9.86 E+05 & 1.08 E+06 & 1.55 E+06 & 1.93 E+05 & 1.24 E-01 \\ 600 & 239 U & 2.26 E+01 & 2.27 E+01 & 2.36 E+01 & 3.57 E+01 & 1.15 E+02 & 1.21 E+02 \\ 610 & 231 P a & 1.57 E+04 & 1.57 E+04 & 1.54 E+04 & 1.27 E+04 & 1.95 E+03 & 1.21 E+02 \\ 620 & 250 \mathrm{Cm} & 5.59 E-08 & 5.57 E-08 & 5.37 E-08 & 3.75 E-08 & 1.04 E-09 & 2.82 E-25 \\ 630 & 250 \mathrm{Cf} & 1.31 E+01 & 6.53 E-02 & 5.37 E-08 & 3.75 E-08 & 1.04 E-09 & 2.83 E-25 \\ 640 & 249 \mathrm{Cf} & 7.86 E+00 & 6.53 E+00 & 1.11 E+00 & 2.24 E-08 & 0 . & 0 . \\ 650 & 251 \mathrm{Cf} & 2.20 E-01 & 2.04 E-01 & 1.02 E-01 & 9.98 E-05 & 0 . & 0 . \\ 660 & 252 \mathrm{Cf} & 3.73 E+00 & 1.58 E-11 & 0 . & 0 . & 0 . & 0 .\end{array}$

(a) Includes all high-level waste from the U.S. nuclear power economy through Year 2000 plus all tritiu, carbon, and iodine from spent fuel and activation products from the cladding. The colums show the inventories of each nuclide in curie units at various times after Year 2000. Thus, the first colum shows the inventories at the Year 2000 , the second colum at the Year 2100 , the third at the Year 3000 , etc. 


\section{ELEEINT LITERATLRE REVIEW}

The chenistry and geochenistry of the elements chosen for review are examined in wis following section from the standpoint of radionuclide migration and retention by suspended and bottca sediments. Literature reviews on the interaction of radionuclides with soils and rocks have recently been performed by investigators at Pacific Nortmest Laboratory (PNL) for the Department of Energy (DOE) and the United States Environmental Protection Agency (EPA) [Rai and Serne (1978) and Ames and Rai (1978)].

Efforts were taken to use available thermodymanic data to predict the stable solid phases and dominant solution species. The authors, however, pointed out that these predictions should only be regarded as estimates because of the many limitations of this approach. They made the predictions for different assumed weathering envirorisents $\left(\mathrm{pO}_{2}, 0.68\right.$ to $80 ; \mathrm{PCO}_{2}, 1.52$ to 3.52; $\mathrm{pH}, 4$ to $1 \mathrm{C} \mathrm{pCl}^{-}=\mathrm{prO}_{3}^{-}=\mathrm{pSO}_{4}^{2-}=2.5$ to 3 ; $\mathrm{pf}^{-}=4.5$; and phosphate levels in equilibriv with variscite or dicalcium phosphate dihydrate or $\left.\mathrm{H}_{2} \mathrm{PO}_{4}^{-}=5.0\right)$. Their assumed solution composition is significantly different than seawater and river water only for the concentration of chloride in sea water as shown in Table 8.7 .

TABLE 8.7. Average Activities of Solution Constituents $(p x=-\log$ of the activity of $x$ )

\begin{tabular}{|c|c|c|c|}
\hline Component & Sea Hater & River Hater & Ground Water \\
\hline $\mathrm{p}\left(\mathrm{SO}_{4}^{2-}\right)$ & 2.34 & 3.9 & 3. \\
\hline $\mathrm{p}\left(\mathrm{Cl}^{-}\right)$ & 0.45 & 3.66 & 3. \\
\hline$p\left(\mathrm{H}_{2} \mathrm{PO}_{4}^{-}\right)$ & 6. & 6. & 5. \\
\hline$p\left(F^{-}\right)$ & 4.32 & 5.28 & 4.5 \\
\hline$p\left(m_{3}^{-}\right)$ & 5. & 5. & 3. \\
\hline $\mathrm{p}\left(\mathrm{CO}_{2}\right)$ & 3.40 & 3.40 & 3.52 \\
\hline
\end{tabular}

For convenience the thermodynamic data presented by mes and Rai (1978) under the sponsorship of EPA will be used to outiine the nature of solution species that may be expected in sea water and river water. The 
influence of the high chloride concentration in sea water yersus terrestrial gra : waters will be discussed : this change drastically alters the type or $: "$ edominant solution spec 5 .

For several of the elements little or no data were found in the literature on adsorption/desorption onto suspended or bed sediments. Rather than present no information the authors elected to present elesent adsorption/desorption data from soil-groundwater regiwes. In general as presented in Table 8.7 the compositions of groundwater complexing ligands are quite similar to marine and freshwaters excepting the $\mathrm{Cl}^{-}$anion. Thus, the use of soil-groundwater data to predict the general fate of elenents in marine and 1 ianetic regimes is warranted. As the adsorption/desorption $\mathrm{KJ}$ values are also dependent upon the particie size or available surface area and mineralogy, one should consider data on sorption onto clay or fine particulate soil to better predict the sorption on suspended sediments. To predict sorption onto bed sediments one should consider the bed sediment particle size distribution and mineralogy and then choose available soils data of a similar nature. Finally, in all cases the anount of organic matter in the sediments should be measured and considered when comparisons with soils are being performed. In general, higher organic-laden geonedia exhibit larger sorption of trace constituents. 


\section{MERICIUM}

Matural Sediment and Rock Distributions

The element anericium has not been reported to occur naturally in sediments or rocks.

\section{Brief Chenistry}

Americiu exists in radioactive wastes as two radionuclides, ${ }^{241}$ Am with a half-life of 433 years and ${ }^{243} \mathrm{Am}$ with a half-life of 7,370 years. It is found in the following four oxidation states: $A(I I I), A(I V), A(V)$ and Aa(VI). The wost stable state of anericium is the trivalent. The higher oxidation states are strong oxidizing agents and are therefore stable only in media that contain no oxidizable substances (Coleman, 1963). The ionic radius of $A^{+3}$ is $1.07 \AA$ (Ahrens, 1952).

The stability constants and complex formation of An(III) are probably more well known and studied than any of the other trivalent actinides. The tendency to complex ion formation is a function of factors such as ionic size and charge. In order of decreasing complexing tendency, the actinide series is generally $\mathrm{M}^{+4} \times \mathrm{MO}_{2}^{+2} \mathrm{MH}^{+3} \mathrm{NO}_{2}^{+}$. For univalent anions, complexing ability with $\mathrm{A}$ (III) follows the order for $\mathrm{F}^{-} \mathrm{NO}_{3}^{-} \mathrm{Cl}^{-} \times \mathrm{ClO}_{4}^{-}$, and for bivalent anions, $\mathrm{CO}_{3}^{-2}$ ×xalate ${ }^{-2} \mathrm{SO}_{4}^{-2}$ (Keller, 1971).

\section{Solution Equilibria}

The activity of various americiu species in solution in equilibrium with $\mathrm{Am}_{2}(\mathrm{~s})$ in an oxidizing enviroment $\left(\mathrm{PO}_{2}=0.68 \mathrm{~atm}\right)$ is given in Figure 8.1. The thermodynaic data for all the species except $\mathrm{OH}^{2+}$ and $\mathrm{H}_{2} \mathrm{PO}_{4}^{2+}$ were selected from Sillen and Martell (1964). The AnOH ${ }^{2+}$ and $\mathrm{AmH}_{2} \mathrm{PO}^{2+}$ data were selected from Keller (1971). In the nomal fresh water environment the dominant solution species of at ph $<6.5$ and $>6.5$ would be $\mathrm{mSO}_{4}^{+}$and $\mathrm{Am}(\mathrm{OH})^{2+}$, respectively. $\mathrm{m}^{3+}$ would be of lesser importance. In the $\mathrm{high}$ chloride environment of sea water, $\mathrm{AMCl}^{2+}$ and $\mathrm{mSOO}_{4}^{+}$would dominate at $\mathrm{DH}<6.5$ and again $\mathrm{Am}(\mathrm{OH})^{2+}$ would predoninate at pH $>6.5$.

With an increase in $\mathrm{PO}_{2}$ (more reducing environment) and the concentration of anions, the curves given in Figure 8.1 would wove upwards. However, 


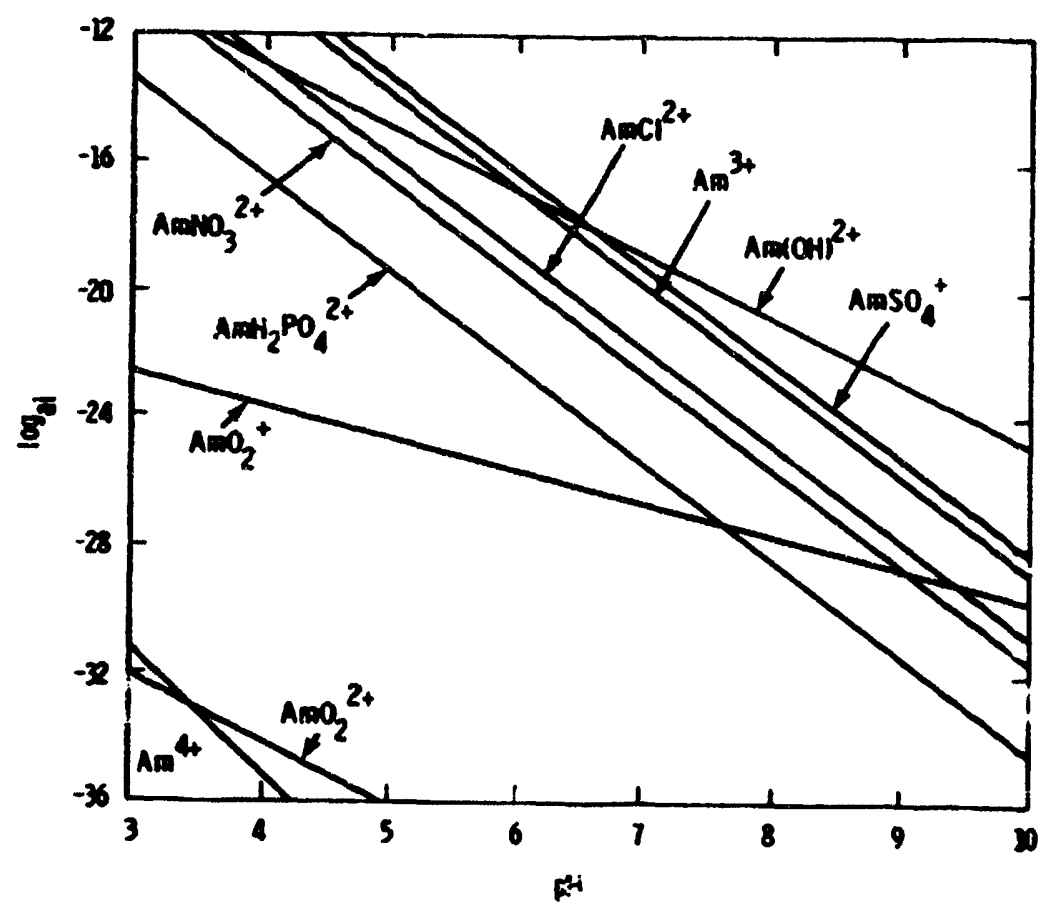

FIGURE 8.1. The Activity of Various mericium Species in Equilibrium with $\mathrm{O}_{2}(\mathrm{~s})$ in an Oxidizing Soil Environment $\left[\mathrm{PO}_{2}(\mathrm{~g})=\right.$ 0.68 ata], $\mathrm{pSO}_{4}^{2}=\mathrm{PMO}_{3}=3.0$ and $\mathrm{pH}_{2} \mathrm{PO}_{4}=5.0$

the relative position of most of the isotherms would not change. The anericiu species are cationic in the ph range of from 4 to 8 . It is to be expected, therefore, that ion exchange could be an important anericiun resoval mechan ism.

hericium found in the environment exists principally from $241_{\text {pu decay }}$ in nuclear fallout and liquid and solid wastes from fuel reprocessing plants. Laboratory Adsorption Studies

There have been a few laboratory studies wich address the adsorptiondesorption reactions of americiun in sediments and soils.

Fukai and murray (1974) studied the fate of anericium in river water and sea water and its interactions with sediments. Their first experiment addressed the fate of anericiu added to waters devoid of suspended sediments. Tracer quantities of $241 \mathrm{~m}(I I I)$ were added to filtered water, the pH adjusted between 3 and 10, and were mechanically shaken for 4 days. The sauples were 
then filtered through 0.45 meabranes and the fraction anericium removed as particulate deterwined. Results are shown in Figures 8.2 and 8.3 . More than $95 \%$ of the americiu in both waters becane associated with particles larger than 0.45 above 8 .

In sorption experiments (III) was added to $100 \mathrm{ml}$ of Var River water containing $1 \mathrm{~g}$ of river sediment and contacted for up to $250 \mathrm{hr}$. After adsorption the sediments were contacted with $100 \mathrm{ml}$ of sea water. Both sorption and desorption reached equilibrium after $180 \mathrm{hr}$ at $\mathrm{pH} 8$ (see Figure 8.4). Adsorption was pH dependent as shown in Figure 8.5 where anericium adsorption changes sharply between pH 6.5 to 8.5. Desorption of americium from Var River sediments by sea water was also slightly pH dependent as shown in Figure 8.6. In general desorption would be low $(<20 x)$. At $D H 7$ and 8 in fresh water the Var River sediment $\mathrm{Kd}_{\mathrm{Am}}$ is approximately 85 and $900 \mathrm{~m} / \mathrm{s} / \mathrm{g}$ given the experimental conditions. The desorption $\mathrm{Kd}_{\mathrm{fm}}$ into sea water would be about $900 \mathrm{~m} / \mathrm{s} / \mathrm{g}$ also.

Sanchez (1977), Seymour (1977), Schell et al. (1979) and Schell et al. (1980) report on batch $\mathrm{Kd}_{\mathrm{Am}}$ experiments performed on the following sedimentwater systens: a) anoxic marine sediment-sea water, b) oxic marine sedimentssea water, and c) lake sediments-fresh water. The particle size distribution, total carbon and total nitrogen contents are reported in Table 8.8 .

Salinities, tenperature, and nutrients were measured on the fijtered water sapples. Both sediment and water were frozen until laboratory experinents commenced. A portion of each sediment was irradiated with $10^{6}$ rads of ${ }^{0} C_{0}$ to reduce if not destroy all microbial activity. $241 \mathrm{Am}(0.5 \mathrm{mCi} / \mathrm{ml}$ in $4 \mathrm{in}$ $\mathrm{HiO}_{3}$ ) was added to a slurry of sediment water, $\mathrm{PH}$ was adjusted and batch shaking experiments performed. An aliquot of the suspension was removed at set times and sediment separated by filtration $(0.45 \mathrm{w})$. Both filter and filtrate were counted. Various sediment concentrations $(100 \mathrm{mg} / \ell$ to $1000 \mathrm{mg} / \mathrm{l}$ ), and $\mathrm{pH}$ 's (4 to 10) were utilized at a total system 241 concentration of about $1 \mathrm{wCi} / \mathrm{l}$. After about $120 \mathrm{hr}$ of contact the contaninated sediments were placed in unspiked water and desorption experiments performed. 


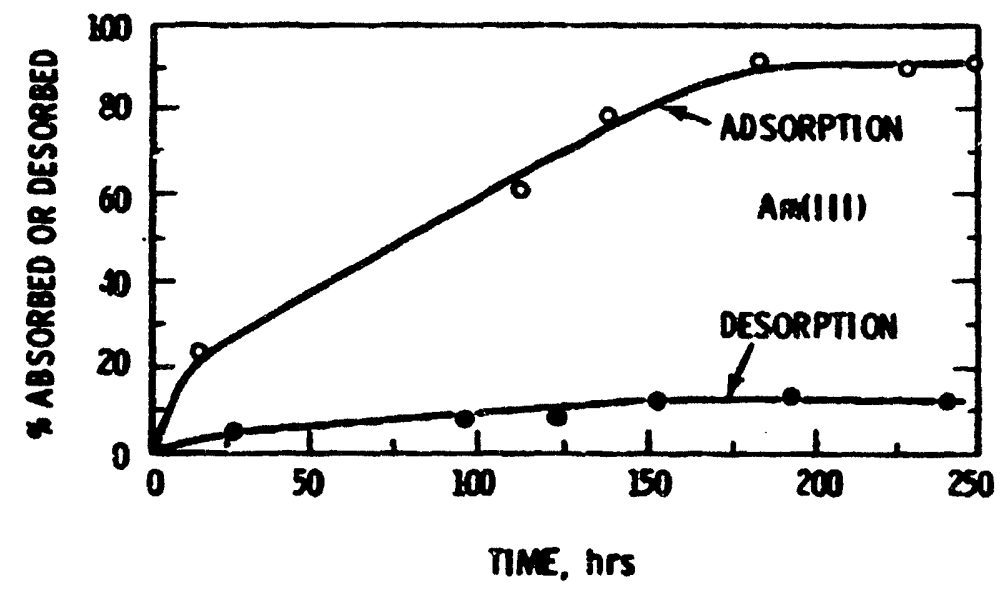

FIGURE 8.2. Particulate Formation of Am(III) in Var River Hater as a Function of Changes in $\mathrm{DH}$

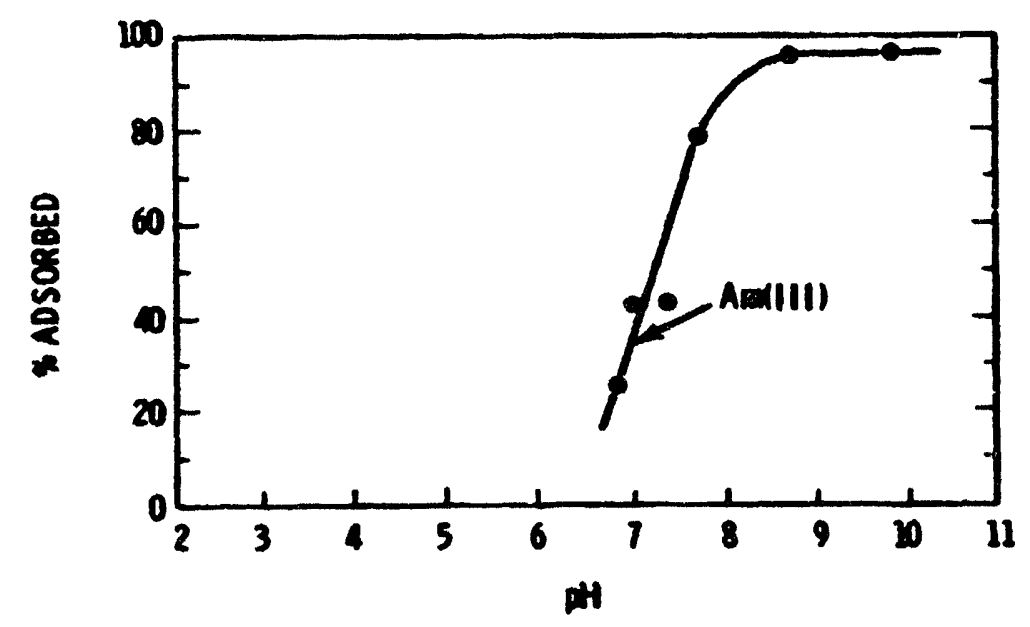

FIGURE 8.3. Particulate Formation of (III) in Sea Hater as a Function of Changes in pH 


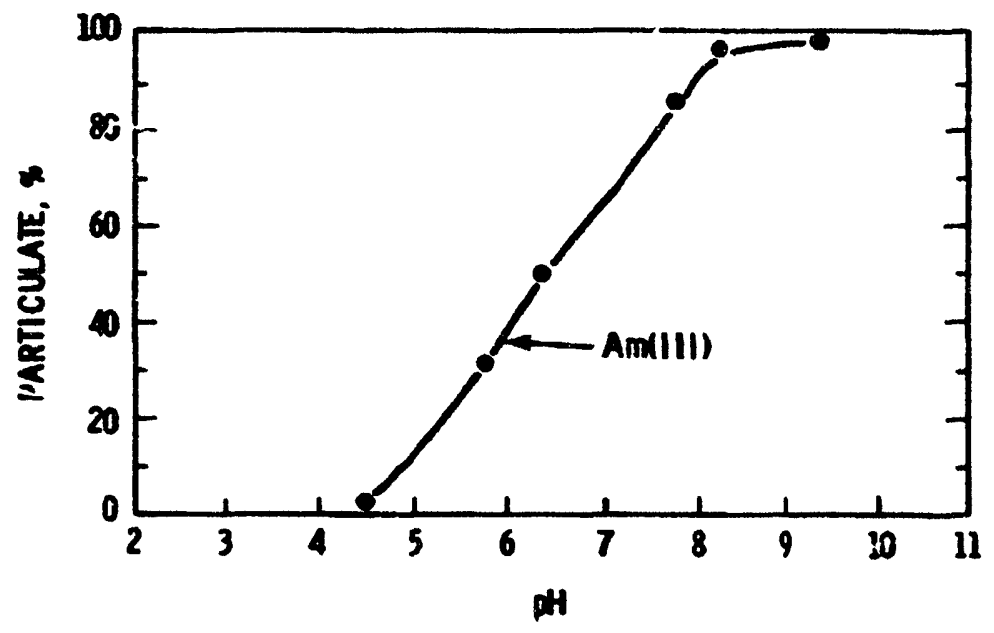

FIGURE 3.4. Equilibriu Time for Particulate Formation and Adsorption on Sediments of (III) in Var River Hater (pH = 8) and Its Desorpion from Sediments in the Sea Water

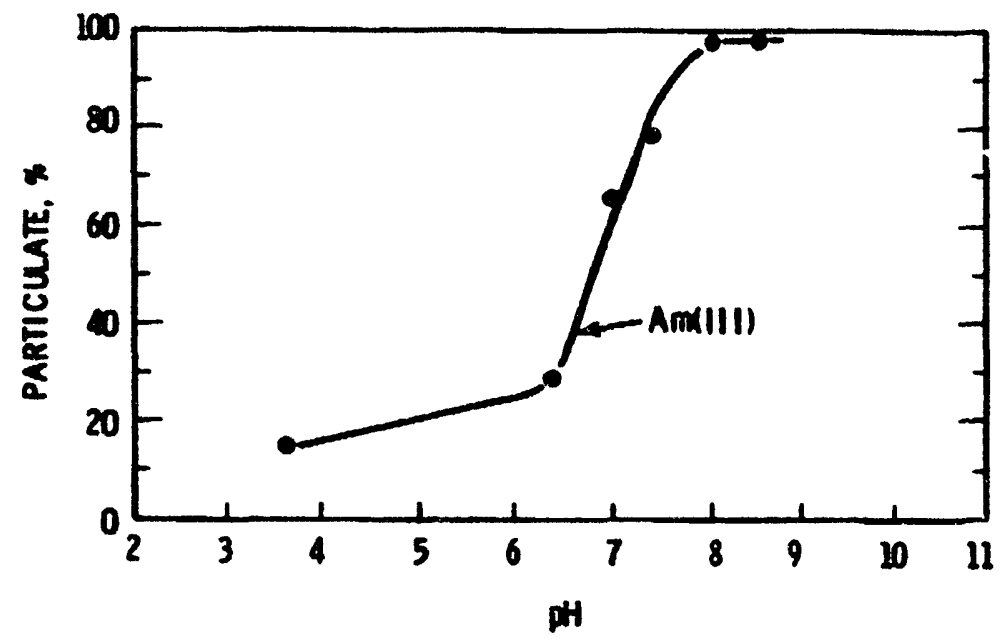

FIGURE 8.5. Adsorption of Am(III) on Sediments in Var River Water at Different pH Values 


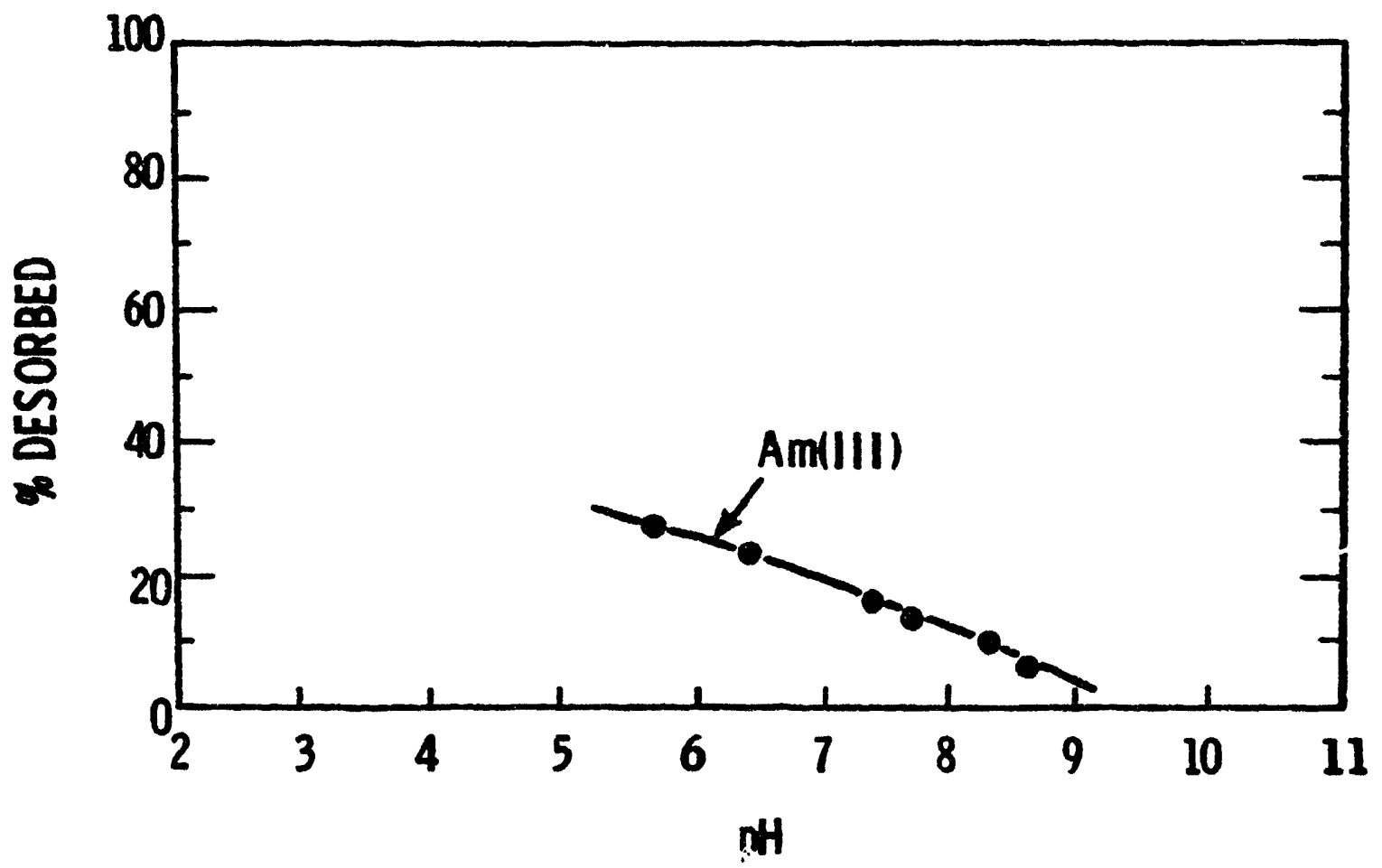

FIGURE 8.6. Desorption of $A$ (III) from Sediments in the Sea Nater Medium at Different pH Levels

TAB' 8.8. Sediment Character istics and Average $K d_{A m}$ Particle Size Distribution

\begin{tabular}{|c|c|c|c|c|c|c|}
\hline $\begin{array}{l}\text { Sand, } \\
\times 62 \\
\end{array}$ & Silt & $\begin{array}{l}\text { Clay, } \\
\text { S2 U }\end{array}$ & \% Carbon & $\$ N$ & $\mathrm{Kd}_{\mathrm{An}}, \mathrm{N}, \mathrm{g}$ & $x d_{\text {men }}=1 / g$ \\
\hline & & & & & ADSORB & DESORB \\
\hline
\end{tabular}

$\begin{array}{lrllllll}\text { Fresh Hater } & 2 \% & 16 \% & 82 \% & 5.2 & 0.44 \times 10^{5} & 1.2 \times 10^{6} \\ \text { Anoxic Marine } & 4 \% & 21 \% & 75 \% & 2.8 & 0.3 & 6.5 \times 10^{5} & 6.7 \times 10^{6} \\ \text { Oxic Marine } & 40 \% & 21 \% & 39 \% & 1.8 & 0.1 & 2.6 \times 10^{5} & 1.8 \times 10^{5}\end{array}$

The $\mathrm{Kd}_{\mathrm{Am}}$ versus sediment concentration for the unirradiated fresh water system is show in Figure 8.7. As the sediment concentration increases the $\mathrm{Kd}$ decreases. A similar result was seen for an irradiated system except that the Kd for low sediment concentrations were an order of magnitude larger. The sorption of americium versus $\mathrm{pH}$ for both a fresh water and marine water system (not irradiated) are sham in Figures 8.8 and 8.9. At pH less than 7, amer icium adsorption appears to be rather sensitive to $p H$. Above pH 7 sorption 


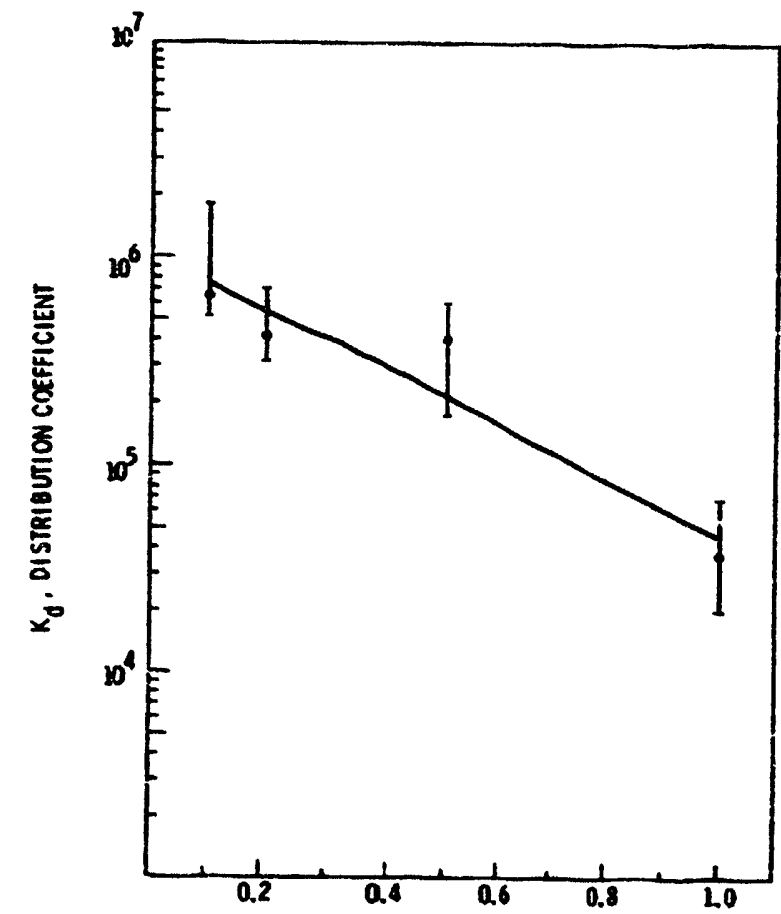

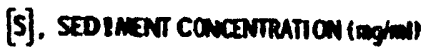

FIGLAE 8.7. Distribution Coefficient for $241 \mathrm{Am}$ as a Function of Sedinent Concentration in Fresh Hater. Sars indicate range in Kd values.

dependency on pH diminishes. Both the dependency on pH and sediment concentration suggest that precipitation is important. If ion exchange alone were causing the americium adsorption, the Kd should be independent of sediment conientration because there is not enough americium present in the system to significantly load exchange sites. On the other hand, if a certain fixed percentage of aricium was forming radiocolloids or precipitates which are removed from the system by any amount of sediment, the calculated Kd would increase as sediment concentration decreases which is what was observed. As seen for the average $\mathrm{Kd}_{A m}$ reported in Table 8.8, the coarser grained marine sediment has the lowest $K d$ whereas fine grained fresh and marine sediments have larger $K d_{\text {Am. }}$. In two cases the $K d_{A-m}$ measured on desorption is significantly 


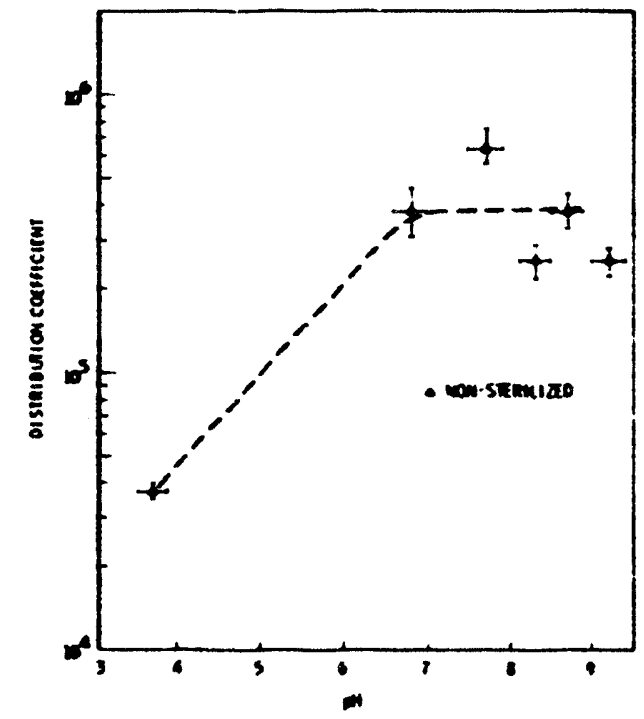

FIGURE 8.8. Distribution Coefficient for 241 $\mathrm{Am}$ as a Function 0 . $\mathrm{pH}$ in Fresh Mater Sediment Systew. Horizontal bars indicate range in pH values and vertical bars indicate the range in $\mathrm{Kd}$.

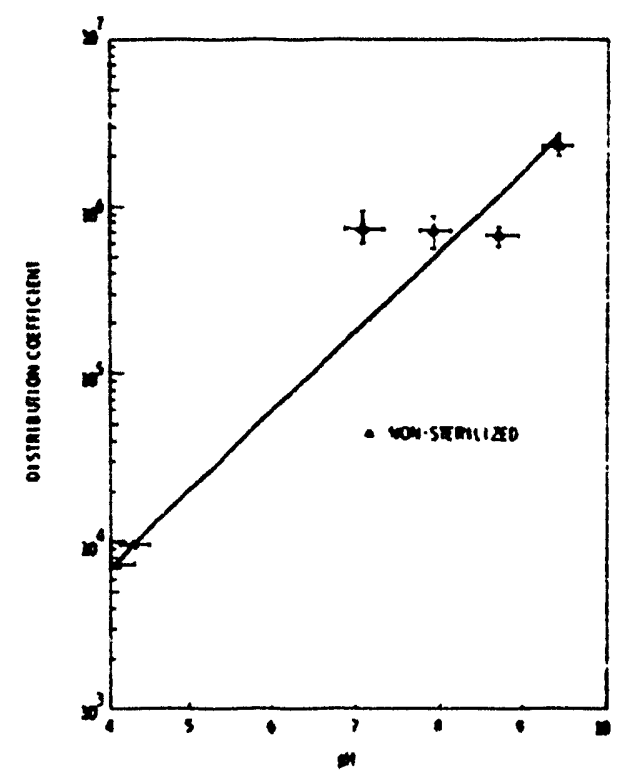

FIGURE 8.9. Distribution Coefficients for $241 \mathrm{~km}$ as a Function of oH in Marine Mater-Sediment System. Horizontal bars indicate the range in $\mathrm{PH}$ values and vertical bars indicate the range of $\mathrm{Kd}$. 
significantly larger. The results of ${ }^{60}$ Co irradiation are also presented in the cited papers but not addressed herein because interpretation of the total effect of irradiation on the syste is obscure.

In a separate experiment Schell et al. (1979) found that $90 \%$ of the th added to filtered seawater becomes filterable $(0.45 \mathrm{um}$ ) rapidiy (<l hr). A possible explanation is that $A$ is very insoluble at neutral pH and tracer addition exceeds the solubility limit.

In a continuing study of anericiun sorption a sandy sediment from the Skagit River estuary (Washington) was deterwined with $30.2 \%$ marine water by Schell et al. (1979). It was found by use of blank samples (traced water with no sediments) that 87 to $92 \%$ of the $A$ was filtered by 0.45 menbranes. Thus $\mathrm{Kd}$ values wich were not corrected for blank particle formation 1 to $2 \times$ $10^{5} \mathrm{ml} / \mathrm{g}$ would drop to 3 to $7 \times 10^{4} \mathrm{~m} / \mathrm{g}$ upon blank correction. A second system, an ar Jxic marine sediment-anoxic water, gave essentially $100 \%$ renoval of Am. The control (traced water by itself) led to $100 \%$ retention on a 0.45 an filter.

Sanchez (1977) used a dialysis membrane bag which perwits particles the equivalent of 6000 to $8000 /$ molecular weight (based on organic molecules) and lower to pass were filled with unspiked sea water and anoxic marine sediment. The bag was suspended in spiked sea water. After 10 days the spiked sea water and suspended sediment were analyzed. The resultant $\mathrm{Kd}$ was $97 \mathrm{ml} / \mathrm{g} \mathrm{mich}$ is wuch lower than found previously. Also the anericium outside the dialysis bag upon filtration $(0.22 \mathrm{~m}$ ) was distributed $50 \%$ in solution and $50 \%$ retained on the filter. Both results tend to support the hypothes is that anericiu forms colloids or precipitates in the laboratory systeas used and that reported $\mathrm{Kd}$ values obtained from addition of acid americiu spike may be unintentionally inflated.

In a dialys is experiment which lasted 11 days Schell et al. (1979) placed 3 liters of spiked seawater in a large glass beaker. They also added three dialysis sacs containing: (a) distilied water (control sac), (b) $765 \mathrm{mg}$ of oxic arine sediment (see Table 8.8) and (c) plankton. Outside the sacs 
and within the sacs, samples were filtered through 0.22 memanes. Results are presented in Table 8.9. The Am wich entered the secinent sac becane attached to sedinent aleost exclusively. Less an was found outside the dialys is sacs than any other radionuclide studied. In a second dialysis experiment with estuarine water, dialysis sacs filled with: (a) unspiked estuarine water, (b) phytoplankton, (c) organic detritus and (d) montmorilIonite clay were studied for 4 days. Again, sasples outside and with in the dialys is sacs were filtered through $0.40^{\circ}$ meabranes. Results are shom in Table 8.10. Americium predominantly is found bound to organic detritus, plankton and clay.

Schell et al. (1980) report on laboratory determinations of $\mathrm{Kd}_{\mathrm{Am}}$ in numerous fresh and marine water environments with sediments. Table 8.11 summarizes the results. The Kds for freshwater enviroments are at least 2 to 3 times larger than marine environments. Further desorption experiments yield higher Kd values than sorption experinents by factors of 3 to 5 suggesting that once bound $h$ is not easily resolubilized.

Schell et al. (1980) studied the effects of organic ligands on nuclide sorption from a fresh water onto a lake sediments in the laboratory. Table 8.12 sumarizes results for four elenents. Three organics significantly increased the $\mathrm{Kd}_{\mathrm{m}}$ wile one EDTA decreased the $\mathrm{Kd}_{\mathrm{m}}$. Caution is needed in interpretation of these results since the concentration of organics used is quite high. Figure 8.10 shows the effect of varying EDTA concentration on $\mathrm{Kd}_{\mathrm{Am}}$ for a different fresmater/sediment system. There is no effect on $\mathrm{Kd}$ unt il the EDTA concentration is raised to $10^{-4} \mathrm{~m}$, wich is extrenely high for natural environments.

Schell et al. (1980) continued dialysis experinents using a Lake Michigan freshwater systen. A sediment slurry, phytoplankton slurry and organic detritus slurry were placed in dialysis sacs. Spiked Lake Michigan water surrounded the dialys is sacs. After 20 the was predominantly found bound to particulates. 
TAME 8.9. Percent Distribution of Radionuclides After 11 Days of Dialys is Experiment

\begin{tabular}{|c|c|c|c|c|c|c|c|}
\hline Conertents & & $241 n$ & $137 \mathrm{cs}$ & 238pu & $2048 i$ & $652 n$ & $60 c_{0}$ \\
\hline Spiked Mater & $\begin{array}{l}0.22= \\
30.22=\end{array}$ & $\begin{array}{r}26.1 \\
8.2\end{array}$ & $\begin{array}{r}86.3 \\
0.0\end{array}$ & $\begin{array}{r}77.7 \\
3.0\end{array}$ & $\begin{array}{r}64.4 \\
0.0\end{array}$ & $\begin{array}{r}44.7 \\
0.8\end{array}$ & $\begin{array}{r}54.2 \\
0.8\end{array}$ \\
\hline Control Sac & $\begin{array}{l}0.22= \\
x 0.22=\end{array}$ & $\begin{array}{l}0.7 \\
0.5\end{array}$ & $\begin{array}{l}2.2 \\
0.1\end{array}$ & $\begin{array}{l}0.5 \\
0.1\end{array}$ & $\begin{array}{l}0.0 \\
0.6\end{array}$ & $\begin{array}{l}1.0 \\
0.1\end{array}$ & $\begin{array}{l}8.4 \\
0.1\end{array}$ \\
\hline Sedinent Sec & $\underset{x 0.22}{<0.22}=$ & $\begin{array}{r}0.0 \\
47.1\end{array}$ & $\begin{array}{l}2.1 \\
1.6\end{array}$ & $\begin{array}{l}0.2 \\
9.2\end{array}$ & $\begin{array}{r}0.0 \\
22.3\end{array}$ & $\begin{array}{r}1.1 \\
25.8\end{array}$ & $\begin{array}{r}1.4 \\
30.5\end{array}$ \\
\hline Placton Sic & $\begin{array}{l}\mathbf{0} .22 \\
>0.22\end{array}$ & $\begin{array}{c}0.8 \\
12.4\end{array}$ & $\begin{array}{l}2.2 \\
0.3\end{array}$ & $\begin{array}{l}0.4 \\
2.7\end{array}$ & $\begin{array}{r}1.9 \\
11.5\end{array}$ & $\begin{array}{r}2.4 \\
16.9\end{array}$ & $\begin{array}{l}1.7 \\
0.3\end{array}$ \\
\hline $\begin{array}{l}\text { Saples dering } \\
\text { experiment }\end{array}$ & & 4.5 & 0.7 & 2.5 & 2.8 & 7.3 & 4.5 \\
\hline $\begin{array}{l}\text { Miscellzacous } \\
\text { pparatus }\end{array}$ & & 0.5 & 0.0 & 3.8 & 0.6 & 0.0 & 0.0 \\
\hline
\end{tabular}

TABLE 8.10. Distrjbut ion (x) of $241 \mathrm{~m}, 137 \mathrm{Cs}, 106 \mathrm{Ru}, 65 \mathrm{Zn}, 60 \mathrm{Co}$ and 59 Fe After $96 \mathrm{hr}$ in a Dialys is Experiment

\begin{tabular}{|c|c|c|c|c|c|c|}
\hline \multirow[b]{2}{*}{$\begin{array}{l}\text { Radio- } \\
\text { anclice }\end{array}$} & & \multirow[b]{2}{*}{$\begin{array}{l}\text { Spiked Semate } \\
\text { coplelez } 5 \text { o, }\end{array}$} & \multicolumn{4}{|c|}{ Oialys is cheoers } \\
\hline & & & $\begin{array}{l}\text { Brik } \\
\text { cosplez } 50,8\end{array}$ & 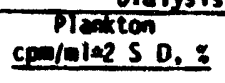 & 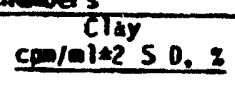 & $\begin{array}{l}\text { Detritus } \\
\text { coplale2 } 5 \mathrm{O}, 2\end{array}$ \\
\hline $241 \mathrm{~m}$ & $\begin{array}{l}\text { Solwble } \\
\text { Perticalate }\end{array}$ & ? & 2 & 23 & 9 & $\begin{array}{r}8 \\
35\end{array}$ \\
\hline $137 \mathrm{Cs}$ & $\begin{array}{l}\text { Solvole } \\
\text { Perticulate }\end{array}$ & $\begin{array}{l}19 \\
50.2\end{array}$ & $\begin{array}{l}19 \\
<0.2\end{array}$ & $\begin{array}{l}19 \\
60.2\end{array}$ & 21 & 212 \\
\hline 105er & $\begin{array}{l}\text { Solicile } \\
\text { Perticulate }\end{array}$ & 13 & $\begin{array}{l}16 \\
0.9\end{array}$ & $\begin{array}{l}17 \\
11\end{array}$ & $\begin{array}{r}18 \\
4\end{array}$ & ${ }_{3}^{13.2}$ \\
\hline $65 z$ & $\begin{array}{l}\text { Soluble } \\
\text { Perticulate }\end{array}$ & $\begin{array}{l}24.8 \\
<0.2\end{array}$ & $\begin{array}{r}21.7 \\
0.5\end{array}$ & ${ }_{1.6}^{17}$ & $\begin{aligned} 21 \\
2\end{aligned}$ & q \\
\hline $60 c_{0}$ & $\begin{array}{l}\text { Solvole } \\
\text { Particulate }\end{array}$ & $\begin{array}{r}21.7 \\
0.1\end{array}$ & $\begin{array}{r}24.3 \\
0.2\end{array}$ & $\begin{array}{l}8.4 \\
0.7\end{array}$ & $\begin{array}{r}19.5 \\
0.5\end{array}$ & $\begin{array}{r}24.4 \\
0.2\end{array}$ \\
\hline SFFe & $\begin{array}{l}\text { Solusle } \\
\text { perticulate }\end{array}$ & $\begin{array}{r}14.7 \\
8.0\end{array}$ & $\begin{array}{l}4.7 \\
5.3\end{array}$ & $\begin{array}{r}6.7 \\
14.7\end{array}$ & $\begin{array}{r}5.2 \\
17.7\end{array}$ & $\begin{array}{r}8.4 \\
14.6\end{array}$ \\
\hline
\end{tabular}


TABLE 8.11. Summary of Adsorpt ton/Desorption Distribution Coefficients
with Propertios of the Sedinent/Water Systens

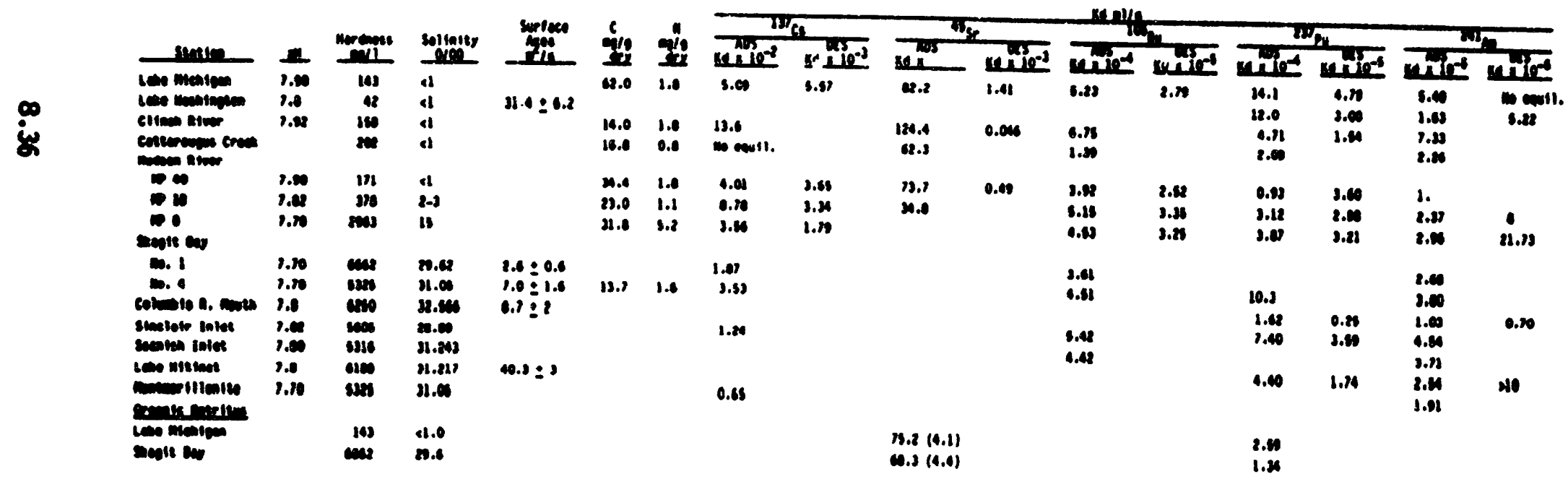

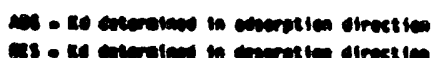


TABLE 8.12. Sediment/Mater Kd Values for Lake Mashington System as a Function of Different Organic Compounds

\begin{tabular}{|c|c|c|c|c|}
\hline \multirow{2}{*}{$\begin{array}{l}\text { Organic componid nded, } \\
\text { concentret tion }\end{array}$} & \multicolumn{4}{|c|}{ Kd } \\
\hline & $21 /\left(x 10^{-1}\right)^{(0)}$ & ${ }^{51} \operatorname{co}\left(\times 10^{-7}\right)^{(2)}$ & ${ }^{10} \mathrm{Bu}\left(\times 10^{-1}\right)^{(0)}$ & ${ }^{131} \operatorname{cs}\left(210^{-2}\right)$ \\
\hline $\operatorname{mose}_{x \pm s}(i, e .$, control) & $2.26 \pm 0.71$ & $0.32 \div 0.0 B$ & $1.09 \pm 0.39$ & $4.15 \pm 1.00$ \\
\hline $\begin{array}{l}1-a \text { itroso-2-andintiol } \\
\left(10^{-5} \text { w) }\right. \\
x \pm s(0)\end{array}$ & $7.76 \div 3.01$ & $35.82 \div 18.00$ & $2.61 \pm 1.03$ & $5.04 \div 0.69$ \\
\hline 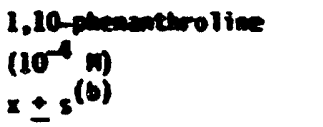 & $25.30 \pm 2.44$ & $16.81 \pm 4.18$ & $3.78 \div 0.00$ & $3.22 \div 0.39$ \\
\hline $\begin{array}{l}\text { catic exid } \\
\left(10^{-4} m\right. \\
x \pm s^{(b)}\end{array}$ & $5.60 \div 2.43$ & $0.44 \div 0.04$ & $2.30 \pm 0.84$ & $2.70 \div 0.77$ \\
\hline $\begin{array}{l}\text { Solticylic acid } \\
\left(10^{-4} \text { (n) }\right. \\
x \pm s(b)\end{array}$ & $2.94 \pm 1.04$ & $0.30 \div 0.07$ & $1.23 \div 0.48$ & $3.77 \div 0.61$ \\
\hline $\begin{array}{l}\operatorname{cota}\left(10^{-4}(w)\right. \\
x \pm s(b)\end{array}$ & $0.05 \pm 0.02$ & $0.01 \pm 0.01$ & $3.45 \pm 0.54$ & $3.47 \div 0.76$ \\
\hline
\end{tabular}

(a) Significat differences betueen grops at $0-0.06$ level by Rruskal-wall is statistical test

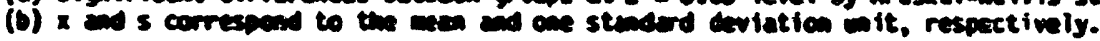

Van Dalen et al. (1975) detemined the batch $K_{\text {Am }}$ for four geologic aterials; caprock (gypsu), river sand (quartz), sandstone and clay (illitekaolinite wixture) with $90 \%$ saturated MaCl solution at pH 7 to 8 using a solids to solution ratio of $100 \mathrm{mg} / 15 \mathrm{ml}$ and correcting for nuclide sorption on the walls of the test tubes. The following $K_{h}$ values were obtained $3,000,400$, $20,000,50,000 \mathrm{Dl} / 9$, respectively. The pH dependence on sorption processes for anericiun between ph 5 to 8 was minor.

Routson et al. (1975) used batch adsorption experiments (10 g soil to $25 \mathrm{ml}$ solution) and 24-hr equilibrations to deterwine the Kd for anericion with desert sand and an eastern sandy clay. The Kd was determined as a function of solution calciu and sodiu concentration at an initial ph of 2.5 to 


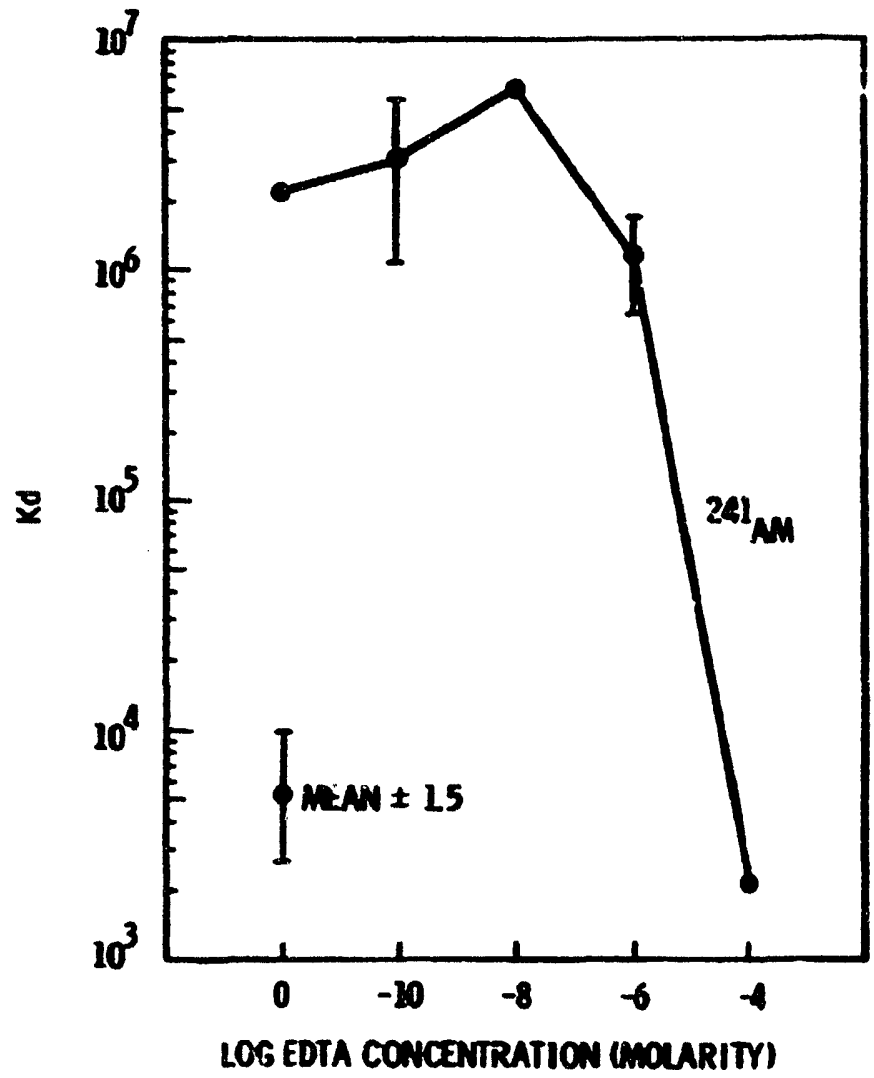

FIGURE 8.10. Effect of Varying EDTA Concentration on Xd Values of $241 \mathrm{~m}$. Values at $0 \mathrm{M}, 10^{-8} \mathrm{M}$ and 10-4 $\mathrm{M}$ EOTA are single point measurements. Values at $10^{-10} M$ and 10-6 $\mathrm{F}$ EDTA are the mean + one standard deviation unit for triplicate samplë measurements.

3.1. For the sandy clay, $\mathrm{Kd}_{\mathrm{m}}$ decreased as the calcium concentration increased. At $0.002 \mathrm{M} \mathrm{Ca}$ the anericiun $\mathrm{Kd}$ was $67 \mathrm{mI} / \mathrm{g}$; at $0.20 \mathrm{~N} \mathrm{Ca}$ the $\mathrm{Kd}$ was $1 \mathrm{al} / \mathrm{g}$. For the burbank sand the $\mathrm{Kd}$ was greater than 1200 for all concentrations of calciun. The antericiun Kd for the sandy clay also was a function of the sodium concentration in solution; 280 at $0.015 \mathrm{M} \mathrm{Ma}$ and 1.6 at 3.00 $\mathrm{Ma}$. Although a final pH was not given, the Burbank sand is known to be alkal ine, suggesting that anericiu adsorption may be sensitive to pH.

Fried et al. (1974a, 1974b) deternined the adsorption of anericiu onto a basalt. Addition of salts to the solution lowered the adsorption of aericiun. 
$\mathrm{La}^{+3}$ and $\mathrm{Zr}^{+4}$ cations lowered the anericium adsorption much more than $\mathrm{Sr}^{+2}$ and $\mathrm{Ka}^{+}$suggesting ion exchange as the mechanisa controlling adsorption of anericiu.

Sheppard et al. (1976) reported distribution between 12 characterized soils from various locations and a solution containing $241_{A m}$ (III). The locations included Muscatine, Illinois; Richland, Mashington; Barnwell, South Carolina; and Idaho Falls, Idaho. Equilibrations were for up to 4 wonths with sapling of the solution at intervals. The distribution results are given in Table 8.13. The distribution values ranged from 43,500 $\mathrm{ml} / \mathrm{g}$ for an Idaho soil

TABLE 8.13. Mericiu S0-Day Distribution (Calculated from the Data of Sheppard et al., 1.976)

\begin{tabular}{|c|c|c|}
\hline Soil Identity & $\begin{array}{c}\text { An Distribution, } \\
\text { wl/g }\end{array}$ & $\begin{array}{c}\text { Monthly Change } \\
\text { in Distribution Ratio, } x\end{array}$ \\
\hline $\begin{array}{l}\text { muscatine } \\
\text { silt loan }\end{array}$ & 4,830 & +137 \\
\hline $\begin{array}{l}\text { Burbank } \\
\text { loany sand }\end{array}$ & 714 & $-13 x$ \\
\hline $\begin{array}{l}\text { Ritzville } \\
\text { silt loam }\end{array}$ & 971 & $+1 \%$ \\
\hline $\begin{array}{l}\text { Fuquay sand, } \\
0-5 \text { on depth }\end{array}$ & 476 & $+32 \%$ \\
\hline $\begin{array}{l}\text { Fuquay sand, } \\
\text { 5-15 an depth }\end{array}$ & 417 & $+32 \%$ \\
\hline $\begin{array}{l}\text { Fuquay sand, } \\
15-50 \text { an depth }\end{array}$ & 249 & +278 \\
\hline Hanford A & 125 & ox \\
\hline Hanford 8 & 833 & +348 \\
\hline Idano A & 3,920 & $+30 \%$ \\
\hline Idaho B & 43,500 & $+86 \%$ \\
\hline Idaho C & 37,000 & +818 \\
\hline Idano 0 & 10,900 & $+53 x$ \\
\hline
\end{tabular}


to $125 \mathrm{ml} / \mathrm{g}$ for a Mashington soil. The distribution values were not constant with time, but steadily increased $1 \%$ to $86 \% /$ month. With Burbank soil, there was a $13 \%$ decrease/month. No change was detected for another Mashington soil (Henford). It was postulated that such adsorption behavior was consistent with the $\mathrm{m}$ (III) being in the form of charged colloids or hydrolysis products including $n^{+3}, A m(\mathrm{OH})^{+2}, \mathrm{~m}(\mathrm{OH})_{2}^{+}$and $m_{n}(\mathrm{OH})_{2 n}^{n^{+}}$and resoval by cation exchange and adsorption. It was reported that the removal of soil organics and raising the systen temperature did not appreciably affect the rate of approach to equilibriu or the distribution values. Analysis of the soil cation exchange capacity data indicated a high correlation $(r=0.96)$ between soil cation exchange capacity arf clay content. Correlation does not appear as marked between soil clay content and anericium distribution.

Glover et al. (1977) also studied anericium sorption by soils. Seventeen characterized soils from around the United States were equilibrated for $48 \mathrm{hr}$ with distilled water solutions containing $10^{-10} \mathrm{M}$ Am and $10^{-8} \mathrm{M} \mathrm{Am}$. Eight replicates were run per soil at eact, americium concentration. Results were expressed as Kd values. Kd values ranged from 82 to 10,000 on the sifferent soils. Generally, the $K d$ values for $10^{-10} \mathrm{M}$ and $10^{-8} \mathrm{M}$ A were the sane, or nearly so, with some exceptions. Regression analyses were perfoned on the americiu sorption data to determine whether or not significant relationships existed between americium sorption and soil physical or chemical characteristics. Initial rusults indicated that a direct relationship existed between soil cation exchange capacity, clay content and aericiu Kd value.

Polzer and Miner (1977) relate anericiu adsorption data on the same soils to differences in the effective positive charge of anericium (Korotkin, 1972) as influenced by system pH. Kd values for anericium with several soils from around the Inited States are given in basic and acidic systens.

\section{Field Studies}

Fowler and Essington (1974) detected a possible difference in solubility between anericiu and plutoniu fallout in soils. Anericiu way be more solubie than plutoniu and aay becone the radionuclide of prime concern because it has a faster wigration rate in soils. Several instances of decreasing Pu/hm ratios with depen in the soil profile could be expiained by differential plutoniu and anericium solubilities. 
Bowen (1975) revieved the distribution of anericiu in the marine environment and suggested anericium may be more mobile than plutonium. Hetherington et al. (1975) measured the anericium and plutoniu concentrations in the top two centimeters of marine sediments around the Hindscale nuclear power facilities effluent. The $\mathrm{m} / \mathrm{Pu}$ ratio in the sediments did not vary and there was no evidence that the ratio changed with distance from the outfall. It was concluded that the behavior of anericium was qualitatively similar to plutonium. One core taken to 25 centimeters also gave supporting evidence that both plutoniu and anericiu become incorporated into the sediments and renained fixed to the same extent. Variable ratios of $\mathrm{Am} / \mathrm{Pu}$ from month to month and year to year in the outfall effluent may mask small differences in the mobility of these transuranics.

Mevissi and Shell (1975) reports on the distribution of awericiun around Bikini Atoll. Inside Bikini Lagoon surficial sediments contain 0.3 to $77.0 \mathrm{PCi}$ $241 \mathrm{~m} / \mathrm{g}$ wile the waters contain 5.5 to $24 \mathrm{pCi} / \mathrm{m}^{3}\left(\sim 5.5\right.$ to $\left.24 \times 10^{-6} \mathrm{pCi} / \mathrm{ml}\right)$ which give a $K_{A}$ assuning system equilibriu of $-10^{6}$ to $10^{7}$. Murray and Kautsky (1975) report the waters in the North Sea contain -0.09 to $1.60 \times$ $10^{-3} \mathrm{pCi} / \mathrm{e}^{241} \mathrm{~m}$ from nuclear fallout. The ecological behavior of anericium in a freshwater waste pond on the Hanford Site has been reported by Enery et al. (1975). Results pertinent to migration of americium include the fact that $93 \%$ of the anericiu in the ecosystem is tightly bound to sediment particles and transportable only with the particles. Mericium in the water colum is low and associated with fine particles. Algal detritus concentrates anericium to twice the value of sediments on a ory weight basis. Americium in the interstitial waters appear to be cationic in form. The average sediment anericium concentration is $83 \mathrm{pCi} / \mathrm{g}$ wile the water contained $1.1 \mathrm{PCi} / \mathrm{l}$ wich gives a $\mathrm{Kd} / \mathrm{m}-3.3 \times 10^{4}$.

Edgington et al. (1975) concluded after studies of the concentrations of $241 \mathrm{~m}$ with depth in Lake Michigan that there was little or no preferential nobility of americiu over plutonium. 


\section{Sumary}

Schell et al. (1980) sumarize their work on sorption in fresh and marine environments. In general an sorption is greater in freshwater by a factor of 2 to 3. Also Am sorption is dependent on pH especially for marine environments. At neutral Dis $\mathrm{Kd}_{\mathrm{Am}}$ is quite large, $10^{2}$ to $10^{6} \mathrm{ml} / \mathrm{g}$. Soil science studies tend to corroborate the above generalities. mericium adsorption (Kd values) on various soils and sediments have been correlatizd with: 1) cation exchange capacity of soils (Sheppard et al., 1976; 6lover et al., $1977)$ and 2) the concentration of the competing cations $\left(\mathrm{ma}^{+}, \mathrm{Ca}^{2+}, \mathrm{Sr}^{2+}\right.$, $\mathrm{La}^{3^{+}}$and $\mathrm{Zr}^{4+}$ ), so that the adsorption of anericiun decreases with an increase in concentration of competing cations (Fried et al., 1974a; fried et al., 1974b; Routson et al., 1975; Sheppard et al., 1976; fried, 1977). Although none of the workers have tried to distinguish the contributions of polymer adsorption, cation exchange, hydrolysis and precipitation to the Kd value, the laboratory data indicate that anericiu resoval from solution may be controlled by ph-dependent hydrolysis-culloidal formation and ion exchange. 


\section{AMTImony}

\section{Matural Sedinent and Rock Distributions}

The average concentrations of antimony found in igneous and sedimentary rocks and sediments are given in Table 8.14. Little is knom about the behavior of ant hony during weathering. Ant imony may accuulate in shales by adsorption on clay minerals and hydrous oxides such as in and Fe precipitates. Antimony may be concentrated in sediments relative to igneous rocks.

TABLE 8.14. Antimony Concentrations in Rocks and Sediments (Turek ian and Wedepoh 1, 1961)

\begin{tabular}{|c|c|c|c|c|c|c|}
\hline \multicolumn{4}{|c|}{ Igneous, pin } & \multicolumn{2}{|c|}{ Sedimentary, } & \multirow{2}{*}{$\begin{array}{l}\text { pparbonate } \\
\text { Carbol }\end{array}$} \\
\hline UtEramafic & basaltic & Eranitic & Syenite & shate & Sandstone & \\
\hline 0.1 & 0.2 & 0.2 & 0.1 & 1.5 & 0.01 & 0.2 \\
\hline \multicolumn{7}{|c|}{ Sediments } \\
\hline & Pacific & AtTantic & Indian & Carbonates & Clays & \\
\hline & 3.0 & 0.8 & 1.1 & 0.2 & 1.0 & \\
\hline
\end{tabular}

Brief Chenistry

The stable isotopes of antimony found in nature are ${ }^{121}$ So $(57.25 \%)$ and ${ }^{123} \mathrm{Sb}(42.75 \%)$. The radionuclides of interest in waste disposal include ${ }^{124} \mathrm{Sb}$ (half-l ife $=60.3$ days) and ${ }^{125} \mathrm{Sb}$ (half-life $=2.7$ years).

Antimony may exist in $(-I I I),(0)$, (III) and (V) oxidation states, readily losing its $2(s)$ and $3(p)$ electrons. Ionic radii are $\mathrm{Sb}^{-3} 2.45 \AA, \mathrm{Sb}^{+3} 0.76 \AA$ and $\mathrm{Sb}^{+5} 0.62 \AA$ (Ahrens, 1952). The iaportant antimony minerals include native antimony $(\mathrm{Sb})$, stibnite $\left(\mathrm{Sb}_{2} \mathrm{~S}_{3}\right)$, jamesonite $\left(2 \mathrm{PbS}{ }^{\circ} \mathrm{Sb}_{2} \mathrm{~S}_{3}\right)$, boul angerite $\left(5 \mathrm{PbS} \cdot 2 \mathrm{Sb}_{2} \mathrm{~S}_{3}\right)$, kermesite $\left(\mathrm{Sb}_{2} \mathrm{~S}_{2} \mathrm{O}\right)$ and senarmontite $\left(\mathrm{Sb}_{2} \mathrm{O}_{3}\right)$. Stibnite is the most comon ant imony mineral.

Antibony, in the form of $\mathrm{SO}^{+3}$, forms complexes such as $\mathrm{Sb}(\mathrm{OH})_{2}^{+}$, $\mathrm{SO}(\mathrm{OH})_{4}^{-}, \mathrm{SOCl}_{3} \mathrm{OH}^{-}, \mathrm{SbCl}_{5}^{-2}$ and $\mathrm{SbS}_{3}^{-3}$ (Sillen and Martell, 1964). The existence of simple $\mathrm{Sb}^{+3}$ and $\mathrm{Sb}^{+5}$ is unlikely. Further, Sb is amphoteric. 
$\mathrm{Sb}^{+3}$, for example, reacts as $\mathrm{Sb}_{2} \mathrm{O}_{3}+3 \mathrm{H}_{2} \mathrm{O}+2 \mathrm{OH}^{-} 2 \mathrm{Sb}(\mathrm{OH})_{4}^{-}$in bases, and in acids, $\mathrm{Sb}_{2} \mathrm{O}_{3}+\mathrm{H}_{2} \mathrm{O}+2 \mathrm{H}^{+2} \rightarrow 2 \mathrm{Sb}(\mathrm{OH})_{2}^{+}$. $\mathrm{Sb}^{+5}$ dissolves in strong acids forming complexes such as $\mathrm{SbCl}_{6}$, and in strong bases forms complex antimonides such as $\mathrm{Sb}(\mathrm{OH})_{6}^{-}$(Latimer, 1952). $\mathrm{SbCl}_{3}$ dissolves in a limited anount of water to give a clear solution which, upon dilution, precipitates insoluble oxochlorides such as $\mathrm{SbOCl}_{1}$ and $\mathrm{Sb}_{4} \mathrm{O}_{5} \mathrm{Cl}_{2}$ (Cotton and Wilkinson, 1962). Izrael et al. (1969) mentioned that ${ }^{125}$ Sb was amphoteric, with a solubility

Solution Equilibria

The relative activity of various solution species in equilibrium with $\mathrm{Sb}_{2} \mathrm{O}_{3}(\mathrm{~s})$ is given in Figure 8.10. If equilibrium with $\mathrm{Sb}(\mathrm{OH})_{3}(\mathrm{~s})$ is assuned, the activity of all the species would be approximately $2.9 \log$ units lower with the lines still parallel to the lines given in Figure 8.11. Thermodynanic data for $\mathrm{Sb}(\mathrm{OH})_{2}^{+}$were obtained from Baes and Mesmer (1976) and all the other data were selected from Hagman et al. $(1968 \mathrm{a}, \mathrm{b})$. In the envircrsental pH range of interest (4 to 8), for either fresh or marine waters $\mathrm{HSbO}_{2}^{\circ}$ and $\mathrm{Sb}(\mathrm{OH})_{3}^{\circ}$ are the species that would govern the total activity of antimony present in solution. The other species [SbOF, $\mathrm{Sb}^{\circ}(\mathrm{OH})_{2}^{+}, \mathrm{SbO}^{+}, \mathrm{Sb}(\mathrm{OH})_{4}^{-}$or $\mathrm{SbO}_{2}^{-}$and ${ }_{4} \mathrm{SbO}_{2}^{\circ}$ ] do not contribute significantly to the total antiwony present in the solution and hence can be ignored. Since the predominant solution species $\left[\mathrm{HSbO}{ }_{2}^{\circ}, \mathrm{SO}(\mathrm{OH})_{3}^{\circ}\right.$ are neutral, ion exchange as an antiwony adsorption mechan is is not expected to be important.

Laboratory Adsorption Studies

There have been no laboratory studies reported in the literature addressing ancimony sorption onto aquatic sediments.

\section{Field Studies}

Cerrai et al. (1970) reported on the ${ }^{125}$ Sb concentration of surface sediments in the Adriatic and Ligurian Seas. The sediments were separated into $<100$ and $>100$ fractions. The observed concentrations were $<0.11$ and <0.15 $\mathrm{PCi} \mathrm{SO/g}$ dry sediment for the Adriatic Sea ard for the total 


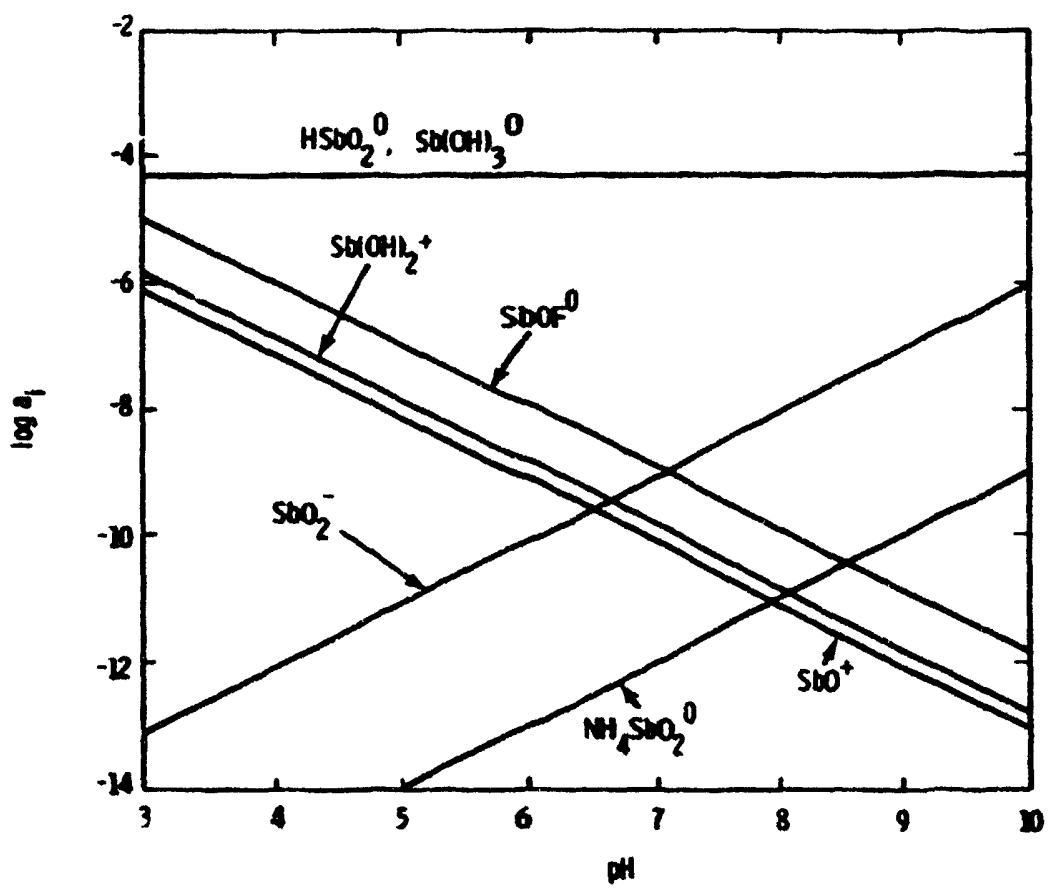

FIGURE 8.11. The Activity of Various Antimony Species in Equilibrium with $\mathrm{Sb}_{2} \mathrm{O}_{3}$ (s) (cubic) with pilit $=3.0$ and $\mathrm{pf}-=$ 4.5. Oxidation-reduction changes do not affert the concentration of species reported in this figure.

Ligurian Sea sample $0.433 \mathrm{pCi} / \mathrm{g}$. Unl ike many metallic radionuclides (Eu, Cs, Ce, $S r)$ the coarse fraction did not exhibit much lower concentrations possibly suggesting $S b$ is not preferentially bound by clays.

Perkins et al. (1966) and Haushild et al. (1973b) report that most of the radionuclides introduced into the Columbia River at Hanford were in a dissolved state but quickly became associated with particulate phases such as suspended matter, aquatic biota and bottom sediments. At Vancouver, Washington, $425 \mathrm{~km}$ downstream the ${ }^{124} \mathrm{Sb}$ remaining was found to be $>90 \%$ in the dissolved state. Evans (1973) found no suggestion that any so sorbed on suspended matter reaching the mouth of the Columia River would desorb upon contacting sea water. His hypothes is was that antimony was basically present in the soluble phase and travelled without reacting through the estuarine region. Melson et al. (1966) reports that antimony found in solution near the estuary is mainly uncharged (84\%). 
Robertson and Perkins (1975) report on the physicochemical states of antieny in a waste trench wich directly receives $N$-Reactor cooling water (Hanford, Hashington) and in spring seepage waters on the banks of the Colubia River. The trench water feeds the springs after a feu hundred foot travel through coarse sands. The total concentration and percent of each antimony isotope found in the particulate (will not pass 0.3 filter), cationic (sorbs on cation resin), anionic (sorbs on anion resin) and nonionic (passes through wole system) for trench and spring waters are show in Table 8.15.

TABLE 8.15. Activity and Percentages of Antimony Isotopes

$122 \mathrm{Sb}$

$\frac{\text { Trench Water }}{\mathrm{dp} / \mathrm{l}} \frac{\text { Spring Mater }}{\mathrm{dp} / \mathrm{l}}$

\begin{tabular}{|c|c|c|c|}
\hline Particulate & 410 & $>17.4$ & $<0.03$ \\
\hline Cationic & $<270$ & $<11.2$ & $<0.2$ \\
\hline Anionic & 1160 & 248.1 & $<1.0$ \\
\hline Monionic & 560 & $>23.2$ & 0.2 \\
\hline TOTAL & $\sim 2410$ & & $\mathrm{kl} .43$ \\
\hline
\end{tabular}

$124 \mathrm{Sb}$

$\begin{array}{lrrrr}\text { Particulate } & 74 & >29 & <0.04 & <0.09 \\ \text { Cationic } & <90 & <35 & <0.2 & <0.5 \\ \text { Anionic } & 59 & >23 & 2.2 & 5.4 \\ \text { Monionic } & 34 & >13 & \frac{38.3}{-40.7} & 94.5 \\ \quad \text { TOTAL } & <i 57 & & \end{array}$

$125 \mathrm{Sb}$

$\begin{array}{lrrrr}\text { Particulate } & <100 & \cdots & <0.05 & <0.06 \\ \text { Cationic } & <200 & \cdots & <0.3 & <0.3 \\ \text { Anionic } & 80 & \cdots & 3.8 & 4.2 \\ \text { monionic } & \frac{55}{40} & -- & \frac{86.4}{-90.2} & 95.8 \\ \text { TOTA } & <435 & & \end{array}$


In the trench water antimony is partitioned mainly as anionic and particulate; however, upon reaching t.e springs the nonionic form predowinates, showing its cobility in soils. Overall, the antimony shows about $80 \%$ sorption in the soil.

Israel and Rovinskii (1970) measured the chemical states of fission products in bonb crater water and reported that ${ }^{125}$ Sb was $85 \%$ anionic. $8.5 \%$ cationic, and $6.5 \%$ colloidal.

Movesent of ${ }^{125} \mathrm{Sb}$ from trenches and seepage pits in the Melton and Bethel Valleys, Oak Ridge, Tennessee, to thite Oak Creek was investigated by Duguid (1975, 1976). Typical results are given in Table 8.16. Relatively minor anounts of the ${ }^{125} \mathrm{Sb}$ are found in the ground water or seepage water compared to the amounts located on the soil. Similar ${ }^{125}$ Sb values for burial ground 4 in melton Valley showed a range of from 1.0 to $1.3 \times 10^{-2} \mathrm{dpm} / \mathrm{al}$ in the ground water and seepage water. This also represents a relatively minor antibony wovenent from the soil in the ground water. Computed antimony $K d$ values ranged from $10^{3}$ to $10^{6} \mathrm{w} 1 / \mathrm{g}$.

Magno et al. (1970) investigated the fate of the radionuclides from the Muclear fuel Services plant in western Men York state. The plant lagoon systen waters and soils were saupled and analyzed. They estimated from these data that approximately $90 \%$ of the ${ }^{125} \mathrm{Sb}$ in the plant effluent passed through the Iagoon system and into nearby surface streans. Ninety-eight percent of the ${ }^{125}$ Sb was described as "dissolved" (in solution), exiting from the last lagoon. The antiany is not, therefore, associated with suspended solids, but is in solution, as Figure 8.11 postulates that it should be.

Saas and Grauby (1973) studied the transfer wechanisas of ${ }^{124} \mathrm{Sb}$ found in reactor cooling water and other wastes to river, irrigated soil and ground water. The river water contained organcineral pollution in the form of industrial and municipal sewage wastes that interacted with the ${ }^{124}$ Sb to form chelates, an exchangeable fraction and hydrosoluble components defined as the totality of the organic and mineral components of a soil that are soluble in water. The percentage of the above hydrosoluble ${ }^{124} \mathrm{Sb}$ fraction was plotted versus depth in a for an alluvial, calcareous soil colum receiving 
TABLE 8.16. 12550 Analysis of Water and Soil Saples from a Seep Mear Trench 7 (Duguid, 1976)

\begin{tabular}{|c|c|}
\hline $\begin{array}{l}\text { Sapple } \\
\text { Date }\end{array}$ & $\begin{array}{l}\text { Hater saples } \\
\text { Count Rate, dom }\end{array}$ \\
\hline $3-5-73$ & $\leq 2.0$ \\
\hline $3-19-73$ & $\leq 4.0$ \\
\hline $5-11-73$ & 6.7 \\
\hline Depth & $\begin{array}{l}\text { Soil Saples } \\
\text { Comt kate, dig/g }\end{array}$ \\
\hline 0 to 3 & $\leq 690$ \\
\hline 3 to 6 & $\leq 240$ \\
\hline 6 to 9 & $\leq 120$ \\
\hline 9 to 12 & $\leq 41$ \\
\hline 12 to 15 & $\leq 18$ \\
\hline 15 to 18 & $<13$ \\
\hline 18 to 21 & $<9.7$ \\
\hline
\end{tabular}

${ }^{124} \mathrm{Sb}$ in river water. Ten to $30 \%$ of the ${ }^{124} \mathrm{Sb}$ was in the hydrosoluble form. The point of this work was the demonstration that interactions between pollutants in the river water and ${ }^{124} \mathrm{Sb}$ results in increased ant imony migration. These pollution interactions with radionuclides should be addressed in nuclear reactor siting studies.

Sumary

The principal aspect of antinony chemistry that governs its adsorption reactions with sediments and rocks over the pH range 4 to 8 is the prevalence of neutral and conplexed species. Lon Kd values are found with relatively rapid wigration through soils (Robertson and Perkins, 1975) and surface waters 
(Magno et al., 1970). In low redox conditions $\left(0_{2}<10^{-35}\right.$ atmospheres), antimony trihytroxide may precipitate and may be a stable conpound that controls antizony concentrations. Many of the antimony species associated with orgmopollutants are water soluble (Saas and Grabby, 1973) and inigrate readily with the water. Thermodymanic data on the ant imony complexes formed with soil orgenic anterials do not exist at present because the complexes are chenically poorly defined and, in many cases, unknown. The high retent ion of Sb at Oak Ridge conflicts with the above information. 
Cain

Mtural Sedfent and Rock Distributions

Carbon is fount in goologic materials in several forms: "elenental" as in graphite, diemond: "combined" as in carbonates; and "organic" as in plant and animi detorites. Carbon is unique in forming an almost infinite muber of conponads, oftea linking carbonation to carbonation. In general, sedimentary

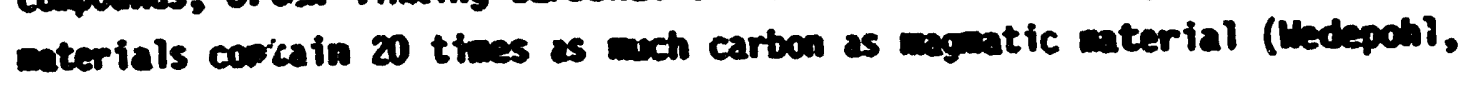
19s9).

Parker (1957) reports the following average concentrations of carbon in rocks: igneous, 320 ppo; sandstone, 13,800 ppo; shales, 15,300 pom; and carbomates, 113,500 ppom. Most oceanic sedicments also contain 2 to 33 organic metter wich is high in carbon.

Erief Cheristry

There are two stable isotopes of carbon ${ }^{12} \mathrm{C}$ (98.89\% abundance) and ${ }^{13} \mathrm{C}$ (1.115 abundance). Carbon-14 is the only radioactive isotope with a $t / 2$ greater than 20 minutes. Its $t / 2$ is 5730 years. Carbon-14 is produced maturally in the upper atuosphere by cosmic ray bobardment of $14 \mathrm{n}$. The steady-state ${ }^{14} \mathrm{C}$ budget on earth is $2.70 \times 10^{8}$ curies with 918 found residing in the ccean (Ri ley and Skirrow, 1965). Atwospheric bon testing added 5 $x 10^{6}$ curies to the natural pool. For brief periods in 1962-63 this additional source increased the natural ${ }^{14} \mathrm{C} /{ }^{12} \mathrm{C}$ ratio in the atwosphere by tho times. The amual production rate of ${ }^{14} \mathrm{C}$ by cosicic rays is $2.8 \times 10^{4}$ curtes. The ocean is the great scaveager of ${ }^{14} \mathrm{C}$ by the gaseous exchange of $\mathrm{CO}_{2}$. Once in the ocean 903 of the ${ }^{14} \mathrm{C}$ becomes bicarbonate ions (Riley and Skirrow, 1965 ). A seall portion of ${ }^{14} \mathrm{C}$ becones entrapped in biological life. Hedepohl (1959) estinates the ammal production of organic carbon to be $10^{11}$ metric tons.

Carbon-14 has been measured in nuclear reactor effluent waters in low concentrations (<1 to $34 \mathrm{pCi} / \mathrm{ml}$. Dawes and moore, 1978). Although the contribution from reactors is infinitesimal compared to natural sources a chronic release of this biologically active agent could potentially create an isolated hazard. 
Solution Equilibria

Carbon can be found in all valence states from 4 to +5 . In witers inorganic carbon is predaminately foend in the valeace state as $\mathrm{HCO}_{3}^{-}$ or $\mathrm{CO}_{3}^{2-}$. The man composition of river weters in Horth funerica contains 68 gp bicarbonate (Hedepoh1, 1959). Sea water contains 28 pom inorganic carbon or 103 ppo bicarbonate (Riley and Skirrow, 1965). The range of organic carbon found in sea meter is 0.2 to 2.7 pow. Thus, wost ${ }^{14} \mathrm{C}$ could be assined to be present as carbonate spectes and be capable of escape to the atwosphere as ${ }^{14} \mathrm{CO}_{2}$ also. Reactor-derived ${ }^{14} \mathrm{C}$ forned by activation has not been studied in any detail to identify the spectation at production.

Laboratory Adsorption Studies

There were no experimental studies of ${ }^{14} \mathrm{C}$ sediment-suspended solids adsorption identified in the literature search.

Field Studies

Foster (1973) and Baranov and Khitrovi (1966) reported that the oceans contain on the average $0.1 \mathrm{DCi} / \mathrm{l}$ of ${ }^{14} \mathrm{C}$.

Suess and Bien (1973) reported on the ${ }^{14} \mathrm{C}$ surveys of the oceans conducted by the Scripps Institution of 0ceanography. As it takes 55 gallons of sea water to process one sample it is little vonder that few persons have studied ${ }^{14} \mathrm{C}$ in the environment.

Sumy

Very little data are available on ${ }^{14} \mathrm{C}$ fate after release from muclear power generation activities. It appears that the efflient levels are $10^{3}$ to $10^{4}$ tines as large as matural sea-water values. As carbon can be assinilated into biological tissues, chronic releases in isolated areas could lead to biological concentration. Most likely the large anount of stable carbon would hold the bioconcentration at the specific activity level present in the area. 
CERICI

\section{Matural Sedfoneat and Rock Distributions}

The abundance of ceriva in rocks and sediments is given in Table 8.17. Ceriu generally increases in concentration from basaltic to granitic rocks. In a study of Russia platform soils, it wa found that the soils with highest cer iv contents were alkaline, suggesting precipitation as the hydroxide. The acid solls were lawer in ceriun because cerium had been renoved and had wigrated. Sediments derived from granitic rocks could be expected to show the highest ceriu contents if the weathering resulted in an alkaline envirocinent. Vinogrador (1959) gave the average ceriu content of soils as 50 pim. Haif, or more, of the ceriun in rocics is found in accessory ninerals such as apatite,

Thae 8.17. Cer iu Abundance in Rocks

\begin{tabular}{|c|c|c|}
\hline Type & Ce, P. & Reference \\
\hline Continental basalts & 59 & Frey et al., 1968 \\
\hline Kimberlite & 119 & Burkor and Potporim, 1966 \\
\hline Uitramafic & 0.1 & Turekian and Hedepoh 1, 1961 \\
\hline Basaltic & 48 & Turekfian and thopoht, 1961 \\
\hline Granitic, high Ca & 81 & Turekian and thodepoh1, 1961 \\
\hline Granitic, low Ca & 92 & Turekian and tedepoht, 1961 \\
\hline Syenites & 160 & Turekian and ledepoht, 1961 \\
\hline Shales & 59 & Turekian and Medepoht, 1961 \\
\hline 8616 Russian p?atform shales & 67 & Ronov et al., 1967 \\
\hline 6051 Russian platform sandstones & 33 & Ronor et al., 1967 \\
\hline 11205 Russian platform !leestones & 6.5 & Roror et al., 1967 \\
\hline Average of above & 57 & Ronow et al., 1967 \\
\hline Sandstones & 92 & Turekian and ledepoht, 1961 \\
\hline Dolonite and limestones & 11.5 & Turek ian and thedepoh 1, 1961 \\
\hline Brown Clay SAM & 56 & Mildean and Mask in, 1965 \\
\hline Manganese Module, Hawaii & 518 & coldberg et al., 1963 \\
\hline Marine carbonates & 35 & Turekian and Indepoh 1, 196! \\
\hline Marine clays & 345 & Turekian and Hedepoh1, 1961 \\
\hline
\end{tabular}


wile the rewinder also substitutes for calciu but only in the main stage minerals such as plagioclase. Marime clays appear to concentrate cerin compared to parent rock material.

\section{Brtef Cheaistry}

Ceriu occurs maturally in four stable isotopes shom in Table 8.18. The radioisotopes ${ }^{141} \mathrm{Ce}$ and $144_{C e}$ are both present in radioactive wastes as fission products with half-lives of 33 days and 284 days, respectively. After $100 \mathrm{~g}$, little fission product ceriun remains.

TABLE 8.18. Stable Isotopes of Ceriu

\begin{tabular}{lc} 
Isotope & matural Abundance, \& \\
\cline { 2 - 2 }${ }_{136} \mathrm{ce}$ & 0.15 \\
$138 \mathrm{ce}$ & 0.25 \\
$140 \mathrm{ce}$ & 88.5 \\
$142_{\mathrm{Ce}}$ & 11.1
\end{tabular}

The usual oxidation state of ceriun is tripositive with ionic radius of $1.03 \AA$ (Amrens, 1952).

The solubility product of Ce(III) hydroxide was given by Vickery (1953) as $1.5 \times 10^{-20}$. For comparison, the solubility products of $A 1(\mathrm{OH})_{3}$ and $\mathrm{Fe}(\mathrm{OH})_{3}$ are $3.7 \times 10^{-5}$ and $3.8 \times 10^{-38}$, respectively (D'Ans and Lax, 1967).

In geologic environments, ceriun forms meak complexes. The wost inportant and the wast comon cerium winerals include monazite (light rare earths, Th) $\mathrm{PO}_{4}$ and bastnaesite (1ight rare earths, $\mathrm{Th}$ ) $\mathrm{FCO}_{3}$. Hany other ceriucontaining minerals exist but wost are relatively rare.

Solution Equilibria

The activity of soluble cerium species assuning solid CePO, are shom in Figure 8.12. Trivalent cerium species in increasing order of inportance are $\mathrm{CeCl}^{2+}, \mathrm{CemO}_{3}^{2+}, \mathrm{Cef}^{2+}, \mathrm{Ce}^{3+}$, and $\mathrm{CeSO}_{4}^{+}$. Thus, CeSO 4 would be the wost dominant solution species in the environmental pH range of interest (ph 4 to 8) for both fresh and warine witers. 


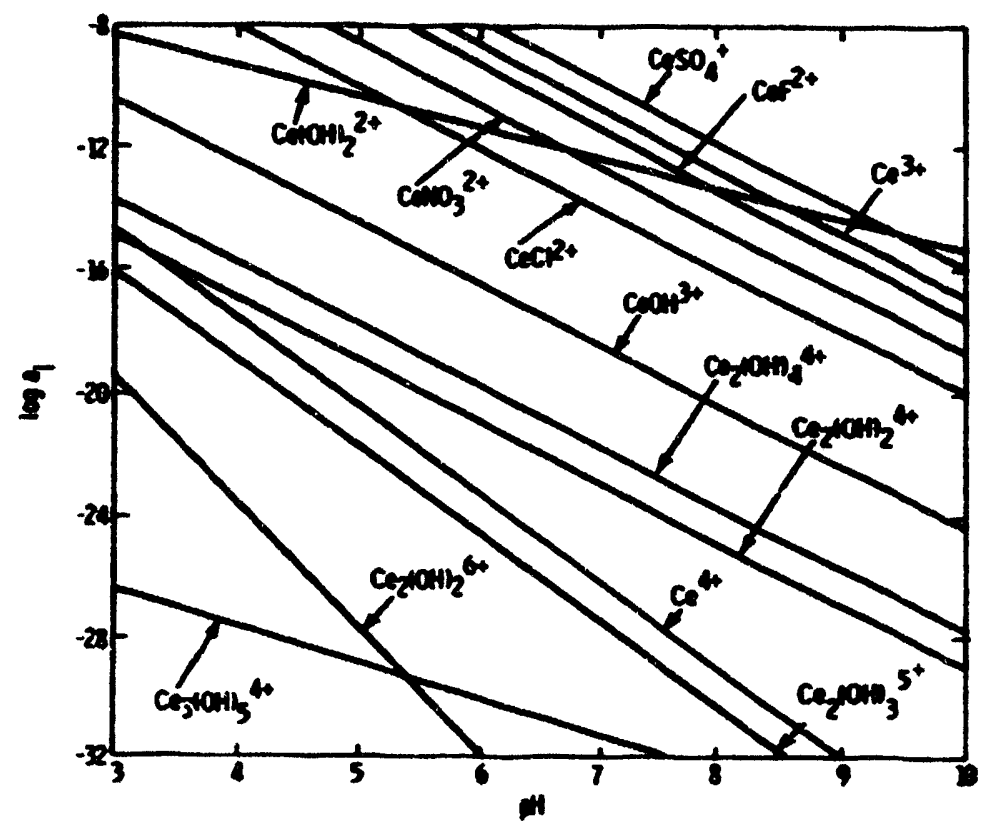

FIEURE 8.12. The Activity of Various Ceriun Species in Equilibriu with CePO4(s) in an Oxidizing Soil Environent $\left[\mathrm{pO}_{2}(g)=\right.$ $0.68 \mathrm{ata}$ ], $\mathrm{pf}^{-}=4.5, \mathrm{DCl}^{-}=\mathrm{psO} \mathrm{F}^{-}=$

2.5, $\mathrm{PmO}_{3}=3.0$ and $\mathrm{pH}_{2} \mathrm{PO}_{4}=\mathbf{5 . 0}$

\section{Laboratory Adsorption Studies}

Baranova and Polikarpor (1966) studied the adsorption/desorption of ceriu on sediments from the Black Sea. The sediments showed a large adsorptivity for ceriun, cesium and zirconium when compared to strontion and ruthenium. Sea water desorbed little of the adsorbed ceriun, but 0.2 miCl resoved auch of the adsorbed cerium.

Collet et al. (1968) studied the adsorption of ceriun on Rhine River silt. The sediments were separated into three fiactions (sand, clay and organic material) to obtain conclusions on the effect of the individual constituents. Data are available in Cerman.

Dawson and Dursina (1974), Duursma and Gross (1971), Dursina and E'sia (1973), and Dursma, Parsi and Stathan (1974) determined the sorption/desorption of ceriu onto marine sediments. Cerium added to sea water shows a great 
affinity to adsorb onto sediments. In Appendix 4 Dursen and Eisea (1973) report $\log K$ (unitiess) values and $t 1 / 2$ (half period of sorption) for mumerous sediments. A sumary of cerium results are included in Table 8.19.

IABLE 8.19. Ceriun Data

\begin{tabular}{|c|c|c|c|}
\hline Sedicent & $\log x$ & $\mathrm{Kd}$ (est), $=1 / \mathrm{g}$ & $+1 / 2$ \\
\hline Atlantic Dcean & $5.0 \pm 0.4$ & $1.5 \times 10^{5}$ & $8.1 \pm 6.5$ \\
\hline Pacific Ocean & $4.8 \pm 0.3$ & $9.5 \times 10^{4}$ & $13 \pm 8$ \\
\hline Indian Ocean & $4.5 \pm 0.5$ & $4.7 \times 10^{4}$ & \\
\hline Baltic Sea & $4.8 \pm 0.1$ & $9.5 \times 10^{4}$ & 4.4 \\
\hline Morth Sea & $4.8 \pm 0.5$ & $9.5 \times 10^{4}$ & \\
\hline Mediterranean Sea & $4.6 \pm 0.3$ & $6.6 \times 10^{4}$ & $7.1 \pm 3.5$ \\
\hline Black Sea & $4.5 \pm 0.6$ & $4.7 \times 10^{4}$ & \\
\hline Red Sea & 5.4 & $3.8 \times 10^{5}$ & \\
\hline
\end{tabular}

The cerium was not readily desorbed even with treatwent in II $\mathrm{MH}_{4} \mathrm{C}_{2} \mathrm{H}_{3} \mathrm{O}_{2}$ at pH 5.4 (50\% removed) but $1 \mathrm{~h}$ acetic acid pH 2.3 removed $90 \%$. The adsorption of ceriun appears to involve precipitation (ptl-dependent hydrolysis) wore than ion exchange. In other studies of sorption onto Black Sea sediments under oxidizing and reducing conditions Dwursan found $\mathrm{Kd}$ of $9 \times$ $10^{4}$ and $1 \times 10^{4}$ (unit less rolume basis), respectively.

Doshi et al. (1973) studied the adsorption of cerium from sea water on anganese axide precipitated in situ. All cerium present in solution co-precipitated.

Garder and Skulberg (1964) studied the adsorption of cerium onto post glacial arire clay taken from the Nitelva River (Morway). The clay fraction (20\%) was wica and the remining silt sized material $40 \%$ quartz and $40 \%$ feldspar. The cation-exchange capacity was $6.9 \mathrm{meq} / 100 \mathrm{~g}$. The ceriun ( $\mathrm{l} \mathrm{pCi} / \mathrm{ml})$ was added to distilled water. Ground sediment ( $<200$ mesh) was shaken in the traced water at concentrations between 16 to $256 \mathrm{ppm}$ sediment. The sorption of ceriun versus tive (1 to 9 days) was observed for the 64 ppm clay suspension. After $2 \mathrm{hr} 60 \%$ of the cerium was adsorbed but after 1 and 9 days an 
unexplained drop to $33 \%$ and $26 \%$ was observed. The $\mathrm{Kd}$ ce versus suspended sedivent concentrations after $24 \mathrm{hr}$ are shom in Table 8.20. The deperidence on sediment concentration may indicate mucleation of cer iun precipitation. For true ion exchange at trace ceriun levels the $\mathrm{Kd}$ should be independent of sediment concentration. Hirano et al. (1973) performed extensive studies of the physicochemical behavior of ceriun in sea water.

TABLE 8.20. Kde orco Post-6lacial Clay from Distilled Mater

\begin{tabular}{|c|c|}
\hline Sedinent Present, & $\mathrm{Kd}, \mathrm{Dl} / \mathrm{g}$ \\
\hline 16 & 14,200 \\
\hline 32 & 13,200 \\
\hline 64 & 7,800 \\
\hline 128 & 5,100 \\
\hline 256 & 4,600 \\
\hline
\end{tabular}

An imvestigation was performed on the nature of chenical species and existing states of radioactive cerium in sea mater by means of filtration, ion exchange and solvent extraction with carrier-free ${ }^{144}$ Ce as a tracer in pursuit of the physicochemical behavior and its effect on biologica! concentration. From the results of the experiments it mas conciuded that: radioactive ceriu added into sea water exists mainly in dissolved forms and 20 to $25 \%$ of ceriu becomes particulate forms having a diameter more than 0.01 ya after the aging for 40 days. Almost all of the radiaactive ceriun exists as ionic species in sea water or easily dissociated into ionic forms even after being associated with other anions present in sea water; although the ionic forms or easily dissociable species are the dominant existing states in the sea mater with lowered pH below 6, radioactive cerium is hydrolyzed slowly when the pH is greater than 6 and forms complexes with hydroxide or chloride ions in sea water or changes to polymerized forms. It was reported that the residence time of natural cerium in the sea is about 80 years and the precipitate formed for natural cerium is $\mathrm{CeO}_{2}$. Therefore, it is inferred that the equilibriun between natural cerium and radioactive ceriu added in sea water is achieved after a considerable time. Hirano et al. (1973) suggested that many of the 
laboratory $\mathrm{Kd}$ values reported wight be inflated because of outright precipitation of excess tracer. At any rate ceriun concentrations in natural waters should be very sall as predicted by the thernodymanic figure.

Kuznetsov and Schebetkorskif (1971) and Schebetkorskif and Kuzmetsov (1971) deterwined the sorption/desorption of ${ }^{144}$ Ce in sea water onto foraminiferal, diatomaceous, and icetherg silt and red shallow-water clays. The cerica added to sea water was allowed to equilibrate $24 \mathrm{hr}$ before contact with sediments such that precipitates would settle. The $\mathrm{Kd}$ Ce values for the four sediments were $5 \times 10^{5}, 9 \times 10^{3}, 0.35$ to $3.5 \times 10^{5}$ and 1 to $5 \times$ $10^{6} \mathrm{ml} / 9$, respectively.

The sediment to water ratio was varied from $10^{-4}$ to $10^{-3} \mathrm{~g} / \mathrm{ml}$ during this experiment. Leaching of cerium from the contaminated sediments showed a degree of irreversibility with each Kdce desorption being about twice as large.

Pirs (1974) deterwined the sorption capacity on hums material, calcite and dolomite for cesiun, strontiun, and ceriun by static and dymamic measurements. The dependence of the equilibrium concentration on the solution pH, the presence of foreign salts and the stability of the fixation of the abovementioned ions has been investigated. The elution curves for cesium, strontium and cerium from the hums material, sand, calcite and dolomite with water, salt solutions and acids were calculated.

Several investigations have been performed on the interaction of cerium with organic complexants [Bovard et al. (i968), Brom et al. (1969), Essington and Mishita (1966), Kulikov (1968), and Kulikov and Molchanova (1972)]. Bovard found cerium humic complexes formed more readily than iron, manganese, cobalt, ruthenium, strontium or cesium complexes and may be significant in the movenent of fission products in geologic environments especially in light of the high retention of inorganic cerium by soils and sediments.

Brom et al. (1969) performed systemat ic studies on the formation of radiocolloids by 144 ce and adsorption of ce by haic acid-bentonic clay wixtures. Ionic strength, cerium concentration and pH were important factors affecting the distribution between colloids and monomeric cerium. At low ionic strength and cerium concentration and high ph more radiocolloids are 
formed. At low ionic strength $10^{-3}$ and pH 6.5, 90\% of the cerium in a solution was found to be colloidal. Humic acids absolb wore cerium than bentonite clay in a calcium dominated system but in a potassiu-dominated system sorption was comparable. At environmental pH's cost humic substances are insoluble and thus cerium bound to hate should reain inmobile provided biological degradation of the organic matter is slow.

Nishita and Essington (1967) observed the effects on ceriun wovenent of flushing $10^{-4} \mathrm{M}$ solutions of organic che lators through contaninated soils. Ceriv bound to solls is little affected by water or EDOHA flushing, and only slightly affected by EDTA and DTPA flushing, signifying strong sorption to soils. As the concentrations of organic chelators in nature seldon reach $10^{-4} M$ remobilization of sorbed cerium by organics may be minimal.

The adsorption capacity of the botton deposits and surface suspension, collected in different portions of the Indian Ocean, was investigated by Growov et al. (1972). It was established that various groups of sorbents studied can be arranged in the following series according to the degree cf their aisorptive capacity: botton deposits, foraminifera > surface suspension > zooplankton. Regardless of the nature of the sorbent, radio-ceriu is adsorbed wost effectively from sea wer ( $K d>10^{-6}-10^{7}$ ). Jenne and Mahlberg (1968) studied the adsorption of ceriu identified as radiocolloid formation. Cerium sorption was not related to competing ion concentration in solution. As the sorption was more related to precipitation reactions the data could not be reduced to selectivity coefficients (see section on mechanisus) and was not reported. Mishiwaki et al. (1972) studied the adsorption of ceriun onto estuarine sediments as a function of chlorosity and pH. Meither pH (5.3 to 8.12) nor chlorosity $(0.1$ to $19 \mathrm{~g} / \mathrm{l})$ significantly changed cerium sorption for sand. For silt and clay the low pH-low salinity mater showed the lowest Kd. Most likely the pH 5.3 reduced ceriun hydrolysis and precipitation. Figure 8.13 shows the $\mathrm{Kd}_{\mathrm{Ce}}$ for coarse waterial was $\sim 10^{3}$ and $10^{4}$ for fine sediment. Taratani and Misuni (1962) studied the adsorption of cerium on suspended matter in river water and sea water. Between pH 6 to 8, 90\% of the cerium 
present in solution was adsorbed onto suspended sediments present at $<1 \mathrm{~g} / \mathrm{l}$. For some materials, kaolinite and calcite, cerilu adsorption increased with pH increases. Adsorption of cerium followed a Freunchlich adsorotion isotherm.

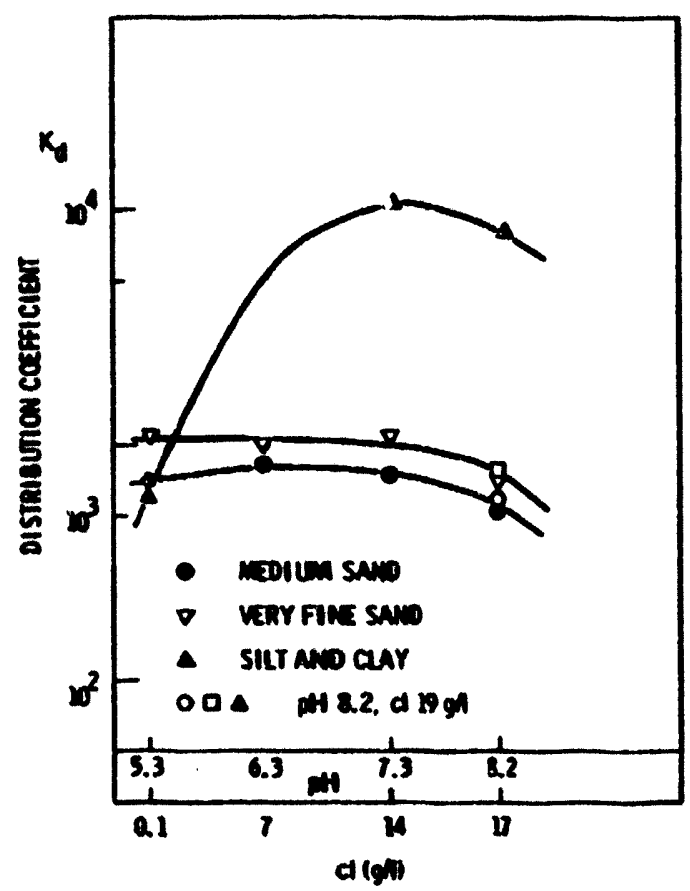

FIQURE 8.13. Distribution Coefficient of ${ }^{144} \mathrm{Ce}$ in Sediment

Mishita et al. (1966) studied five soils and two clay minerals in systems with ${ }^{144} \mathrm{Ce}$. Pretreatment of bentonite with dilute acid gave much less cerium uptake by the clay than the untreated bentonite. The hydrogen ion was more strongly adsorbed than ${ }^{144} \mathrm{Ce}$. The $\mathrm{pH}$ of the leaching solution had a profound effect on release of cerium by the soils. At pH values less than 5, $99.5 \%$ recoveries of ${ }^{144} \mathrm{Ce}$ were reported.

Rhodes (1957b) studied the uptake of ${ }^{144} \mathrm{Ce}$ on a Hanford soil as a function of pH. The Kd values rose steadily from 3.0 at pH 1.6 to $>1980$ at pH 6.1. The $\mathrm{Kd}$ then decreased to a minimum of about 100 at $\mathrm{pH} 10$ and increased again to $>1980$ at $\mathrm{pH} 12$ and above. The reduced uptake by soil of ceriun between pH 7 to 12 did not occur in the presence of macroconcentrations (39) of sodium 
ions. Thes, the ${ }^{144}$ Ce was present either as a radiocolloid in this region, wich was flocculated by the high concentration of sodiu ions, or as an ion species that as altered by the sodium ions to increase uptake by the soil. The copplete renoval of $4.2 \times 10^{-2} \mathrm{H}$ ceriun at pit 5.5 to 6 was reported, wich at this concentration exceeded the capacity of the soil by ten tines. The precipitation of cerium hydroxide was indicated.

Benson (1960) reported that ceriu adsorbed on the soil could not be exchanged above pH 7.4 and wa difficult to exchange at pH 5.5 to 7.4. The fraction of ceriu exchanged by barium at pH 5.5 was $10 x$ and virtually none at pH :.4. All of the ceriun could be renoved by ion exchange at pit 2.2, with less removal as a function of pH to 7.4 when none of the ceriun was exchangeable from the soil. Nove pH 7.0, the presence of $0.5 \mathrm{M}$ alkali metal cations and 0.254 alkaline earth netal cations did not affect ceriu resoval from solution by soll. Below pi 3.0, the adsorption of ceriun was depressed sinilarly by accompaning salts, inplying that the ceriu is ionic below pH 3.0 and reared by ion exchange on the soil.

Benson (1960) reported that the soil uptake of cerium added as Ce(III) was identical to that added as Ce(IV). However, when an oxidizing agent $\left(\mathrm{MaBiO}_{3}\right)$ mas added, uptake of Ce(IV) increased to $99 x$ at pH 1 , wile only 583 of the Ce(III) was adsorbed at this ph. Bensen concluded that the absence of sufficient holding oxidant resulted in an inediate reduction of Ce(IV) to Ce(III) by contact with the soil.

Kapbell (1964) investigated ${ }^{144}$ Ce uptake by colloidal suspensions of kalinite, illite and wontroorillonite type clays, all of mich had a high affinity for ${ }^{144} \mathrm{Ce}$. Only under very acid conditions did the ceriu rezain in solution. DPTA also was effective in keeping ceriu in solution at trace levels.

\section{Field Studies}

Cerrai et al. (1965, 1967, 1970) reported on the concentration of fallout ceriv isotopes in the Ligurian and Morth Morlatic Seas. The Morth Mdriatic Sea sediments were split into two size fractions ( $<100 \mu a$ and $>100 \mu a)$. The and of ceriu in the fine fraction was significantly greater than the 
coarser fraction, i.e., 2.31 to $3.61 \mathrm{pCi} / \mathrm{g}$ versus $0.16 \mathrm{pCi} / \mathrm{g}$. The average 144 ce concentrations in the North Adriatic and Ligurian Seas were 1.4 and $1.7 \mathrm{pCi} / \mathrm{g}$, respectively.

Juguet et al. (1966) measured the concentration of radio ceriun in waters and sediments in French rivers. The sediments were partitioned into sand, clay and organic matter. Ceriu is almost totally fixed to sediments in the French river systems studied.

Magaya and Saiki (1967) analyzed 19 saples of sediment from Tokyo Bay and found cerium content in fine and to be much greater than in sand. Relative to strontion the distribution of cerium between sedinent and water is auch greater towards the sediment.

Ruf (1968) studied the concentration of fallout and reactor muclides in fresh mer within Bavaria. In sludge behind river dass Ruf found the ${ }^{144} \mathrm{Ce}$ activity reached 12,000 to 15,000 fold the concentration in mater.

Spitsm et al. (1973) studied the adsorption of ${ }^{144} \mathrm{Ce}$ in Indian Ocean botton sediments. The best adsorbent for cerium was fine aleuritic radiolariu and and the extraction mechanisa was hypothesized to be trapping of colloids and true adsorption of dissolved cerium.

Magno et al. (1970) determined the forms and relative nobilities of radiomuclides from the lagoon system of the Muclear Fuel Services plant in mestern New York State. They reported that $0.02 \mathrm{Ci}$ of ${ }^{144}$ Ce were discharged from the last lagoon from may to October 1969. None of the discharged 144 Ce activity was dissolved in the water. All of the 14 Ce activity discharged was found in the suspended solids. Approximately $8.5 \mathrm{Ci}$ of ${ }^{144} \mathrm{Ce}$ were discharged from the plant to the lagoon system over the sane time period (May-October 1969). Thus, although all of the ceriu was in particulate form, about $3 \%$ migrated through the lagoon system in the for of suspended solids.

Eichholz et al. (1967) studied the fractionation of several radioactive elements between several natural waters and the suspended solids contained in them. The results gave an indication of the ability of ceriu to migrate as a suspended solid or adsorb on the suspended solids already present in cost 
matural waters. The suspended solids are characterized in Table 8.21. The cost obvious relationship is a direct one between the suspended solids content and ceriun adsorption. However, there also is a suggestion of an imverse relationship between cerium adsorption and solution pH. At the lower pH, wore of the ceriu should be present as cationic species and hence better able to adsorb on the suspended solids. It should also be pointed out that the Lodgepole Creek solids are largely montmorillonite, a high exchange capacity clay wineral.

TABLE 8.21. Adsorption of 144Ce on Suspended Solids (Eichiolz et al., 1967)

\begin{tabular}{|c|c|c|c|c|}
\hline Mater Source & $\begin{array}{c}144 c e \\
\text { Rewoved, } 8 \\
\end{array}$ & $\begin{array}{l}\text { Suspended } \\
\text { Solids, a/le }\end{array}$ & $\begin{array}{l}\text { Dissolved } \\
\text { Solids, } \mathrm{ma} / \mathrm{l}\end{array}$ & pH \\
\hline Colorado River & 72.0 & 299 & 350 & 7.5 \\
\hline Camp necoy & 44.6 & 12 & 60 & 6.9 \\
\hline Bayou Amacoco & 36.9 & 24 & 63 & 6.2 \\
\hline Lodgepole Creek & 96.9 & 965 & 200 & 6.8 \\
\hline Chat tahoochee River & 26.1 & 131 & 31 & 7.3 \\
\hline
\end{tabular}

Semary

In all aquatic environents Ce(IV) and its complexes would have insignificant effects on ceriu concentration (Figure 8.12). Thus, ceriun would be expected to be present as Ce(III) (Figure 8.12 and Ahrens, 1952; Bensen, 1960). In the absence of strong complexing ligands, and especially in acidic environwents, cerium would be expected to be present as $\mathrm{Ce}^{3+}$ (Figure 8.12; Bensen, 1960) and ion exchangeable. The increase in ph has been shom to increase the ceriu adsorption. As expected, the presence of complexing ligands such as DTPA increases ceriu concentration in solution and reduces adsorption. In slight acidic (pH 6.5) to alkaline conditions, cerium is thought to be present as radiocolloid wich has been shom to increase adsorption. Cerium adsorbed on suspended solids has been shown to migrate in field and laboratory studies 
(Kagno et al., 1970; Eictholz et al., 1967). However, this type of movement nould be expected to be dependent upon the particle $s^{5}$ of the suspended solitis and the pore size distribution of soils and rocks.

Mdsorption exper fments in general show high adsorption Kd $\left(10^{4}\right.$ to $\left.10^{6}\right)$ with precipitation and colloid formation probable mechanisas. Depression of Kd by high salt competition is not apparent or at least not significant. 


\section{CEsiun}

Matural Sediments and Rock Distribution

The cesium content of several geologic media is given in Table 8.22. In gereral, cesiu is enriched in the potassium ninerals, although enrichwent may only consist of a few hundred pon cesiun. The large size of the cesiun cation makes it difficult for it to substitute in crystal positions normally occupied by potassium, its nearest geochemically abundant, alkali metal relative. Hence, cesiun often becomes concentrated enough to form its own mineral phase (pollucite).

TABLE 8.22. Cesium Content of Rocks and Sediments

Rock Type

Basalt (estimated average)

Basalt (estimated average)

Basalt (estimated average)

Basalt (estimated average)

Eranodiorite

Granite

Granite

Granites, Russia

Marine shales

Sandstone

Linestone

Hodern sediments

U.S. strean sediments

Marine sands

Marine clays

Marine carbonates
Cs Content, pom

1.1

1.7

1.0

1.0

3.0

6.8

5.0

5.5

5.0

1.0

1.0

6.0

2.6

1.0 to 3.2

7.9 to 13

0.4
Reference

Turek $i$ an and Hedepohl, 1961

Heier and Adams, 1964

Tayior, 1964

Taylor and thite, 1566

Heier and Adams, 1964

Heier and Adans, 1964

Taylor, 1964

Beus and Fabrikova, 1961

Horstanan, 1957

Horstman, 1957

Horstman, 1957

Horstman, 1957

Sreekumaran et a1., 1968

Hirst, 1962

Hirst, 1962

Turekian and Hedepohl, 1961 


\section{Brief Chenistry}

The colly stable isotope of cesium is ${ }^{133} \mathrm{Cs}$. Fission product cesiun radioisotopes include four min cesium isotopes, with only ${ }^{134} \mathrm{Cs},{ }^{135} \mathrm{Cs}$ and ${ }^{137} \mathrm{Cs}$ (half-lives of 2.05 years, $3 \times 10^{6}$ years and 30.23 years, respectively) of significant concentrations 10 years after separation fron PiR (Pressurized Hater Reactor) fuels (Schneider and Platt, 1974). Pollucite, $(\mathrm{Cs}, \mathrm{Ma})\left(\mathrm{AlSi}_{2} \mathrm{O}_{6}\right) \times \mathrm{H}_{2} \mathrm{O}$ containing 22 to 36 wt\% sesiu, is the only independent cesium mineral of any importance.

In all its matural compounds, cesium occurs as a monovalent cation with a radius of $167 \AA$ (Ahrens, 1952). There is little, if any, tendency for cesiun to form complexes in natural environments, and the solubility of cost cesiu compounds in water is very high.

Solution Equilibria

Baes and Mesmer (1976) reported that cesium may :e associated with $\mathrm{OH}^{-}$ ions in solution and that the extent of this association cannot be estimated accurately. Charlot (1957) reported that cesiun rarely forms solution complexes. Therefore, cesium would be expected to appear in solutions predaninantly as $\mathrm{Cs}^{+}$. Only $1.5 \%$ of the cesiu from underground muclear explosions was found (Izrael et al., 1970) to be colloidal with the rest cationic, which may have been adsorbed on other colloids. The wain soil and rock reaction with cesiun is expected to be ion exchange.

\section{Laboratory Adsorption Studies}

Aston and Dursima (1973) studied the adsorption of Cs onto sediments contacting spiked mediterranean sea water $(1.125 \mu \mathrm{g} C s / l)$. Stirred suspansions 20 to $2000 \mathrm{mg} / \mathrm{l}$ mere studied at pH 8. Blank samples were run (without sediments) to study radionuclide precipitation and adsorption on reaction vessels. At several times an aliquot of suspension was filtered and the cesiun distribution on sediment and in the filtrate determined. Only $2 x$ of the spiked cesium sea water was observed to form particulates in the blank vessels. The equilibration of cesion was quite rapid $(0.4$ to $0.5 \mathrm{hr})$ and was not affected by the range of sediment concentrations studied. The KdCs value mas not dependent on sediment concentration below $200 \mathrm{mg} / \mathrm{l}$ and became 
independent above $200 \mathrm{mg} / \mathrm{l}$, but did not depend upon sediwent wineralogy, thus suggesting particle formation rather than ion exchange as the predominant mechanism. At sediment concentrations of $500 \mathrm{mg} / l \mathrm{Kd}$ ws a direct function of sedinent illite content, which suggests ion exchange reactions. At the total cesiu concentration expected in sea wer and neglecting cesium wich forms colloids, Kds for two carbonate sediments were about $40 \mathrm{ml} / 9$, but for two illitic fine grain sediments $\mathrm{Kd}_{\mathrm{C}}$ values were 450 and $900 \mathrm{ml} / \mathrm{g}$. Kd was dependent on amount of stable cesiu added as a carrier and data followed a Freundlich isotherm. Aston and Duursm concluded that at low sedicent concentrations mucleation of colloids controls the $\mathrm{Kd}$.s but at higher sediment concentrations ion exchange predominates. They also warned that tracer results cannot show the behavior and distribution of the stable counterpart of the element. Radioisotope adsorption might be occurring wile at the same tire sedinentary particles are desorbing the stable element.

Baker et al. (1964) deternined the $\mathrm{Kd}_{\mathrm{Cs}_{5}}$ on 17 samples collected in the vicinity of Cape Thompson, Alaska. Cesium adsorption, at 1 day, was found to be represented by the ass-action equation. The distribution coefficients for cesiu adsorption were so large that, in all but a few cases, very little of this muclide would reatin long in solution in the natural waters of the area. Equilibriu was reached within 1 day.

Baranova and Polikarpov (1966) found that, awong the sediments studied, a large adsorptivity for ${ }^{137}$ Cs as exhibited by sialllow-water silts (aleuritic silt with mussel bioccenosis and phaseoline silt). Despite differing mechanical and cheaical properties, these silts have similar affinity coefficients for each isotope, an effect for which the size and fraction of particles of less than 90 is resporsible. Phaseoline silt and aleuritic silt with mussel biocoenosis most effectively adsorb ${ }^{91} \mathrm{Y},{ }^{95} \mathrm{Zr},{ }^{137} \mathrm{Cs}$ and ${ }^{144} \mathrm{Ce}$. Their affinity coefficients for ${ }^{90} \mathrm{Sr}$ and ${ }^{106} \mathrm{Ru}$ are $10 \mathrm{w}$.

of the radionuclides tested, ${ }^{137} \mathrm{Cs}$ is most strongly retained by the silts. None was desorbed by sea water or $0.2 \mathrm{~N} \mathrm{KCl}$ (within the limits of the experimental error), which seems to preclude ion exchange as the sorption mechanism. 
Cheng and Hamaguchi (1968) studied the sorption of cesium on marine and terrigeneous sediments. Batch experiments $0.03 \mathrm{~g}$ of sediment/30 als solution were shaken overnight. Desorption was carried out by loading the contaninated sediments into colunis and washing with water. $K C_{C_{s}}$ values in distilled water and sea mater at pH 7 to 9 were constant. The $K d_{C_{s}}$ was dependent on the ratio of exchangeable potassium to total potassium and exchangeable magnesiur to total magnesium. In other words, the competition of cesiun for sites bound with potassium and agnesium obeys mass action law. Cesium sorption is most favorable on calciu based sediments, followed by magnesiun, sodiu and potassium. The $\mathrm{Kd}_{\mathrm{Cs}}$ for marine red clay varied from 2 to $9 \times$ $10^{3}$ in distilled and sea mater, depending on sediment characteristics.

Collet et al. (1968) determined the distribution of cesiu between sediments and waters in the Rhine River basin. Dursma and comorkers have studied the adsorption of cesium onto sea sediments [Dawson and Duurswa (1974), Duursma et a1. (1974), Duursma and Eisma (1973), Duursma and Gross (1971), and Ouursa (1973a)]. In general cesiu was found to adsorb rapidly (half-tine period of sorption $t 1 / 2=0.7 \pm 0.4$ days) and appeared to be controlled by ion-exchange reactions. The higher the cation-exchange capacity of the sediment is, the larger will be the $\mathrm{Kd}_{\mathrm{Cs}}$. The $\mathrm{Kd} \mathrm{Cs}_{\mathrm{s}}$ correlated very well with the exchangeable potass in content of the sediments. If the sediwent had high concentrations of exchangeable potassiu the $\mathrm{Kd} \mathrm{Cs}_{\text {sas }}$ large. The ${ }^{K d}{ }_{C_{s}}$ as also dependent on the concentration of stable cesium in solution. For every $10 \mathrm{\mu g} / \mathrm{l}$ increase in cesiu concentration, the observed $\mathrm{Kd} C \mathrm{~s}$ dropped 1 to $6 \%$. As the average concentration of stable cesium is $1 \mu \mathrm{g} / \ell$ in the marine enviroment, a change of $\pm 10 \mu \mathrm{g} / \mathrm{l}$ would be highly unlikely.

The $\log K$ (unitless volume $K d$ ) values for sediments frow various oceans and seas are shom in Table 8.23.

Garder and Skulberg (1964) investigated the sorption of radionuclides to river sediments (post-glacial marine clay) from the Nitelva River, Norway. A description of the sediment and water is given in the ceriun discussion. At a sediment concentration of 64 parts per million, cesium in distilled water was 
found to reach adsorption steady state between 2 to $24 \mathrm{hr}$ of contact. $\mathrm{Kd}_{\mathrm{Cs}}$ values for various sediment concentrations contacting distilled water and river water after 1-day contact are shown in Table 8.24.

TABLE 8.23. $\mathrm{Kd}_{\mathrm{CS}}$ in Various Sediments from Du.rima and Eis.m (1973)

Estinated Kd

\begin{tabular}{|c|c|c|c|c|c|}
\hline Sediment & \multicolumn{2}{|c|}{$\log K$} & Average (at/g) & \multicolumn{2}{|c|}{ t 1/2 (days) } \\
\hline Atlantic Ocean & 3.1 & 0.9 & 1,800 & 1.1 & 1.0 \\
\hline Pacific Ocean & 3.1 & 0.8 & 1,800 & 0.8 & 1.3 \\
\hline Indian Ocean & 3.3 & 0.4 & 3,000 & 0.6 & 0.2 \\
\hline Baltic Sea & 3.3 & 0.4 & 3,000 & 0.6 & \\
\hline Morth Sea & 3.5 & 0.2 & 4,275 & 1.0 & \\
\hline Mediterranean Sea & 3.1 & 0.6 & 2,000 & 0.6 & 0.3 \\
\hline Black Sea & 3.3 & 0.2 & 3,000 & 0.6 & \\
\hline Red Sea & 2.4 & & 380 & 0.6 & \\
\hline
\end{tabular}

TABLE 8.24. KdCs on Nitelva River Sediments

Sediment

\begin{tabular}{|c|c|c|}
\hline $\begin{array}{c}\text { Concentration } \\
\text { (ppo) }\end{array}$ & $\begin{array}{l}\text { Kdes } \\
\text { Distliled }\end{array}$ & $\begin{array}{l}\text { KdCs } \\
\text { River } \\
\end{array}$ \\
\hline 16 & 15,600 & 8,900 \\
\hline 32 & 13,600 & 7,300 \\
\hline 64 & 11,800 & 5,500 \\
\hline 128 & 10,800 & 5,000 \\
\hline 256 & 7,300 & 3,900 \\
\hline
\end{tabular}

Increased sediment concentration causes $\mathrm{Kd}_{\mathrm{Cs}}$ to decrease and the dissolved salts in the river water compete with Cs for sorption sites and effectively half the observed $\mathrm{Kd}$. It is also possible that container adsorption is causing part of the difference. The high $\mathrm{Kd}_{\mathrm{Cs}}$ ma be caused by the illite content of the sediments (15 to $30 x$ ). 
Jenne and Mahlberg (1968) studied the adsorption of cesium onto initeoak Creek, Temessee, sediments from strean water. Detailed mineralogy of various size fractions of stream sediments mas performed. It was shom that illite

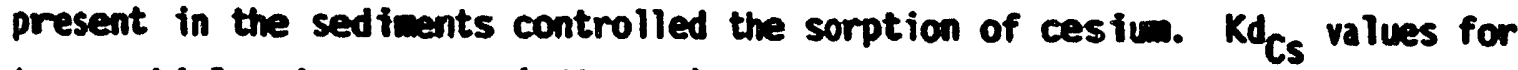
two particle size ranges (<60 mesh) and 9 to 60 mesh were 800 to 1000 and 650 to $790 \mathrm{ml} / \mathrm{g}$, respectively.

Kamabata (1967) studied factors affecting the sorption of various radiomuclides by a river sediment sample in the fresh or saline water. In addition, re lease of radionuclides in the sediants when it was exposed to the sea water was studied. Water and sediment samples were collected at several places along the Sagani River. Cation-exchange capacity of the river sediments (less than 120 mesh fraction) was 1 meq/100 g. Uptakes of radionuclides by the sediments were much affected by various competing cations, and the rate of imhibition depends not only on the cationic species but also concentration of cations. The higher in the concentration of a competing cation, the more inhibitive to the uptake of radionuclides by river sediments. Release of radionuclides Which had been sorbed by the river sediments in the filtered sea water was exanined during 12 days storage. Cesium-137 was released easily, and never was reassorbed.

Kuznetsov and Schebetkorskii (1971) and Schebetkovskii and Kuznetsov (1971) studied the distribution of ${ }^{137}$ Cs in the sea water and major types of sediments covering the Pacific Ocean floor. The foraminiferal, diatomaceous, and iceberg silt and red shallow-water clays are favorable locales for the sorption of these isotopes. These sediments show a high affinity for ${ }^{137} \mathrm{Cs}$. Results for four sediments are show in Table 8.25.

Desorption of ${ }^{137}$ Cs from the sediments into sea maters was studied. An expirical relation was established between the percentage of desorption and volume of wer with $P=V / a+b V$, where $V=$ volume of water, $P=$ desorption percentage, and $a$ and $b$ are empirical constants. The distribution of ${ }^{137} \mathrm{Cs}$ between sea water and sediments occurs as a homogeneous sorbate, i.e., follows Henry's Law. 
TABLE 8.25. Distribution of ${ }^{137}$ Cs Between Sea Hater and Sediments

\begin{tabular}{|c|c|c|c|c|}
\hline Sediment & Adso & tion & Desoi & \\
\hline Iceberg Silt & 559 & 21 & 590 & 20 \\
\hline Red Clay & 42 & 5 & 54 & 11 \\
\hline Foraminiferan Silt & 104 & 9 & 115 & 10 \\
\hline Diatom Silt & 147 & 6 & 230 & 10 \\
\hline
\end{tabular}

Mahmoud et al. (1968, 1973) studied the sorption of cesiun by botton sediments from Ismailia Canal adjacent to the United Arab Republic Atomic Energy Establishment. Laboratory studies, using slurry tests, on sorption of ${ }^{134}$ Cs by bottom sediments mere conducted. The affinity of these sediments for sorption of radiomuclides was influenced by grain-size distribution, contact time and carrier concentration. Linear relationships were noticed between logarith of capacity of bottom sediments for sorption of radionuclides versus logarith of carrier concentration. A Freundlich sorption isotherm was identified.

Meussen et al. (1975) studied the sorption of cesiun on Belgium sediments. Using ${ }^{60} \mathrm{CO},{ }^{85} \mathrm{Sr}$ and ${ }^{137} \mathrm{Cs}$ as tracer ions, the sorption capacity of Scheldt sediments for $\mathrm{CO}^{2+}, \mathrm{Sr}^{2+}$, and $\mathrm{Cs}^{+}$was studied and the ir distribution coefficients between sediment and Scheldt water were determined.

It is found that clay and silt saples show relatively high sorption capacities for cobalt and cesiun, compared with the lon fixation rate for strontive.

The selectivity of the sediments for a particular ion, in competition with other ions, was studied and the sequence found is in accordance with the distribution coefficients. From these experiments it may be concluded that the high salt concentrations, present in normal scheldt water, will limit the risks of radioactive isotopes accumalation in the sediments.

Puschaan (1970) studied the sorption behavior of fine-grained sediments from the Heser, Donau and Elbe Rivers. The experiments with closed systems give the course of the sorption and the possible sorption rate after the 
equilibrium has been established. The sorption rates are converted to grams of the element per $a^{3}$ sand as used in the laboratory experiment. The results are compared with the sorption rates dealt with by Weisflog (1968), which were made with low-terrace sediments from the river Rhine.

Schneider and Block (1968) studied the sorbability of deposits of the Rhine for several muclides. The sorbability increases in the following order: $I^{-}, \operatorname{Sr}(I I), \mathrm{Pu}(\mathrm{IV}), \mathrm{Zn}(\mathrm{II}), \mathrm{CS}(\mathrm{I})$. Saturation was reached by sediments after $24 \mathrm{hr}$ at the latest for all muclides. The sediment samples were taken from Oetningen (Upper Rhine), Koblenz (Middle Rhine), and Vessel (Lower Rhine). Data were compared with the organic content for each sample. The sorption of ${ }^{137} \mathrm{Cs}$ is dependent on grain size but not on organic material. A sudden release by living or dead organic material of radionuclide is not possible, though desorption from mineral suspended material is more rapid, often occurring within a few hours. Less than $1 \%$ of transported nuclides in the Rhine under any conceivable conditions would be bound to suspended material or sediments.

Seymour (1977) and Seymour et al. (1979) reported on batch experiments on three sediments: anodic marine, oxic marine and fresh-water sediment in contact with ${ }^{-7} C_{s}$ traced waters in the overlying water. The observed $K_{C} C_{s}$ values were $52 \pm 3,17 \pm 1$ and $50 \pm 4 \mathrm{ml} / 9$, respectively. Equilibrium was reached prior to the first counting period $(48 \mathrm{hr})$. In a separate experiment anoxic marine sediment was placed in a dialysis bag suspended in traced sea water. After 10 days the sediment had accumulated some radioactivity as did the rigially clean sea war within the dialysis bag. The apparent $\mathrm{Kd}_{\mathrm{Cs}_{s}}$ by this method was $0.09 \mathrm{ml} / \mathrm{g}$. The sea water originally spiked with cesium also showed 208 of the cesium had become filterable $(0.22 \mu \mathrm{m})$, suggesting particulate formation of added tracer had occurred.

Shell et al. (1979) measured the sorption of cesium from $30.2 \%$ salinity water by a sandy sediment from the Skagit River estuary. The values obtained varied from 90 to $134 \mathrm{ml} / \mathrm{g}$. In separate blank controls (traced water without sediment) $95 \%$ of the Cs remained in solution showing little problem with

8.71 
colloid forwation exists for Cs. A second sedinent from an anoxic marine basin, Saanich Inlet, contacting a traced water from Saanich Inlet was found to yield a $\mathrm{Kd}_{\mathrm{Cs}}$ of $61 \pm 24 \mathrm{ml} / \mathrm{g}$.

In two dialysis experiments on oxic marine sediments and contworillonite contacting seavater Cs was found to remain alnost exclusively in the soluble phase. Percentages of cesiu in the various compartwents can be found in Tables 8.9 and $\mathbf{8 . 1 0}$ in the Americiun section.

Schell et al. (1980) report on laboratory determinations of $K_{C_{s}}$ in mumerous fresh and arine water environients with sediments. Table 8.11 summarizes the results. The cesiu Kds for fresh waters exceed those for marine waters by about a factor of 5 , suggesting ion competition by $\mathrm{Ma}$ in seavater reduces cesiu sorption. $\mathrm{Kd}_{\mathrm{Cs}}$ for desorption exceeds the adsorption values and thus models wich assume quantitative reversicility $\mathrm{Kd}_{\mathrm{ADS}}=\mathrm{Kd}_{\mathrm{DES}}$ will over-estimate cesium mobility.

Schell et al. (1980) studied sorption of cesiun versus pH for a Clinch River, Tennessee sediment/freshmater slurry. From pH 4 to 9 there was no effect. Between pH 9 and 10 there appeared to be an order of magnitude increase in $\mathrm{Kd}$.

Schell et al. (1980) studied the effects of five organics on cesiun sorption in a freshwater environment. In no case did the organics significantly alter cesiun sorption (see Table 8.12).

Schell et al. (1980) continued dialysis experiments using Lake Michigan sediments and rater. Cesiun remains primarily in solution, but some sorption onto the sediment is also observed within 1 day.

Dunigan and Francis (1972), Essington and Nishita (1966), Nishita and Essington (1967), Kulikov and Molchanova (1972), and Salo and Saxen (1974) investigated cesium interaction with muic substances and chelators. In general, organic complexes with cesiu are not observed or not stable. Thus, soluble organic complexing of cesium has little effect on cesium movenent. 
Cerrai et al. (1969) contacted $200 \mathrm{mg}$ sediments with $40 \mathrm{ml}$ of traced sea water or distilled water for $1 \mathrm{hr}$. Resultant $\mathrm{Kd}_{\mathrm{Cs}}$ values for distilled water and sea water were 249 and $114 \mathrm{ml} / \mathrm{g}$.

Hahlberg and Fishman (1962) determined cesilu Kd values with kaolinite, illite, montmorillonite and halloysite over a large cesium concentration range and in competition with sodium, potassium, calcium or magnesiun. The type and amount of competing ions and the cesium concentration determined the cesium $\mathrm{Kd}$ variation with potassium having the most depressing effect. Thirty-four figures showing $\mathrm{Kd}_{\mathrm{CS}}$ versus cesium concentration $\left(10^{-10}\right.$ to $\left.10^{-1} \mathrm{M}\right)$ in $\mathrm{MaCl}, \mathrm{KCl}$, $\mathrm{MgCl}_{2}$ and $\mathrm{CaCl}_{2}$ solutions $(0.002 \mathrm{~N}$ to $0.2 \mathrm{~N})$ are presented for the above minerals. The logarith of $\mathrm{Kd}_{\mathrm{Cs}}$ on a particular clay mineral, at very low cesium concentrations, is a linear function of the logarith of the competing ion.

Tamura (1972) measured thre $\mathrm{Kd}_{\mathrm{Cs}}$ versus sodium concentration in a pure brine system for several minerals. The $\mathrm{Kd}_{\mathrm{Cs}}$ decreased as a function of increasing sodium concentration and for the mineral order illite, biotite, hydrobrotite, montmorillionite, kaolinite (figure 8.14).

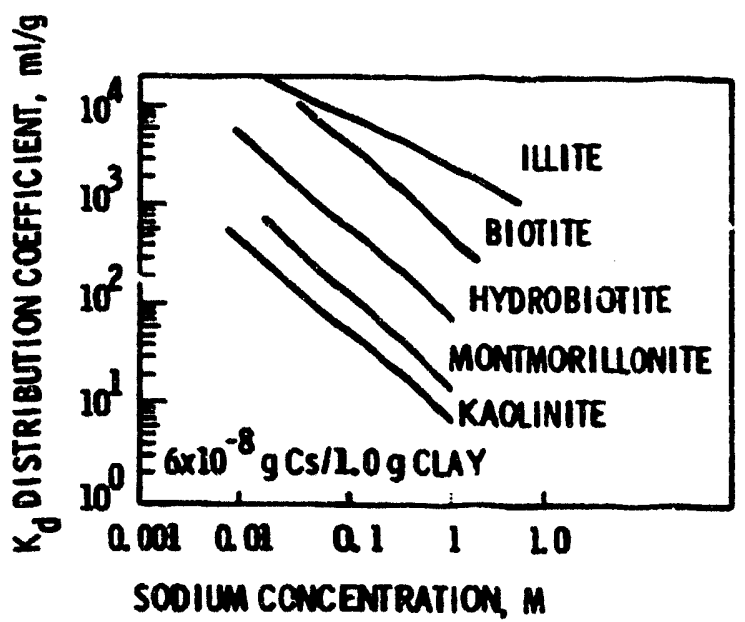

FIGLRE 8.14. Distribution Coefficient (Kd) of Several Minerals as a Function of Sodiun concentration 


\section{Field Studies}

Alberts, Hohlgren and coworkers studied the distribution and transport of fallout cesium in Lake Michigan and its watersheds. The results showed ${ }^{137}$ Cs from mapons testing is concentrated in the sediments. The mean half-life of cesiun entering the lake vater is $1.4 \pm 0.3$ years before incorporation into botton sediments. Convection wixing causes resuspension of surface sediments during sumer months. Residual fractions of ${ }^{137}$ Cs in the mater colum 10.04 to $0.08 \mathrm{pCi} / \ell$ ) are homogeneously distributed throughout the lake primarily in particle size fractions less than 0.4 un [alberts et al. (1974b), Edgington et al. (1975), Wahlgren and Melson (1973, 1974), and Wahlgren et al. (1976)].

Bowen and co-workers reported the concentrations of fallout cesium found in the Atlantic Ocean and Lake Ontario waters and sediment [Bowen (1971, 1974a) and Bowen et al. (1972)]. Cerrai et al. (1970) measured fallout concentrations of ${ }^{137}$ CS in Adriatic and Liguarian Sea sediments and found 0.17 and $0.38 \mathrm{PCi} / \mathrm{g}$, respectively. All of the cesium in the Adriatic sediment was found on fine sedicent $(<100 \mathrm{rm})$.

Field and laboratory studies of cesiun eanating from the Savannah River plant were performed by Brisbin et al. (1974), Dupont (1965) and Marter (1974). Brisbin sampled three transects across Steel Creek 15.5, 16.2 and $16.9 \mathrm{~km}$ domstrea frow the reactor effluent. Fine particle silt and clay sediments averaged $170.47 \mathrm{pCi} / \mathrm{g}$ (562 pCi/g maximu) mile coarser sedinents averaged 18.1 pCi/g. Differential distribution of fine and coarse sediments in the strean chamel have resulted in a complex mosaic of radiocontamination. Samples collected 1 a apart differed in radiocesium content by as much as i90\%. Rodiocesiun was correlated with both available potassium and organic matter. In desorption experiments $(24 \mathrm{kr})$ distilled water resoved $0.9 \%$, in $\mathrm{MaCl} 12.0 \%$, Steel Creek wer 6.3\%, Savamah River ater 6.0 to $6.7 \%$ of the cesium bound to the sediments. The desorption experiments suggest cation competitial of high ionic strength vaters can remove some of the bound cesium. - -

Brungs $(1963,1964)$ reported on the distribution of cesium added to a 30,000 gallon pond with a sand substrate over an 80-day period. The disappearance of cesium ras rapid, $95 x$ after 4 days. At the end of 80 days the 
sediments contained about $400 \mathrm{pCi} / \mathrm{g}$ wile the mater coatained $86 \mathrm{pCi} / \mathrm{l}$ for an apparent $K_{C_{S}}=4.6 \times 10^{3}$. At day $80,0.25 \%$ of the cesium was in the dissolved state, $0.33 \%$ on suspended eaterial, $0.03 \%$ on biota and $99.39 \%$ on the sedicent. The pond water contained $10 \mathrm{ppm} \mathrm{Ma,} 8 \mathrm{ppm} \mathrm{K}, 24 \mathrm{ppm} \mathrm{Ca,} 22 \mathrm{ppm} \mathrm{mg}$. $31 \mathrm{ppa} \mathrm{SO}, 8 \mathrm{ppm} \mathrm{C1,} 72 \mathrm{ppm} \mathrm{HCO}_{3}-\mathrm{CO}_{3}$ and ph 8.8.

Comprehensive field and laboratory studies of radiomuclides in the strean and river leaving Oak Ridge Mational Lab were perforned by Carrigan, Pickering and coworkers [Carrigan et al. (1967), Carrigan (1968, 1969), Lamers (1968), Lomenick and Tamura (1965), Pickering et al. (1965, 1966), and Pickering (1969, 1970)]. A comprehensive inventory of radionclides over a 21-nile reach of the Clinch River shows 218 of the cesiun released rewins bound to bottom sediments. High adsorption of cesium is related to the illite clay present in the sediments. Coplete sediment and wter characterization is provided such that the functional dependency of sorption can be addressed. For a clay bed sediment (60\% illite, $15 \%$ kaolinite, 10 to $15 \%$ vermiculite, 10 to $15 \%$ quartz) contacting tap water, the following $K_{C_{\text {s }}}$ values mere obtained (Table 8.26).

TABLE 8.26. Cs Sorption by Clinch River Sedient

\begin{tabular}{crrr} 
Contact Tine & pH 6 & pH 9 \\
\cline { 1 - 1 } 1 hour & 2,326 & 3,169 \\
3 days & 50,152 & 50,152 \\
7 days & 88,048 & 82,769
\end{tabular}

Most of the cesiun in solution in the Clinch River is bound to suspended sedinent with a particle size greater than 0.7 in $(69$ to 923 depending upon location). Cesiu content in water correlates with suspended solids, turbidity, color, iron and anganese, all of wich relate to suspended solids content. Lamers (1968) and Lomenick and Taura (1965) studied the distribution of cesium in thite Cak Lake. More than 802 of the ${ }^{137}$ CS is associated with the clay fraction of the material, which was found to be predominantly illite. Significant quantities of ${ }^{137}$ Cs were reaved from the zaterial only 
by treatment with strong acids. Studies of several selected clays showed illite to have a high affinity for ${ }^{137} \mathrm{Cs}$ at levels of the same order of magnitude as those observed in lake bed sedinent and that desorption is only accomplished after disruption of the lattice structure. The desorption behavior of the sediments and the corroborative behavior of the reference winerals are evidence that cesium in the sediment will not be leached by percolating ground water to any appreciable degree. However, novenent of cesiun can occur by erosion of the sediment.

Cushing and Matson (1974) studied the biotic and abiotic components of a cooling water pond ecosystem at Hanford. Most of the ${ }^{137}$ Cs in the pond is associated with the sediments mich are probably the min source of ${ }^{137}$ Cs for uptake by the biota. Cenerally, highest concentrations of ${ }^{137} \mathrm{Cs}$ and other radioisotopes were found in the upper 2 in. of sediments in the northwest end of the pond and in the deeper areas alng the long-axis of the pond. Sediment could be a source of high concentrations of radioactivity or radioactive contamination concern if the concentration of radiocontaminants increased and/or the pond dries up, and the contaninated sediments becowe windborne.

DeBortoli and Gaglione (1970) surveyed the ${ }^{137}$ Cs in Lake Maggiore to evaluate the abount and distribution of the contamination in botton sedicents. Through these measurements the vertical profile of the contanination has been also deterwined and found very irregular. The contanination in the bay is confined to an area of approximately $0.03 \mathrm{~km}^{2}$ and the activity levels found are very low, as expected on the basis of the activity released.

Eyan and Kevern (1975) studied the distribution of cesium in a hypereutrophic lake. The inputs of ${ }^{137} \mathrm{Cs}$ and stable cesiun and their distribution anong the water, sedirents, macrophytes, filamentous algae, 200plankton, and several species of fish were studied in a lake exhibiting an advanced stage of entrophy. Nost of the cesium pool (97\% ${ }^{137}$ CS, $98 \%$ stable cesium) was found to be associated with the sedinents. Stable cesiu enters the lake primarily in a bound state as wigratory mterfowl excreta and is deposited to the sediments. Cesiu-137 is associated with fine particulates in the 
inorganic form as it enters the lake. This results in a longer residence time in the vater colum with distribution throughout the lake. Specific activity (pCi ${ }^{137}$ Cs/ng stable cesiva) of the sediments was lower than other components of the system due to the different nodes of entry for the two cesiu isotopes.

Gloyma and co-workers studied the movenent of radiocesiun in model rivers (flumes) and in the field (Euadalupe River) [Clanton (1968), Gloyma et al. (1966, 1971), Kudo (1969), Kudo and Glosma (1971), Purushothaman (1968, 1971), Purushothaman and 6loym (1968), Reynolds (1963), Reynolds and 6loyma (1963), Texas Chiversity (1968), and Yousef et al. (1970)]. A fully-instrunented flume and reservoir complex was used to simlate typical ecological environments. A model river as represented by the flume has been used to develop wore fully a comprehensive transport equation, thereby defining the transport coefficients needed to satisfy any prediction model. This system has been used to evaluate the effect of various environmental conditions $m$ the net transport of the radionuclides. Rates of radiocesiun sorption and desorption were highest uring the first few moments of contact, but total mass adsorbed continued to increase slowly throughout 7-day experiments. Organic fractions in sediments increased cesiu sorption substantially. When the contaminated sediments were placed in conditions simulating a mar ine environment, $43 \%$ of the ${ }^{137}$ Cs was released because of competition for the exchange sites from the more abundant ions in sea water. Even though fluvial releases are considered an acceptable means of radionuclide disposal, it should be emphasized that all strea systems are dymaic, and this disposal is at best temporary. The distribution of the radionuclides in the botton sediment, plants, algae, and water was deternined. Under the conditions of the release, less than maxima permissible concentration, the radioactivity cont inued to increase on the surface of botton sediments until a quasi-equilibriu level was reached at approximately 25 days after initiation of release. At this condition or saturation, the specific activity of bottcm sediments associated with ${ }^{134} \mathrm{Cs}$ approached $55 \mu \mu \mathrm{c} / \mathrm{cm}^{2}$ and sediment $K_{v}$ was 275 (Kd $410 \mathrm{al} / \mathrm{g}$ ). 
The delay in transport of radionuclides caused by the interaction between floring water and bed sediments was deternined. This interaction phenomenon for ${ }^{137}$ Cs mas observed by using a set of flumes, each $50 \mathrm{ft}$ in length and a codel river wich was $200 \mathrm{ft}$ long; The greatest uptake rate, $K_{s t}$, by bed sediment was $88.7 \times 10^{-4}\left[\left(\mathrm{cp} / \mathrm{cm}^{2}\right) /\left(\mathrm{cpm} / \mathrm{cm}^{3}\right)\right] /(\mathrm{sec})$ with a velocity of $1.65 \mathrm{fps}$ and a flow rate of $0.345 \mathrm{cfs} / \mathrm{ft}$. In this case the sediment transport rate was $0.0795 \mathrm{lb} / \mathrm{sec}-\mathrm{ft}$. A mathematical nodel was developed describing the aigration of radiomuclides into the sedicents. The relative concentration of radionuclides on the surface of the botton sediments to that in the bed sediment was found to be a function of $z /(2 \sqrt{D t})$, where $z, D$, and $T$, respectively, are the depth of bed sediment from the surface, diffusion coefficient of ${ }^{137} \mathrm{Cs}$ in mater, and time after migration started.

Hakonson (1972), Hakonson and Whicker (1975), Hubbard (1968) and Hubbard and Striffler (1973) studied transport in mountain lakes and streans. For the mountain lake to wich $0.2 \mathrm{Kg}_{\mathrm{Cs}_{5}}$ /hectare were added, the loss of ${ }^{137}$ Cs from water occurred in two phases. The rapid phase, which resulted in the loss of 603 of the cesiun from water, had a loss half-time of 0.5 days wile the slow phase had a loss half-time of 130 days. The seston fraction of each water sample contained from 25 to $80 \%$ of the ${ }^{137}$ Cs present in each :iter of unfiltered water. Botton sediments were identified as the major site of deposition of the ${ }^{137}$ Cs dose. The sediment, at 393 days post-dosing, accounted for $82 \%$ of the ${ }^{137}$ Cs inventory in the lake whereas water ard seston accounted for only 3 and 14\%, respectively.

137 The strean study showed the distribution of the fallout radionuclide ${ }^{137}$ Cs on the surface and in the strean channel of an alpine matershed in the Colorado front Range. Cesium-137 activities of the surface (wean = $222 \mathrm{nCi} / \mathrm{m}^{2}$ ) were considerably higher than at fort Collins, Colorado. The effects of snow-accumlation, soil-vegetation complexes, and the hydrologic surface were studied in relation to ${ }^{137}$ Cs activity. Snow-accumlation areas contained significantly more ${ }^{137}$ Cs than snow-free areas. Alpine bog contained significantly wore ${ }^{137}$ Cs than did Alpine turf and Alpine meadow soils. Micro-channels and wicro-depressions had significantly higher levels of ${ }^{137}$ Cs activity than areas characterized as surface runoff. Concentrations 
of ${ }^{137} \mathrm{Cs}$ in strean botton sediments and strean vegetation decreased exponentially downstrea with distance from a permanent snowfield at the headuters. There is some evidence that ${ }^{137} \mathrm{Cs}$ in sediments is accumlating in a marshy area where the strea flows across the worrain of a former wountain glacier. ${ }^{137}$ Cs activities of the sediments were not highly related to percent silt + clay. Evidence did not support the hypothesis that wost ${ }^{137}$ Cs would concentrate in the silt + clay as it noved dounstrea. Significant quantities of ${ }^{137}$ Cs were not found in strean mater or the 1967 or 1968 snompack. Measurable ${ }^{137}$ Cs activities were found in litter and inorganic materials in and about the permanent snowfield, and in woss on rocks in the strea channel.

Lerman (1971), Lerman and Taniguchi (1971), and Lerman and Lietzke (1975) have studied the uptake and migration of tracers in the Great Lakes. For woding efforts, field observations and a few laboratory experiments have been performed on the sorption of cesiun. $K_{d_{C s}}$ values of 5,200 to 15,000 $\mathrm{ml} / \mathrm{g}$ have been obtained, depending upon sediment characteristics.

Makanura and Magaya (1975) studied the concentration of ${ }^{137} \mathrm{Cs}$ in the marine sediment of Tokyo Bay and of the coastal seas of Ibaraki, Fukushima and Fukui prefectures. The radiocesium ranged from 5.3 to $220 \mathrm{pCi} / \mathrm{kg}$ ory sediment. The degree of radionuclide enrichment versus sea water was in the hundreds for 137 Cs.

Urenn et a1. (1971, 1974) have studied the distribution of ${ }^{134} \mathrm{Cs}$ and ${ }^{137}$ Cs in the Hudson River estuary. The spatial and temporal distribution of ${ }^{137} \mathrm{Cs}$ and ${ }^{134} \mathrm{Cs}$ was measured in fish, plants, water, and sediments of the Hudson River Estuary along an 80-wile stretch of the river, encompassing salinities from one-fifth sea water to fresh water, in order to better understand the cycling of this radiomuclide in an estuarire environent. Although the ${ }^{137}$ Cs content of Hudson River water has dropped tenfold since 1964, the average content in $f$ ish and sediments has reained relatively constant. This implies that the ${ }^{137}$ Cs content of fish residing in the river has depended primarily on the cumlative deposit in the sedinents. The major source of this ${ }^{137}$ Cs has been fallout, although in a limited section of the river an 
elevation of ${ }^{137} \mathrm{Cs}$ in sediments from the Indian Point nuclear piant can be seen. In order of decreasing content, ${ }^{137}$ Cs was found in sediments, aquatic plants, and fish, roughly in the ratios of $30: 1: 1$.

Magno et al. (1970) determined radionuclide migration through the effluent Jagooning system of the Muclear Fuel Services plant in Hestern Mew York. From their analytical data, they estimated that $75 \%$ of the ${ }^{134}$ Cs and ${ }^{137}$ Cs discharged from the plant was deposited in the sediments in the lagoon system. From 40 to $95 \%$ of the cesiu at the lagoon system exit as associated with suspended solids.

Eichtolz et al. (1967) imvestigated the partitioning of dissolved radionuclides between suspended sediment particles and aqueous solutions. The ir work does not necessarily have a direct application to particulate migration through sediment, but it does give a feeling for the types and acounts of radionuclides that can be transported on suspended solids. Several bodies of

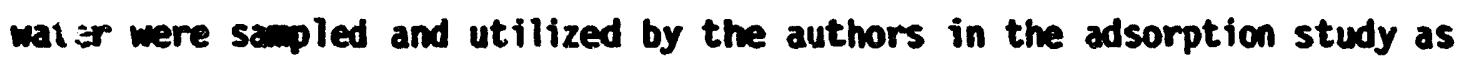
sources of suspended solids. Some of the properties of the natural water samples are listed in Table 8.27. A fission product mixture was added; the system allowed to come to equilibrium; and the water was recovered and passed through a wixed-bed ion-exchange resin. The resin and sediwent were then counted with the radionuclides extraction results show in Table 8.28. It is noteworthy that a large portion ( 80 to $90 \%$ ) of the radionuclides was associated and traveled with the particulate watter in a highly concentrated form. There is a direct correlation between cesium adsorption and the suspended solids concentration, with some effect of dissolved solids in the water.

Sumary

Cesium mainly exists in solutions as $\mathrm{Cs}^{+}$. Schell et al. (1979) found very little tendency for Cs to form colloids or to be unstable in solution. Therefore, the principal reaction mechanisin of cesium adsorption on sediments, soils and rocks is expected to be cation exchange. In fact, some researchers have determined adsorption isotherws on several natural aterials, and from the isotherms, derived therwodymanic functions for the specific cation exchange reactions. Some of the thermodymanic studies include Thomas (1967), 
TABLE 8.27. Properties of Matural Mater Samples (Eichholz et al., 1967)

\begin{tabular}{|c|c|c|c|c|c|}
\hline Source & $\begin{array}{l}\text { Suspended } \\
\text { Solids, ppen }\end{array}$ & $\begin{array}{c}\text { Dissolved } \\
\text { Solids. Pom }\end{array}$ & pH & $\begin{array}{c}\text { Conductivity } \\
\text { Lenos }\end{array}$ & $\begin{array}{c}\text { Solids } \\
\text { composition }\end{array}$ \\
\hline $\begin{array}{l}\text { Colorado River, } \\
\text { Utah }\end{array}$ & 229 & 350 & 7.5 & 540 & $\begin{array}{l}95 \% \text { quartz. } \\
\text { 5\% calcite, } \\
\text { feldspar, illite, } \\
\text { kalinite }\end{array}$ \\
\hline $\begin{array}{l}\text { Cap mecoy, } \\
\text { Misconsin }\end{array}$ & 12 & 60 & 6.9 & 80 & $\begin{array}{l}30 \% \text { quartz + } \\
\text { feldspar, } \\
6 \% \text { kaolinite, } 248 \\
\text { illite }\end{array}$ \\
\hline $\begin{array}{l}\text { Bayou Anacoco, } \\
\text { Lousiana }\end{array}$ & 24 & 63 & 6.2 & 60 & $\begin{array}{l}30 \% \text { qurtz, } \\
2 \% \text { kaolinite. } \\
6 \% \text { swectite }\end{array}$ \\
\hline $\begin{array}{l}\text { Lodgepole Creek } \\
\text { Nebraska }\end{array}$ & 965 & 200 & 6.8 & 300 & $\begin{array}{l}208 \text { illite. } \\
806 \text { sinectite }\end{array}$ \\
\hline $\begin{array}{l}\text { Chattahoochee } \\
\text { River, Georgia }\end{array}$ & 131 & 31 & 7.3 & 45 & $\begin{array}{l}\text { 33: qurtz, } \\
\text { 44: kaolinite } \\
\text { 23: illite }\end{array}$ \\
\hline $\begin{array}{l}\text { Billy's Lake } \\
\text { Georgia (swaw) }\end{array}$ & 8 & 68 & 4.2 & 45 & $\begin{array}{l}\text { 2: quartz, } \\
\text { balance was } \\
\text { amprohous } \\
\text { and/or organic }\end{array}$ \\
\hline
\end{tabular}

TABLE 8.28. Adsorption of Radionuclides on Suspended Solids (Eichholz et al., 1967)

\begin{tabular}{lrr}
\multicolumn{1}{c}{ Source } & & 137 Cs, $x$ \\
Colorado River & & 83.9 \\
Canp McCoy & & 3.3 \\
Bayou Anacoco & & 16.2 \\
Lodgepole Creek & & 96.3 \\
Chattahoochee & & 26.1 \\
$\quad$ River & & \\
Billy's Lake & & 0.3
\end{tabular}

Tamers and Thomas (1960), Merriam and Thomas (1956), Gaines and Thomas (1953), Lewis and Thowas (1963), and Eliason (1966) on cesium ion exchange on systems of cations with clays. Ames (1959b), Frysinger (1962) and Howery and Thomas (1965) studied ion exchange and cesium thermodymanics on the natural zeolite clinoptilolite. Ion exchange reactions are rapid, thus in most instances sorption of cesiun is observed to reach steady state rapidly (within hours). 
There is the tendency for cesiun to become "fixed" or preferentially sorb on $10 \AA$ aica, illitic-like minerals as witnessed by the tenacious adsorption of cesiun on clays around Oak Ridge Mational Lab. Most field studies show cesium becomes rapidly associated with bottom and suspended sediments.

Schell et al. 1980 show data mich supports ion exchange like processes control cesium sorption in aquatic environents. In general $\mathrm{Kd} / \mathrm{Cs}$ for freshmater environments is about five times greater than $\mathrm{Kd}_{C_{s}}$ for sea water. Organic ligands appear to have little effect on cesium sorption. 
Chemila

Matural Sedimant and Rock Distribution

Some average values for chromiu content of sedinents are found in Table 8.29.

There 8.29. Chromium Concentrations (ppom)

\begin{tabular}{|c|c|c|c|}
\hline Tye & Rance & Average & Reference \\
\hline Atlantic Ocean Sediment & 8 to 190 & 65 & Durssa, 1974 \\
\hline Pacific Ocean Sediment & 7 to 93 & 52 & Dursin, 1974 \\
\hline Indian Ocean Sediment & 84 to 160 & 116 & Dursma, 1974 \\
\hline Pelagic Carbonate & & 11 & Turektian and Hedepoh1, 1961 \\
\hline Pelagic Clays & & 90 & Turekian and Iedepoh1, 1961 \\
\hline Red Clay & & 55 & El Hakeel and Riley, 1961 \\
\hline All ccean Sediments & & 93 & EI Wakeel and Riley, 1961 \\
\hline Monganese Module & & 10 & Riley and Sinhaseni, 1958 \\
\hline
\end{tabular}

\section{Brief Chemistry}

Chromiu is a metallic element, resembling iron, occurring chiefiy in chrome iron ore $\mathrm{FeO} \cdot \mathrm{Cr}_{2} \mathrm{O}_{3}$. There are four stable isotopes with the following abundances: ${ }^{50} \mathrm{Cr}(4.418),{ }^{52} \mathrm{Cr}(83.46 \%),{ }^{53} \mathrm{Cr}$ (9.548) and ${ }^{54} \mathrm{Cr}$ (2.618). The only radioactive isotope of consequence is ${ }^{51} \mathrm{Cr}$ with a 26 -day malf-life. Solution Equilibria

Crromive occurs in the $+2,+3$, and +6 oxidation states in water. The trivalent state is the only one that has a broad stability with ph and Eh (Pourtuix, 1966). The divalent state is unstable with respect to evolution of hydrogen (Baes and Mesiner, 1976). The hexavalent chromiun occurs in strongly oxidizing conditions only. Pourhaix (1966) and Baes and reswer (1976) disagree as to the most predominant solution species of $\mathrm{Cr}$ (III) in solution. According to Pourbaix the dominances of $\mathrm{Cr}^{3+}, \mathrm{CrOA}^{2+}, \mathrm{Cr}(\mathrm{OH})_{2}^{+}$are $\mathrm{PH}<4,4$ to $6 \mathrm{pH}$, and 6 to $9 \mathrm{pH}$, respectively. According to Baes and Mesiner (1976), the 
predominant solution species in solutions of $\mathrm{pH}<7.5$ is $\operatorname{Cr}(0.1)_{4}^{5+}$, and in solutions of 7.5 to 9 is $\mathrm{Cr}(\mathrm{OH})_{2}^{+}$. Mevertheless it is obvious that the hydrolysis species of $\mathrm{Cr}$ (III) will predominate above pH 6.

\section{Laboratory Adsorption Studies}

Bart lett and Kimble (1976a, 1976b) studied the behavior of $\mathrm{Cr}$ (III) and Cr(VI) in three acid soils with relatively high organic watter content $5 \%$ and a neutral clay soil without organic matter. The soils mere shaken at various pits in contact with $5 \mathrm{~m} \mathrm{Cr}$ (III)/m/solution for 24 hours. As pH in blank tubes (no soil) was raised above 4 the solubility of $\mathrm{Cr}$ (III) decreased with apparent complete precipitation at pH 5.5. When acidic organic soils mere added to the system $\mathrm{Cr}$ (III) was adsorbed totally when pH exceeded 4.5. Below pH 2.5 less than $20 \%$ of the $\mathrm{Cr}$ (III) was adsorbed.

Soil organic complexes of $\mathrm{Cr}$ (III) formed at low $\mathrm{DH}$ and appeared to remain stable and soluble even when soil pH's mere raised to levels where the $\mathrm{Cr}$ would be expected to precipitate. Adsorption and solubility behavior of $\mathrm{Cr}$ (III) as it varied with $P H$ and $P$ treatment was similar to that of $A$.

Oxidation of $\operatorname{Cr}(I I I)$ to $\mathrm{Cr}$ (VI) was not deanstrated at all, even under conditions of maxim aeration and high pH.

Adsorption and reduction of added $\mathrm{Cr}$ (VI) were characterized in soils with contrasting pH's, organic matter contents, and chemical and mineralogical properties.

Presence of soil organic matter brought about spontaneous reduction of $\mathrm{Cr}$ (VI) to $\mathrm{Cr}$ (III), even at pH's above neutrality. Reduction did not occur in soils very low in organic matter unless an energy source was added. Cou manure added to practically organic-free Cecil $\mathrm{B} 2$ reduced $\mathrm{Cr}$ (IV) only after the pH had been lowered below 3 with $\mathrm{KCl}$.

The solubility of $\mathrm{Cr}$ (VI) in the presence of excess Al changed in a pattern remindful of orthophosphate. All of the soils, except a DH 7.8 Cca horizontal material, adsorbed $\mathrm{Cr}(\mathrm{VI})$. Presence of orthophosphate prevented the adsorption of $\mathrm{Cr}(\mathrm{VI})$, presumably by competition for the adsorption sites. Consistent with this finding, $\mathrm{KH}_{2} \mathrm{PO}_{4}$ was found to be the best extracting agent for $\operatorname{Cr}(V I)$. 
It was concluded that behavior of $\mathrm{Cr}(\mathrm{VI})$, if it reanins in soils, is sinilar to that of orthophosphate. However, unlike phosphate, $\operatorname{Cr}(V I)$ is quickly reduced by soil organic matter. Thus, $\mathrm{Cr}(\mathrm{VI})$ added to a soil will remain mobile only if its concentration exceeds both the adsorbing and the reducing capacities of the soil.

Kamabata (1967) studied factors affecting the sorption of various radio- . muclides by a river sediment saple in the fresh or saline water. In addition, release of radionuclides in the sediments when it was exposed to the sea mater was studied. Hater and sediment samples mere collected at several places along

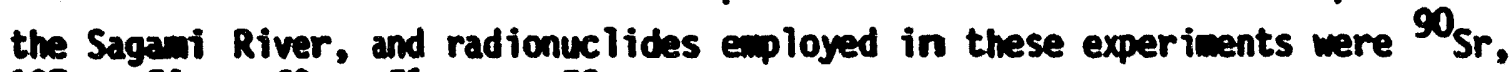
${ }^{137} \mathrm{Cs},{ }^{54} \mathrm{Mn},{ }^{60} \mathrm{Co},{ }^{51} \mathrm{Cr}$ and ${ }^{59} \mathrm{Fe}$. Cation-exchange capacity of the river sediments less than 120 mesh fraction was $1 \mathrm{meq} / 100 \mathrm{~g}$. Uptakes of radionuclides by the sediments were much affected by various competing cations, and the rate of inhibition depends not only on the cationic species but also on concentrations of cations. The higher in the concentration of a competing cation, the more inhibitive to the uptake of radionuclides by river sediments. Release of radionuclides wich had been sorbed by the river sediments in the filtered sea water was examined during 12 days storage. Both ${ }^{60} \mathrm{Co}$ and ${ }^{137} \mathrm{Cs}$ were released easily, and never were re-adsorbed. The release of ${ }^{90} \mathrm{Sr}$, however, increased for the first 2 days, then gradually decreased, which wight be due to the re-adsorption of the muclide ty sediments in the sea water. The rate of re lease of ${ }^{54} \mathrm{~m}$ was rather low, in addition, the amount released in the sea water decreased gradually, which might be due to the precipitation in the form of $\mathrm{mnO}_{2}$.

Melson et al. (1966) studied the uptake of $\mathrm{Cr}(\mathrm{III})$ and $\mathrm{Cr}$ (VI) onto Coluebia River sediment both untreated and oxidized with hydrogen peroxide. $\mathrm{Cr}$ (III) was taken up rapidly. For $\mathrm{Cr}$ (YI) contacting "oxidized" sediment uptake was much slower suggesting that in nature reducing material in sediments will reduce chromiun to the +3 valence state and will substantially increase sorption.

Field Studies

Arnstrong et al. (1968) and Eromiec and 61oyma (1973) studied the novement of chromila in model flumes. The design of the model river system, its 
instrumantation, and its uses are described in detail. The ground water supply, depth control, and aquatic life environment are itemized. The instruments installed measure several environmental factors, such as pH, dissolved 0, temperature, sunlight, and oxidation-reduction poteritial. To measure sunlight energy, two pyrtielioneters were used $\sim$ midway between the inlet and outlet. The digital data acquisition systen and its operation are described briefly. The dispersions of 8 radionuclide tracers at various velocities, water depths, and bed slopes were studied to deternine how their transport is affected by environmental conditions. Transport data were obtained by conducting laboratory, model river, and field tests. Canal, river, and estuarine environments provided the necessary field information on hytrodymanic dispersion and on uptake and release of radionuclides by sediments.

The dispersion of ${ }^{51} \mathrm{Cr}$ (III) is illustrated. The approximately Gaussian curves at each station indicated typical dispersion, but the long tails were the result of uptake and subsequent release of radioactivity by sediments and plants showing the effects of one environmental condition on radionuclide transport and also indicating the importance of geochemical and biochenical relations in transport. The effect of organic pollution on sediment uptake of ${ }^{51} \mathrm{Cr}(\mathrm{VI})$ is shom. On the control side of the nodel river, where no organic load was added, the percentage rise in the sediment was only moderate, whereas on the polluted side, the rise was rapid to a level 3 times that of the control side, because of ${ }^{51} \mathrm{Cr}$ sorbing onto settling particles. Sediment transport and its role in radionuclide transport is being considered now for study in the model river. Mathematical models are being developed to describe and predict radionuclide transport and the manner in which it is affected by environmental conditions.

The release of radiochromiun to the Columbia River from Hanford reactors has been extensively studied [Cutshall (1967), Evans (1973), Evans and Cutshall (1973), Forster and Hanson (1969), Glenn (1971), Gross (1965, 1967, 1972), Gross et al. (1963), Hanson (1967), Haushild et al. (1971a, 1971b, 1973a, 1973b), Hubbel and Glenn (1973), Perkins et al. (1966), Nelson and 
Haushild (1970), Melson et al. (1966), Renfro (1971) and Robertson and Perk ins (1975)]. In sumary, ${ }^{51} \mathrm{Cr}$ found in water at various locations between the reactors and the wouth of the Columbia River ( 375 miles) is predominantly in the soluble form $(<0.3 \mu \mathrm{m}), 98 \%$ at the reactor site and $90 \%$ at Vancouver 275 miles downstrean. That which is soluble is predominantly anionic 93 to 99x regardless of location. Most of the chromium passing Pasco, Mashington, (50 miles domnstrean from the reactor) reaches Vancouver, Mashington, (275 ailes downstrean from the reactor) except in the fall when some chromiun is stored in the bed sediments. Upon wixture with sea water, chromium, bound to suspended atter or bed sediments found in the river, does not desorb even after 11 meeks of contact in some instances. Thus, the srall fraction of chromium bound to particulates is tightly held. Nelson et al. (1966) leached Columbia River sediments with various extractants and found chromiun to be non-exchangeable but apparently resolubilized partially by sodiun hyposulfite treatment which rewoves hydrous oxides.

Robertson and Perkins (1975) sampled water directly leaving N Reactor at Hanford and water seeping from springs on the Columbia River bank nearby which are fed by the cooling water. The cooling water itself contains greater than $85 \times$ particulate ${ }^{51} \mathrm{Cr}(>0.3 \mu \mathrm{m})$. The ${ }^{51} \mathrm{Cr}$ wich reaches the spring is greater than 98 anionic and is $0.4 \%$ of the original cooling water concentration.

Sumary

Chromiun exhibits two valence states in aqueous environents: $\operatorname{Cr}(I I I)$ as $\mathrm{Cr}^{+3}$ and $\mathrm{Cr}(\mathrm{VI})$ as $\mathrm{CrO}_{4}^{-2}$. The $\mathrm{Cr}(\mathrm{VI})$ species in water probably do not sorb readily but do appear to reduce readily to $\mathrm{Cr}$ (III) upon contact with sediments, especially those containing organic or other reducing agents. Once adsorbed, chromila is not easily resoved via ion competition. Chrowium adsorption/ desorption will be sensitive to Eh and pH. 


\section{COBMt}

Matural Sediment and Rock Distributions

The average cobalt concentrations found in igneous and sedinentary rocks and sedivents are listed in Table 8.30. As can be seen, the cobalt content of rocks steadily decreases from the dark ultramafic rocks to the light-colored granitic rocks. The ultrabasic rocks usually contain the bulk of the cobalt in olivines and pyroxenes, but an occasional sulfide body in these rocks provides a workable ore deposit (Young, 1957). Cobalt normally is enriched in areas of low redox potential in the environment.

TABLE 8.30. Cobalt Concentrations in Igneous and Sedimentary Rocks and Sedients in ppo

\begin{tabular}{|c|c|c|c|c|c|c|c|c|}
\hline \multicolumn{5}{|c|}{ Igneous } & \multicolumn{3}{|c|}{$\frac{\text { Sedimentary }}{\text { Sand- }}$} & \multirow[b]{2}{*}{ Reference } \\
\hline $\begin{array}{l}\text { Ditra- } \\
\text { mafic }\end{array}$ & Basaltic & Higran & $\frac{\sqrt{\text { tic }}}{\text { Low Ca }}$ & Syenite & Shale & $\begin{array}{l}\text { Sand- } \\
\text { stone }\end{array}$ & $\begin{array}{l}\text { Lime- } \\
\text { stone }\end{array}$ & \\
\hline 150 & 48 & 7 & 1 & 1 & 19 & 0.3 & 0.1 & Young (1957) \\
\hline \multirow[t]{4}{*}{$\operatorname{mar}$} & \multicolumn{4}{|c|}{ Marine Clays } & \multicolumn{4}{|c|}{ Reference } \\
\hline & 7 & & 74 to & & \multicolumn{4}{|c|}{$\begin{array}{l}\text { Turekian and Hedepohl (196i) } \\
\text { El Hakeel and Riley (i961) }\end{array}$} \\
\hline & Nearsh & re Marin & Man & anese $\mathrm{No}$ & ules & \multicolumn{3}{|c|}{ Reference } \\
\hline & & & & 3400 & & Ner & ohl (? & 01 \\
\hline
\end{tabular}

During wathering processes, cobalt is separated from anganese and iron because its (III) oxidation state is normally unstable unless complexed. However, certain bacteria are knom to liberate chelated Co(III), as stable anino acid complexes from soil. Little is known, as yet, of these raactions, but the technique of predicting mineral solubilities for cobalt based on thermodynaic data way not be entirely applicable if the bacterial reactions are ignored (Hoore, 1964). Vinogradov (1959) reported the average soils content of cobalt as $8 \mathrm{ppm}$. Cobalt contents of up to 1.96 wt\% COO have been reported for calcite (Hacquaert, 1925). 


\section{Brief Chewistry}

Only one stable cobalt muclide, ${ }^{59} \mathrm{Co}$, is known to exist in mature. Cobalt -60 is the principal cobalt activation product radionuclide with a halflife over $1 \mathrm{rr}$. Reactor effluents also contain significant quantities of short-lived ${ }^{58}$ Co. Cobalt oxidation states include $\mathrm{Co}$ (II) and $\mathrm{Co}(\mathrm{III})$. Cobalt is geochenically sinilar to the other ferromagnetic and closely related transition etals, iron and nickel.

Sulfides of nickel and cobalt constitute the chief cobalt ore ninerals. $\mathrm{Co}^{+2}$ ionic radius in octahedral coordination is $0.74 \stackrel{\circ}{A}$, intermediate between $\mathrm{Mi}^{+2}(0.70 \AA)$ and $\mathrm{Fe}^{+2}(0.77 \AA)$ (Shannon and Prewitt, 1969). The relative stabilities of the $C O(I I)$ and $C O(I I I)$ states are greatly affected by complexing in aqueous solutions (Latimer, 1952a,b). Although $\mathrm{Co}^{+3}$ cannot exist in aqueous solution, complexing can stabilize the trivalent state wich would normally decompose in water.

Solution Equilibria

Cobalt exists as $\mathrm{CO}^{2+}$ and $\mathrm{CO}^{3+}$ and forms solution complexes with common anions $\left(\mathrm{OH}^{-}, \mathrm{Cl}^{-}, \mathrm{SO}_{4}^{2}, \mathrm{~m}_{3}^{-}\right)$. The relative concentration of these solution species in equilibriu with $\mathrm{COCO}_{3}$ and in an oxidizing environment $\left(\mathrm{O}_{2}=\right.$ $10^{-0.68}$ ) is depicted in figure 8.15. If a solid phase other than $\mathrm{CoCO}_{3}$ or a constant concentration of cobalt is chosen for the diagra, the lines will shift up and down, wile the relative concentration of various solution species would stay the same. The thermodynanic data for $\mathrm{COSO}_{4}^{+}$mere obtained from Sillen and Martell (1964) and the hydrolysis species data were obtained from Baes and Mesmer (1976). Data for ail the other species were obtained from Hagman et a1. (1968, 1969).

It can be seen from the figure that cobaltinous ion $\left(\mathrm{CO}^{2+}\right)$ and its solution complexes are the nost stable and dominant solution species in the oxidizing environdent. The cost dominant solution species up to a pH value of approximately 9.5 is $\mathrm{Co}^{2+}$.

Beyond pH 9.5, CO(OH $)_{2}^{0}$ becomes dominant. The activity of $\mathrm{CO}^{2+}$ ion in solution decreases 100 -fold with an increase of a pH unit, whereas the activity 


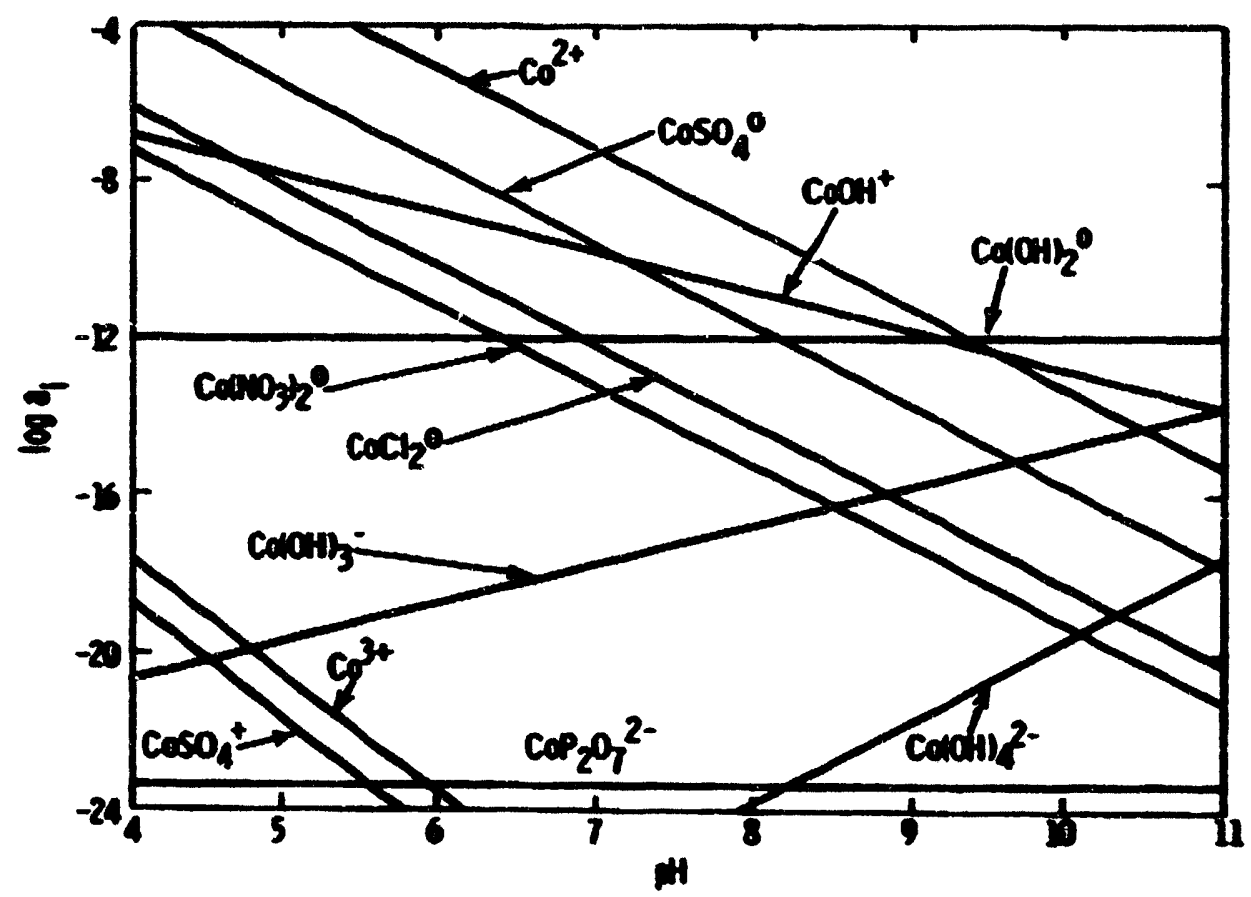

FIERE 8.15. The Activity of Various Cobalt Ions in Equilibrium with $\mathrm{COCO}_{3}(\mathrm{~s})$ in an Oxidizing Soil Environent $\left[\mathrm{pO}_{2}(\mathrm{~g})=0.68 \mathrm{ata}\right], \mathrm{pCO}_{2}(\mathrm{~g})=1.52 \mathrm{~atm}, \mathrm{pCl}^{-}=$ $\mathrm{pSO}^{-}=2.5, \mathrm{pm} 3=3.0$ and phipon 5.0

of $\mathrm{CO}(\mathrm{OH})_{2}^{0}$ does not change with the pH. These predictions are similar to Baes and Meswer (1976). If $\mathrm{COCO}_{3}$ was the solid phase that controlled the solubility, the total cobalt concentration in solution at ph 7 would be approximately $10^{-7} \mathrm{H}$ and approximately $10^{-12} \mathrm{H}$ at pH 9.5 .

\section{Laboratory Adsorption Studies}

Aston and Dursin (1973) studied the adsorption of cobalt onto marine sedisent from sea water. Factors such as sedisent and carrier concentrations and contact tice were varied. Only $0.9 \%$ of the ${ }^{60}$ Co was precipitated from sea water samples wich were filtered $50 \mathrm{hr}$ after spike addition. In adsorption experiments the cobalt reasining in solution reached steady state as early as $5 \mathrm{hr}$ and as long as $20 \mathrm{hr}$ for different sediments regardless of sediment concentration (100 to $2000 \mathrm{mg} / \mathrm{l}$ ). As the stable carrier cobalt concentration was increased from 0.5 to $4 \mu g / l$ (natural sea water contains $0.05 \mu g / l$ Co) the ${ }^{K d} C_{0}$ increased contraỵy to ion exchange theory. For fine grain sediements $\mathrm{Kd}$ increased from about $1 \times 10^{5}$ to $3 \times 10^{5} \mathrm{ml} / \mathrm{g}$. At sedient concentrations below $50 \mathrm{mg} / l_{,} K_{C_{C}}$ for carbonaceous sediments is relatively high 1 to $3 x$ 
$10^{4}$ and drops to 1 to $5 \times 10^{3}$ at sediment concentrations above $50 \mathrm{mg} / \mathrm{l}$. For clay sediments no consistent trend was observed for $\mathrm{Kd}_{\mathrm{Co}}$ versus sediment concentration. The extreane dependency of carbonaceous sediments at low concentration may reflect a cobalt substitution for calciu in lattice sites or $\mathrm{COCO}_{3}$ precipitation. There was $n 0$ direct relationship between $\mathrm{Kd}_{\mathrm{CO}}$ and sed twent aineralogy, exchange capacity or particle size. The mechan isa controlling cobalt sorption could not be identified.

In other studies Durssan and coworkers found the adsorption of cobalt perplexing [Dasson and Dursim (1974), Dursma and Eisma (1973), and Dursina and Gross (1971)]. Using the same sedinent at various agitations (quiescent, vigorous stirring, slight stirring) and various time sequences, variable cobalt sorption and desorption results mere obtained. For Black Sea sediments cobalt appears to be less mobile under anoxic conditions than oxic (Kd $2.1 \times 10^{4}$ versus $9 \times 10^{3}$ ); yet Bonatti et al. (1971) finds natural cobalt to be enriched in oxidizing layers of cores from the Pacific Dcean when compared to reduced layers. Results of $\mathrm{Kd}_{\mathrm{C}_{0}}$ for various sediments and the rate at which cobalt is adsorbed are shown in Table 8.31.

TAPEE 8.31. Kd $C_{0}$ in Various Sediments from Dursma and Eisma (1973)

\begin{tabular}{|c|c|c|c|}
\hline Sedicent & $\begin{array}{c}\log _{K} K_{0} \\
\text { Unitless } \\
\end{array}$ & $\begin{array}{c}K d_{\text {avg }} \text { (est), } \\
1 / g\end{array}$ & $t_{1 / 22 \text { days }}$ \\
\hline Atlantic Ocean & $3.9 \pm 1.1$ & $1.2 \pm 10^{4}$ & $6.9 \pm 7.2$ \\
\hline Pacific Ocean & $4.9 \pm 0.9$ & $1.5 \pm 10^{4}$ & $7.8 \pm 6.7$ \\
\hline Indian Ocean & $3.9 \pm 0.4$ & $1.2 \pm 10^{4}$ & $5.8 \pm 2.6$ \\
\hline Baltic Ocean & $4.8 \pm 0.4$ & $9.5 \pm 10^{4}$ & $12.6^{-}$ \\
\hline Morth Sea & $4.7 \pm 0.6$ & $7.0 \pm 10^{4}$ & 25 \\
\hline Mediterranean Sea & $3.7 \pm 1.0$ & $7.3 \pm 10^{4}$ & $4.9 \pm 5.4$ \\
\hline Black Sea & $4.0 \pm 0.3$ & $1.4 \pm 10^{4}$ & 8 \\
\hline Red Sea & 3.6 & $6.7 \pm 10^{3}$ & 6 \\
\hline
\end{tabular}


Fukai and Lang (1968) and fukai and Murray (1973) report on the stability of tracer ${ }^{60}$ Co added to sea mats: versus $\mathrm{pH}$. Results indicated that nost of the cobaltinous ions stay in solution within the pH range 7 to 9 in sea water and that the formation of a solid phase, if any, is not due to $\mathrm{CO}(\mathrm{OH})_{2}$. They hypothesized that the geochemical behavior of cobalt in marine environients is closely related to that of manganese. Doshi et al. (1973) confirm the quantitative removal of trace cobalt by manganese oxide.

Murray and Murray (1973) studied the adsorption of ${ }^{60}$ Co by sediments in fresh wter and desorption of ${ }^{60} \mathrm{Co}_{0}$ from the sediments when contacted with sea nater. More than $80 \%$ of ${ }^{60}$ Co was adsorbed within $48 \mathrm{hr}$ at pH 8.0 but only $30 \%$ of the ${ }^{60}$ Co was desorbed at ph 8.0 by sea mater in $24 \mathrm{hr}$. Cobalt sorption/desorption was very dependent on ph. For fresh waters at ph 7 sorption dropped to $20 \%$ (versus $80 \%$ at ph 8) as shown in figure 8.16 . For $250 \mathrm{mg} / \mathrm{l}$ sediment the $\mathrm{Kd}_{\mathrm{C}_{0}}$ would be 1000 at pH 7 and 16,000 at ph 8 .

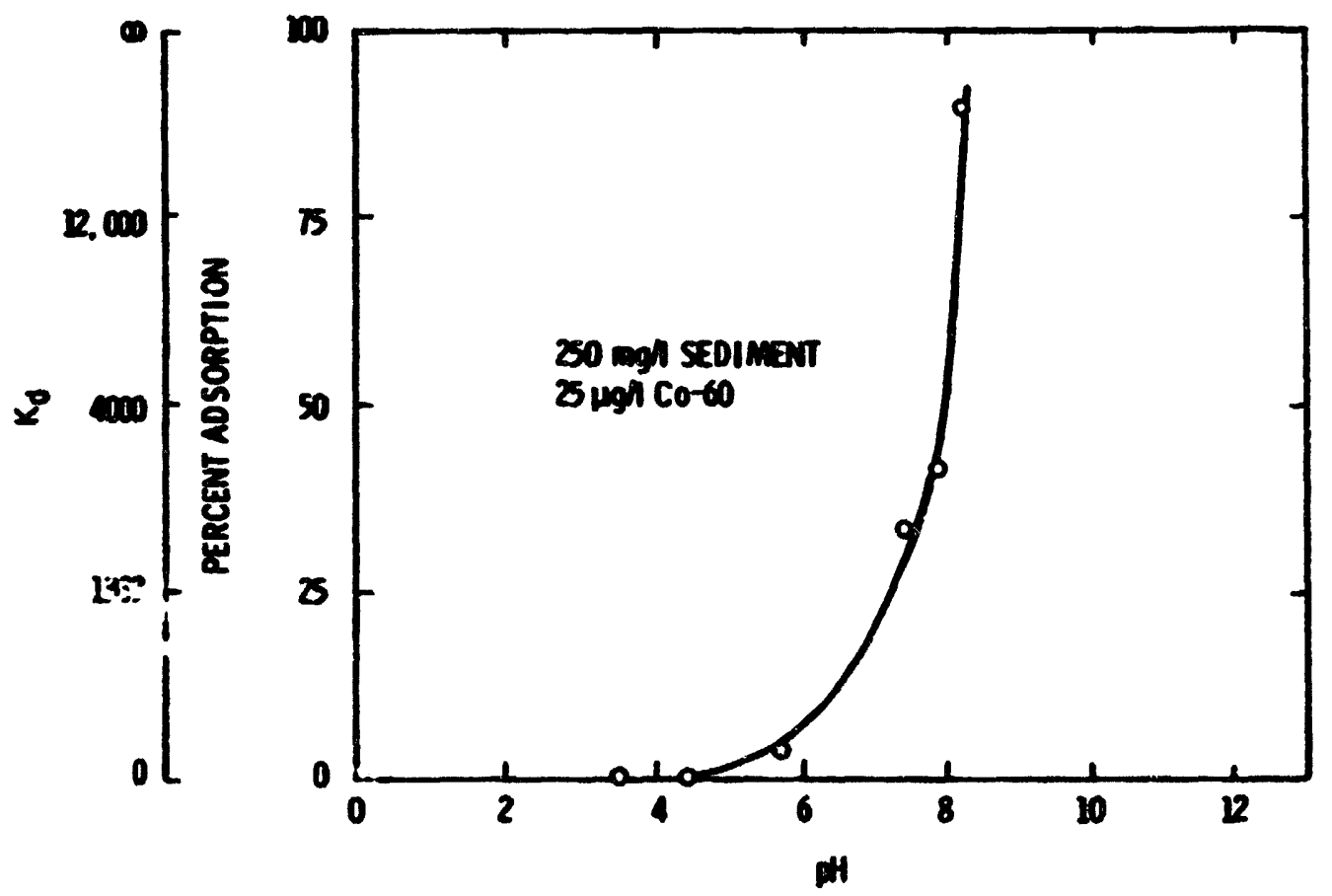

FIGRE 8.16. Variation of 24sorption of ${ }^{60} \mathrm{Co}$ at Constant Carrier Concentration and Sediment Load with Varying oH 
In a sinilar fashion desorption in sea water is dependent on pH as seen in Figure 8.17. The adsorption/desorption reactions reached eqsilibriv within $72 \mathrm{~m}$. Cobalt adsorption from fresh mter onto Var River sediments decreased with increasing concentration of soluble organic matter, but desorption in sea water of adsorbed cobalt was not affected by soluble organic content of sea water. Also investigated was the possibility of scavenging of cobalt by iron hydroxide at $50 \mathrm{\mu g} / \mathrm{l}$ iron. The results showed little scavenging $(<3 x)$ of solule ${ }^{60} \mathrm{Co}$.

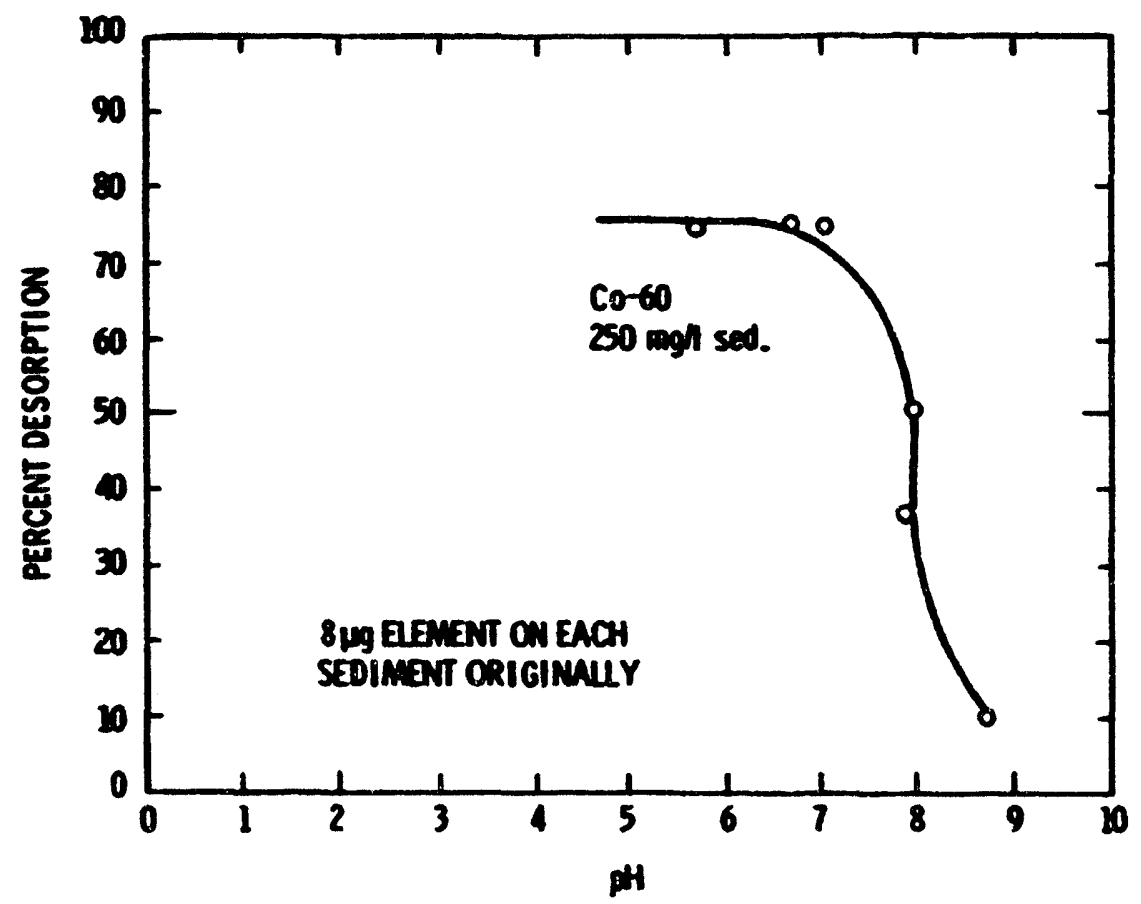

FIGRE 8.17. Variation of Desorption of Trace Elements at Constant Adsorbed Trace-Element Concentration and Sediment Load with Varying pH

Jenne and Hahlberg (1968) found cobalt bound to thiteoak Creek, Tennessee, sediments to be unrewovable with anonium extractants wich typically replace exchangeable elements from sediments. The less than 60 -mesh bed sediments had a ${ }^{K d} C_{0}$ between 1400 to $2400 \mathrm{Dl} / \mathrm{g}$. The adsorption of ${ }^{60} \mathrm{Co}_{0}$ was attributed to scavenging by iron and manganese oxides. 
Ramabata (1967) studied factors affecting the sorption of various radiomuclides by a river sediment in fresh and saline waters. In addition, release of radionuclides from the sediments when they were exposed to sea water was studied. Water and sediment samples were collected at several places along the Sagani River. Cation exchange capacity of the river sediments less than 120 mesh fraction was 1 meq/100 g. Uptakes of radionuclides by the sediments were much affected by various competing cations and the rate of inhibition depents not only on the cationic species but also on concentration of cations. The higher the concentration of a competing cation, the wore inhibitive was the uptake of radionuclides by river sediments. Release of radionuclides which had been sorbed by the river sedinents in filtered sea water was examined over 12 days. Cobait-60 was released easily, and never was re-absorbed.

Hahmoud et a). (1968, 1973) performed laboratory and field tests on cobalt uptake by sediments and biota from the Ismailia Canal. Affinity of these sediments for sorption of radionuclides was influenced by grain-size distribution, contact tiwe and carrier concentration. Linear relationships were noted between the logarith of capacity of botton sediments for sorption of radiomuclides versus logarith of carrier concentration. A freundlich sorption isotherm was identified. Possible applications of the experimental laboratory data to the matural conditions prevailing in the Ismailia Canal are also discussed.

Meeussen et a1. (1975), using ${ }^{60} \mathrm{Co},{ }^{85} \mathrm{Sr}$ and ${ }^{137} \mathrm{Cs}$ as tracer ions, studied the sorption capacity of Scheldt sediments for $\mathrm{CO}^{2+}, \mathrm{Sr}^{2+}$ and $\mathrm{Cs}^{+}$ and their distribution coefficients between sediment and Scheldt water.

It is found that clay and silt samples show relatively high sorption capacities for cobalt and cesiun, compared with the low fixation rate for strontiun.

The selectivity of the sediments for a particular ion, in competition with other ions, was studied and the sequence found is in accordance with the distribution coefficients. From these experiments it way be concluded that the high salt concentrations, present in normal scheldt water, will liait the risks of radioactive isotopes accumulation in the sediments. 
0jim et al. (1965) studied the physico-chemical behavior of ${ }^{89} \mathrm{Sr}$, ${ }^{90} 0_{S r},{ }^{137} \mathrm{Cs}$ and ${ }^{60} \mathrm{Co}$ ions in relation to $\mathrm{pH}$ of marine water, trace elements dissolved in it, fragments of marine organisms living in it, and sea sediments.

Radosavtjevic and Tasovac (1970) studied, as a part of the program for the control of the radioactivity of the Danube, the behavior of different radionuclides and the fixation of ${ }^{60}$ Co by suspensions. The influence of different parzometers on fixation was deternined.

Sctell et al. (1979) studied the fate of $C_{0}$ in seawater via dialysis experiments wich have been described in the section on anericium. Table 8.9 shows that any Co mich passed through the dialysis bag into the sediment slurry becane associated with particulate matter. Plankton did not adsorb Co to any extent. A second experiment with montworillonite clay as the adsorbent showed very little sorption on $>0.45 \mu$ particles. Perhaps the montworillonite was saller than the filter membrane used and appears with the soluble fraction (see Table 8.10, Anericiun section). Schell et al. (1980) performed laboratory experinents to deternine the effect of pH on cobalt sorption for the Clinch River (Temessee) freshmater system. The Kd Co increases by wore than two orders of agnitude between pH 6 and 7.5. Above pH 7.5 td pH 10 there is no further change. Cobalt sorption at neutral pH needs further study iu inderstand this dramatic increase in sorption.

Schell et al. (1980) studied the effect of five organics on cobalt sorption in a freshater environment. Two organics caused $\mathrm{Kd} \mathrm{Co}_{0}$ to increase significantly and one (EDTA) caused a significant decrease (see Table 8.12). Care wust be exercised in interpreting the significance of these results as rather high concentrations of organic ligands were utilized.

Schell et al. (1980) performed dialysis experiments using Lake Michigan fresh water and sediments. Much of the cobalt rearins soluble but the sediment adsorbs a significant percentage. Cobalt does not associate strongly with phytoplankton or ganic detritus. 
Tiller et al. (1963) studied sorption of $\mathrm{CO}^{+2}$ from very dilute solutions by soil clays in the presence of a $0.11 \mathrm{CaCl}_{2}$ and compared with the sorption by pure minerals (mica, montaorillonite, verwiculite, kaolinite, quartz, hematite, geothite) under similar conditions. The cobalt sorption results were not very different. Organic matter in soils containing small to moderate anounts did not seem to affect cobalt adsorption.

Dunigan and Francis (1972) and Fukai and Murray (1973) described the interaction of cobalt with heic acids, EOTA and natural organic decomposition products. Although interaction may be slow, nonionic and anionic complexes of cobalt with matural organics form in sea water and fresh water. At the low concentrations found in matural waters for both chelating agents and cobait, formation of complexes would be slow but if formed could greatly increase the mobility of cobalt.

Friend (1963) reported that suspended solids in a pond environment took up ${ }^{60}$ Co rapidly, with suspended illite having the most selectivity for cobalt rewoval of the clay winerals. Wilding and Rhodes (1963) studied the effects of $100 \mathrm{ppm}$ citrate and EOTA on cobalt equilibrium distribution coefficients with the zeolite clinoptilolite and Mell-81 sediments. At pH 6.5, citrate enhanced cobalt adsorption on clinoptilolite, the $\mathrm{Kd}$ value being 48 with no treatment and 102 with 100 ppo citrate added. Nith EDTA addition at pH 6.5, the cobalt Kd value fell from 100 to $1 \mathrm{ml} / \mathrm{g}$. Hell-81 sedinents adsorbed about the same amounts with and without citrate. At PH 7.7, the cobalt Kd was $30 \mathrm{ml} / \mathrm{g}$ with no citrate and $26 \mathrm{ml} / \mathrm{g}$ with citrate. At 7.7, the cobalt $\mathrm{Kd}$ was $1000 \mathrm{ml} / \mathrm{g}$ with no EOTA and $1.2 \mathrm{ml} / \mathrm{g}$ with EDTA. Tiller et al. (1963) found no correlation between cobalt adsorption and soil mineralogy. Hawkins (1964) described a process of cobalt removal from waste solutions by scavenging on manganese dioxide precipitate and removal of the remaining cobalt by ion exchange on lignite, soil and the natural zeolite clinoptilolite. Distribution coefficients for cobalt iere 56, 800 and $24 \mathrm{ml} / \mathrm{g}$ for Idaho soil, lignite and clinoptilolite, respectively.

Gonzalez and 6omez (1961) found that most of the cobalt in Andalusian soils was found in oxide and hydroxide gels associated with clays. There was a positive correlation between cobalt content of the soil and $\mathrm{Fe}_{2} \mathrm{O}_{3}$ content. 
James and Healy (1972) showed the adsorption isotherm for $1.2 \times 10^{-4} \mathrm{M}$ $\mathrm{Co}^{+2}$ on silica at $25 \mathrm{C}$ as a function of pH. Adsorption is 10 at pH 6 and greater than $90 \%$ at pH 8. Computed hydrolysis data at this cobalt concentration are also shown.

Tewari et al. (1972) investigated the adsorption of $\mathrm{Co}^{+2}$ by $\mathrm{Fe}_{3} \mathrm{O}_{4}, \mathrm{Al}_{2} \mathrm{O}_{3}$ and $\mathrm{mnO}_{2}$ as a function of concentration, solution $\mathrm{pH}$ and temperature in connection with the transport of cobalt adsorbed on corrosion product oxides. Hydrolysis of $\mathrm{Co}^{+2}$ was suggested as a possible mechanisin for the marked dependence of cobait adsorption on $\mathrm{pH}$ and terperature.

\section{Field Studies}

Brungs $(1963,1974)$ studied the fate of ${ }^{60}$ co added to a 30,000 gallon pond with a sand substrate for 80 days after addition of tracers. Sorption was rapid; after 4 days, only $10 \%$ of the cobalt remained in solution, $31 \%$ was found on suspended sediments and $59 \%$ in the bed sediments. After 80 days the distribution was as follars: dissolved $0.68 \%$, suspended particulate $0.33 \%$, bed sediment 98.94\%.

Parker (1966) described a study of the distribution of cobalt between the liquid and solid (suspended particles) portions in 8 lakes in wisconsin. Samples were taken from various depths. Seasonal changes in distribution, differences in distribution in various lakes, and evaluation of the causes of various distributions are presented.

Carrigan (1969), Carrigan et al. (1967), Pickering (1969, 1970) and Pickering et al. (1965) indicated only $9 \%$ of the total ${ }^{60}$ Co released from Oak Ridge National Lab remains in the Clinch River with 21 miles of the discharge. The bulk of cobalt reached the bottom sediments as particulate matter. Sorption of cobalt by Whiteoak Creek sediments showed higher sorption at pH 6 than 9 probably because colloidal cobalt was not as readily centrifuged out at the higher pH due to hydroxyl ion stabilization. Equilibrium was not reached within the 7-day experiment. At $\mathrm{pH} 6 \mathrm{Kd} \mathrm{Co}_{0}$ increased from 1,734 (1 hr) to 28,017 ( 3 days) and 71,567 (7 days). At ph $9 \mathrm{Kd} \mathrm{Co}_{0}$ was 5,120 ( $\left.1 \mathrm{hr}\right), 9,354$ ( 3 days) and 11,445 ( 7 days). The distribution of cobalt in water samples from thiteoak Creek, Clinch River and the Tennessee River showed most of the 
cobalt in a dissolved $(<0.7 \mu \mathrm{m})$ form $(70$ to 983$)$ and very little bound to suspended solids. The cobalt that does reach the bed sediwents does not desorb upon contact with competitive salt solutions but will readily desorb if acid solutions are introduced. This suggests hydrous oxide scavenging or colloid formation as a key mechanisa.

Duguid (1976, 1977) and Means et al. (1976) have shom ${ }^{60}$ co movement from shallow land burial grounds to thiteoak Creek and the Clinch River is miniy caused by soluble organic complexation (85\% by EDTA present for waste disposal and $15 x$ by natural organic acids). Truly inorganic cobalt is found to be quite inmobile $\mathrm{Kd}_{\mathrm{CO}_{0}}{ }^{10^{4}}$. At $10^{-5} \mathrm{n}$ EDTA the $\mathrm{Kd} \mathrm{Co}_{0}$ was reduced to $\sim 3$ a reduction of four orders of magnitude.

Delaplane et al. (1969), Glenn (1971), Gross (1966), Gross et al. (1963), Haushild et al. (1971, 1973a), Hubbell and Glem (1973), Perkins et al. (1966), Robertson (1974), Robertson and Perkins (1974, 1975) and Robertson et al. (1973) have studied the distribution and fate of radiocobalt produced at Hanford, Mashington, and discharged into the Columbia River and Pacific Ocean. The cobalt found in the Columbia River is $98 x$ particulate (>3 $\mu \mathrm{m})$ and bound to susperded matter. Upon reaching the ocean, the high salt content only leaches about $10 \%$ of the cobalt bound to fine bed sediment behind a dam. During high rumoff periods much of this fine material is resuspended and could be carried to the Pacific Ocean. The cobalt does not appear to be bound to readily exchangeatle sites. Cobalt-60 present in cooling water emanting from the Hanford $\boldsymbol{N}$ reactor is about evenly split between particulate $(>0.3 \mu \mathrm{m})$ and cationic with on $1 y$ traces of nonionic or anionic forms but after percolation through soil the cobalt reaching the Columbia River is $73 \%$ anionic, 17\% cationic and 96 nonionic. The soil effectively removes particulate and cationic forns. The fate of the anionic and nonionic forms once in the river have not been determined, but assuming their fate is similar to previous studies of cobalt produced by now idle weapons reactors, the cobalt should rapidly become sorbed on particles.

Gloyma et a1. (1966), Gromiec and Gloyna (1973) and Yousef et al. (1970) investigated the dymanics of cobalt transport in model rivers (flumes). The most significant factors influencing sorption of cobalt by bottom sediments 
mere contact time and pH. Cobalt was not removed by exchange competitive salts but was readily acid soluble at pH 4. Probably sorption mechanisus are precipitation of hydroxides and carbonates.

Ophel and Fraser (1971) studied the fate of cobalt in a fresh water lake on the property of Atomic Energy of Canada (Chalk River, Ontario). Most of the nuclide is confined to the upper few centimeters of the sediment.

Magno et al. (1970) reported that ${ }^{60}$ Co const ituted only $<0.1 \%$ of the beta activity in surface drainage from the huclear Fuel Services piant lagoon system in Hestern Nea York State. The ${ }^{60}$ Co in the effluent was relatively sall, but was all in solution and thus able to travel with the surface water. The implication is that the "soluble" ${ }^{60} C_{0}$ was migrating as a complexed species. The iaplication is that the ${ }^{60} \mathrm{Co}$ is complexed by low molecular weight natural organics. Migration of ${ }^{60}$ Co would be negligible in the absence of organic complexation because the soil adsorption capacity for inorganic forms of ${ }^{60}$ Co was reported to be extremely high. Manganese oxides in the Conasauga shale were the principal adsorbents of ionic and weakly complexed ${ }^{60}$ Co.

Saas and Grauby (1973) studied the migration of cobalt and its transfer mechanisms from nuclear reactor to river water, irrigation water, and finally ground water. Three fractions of ${ }^{60}$ Co mere differentiated including a chelated fraction, an exchangeable fraction and a hydrosoluble fraction. The hydrosoluble fraction was defined as the totality of the organic and mineral components of the soil that are water soluble. The different fractions in a brom, calcareous soil were given. The hydrosoluble fraction constituted about 70\%, the exchangeable fraction about $20 \%$ and about $10 \%$ was chelated from river water containing ${ }^{60} \mathrm{Co}$. The hydrosoluble form on an alluvial calcareous soil colum varied from $10 \%$ at the point of input to $60 \%$ at $17 \mathrm{~cm}$ depth. The water soluble material was only slightly biodegradeable, eventually migrating to the ground water through application in irrigation water. The pollutants in the river water, including industrial wastes and municipal sewage, are responsible for the rapidly migrating hydrosoluble fraction. The authors suggest that the quality of surface drainage water will have to be taken into account during nuclear reaction siting. 


\section{Sumary}

Among the various sediment components, $\mathrm{MnO}_{2}, \mathrm{Fe}_{2} \mathrm{O}_{3}$ and illite have been shown to have a strong affinity for cobalt. With the increase in $\mathrm{pH}$ (especially 6 to 9) the adsorption of cobalt increases. This increase in adsorption with $\mathrm{pH}$ has generally been explained as due to the formation of cobalt colloids and hydrolysis of $\mathrm{Co}^{2+}$. The presence of various complexing ions such as EDTA, cyanide, and fulvic acids has been shown to reduce the adsorption by sediments. These laboratory results are consistent with the theoretical predictions (Figure 8.15) which indicate that in acidic pH values cobalt would predominantly exist as $\mathrm{Co}^{+2}$ and with the increase in $\mathrm{pH}$ it hydrolyzes to $\mathrm{COOH}^{+}$and $\mathrm{CO}(\mathrm{OH})_{2}^{\circ}$.

Discrete cobalt minerals have not been identified in sediments. High concentrations of cobalt are required to precipitate cobalt minerals and thus it is not likely that any of the minerals would exist in the environment. However, in highly alkaline conditions, $\mathrm{COCO}_{3}$ would maintain fairly low concentrations of cobalt in solution and thus might exist.

Cobalt is apparently relatively easily complexed by natural organics and by synthetically-produced organics and as such is able to migrate with relative ease through the geologic media with which it mould normally react by adsorption. 
QRIVI

Matural Sediment and Rock Distributions

The element curium has not been reported to occur naturally in sediments or rocks.

\section{Br jef Chemistry}

Thirteen isotopes of curium are known from ${ }^{238} \mathrm{~cm}$ to ${ }^{250} \mathrm{Cm}$, most with relatively short half-lives. There are no naturally-occurring curium isotopes. The curium isotopes are produced in reactors by $n$ reactions on ${ }^{239} \mathrm{Pu}$ or by decay . californium isotopes (Keller, 1971). The LIMR reprocessing waste isotopes include: ${ }^{243} \mathrm{Cm}$ ( 32 years), ${ }^{244} \mathrm{Cm}$ (18.1 years), ${ }^{245} \mathrm{Cm}(8,265$ years), ${ }^{246} \mathrm{~cm}(4,711$ years $),{ }^{247} \mathrm{Cm}\left(1.6 \times 10^{7}\right.$ years and ${ }^{248} \mathrm{~cm}\left(3.84 \times 10^{5}\right.$ years $)$. Curium-250 also has a long half-life, but yields are normally very low. Curium can exist in $\mathrm{Cm}$ (III) or $\mathrm{Cm}$ (IV) oxidation states, but stabilization of $\mathrm{Cm}$ (IV) requires high concentrations of fluoride ions to form the anionic complexes $\mathrm{CuF}_{5}^{-}$and $\mathrm{CuF}_{6}^{-2}$ (Keller, 1971). Only trivalent curium is normally stable in aqueous solutions. The ionic radius of $\mathrm{Cm}^{+3}$ in coordination number 6 is $0.986 \AA$. Trivalent curium forms many complexes with inorganic ligands found in wastes and in ground waters.

\section{Solution Equilibria}

Curiu (IV) is not stable in solutions because of self-radiation, and it rapidly changes to $\mathrm{Cm}$ (III). Only trivalent curium is stable in aqueous solutions. Keller (1971) reported that the behavior of $\mathrm{Cm}^{3+}$ in solution is similar to lanthanide elements. Most of the lanthanides form trivalent hydroxides in natural waters with solubility prosucts of $<10^{-19}$ (Vickery, 1953). Thomas and Jacobs (1969) found that the activity of curium in $0.1 \mathrm{M} \mathrm{NaCl}$ solutions wich contained approximately $10^{-11} \mathrm{M} / \mathrm{E}$ of curium decreased at $\mathrm{pH}$ values above 3. They attributed this decrease in activity in pure solutions to either precipitation or adsorption on walls. If this is assumed to be due to precipitation, the solubility product of curium hydroxide would be at least as low as the lanthanides, and probably much lower.

Since thermodynamic data for the curium compounds are not available, it was decided to plot the solution species in equilibrium with $\mathrm{Cm}(\mathrm{OH})_{3}$ with an 
assuned $\log \mathrm{K}^{\circ}$ of 2 for the dissolution of $\mathrm{Ca}(\mathrm{OH})_{3}\left[\mathrm{Cm}(\mathrm{OH})_{3}+\mathrm{HH}^{+}+\mathrm{Ca}^{3+}\right.$ $\left.+3 h_{2} 0\right]$ in order to show the relative activity of various solution species of curiu with the changes in pH. Keller (1971) reviewed the curiun data and stated thit little work has been performed on the complex chemistry of curium and since a wide variation occurs in stability constants determined by various authors, these values should be regarded as relative rather than absolute. The thermodymic data used to develop figure 8.18 mere obtained from the following sources: Trotman-Dickinson (1973), $\mathrm{CmCl}{ }^{2+}, \mathrm{CuF}^{2+}, \mathrm{CuSO}_{4}^{+}$; Jones and Choppin (1969), $\mathrm{Cm}_{3}^{2+}$; Shalinets and Stepanov (1972), $\mathrm{CmOH}^{2+}, \mathrm{Cm}(\mathrm{OH})_{2}^{+}$; and Mosk in (1969), $\mathrm{Crl}_{2} \mathrm{PO}_{4}^{2+}$.

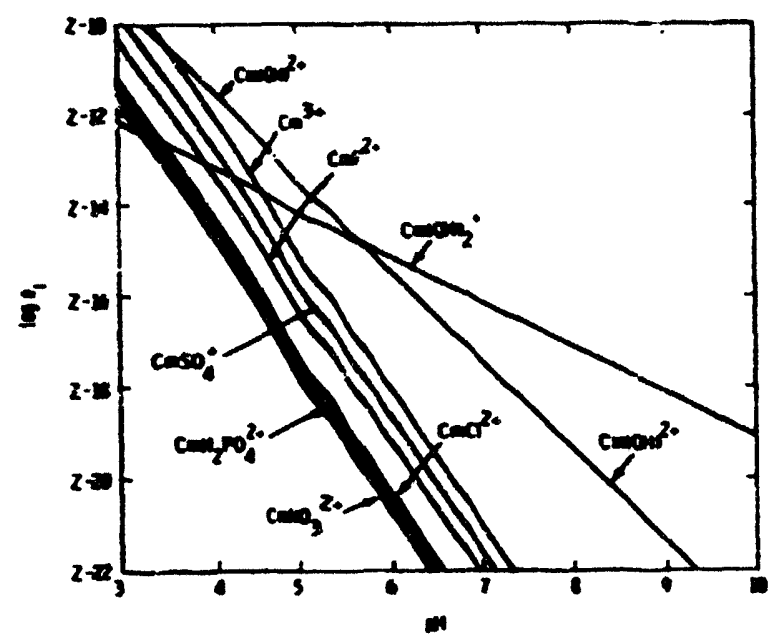

FIEURE 8.18. The Activity of Yarious Curiu Ion Species in Equilibrium with $\mathrm{C}(\mathrm{OH})_{3}(\mathrm{~s})$ with of $-=4.5, \mathrm{PCl}^{-}=\mathrm{PSO}_{4}^{-}=$ 2.5, $\mathrm{PmO}_{3}=3.0$ and $\mathrm{pH}_{2} \mathrm{PO}_{4}=5.0$

It can be seen fro figure 8.18 that curitim forms various solution complexes with $\mathrm{OH}^{-}, \mathrm{F}^{-}, \mathrm{Cl}^{-}, \mathrm{m}_{3}^{-}, \mathrm{SO}_{4}^{2-}$, and $\mathrm{PO}_{4}^{3-}$. The activity of all the complexes decreases with the increase in pH. The solution complexes of $\mathrm{PO}_{4}^{3-}, \mathrm{Cl}^{-}, \mathrm{mO}_{3}^{-}$do not contribute significantly to the total curium concentration in solutions. The most dominant solution species in pH ranges of 3.3, 3.3-5.7, 5.7 and $\mathrm{up}$ are $\mathrm{Cm}^{3+}, \mathrm{Ca}\left(\mathrm{CH}_{1}\right)^{2+}$, and $\mathrm{Cm}(\mathrm{OH})_{2}^{+}$, respectively. 


\section{Laboratory Adsorption Studies}

Wo studies have been performed on curiu adsorption with aquatic sed iments.

The adsorption characteristics of ${ }^{242} \mathrm{Cm}$ on several clays were easured in distilled water and $0.1 \mathrm{M} \mathrm{MaCl}$ by Thomas and lacobs (1969). Alsorption was not a function of ion-exchange capacity because greater adsorption occurred in 0.14 n $=61$ solutions (Jacobs et al., 1966) than in distillied mater solutions. When adsorption studies were cade as a function of ph, some coriun mas renoved from solution even withourt the addition of clay at ph values above 3. This was de to precipitation or to adsorption on glass alls. Addition of clay caused a considerable increase in adsorption possibly because increased surface area as available for deposition. Colum-loading studies of ${ }^{242} \mathrm{Ca}$ tagged $0.1 \mathrm{M} \mathrm{MaCl}$ showed normal ioa-exchange chromatographic breakthrough at pH 1. Nove ph 1, the efflueat deviated from normal chromatographic curves and rewined constant during the entire run. The effluent/inf luent ${ }^{242} \mathrm{Ca}$ concentration ratio at pil 3 was about 0.008; at ph 7 t:e ratio was 0.028; and at ph 10 the ratio as 0.150 . Although 242 Co precipitated from stock solution af ph values above 3, the colum leakage of curium increased with increasing ph. The leakage is probably caused by hydroxy and oxo-coplexes forming radiocolloids. Movenent of curiu through soil is probably restricted by filtration and surface adsorption of radiocolloids rather than by ion exchange.

Sheppard et al. (1976) imestigated the distribution values of ${ }^{244} \mathrm{Ca}$ on several Hashington and South Carolina soils. The 50-day distribution results for trace ${ }^{244} \mathrm{Co}$ in a distilled mater solution are given in Table 8.32. The distribution for curiun between suil and solution increased with time. The distribution values were computed in the same manner as a $K d$ value. However, Kd values are defined as obtained at soil-solution equilibrium wich these values did not attain. The slow increase in distribution values was interpreted by the authors as dre to the presence of colloids. It was also shown that iron and anganese oxides were effective scavengers for curium. 
TABLE 8.32. Curiu 50-day Distribution Computed fred Shepoard et al. (19;5)

\begin{tabular}{|c|c|c|}
\hline Soil Identity & $\begin{array}{c}\text { Distribution } \\
\quad \mathrm{l} / \mathrm{g} \\
\end{array}$ & $\begin{array}{l}\text { Monthly Cinange in } \\
\text { Distribution, } 8\end{array}$ \\
\hline $\begin{array}{l}\text { Muscatine } \\
\text { Silt Loa }\end{array}$ & 1330 & +8 \\
\hline $\begin{array}{l}\text { Burbank } \\
\text { Loany Sand }\end{array}$ & 106 & +27 \\
\hline $\begin{array}{l}\text { Ritzville } \\
\text { Silt Loam }\end{array}$ & 704 & +40 \\
\hline $\begin{array}{l}\text { Fuquay Sand } \\
0 \text { to } 5 \mathrm{~cm} \text { Depth }\end{array}$ & 1850 & +26 \\
\hline $\begin{array}{l}\text { Fuquay Sand } \\
5 \text { to } 15 \text { an Depth }\end{array}$ & 1850 & +28 \\
\hline $\begin{array}{l}\text { Fuquay Sand } \\
15 \text { to } 50 \mathrm{~cm} \text { Depth }\end{array}$ & 1240 & +18 \\
\hline
\end{tabular}

Mishita et al. (1976) determined the extractability of plutonium and curiun from a contaminated soil as a function of pH and soil components. The organic matter and pH influenced hydrolysis, precipitation, coprecipitation and adsorption of the radionuclides. In the work, $2 \mathrm{~g}$ of soil were suspended in $25 \mathrm{ml}$ of extracting water, in cuplicate, and the pH adjusted with MaOH or $\mathrm{HmO}_{3}$. The $\mathrm{Kd}$ values computed from Mishita et al. (1976) are given in Teble 8.33 for the untreated Aiken clay loan, a kaolinitic soil, at several pH values. The Aiken clay loan also was treated sequentially with progressive treatments to remove salts, organic matter, carbonates, manganese oxides, iron oxides, free silica and alumina and amorphous alumino-silicates. The organic matter was show to have the greatest ability to retain curium, but this was a function of pH as well. Below pH 4.5, curium was less strongly adsorbed whether organic matter was present or not.

Field Studies

Duguid (1976) reported that Bondietti had show that the alpha contanination in water from seep S-4 along the south side of burial ground 5, Oak Ridge, 
TngeE 8.33. Kd Values for ${ }^{242} \mathrm{~cm}$ in Untreated arken Clay Loam (Wishita et al., 1976)

\begin{tabular}{|c|c|c|c|}
\hline PH & ${ }^{242} \mathrm{~cm} \mathrm{Kd}, \mathrm{Dl} / \mathrm{g}$ & pH & ${ }^{242} \mathrm{C} \times \mathrm{Kd}_{2}=1 / 9$ \\
\hline 1.21 & $85.7 \pm 12$ & 8.54 & $4608 \pm 1635$ \\
\hline 2.12 & $2,457 \pm 6$ & 9.43 & $1776 \pm 142$ \\
\hline 2.56 & $6,803 \pm 46$ & 10.31 & $690 \pm 38$ \\
\hline 4.69 & $100,000 \pm 30,000$ & 11.25 & $358 \pm 2.7$ \\
\hline 5.55 & $100,000 \pm 10,000$ & 12.22 & $190 \pm 3.3$ \\
\hline 7.08 & $71,429 \pm 10,204$ & 13.25 & $272 \pm 23$ \\
\hline
\end{tabular}

Ternessee, was due to $3.2 \times 10^{-7} \mathrm{\mu Ci} / \mathrm{al}$ of ${ }^{244} \mathrm{Cm}$ and $3.2 \times 10^{-8} \mathrm{\mu Ci} / \mathrm{ml}$ of 238 Pu. The trenches in burial ground 5 mere overflowing because precipitation infiltrated the trenches, reached the less permeable trench botton and flowed out the lower end of the trench in a seep. The ${ }^{244} \mathrm{Cm}$ and ${ }^{238} \mathrm{pu}$ were presuably picked up by the water in its passage through the waste-filled burial trench. Bondietti and Reynolds (1977) reported that seepage water, presumably from burial gre contained 0.3 to $3.2 \times 10^{-7} \mu \mathrm{Ci} / \mathrm{ml}$ of $244 \mathrm{Cm}$ in the filtrate from a $0.4 \quad$ iter sapled at two yearly intervals. White Oak Lake water contained 0.3 to $1 \times 10^{-9} \mathrm{\mu Ci} / \mathrm{ml}$ with about 50 passing through a 0.45 filter. Sedlet (1977) reported on the average concentration of curiu in surface water near Argonne, Illinois, in 1975. Mastes from Argonne Mational Laborators enter Samill Creek which flows into the Des Pla ines River. The ${ }^{244} \mathrm{Co}-{ }^{252} \mathrm{Cf}$ concentration was $<1 . \dot{\mathrm{c}} \times 10^{-15} \mathrm{Ci} / \mathrm{l}$ and the ${ }^{244} \mathrm{Cm}-{ }^{249} \mathrm{Cf}$ concentration was $4.5 \pm 0.8 \times 10^{-15} \mathrm{Ci} / \ell$ in Samill Creek. Ho detectable $\left(5 \times 10^{-16} \mathrm{Ci} / \mathrm{l}\right)$ curium was found in the Des Plaines River.

Sumary

No information is available on possible curium compounds in soils and sediments. It appears that curium precipitation as $\mathrm{Ca}(\mathrm{OH})_{3}$ in alkaline solutions ay control curiu concentrations in those solutions. Theoretical calculations (Figure 8.18) indicate that $\mathrm{Ca}^{3+}$ hydrolyzes even in acidic solutions (pH 3.3 and above). Very little reliable information is available on interactions of curium with soils and sediments, and none on curium 
interactions with rocks. What little data are available indicate that curiu adsorption is not a function of ion-exchange capacity of the soi? (Thumas and Jacobs, 1969; lacobs et al., 1966), and that precipitation and/or formation of radiocolloids may predominately influence curiun adsorption reactions (Thomas and Jacobs, 19c9; Sheppard et al., 1976). 
ELPOPIVI

Matural Sedinent and Rock Distributions

The europium content of several comon rock types and sediments are given in Table 8.34.

TABLE 8.34. Europiu Content of Sediments and Igneous Rocks in ppm

\begin{tabular}{|c|c|c|c|c|}
\hline $\begin{array}{l}\text { Pelagic } \\
\text { Carbomates }\end{array}$ & $\begin{array}{l}\text { Pelagic } \\
\text { Clays }\end{array}$ & $\begin{array}{c}\text { Fresh Water } \\
\text { Clays }\end{array}$ & $\begin{array}{l}\text { Manganese } \\
\text { Module }\end{array}$ & Reference \\
\hline 0.6 & 1.6 & 1.8 & 10.4 & $\begin{array}{l}\text { Turekian and Hedgepohl (1961) } \\
\text { Wildeman and Haskin (1965) } \\
\text { Coldberg et al. (1963) } \\
\text { Durursin (1974) }\end{array}$ \\
\hline
\end{tabular}

Igreous Rocks

\begin{tabular}{|c|c|c|c|c|c|c|c|}
\hline $\begin{array}{l}\text { Pertos- } \\
\text { tite }\end{array}$ & $\begin{array}{l}\text { Low } X \\
\text { Tholeite }\end{array}$ & $\begin{array}{l}\text { Thaitian } \\
\text { Tholeite }\end{array}$ & $\begin{array}{l}\text { ande- } \\
\text { site }\end{array}$ & $\begin{array}{l}\text { Grano- } \\
\text { diorite }\end{array}$ & $\begin{array}{l}\text { Leuco- } \\
\text { granite }\end{array}$ & $\begin{array}{l}\text { Repheline } \\
\text { Syenite }\end{array}$ & Reference \\
\hline 0.2 & 1.9 & 1.3 & 1.0 & 1.2 & 0.17 & 10 & $\begin{array}{l}\text { lask in and } \\
\text { Schmitt (1967) }\end{array}$ \\
\hline
\end{tabular}

Sedimentary Rocks

\begin{tabular}{|c|c|c|c|c|}
\hline siate & grartzite & Linestone & Subgrayacke & Reference \\
\hline 2.0 & 0.09 & 0.14 & 1.3 & Hask in et al. (1966) \\
\hline
\end{tabular}

In a study of rare earths in Russian platform soils, Balashov et al. (1964) reported high europium contents in alkaline soils, the europiu precipitating as hydroxide. Acidic soils probably allow complexing and reavol of the europiu and other rare earths.

Brief Cheoistry

Europiu occurs in two stable isotopes out of a total of 17 isotopes, ${ }^{151_{E u}(47.8 x)}$ and ${ }^{153} \mathrm{Eu}(52.2 x)$. The two radionuclides of interest are ${ }^{152} \mathrm{Eu}(13 \mathrm{gr})$ and ${ }^{154} \mathrm{Eu}(16 \mathrm{gr})$. The oxidation states of europium are trivalent with radius $0.95 \AA$ and divalent with radius $1.09 \AA$ (Ahrens, 1952). The divalent state is typical of europiu occurrence, substituting for Ca+2 and $\mathrm{K}^{+}$in main stage feldspars (plagioclases, aicrocline, orthoclase). The 
potential of the Eu(III)/Eu(II) couple is -0.43 volts (Latimer, 1952). Europous ions are stable in water solution at low hydrogen ion concentrations (basic $\mathrm{pH}$ ), and can be formed from $\mathrm{Eu}^{+3}$ by zinc reduction. However, the europium in interstitiai solutions is more apt to be in the trivalent than divalent state.

\section{Solution Equilibria}

Europium can exist as $\mathrm{Eu}^{2+}$ and $\mathrm{Eu}^{3+}$. However, $\mathrm{Eu}^{3+}$ is the only state wich is stable in water (Baes and Mesmer, 1976). The activity of various solution species of europiva in equilibriu with Eu(OH) 3 and at assuned concentrations of various anions commonly found in ground water is given in Figure 8.19. The thermodymanic data of all the species except EuOH ${ }^{2+}$ and Euf $^{2+}$ were obtained from Schum et al. (1973). The data for EuOH ${ }^{2+}$ and Euf $^{2+}$ were obtained from Baes and Mesmer (1976) and Walker and Choppin (1967), respectively.

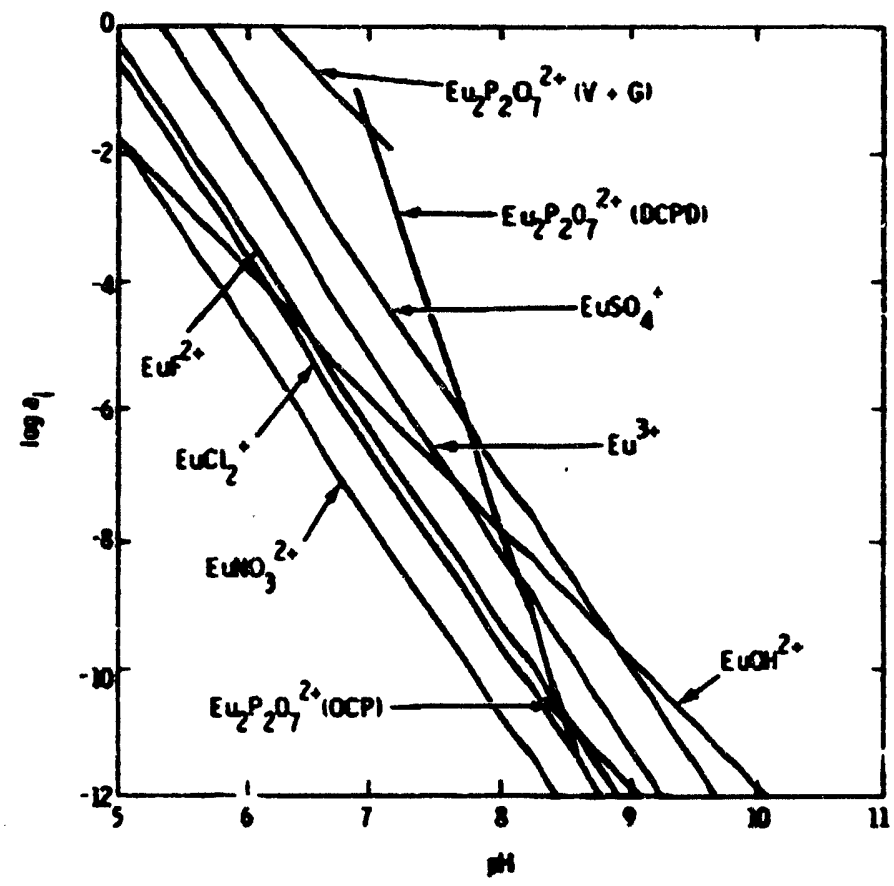

FIGURE 8.19. The Activity of Various Europiun Species in Equilibriun with $\mathrm{Eu}(\mathrm{OH})_{3}(\mathrm{~s})$. Other soil solution conditions included $\mathrm{pSO}_{4}^{2-}=$ $\mathrm{pCl}-=2.5, \mathrm{pm} 3, \mathrm{pF}-=4.5$ and phosphate levels were from Variscite and Gibbsite (V and 6$)$, Dicalciv Phosphate Dihydrate (OCPO) and Octacalciun Phosphate (OCP). 
In a general way the solution complexes of europium in decreasing order of importance can be arranged as follows: $\mathrm{Eu}_{2} \mathrm{P}_{2} \mathrm{O}_{7}^{2+}$, EuSO $\mathrm{SO}_{4}^{+}, \mathrm{Eu}\left(\mathrm{SO}_{4}\right)_{2}^{+}$, Euff ${ }^{2+}$, $\mathrm{EuCl}^{2+}$, and Eulio ${ }^{2+}$. Under the conditions assured in Figure 8.18, the predominant solution species in pH ranges of $<4.5,4.5$ to $7.75,7.5$ to 8.85 , and $>8.85$ will be EuSO$O_{4}, \mathrm{Eu}_{2} \mathrm{P}_{2} \mathrm{O}^{2+}$, EuSO $\mathrm{E}_{4}$, and EuOH $\mathrm{H}^{2+}$, respectively. Thus, significant quantities of uncomplexed europium $\left(\mathrm{Eu}^{3+}\right.$ ) can only be expected in solutions with very low levels of sulfate and phosphate. The solution complexes of europium with fluoride, chloride, and nitrate do not contribute significantly to total europium concentration in solution even for sea water. Laboratory Adsorption Studies

Benson (1960) reported that the uptake of rare earths (cerium, promethium and europium) was virtually complete and unaffected by accompanying $0.5 \mathrm{M}$ alkali metal and $0.25 \mathrm{M}$ alkaline earth metal chlorides at a pH above 7. Below pH 3, however, the adsorption of all rare earths was depressed similarly by the accompanying salts. These results mere interpreted to mean that the rare earths, including europiun, are ionic at $\mathrm{pH}$ below 3 and that they are taken up principally by ion exchange on the geologic media. Above ph 7 , they are precipitated.

Baets le and Dejonghe (1962) gave a europiun $\mathrm{Kd}$ range in Mol soil (mostly quartz sand) at pH 7.7 as 228 to 705 , and reported that at pH >3, europium hydrolyzed. Therefore, above pH 3, the authors did not consider that adsorption was an ion exchange phenomenon.

Baetsle et al. (1964) gave Kd values for trace europium in three different waters. The compositions of these waters were not given. Kd results are shom in Table 8.35. The europium $K d$ values are much larger than the cesium and strontiun $\mathrm{Kd}$ values for the same soils.

Serne and Rai (1976) studied the adsorption/precipitation behavior of europium in soils and pure solutions. The pH of the various europium solutions $(0.15 \mathrm{M} \mathrm{CaCl} 2$ plus trace to $50 \mathrm{mg}$ Eu/ $l)$ was increased in $0.05 \mathrm{pH}$ increments until precipitation was observed by the Tyndall Bean method. At the point of of Eu(OH) 3 precipitation, the europiun activity and pH was 
TABLE 8.35. Variation of Trace Europiu Kd Values on mol Soils (Baets le et al., 1964)

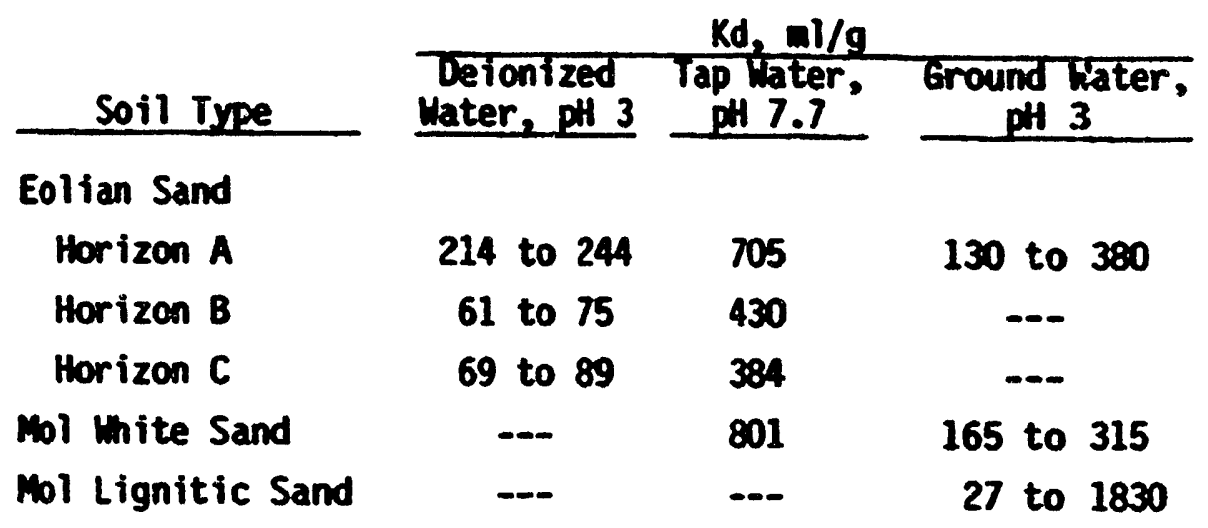

determined. The results are plotted in Figure 8.20 along with the theoretical $\mathrm{Eu}(\mathrm{OH})_{3}$ solubility line. The results indicate that:

1. the kinetics of precipitation of $\mathrm{Eu}(\mathrm{OH})_{3}$ is rapid.

2. the laboratory results agree well with the theoretical Eu(OH) solubility.

3. $E u^{3+}$ does not appear to hydrolyze appreciably because total europium activity in equilibrium with Eu(OH) 3 is similar to the calculated $\mathrm{Eu}^{3+}$ activity.

4. for meaningful $\mathrm{Kd}$ values, the theoretical solubility of $\mathrm{Eu}(\mathrm{OH})_{3}$ should not be exceeded.

Europium adsorption experiments where $\mathrm{Eu}_{\mathrm{u}}(\mathrm{OH})_{3}$ did not precipitate mere conducted and results shown in Table 8.36. The results show that the europium $\mathrm{Kd}$ increases with an increase in $\mathrm{pH}$ and decreases with increasing europium concentration, below the point of $\mathrm{Eu}(\mathrm{OH})_{3}$ precipitation. These reactions suggest that ion exchange is an active mechanism below the point of Eu(OH) 3 precipitation.

Cerrai et al. (1969) looked at ${ }^{152}$ Eu uptake by marine sediments. Sediment (up to $200 \mathrm{mg}$ ) was contacted with $40 \mathrm{ml}$ of sea water (pH 8.1) traced in europium. The contact time was $1 \mathrm{hr}$. Leach experiments with clean water in 


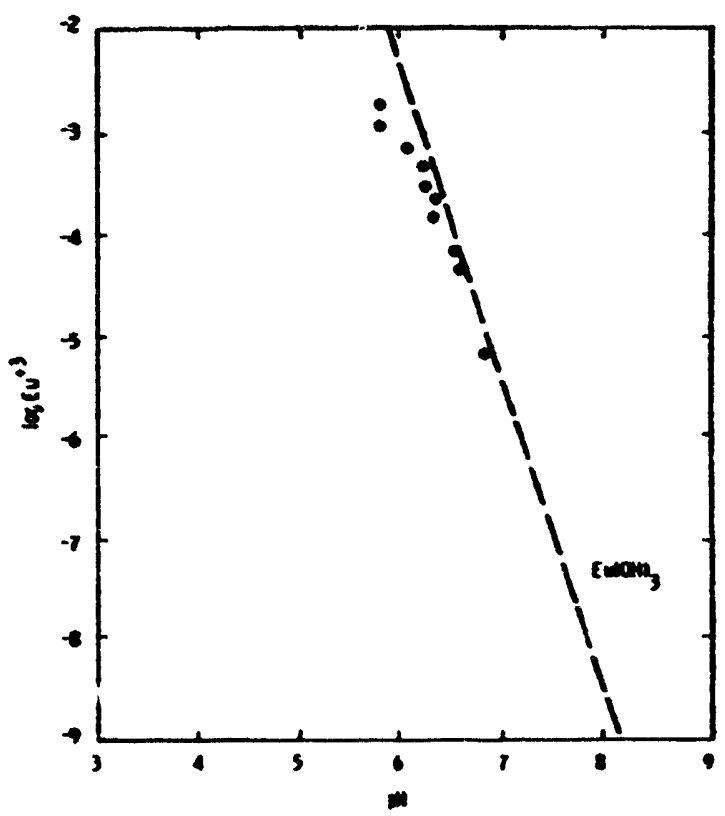

FIGURE 8.20. The Influence of pH on the Activity of Europium in Solution (Serne and Rai, 1976)

contact with the sediment lasted up to $15 \mathrm{hr}$. One experiment was performed with ${ }^{152} \mathrm{Eu}$ and $0.02 \mu \mathrm{g} / \mathrm{l}$ carrier europium in distilled water contacting the sediment. Above a sediment/solution ratio of $1000 \mathrm{mg} / \mathrm{l}$ the $\mathrm{Kd} \mathrm{Eu}_{\mathrm{u}}$ remained constant for the seawater case at a value between $4.9 \times 10^{3}$ tc $1.3 \times$ $10^{4} \mathrm{ml} / \mathrm{g}$. For one sediment as the sediment to solution ratio dropped be ow $1000 \mathrm{mg} / l$, the $K d$ also dropped. For another sediment there was no decrease in $K d$ as sediment concentration dropped. The $\mathrm{Kd}_{\mathrm{Eu}}$ for the sediment contacting distilled water showed no increase over the seawater case. Thus, the high salt concentration does not affect europium sorption. Europium leach experiments showed only 5 of the sorbed ${ }^{152}$ Eu was released in the first hour of icitact with fresh sea water regardless of sediment concentration ( 700 to $5000 \mathrm{~g} / \mathrm{l}$ ). The percentaged leach rises to $14 \%$ after $15 \mathrm{hr}$. The $\mathrm{Kd}_{\mathrm{Eu}_{u}}$ desorption after $1 \mathrm{hr}$ was $4.8 \times 10^{3}$ to $2.8 \times 10^{4} \mathrm{ml} / \mathrm{g}$, depending upon sediment.

Field Studies

Cerrai et al. (1970) measured the concentration of ${ }^{155} \mathrm{Eu}$ in sediments from the Adriatic and Ligurian Seas. The finer fraction of Adriatic Sea 
TABLE 8.36. Effect of pH and Europium Concentration on Europium Kd by Burbank Sand(a) (Serne and Rai, 1976)

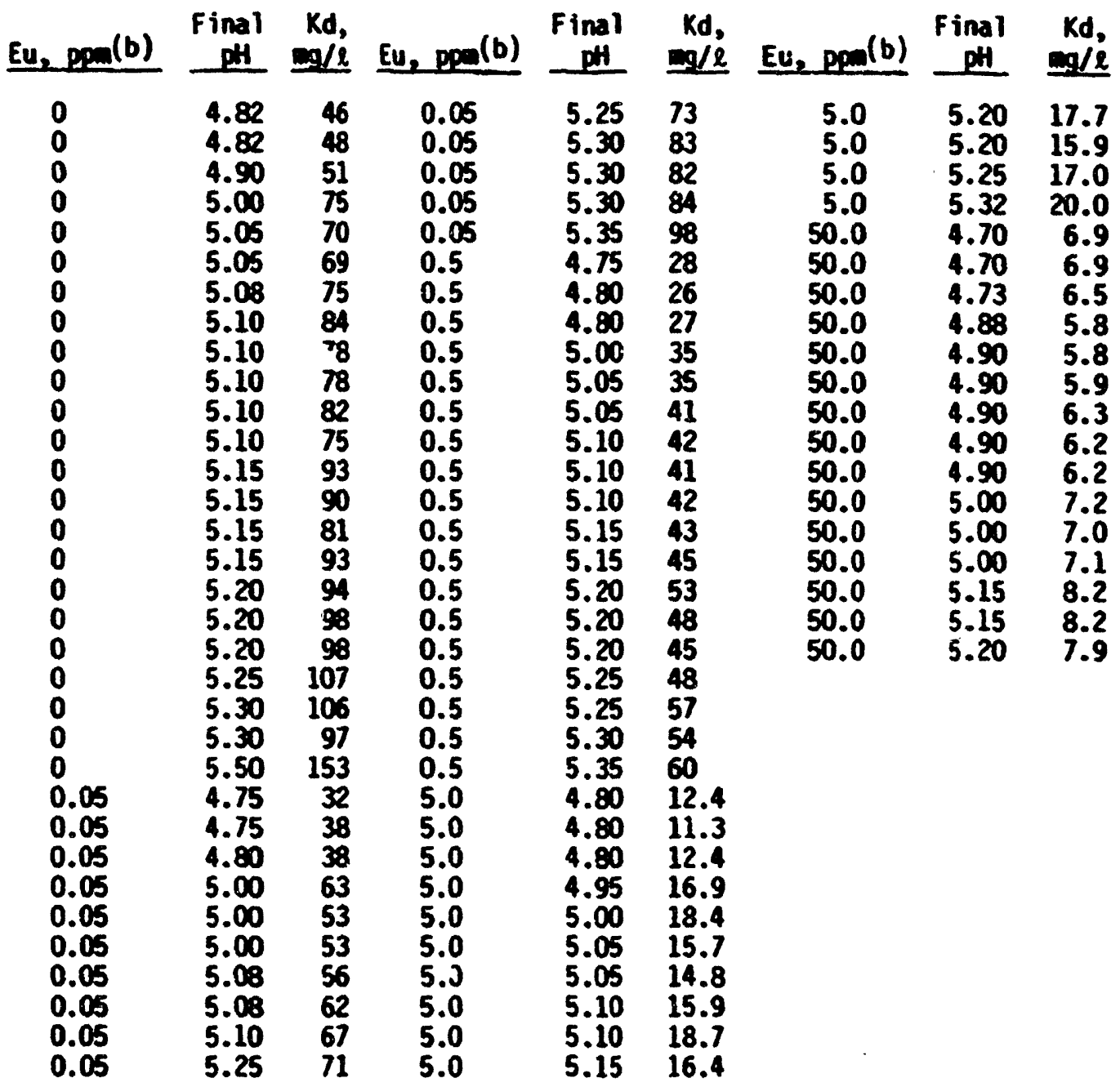

(a) One gram sapples free of $\mathrm{CaCO}_{3}$ and soluble salts were used.

(b) Various concentrations of europiu were added to $0.15 \mathrm{M} \mathrm{CaCl}$ solutions spiked with 152 Eu. Samples mere equilibrates first for $48 \mathrm{hr}$ and then for $24 \mathrm{hr}$ after adjusting the $\mathrm{pH}$.

sediment $(<100 \mu \mathrm{m})$ contained significantly more europium, $0.36 \mathrm{pCi} / \mathrm{g}$ versus $0.02 \mathrm{pCi} / \mathrm{g}$ for coarser fractions $(<100 \mu \mathrm{m})$. The total concentration of ${ }^{155} 5_{\mathrm{Eu}}$ in Adriatic and Ligurian sediments was 0.23 and $0.24 \mathrm{pCi} / \mathrm{g}$. 
Robertson et al. (1973) studied the distribution of ${ }^{155} \mathrm{Eu}$ in the Columbia River. Hater samples were filtered $(<0.3 \mu \mathrm{m})$ and then run through cation and anion exchange resins. The europium was predoainately found on suspended particulates 97 and 98 with the rest being soluble cationic and nonionic species. Europium bound to bed sedimeits are not easily leached by sea water. Only $5 \%$ of the sediment bound europium was removable from $30 \mathrm{~g}$ eluted with $8 l$ of sea water.

\section{Sumary}

Serne and Rai (1976) have shown that the kinetics of precipitation of $\mathrm{Eu}(\mathrm{OH})_{3}$ from pure solutions is rapid. The concentration of europium in equilibriua with Eu(OH) 3 decreases 1000-fold with an increase of one pH unit. The activity of europium in equilibrium with $\mathrm{Eu}(\mathrm{OH})_{3}$ is low under highly alkaline conditions and $\mathrm{Eu}(\mathrm{OH})_{3}$ may control europium concentration in alkaline soils and sediments.

Bensen (1960) and Baetsle and Dejonghe (1962) reported that europium appears to be taken up principally by ion exchange below pH 3. Baetsle and Dejonghe (1962) suggested that ion exchange was not the adsorption mechanism above pH 3 because of europium hydrolysis. Serne and Rai (1976) have show that for meaningful determination of $\mathrm{Kd}$ values in soils, one must be below the solubility line of $\mathrm{Eu}(\mathrm{OH})_{3}$. Their results, thus obtained, showed that between $\mathrm{pH} 4.7$ and 5.5 the $\mathrm{Kd}$ increases with an increase in $\mathrm{pH}$ and $\mathrm{Kd}$ decreases as europium concentration increases, wich suggests an ion exchange as an adsorption mechanism.

Europium in rivers and oceans is found associated almost exclusively with sediments and suspended particulates. Desorption by ion exchange is small. 
IODINE

Matural Sediment and Rock Distributions

The iodine content of rocks and sediments is given in Table 8.37. Yoshida et al. (1971) tried leaching the iodine from volcanic rocks, and usually reaved less than $20 \%$ of the total iodine in the rock. The average iodine value for igneous rocks probably falls within the range of 75 to $150 \mathrm{ppb}$. Nearly the same average value also would be applicable to metaEorphic rocks.

While the iodine content of marine sediments depends on the carbon to a large extent, marine sediments are much richer in iodine than sedimentary rocks.

There is a marked increase in the soil iodine content compared to the rocks they are derived from. For example, the average iodine content of soils was noted as 5 ppm by Vinogradov (1959), wo also suggested that much of the soil iodine is atwospherically derived.

Many of the iodine studies have noted the correlation of iodine content and humus in the soil (Sinitskaya, 1969; Irinevich et al., 1970; Pennington and Lishman, 1971).

\section{Brief Cnemistry}

There are 24 known isotopes with 18 of these isotopes having half-lives of less than 1 day. The only stable isotope is ${ }^{127} 1$. Only ${ }^{129} 1$, with a half-life of $1.7 \times 10^{7}$ years is of long-term interest in high-level waste disposal. The fission product ${ }^{131_{1}}$ with a half-1ife of 8.07 days, and ${ }^{125}$ I with a half-life of 60 days, are often i short-term disposal hazard because of their anionic character and resulting lack of adsorption.

Although iodine is known in the (-I), (I), (III), (V) and (VII) oxidation states, its usual occurrence is as the (-I) (iodide) state in fresh waters with a radius of $2.20 \AA$ (6oldschmidt et al., 1926) and as iodate-iodine in marine or similar aqueous environaents (Sugawara and Terada, 1958). I" tends to be a di-persed element in many environments as a result of its large size in comparison with fluorine, chlorine, bromine and hydroxyl ions. Oxidation of 
TABLE 8.37. Iodine Concentration in Sediments and Rocks

\begin{tabular}{|c|c|c|}
\hline Rock Type & $\mathrm{I}, \mathrm{ppb}$ & Reference \\
\hline \multicolumn{3}{|l|}{ Yolcanic } \\
\hline $\begin{array}{l}\text { Basalt (BCR-1), } \\
\text { Columbia River, }\end{array}$ & 160 & Becker and Manuel (1972) \\
\hline Basalts, Japan, 15 & 29 to 140 & " \\
\hline Andesites, Japan, 10 & 22 to 260 & " \\
\hline Dacites, Japan, 3 & 43 to 220 & $n$ \\
\hline Rhyolite, Japan, 2 & 26 to 320 & “ \\
\hline Obsidians, Japan, 3 & 20 to 65 & $"$ \\
\hline Obsidian, US & 540 to 730 & $"$ \\
\hline Obsidian, Mexico & 1900 & " \\
\hline \multicolumn{3}{|l|}{ Sedimentary } \\
\hline $\begin{array}{l}\text { Sandstones, 11, } \\
\text { Bashkiria, USSR }\end{array}$ & 0.5 to 1.5 & Itkina and Lygalova (1964) \\
\hline $\begin{array}{l}\text { Sandstone, white, } \\
\text { Klondyke, mo }\end{array}$ & 0.068 & Becker et al. (1972) \\
\hline $\begin{array}{l}\text { Sandstone, red, } \\
\text { Potsdam, MY }\end{array}$ & 0.14 & " \\
\hline $\begin{array}{l}\text { Argillaceous Sandstone, } \\
\text { Portageville, } \mathrm{NY}\end{array}$ & 37.6 & “ \\
\hline $\begin{array}{l}\text { Argillaceous Shale, } \\
\text { Rochester, NY }\end{array}$ & 13.0 & " \\
\hline $\begin{array}{l}\text { Calcareous Shale, } \\
\text { Lima, NY }\end{array}$ & 38.0 & " \\
\hline $\begin{array}{l}\text { Limestones, 6, } \\
\text { Paleozoic, } 0 \mathrm{~K}\end{array}$ & 4.2 & Collins et al. (1972) \\
\hline Sediments, & & Price et al. (1970) \\
\hline SH Barents Sea & 68 to 828 & \\
\hline Deep Sea & 11 to 46 & Bennett and Manuel (1968) \\
\hline \multicolumn{3}{|l|}{ Calcareous 0oze } \\
\hline (All Oceans) & 16 to 40 & Shishkima and Pavlova (1965 \\
\hline Deep Sea Clays & 30 to 250 & \\
\hline
\end{tabular}


iodide ions to produce the iodate ion $\left(\mathrm{IO}_{3}^{-}\right)$is easily accomplished in basic solution by the reaction: $3 \mathrm{I}_{2}+6 \mathrm{OH}^{-}+5 \mathrm{I}^{-}+\mathrm{IO}_{3}^{-}+3 \mathrm{H}_{2} \mathrm{O}$ (Cotton and Wilkinson, 1962). Iodine can form complexes with metal ions, but these are generally the least starle of all the halide complexes, with a few exceptions. Iod i 7 also is a volatile element, subliming at atmospheric pressures without melting.

Examples of iodine minerals include marshite (CuI), iodargyrite (AgI) and coccinite $\left(\mathrm{HgI}_{2}\right)$, bellingerite $\left.\left[\mathrm{Cu} \mathrm{iO}_{3}\right)_{2}\right]$, salesite $\left[\mathrm{CuIO} \mathrm{C}_{3}(\mathrm{OH})\right]$ and lautarite $\left[\mathrm{Ca}\left(\mathrm{IO}_{3}\right)_{2}\right]$ (F leischer, 1966). Most such iodine minerals are confined to unusual environments such as the Chilean nitrate deposits.

Solution Equilibria

Iodine can exist in $(-I),(I),(I I I)$, (V) and (VII) oxidation states. Out of all of these oxidation states, $(-I),\left(I^{-}\right.$, iodide) is the most important and its domain of predominance extends all along the pH scale, almost completely covering a large part of the stability domain of water (Pourbaix, 1966). Thus, it is not surprising that iodine in aqueous solutions free from oxidizing agents generally exists as iodide.

Laboratory Adsorption Studies

Baker et al. (1964) determined distribution coefficients for carrier-free cesium, strontiun, and iodine on 17 samples of earth materials collected during July, 1961, in the vicinity of Cape Thompson, northmestern Alaska. I dine sorption varied with percent organic matter in the samples. If the iodine remained in contact with organic matter for several days, a substantial part of it probably would be removed from solution in the natural waters.

Collet et al. (1968) studied the fixation capacities of river silt for radioactive material in order to draw conclusions on the deposition of fission products and other radioisotopes in the river bed. The distribution coefficient $C_{p}$ between river silt and river water (the ratio of the absorbed mass of the element studied per gram silt to the concentration of the same element in the water in equilibrium with the silt) was determined in the laboratory for the elements ${ }^{141} \mathrm{Ce},{ }^{137} \mathrm{Cs},{ }^{131} \mathrm{I},{ }^{32} \mathrm{P},{ }^{103_{\mathrm{RU}} \text {, and }}{ }^{89} \mathrm{Sr}$. Altogether 
756 individual samples mere processed. These saples were separated by a centrifuge method into the three fractions sard, clay, and organic material, in order to obtain conclusions on the effect of the individual constituents of the silt. The methods were outlined, the results were reported, and the fixation capacities found were related to the activity of the individual fallout nuclides present in the silt.

Hawid and Harkent in (1967) evaluated ${ }^{131}$ I retention in marine-deposited clay soils. Adsorption was measured with different competing anions at different salt concentrations and at varying pH values. The ${ }^{13 I_{I}}$ was assayed for $Y$ radiation with a spectrometer using a solid Mal crystal scintillator. Keeping the ph value above 7 or the addition of stable iodide salt prevents the adsorption of ${ }^{131_{1}}$ on the clay particles. The ${ }^{131_{1}}$ can be used as a tracer in acid soils only in the presence of stable $1^{-}$carrier.

Juguet et al. (1966) investigated the fixation capacity of French River mod and its various components for radioisotopes cesium, strontium, ruthenium, plutoniu and iodine. The purifying role of and is confirmed by the results of measurement of fixation capacities. Depending on their nature and chemical form radioisotopes may be only slightly fixed (iodine), or may be alwost totally fixed (cerium). A large part of the activity transported by surface waters is thus eliminated by deposition of ad or by filtration plants.

Knaelmann (1970) found anong the fission products, ${ }^{131_{I}}$ is relatively easily transported in the soil. Therefore, its uncontrolled spreading in the soil constitutes a hazard. The sorption of iodine by 59 different soils was therefore investigated. Iodine was supplied in the form of aqueous iodide solutions of different concentrations. Differences in the relative sorption were noted anong the various soils; however, the plot of concentration supplied versus relative sorption gave similar shaped curves for all soils.

Puschmam (1970) exained fire-grained sediments from the Heser, Donau, and Elve Rivers for their sorption behavior in respect to ${ }^{85} \mathrm{Sr},{ }^{137} \mathrm{Cs}$, and 131. The experiments with closed systems give the course of the sorption and the possible sorption rate after the equilibriu has been established. The sorption rates are converted to grams of the element per $m^{3}$ sand as used 
in the laboratory experiment. The results are compared with the sorption rates dealt with by Heisflog (1968), which were made with low-terrace sediments from the River Rhine.

Schneider and Block (1968) deternined the sorbability of deposits of the Rhine for several nuclides; the sorbability increases in the following order: $1^{-}, \operatorname{Sr}(I I), \mathrm{Pu}(\mathrm{IV}), \mathrm{Zn}(\mathrm{II}), \mathrm{Cs}(\mathrm{I})$. Saturation was reached by sediments after $24 \mathrm{hr}$ at the latest for all nuclides. The sediment samples were taken from Dehningen (Upper Rhine), Koblenz (Middle Rhine), and Wesel (Lover Rhine). Data were compared with the organic content for each sample. Less than 11 of transported muclides in the Rhine under any conceivable conditions rould be bound to suspended material or sediments.

Schneider (1970) investigated the sorptive properties of artificial monomineralic fine sands of uniform grain size. Montworillonite, kaolinite, muscovite, and biotite have a high sorptive power. The sorptive power of quartz oxides, microcline and albite is low. Hornblende and augite occupy a medium position. The highest affinity for the minerals is found for the cations ${ }^{137} \mathrm{Cs},{ }^{90} \mathrm{Sr}$, and ${ }^{65} \mathrm{Zn}$. Phosphorus-32, as complex phosphate anion, is less highly absorbed. The sorption of ${ }^{131}$ I is negligible.

Szabova (1976) followed the sorption of radioiodine by soils under static conditions at different pH values of the initial solution in five soil types. Sorption of radioiodine by soils is affected by the anount of the organic ass and by the pH of solutions. With the sawe pH, solis containing a higher awount of the organic mass adsorb more radioiodine. The highest sorptioi. percentage of $131 \mathrm{I}^{-}$for all $\mathrm{pH}$ values was found in the meadow chernozem soil and the lowest in the rendzina and in carboniferous neadow soils. The highest sorption of ${ }^{131_{I}}$ for degraded chermozem, meadow chermozen soils and brom soil was recorded at pH 5 and for carboniferous meadow soil and rendzina at 7.

De et al. (1971) contacted solls and soil clays with iodide solutions at 20,30 and $40^{\circ} \mathrm{C}$ ccitatifing $0.127,0.635$ and $1.269 \mathrm{~g}: 1 /$. Only the clay minerals shumed iodide uptake, with illite absorbing more fodide than kaolinite or montrorillionite. 
Coldberg et al. (1962) determined iodide absorption on Rainier tuff grourd to 100 to 200 mesh from simulated ground water. The value obtained using ${ }^{131_{I}}$ ms $1.10 \mathrm{ml} / \mathrm{g}$.

Kepak (1965, 1966) studied the sorption of ${ }^{131}$ I on hydrated aluminum and ferric oxide. One meight percent silver oxide was added to the ferric oxide exsorbent. The adsorbent of ferric oxide was 0.06 to 0.1 grain size and the influent solution contained $0.1 \mathrm{M} \mathrm{MaNO}$ at $\mathrm{pH} \mathrm{6.9.} \mathrm{Slow} \mathrm{coluan} \mathrm{break-}$ through of the ${ }^{131}$ I began imediately even from a ${ }^{131}$ I-distilled water solution. Sixty-six free colum volumes (void fraction $=0.66$ ) were loaded to 18 colum breakthrough and 758 free colum volumes to $90 x{ }^{131}$ I breakthrough.

Raja and Babcock (1961) examined the behavior of ${ }^{131_{I}}$ with two California soils, kaolinite and bentonite. Results of pretreatment by autoclaving, peroxide oxidation, alcohol digestion and extraction of ${ }^{131}$ I with various salt solt ons indicated that the bulk of the iodide retained by soils was to to reaction with organic matter.

Malters and Winchester (1971) examined lodine binding in dry marine sediments and found that wost of the iodine was surface-adsorbed or ccvalent bonded to carbon. About $23 \%$ could be extracted with organic solvents.

The est extensive study of iodine retention by soils was made by Wildung et al. (1975). Iodine as applied to the soils as iodide $\left(I^{-}\right)$and aethyl iodide $\left(\mathrm{CH}_{3} \mathrm{I}\right)$, a colorless transparent liquid when fresh, with one part soluble in 50 parts of water. The solution nonally rewained muionic during the distribution studies. Twenty-two soil types were collected for use in the study in Oregon, Washington and Minmesota with a range of properties as listed in Table 8.38. The ${ }^{131} \mathrm{I}^{-}$and $\mathrm{CH}_{3}{ }^{131}{ }_{\mathrm{I}}$ were used in trace quantities in $0.01 \mathrm{CaCl}_{2}$ solution.

TABe 8.38. Range of Surface Soil Properties Used in the Methyl Iodide and Iodide Sorptions (Hildung et al., 1975)

\begin{tabular}{llll} 
Particle Size, \\
\cline { 2 - 3 } Capacity, Exchange \\
\cline { 2 - 3 } & $\frac{10-20}{2.4} \frac{5-10}{2.6} \frac{2-4}{3.6} \frac{1-0.5}{3.8} \frac{0.5-0.25}{3.9} \frac{0.25-0.1}{5.4} \frac{0.1-0.05}{9.5}$
\end{tabular}


The e'ibrium distribution coefficients were treated statistically. Methyl iodia ratention by solls was largely a function of organic carbon and clay content, wile iodide adsorption a partial function of silt content. The mechanisas and causal relationship between the silt and iodide were under further study but were not covered in the report. The mechanisus underlying the cation exchange capacity/methyl iodide relationship are difficult to envision. Regression equations mere listed to obtain iodide and methyl iodide $\mathrm{Kd}$ values over the soil paraneter ranges studied.

lacobs (1955) studied the desorption of radioiodine from clays. The clays and Clinch River (Oak Ridge) flood plain sediment were contaninated with

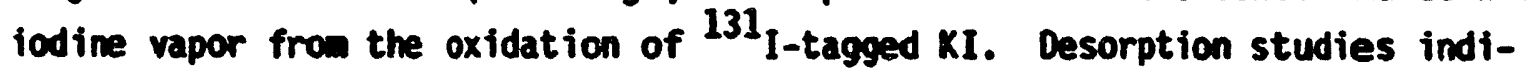
cated that the adsorbed iodine was in the form of a wixture of $\mathrm{HI}$ and $\mathrm{I}_{2}$. The rate of desorption decreased with decreased surface concentration, and after $24 \mathrm{hr}$, the fodine remaining was proporticnal to the reciprocal of the absolute air temperature. Desorption occurs most rapidly in high humidity air. Most of the iodine was readily rewoved with tap water. After ten 25-mil increments of Oak Ridge tap water through a 10-g, iodine-contaminated Clinch River floodplain sediment, less than $5 \%$ of the iodine remaired on the sediment. However, removai from $10 \%$ to $5 \%$ required $60 \%$ of the water leach volume, indicating that part of the iodine is relatively tightly held. Some prelininary work with methyl iodide suggested that this chenical form of iodine would nove readily through the ground without being adsorbed.

\section{Field Studies}

Mun and Bazilevich (1964) determined the abundance and distribution of iodine in lacustrine muds and pore solutions in seven fresh and salt lakes in central kazakhstan. Iodine accumulates in the muds of fresh and salt lakes, and especiaily in the pore solutions of bottom mods regardless of the salinity of the lakes. The concentration of iodine increases with depth below the surface of the mads, possibly as the result of anaerobic decomposition of iodinebearing organic matter. The content of water-soluble iodine always decreases with depth in the mud. Both fresh and salt lakes are much richer in lodine than sea mater, but the iodine content of lacustine sediments is not necessarily distinguishable from that of marine sediments because the organisas in 
lakes way concentrate less jodine than marine organisins, and there is a direct correlation between content of organic carbon and iodine content.

Pennington and Lishman (1971) studied lake sediments in northern England and Scotland. Their conclusions follow:

1. In these profiles there is no evidence for changes in iodice content due to diagenesis after burial of the source material in the sediments.

2. The lodine content shows a very close correlation with the carbon content, indicating association of iodine with organic matter in the sediments.

3. This association is not, however, quite complete, for some late-glacial clays of very low carbon content contain appreciable amounts of fodine. The evidence indicates that these ilays originated from scils during cold periods with freeze-thaw cycles. The lodine content can be explained by the power of clay colloids to adsorb jodine wile present in soils. Varied clays, originating by fresh glacial erosion of coarse rock, contain only very small traces of iodine.

4. These facts can be explained by the hypothes is that lake sediments wich are richer in iodine than the source rocks of the region must be derived frow solls in the catchwent area, where iodine from the atwosphere, washed down by rain and absorbed by plants, accumulated in association with hums and with clay colloids.

5. Differences from lake to lake in the lodine content of the sediments and in the ratio of lodine to carbon did not show any correlation with differences in the present anmul rainfall; that is, with the supposed rate of supply of iodine from rain.

6. Changes in the iodine content and in the lodine:carbon ratio from one horizon to another in the profiles, and differences between the sites in their lodine contents and in their fodine:carbon ratios, have been shown to correlate well with changes in solis on the catchments as deduced from pollen analysis and qualitative changes in the organic fraction of the sediment. 
Price et al. (1970) found in 42 surface sediments from the southwestern Barents Sea that both I and Br are related to organic atter; the dependence of halogens on the grain size of the sediment is small. With depth, all sediments showed a marked decrease in $\mathrm{I}$ and $\mathrm{Br}$ and in $I / C$ and $\mathrm{Br} / \mathrm{C}$ ratios; the ratios often reach a constant value. This decrease is caused by a loss of halogens during the burial of the sediments. The rate of decrease in lodine concentrations per unit length in the cores has provided a means of estinating the accumlation rates in the sediments.

Reynolds and Gloyna (1963) investigated factors involved in the transport of radioisotopes by suspended and bottom sediments in fresh-water streans, lakes, and estuaries in watersheds of Texas and San Antonio Bay. Uptake and release data for ${ }^{103} \mathrm{Ru},{ }^{51} \mathrm{Ci},{ }^{137} \mathrm{Cs},{ }^{89} \mathrm{Sr},{ }^{59} \mathrm{Fe}$, and ${ }^{131} \mathrm{I}$ were collected. The bodies of water selected were the Guadalupe River, Lake Austin on the Colorado River, Lake Falcon on the Rio Grande River, and San Antonio Bay. These sampling areas provided a variety of geographical and environmental factors.

Tritremel et al. (1966) studied the behavior of various radionuclides in surface water by field experiments in the Leitha-Muhl Canal and by complementary experiments in the laboratory. The boundary and profile characteristics of the strea were ascertained and flow rates calculated. Suspensions were examined for size and mineral or organic content in relation to current velocities, and core samples were collected from the bed at selected regions of deposition. Experinef.. mere carried out on dispersion and transport of wastes under varying outlet conditions and the diffusion constant was measured. In the laboratory, sedimentation and uptake experiments were conducted on mineral and organic suspensions in conjunction with muclides such as ${ }^{90} \mathrm{Sr},{ }^{131} \mathrm{I},{ }^{14 Q_{\mathrm{La}}}$ 24 $\mathrm{Ha}$ and wixed fission products. Uptake was found to be dependent on mineral species and varied inversely with particle size. Elution experiments were also carried out on accumblated sediments. From these results it is possible to assess the radioactive content and frequency of batch discharges of effluents that ay be released to a river without causing unacceptably high concentrations. 
A plot of iodine sorption versus grain size is show in Figure 8.21.

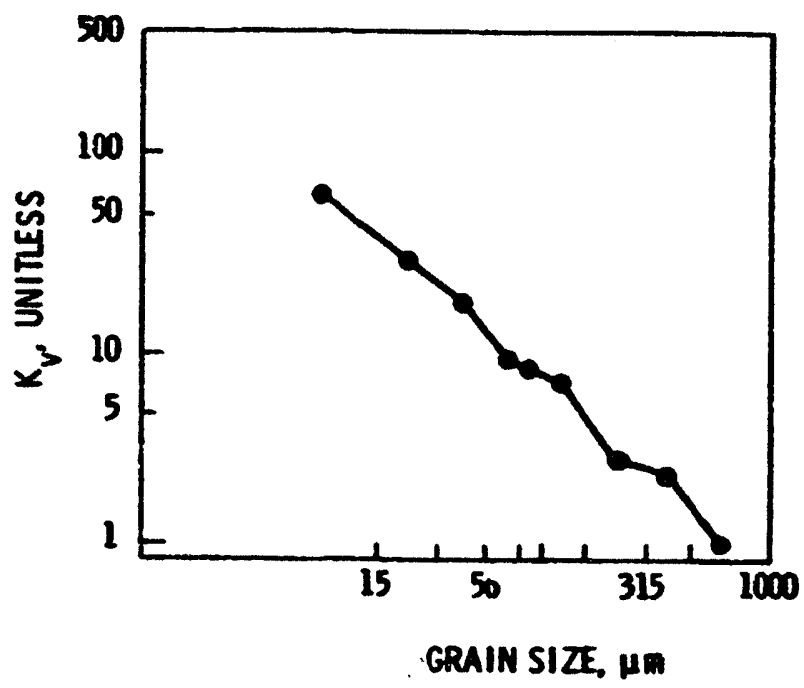

FIGURE 8.21. Sorption of 131 I onto Leitha Sediment as a Function of Grain Size

Sumary

Because the anion exchange capacities of most sediments are minimal over a normal pH range of 6 to 8 , the adsorption of iodide $\left(\mathrm{I}^{-}\right)$, iodate $\left(10_{3}^{-}\right)$ and organic-iodine molecules is normally swall. However, with soils of low pH (4 to 6) the iodide Kd value can rise to $50 \mathrm{ml} / \mathrm{g}$. Wi idung et al. (1975) reported no statisticai correlation between organic content and iodide $\mathrm{Kd}$, as they did for methyl iodide. Others (Baker et al., 1964; Szabova, 1976; Pemington and Lishanan, 1971) have show a positive correlation between iodine content and organic material in sediments mere the iodine is apparently covalently bonded to carbon (Walters and Winchester, 1971). It should be kept in wind that iodine, especially when present as an organic-iodine nolecule, can change to a vapor phase and wigrate much more rapidly than in an aqueous phase. 
IRON

Natural Sediment and Rock Distributions

Iron is one of the major constituents of geologic aterials and is found in both the $\mathrm{Fe}^{2+}$ and $\mathrm{Fe}^{3+}$ state typically described as $\mathrm{FeO}$ and $\mathrm{Fe}_{2} \mathrm{O}_{3}$. Average values or typical ranges for sediments are shom in Table 8.39.

TABLE 8.39. Iron Contents of Sediments (X)

\begin{tabular}{|c|c|c|c|c|}
\hline Sediment Type & FeO & $\mathrm{Fe}_{2} \mathrm{O}_{3}$ & Total Fe & Reference \\
\hline Pelagic Carbonates & & & 0.9 & Turekian and Hedepoh1, 1961 \\
\hline Pelagic Clays & & 9.3 & 6.5 & Turekian and Wedepoh1, 1961 \\
\hline Mississippi Delta Mud & & 3.47 & & Niggli, 1952 \\
\hline Deep Sea Clay & 1.13 & 7.04 & & El Hakeel and Riley, 1961 \\
\hline Deep Sea Sediments & 0.94 & 4.89 & $3.5-5.2$ & El Hakeel and Riley, 1961 \\
\hline Manganese Modules & & & 22.44 & Riley and Sinkaseni, 1958 \\
\hline Soils & & & 3.8 & Vinogradov, 1959 \\
\hline
\end{tabular}

\section{Brief Chemistry}

There are 8 known isotopes of iron; stable isotopes include ${ }^{54}$ Fe (5.9\%), ${ }^{56} \mathrm{Fe}(91.52 x),{ }^{57} \mathrm{Fe}(2.24 \%)$ and ${ }^{58} \mathrm{Fe}(0.33 \%)$. The radioactive isotcpes present in reactor effluents are ${ }^{55} \mathrm{Fe}\left(2.94\right.$ years) and ${ }^{59} \mathrm{Fe}$ (46 days).

\section{Solution Equilibria}

Iron can exist in Fe(II) and Fe(III) oxidation states in solution. In the oxidizing environent, the $F e(I I I)$ species will predominate. The nature of the species will be dependent upon the solution pH. Predominant iron species in oxidizing environment in $<3$ pH solutions if $\mathrm{Fe}^{3+}, \mathrm{Fe}(\mathrm{OH})_{2}^{+}$in pH 3 to 6, $\mathrm{Fe}(\mathrm{OH})_{3}^{0}$ in pH 6 to 9.5, and $\mathrm{Fe}(\mathrm{OH})_{4}^{-}$in pH >9.5 (Baes and Mesmer, 1976). In reducing conditions, the predominant iron species in solutions of $\mathrm{pH}<10$ will be $\mathrm{Fe}^{2+}$ (Baes and Mesmer, 1976). 


\section{Laboratory Adsorption Studies}

The sorption of radiotracer iron onto marine and river sediments was investigated by Dawson and Dursina (1974), Duursma and Eisma (1973), Dursma and Gross (1971) and Dursima and Bosch (1970). Iron-59 added to sea water appears to precipitate from solution onto sedimentary particles. The half period of sorption is $18 \pm 6$ days. Because there is no observable correlation with sediment exchange properties precipitation probably is the controlling mechan ism. Depending upon the experimental method used, the $\mathrm{Kd}_{\mathrm{Fe}}$ observed for Mediterranean sediments in sea water for $>2$ to $45 \times 10^{4}$ ml/g. Two sediments, Wadden Sea (Holland) and Mediterranean Sea, were fractioned and $\mathrm{Kd} F$ determined on the various size fractions. The Hadden Sea sediment shows an increasing $\mathrm{Kd}_{\mathrm{Fe}}$ as particle size decreases. Average sorption values determined by Duursma and coworkers is found in Table 8.40 .

\section{TABLE 8.40. $\mathrm{Kd}_{\mathrm{Fe}}$ Observed in Marine Sediments}

\begin{tabular}{lcccc}
\multicolumn{1}{c}{ Sediment } & & $\log K$ & $\begin{array}{c}\text { Estimated } \\
K d_{f e 2 m l / g}\end{array}$ & $t_{1 / 2 \text {, days }}$ \\
\cline { 1 - 2 } \cline { 5 - 5 } Atlantic Dcean & $4.4 \pm 0.8$ & $4.2 \times 10^{4}$ & $16 \pm 11$ \\
Pacific Ocean & $4.4 \pm 0.5$ & $4.0 \times 10^{4}$ & $21 \pm 13$ \\
Indian Ocean & $4.2 \pm 0.6$ & $2.6 \times 10^{4}$ & $15 \pm 8$ \\
Baltic Sea & $4.5 \pm 0.4$ & $4.9 \times 10^{4}$ & 18 \\
Morth Sea & $4.6 \pm 0.3$ & $5.6 \times 10^{4}$ & 18 \\
Mediterranean Sea & $4.2 \pm 0.7$ & $2.3 \times 10^{4}$ & $14 \pm 6$ \\
Black Sea & $3.8 \pm 0.3$ & $1.0 \times 10^{4}$ & 18 \\
Red Sea & 3.9 & & $1.2 \times 10^{4}$ & 14
\end{tabular}

Kawabata (1967) studied the sorption and release of radionuclides including ${ }^{59} \mathrm{Fe}$ by Sagami River sediments.

Silo and Saxen (1974) atteapted to elucidate the role of humic substances in the transport of radionuclides in water. The surface waters of Bolhnian Bay, Fin'and, were studied by gel chromatography. The effect of salinity or organic-iron complexes was addressed. Part of the organic bound iron is readily destroyed by increases in salinity. 
Schell et al. (1979) studied the fate of ${ }^{59} \mathrm{Fe}$ added to sea water in contact with montworillonite clay, plankton and organic detritus separated from the sea water by dialysis bags. of the six elements studied, iron showed the greatest tendency to become associated with particulate matter (see Table 8.10 in the aricium section).

Field Studies

Robertson et al. (1973) and Robertson and Perkins (1975) studied the physicochemical state of iron in cooling water, Columia River water and bed sediments. Iron bound to river sediments was not leached by sea water. Thirty grams of sediment were placed in a colum and leached with 8 liters of sea water but less than $1 \%$ of the iron was removed from the sediment, which confirms iron is not controlled by ion-exchange reactions. Iron present in cooling waters emanating from $N$-Reactor is $98 \%$ particulate $(<0.3 \mu \mathrm{m})$. No quantifiable iron is reaching the springs on the banis of the Columbia River wich are fed by the cooling water.

Labeyrie et al. (1975) present data showing the distribution of ${ }^{55} \mathrm{Fe}$ radioactiyity in marine sediment cores and water. Iron appears to move different" than fallout plutonium. The iron is present in particles sinking at a mean rate of $350 \mathrm{~m} / \mathrm{yr}$. Part of the iron in coastal sediments is redissolved probably by reduction associated with decaying organic matter, but the solubilized iron should reprecipitate after return to overlying water. Oxidation mould form microparticulates wich could be dispersed and translocated to the open sea. Reynolds and 6loym (1963) studied the uptake and release of iron in model river flumes.

Sumary

The fate of radioiron in marine and fresh-water environments is probably controlled by the stable iron cycle in the system. Under oxidizing conditions iron is rather insoluble and readily forms wicroparticulates or amphous coatings on sediment. Under mildily reducing conditions $\mathrm{Fe}^{+2}$ wight be solubilized with the potential of being precipitated in sulfide-bearing sediments. The observed $\mathrm{Kd}_{\mathrm{Fe}}$ in the marine environment is quite large for either oxidizing or reducing conditions, $10^{3}$ to $10^{4} \mathrm{ml} / \mathrm{g}$. 


\section{MAIGAMESE}

Matural Sediment and Rock Distributions

Average concentrations of manganese in sediments consist of structural wanganese and amorphous hydrous manganese oxides and are listed in Table 8.41.

TABLE 8.41. Manganese Content of Various Sediments $(X)$

\begin{tabular}{|c|c|c|c|}
\hline Type & Mno & Total m & Reference \\
\hline Pelagic Carbonates & & 0.10 & Turekian and Hedepoh 1, 1961 \\
\hline Pelagic Clays & & 0.67 & Turekian and Wedepoh1, 1961 \\
\hline Mississippi Delta Mud & 0.06 & & Niggli, 1952 \\
\hline Deep Sea Red Clay & 0.48 & & El Hakeel and Riley, 1961 \\
\hline Deep Sea Sediments & 0.41 & & El Wakeel and Riley, 1961 \\
\hline Manganese Modules & & 32.04 & Riley and Sinhaseni, 1958 \\
\hline Atlantic Sediments & & $0.006-0.08$ & Duursma, 1974 \\
\hline Pacific Sediments & & $0.04-1.08$ & Duursma, 1974 \\
\hline Indian Ocean Sediments & & 0.42 & Duursma, 1974 \\
\hline Soils & & 0.085 & Virogradov, 1959 \\
\hline
\end{tabular}

Brief Chemistry

There are five known isotopes of manganese including only one stable one, $55 \mathrm{~m}$. Manganese-54 (t 1/2 310 days) and $52 \mathrm{~mm}$ (t 1/2 6.2 days) are the only radioactive isotopes of interest in reactor liquid effluents.

Solution Equilibrie

Manganese can occur in solution in $+2,+3$, and +7 oxidation state (Baes and Mesmer, 1976). However, the +2 is the most stable. Lindsay (1972) reported that none of the manganese complexes with cominon inorganic ligands, present in soils $\left(\mathrm{OH}^{-}, \mathrm{CO}_{3}^{-}, \mathrm{SO}_{4}^{2-}\right)$, are important. The manganese in solution below pH 9.5 will be expected to be present as $\mathrm{m}^{+2}$ (Lindsay, 1972). 


\section{Laboratory Adsorption Studies}

The sorption of trace manganese onto marine sedimerits was investigated by Dawson and Duursma (1974), Duursma and Eisma (1973), Duursma and Gross (1971) and Duursma and Bosch (1970). It appears that trace ${ }^{54} \mathrm{mn}$ added to sea water forms insoluble compounds on the surfaces of sediments with a half-time period of reaction equivalent to 6 days but observations were quite irregular. The distribution coefficient $\mathrm{Kd}_{\mathrm{m}}$ versus particle size of two marine sediments (Table 8.42) shows a somewhat irregular tiend of higher sorption on sma!ler particle sizes.

TABLE 8.42. $K d_{\text {mn }}$ Versus Particle Size

\begin{tabular}{|c|c|c|}
\hline Sediment & $\begin{array}{c}\text { Size Fraction, } \\
\end{array}$ & $\mathrm{Kd}_{\mathrm{m} n} \mathrm{ml} / \mathrm{g}$ \\
\hline \multirow[t]{6}{*}{ Madden Sea } & $>64$ & 0 \\
\hline & $32-64$ & $2.1 \times 10^{2}$ \\
\hline & $16-32$ & $5.2 \times 10^{3}$ \\
\hline & $8-16$ & $1.2 \times 10^{3}$ \\
\hline & $4-8$ & $7.2 \times 10^{4}$ \\
\hline & $<4$ & $1.5 \times 10^{4}$ \\
\hline \multirow[t]{6}{*}{ Mediterranean Sea } & $>64$ & 0 \\
\hline & $32-64$ & $2.9 \times 10^{3}$ \\
\hline & $16-32$ & $6.2 \times 10^{3}$ \\
\hline & $8-16$ & $9.2 \times 10^{3}$ \\
\hline & $4-8$ & $1.1 \times 10^{4}$ \\
\hline & $<4$ & $3.5 \times 10^{3}$ \\
\hline
\end{tabular}

There was also an order of magnitude larger Kd observed for manganese in oxidizing conditions versus reducing conditions for a Black Sea sediment/ seawater system $\left(6.9 \times 10^{4}\right.$ versus $\left.6.45 \times 10^{3}\right)$.

The type of experimental method used to obtain the $\mathrm{KJ}_{\mathrm{Mn}_{\mathrm{n}}}$ also affected the value somewhat (Duursma and Bosch, 1970). A value of 1.2 and $4.5 x$ $10^{4} \mathrm{ml} / \mathrm{g}$ was obtained on the same sediment using two different techniques. A list of average $\mathrm{Kd}_{\mathrm{m}}$ for sharine sediments is found in Table 8.43 . 
TABLE 8.43. $K d_{\text {in }}$ and $t 1 / 2$ for Various Sediments

\begin{tabular}{|c|c|c|c|}
\hline Sedinent & $\begin{array}{c}\log K, \\
\text { Unitless } \\
\end{array}$ & $\begin{array}{c}\text { Kd (est jmated), } \\
01 / 9\end{array}$ & $t 1 / 2$, days \\
\hline Atlantic Ocean & $3.8 \pm 0.8$ & $1.0 \times 10^{4}$ & $6 \pm 6$ \\
\hline Pacific Ocean & $4.2 \pm 0.9$ & $2.5 \times 10^{4}$ & $4+3$ \\
\hline Indian Ocean & $4.1 \pm 0.4$ & $1.8 \times 10^{4}$ & $8 \pm 10$ \\
\hline Baltic Sea & $4.6 \pm 0.3$ & $6.0 \times 10^{4}$ & $7^{-}$ \\
\hline Morth Sea & $4.6 \pm 1.0$ & $6.4 \times 10^{4}$ & 17 \\
\hline Mediterranean Sea & $3.8 \pm 1.0$ & $9.5 \times 10^{3}$ & $2 \pm 2$ \\
\hline Black Sea & $4.2 \pm 0.7$ & $2.1 \times 10^{4}$ & 8 \\
\hline Red Sea & 3.6 & $8.6 \times 10^{3}$ & 0.5 \\
\hline
\end{tabular}

Gromov (1975) studied the adsorption/desorption of ${ }^{54} \mathrm{~mm}$ by various sorbents in sea water. Saples of orean sediments mere contaminated with radioisotopes and desorption carried out in fresh water.

Kawabata (1967) studied factors affecting the sorftion of $54 \mathrm{~mm}$ by river sediment in fresh and saline water. Release of ${ }^{54} \mathrm{~mm}$ adsorbed on river sediments upon exposure to sea water was slow, and with time readsorption was observed.

Salo and Saxen (1974) studied the relationship of huic acids and soluble manganese in Bothnian Bay, finland. The greatest percentage of manganese in the water was uncomplexed and would be expected to sorb on suspended particles both mineral and high molecular weight huics.

Field Studies

Evans (1973) and Evans and Cutshall (1973) mixed unfiltered Columbia River water with filtered sea water. After $4 \mathrm{hr}$ the samples were filtered and soluble and particulate manganese measured. Some of the manganese bound to suspended sediment in the river water was desorbed by sea water (particulate manganese dropped froin 71 to 53\%). When suspended river sediments were put in sea water the manganese showed desorption from $5 \%$ in the first hour to $55 \%$ within 1 meek. For river bottom sediments suspended in sea vater after 
11 weeks, 50\% of the manganese was released to the water. Thesc results can be explained by ion exchange-like adsorption of manganese on fresh-water sediments. Robertson et a1. (1973) confirmed a large release or manganese (40X) from river bed sedinent upon leaching with sea water.

Nelson et al. (1966) and Perkins et al. (1966) determined the physicochemical state of manganese in the cooling water and at various stations along the Columbia River. The anganese present in reastor cooling water is $3 \%$ particulate, and the percentage particulate increases domstrean to 20 to 508 at Pasco and 70 to $88 \%$ at Vancouver, Hashington. The soluble manganese in the cooling and river water is over $90 \%$ cationic. Upon reaching the saline estuary portion of the river the soluble anganese is significantly different (48\% cationic, $43 \%$ anionic and 103 uncharged).

Robertson and Perkins (1975) found the 54/m present in N-Reactor cooling water was $10 \%$ particulate and $89 \%$ cationic. Quantifiable manganese is not observed in spring water on the banks of the Colubia River wich is fed by the cooling water.

Bonatti et al. (1971) observed that wanganese is enriched in the upper oxidized zone of deep sea cores versus reduced layers.

Sumary

The fate of manganese in the marine environment appears to be controlled by oxidation-reduction precipitation-dissolution of hydrous oxides. The observed $k \mathrm{~A}_{\mathrm{h}}$ in sea water is large $10^{3}-10^{4} \mathrm{ml} / \mathrm{g}$. The fresh-water oxidizing environments, manganese appears to exhibit ion-exchange-like behayior. No $K_{\text {inn }}$ values are reported but studies on the Columbia River suggest manganese is found on particulates. 
iptritur

Matural Sediment and Rock Distributions

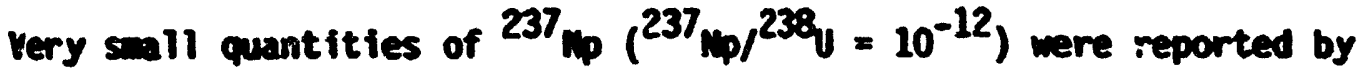
Reller (1971) but for practical purposes neptuniu does not occur naturally in sedinents or rocks.

\section{Brief Cheaistry}

There are 16 ' 30 m isotopes of neptunium from 228 np to $241_{n p}$ (Keller, 1971). Only $237_{n p}$, a neutron reaction product of $238_{U}(n, 2 n)$ and $235_{U}(n, y)^{2}$, with a mif-life of $2.14 \times 10^{6}$ years is of interest here. The 5000 year halflife ${ }^{236}$ mp is a cyclotron product conly. Meptunium exists in aqueous solutions in five oxidation states, $n_{p}($ III $), n_{p}\left(\right.$ IV) $, N_{p}(V), m_{p}(V I)$ and $n_{p}(V I I)$. In the absence of complexing agents, the first four oxidation states exist as hydrated ions $\mathrm{mp}^{+3} \cdot \mathrm{aq}, \mathrm{np}^{+4} \cdot \mathrm{aq}, \mathrm{mpO}_{2}^{+} \cdot$ aq and $\mathrm{npO}_{2}^{+2} \cdot$ aq (Keller, 1971). $\mathrm{h}$ (VII) is a strong oxidizing agent that is stable in strong alkaline solutions as $\mathrm{m}_{\mathrm{m}} \mathrm{O}_{5}^{-3}$. The most stable oxidation state in solution is the pentavalent one were neptunium exists as a single charged neptunyl ion, $\mathrm{mpO}_{2}^{+} \cdot$ aq, with symetrical linear bonding $(0-1 \mathrm{p}-0)^{+}$. It hydrolyzes only at a pH of greater than 7, disproportionates only at high acid concentrations and forms no polymuclear complexes (Keller, 1971). The $\mathrm{npO}_{2}^{+}$ion is a poor complexing agent with inorganic ligands.

Solution Equilibria

The activity of various solution complexes of neptuniu in equilibrium with $\mathrm{MpO}_{2}(\mathrm{~s})$ in an oxidizing environment $\left(\mathrm{pO}_{2}=0.68\right)$ and assuned weather ing environment is given in Figure 8.22. Thernodymanic data for $\mathrm{nPO}_{2} \mathrm{HPO}_{4}^{-}$ were obtained fro sillen and martell (1964). The remaining data were from Burmey and Harbour (1974). The solution complexes of $\mathrm{IP}_{\mathrm{p}}(\mathrm{IV}), \mathrm{n}_{\mathrm{p}}(\mathrm{V})$, and $\mathrm{mp}_{\mathrm{p}}(\mathrm{VI})$

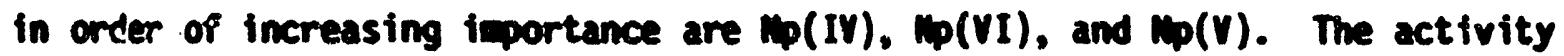
of $\mathrm{MP}_{\mathrm{p}}$ (IV) and $\mathrm{hp}$ (VI) complexes is so small that these complexes can be safely ignored since they would not contribute significantly to the total activity of $n_{p}$ in solution (Burmey and Harbour, 1974). The lines of $n_{p}(V)$ and $n_{p}(V I)$ coinplexes will shift dommard with the increase in reducing environment but stiil 
be parallel to the present lines. Under the oxidizing conditions assuned in Figure 8.22, $\mathrm{MO}_{2}^{+}$is the most dominant solution species in a pH range of 0 to approxiciately 9. Beyond $\mathrm{pH} \mathrm{9,} \mathrm{MPO}_{2} \mathrm{HPO}_{4}^{-}$and $\mathrm{MpO}_{2} \mathrm{HCOO}_{3}^{\circ}$ would control the total concentration of neptuniun in solution. In reducing environments, whe expected predominant solution species are nport ${ }^{3+}$ and $n^{4+}$.

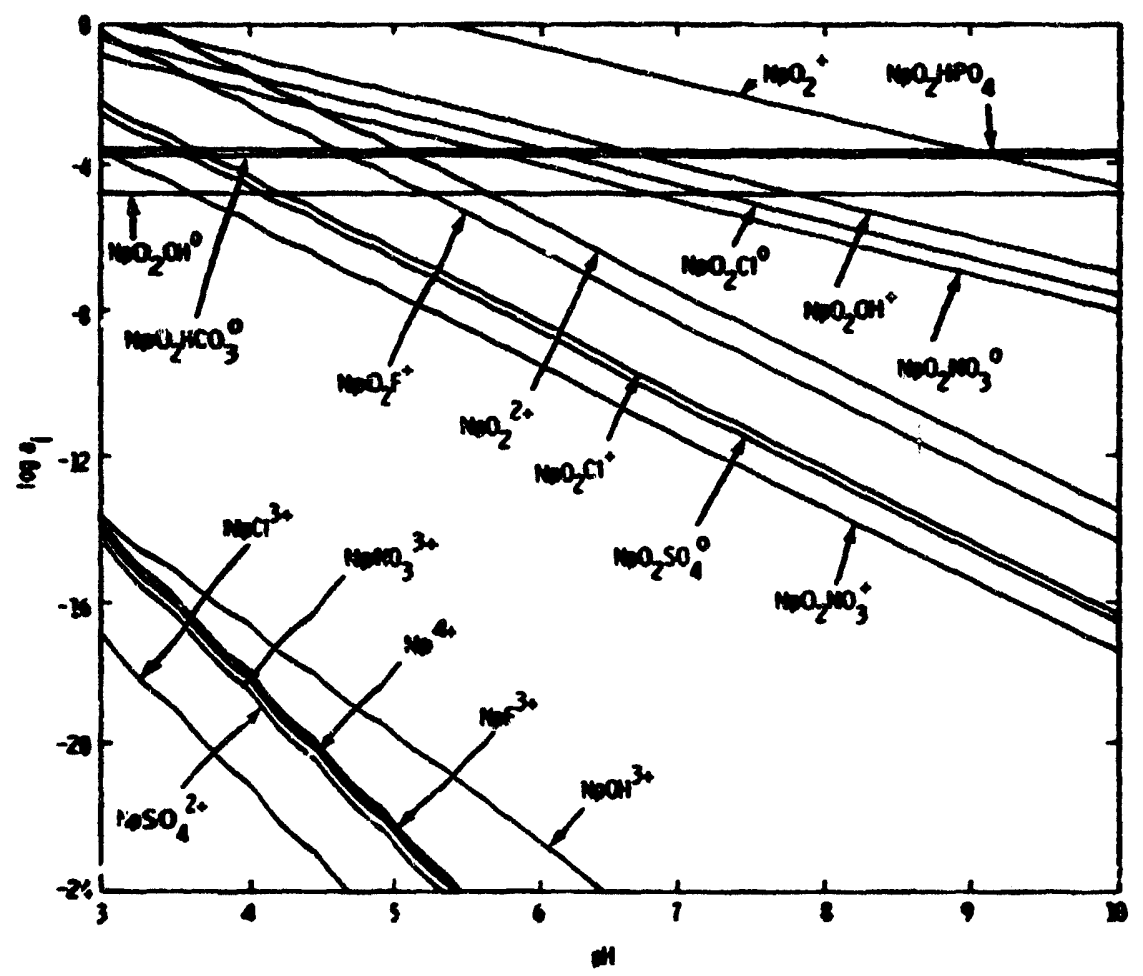

FIGURE 8.22. The Activity of Various Meptuniu Species in Equilibriu with $\mathrm{ppO}_{2}(\mathrm{~s})$ in an Oxidizing Soil Enyironment $\left[\mathrm{pO}_{2}(\mathrm{~g})=0.68 \mathrm{ata}\right]$, $\mathrm{PC}^{2}=\mathrm{PSO}^{2-}=2.5$, $\mathrm{pH}_{3}=3.0, \mathrm{pF}=4.5$ and $\mathrm{PH}_{2} \mathrm{PO}_{4}=5.0$

$\mathrm{MpO}_{2}$ is the usual form of charged neptunium species up to pH 9. Above ph 9, an uncharged bicarbonate caplex is formed. According to Keller (1971) neptunium $(V)$ does not hydrolyze below a pH of 7. Consequently, a singly charged neptunyl ion is the usual form. Hence, $\mathrm{MO}_{2}^{+}$would be expected to enter 
into ion-exchange reactions. $\mathrm{np}_{2}^{+}$does not compete favorably with $\mathrm{Ca}^{+2}$ and other comon divalent ions, and the distribution coefficients are usually relatively low on most solis (Routson et al., 1976b; Sheppard et al., 1976). Laboratory Adsorption Studies

Bensen (1961) examined the adsorption on minerals of radionuclides in reactor effluent cooling water. One of the radionuclides studied was $237_{\text {np, }}$ mich was adsorbed on 25 different comon sulfide, silicate and carbonate winerals, 0.05 to $0.25 \mathrm{~m}$, in equilibriun tests with trace anounts in columia River water at $80^{\circ} \mathrm{C}$. According to Bensen, neptuniun was adsorbed poorly or not at all by the minerals tested.

Robertson (1974) determined the speciation of neptunium in the cooling water effluent from the Hanford $n$ reactor. Through the use of filter membranes and cation and anion exchange resins, the following distribution as observed: $26 x$ particulate, $70 x$ cationic, $<3 \%$ anionic and $<18$ nonionic.

Routson et al. (1975, 1976) determined neptuniu Kd values for a lashington sand and a South Carolina sandy clay. The properties of these soils are given in Table 8.44. The neptunium Kd values are given in Table 8.45. Preequilibrations of the solis with nonradioactive solutions prior to contact with the traced solution containing $237_{10}$ we carried out. Calcium nitrate and sodiu nitrate salts mere used as calciu and sodiu ion sources. Cation exchange of $\mathrm{MpO}_{2}^{+}$cannot be the principal adsorption mechanisn because $\mathrm{Ha}^{+}$ concentration essentially does not affect the meptuniu Kd values from no sodiun competition to $3.0 \mathrm{M} \mathrm{ma}^{+}$competition. Calcium has some effect on the neptiniun Kd, but much less than there would be if neptuniun adsorption were due to ion exchange.

Sheppard et a1. (1976) deternined neptuniun distributions on several Mashington and horth Carolim solls. The distilled mater-trace ${ }^{237}$ Np solu. tions and soils were equilibrated over iong periods of time to obtain a rate of change per wonth in the distribution values. The 50-day values are given in Table 8.46. A positive value for the conthly change in the distribution 
TheE 8.44. Properties of Soil Saples

(Rourson et al., 1976)

\begin{tabular}{|c|c|c|c|c|}
\hline Soll & $\begin{array}{l}\mathrm{CaCO}_{3} \\
\mathrm{ag} / \mathrm{g}\end{array}$ & $\begin{array}{l}\text { Silt, } \\
\text { wtes } \\
\end{array}$ & $\begin{array}{l}\text { Clay, } \\
\text { wts. }\end{array}$ & $\begin{array}{c}\text { CEC, } \\
m=a / 100 \\
\end{array}$ \\
\hline $\begin{array}{l}\text { Lashington Soil } \\
\text { (Burbank sandy ioan) }\end{array}$ & 0.8 & 10.1 & 0.5 & 4.9 \\
\hline $\begin{array}{l}\text { South Carolina } \\
\text { Subsoil }\end{array}$ & 0.2 & 3.6 & 37.2 & 2.5 \\
\hline
\end{tabular}

TABCE 8.45. Meptunium Kd (al/g) as a Function of Soll and Solution (Rouston et al., 1976)

\begin{tabular}{|c|c|c|c|c|}
\hline & & & & \\
\hline Soil & $0.00 \mathrm{~K}$ & 0.27 & $0.025 \mathrm{i}$ & $3.00 \mathrm{n}$ \\
\hline Mashington & 2.37 & 0.36 & 3.9 & 3.2 \\
\hline South Carolina & 0.25 & 0.16 & 0.7 & 0.4 \\
\hline
\end{tabular}

TABLE 8.46. Meptunion 50-day Distribution Values Computed from Sheppard et al. (1976)

\begin{tabular}{|c|c|c|}
\hline Soll Identity & $\begin{array}{c}\text { Distribution, } \\
\text { w/a }\end{array}$ & $\begin{array}{l}\text { Monthly Change } \\
\text { in Distribution, } 8\end{array}$ \\
\hline $\begin{array}{l}\text { Miscatine } \\
\text { silt los }\end{array}$ & 127 & +10 \\
\hline $\begin{array}{l}\text { Burbank } \\
\text { lowy sand }\end{array}$ & 15.4 & +48 \\
\hline $\begin{array}{l}\text { Ritzville } \\
\text { silt loan }\end{array}$ & 20.2 & +28 \\
\hline $\begin{array}{l}\text { Fuquay sand } \\
0 \text { to } 5 \mathrm{~cm} \text { depth }\end{array}$ & 33.7 & +25 \\
\hline $\begin{array}{l}\text { Fuquay sand } \\
5 \text { to } 15 \text { a depth }\end{array}$ & 37.2 & +25 \\
\hline $\begin{array}{l}\text { Fupuay sand } \\
15 \text { to } 50 \mathrm{~cm} \text { depth }\end{array}$ & 32.4 & +19 \\
\hline
\end{tabular}


means an increase in the size of the distribution value. The distribution was determined in the same way that a Kd value is determined, but does not have the comnotation that equilibriu has been attained.

The neptuniu Kd value of about $3.9 \mathrm{ml} / \mathrm{g}$ was given by Routson et al. (1975, 1976) for the Burbank sandy lam without sodium in the solution. Sheppard et al. (1976), apparently for the same conditions, gives a neptunion 50-day distribution value of $15.4 \mathrm{ml} / \mathrm{g}$ for Burbank and states that this value is increasing at the rate of $\$ 48 \% /$ month. At 100 days, the distribution was approximately $50 \mathrm{ml} / \mathrm{g}$ on the Burbank iosm sand. The differences in neptunium distribution between soll and solution probably resulted from the experimental differences because the Burbank sandy lose of Sheppard was obtained from Routson. However, Sheppard showed the Burbank saple to contain $21.2 \%$ silt and $2.8 \%$ clay with a pH of 8.1 and a cation-exchange capacity of 5.94 meq/100 $\mathrm{g}$ compared to Routson's Burbank soil saple (Table 8.44). Sheppard's Burbank must have contained calcite $\left(\mathrm{CaCO}_{3}\right)$ to attain a pH of 8.1. There is no evidence in Sheppard et al. (1976) that the soil saples were pre-equilibrated in any wy with the nonradioactive solution before the neptunium tracer was added, or that a blank solution without the soil was run with the soil equilibrations for reference and to observe container adsorption. In addition, Sheppard reported that his ${ }^{237} \mathrm{hp}_{\mathrm{P}}(V)$ in the aqueous phase equilibrating with Ritzville soll was partially filterable on thatman numer 50 filter paper. Routson, on the other hand, reported that upon filtering previously centrifuged samples of solution containing neptunium and in contact with Burbank or South Carolina subsoll through 0.01 and 0.45 un filters, no evidence of colloidal ${ }^{237}$ Mp was found. This is further evidence that Sheppard's high neptuniun distribution values require further elucidation in light of Routson's results.

\section{Field Studies}

Sedlet and Colchert (1977) measured the ${ }^{237}$ mp content of Samill Creek wich receives wiste weter from Argonne Mational Lab. They found detectable np $\left(10^{-14} \mathrm{Ct} / \mathrm{l}\right)$. Ninety percent of the neptunium appeared to pass through an unspecified filter size after acidification to phl. 


\section{Sengy}

The existing thermodymanic data (figure 8.22) show that neptuniu should exist in an oxidizing soil environent as $\mathrm{rp}_{\mathrm{p}}(V)$ in the form of $\mathrm{npO}_{2}^{+}$. However, existing adsorption results, a study by Routson et a1. $(1975,1976)$ and Sheppard et al. (1976), inferred that there is little evidence of $\mathrm{MpO}_{2}^{+}$ion exchange as a neptuniu adsorption nechanisa. Sheppard et al. (1976) reported neptunitu colloids present in the soil-solution environment, wile Routson et al. $(1975,1976)$ specifically showed that they were absent from his solutions that had contacted soils. Little more can be said based on the adsorption and igration studies now available in the literature. Additional research is required on neptur $a /$ sediment reactions. Attention should be focused on whether $\mathrm{MpO}_{2}^{+}$can be reduced to much less soluble $\mathrm{mp}$ (IV) forms by reducing sediments. 


\section{PHOSPHDRUS}

\section{Matural Sediment and Rock Distribution}

Phosphate minerals, in addition to schreibersite and perryite, are the only phosphorus compounds knom to occur in nature. Average values for phosphorus often reported as $\mathrm{P}_{2} \mathrm{O}_{5}$ are found in Table 8.47.

TABLE 8.47. Phosphorus Content of Rocks and Sediments

\begin{tabular}{|c|c|c|c|}
\hline Iype & $p, \%$ & $\mathrm{P}_{2} \mathrm{O}_{5} \mathrm{x}$ & Reference \\
\hline Sandstone & & 0.08 & Hedepohi, 1969 \\
\hline Shale & & 0.16 & Hedepoh1, 1969 \\
\hline Carbonates & & $\begin{array}{l}0.07 \text { to } \\
0.16\end{array}$ & Wedepohl, 1969 \\
\hline Pelagic Clays & & 0.72 & Hedepoh1, 1969 \\
\hline Igneous Rocks & 0.11 & & Hen, 1970 \\
\hline Sandstone & 0.05 & & Hew, 1970 \\
\hline Shale & 0.07 & & Hen, 1970 \\
\hline Carbonates & 0.028 & & Hean, 1970 \\
\hline
\end{tabular}

\section{Brief Chemistry}

There is only one stable isotope of phosphorus, ${ }^{31} p$. There are two radioactive isotopes with half-lives larger than a few ainutes $p^{32}$ (14.3 days) and $p^{33}$ (25 days). Phosphorus in the environment is typically found in the +5 va?ence state as a phosphate $\mathrm{PO}_{4}^{3-}, \mathrm{HPO}_{4}^{2-}, \mathrm{H}_{2} \mathrm{PO}_{4}^{-}$anions both in the water colum and sediments. Phosphorus along with carbon and nitrogen form the building blocks of wost organic matter. Thus organic bound phosphorus cari contribute to the overall distribution. The average concentrations of phosphorus in oceans and Morth Nmerican streams are 0.088 and $0.019 \mathrm{ppm}$, respectively (Hedepoh1, 1969). In sea water phosphorus is found as $\mathrm{H}_{2} \mathrm{PO}_{4}^{-}$and ion pairs with cations (Kester and Pytkowic2, 1967). In fresh waters phosphorus is likely to be present as phosphate anions, complexes with metal ions and collofdal particulate matter (Hea 1970). 


\section{Laboratory Adsorption Studies}

Mumerous imvestigators have observed that under oxidizing conditions phosphorus (phosphates) is readily adsorbed by sediments and under reducing conditions phosphates are resolvbilized (Berner, 1975, Khalid et al., 1978, Fitzgerald, 1970, Harter, 1968, Li et a1., 1972, Mortimer, 1941, Shukla et al., 1971, Syers et al., 1973, and willians et al., 1971). The key to this redox sensitive reaction is the very high affinity for hydrous oxides of aluminu, manganese and iron for phosphate anions. Under oxidizing conditions these hydrous oxides lower the phosphate concentrations to less than $0.1 \mathrm{ppo}$ typically. Other sorbates include the precipitation of apatites $\mathrm{Ca}_{3}\left(\mathrm{PO}_{4}\right)_{2}$ and organic matter. Urder reducing conditions the reduction of hydrous oxides, degradation of organic material releases phusphates.

Green et al. (1978) studied the adsorption-desorption characteristics of Onio river sediments and suspended sediments. Suspended sediment contained more total phosphoris than bottom sediments $1350 \mathrm{ppm}$ versus $900 \mathrm{ppm}$. The suspended sediments and botton sediments adsorption followed Langmir isotherns. The higher phosphorus suspended solids way be caused by the increased contact with soluble phosphorus, wore oxidizing conditions, algae measured as suspended solids or saller particle size (larger surface area) distribution than botton sediments. The energy of adsorption (resistance to desorption) was larger for botton sediments than suspended solids.

Kuo and Lotse (1974) studied the rate and extent of phosphate adsorption and desorption and the energy of phosphate adsorption by lake sedicents. They found that phosphate adsorption could be described by the Freundlich equation over a large phosphorus concentration range ( 0 to 200 ppo phosphorus) wile Langmir adsorption isotherms provided a good data fit only at low phosphorus concentrations 0 to $75 \mathrm{ppm}$ phosphorus. The rate of phosphorus adsorption by the sediments could be described by the equation $X=k C_{0} t^{1 / m}$ where

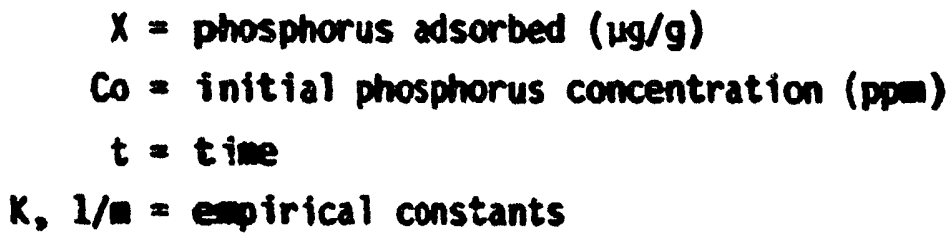


The activation energy of sorption and desorption mere found to be quite low suggesting phosphate adsorption desorption are diffusion controlled processes. They also noted that freshly adsorbed phosphorus exhibited a much higher degree of "exchangeability". Desorption of native phosphorus from sedicents using $2.5 \times 10^{-3} \mathrm{~W} \mathrm{EDTA}^{2-}, \mathrm{F}^{-}, \mathrm{HC}_{2} \mathrm{O}_{4}^{-}$or $\mathrm{OH}^{-}$showed that only EDTA $^{2-}$ significantly increased desorption. As EDTA is a strong complexer of iron it probably induced decomposition of anorphous hydrous iron oxides. At a sediment to solution ratio of $0.01 \mathrm{~g} / \mathrm{ml}$ adsorption and desorption reached steady-state after 48 hours.

Enfield and Bledsoe (1975) measured the kinetics of orthophosphate sorption with 25 soil minerals. They found the reaction of phosphorus with soil minerals is not instantaneous. Thus, using equilibrium isotherms will yield erroneous conclusions as to the ability of soil to adsorb phosphorus. A diffusion-limited process paralleling heat flow theory for the storage of heat in spheres best describes the experimental data.

Collet et al. (1968) deterwined the fixation capacities of the Rhine river silt for radioactive material in order to draw conclusions on the deposition of fission products and other radioisotopes in the river bed. Therefore, the distribution coefficient $C_{p}$ between river silt and river water (the ratio of the absorbed mass of the element studied per gram silt to the concentration of the same element in the mater in equilibriun with the silt) was determined in the laboratory $\mathrm{fl}:$ the elements $\mathrm{Ce}, \mathrm{CS}, \mathrm{I}, \mathrm{P}, \mathrm{Ru}$, and Sr.

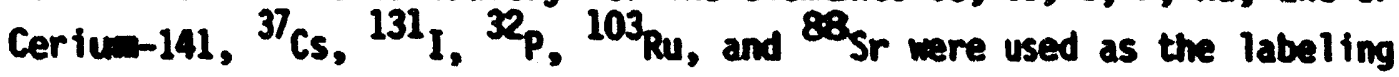
isotopes. Altogether 756 individual samales were processed. These samples were separated by a centrifuge method into the three fractions sand, clay, and organic material, in order to obtain conclusions on the effect of the individwal constituents of the silt. The methods mere outlined, the results were reported, and the fixation capacities found mere related to the activity of the individual fallout muclides present in the silt.

Schneider (1970) investigated the sorptive properties of artificial monomineralic fine sands of uniform grain size. Montumpillonite, kaolinite, muscovite, and biotite have a higher sorptive power. The sorptive power of quartz 
oxides and magnetite and of microcline and albite is low. Hornblende and augite occupy a medium position. The highest affinity for the minerals show the cations ${ }^{137} \mathrm{Cs},{ }^{90} \mathrm{Sr}$, and ${ }^{65} \mathrm{Zn}$. Phosphorus-32, as complex phosphate anion, is less highly adsorbed. The sorption of ${ }^{131}$ I is negligible.

Carritt and 6oodgal (1954) studied the sorption of dissolved substances on suspended solids in natural waters using Chesapeake Bay materials in the Iaboratory and field. The field results did not conclusively fit a Freundlich isotherm. Laboratory studies of phosphate uptake showed a rapid adsorption process and a whech slower diffusion controlled reaction. In the laboratory a log-log plot of percent phosphorus sorbed versus time remained linear up to 70 hours. In order words adsorption continued throughout the experimental period without reaching equilibrium. Phosphorus adsorption versus pH is shown in Figure 8.23.

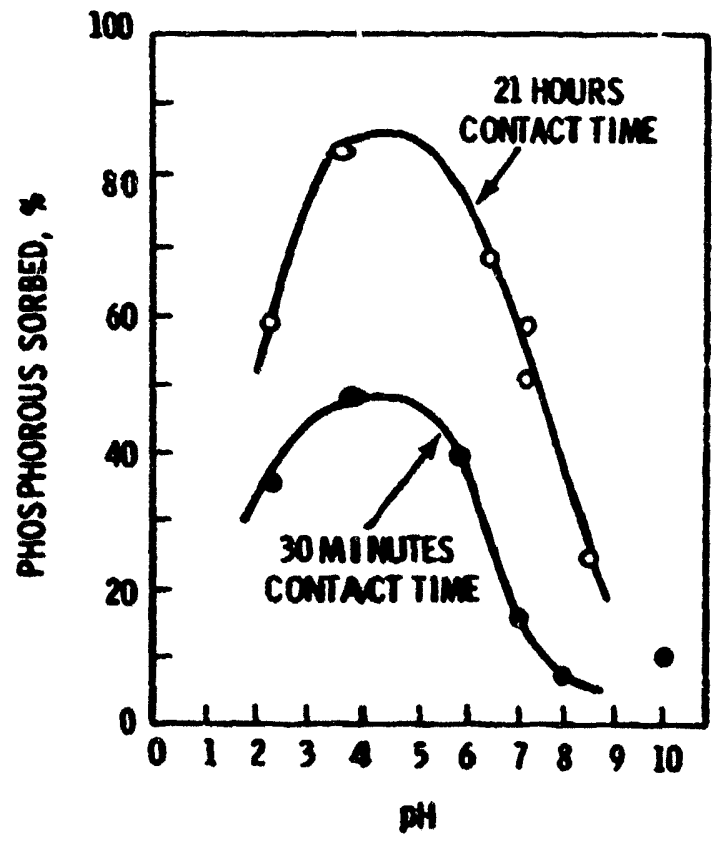

FIUSEE 8.23. Rewoval of Phosphate by Roanoke River Solids as a Function of pH. Initial conditions; temperature $21^{\circ} \mathrm{C}$, solids $310 \mathrm{ppm}$, total phosphorus $0.5 \mathrm{\mu g}$ at $P / 1$. 
A comparison of these curves with phosphoric acid dissociation curves indicates that aximm uptake occurs in the pH range in wich $\mathrm{H}_{2} \mathrm{PO}_{4}^{-}$is the predominant species. Temperature also affects phosphorus sorptior. For a given initial phosphorus concentration in solution more phosphorus is adsorbed by sediments at higher temperatures. Time dependent studies show a rapid $<1$ win portion and a slow diffusion controlled portion. The driving force for the slow reaction was identified as the phosphorus gradient in and near the adsorbed layer on the solid surface. During desorption the amount of phosphorus and rate of removal will depend upon the length of time the complex has had to form. With long contact time a greater fraction of the phosphorus will have diffused into the solid and so will be slower to desorb. For example, Figure 8.24 contains results of successive 2-min desorption experiments on sediments on two samles, which have been in contact with phosphorus for 4 days and 30 min.

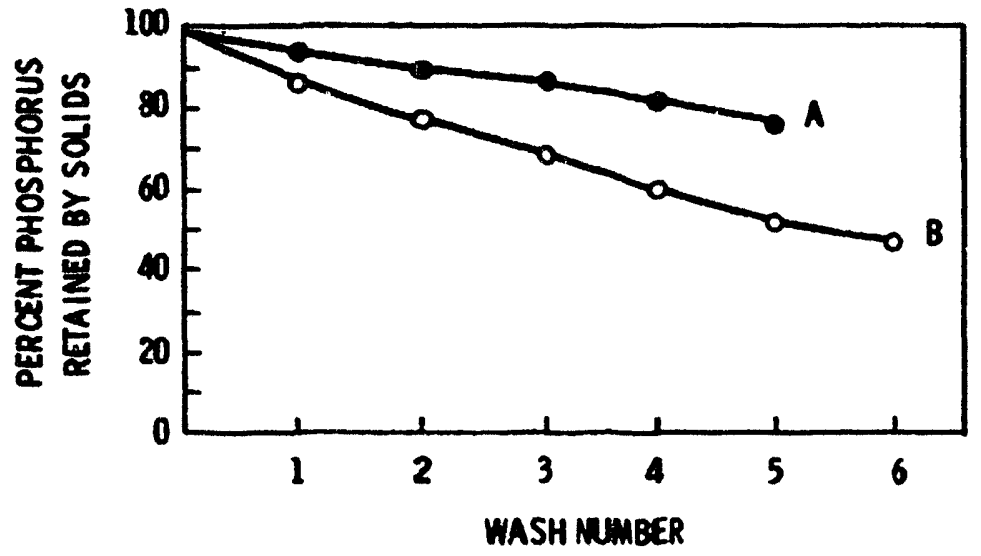

FIGRE 8.24. The Effect of Prior Contact Time on the Desorption of Phosphorus from Solids (pH of wash 3-4)

A. 4 days contact.

B. 30 min contact.

The effect of salinity on phosphorus adsorption are show in Figure 8.25. The reduction in adsorption of phosphorus at higher salinities was hypothesized to be due to agglomeration or clumping of the finely dispersed solids, wich reduces surface area for adsorption. Competition of other anions such as suifates also cannot be ruled out. 
Lean and Chariton (1976) measured the siological (algae) interaction of phosphorus in a leak ecosystem but found the interpretation difficult.

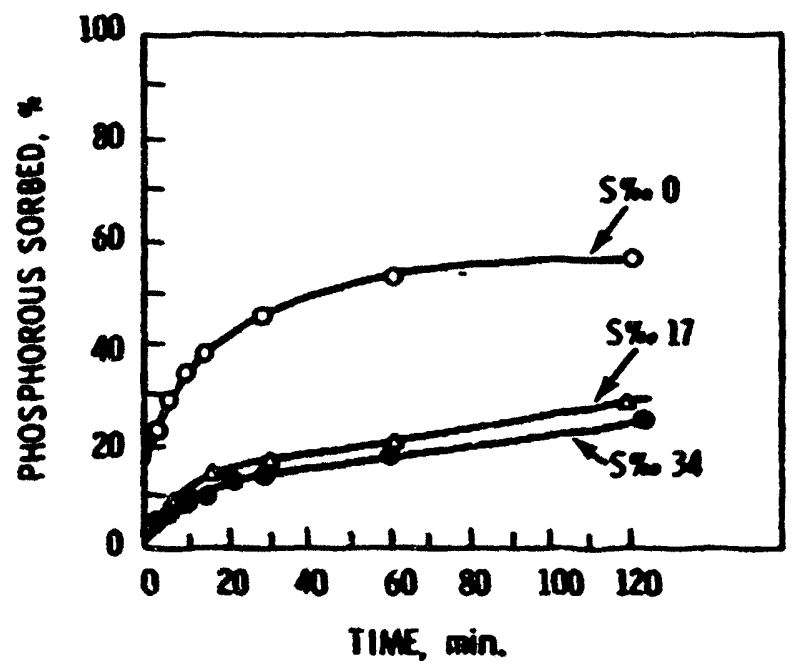

FIGRE 8.25. The Effect of Variations in Salinity on the Uptake of Phosphorus. Initial conditions; pH 3.4, solids 310 , phosphorus $0.9 \mu \mathrm{g}$ at $\mathrm{P} / \mathrm{l}$, salinity as noted.

\section{Field Studies}

Plutoniu-32 is an activation product formed in maclear reactors. At Hanford through the mid-1960s an average of about 40 curies/day mere released to the Columbia River from Hanford plutonium producing reactors (Fosier 1963a, 1963b, 1964) and Wilson and Eggers (1970). The average columbia River ${ }^{32} \mathrm{p}$ concentration varied seasonally with river flow rate between 80 and $500 \mathrm{DCi} / \mathrm{l}$. thitefish caught in the vicinity of the chronic release were found to contain $10^{-4} \mathrm{ug} / \mathrm{g}$ of ${ }^{32} \mathrm{P}$. After the reactors were shut down the ${ }^{32} \mathrm{P}$ rapidly decayed avay. In 1970, the year that the last plutonium reactor was shut dow, the estimated total Colubia River-Morth Pacific Ocean imentory of $32 \mathrm{p}$ was 600 curies. Within 1/2 year this inventory had decayed to 0.15 curies.

In a draft document on reactor coolant water Dames and Moore (1978) showed a typical range of 4 to $110 \mathrm{pCi} / \mathrm{ml}$ of $32_{\mathrm{p}}$. 
Simpson et al. (1975) studied the phosphorus budget in the Hudson River estuary. Sewage pollutants rich in phosphorus were found. Once aixed in the estuary the organic phosphorus content was quite low mile particulate phosphorus reached levels of 30 to $50 \%$ of the total phosphorus.

Taft and Taylor (1975) described the annual cycle of phosohorus in Chesapeake Bay and not for the dissolved component, organic nitrogen is often abundant as orthophosphate species.

\section{Semary}

Phosphorus is found to adsorb readily to suspended sediments and botton deposits under oxidizing conditions. The main adsorbate mechanisa is hydrous aluminu iron and manganese oxides. Under reducing conditions these amorphous precipitates readily dissolve releasing bound phosphorus. Phosphorus also enters biological processes and can be found in Jiving and decaying biomass. A $K d 2_{p}$ is dependent upon the specific activity (amount of radioactive $32 \mathrm{p} /$ awount of stable phosphorus). The wore stable phosphorus present the saller will be the $K d 2_{p}$ caused by isotope dilution.

The half-life of ${ }^{32} p$ (14.3 days) would require chronic releases to contimually supply a renewed source before serious environmental consequences would be expected. 


\section{PLUTCill}

\section{Matural Soil and Rock Distributions}

Except for extremely small quantities of plutonium in the natural environments, plutoniu does not occur in any significant awount in sediments or rocks. Cherdyntser et al. (1968), for exapie, lists 239 pu values in natural rocks and minerals varying from $7 \times 10^{-12}, 239 \mathrm{Pu} / \mathrm{g}$ to $1 \times$ $10^{-15} \mathrm{~g}^{239} \mathrm{Pu} / \mathrm{g}$.

\section{Brief Chemistry}

Fifteen isotopes of plutoniu are known, including 10 isouers with different decay modes (Keller, 1971). Most of the isotopes are formed by witiple neutron sapture and, therefore, are not ordinarily encountered in matural emvironments. An exception is the natural reactor at 0 klo, Cabon (LEA, 1975) and very small acounts $\left(P u / N=10^{-11}\right.$ ) found in the uranium mineral pitchblende (Cleveland, 1970).

The plutoniu isotopes of concern to waste disposal, either because they are contained in the fission product wastes or are a part of an inportant decay chain for waste constituents, are listed in Table 8.48. In the short term, almost any platonium radionuclide would be of concern in wasteradionuclide reactions although, on a weight basis, longer-lived ${ }^{24 Z_{\mathrm{Pu}}}$ is not nearly as hazardous as ${ }^{239} \mathrm{Pu}$. Long irradiation tives and high neutron fluxes are required to produce significant aunts of ${ }^{242} \mathrm{pu}$, so that a prevalence of the higher mass $\mathrm{Pu}$ isotopes usually will not occur in waste solutions from comercial fuel treatment facilities.

TABLE 8.48. Plutoniv Radionuclide Data (Keller 1971)

$\begin{array}{ccc}\text { Isotope } & \text { Half-Life, } y & \text { Decay Hode } \\ 238_{\mathrm{Pu}} & 86.4 & \alpha \\ 239_{\mathrm{Pu}} & 24,400 & \alpha \\ 240_{\mathrm{Pu}} & 6,600 & \alpha \\ 241_{\mathrm{Pu}} & 14.1 & B \\ 242_{\mathrm{Pu}} & 387,000 & \alpha\end{array}$


Plutonium exists in five oxidation states in aqueous solutions: Pu(III), $\mathrm{Pu}(\mathrm{IV}), \mathrm{Pu}(\mathrm{V}), \mathrm{Pu}(\mathrm{VI})$, and $\mathrm{Pu}(\mathrm{VII})$. These staies can occur as the hydrated ions $\mathrm{Pu}^{+3} \cdot a q, \mathrm{Pu}^{+4} \cdot a \mathrm{PuO}_{2}^{+} \cdot \mathrm{aq}_{2} \mathrm{PuO}_{2}^{+2} \cdot$ aq and $\mathrm{PuO}_{2}^{-3}$. aq (Keller, 1971). The most stable state of plutoniu in aqueous solution is Pu(IV). However, disproportionation, in mich Pu(III), Pu(IV), Pu(V) and Pu(VI) states can coexist in unequal quantities, tends to further comlicate plutonium chemistry in its reactions with soils and sediments. According to Cleve!3nd (1970), plutoniu in near-neutral solutions occurs in the order: $\mathrm{Pu}^{+4}>\mathrm{PuO}_{2}^{+}$ $>\mathrm{Pu}^{+3}>\mathrm{PuO}_{2}^{+}$. Hydrolysis reactions lead to the formation of positively charged to neutral colloidal polymers in a stepwise a mer. For examle, $\mathrm{Pu}^{+4}+$ $\mathrm{OH}^{-} \rightarrow \mathrm{POHH}^{+3}+\mathrm{OH}^{-} \rightarrow \mathrm{Pu}(\mathrm{OH})_{2}^{+2}$, etc., leads finally to $\mathrm{Pu}(\mathrm{OH})_{4}$ wich loses water to produce thermodymanically stable $\mathrm{PuO}_{2}$ (Keller, 1971). Complexing agents such as fluoride or sulfate ions can accelerate the process. Plutonium can form complexes with wost of the ions comonly encountered in natural solutions. Thus disproportionation, complex formation and hydrolys is reactions, all relatively pronounced with aqueous plutoniva solutions, combine to add to plutonium chemistry complexity.

Figure 8.26 demonstrates the activity of various plutonium species expected in equilibrius with $\mathrm{PuO}_{2}(\mathrm{~s})$ and in an oxidizing ensironment $\left(\mathrm{PO}_{2}\right.$ $16 \mathrm{~atm})$. Plutoniu in solution exists in four oxidation states $\left(\mathrm{Pu}^{3+}, \mathrm{Pu}^{4+}\right.$, $\mathrm{PuO}_{2}^{+}, \mathrm{PuO}_{2}^{2+}$ and forms complexes with $\mathrm{OH}^{-}, \mathrm{Cl}^{-}, \mathrm{F}^{-}, \mathrm{SO}_{4}^{2-}, \mathrm{H}_{2} \mathrm{PO}_{4}^{-}$and $\mathrm{CO}^{2-}$ ions. In general, the activity of all positively charged ions and ion-complexes and a few neutral ion-pairs decreases with the increase in pH, while the activity of all negatively charged ion-complexes increases with the increase in pH. In an oxidizing environment, $\mathrm{Pu}^{3+}$ and $\mathrm{Pu}^{4+}$ and their ion-pairs have an insignificant effect on the total activity of plutoniu in solution. At any given pH, the total activity of plutoniu in solution can be obtained by adding the appropriate activities of various plutonition species. Since the lines for some plutoniu species are based on concentration constants, the position of the lines way change when converted to thernodynaic equilibriu constants. Figures 8.26 and 8.27 were constructed by assuing a weathering environient $\left(\mathrm{pCO}_{2}=3.53 ; \mathrm{PCl}^{-}=\mathrm{pSO}_{4}^{2-}-2.5 ; \mathrm{pF}^{-}=3.5\right)$ and $\mathrm{PuO}_{2}(\mathrm{~s})$ as the compound that ma be present in the environment at equilibriv. 


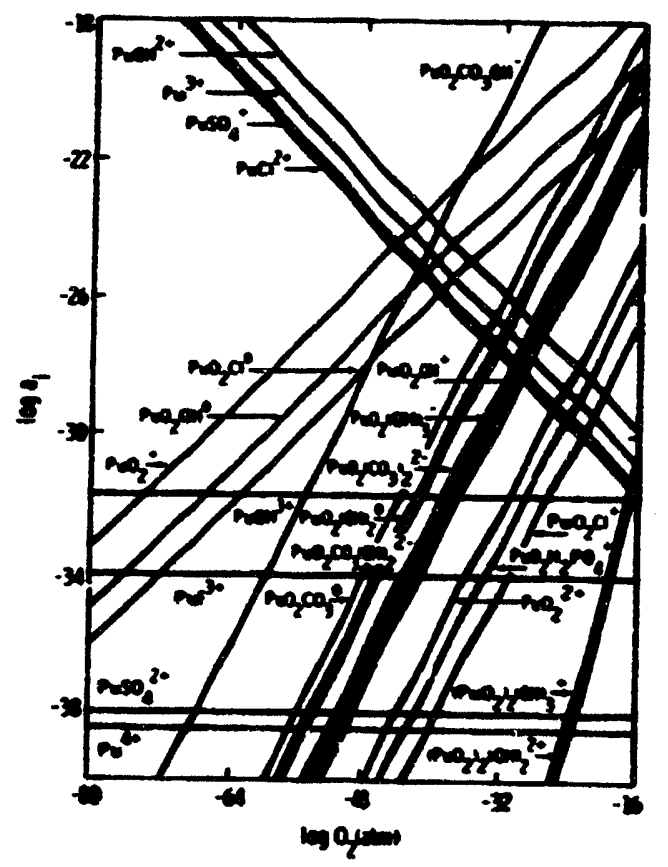

FIEURE 8.26. The Activity of Various Plutoniun Species in Soil Solution in Equilibrju with $\mathrm{PuO}_{2}(\mathrm{~s})$ at $\mathrm{pH} 8, \mathrm{PCO}_{2}=$ 3.52 atm, $\mathrm{pCl}^{-}=\mathrm{pSO}^{-}=2.5$ and $\mathrm{pH}_{2} \mathrm{PO}_{4}=5.0$ (Rai and Serne, 1977)

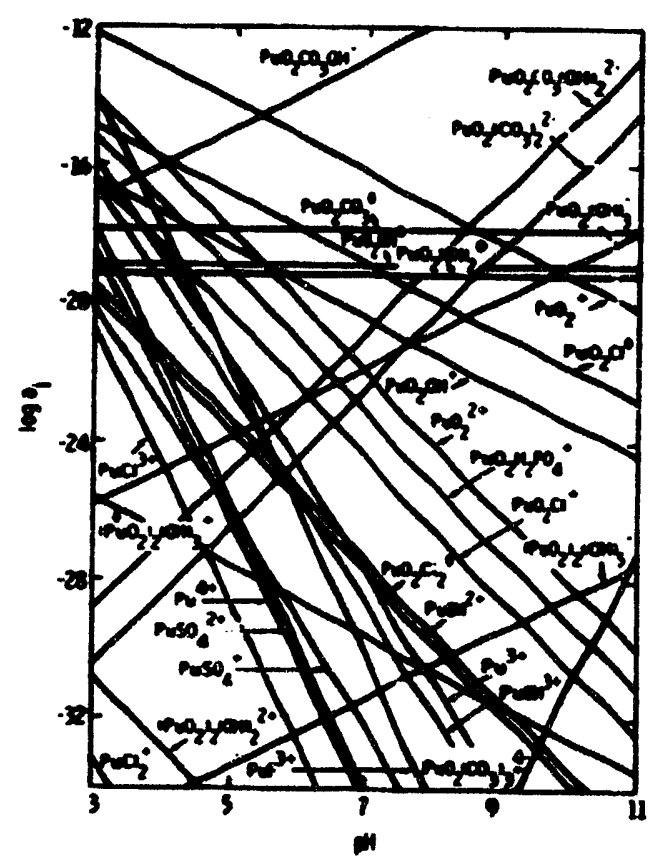

FIERE 8.27. The Activity of Various Plutonium Species in Soil Solution in with PuOz(s) in a Mildly Oxidizing Soil Environient $\left[\mathrm{pO}_{2}=16 \mathrm{ata}\right], \mathrm{PCO}_{2}=3.52 \mathrm{~atm}, \mathrm{pCl}=2.5, \mathrm{pf}-=3.5$. and $\mathrm{pH}_{2} \mathrm{PO}_{4}=5.0$ (Rai and Serme, 1977) 
Figure 8.26 relates the activities of $\left(a_{i}\right.$, moles/ $\left.l\right)$ of various solution species at pH 8 to the oxidation potential as represented by the various oxygen pressures. In general, with a decrease in oxygen pressure (increases in reducing conditions), the kind of activity of the solution species changes: 1) $\mathrm{Pu}^{3+}$ species increase in activity, 2) $\mathrm{Pu}^{4+}$ species are unaffected, and 3) $\mathrm{PuO}_{2}^{2+}$ and $\mathrm{PuO}^{2+}$ species decreast in activity.

A few of the reactions are not plotted in the figures because either the activities of the species fall beyond the graph boundaries or the equilibriu constant data are not reliable. Cleveland (1970) suggested that the values for the formation constants of $\mathrm{PuCO}_{3}^{2+}$ and $\mathrm{Pu}(\mathrm{CH})_{4}^{0}$ were suspect; the values for $\mathrm{PuO}_{2}(\mathrm{OH})_{3}^{-} ; \mathrm{PuO}_{2}(\mathrm{OH})_{2}^{\mathrm{O}}$, and $\mathrm{PuO}_{2} \mathrm{OH}^{+}$should be viewed with skepticism; and the value for $\mathrm{PuO}_{2} \mathrm{OH}^{\mathrm{O}}$ should be considered only approximate. Under the assumptions of Figure 8.27, the lines for $\mathrm{Pu}(\mathrm{OH})_{1}^{0}$ and $\mathrm{PuO}_{2}(\mathrm{OH})_{2}^{0}$ would be parallel to the $X$-axis with $10^{-12.51}$ and $10^{-16.16}$ moles/ 2 activity, respectively. Many researchers (Andelman and Rozzel1, 1970; Fukai and Murray, 1974; Grebenshchikova and Davydov, 1961, 1965; Sheidina and Kovarskaya, 1970) have reported that plutoniu in solution alsc exists as colloidal species over a wide pH range. Colloidal species and neutral ion-complexes [Pu(OH) ${ }_{4}^{0}$, $\mathrm{PuO}_{2}(\mathrm{OH})_{2}^{\circ}$ ] are not reported in figures 8.26 and 8.27 . If present in large quantities, these species would significantly influence the nature of the species and the total concentratior of plutonium in solutions.

In an oxidizing environment, $\mathrm{Pu}^{3+}$ and $\mathrm{Pu}^{4+}$ and the ir ion-pairs have an insignificant effeci on the total activity of plutonion in solution and the dominant plutonium species in $\mathrm{low}$ and high pH ranges are $\mathrm{PuO}_{2}^{+}$and $\mathrm{PuO}_{2} \mathrm{CO}_{3} \mathrm{OH}^{-}$, respectively. In general, with a decrease in oxygen pressure (increase in reducing conditions), the kind of activity of the solution species changes: $\mathrm{Pu}^{3+}$ and its complexes will increase in activity mile $\mathrm{PuO}_{2}^{+}$and $\mathrm{PuO}_{2}^{2+}$ and their complexes will decrease in activity. In moderately to will reduced conditions, the predominant solution species would be $\mathrm{PuOH}^{2+}$, with $\mathrm{Pu}^{3+}$ of lesser importance. In reducing seamater solutions high in $\mathrm{Cl}^{-}\left(\mathrm{pCl}^{-}=0.45\right)$, $\mathrm{PuCl}^{2+}$ would be the wost dominant solution species. 


\section{Laboratory Adsorption Studies}

Davydor (1972) investigated the hydrolys is of $\mathrm{Pu}(\mathrm{IV})$ and sorption under acidic conditions.

- The sorption of Pu(IV) by silica gel was investigated in the range 0.5N $\mathrm{HMO}_{3}$ to $\mathrm{PH}=2.5$.

- It was shown that in the region of hydrolysis of Pu(IV), hydrolyzed ions $\mathrm{Pu}(\mathrm{OH})_{n}^{4-n}$ are sorbed, and the ir sorption capacity is either equal to or greater than the sorption capacity of $\mathrm{Pu}^{4+}$ ions.

- It was shown that the sorption of hydrolyzed Pu(IV) ions does not depend on the concentration of the extraneous electrolyte in the range $0.1 \mathrm{IN}$ to 3. $\mathrm{OM} \mathrm{NamO}_{3}$.

Duursma and Eisma (1973) and Dursma and Parsi (1974) have determined the proclivity of plutoniu to sorb in the marine environment. The adsorption of plutonium is intermediate; less than Cs, Rb, $\mathrm{Zn}, \mathrm{Fe}, \mathrm{Zr}-\mathrm{lb}, \mathrm{Ru}$ and $\mathrm{Pm}$ and greater than $\mathrm{Ca}$ and $\mathrm{Sr}$. Plutonium has been observed to penetrate sediments at least to 8-14 cm and in the early 1970's, inventories in the sediment appear to show losses. Biological processes or upward migration in interstitial waters as a reduced species are two possible explanations although to and Loman (1975) show data wich find reducing conditions tend to lower Pu mobility. Changes in the $\mathrm{Am} / \mathrm{Pu}$ ratio from waters to sediments in the ocean led Ouursa to conclude americium is preferentially sorbing or not being remobilized as fast as plutonium. In sea water $\mathrm{PuO}_{2}\left(\mathrm{CO}_{3}\right)_{3}^{-4}$ may predominate and cause the lower plutonium sorption. Using a ${ }^{23} \mathcal{P u}_{\mathrm{Pu}}$ tracer in valence states $+3,+4$, and +6 in both oxic and anoxic sea waters at pH 7.8 to 8.0 , the $\mathrm{Kd}_{\mathrm{Pu}}$ for marine sediments was found to be about $10^{4}$. Valence states and solution Eh states did not cause marked differences.

The $t$ 1/2 sorption times for Pu(III) were about 3 days, Pu(IV) about 1.4 days and $P u(V I)$ about 4 days. The spiked sea water wen allowed to sit in blank reaction vessels (no sediment) showed significant losses of PU. The Pu(III) and Pu(IV) loss was 30 to $50 \%$ mile the Pu(VI) loss was $9 \%$ over a 
three week period suggesting Pu(VI) is more prone to remain soluble in water. The fact that the $\mathrm{Kd}_{\mathrm{Pu}}$ for all three valence states were siailar probably reflect the reduction of $\mathrm{Pu}(\mathrm{VI})$ to $\mathrm{Pu}(\mathrm{IV})$ or $\mathrm{Pu}(\mathrm{III})$.

Fukai and Murray (1974) perforwed plutonium sorption-desorption experiwents for boin freshwater and saline conditions. Plutoniun (III) sorption experiments from river water to river sediments (100 ml traced solution/g sediments) were performed. The initial stage of adsorption was rapid; $50 x$ within $10 \mathrm{hr}$. For pts 3 to 11 over $90 \%$ of the Pu(III) was adsorbed by the river sediment. Desorption experiments mere performed where in the sediments used in the adsorption experiments were suspended in sea water. Over the pH range 4 to 10 about $10 x$ of the adsorbed plutonium was released without apparent pH differences. Similar adsorption-desorption experiments were performed with river sediments contacted with various dilutions of fresh water sewage effluent at pH 8.1. The Pu(III) adsorption increased from $85 \%$ in river water to over $95 \%$ at $100 \%$ sewage effluent. These sediments were next contacted with sea water and desorption monitored. At equilibrium, river sediments wich had not been contacted with sewage effluent released only $5 \%$ of its plutonium whereas sedinents contacted with 5 to $100 x$ by volume sewage effluent released $12 x$ of their plutoniu burden.

In blank experiments Pu added to filtered river water and sea water $(0.45 \mathrm{jm})$, particulate formation is shown to be dependent upon the nature of solution and the pH. The particulate fractions of all species increased with the increase in pH. For river water at pH 4, some 25, 20, and 30 of the added Pu-237 were associated with particulate $(=0.45 \mu)$ for the III, IV, and VI valence states, respectively. The percentage of particulate formation was $>60$ at pH 8 for all species, except Pu(VI). These results for Pu stability in river water and sea water are shown in Figures 8.28 and 8.29 . Figure 8.28 shows the adsorption of Pu(III) versus Am(III) onto Var River sediments from river water. The Pu(III) readily adsorbs at all phis studied (3 to 11). Figure 8.30 shows the adsorption of Pu(IV) onto the same sediment at pH 8 versus tias as well as the desorption of Pu when the river sediments contact sea water. Figure 8.31 shows the desorption of Pu(III) and An(III) from river sediments versus phl of sea water. For both adsorption and ciesorption Pu shows a greater affinity for sediments at lower phs. 


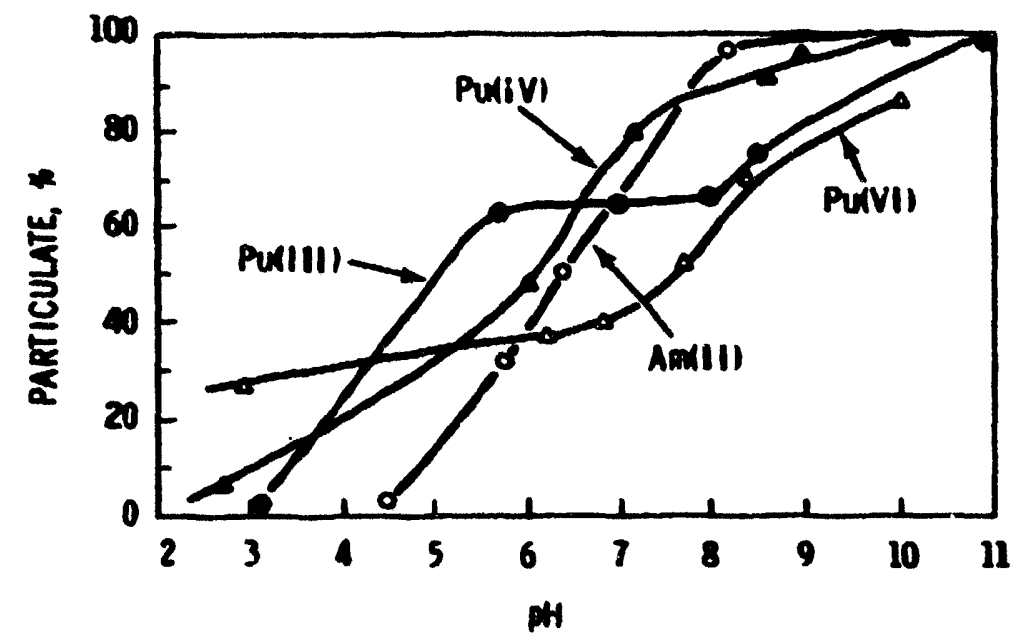

FIERE 8.28. Particulate Formation of Pu(III, IV, VI) in Var River Hater as a Function of Changes in pH

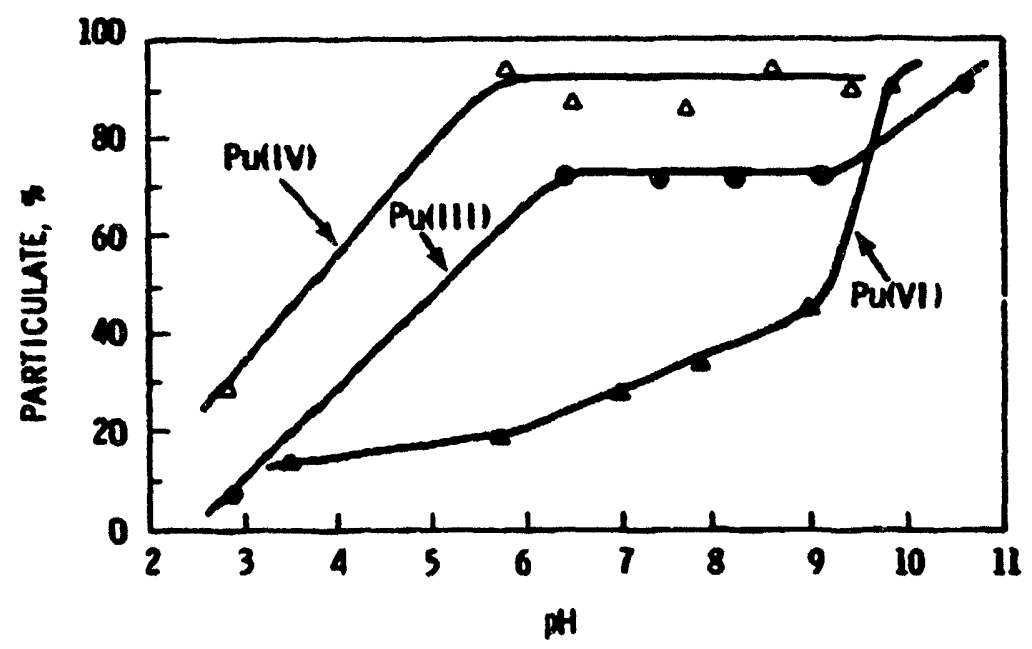

FIGURE 8.29. Particulate Formation of Pu(III, IV, VI) in Sea Water as a Function of Changes in $\mathrm{PH}$ 


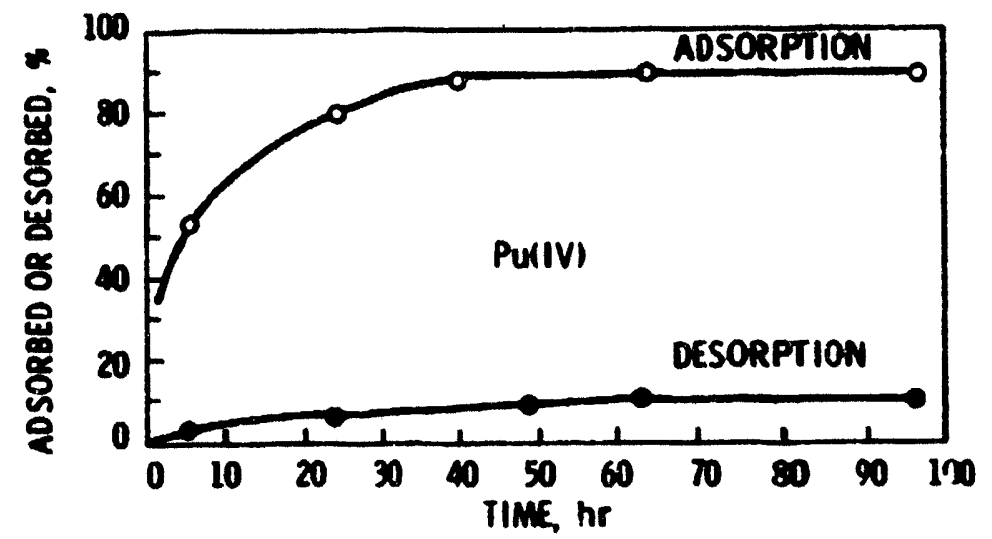

FIGURE 8.30. Equilibrium Time for Adsorption on Sediments of Pu(IV) in Var River Water (pH $\simeq$ 8) and Its Desorption from Sediments in the Seawater Medium

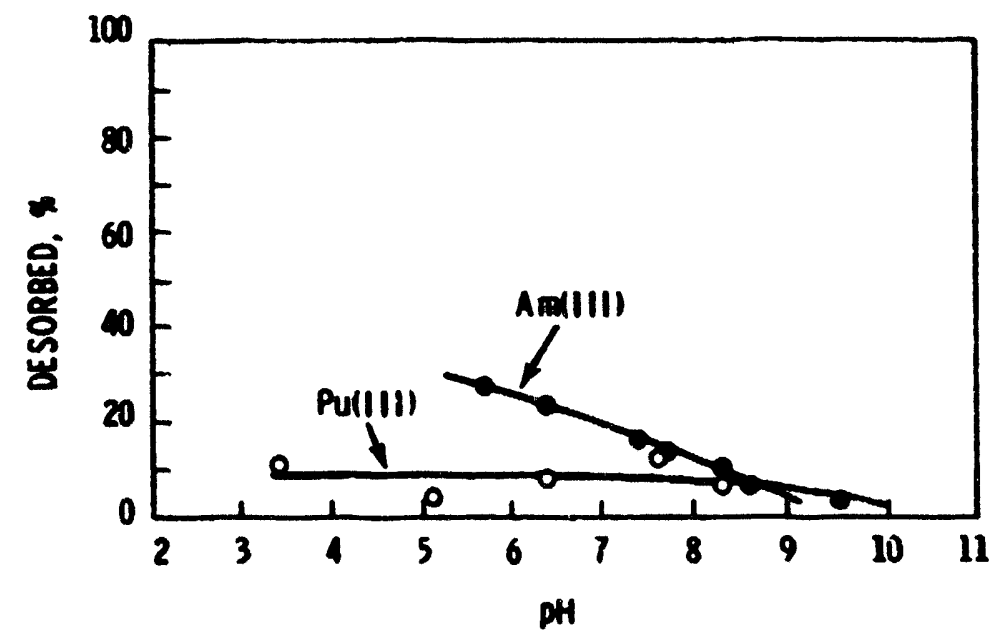

FIGURE 8.31. Desorption of Pu(III) and Am(III) from Sediments in the Seawater Medium at Different pH Levels 
$\mathrm{Kd}_{\mathrm{Pu}_{3}} \mathrm{calculated}$ from data in the figures for neutral pHs were typically around $10^{3} \mathrm{ml} / \mathrm{g}$ whether measured in the adsorption or desorption direction.

Gromov and Spitsyn $(1974 a, b)$ and Growov (1975) investigated the change in the physiochemical state of $\mathrm{Pu}$ due to its interaction with phytoplankton and the adsorption-desorption of ${ }^{239}$ pu onto Pacific Ocean red clays, carbonates, diatomaceous ooze. Red clay and carbonaceous sediments adsorb wore Pu. The phytoplankton interactions change the $\mathrm{Pu}$ form and thus alter the entrapment of $\mathrm{Pu}$ in bottom and suspended sediments.

To and Loman (1975) placed plutoniu contaminated calcareous sediment in aerated sea water and anoxic sea water and stirred the system until solution activities were at equilibrium. The resultant $\mathrm{Kd}_{\mathrm{Pu}_{u}}$ desorption distributions were $1.64 \times 10^{4}$ and $3.85 \times 10^{5}$.

Pillai and Mathew (1975) quantitatively leached the plutonium present in Bombay sediments with $\mathrm{mon}_{3}$. Hydrogen peroxide treatment at $80^{\circ} \mathrm{C}$ and pH 5.8 did not appear to release plutonium but under these conditions it is likely released $\mathrm{Pu}$ would precipitate or quickly resorb. Alkali treatment to extract organics removed 0.4 to $7.5 \%$ of the total plutonium. Contaminated sediments stirred with uncontarminated sea water for $8 \mathrm{hr}$ before filtration did not release any plutoniua into the sea water. Kd values for suspended silt and bottom sediments mere observed to average $9 \times 10^{4} \mathrm{ml} / 9$ with a range of $4.8 \times 10^{4}$ to $1.3 \times 10^{5}$.

In laboratory experiments to study the speciation of $\mathrm{Pu}$ in sea water and soluble organic effects, Pillai and Mathew found at pH 7.4 to 7.8 that the soluble Pu concentration in sea water calculates to $10^{-11} I_{M}$. Both cationic and anionic species decreased with time while nonionic species increased.

In the case of sea water to mich soluble organic matter had been added more $\mathrm{Pu}$ was retained in solution for the first 30 days, then there was a tendency for more Pu precipitation along with organic matter. The rewaining soluble $\mathrm{Pu}$ in the organic rich water had a larger anionic distribution. The implication is that organic matter reduces the tendency of Pu to hydrolyze and form colloids. 
Rozzell and Andelman (1971) studied the sorption-desorption of aqueous Pu $\left(10^{-8}\right.$ to $\left.10^{-7} \mathrm{M}\right)$ on quartz and other silica surfaces. Sorption contimued typically for 12 to 15 days before apparent equilibrium was reached. At pH 7 . sorption increased with increasing ionic strength, but decreased when $\mathrm{HCO}_{3}^{-}$ was added. The anount of sorption varied at pH 5 and 7, but differently at high and low ionic strengths, as well as with age of the solution. Plutonium desorption indicated that there were two basically different sorbed species. There was a greater net desorption at pH 5 versus pH 7 to 9.

Many investigations have been performed on plutoniu adsorption by sediments, both fresh water and marine. Schneider and Block (1968) found plutonium tc sorb wore than $\mathrm{I}^{-}$and $\mathrm{Sr}^{+2}$ but less than $\mathrm{Zn}^{+2}$ or $\mathrm{Cs}^{+1}$ on Rhine River sediments. Equilibrium was reached within $24 \mathrm{hr}$.

Seymour (1977), Sanchez (1977), Sanchez and Schell (1977), and Schell et al. (1979, 1980) studied the distribution of plutonium in both fresh and marine environments. The experimental design used was to place a known anount of sediment in a known volume of water and add Pu tracer. After pH adjustment the system is shaken for a set time and an aliquot of the suspension rewoved. This aliquot is filtered to separate solution from solids. Both the solution and solids are counted to obtain a $\mathrm{Kd}_{\mathrm{Pu}}$. The contaminated sediments after centr ifugation to remove tracer solution were contacted with "clean" water in a similar fashion to allow determination of $\mathrm{Kd}_{\mathrm{Pu}}$ desorption. Three sediments were investigated: a fresh-water lake (Lake Nashington), an oxic marine sediment (Colunia River Mouth) and an anoxic marine sediment (Lake Mitinat). The sedinents were contacted with fresh and marine waters obtained during the sediment sapling. The sediment particle size distribution, total carbon and nitrogen contents are shown in Table 8.49 .

The time needed to reach steady-state solution concentrations for the fresh water system was less than $30 \mathrm{hr}$. The average $K_{P_{u}}$ for the three systews under study observed both in the adsorption and desorption direction after 48 to $60 \mathrm{hr}$ of contact are presented in Table 8.50 . 
TABLE 8.49. Sediment Characterization

\begin{tabular}{|c|c|c|c|c|c|}
\hline & $x$ Sand & $x$ silt & Xclay & $\begin{array}{c}x \\
\text { Carbon }\end{array}$ & $\begin{array}{c}x \\
\text { nitrogen }\end{array}$ \\
\hline gton & $\overline{2.5}$ & $\overline{16.0}$ & $\overline{81.5}$ & $\overline{5.2}$ & 0.41 \\
\hline Olumbia River Mouth & 40.2 & 20.8 & 39.0 & 1.8 & 0.08 \\
\hline Lake Niti & 3.7 & 21.4 & 74.9 & 2.8 & 0.26 \\
\hline
\end{tabular}

TABLE 8.50. K Ku Results (Unitless Kd)

\begin{tabular}{|c|c|c|}
\hline Sediment & K. Adsorption & $K_{4}$ Desorption \\
\hline $\begin{array}{l}\text { Lake Mashington } \\
\text { Columbia River Mouth } \\
\text { Lake Mitinat }\end{array}$ & $\begin{array}{l}2.8 \pm 0.3 \times 10^{5} \\
3.9 \text { to } 11.1 \times 10^{4} \\
1.4 \pm 0.2 \times 10^{5}\end{array}$ & $\begin{array}{l}7.1 \pm 0.3 \times 10^{5} \\
5.4 \text { to } 11.3 \times 10^{4} \\
4.4 \pm 0.4 \times 10^{5}\end{array}$ \\
\hline
\end{tabular}

In general, the coarse grained oxic marine sediment shows the lowest $\mathrm{Kd}_{\mathrm{Pu}}$ and the finer grained fresh water sediment the largest $\mathrm{Kd}_{\mathrm{Pu}_{u}}$. The anoxic marine sediment $\mathrm{Kd}_{\mathrm{Pu}}$ is intermediate. In all cases the $\mathrm{Kd}_{\mathrm{Pu}_{u}}$ desorption is larger suggesting plutonium is harder to remove from the sediment than mould be expected if one assumed ideal reversibility between adsorption-desorption. The $K_{v}$ values can be changed to $K d$ values by roughly multiplying by 1.5 .

Schell et al. (1980) report on laboratory deterninations of $\mathrm{Kd}_{\mathrm{Pu}}$ in numerous fresh and marine water environents (see Table 8.11). The $\mathrm{Kd}_{\mathrm{Pu}}$ is quite high for either fresh and marine environments. There is no clear trend in the observed Kd with increasing salinity. Kds determined by desorption methods were consistently much greater than those determined by adsorption. As seen for most elements Pu would not become soluble to the extent predicted by current models wich assume reversibility if $\mathrm{Kd}_{\text {ads }}$ values were used.

In a separate experiment, Seymour (1977) placed Lake Mitinat sediments and "clean" sea water in a dialysis bag and suspended them in traced sea water for 10 days. The sediment contained $20.2 \mathrm{dpa} / \mathrm{g} 238_{\mathrm{pu}}$ while the intimate sea 
water contained $0.32 \mathrm{dpm} / \mathrm{ml}$. The resultant $\mathrm{Kd} \mathrm{ml} / \mathrm{g}$ was 63 which is much lower than observed in the batch experiments. The dialys is experiment may ref lect a true $\mathrm{Pu}$ ion exchange-like Kd wille the other results include hydrolysis, precipitation and colloid scavenging. The experimental procedure of adding acid spike to the sediment slurry can artifically inflate the Kd if much of the Pu would automatically precipitate upon neutralization. This author prefers to add tracer to the solution, let it equilibrate several days and filter before contact with sediments.

Schell et al. (1979) studied the distribution of ${ }^{238} \mathrm{pu}$ in a laboratory dialysis experiment between sediment, plankton and seawater. For some unknown reason $80 \%$ of the Pu remained outside the dialysis bags with most of this $\mathrm{Pu}$ in a soluble form. The Pu wich did pass through the dialysis sac and cortact the sediment became predominantly sorbed. The distribution of $\mathrm{Pu}$ in this dialysis experiment is shom in Table 8.9 in the americium section.

In continuing dialysis experiments Schell et al. (1980) found that $\mathrm{Pu}$ in a Lake Michigan freshwater environment rapidly became associated with sediment and particulate organic detritus and possibly colloids. Plutonium in the soluble form seemed to be stabilized in dialysis sacs which contained phytoplankton and organic detritus suggesting that soluble organic complexes might have been formed.

VanDalen et al. (1975) determined the distribution coefficient, $\mathrm{Kd}_{\mathrm{Pu}_{u}}$, for several Dutch subsoils from 90X saturated $\mathrm{MaCl}$ solutions between $\mathrm{pH} 7$ and 8. Clay samples of mainly illite and kaolinite had a $\mathrm{Kd}_{\mathrm{Pu}}$ of $\sim 10^{4}$ and for a river sand a $\mathrm{Kd}_{\mathrm{pu}}$ of $200 \mathrm{ml} / \mathrm{g}$. Gypsum bearing and clay bearing sandstones were intermediate. The pH dependence on sorption of plutonium was minor between DH 5 and 8 .

The dissolution rate of plutonium oxide particles by sea water and tap water have been reported by Adans (1971), Kubose et al. (1968) and Patterson et al. $(1974 a, b)$. The dissolution rate is quite complex and dependent on such properties as $\mathrm{pH}, \mathrm{T}^{\circ}$, Eh, complexing agents, oxide surface area, and radiation 
field intensity. Environmental chamber work showed that rain on large chionks of $23 \mathrm{PuO}_{2}$ radioactively heated to $200^{\circ} \mathrm{C}$ led to increases in release of $\mathrm{Pu}$ of three orders of agnitude due to spallation.

Desai and Gangely (1970) determined the ability of muic and fulvic acid in aconiacal solutions to solubilize plutonium. In this basic solution without haic or fulvic extract, only $13 \%$ of added plutonium remined in solution, with huic extract present $54 \%$ of the added plutoniu remained in solution and further testing showed that the soluble plutoniu was noncationic. The fulvic acid extract solubilized $58 x$ of the plutoniu and again the complex was noncationic.

Bondietti (1974, 1975) found purified soll mates to absorb plutonium strongly $(99.99+8)$ wile reference clays (montworillonite and kaolinite) adsorbed about $98 \%$ and $96 x$ of plutoniun added to a water solution at $163 \mathrm{\mu g}$ Pu/g of solid. If clay materials had their organic matter and iron oxide coating renoved, plutoniu adsorption as $95 \%$ versus $99.9 \%$ while intact. Leaching solutions, citrate, DTPA, and fulvate rewoved small amounts of adsorbed plutoniu as shom in Table 8.51.

Thus, it appears that natural soil organic eatter can very strongly adsorb plutonium. The ability of soil organic matter to alter the valence state of plutonium in soil water solutions was also verified. Pu(VI) and by inference $\mathrm{Pu}(y)$ were unstable in the presence of fulvic acid, polygalacturonic acid and alginic acid. Positive proof of reduction to Pu(IV) was show at environmental pils 6.5 to 3 . Plutoniu (IV) was the wost stable valence upon interaction with these organics. Further reduction of Pu(IV) to Pu(III) occurred in the presence of muic or fulvic acids, but was not observed above pH 3.1 under aerobic conditions. Bondietti also demonstrated that plutoniu is at least partially associated with huic aterials in CRML soil contaninated 30 years ago.

The rewoval of plutoniu in wastes and drinking waters by precipitation and/or sorption techniques has been studied by Lauderdale (1951), Christenson et al. (1951), Grebenshahikova et al. (1971), Blaine et al. (1974) and Corey and Boni (1975). Calciu phosphate, alu, ferric hydroxide, and barium 
TABLE 8.51. Percent Pu Rewoved by Extractants

\begin{tabular}{lcccc}
\multicolumn{1}{c}{ Extractant } & & Huate & Mont. & Koal. \\
\cline { 1 - 1 } $10^{3}$ M Citrate & & 0.3 & 8 & 11 \\
$10^{-3}$ M DTPA & 30 & 15 & 20 \\
$10^{-2}$ n Fulvate & 5 & 0.9 & 3
\end{tabular}

phosphate flocculations all are effective in rewoving wost of the plutonium in waste streans at basic pHs. Adsorption on kaolin, puice, tuff, celite and activated carbon has also been used to remove plutonium. In all wethods a variable percentage of plutonium reains in solution, probably as a polymeric or colloidal form. Ultracentrifugation results tend to corroborate that colloidal species are less readily adsorbed or likely to precipitate.

Thorburn (1950) reported a sorption experiment in mich plutoniu in water was percolated through a soil colum. The soil was then wet sieved and the activity of each particle size fraction counted. In general the decrease in particle size increased the anount of plutoniu adsorbed (Table 8.52). In other adsorption expericents. Thorburn placed small alicuots of actual plutonium waste on top of soil columns and eluted with distilled water or saturated magnesiu-calcium carbonate. There were no significant differences in the elution curves. It is interesting to note that the elution curves had higher plutoniu activity in the first volume out of the colum and always showed a smal! leakage wich might signify physical transport of fine particulates. neutral polymers or colloids. Thorburn took the effluent from the distilled water leached colum and percolated it through a second soil colum at various flow rates. The data show that plutoniu concentration in effluents through the second colum varied with flow rate. The faster the flow the more plutoniv in the effluent. Filtration of the influent through a fine filter paper did not change the results. Explanations of these phenomena are obscure but would seen to indicate plutoniu transport as polyerer. Final adsorption studies of plutoniu in water versus py by soil columens showed $87 \%$ adsorption 
TABLE 8.52. Plutoniun Adsorption Versus Particle Size (Thorburn, 1950)

\begin{tabular}{|c|c|}
\hline Size, $=$ & $\mathrm{Pu}, \mathrm{d} /$ ain $/ \mathrm{g}$ \\
\hline$>1.19$ & 39.3 \\
\hline 1.19 to 0.25 & -- \\
\hline 0.25 to 0.15 & 1,171 \\
\hline 0.25 to 0.10 & 929 \\
\hline$<0.105$ & 8,578 \\
\hline $\begin{array}{l}\text { Uncentrifugible } \\
\text { Silt and Clay }\end{array}$ & 62,750 \\
\hline
\end{tabular}

at pH 3.8, $77 x$ at pH 7.2 and $24 x$ at pH 10. Note that this falling of plutoniv adsorption with increasing pHt is supported by the thernodynamic data of Figure 8.27.

Evans (1956) reported on percentage of plutoniun removed from a 0.001 n $\mathrm{mon}_{3}$ solution by various grain sizes of quartz. The plutoniun Kd values may be computed from these data, and are listed in Table 8.53. Data also were given on plutonila adsorption on different minerals of coarse clay size $(2$ to $0.2 \mathrm{ma}$ ). Plutonim Kd values were computed from these data and are listed in Table 8.54. Evans suggested that the lower $\mathrm{Kd}$ for plutonium by montioorillonite is probably de to experimental difficulties and believed that Rhodes' (1952) data may represent preferred plutoniu Kd results. Rhodes' data, as reported by Evans, are given in Table 8.55, assuming a $1 \mathrm{ml}$ to $1 \mathrm{~g}$ solution to soil ratio. This ratio not given, but the results are proportional in any case.

Rhodes $(1952,1957 a, b)$ performed similar plutoniun Kd determinations on a Hanford sand soil ( $92 \%$ sand) with $2 x$ calciu carbonate content. Using a soil to solution ratio of 1:20 and neutral pH, Rhodes found rapid adsorption. Analys is versus time yielded an equation for the anount adsorbed versus con-

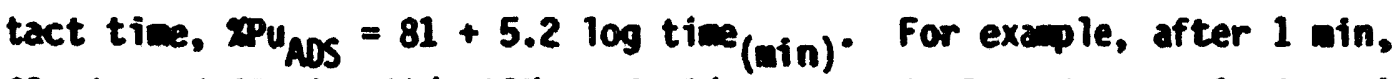
20 min and $60 \mathrm{~min}, 81 \%, 88 \%$, and $90 \%$, respectively, of the solution plutonium concentration was adsorbed. Increases in the soil to solution ratio were also 
Tha: 8.53. Plutoniun Kd Values for Quartz of Various Particle Sizes from a $0.001 \mathrm{Nm}_{3}$-Plutonion Solution ( $r$ ans, 1956)

\begin{tabular}{lc} 
guartz Particle Sizes & $\mathrm{Kd} / \mathrm{ml} / \mathrm{g}$ \\
\cline { 2 - 2 } Coarse Sand & 5.6 \\
Fine Sand & 10.0 \\
Coarse Silt (50 to $20 \mathrm{\mu m})$ & 11.3 \\
Mediun Silt (20 to $5 \mathrm{\mu m})$ & 33.5 \\
Fine Silt (5 to $2 \mathrm{\mu m})$ & 48.8 \\
Coarse Clay (2 to $0.2 \mathrm{um})$ & 80.9
\end{tabular}

TAB2E 8.54. Plutoniun Kd Values for Different Minerals of Coarse Clay Size $\left(2\right.$ to $0.2 \mathrm{H}$ ) from $0.001 \times \mathrm{hwO}_{3}$-Plutonium Solution (Evans, 1956)

\begin{tabular}{lc}
\multicolumn{1}{c}{ Mineral } & Kd $\mathbf{m l} / \mathrm{g}$ \\
\cline { 3 - 3 } Feldspar & 170.4 \\
Quartz & 82.0 \\
Glauconite & $\infty$ \\
Montmorillonite & 157.0 \\
Kaolinte & 1091.0
\end{tabular}

TABLE 8.55. Rhodes' Plutoniun Kd Data as Reported by Evans (1956)

\begin{tabular}{lcc}
\multicolumn{1}{c}{ Material } & & $K d_{2}, i / g$ \\
Montmorillonite & & 4990 \\
Kine Micaceous Sand & & 49 \\
Kaolinite & & 42.5 \\
Soil & 36 \\
Coarse Sand & & 0.87
\end{tabular}

cbserved to increase the percent adsorbed. Rhodes also obtained adsorption versus pif data (see Ffgure 8.32) and found a rapid decrease in adsorption below ph 2 but alnost total adsorption (Kd $>2000$ ) between ph 3 and 8.5 . 


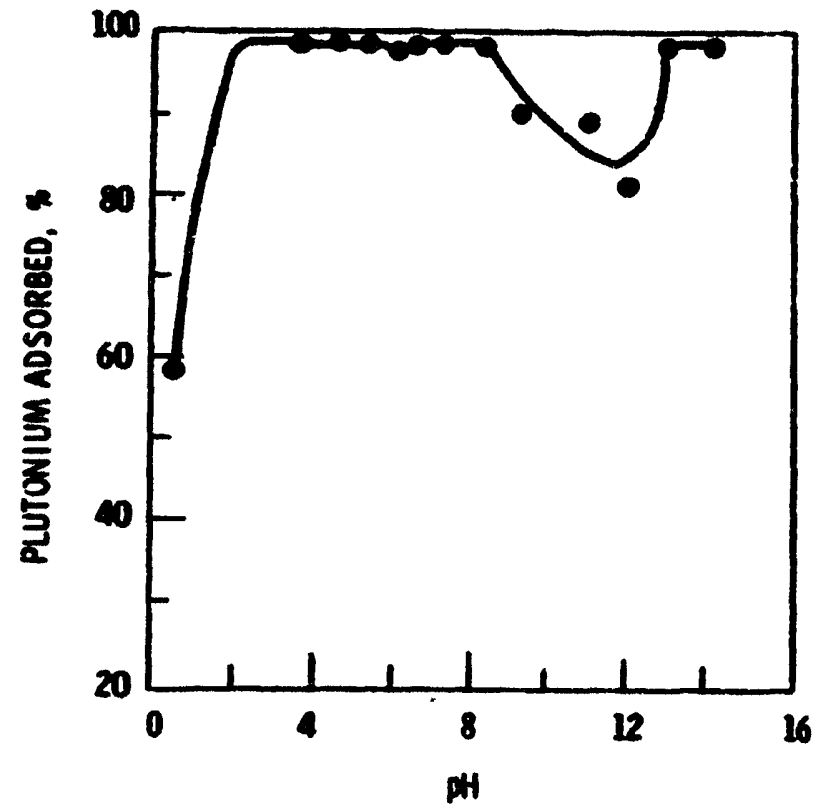

FIGURE 8.32. Adsorption of Plutonium by Soil as a Function of pH (Rhodes, 1957a)

Decreases at pH 10 to 12 were believed to indicate changes in plutonium speciation. In other experiments, coarse sand was obser is to adsorb only $47 \%$ of the plutonium present compared to 97 to $99.8 \%$ for soils and clay minerals. Rhodes felt all these data indicated ion exchange adsorption mechanisas. Yet plutonium adsorption from distilled water, a synthetic high salt waste and an actual high salt waste all showed greater than $98 \%$ rewoval. Plutonium solution loading experiments onto soil colums at various pH's $(1,4,10)$ showed good removal at the first two pH's until the high acid case had destroyed the $\mathrm{CaCO}_{3}$ buffering capacity. As the effluent pH dropped to pH 1, increasing plutonium breakthrough was observed. Plutonic breakthrough at pH 10 was highly variable and rapid, possibly caused by fine plutoniun particulate dispersion or polymer formation. Plutonion adsorption from distilled water, 4M

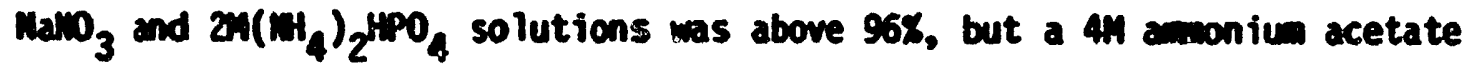
solution showed only 59\% adsorption. Acetate complexing of plutonium was probably responsible for the diminished adsorption rather than any effects from competing ions. 
Further studies showed increasing the acetate concentration from $0.01 \mathrm{H}$ to 8il dropped plutoniu adsorption from 74 to 21\%. Acetate solutions mere also observed to have the capability of extracting plutoniu adsorbed on soils. Benson (1960) presented data showing that oxalate salts also imhibit plutoniu adsorption by soluble Pu-oxalate complex formation. Bensen also reinterpreted Rhodes ' data and concluded precipitation reactions, not ion exchange, probably control plutoniu adsorption on soils.

Other investigations on plutonilu mere performed at Savannah River by Prout (1958, 1959). Plutoniu adsorption by a soil (80x sand to $20 \%$ clay) with the clay mineral kaolinite dominant was determined versus pH for distilled water traced with plutonion $\left(\sim 10^{-6} w\right)$. The soil/solution ratio was $1: 10$ and the aixtures shaken for 2 hr before phase separation by centrifugation. Adsorption of plutonium depended on pH and the valence state of the plutonium added to solution. Adsorption was more than $90 \%$ complete from solutions of Pu(III) and Pu(IV) between PH 2.5 and 12 and from solutions of Pu(VI) at pHs greater than 6. Strong adsorption at wildiy acidic to wildly basic pHs is probably due to a combination of cation exchange and precipitation of hydrolysis products. Decreased adsorption above pH 9 possibly represents the formation of soluble negatively charged plutonium polywers wich do not readily exchange with the soil (see Figure 8.33).

Tamura (1972) discussed the adsorption of plutonium on several materials including the soil constituents listed in Table 8.56. The suspension pH represents the final system pH.

Miner et al. (1973, 1974), Polzer and Miner (1974, 1977) and 6lover et al. (1977) described experiments in progress to measure the adsorption of both "soluble" plutoniva and particulate plutoniu $\left(\mathrm{PuO}_{2}\right)$ in merous soils at three plutoniu levels between $10^{-6}$ and $10^{-8} \%$. The plutoniu adsorption was rapid and quite high: $59 \%$ of the time, adsorption was greater than $99 \%$ (Kd > 430) and only 5\% of the time was it below $90 \%$ adsorption (Kd <39). Correlations were found between soil characteristics associated with soil ion 


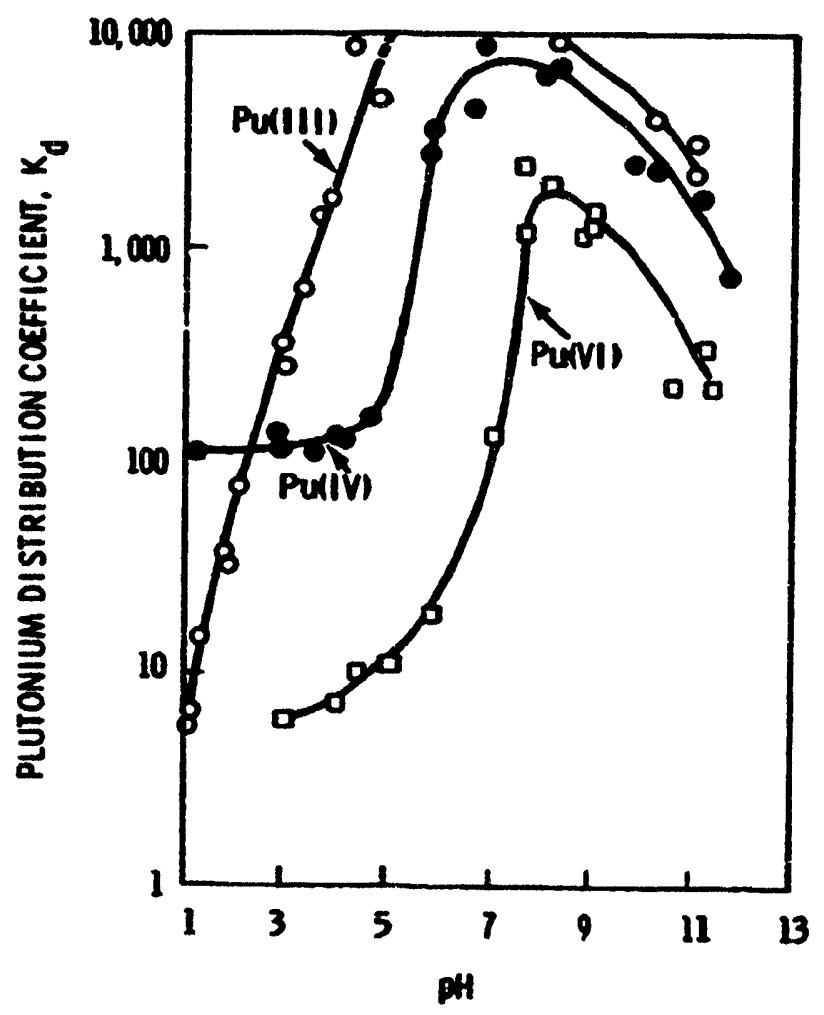

FIGURE 8.33. Effect of pH and Plutoniun 0xidation State on the Adsorption of Plutonium by Soil (Prout, 1959)

TABLE 8.56. Removal of Plutonium from pH 7 Water by Several Soil Minerals (Tamura, 1972)

Constituents

Kd, mi/g Suspension pH

Attapulgite

4,370

9.60

Montaorillonite

630

9.20

Alumina, activated

755

8.35

Kaolinite

352

6.25

Illite

129

5.90

Quartz

0

6.35

exchange or acidity. The adsorption also depends on the initial plutoniu concentrations for wich several possible causes are discussed including precipitation with increasing plutoniu concentration and the formation of carbonate complexes. 
Lindenbaum and Vestfall (1965) prepared several dilute solutions of colloidal plutoniu with citrate to plutonium ratios of $1800\left(3.4 \times 10^{-2} \boldsymbol{n}\right.$ citrate) to 1. The colloid was about $80 \%$ ultrafilterable at pH 4.0 and a citrate to plutoniu ratio of 1 . The cellophane used in the ultrafiltration had a pore size that corresponded to a plutonium hydroxide molecular weight of about 200,000. At ph 10 and a citrate to plutonium ratio of 1 colloid, 65\% of the Pu was ultrafilterable and only $5 \%$ was filterable at pH 11 . At citrate to plutonium ratio of 1800 , the colloid behaved in a similar fashion decreasing fro $92 \%$ ultrafilterable at pH 4 to $72 \%$ at pH 11. With no citrate present, the plutonium about $13 \%$ ultrafilterable at pH 4 and fell to near of at pH 11. Qualitatively, $\operatorname{Ir}(I V), \operatorname{Th}(I V)$ and the rare earths may behave in a similar manner, peptizing at higher pH, as suggested by the works of Rhodes (1957b). The dispersed polymers are less soil-reactive and should migrate farther through the soil.

Bondietti (1974) determined the plutonium Kd for clays separated from a soil (Miami silt loam) and montworillonite using $5 \times 10^{-3} \mathrm{M}$ calcium solutions at pH 6.5 for two plutonium valence states. The results are shown in Table 8.57. The high adsorption of PU(VI) on the soil clay, in contrast to or as compared with montworillonite, indicated that plutonium reduction by clay components must have occurred, since adsorption values similar to the Pu(IV) were obtained. Pu(VI) appeared to adsorb less than Pu(IV).

Nishita et al. (1976) determined the extractability of plutonium from a contaminated soil as a function of pH. The pH influences hydrolys is and precipitation of the plutonium. In the study, $2 \mathrm{~g}$ of contaminated soil was agitated in $25 \mathrm{ml}$ of solution, in duplicate, and the pH adjusted with $\mathrm{NaOH}$ or $\mathrm{Hm}_{3^{\circ}}$. The $\mathrm{Kd}$ values are given in Table $\mathbf{8 . 5 8}$ for the Aiken clay loam, a kaolinitic soil, at several $\mathrm{pH}$ values. It is not clear from the report whether these values are initial or final system pH measurements. The pH values at the high and low ends of the range especially, usually drift considerably during equilibrations with soils so a final pH measurement is most meaningful. 
TABLE 8.57. Plutoniun Kd as a Function of Oxidation State (Bondietti, 1974)

\begin{tabular}{|c|c|c|}
\hline Mterial & Initial Oxidation & $\mathrm{Kd}, \mathrm{al} / \mathrm{g}$ \\
\hline \multirow[t]{2}{*}{ Soil Clay Fraction } & $\operatorname{Pu}(I V)$ & 1.0 to $1.7 \times 10^{5}$ \\
\hline & Pu(VI) & $7.5 \times 10^{4}$ \\
\hline \multirow[t]{2}{*}{ Montmorillonite } & $P u(I V)$ & $2.1 \times 10^{4}$ \\
\hline & $\operatorname{Pu}(V I)$ & $2.5 \times 10^{2}$ \\
\hline
\end{tabular}

TABLE 8.58. Kd Values of $238 \mathrm{Pu}$ in Untreated Aiken Clay Loaa (Nishita et al., 1976)

\begin{tabular}{|c|c|c|c|}
\hline pH & ${ }^{238} \mathrm{Pu} \mathrm{Kd}, \mathrm{mg} / \mathrm{l}$ & pH & ${ }^{238} \mathrm{Pu}_{\mathrm{Kd}}, \mathrm{mg} / \mathrm{l}$ \\
\hline 1.21 & $430 \pm 44$ & 8.54 & $963 \pm 130$ \\
\hline 2.12 & $862 \pm 33$ & 9.43 & $512 \pm 14$ \\
\hline 2.56 & $796 \pm 59$ & 10.31 & $302 \pm 1.6$ \\
\hline 4.69 & $2591 \pm 591$ & 11.25 & $213 \pm 5.8$ \\
\hline 5.55 & $2347 \pm 220$ & 12.22 & $138 \pm 4.8$ \\
\hline 7.08 & $3086+19$ & 13.25 & $207+14$ \\
\hline
\end{tabular}

\section{Field Studies}

In investigations at the Thule Greenland air crash site, Aarkrog (1971, 1972), two years after the incident, shows plutonium levels above background as far as $15 \mathrm{~km}$ from the point of impact. Samples of bottom sediments yield a vertical movement of plutoniun to a depth of at least $10 \mathrm{~cm}$. Close to the crash site sediment plutonium values were $16 \mathrm{pCi} / \mathrm{g}$ mile overlying waters were $6.5 \times 10^{-3} \mathrm{pCi} /$, further from site sediments contained $1.3 \mathrm{pCi} / \mathrm{g}$ wile the overlying ter $4.5 \times 10^{-3} \mathrm{pCi} / l$. These results yield field $\mathrm{Kd}$ 's of 2.5 $\times 10^{6} \mathrm{ml} / \mathrm{g}$ and $2.9 \times 10^{5} \mathrm{ml} / \mathrm{g}$, respectively.

Articles which describe the distribution of $\mathrm{Pu}$ fallout in the marine environment include Bowen (1971, 1974b, 1975, 1977), Bowen et ai (1971, 1975), Goldberg (1975), Labeyrie et al. (1975), Miyake and Sugimura (1975), Mong et al. (1970), and Moshkin and Bowen (1973). In the marine water colum these 
imvestigators find plutoniun to become geochemically separated from ${ }^{90} \mathrm{Sr}$ and 13? is and rewored more quickly, possibly because of biological processes as well as particulate sedimentation.

Bowen et a1. (1975) described in detail the role of biological processes in the vertical migration of plutoniu and present some core data to substantiate their hypothesis. They believe biota are responsible for both the downward migration and upward migration with possible water remobilization, especially in shallow water marine environments. Buzzard Bay, Massachusetts, sedivents showed no concentration of plutonium in the fine fraction of the sediments. Contradictory evidence showing plutoniu concentrations in the ocean sediments to increase with decreasing particle size is presented by fukai et al. (1974). Typical fallout values for $239,240 \mathrm{Pu}$ in ocean waters are: At lantic Ocean $0.22 \times 10^{-3}$ to $1.2 \times 10^{-1} \mathrm{pCi} / \mathrm{l}$, Pacific Ocean 0.1 to $17 \times$ $10^{-3} \mathrm{pCi} / \mathrm{l}$. The overlying sediments were found to contain 5 to $73 \times$ $10^{-3} \mathrm{pCi} / \mathrm{l}$. A range of $\mathrm{Kd}_{\mathrm{Pu}}$ based on fallout in the Atlantic would be 40 to $3300 \mathrm{ml} / \mathrm{g}$. much of the observed plutoniu in solution is really already bound to filterable suspended solids such that the observed $\mathrm{Kd}_{\mathrm{Pu}}$ would be higher. Fallout plutonium seems to be settling at a rate of 70 to $392 \mathrm{~m} / \mathrm{yr}$ in the open ocean.

Fukai et al. (1974) reported 239,240 pu values for Ligurian Sea surface water $(5 \mathrm{depth})$ of 0.5 to $2.8 \times 10^{-15} \mathrm{Ci} / \mathrm{kg}$, which are similar to values reported for Pacific and Atlantic Ocean waters. The $239,240 \mathrm{Pu}$ content of the sediments ranged from 0.3 to $4.2 \times 10^{-12} \mathrm{Ci} / \mathrm{kg}$. In general, the plutonium plutoniu concentration decreased with the increase in particle size. The field Kd can be calculated 0.2 to $2.2 \times 10^{3} \mathrm{ml} / \mathrm{g}$.

Mevissi and Schell (1975), Moshkin et al. (1971, 1975) and Schell and Halters (1975) investigated the distribution of plutonium in Bikini and Enewetak lagoons and ground-water environents in the Pacific at which nuclear weapuns tests were performed. Plutonium released to the lagoon system became insoluble and rapidly settled. Up to $90 \%$ of the plutonium in the lagoons is associated with particulates but heterogeneity abounds. Resuspension of fine material and wave driven water transport actively cause redistribution. Detailed studies show plutonium to exist in particulate, soluble and colloidal 
states in the lagoon waters. Studies of the ground waters at several islands in Enewetak Atoll show that small quantities of plutoniu radionuclides have migrated through the soil colums ( $80 \mathrm{~m}$ in one instance) and are redistributed throughout the ground-water reservoirs. Distribution of plutoniu is spatially heterogeneous and independent of processes controlling the cycling of ${ }^{137}$ Cs and fresh water. A linear correlation was found between the average surface water concentrations and soil plutonium concentrations independent of the physical, chemical and biological character istics of the islands. Whatever the transport mechanism, plutoniu has proven to be very wobile in the water-saturated coral-soil environment.

The plutonium distribution of surface soils on Bikini Atoll followed the same pattern as fission products. Horizontal wovement of plutonilu due to soil erosion and transport was localized and restricted to areas without vegetation and organic detritus. Air resuspension appeared to be minor. A vertical soil profile showed $70 \%$ of the plutonium retained in the top $5 \mathrm{~cm}$, $28 \%$ retained in the 5 to $25 \mathrm{~cm}$ layer and the rearining $2 \%$ as deep as $100 \mathrm{~cm}$. Of the possible transport mechanisus: solution, biological and suspension and resuspension of particles, the latter probably dominates.

Moshkin et al. (1975) took seven plutonium contaninated soil samples from Enewetak and equilibrated them with uncontaminated sea water. At equilibrium water filtered through $0.4 \mu$ filters and soils were analyzed for plutoniu contents. The $K d_{\mathrm{Pu}}$ calcu'ated from these samples was $8 \times 10^{4} \mathrm{ml} / \mathrm{g}$. Particulates in the ground water versus the ground waters themselves gave an average $\mathrm{Kd}$ equal to $2.5 \times 10^{5} \mathrm{ml} / \mathrm{g}$. The observed concentrations of $239,240_{\mathrm{Pu}}$ and 238 $\mathrm{Pu}_{\mathrm{u}}$ from bomb testing for Bikini Atoll and environs are shown in Table 8.59.

The suspended sediments contained 4 to $75 \%$ of the total ${ }^{239,240} \mathrm{Pu}$ found in the total water sample. $K d_{P_{y}}$ for the bottom sediments range as follows: Bikini lagoon, 0.01 to $120 \times 10^{3} \mathrm{ml} / \mathrm{g}$; Bikini crater, 0.6 to $71 \times 10^{3} \mathrm{ml} / \mathrm{g}$; and neighboring Pacific Ocean, 0.1 to $51 \times 10^{3} \mathrm{ml} / \mathrm{g}$. 
TABLE 8.59. Bikini Atoll Data

\begin{tabular}{|c|c|c|c|}
\hline Location & Material & $239,24 \mathrm{Pu}_{\mathrm{Pu}}$ & ${ }^{238} \mathrm{pu}_{\mathrm{Pu}}$ \\
\hline Bikini Lagoon & Botton Sediments & 0.4 to $120 \mathrm{pCi} / \mathrm{g}$ & 0.02 to $3 \mathrm{pCi} / \mathrm{g}$ \\
\hline Bikini Craters & Bottom Sediments & 29 to $71 \mathrm{pCi} / \mathrm{g}$ & 0.3 to $17 \mathrm{pCi} / \mathrm{g}$ \\
\hline & Bottom Sediments & 2 to $31 \mathrm{pCi} / \mathrm{g}$ & 0.2 to $0.5 \mathrm{pCi} / \mathrm{g}$ \\
\hline Bikini Craters & Maters (Filtered) & 1 to $45 \times 10^{-3} \mathrm{pCi} / \ell$ & \\
\hline Pac if ic Ocean & Maters (Filtered) & 0.6 to $17 \times 10^{-3} \mathrm{pCi} / \mathrm{l}$ & \\
\hline Bikini Lagoon & $\begin{array}{l}\text { Suspended Solids } \\
(>1 \mu \sim)\end{array}$ & 0.3 to $97 \times 10^{-3} \mathrm{pCi} / \mathrm{l}$ & \\
\hline Bikini Craters & $\begin{array}{l}\text { Suspended Solids } \\
(>1 \mathrm{ln})\end{array}$ & 6 to $35 \times 10^{-3} \mathrm{pCi} / \mathrm{l}$ & \\
\hline Pac ific Ocean & $\begin{array}{l}\text { Suspended Solids } \\
(>1 \mu \text { in) }\end{array}$ & 0.1 to $8 \times 10^{-3} \mathrm{pCi} / \mathrm{l}$ & \\
\hline
\end{tabular}

A lberts et al. (1974a, 1974b), Bowen (1974), Bowen and Moshkin (1973), Edgington et al (1975), Karttunen and Edgington (1974), Marshall et al. (1973), Wahlgren and Melson (1972, 1973a, 1973b, 1973c, 1974), and Malgren et a1. (1976) measured the distribution of fallout plutonium in the Great Lakes. Plutonium impinging on the lake's surface rapidly falls to the botton sediments with a removal half-live of about one year. Some evidence points to a biological ananism such as incorporation in plankton followed by rapid settling of fecal pellets and dead plankton. The particle size of the plutonium reaching the water is greater than $75 x$ colloidal or subcolloidal, i.e., passes through 0.45 filters. In all cores studied, plutonium activity was confined to the top six centimeters and in many to the top three centimeters which agrees with known deposition rates. Cesium and plutonium from fallout appear to be depositing with equal efficiency and mobility is reduced to only a periodic resuspension by physical or biological means. Plutonium to americium ratios in the sediments show no elemental differences in mobility. Chemical leaching experiments to be described later show plutonilim to be 
chemically imobile as long as oxidizing conditions are present. A field $\mathrm{Kd}_{\mathrm{Pu}}$ of 2 to $7 \times 10^{5}$ is observed from surficial sediwents and filtered lake water.

Edgington et al. (1975) treated fallout contaminated Lake Michigan sediments with various extractants to investigate plutonium speciation. A sequential treatment with $0.1 \mathrm{M} \mathrm{m} \mathrm{Cl} \mathrm{Cl}_{2}$, sodiu dithionite - $0.3 \mathrm{M}$ sodiu citrate. 0.1I MaOH and finally total fusion was tried. In general the results showed none or sall amounts of plutonium in the $\mathrm{Mg} \mathrm{Cl} \mathrm{Cl}_{2}$, MaOH and fision extracts. Almost all of the plutoniu was found in the citrate-dithionite extract. Changing the sequence of the chewical extractions did not significantly change the results. It was, therefore, concluded that plutoniu in the sediments was present in a reductant soluble form such as hydrous iron and manganese ox ides and not as ion exchangeable, humic bound or refractory particles.

Edgington et al. (1977) and Sprugel et al. (1975) have observed the transport of Pu disposed into the Great Miani River (Ohio) from sporadic controlled releases of low level muclear liquid wastes at Mound Laboratory. The field studies show Pu transport occurs essentially totally on suspended particulates. Mass balances necessitate a larger source of $\mathrm{Pu}$ than these sporadic releases. Two possible sources of the excess $\mathrm{Pu}$ are release/resuspension of plutonium from bed sediments or seepage from other land burial sites.

Wahlgren and Nelson (1976) have calculated the Kd for Pu on suspended particles within the Great Miami River to be $\geq 10^{5} \mathrm{ml} / \mathrm{g}$.

Wahlgren et al. (1977a) have followed the seasonal cycling of Pu in Lake Michigan for several years. Pu in the upper water colum $(0$ to $60 \mathrm{~m})$ is removed each spring coincident with a diatom bloom. Presumably Pu retained on diatom carcasses settles out. Each fall (late November) turnover occurs and the lake water colum becomes uniform again in regard to Pu concentration. 
Wahlgren et a1. (1977b, 1977c) have studied the distribution of total concentrations, and valence states of $\mathrm{Pu}$ in freshuter lakes. A simple plot of total Pu concentration versus pH over the observed range (4 to 8.5) shows mo straightforward trend but at $\mathrm{pH}<7 \mathrm{Pu}$ concentrations on the average are ten times greater than Pu concentrations at $\mathrm{pH}>7$. Other variables such as alkalinity, redox potential (Eh), organic content need to be considered. Speciation tests show Pu dissolved in Lake Michigan is present predominantly ( $\mathbf{8 0 x})$ as $\mathrm{Pu}(\mathrm{Y}, \mathrm{VI})$ wile less than 10 of $\mathrm{Pu}$ adsorbed to suspended particulate atter is in these oxidation states. These results strongly suggest that reduction of Pu from VNI) to Pu(IV) is a mojor factor in controlling its distribution between solution and solids in mature. Tracer additions of Pu(IV) and/or Pu(VI) showed that steady-state valence distributions would occur within a few months. Data for other lakes with $\mathrm{pH}>7$ are similar to Lake Michigan while lakes with acidic pHs show Pu(III/IV) predominate over Pu(V/VI).

Melson and Lovett (1976) in a similar species study determined the oxidation state of $\mathrm{Pu}$ in the Irish Sea near the Hindscale reprocessing plant. Seawater samples both unfiliered and filtered $(<0.22 \mu \mathrm{m})$ were analyzed. Plutonium which was filtered was predominant Iy Pu(III and IV) wile Pu mich reasained in solution was $P u(V$ and VI). Kds for the total Pu based on dissolved Pu versus filtered Pu and for Pu(III and IV) and Pu(V and VI) show unnistakeably that Pis in the lower valence states have a $\mathrm{Kd}$ up to 1000 times larger.

Emery and coworkers (1974a, 1974b, 1975 and 1977) have studied the ecological behavior of one Hanford liquid waste pond. Ninety-five percent of the incoming low level waste percclates through the desert sands. The sediments are the principal repository ( $>99 \%$ ), with the top ten centimeters containing an average $390 \mathrm{pCi} \mathrm{Pu} / \mathrm{g}$. The over lying water contains $0.01 \mathrm{pCi} \mathrm{Pu} / \boldsymbol{l}$. Assuming that these values constitute equilibriu conditions, an estimate of the $K \mathrm{dPu}_{\mathrm{Pu}}$ can be made. The resultant $\mathrm{Kd}_{\mathrm{Pu}}$ value is $3.7 \times 10^{7} \mathrm{ml} / \mathrm{g}$. Plutonium in the interstitial waters appeared to be mainly cationic or nonionic forms. Plutoniu in the pond water appeared to be mainly fine particulates, possibly signifying that the waste stream plutonium content is predominantly $\mathrm{PuO}_{2}$ particles. 
Sequential chemical extraction of Hanford Uranium Pond sediments with $0.1 \mathrm{NaCl}, 0.1 \mathrm{M}$ axalic acid - $2.0 \mathrm{OH}\left(\mathrm{m}_{4}\right)_{2} \mathrm{C}_{2} \mathrm{O}_{4}$, and $0.01 \mathrm{H}$ EDTA revealed releases of 1 to $3 x, 3$ to $5 x$, and 2 to 22x, respectively, of the total plutoniv. The first extractant should have removed ion exchangeable plutonium, the second anorphous hydrous oxide bound, and the third complexible plutoniun.

Hayes et al. (1975) surveyed the plutonium content in the Savannah, Neuse and nemport estuaries in the southeastern United States. The sediments contained 2 to $20 \times 10^{-3} \mathrm{pCi} / \mathrm{g}$ mile filtered $(1 \mathrm{~m})$ maters contained 0.24 to $2.4 \times 10^{-6} \mathrm{pCi} / \mathrm{ml}$ for a field $\mathrm{Kd}_{\mathrm{pu}}$ range of 0.8 to $80 \times 10^{3} \mathrm{ml} / \mathrm{g}$. A $5 \mathrm{um}$ filter would rewove one-third the anount of plutoniun that a 1 us filter would. then the salinity increased above 10 parts per thousand in the estuaries, plutoniun content of suspended solids was seen to decrease, suggesting some desorption from suspended particulates.

Hetherington (1975), Hetherington et al. (1975), and Templeton and Preston (1966) studied the migration of plutoniu from the effluents pumed into the Irish Sea wich are produced from the reprocessing plant at Mindscale. Plutoniva is resoved rapidly to the sediments (95x). The highest concentration of plutonium is found in fine wck close to the outfall, the lomest in sand. The observed field $\mathrm{Kd}_{\mathrm{Pu}_{U}}$ is $1 \times 10^{3} \mathrm{ml} / \mathrm{g}$ for sand and $2 \times 10^{5}$ for fine mack. The residual fraction wich apparently remains in solution in sea water appears to behave conservatively and in a fashion wich is qualitatively similar to ${ }^{137}$ Cs. An interesting sim:larity between the distributions of ${ }^{239} \mathrm{Pu}$ and ${ }^{137} \mathrm{Cs}$ with depth in core samples is confinmed and this is taken as evidence of the fact that sedimentation of material that has become contaminated wile in suspension is the primary mechanise by which both these nuclides are being incorporated into the sediments of this area. Support for this belief is provided by the behavior of the ratio of ${ }^{239} \mathrm{Pu}:{ }^{238} \mathrm{pu}$ with depth in some core samles. This ratio in the cores has been related to that in the Mindscale effluent during the past decade in order to estimate the sedimentation rates in the areas from wich the cores were taken. 
Murray and Kaursky (1975) feel the Morth Sea is probably a unique sea region in that the distribution of artificial radionuclidks is influenced by the discharge of activity from three nuclear fuel reprocessing plants, those situated at La Hague in Morthern France, Windscale in the northuest of England and Dounraey in Morthern Scotland, as well as from fallout from muclear weapon testing. Data is presented on the distribution of $239+240 \mathrm{Pu}, 238_{\mathrm{Pu}}$ and $241 \mathrm{Am}$ in seamater saples taken from the Cerman Bight and Cerman Baltic coastines as will as from other parts of the morth Sea up to latitude $60^{\circ} \mathrm{n}$.

Results from the Pentland Firth in the north of Pentland and the English Channel show 239+240 pu activities in sea mater between 5 to 15 times higher than morth At lantic fallout levels. The ratio ${ }^{238} \mathrm{Pu} / 239+240$ Pu is significantly higher in the Pentland Firth area $(0.21 \pm 0.01)$ than in the Chamel $(0.15 \pm$ 0.02 ) and this difference way well be a reflection of different input sources of plutoniu in the water. Cerman coastal sea water and sediment plutonium activities appear to be due only to fallowt, the isotope ratio being about $0.06 \pm 0.02$, a value in good agreement with accepted Morth Atlantic values. Field $K_{d_{p y}}$ for the Baltic Sea and Morth Sea were calculated from data presented in this paper and are about 3 to $15 \times 10^{3}$ and 0.08 to $30 \times 10^{3} \mathrm{ml} / \mathrm{g}$, respectively.

Pillai and Mathew (1975) studied the aigration of plutoniu from a fuel reprocessing plant in the arine environment off Trombay, India. Mearly 99\% of the plutonim in the waste was rapidly removed by sediments. Sediments near the outfall contained 10 to $\mathbf{1 0 0}$ times the plutoniu concentration of background sediment. Plutoniu levels decreased with distance from the discharge site although resuspension, tidal transport and seasonal effects complicated the distribution. Resuspension of plutoniu-laden sediwents in sea water did not increase the filtered water concentration, therefore, plutonium transport is mainly with silt movement. A field $\mathrm{Kd}_{\mathrm{Pu}}$ of $9 \times 10^{4} \mathrm{ml} / \mathrm{g}$ can be calculated from their data.

Sedlet and 6olchert (1977) weasured the $239,240 \mathrm{Pu}$ in the creek and rivers nearby Argonne National Lab. Near a waste outfall the plutonium present in an acidified water sample found to distribute $64 \%$ on an unspecified filter and $36 \%$ in the filtrate. The filtrate waters contained the following Pu 
concentrations: Samill Creek $9.4 \pm 1.3 \times 10^{-3} \mathrm{pCi} / \ell$, Des Plaines River $0.7 \pm$ $0.2 \times 10^{-3} \mathrm{pCi} / \ell$, and 111 inois River $0.3 \pm 0.1 \times 10^{-3} \mathrm{pCi} / \ell$. Respective strean sedienents contained 19, 25 and $1 \times 10^{-3} \mathrm{pCi} / \mathrm{g}$. Field Kds are Samill Creek $2 \times$ $10^{3}$. Des Plaines River $4 \times 10^{4}$ and Illinois River $3 \times 10^{3} \mathrm{al} / 9$, respectively.

Simpson et al. (1980) have masured the fallout $238,239,240_{\mathrm{Pu}}$ in unfiltered mono Lake (California) water and sediments. Mono Lake is a high pH (10) high carbonate ( $0.3 \mathrm{~m}$ ) saline (2 times seawater) lake. Results show an abnorwally high acount of $\mathrm{Pu}$ in solution versus the sediments and yield a $\mathrm{Kd}$ of only $10^{3}$ compared to usual field values of $10^{5} \mathrm{ml} / \mathrm{g}$. The authors feel that soluble carbonate complexes may be the cause.

Magno et al. (1970), in imvestigations of radionuclide migration from the Muclear Fuel Services plant in West Valley, Mew York, estimated that wore than 90 of the ${ }^{238} \mathrm{Pu}, 239 \mathrm{Pu}$, and ${ }^{241} \mathrm{Pu}$ contained in the plant effluent remained in the sediments of the lagoon system.

Water infiltration and plutoniu migration at haxey Flats burial grounds were studied by meyer (1975). A hydrostatic head of 4 to 6 was found in some trenches, causing lateral and dommard migration of leachates. Surficial plutonium migration also had occurred from trench leakage. Above background plutoniu concentrations have been detected in onsite and offsite surface soils and strean sediments, in soil cores to $90 \mathrm{~cm}$ and in wells 15 to 27 a deep. Other radionuclides accompanying the plutonium included tritiun, ${ }^{60} \mathrm{Co},{ }^{89}, 90 \mathrm{Sr}$ and 134,137 Cs.

Radiological measurements at the Maxey Flats burial site, Kentucky, also have indicated some radionuclides physically transport on particulate matter (Meyer, 1975; montgowery et al., 1977). The authors mentioned that ${ }^{54} \mathrm{~m},{ }^{60} \mathrm{Co}$,

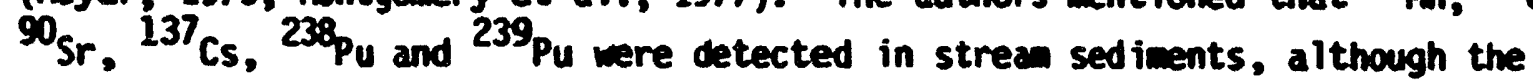
water levels we quite low. In E-Series test well measurements, all plutoniw within the detection limit was associated with sediment. The authors

- suggest that this raises a question as to the mechanisa of plutonium aigration from the disposal trenches. 
Bondietti and Reymolds (1977) investigated the species of plutonium found in Oak Ridge seepage water from a solid waste burial ground. Pu(VI) was identified as the min plutoniu species in the seepage solutions. The implication is that Pu(VI) is more wobile than Pu(IV).

Christenson et al. (1958), Christenson and Thomas (1962), Purtymun (1971, 1974), Hakonson et al. (1973a,b, 1975) and Richwond and Sullivan (1974) conclude that the plutoniun concentration of LASL canyon soils receiving low level wastes has noved slowly domstrea. Sorption studies on the tuff material wich lies below the alluvial soils show high plutonium retention. The tuff contains many cracks and fissures through which plutonium has penetrated to a depth of $28 \mathrm{ft}$ in localized areas. High percentages of clays, deposited by local weathering, surbed plutoniu and result in local high alpha activity. Since 1963 nearly $2 \times 10^{5} \mathrm{l} /$ day of low-level waste has beer discharged. Comprehensive sapling of the strean bed from the outfall to a distance of $10 \mathrm{~km}$ domintrean show 35 to $\mathbf{4 0 \%}$ of the calculated inventory present in the first kilometer downstrean, which happens to represent the region containing permanent surface vater. Over $50 \%$ of the plutonium is present in the lower portion of the canyon where the strean chamel is normally dry, indicating that considerable downstrean transport had occurred. Rainstorm runoff has been shown to be the transport mechanism. During one runoff study $99 \%$ of the radionuclide imventory in the slurry was associated with suspended particulates. The faster strea velocities suspend wore and larger particles and physically wove plutoniu dow the canyon. To date plutonium migration down the canyon has been less than $5 \mathrm{~km}$ and held within the Los Alamos boundaries. Plutoniun concentration patterns with depth are not consistent and show considerable vertical mixing has occurred.

Sumary

In wost oxidizing environments, ionic plutonium is expected to be present in solution predoainantly as Pu(V) or Pu(VI). With high plutonium concentrations, $\mathrm{PuO}_{2}$ could be expected as a stable solid phase. The plutonium adsorption data indicate that more than one mechanisa is operating during reactions with rocks and sediments. There is a direct correlation of plutoniu adsorption results with cation exchange capacities, indicating that part of the 
adsorption is due to ion exchange. However, little effect on adsorption was obvious from competing cation concentrations that were very high (Rhodes, 1957a; Ho and Loman, 1975). Perhaps the principal correlation of plutonium adsorption is with pH. A relatively rapid soil colum breakthrough of plutonium was obtained with a low pH $(<1)$ solution. Strong adsorption occurs over the pH range of from 4 to 8 , but above pH 8 the formation of negative complexes or polymers with low charge densities can cause lowered adsorption. In addition, plutconium is easily complexed with humic acids, oxalate, acetate, and a large muber uf phosphorus-bearing organics used in the muclear fuel reprocessing industry. Even the precipitated or absorbed plutonium can be readily moved through the aqueous environents in the form of particulates or suspended sediments. If the Eh environment allows it, Pu(IV) can be oxidized to Pu(V) or (VI), with much lower plutonium adsorption values resulting. The plutoniu polymers usually are adsorbed readily, but can migrate more rapidly than soluble plutonium in some instances mere the surface charge density is low. much experimental work reasains to be done to separate and understand the several reactions or mechanisus occurring in plutonium adsorption. A controlled Eh environment for the adsorption work is important as an experimental condition when an element disproportionates as readily as plutonium. 


\section{PRONETHION}

\section{Matural Sediment and Rock Distributions}

Promethiu has not been found to occur naturally in sediments and rocks. Brief Chemistry

There are 16 known radioactive isotopes and isomers or promethium with mass mubers from 141 to 154 and half-lives ranging from $34 \mathrm{sec}$ to $17.7 \mathrm{yr}$. Promethiu-147 (half-1ife $2.5 \mathrm{yr}$ ) is the only promethiu isotope obtained in large amounts from $235 \mathrm{U}$ fissioning by thermal neutrons, and is present in fuel reprocessing fission products.

Promethiu is a lanthanide and like cost lanthanides exists in a trivalent state. Only the (III) oxidation state of promethiu is stable in aqueous solutions. Starik and Lambert (1958) studied the state of micro-anounts of promethiu in aqueous solutions at different pH values by ultrafiltration and centrifugation. The results showed that promethium was present as $P^{+3}$ at pH $\leq 3$. With an increase in pH, hydrolysis products gradually accumlate as mitiply-charged aggregates. After a maxim is reached at pH of about 7, the charged aggregates begin to flocculate. At higher pH values, the aggregates become neutral or negatively charged. Electrophoteric measurements showed that from pH 5.3 to 6.7, the bulk of the polynuclear particles was positively charged. At pH 9, no mobility is seen, indicating neutrally charged particles. At pH 5 to 8, no promethiu can be centrifuged, indicating a colloid in solution. At pH 9, uncharged forms such as $\left[\mathrm{Pm}(\mathrm{OH})_{x}\left(\mathrm{MO}_{3}\right)_{3-x}\right]^{0}$ predominate (Starik et al., 1959).

Promethiu is a lanthanide and like wost lanthanides exists in a trivalent state $\left(\mathrm{Pm}^{3+}\right)$. No data were found on solution species of promethium except for $\mathrm{PminO}_{3}^{2+}\left(\mathrm{Pm}^{3+}+\mathrm{WO}_{3}^{-}+\mathrm{PminO}_{3}^{2+} \log \mathrm{K}^{\circ}\right.$ at $\mathrm{I}=1$ is 2.48). The solution species is probably predominant ly $\mathrm{Pm}^{3+}$, much like europium. If it assumed that promethiu does not for any other complexes, then the concentration of promethium in solution will be governed mainly by Pa ${ }^{3+}$. Under these conditions, ion exchange can be an important promethiu renoval mechenism in acidic environments and at trace promethiu concentrations. 


\section{Labora fory Adsorption Studies}

Cerrai et al. (1969) contacted Ligurian Sea Sediments with sea water traced with ${ }^{147} \mathrm{Pm}$. Up to $200 \mathrm{mg}$ sediment in $400 \mathrm{ml}$ of traced sea water (pH 8.1) was shaken in a batch experiment for $1 \mathrm{hr}$. The saples were then centrifuged 20 min at $5000 \mathrm{rpm}$ and the supernatant removed. The supernatant and sediment were both counted. The $\mathrm{Kd}_{\mathrm{pm}}$ was relatively independent of the amount of sediment in contact with the sea water aliquot. The sediment/ volume ratio was varied between $750 \mathrm{mg} / \mathrm{l}$ to $5000 \mathrm{mg} / \mathrm{l} \mathrm{mile}$ the average $\mathrm{Kd}$ was $3.8 \times 10^{3}$. Uptake onto the same sediment in contact with distilled water shomed $\mathrm{Kd}_{\mathrm{Pm}}$ sensitivity to sediment-solution ratio. As the acunt of sediment encountering $40 \mathrm{ml}$ of traced distilled water increased from 5 to 100 the $K d_{p m}$ dropped from $9.4 \times 10^{3}$ to $2.9 \times 10^{3}$. The addition of $0.02 \mu \mathrm{g} / \mathrm{l} \mathrm{nd}$ to the distilled water did not affect the sorption of ${ }^{147} \mathrm{Pm}_{\mathrm{m}}$. The leaching of previously sorbed Pa by "clean" sea water was between 6 to $13 \%$ after $1 \mathrm{hr}$ contact and depended upon sediment weight present. The more sediment contarited with 40 il sea water the wore $P$ released. The effect of increasing leaching tive from 1 to $15 \mathrm{hr}$ was small $9 \%+12 \%$. The $K \mathrm{C}_{\mathrm{Pm}}$ desorption was $4.0 \times$ $10^{3} \mathrm{ml} / \mathrm{g}$ compared with $3.8 \times 10^{3} \mathrm{ml} / \mathrm{g}$ for the adsorption.

Dauson and Duursma (1974), Duursma and Gross (1971) and Duursma and Eisma (1973) report on Pm sorption for marine sediments. Promethium was found to hydrolyze in sea water and precipitate out without sediments present although some resolubilization appeared to occur with time. $K d_{P m}$ is usually lower than another rare earth, Cerium. The sorption versus particle size for two marine sediments shows Pm to be retained predominately by the the < 8 um fractions. Promethium sorption on a Black Sea sediment appears to be quite sensitive to redox conditions. Under oxidizing conditions a $\mathrm{Kd}_{\mathrm{Pm}} 7.2 \times 10^{4} \mathrm{ml} / \mathrm{g}$ occurs wile under reducing conditions $7.7 \times 10^{3}$ is observed. The average $K d_{p m}$ and $t / 2$ sorption rate observed on experiments on various marine sediments are shown in Table $\mathbf{8 . 6 0}$.

Essington and Mishita (1966) evaluated the removal of soil bound ${ }^{147} \mathrm{Pm}$ with distilled water, irrigation water ard soluble chelating agents. Haters devoid of chelating agents would not leach Pm. The chelates CDTA and EDOHA were also uneffective but DTPA did remove significant amounts of Pm. 
TABLE 8.60. $\mathrm{Kd}_{\mathrm{Pm}}$ and $\mathrm{t} 1 / 2$ Values on Selected Sediments

\begin{tabular}{|c|c|c|c|}
\hline Sed iment & $\begin{array}{c}\log K \\
\text { Unitless } \\
\end{array}$ & $\underline{K d}_{\text {est }} \mathrm{ml} / \mathrm{g}$ & t $1 / 2$ Days \\
\hline At lantic Ocean & $4.8 \pm 0.5$ & $9.8 \times 10^{4}$ & $9 \pm 6$ \\
\hline Pacific Ocean & $4.9 \pm 0.6$ & $1.1 \times 10^{5}$ & $9 \pm 6$ \\
\hline Indian Ocean & $4.6 \pm 0.7$ & $5.7 \times 10^{4}$ & $10 \pm 2$ \\
\hline Baltic Sea & $4.6 \pm 0.2$ & $5.6 \times 10^{4}$ & 7 \\
\hline Morth Sea & $4.7 \pm 0.6$ & $7.0 \times 10^{4}$ & 13 \\
\hline Mediterramean Sea & $4.9 \pm 0.2$ & $1.2 \times 10^{5}$ & 14.4 \\
\hline Black Sea & $4.2 \pm 0.7$ & $2.4 \times 10^{4}$ & 12.6 \\
\hline Red Sea & 4.4 & $3.8 \times 10^{4}$ & 5 \\
\hline
\end{tabular}

Bensen (196C) reported the complete uptake of promethiu and other trivalent rare earths at $\mathrm{pH}>6$. Promethium behavior in soil systems was said to be identical to cerium behavior. The uptake of promethium is nearly complete and unaffected by $0.5 \mathrm{M}$ alkali metal and $0.25 \mathrm{M}$ alkaline earth metal cations at above pH 7. Below pH 3, the adsorption of all rare earths including promethium is depressed similarly by accompanying salts. The results indicate that promethium and other rare earths are ionic species below pH 3, and begin to precipitate as charged polymers above pH 3. Bensen (1960) also reported that the species and anount of accompanying anion affect promethium adsorption by soils. Citrate, acetate and carbonate ions were found to inhibit rare earth adsorption on soils. This was attributed to formation of complex ion species. Chloride and nitrate ions had no appreciable effect on adsorption, and sulfate had very little effects.

Ames (1960) reported the removal of promethium during a replacement reaction of calcite with phosphate in solution. The promethium was finaliy immobilized in apatite, $\mathrm{Ca}_{5}\left(\mathrm{PO}_{4}\right)_{3} \mathrm{OH}$, where $2 \mathrm{Ca}^{2+}$ are replaced by a $\mathrm{Pm}^{3+}$ and $\mathrm{Ma}$ or some other univalent cation.

Schulz (1965) classified promethium with other rare earths as imobile in soils due to either very strong adsorption by clay particles or present as inso luble hydroxide. 


\section{Field Studies}

Cerrai et al. (1967) measured the ${ }^{147}$ Pm content of sediments from the Adriatic and Ligurian Seas. There was much wore $P$ in in the fines $(100 \mathrm{lim})$ of the Adriatic sedicients cimpared to the coarser fractions $1.69 \mathrm{pCi} / \mathrm{g}$ versus $0.078 \mathrm{pCi} / \mathrm{g}$. The total sediment concentrations reported were $0.98 \mathrm{pCi} / \mathrm{g}$ and 2.35 $\mathrm{PCi} / \mathrm{g}$ for the Adriatic and Ligurian samples.

Magno et a1. (1970) investigated migrating radionuclides from the Muclear Fuel Services plant in western Mew York State. They estimated from analytical data that greater than $90 \%$ of the ${ }^{147} \mathrm{Pm}$ discharged from the plant was deposited by sedimentation in the lagoon system. These results imply that most of the promethiun was a precipitate, probably Pa $(\mathrm{OH})_{3}$, or adsorbed on other solids in the water that settled out in the lagoons.

Sumary

Low concentrations of promethiu are expected in equilibriu with $\mathrm{Pa}(\mathrm{OH})_{3}$ in slightly acidic to slightly alkaline conditions so that $\mathrm{Pm}(\mathrm{OH})_{3}$ precipitation may control promethiu concentrations in soil and sediment solutions. Promethiun, like europium, would be expected to be ion exchangeable below the concentration required for $\mathrm{Pm}(\mathrm{OH})_{3}$ precipitation. Only limited data are available on promethium adsorption on soils and sediments, but these data tend to support the above predictions.

The ar ine environments promethiu is readily adsorbed $\mathrm{Kd} 10^{3}$ to $10^{5} \mathrm{ml} / \mathrm{g}$ apparently via precipitation. The removal of promethium is nearly complete on soils and rocks above pH 6 (Bensen, 1960). The effect of competing cation on promethiu adsorption above pH 7 is minimal. Below pH 3, the adsorption of all rare earths including promethium are similarly depressed by competing salts. Charged polywers can form under the proper conditions during $\mathrm{Pm}(\mathrm{OH})_{3}$ precipitation (Starik et al., 1959; Bensen, 1960). Citrate, acetate and carbonate ions inhibited rare earth adsorption on soils, probably due to the formation of complex ion species. Over $90 \%$ of the promethiu discharged to a lagoon system remained in the lagoon (Magno et al., 1970) as strongly adsorbed on clay particles or present as an insoluble hydroxide (Schul2, 1965). Promethium can be rewoved from solution during replacement reactions (Ames, 1960). 


\section{RADIUM}

\section{Matural Sediment and Rock Distributions}

The radium content of various sediments and rocks is given in Table 8.61. Vinogradov (1959) reported that the radium content of soils ranged from $0.5 \times$ $10^{-6}$ to $1.1 \times 10^{-6} \mathrm{ppm}$. The small amount of radium present in soils has become separated from parent thorium and uranium during rock weathering processes, and wost closely follows barium. The radium content of igneous rocks increases by 100 times from ultra-basic to granitic rocks. The radium content of most sedimentary rocks is about the same as that for granites.

TABLE 8.61. Average Radium Content of Various Geologic Media

\begin{tabular}{|c|c|c|}
\hline Type & Ra, ppom & Reference \\
\hline Ultrabasic Igneous & $0.009 \times 10^{-6}$ & Davis, 1947 \\
\hline Basic Igneous & $0.6 \times 10^{-6}$ & Evans et a1., 1942 \\
\hline Intermediate, Igneous & $0.917 \times 10^{-6}$ & Senftle and Keevil, 1947 \\
\hline Granitic Igneous & $1.395 \times 10^{-6}$ & Senftle and Keevil, 1947 \\
\hline Sandstones & $0.71 \times 10^{-6}$ & Bell et al., 1940 \\
\hline Shales & $1.08 \times 10^{-6}$ & Bell et al., 1940 \\
\hline Limestones & $0.42 \times 10^{-6}$ & Evans and Goodman, 1941 \\
\hline Marine Sediment & 1 to $50 \times 10^{-6}$ & Turekian and vedepoh1, 1961 \\
\hline River Muds & $1 \times 10^{-6}$ & Shearer, 1962 \\
\hline $\begin{array}{l}\text { Uranium-Polluted } \\
\text { River Muds }\end{array}$ & $374 \times 10^{-6}$ & Shearer, 1962 \\
\hline
\end{tabular}

\section{Brief Chemistry}

There are 16 isotopes of radium from ${ }^{213} \mathrm{Ra}$ to ${ }^{230_{\mathrm{Ra}} \text { with no }}{ }^{218_{\mathrm{Ra}} \text { or }}$ ${ }^{229} \mathrm{Ra}$. All of the isotopes of radium are unstable, and all of the naturally-

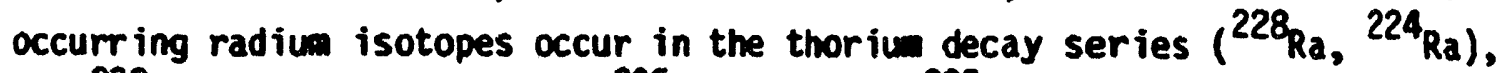
the ${ }^{238} U$-radium decay series $\left({ }^{226} \mathrm{Ra}_{\mathrm{a}}\right)$, and the ${ }^{235} \mathrm{U}$-Actinium decay series $\left({ }^{223} \mathrm{Ra}\right)$ (Vdovenko and Dubasov, 1973). The half-lives of ${ }^{228} \mathrm{Ra},{ }^{22 \mathrm{~A}} \mathrm{Ra}$, ${ }^{226}{ }_{R a}$ and ${ }^{223} \mathrm{Ra}$ are $5.77 \pm 0.02$ years, 3.65 days, 1622 years and 11.43 days, 
respectively. All are alpha emitters except ${ }^{228_{\mathrm{Ra}}}$ wich is a beta enitter. With the present uraniu fuel cycle and the much longer half-life, only the ${ }^{226} \mathrm{Ra}$ isotope is of long-tera concern in waste disposal. If future energy production includes thoriu fuels, then ${ }^{228} \mathrm{Ra}$ also wust be included in waste disposal management plans.

Radiu is a homolog of the alkaline-earth elements, with a (II) oxidation state. The radius of the +2 radiun ion is $1.52 \AA$ compared to $1.43 \AA$ for $\mathrm{Ba}^{+2}$. The compounds formed by radium and their solubilities are similar to barium. For example, the solubility product of radiu sulfate is $4.25 \times$ $10^{-11}$ at $25^{\circ} \mathrm{C}$ (Ydovenko and Dubasov, 1973) and the solubility product of bariu sulfate is $1.08 \times 10^{-10}$ at $25^{\circ} \mathrm{C}$ (Meast, 1976). Metallic radiun dissolves in water with the evolution of hydrogen and the formation of readily soluble $\mathrm{Ra}(\mathrm{OH})_{2}$. Of the alkaline-earth metal cations, $\mathrm{Ra}^{+2}$ shows the least tendency foi complex formation, although 1:1 complexes with citric, tartaric, succinic and several other acids were detected at pH 7.2 to 7.4 by Schubert et al. (1950). It may be assumed that $\mathrm{Ra}^{+2}$ is not hydrolyzed in aqueous solutions, by analogy with $\mathrm{Ba}^{+2}$, although there is no specific literature on the subject.

\section{Solution Equilibria}

No thermodynamic data were located for radiu hydrolysis or complex ion species. It is expected that radium will behave in solution much like strontiun does. The species $\mathrm{Ra}^{2+}$ is expected to be the most important over the pH range from 4 to 8 .

\section{Laboratory Adsorption Studies}

Holland and Kulp (1954) studied the adsorption of radium onto deep sea red clay, globigerina ooze and green clay. The amount of radium left in solution at equilibrium was independent of the amount of tracer added to the sea water. Ion exchange appeared to be controlling the removal of radium.

Iskra et al. (1969) studied the distribution of ${ }^{226} \mathrm{Ra}$ in an experimental nonrunning fresh water basin. Radiu appeared to be adsorbed by sediments and plants less than thorium but more than uranium. 
Joshi and Ganguly (1970) showed radium could be leached from marine sediments and probably is in nature by sea water.

Titaeva (1967) found radium to adsorb readily by clay sediments and peat. Under oxidizing conditions the bonding was exchangeable for both clays and humics. If high concentrations of calcium carbonate are present radium adsorption loses its exchange properties, suggesting coprecipitation of radium into $\mathrm{CaCO}_{3}$.

Stead (1964) gave a radium Xd value of $6700 \mathrm{ml} / \mathrm{g}$ for NTS tuff. Arnold and Crouse (1965) ran batch adsorption tests on some exchange materials that included the natural zeolites, clinoptilolite and chabazite, as represented by a pelletized molecular sieve (AH-500) and barite (barytes), a natural $\mathrm{BaSO}_{4}$. The results of the adsorption tests mere recomputed as distribution coefficients or Kd values. The solution was a lime-neutralized waste that contained $4100 \mathrm{PCi}{ }^{226} \mathrm{Ra} / 1,500 \mathrm{mg} / 1 \mathrm{Ca}^{+2}, 80 \mathrm{mg} / \mathrm{i} \mathrm{mg}{ }^{+2}, 1000 \mathrm{mg} / 1 \mathrm{aa}^{+}, 2500 \mathrm{mg} / 1 \mathrm{sO}_{4}^{-2}$ and $900 \mathrm{mg} / 1 \mathrm{Cl}^{-}$at $\mathrm{pH}$ 7.7. The radium $\mathrm{Kd}$ values are given in Table 8.62.

TABLE 8.62. Radiun Kd Values from Lime-Meutralized Maste; $1.25 \mathrm{~g}$ Exchanger/ $l$ of Maste (Arnold and Crouse, 1965)

\begin{tabular}{lcccc}
\multicolumn{1}{c}{ Exchanger } & & Mesh Size & $\begin{array}{c}\text { Exchanger Loading, } \\
\text { Clinoptilolite }\end{array}$ & Kd, ml/g \\
Chabazite & 20 to 50 & 2650 & 646 \\
Barite & 20 to 50 & 2900 & 707 \\
& 20 to 50 & 2000 & 490
\end{tabular}

R. J. Serne (1974) of PMl used soils from Utah and simulated river waier to determine radium distribution coefficients. The soils were pre-equilibrated by four washings with the simulated river water composition shown in Table 8.63 minus the ${ }^{226} \mathrm{RaCl}_{2}$. The fifth solution contained the ${ }^{226} 6_{\mathrm{Ra}}$ as well as the other constituents, and was used for the radium Kd determinations. The $k d$ values mere determined in triplicate to allow measurement of 
precision. The Utah soils contained 2 to $5 x$ calcite, with quartz and feldspar constituting the bulk of these sandy, arid soils. Minor constituents included hydromica and a small amount of a swectite clay. The radium kd results are listed in Table 8.64. The Kd correlated with the cation exchange capacities of the soils.

TABLE 8.63. Simulated River Hater Composition (Serne, 1974)

\begin{tabular}{|c|c|c|}
\hline Constituent & Added as- & $m / l$ \\
\hline $\mathrm{Ca}$ & $\mathrm{CaSO}_{4} \cdot 2 \mathrm{~h}_{2} \mathrm{O}, \mathrm{CaCl}_{2}$ & 82 \\
\hline $\mathrm{Mg}$ & $\mathrm{MgSO}_{4}$ & 26 \\
\hline $\mathrm{Na}$ & $\mathrm{MaCl}^{\top}$ & 75 \\
\hline K & $\mathrm{KCl}$ & 3.4 \\
\hline $\mathrm{HCO}_{3}$ & $\mathrm{NaHCO}_{3}$ & 171 \\
\hline $\mathrm{SO}_{4}$ & $\mathrm{CaSO}_{4} \cdot 2 \mathrm{H}_{2} \mathrm{O}, \mathrm{MgSO}_{4}$ & 246 \\
\hline Cl & $\mathrm{CaCl}_{2}, \mathrm{NaCl}, \mathrm{KCl}$ & 57 \\
\hline $\mathbf{u}$ & $\mathrm{UO}_{3}$ & 1 \\
\hline $\mathbf{R a}$ & $\mathrm{RaCl}_{2}$ in $\mathrm{HCL}$ solution & $7 \mu \mathrm{g} / \mathrm{l}$ \\
\hline
\end{tabular}

TABLE 8.64. Radium Distribution Coefficients with the Solution of Table 8.63 (Serne, 1974)

\begin{tabular}{|c|c|c|}
\hline Soil & Final pH & $\mathrm{Kd}, \mathrm{ml} / \mathrm{g}$ \\
\hline I & $\begin{array}{l}7.9 \\
7.9 \\
8.0\end{array}$ & $354 \pm 15$ \\
\hline II & $\begin{array}{l}7.6 \\
7.7 \\
7.6\end{array}$ & $289 \pm 7$ \\
\hline III & $\begin{array}{l}7.8 \\
7.9 \\
7.8\end{array}$ & $467 \pm 15$ \\
\hline IV & $\begin{array}{l}7.8 \\
7.6 \\
7.8\end{array}$ & $214 \pm 15$ \\
\hline
\end{tabular}


Several reports have been concerned with the leaching of ${ }^{226}$ Ra from uraniu recovery process tailings and wastes (Whitman and Porter, 1958; Anonymous, 1960; Feldman, 1961), and other authors have show that radiun can be leached from stream sediments, winerals and uraniu ill wastes (Starik and Polevaya, 1958; Starik and Lazerev, 1960). The factors that influence leachability of ${ }^{226} 6_{\mathrm{Ra}}$ from uraniu mill waste solids and river sediments were investigated by Shearer (1962) and Shearer and Lee (1964). Less than 1.5 wtx of the river sediments and mill waste solids mere greater than plus 20 mesh size and iess than 30 wtx mere minus 140 mesh in particle size. The amounts of radiu leached with distilled water versus time showed that essentially all radium was leached after 15 min. Diffusion of rad"un from the interior of the particles relatively insignificant. By varying the liquid to solid ratio in distilled water-solid leaching equilibria, it was show that the ratio affects the anount of radium leached. The largest ratio effect was shown with leaching of the acid leach process tailings, less with alkaline leach process tailings and the least from river sediments. It was demonstrated that sulfate was present in the waste solids and that the sulfate was easily solubilized. Trace amounts of barium present led to precipitation of $\mathrm{BaSO}_{4}$ and the coprecipitation of $\mathrm{RaSO}_{4}$. If radium was added prior to the solids-distilled water equilibria, it too was removed from solution by coprecipitation with $\mathrm{BaSO}_{4}$. One-hundredth molar solutions were used in leaching equilibria $(100 \mathrm{ml} / \mathrm{g}$ river sediment) to determine effects on radium leaching. $\mathrm{MgCl}_{2}, \mathrm{KCl}, \mathrm{MaCl}, \mathrm{HCl}$ and water solutions all leached less than $1 \mu \mu \mathrm{g}$ of radium mile $\mathrm{CaCl}_{2}$ leached

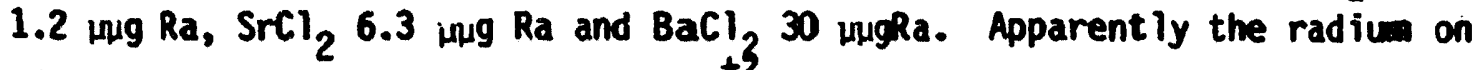
river sediments is in the form of $\mathrm{Ra}^{+2}$ and is exchangeable.

Havlik et a1. (1968a) investigated the leaching of ${ }^{226} 6_{\mathrm{Ra}}$ from uranium mill solids and uranius ores. The first report concerned the effects of pH on leaching rates. The authors found, like Shearer and Lee (1964), that equilibrive leaching was rapidly ascomplished in 15 to 30 min. Homogenized uranium ores (540 pCi Ra/g and $85 \mathrm{pCi} \mathrm{Ra/g}$ ) and milling tailings (14 pCi Ra/g) were shaken for varying lengths of time as a $3 \mathrm{~g}$ solid/30 $\mathrm{ml}$ solution ratio. The pH was modied from 1 to 14 with hydrochloric acid, boric acid and sodium 
hydroxide. At pH 1, 226 of the ${ }^{226}$ Ra was liberated. At pH 9, the anount leached had decreased to 2.8\%. At pH 13, the anount of leached ${ }^{226} 6_{R}$ increased to $5 \%$.

The second eport by Havlik et al. (1968b) studied the leaching of radiu fro the same solids as affected by leaching solution composition in addition to acidity. Unlike the leaching results of Shearer and Lee (1964), Havlik et al. found that the largest concentrations of radium were leached by $\mathbf{I N ~} \mathrm{KCl}$ and In MaCl solutions. $\mathrm{BaCl}_{2}, \mathrm{SrCl}_{2}$ and $\mathrm{CaCl}_{2}$ also were used, but with much less radiu liberated. The $1 \mathrm{~K} \mathrm{KCl}$ leached $100 \%$ of the radiu in will tailings and $\mathrm{kaC1}$, 95\%. Uranium ore leaching results were lower, showing 22 and 31 leached by $\mathrm{KCl}$ and 14 and $17 \%$ leached by MaCl. In all cases, the one normal salt solution resoved more radiu than ten normal salt solutions.

\section{Field Studies}

Baranov and Khristianova (1963) found in Pacific Ocean cores that clay fractions contained ten times core radium than sand fractions.

Bernat and coldberg (1969) ascertained that radium in Pacific Ocean cores has diffused within the vertical profile.

Bhat and Krishnaswamy (1969) measured the dissolved radium content in severai Indian Rivers. The range observed for ${ }^{226}$ Ra was 0.02 to $0.05 \mathrm{pCi} / \mathrm{l}$.

Cerrai et al. (1970) easured the ${ }^{226}$ Ra content of Ligurian and Adriatic Sea sediments. There was little difierence in the radica content in fine $(<100 \mathrm{~L}$ ) and coarse (>100 im) fractions. Total sediment radiu concentrations were $0.578 \mathrm{pCi} / \mathrm{g}$ and $0.348 \mathrm{pCi} / \mathrm{g}$, respectively.

Hamaguchi (1971) found the radium content of 13 deep sea sediments (Pacific Ocean) to be proportional to the iron and manganese content.

Havlik (1970) studied the content of ${ }^{226} 6_{R a}$ in river water, sediments and plants in the vicinity of the Jachymov uranicm mine.

Kurokawa (1971) masured the natural occurrence of ${ }^{226} \mathrm{Ra}$ in 40 Japanese soils and 10 rivers. He found 0.09 to $1.3 \mathrm{ppm}$ in the soils ano $8.2 \times$ $10^{-10} \mathrm{ppm}$ in the rivers wich yield an apparent $\mathrm{Kd}_{\mathrm{Ra}}>10^{7}$. 
Starik et al. (1961, 1963) studied the geochemistry of radium in oceans. The leaching of radiu from minerals suggests that the content of radiun in ocean water should be higher than that of uranilm, yet data show the opposite. The suggested reason is radiun sorption by suspended and colloidal particles with precipitation into botton sediments. Ocean deposits had a radium content of 4 to $50 \times 10^{-6} \mathrm{ppm}$, Black Sea deposits had 5 to $9 \times 10^{-7} \mathrm{ppa}$ radium, and Azov Sea sediments $7.2 \times 10^{-7} \mathrm{ppm}$ radium.

Somayajulu and Church (1973) found the interstitial waters of Pacific ocean.cores to contain 1 to 3 orders of magnitude greater radium contents than sea water. Radiu release from sedimentary phases with aigration into the water colum is indicated.

Granger et al. (1961) and Granger (1963) showed that radium had migrated out of Ambrosia Lake, Mew Mexico, uranium ores and had been partly reconcentrated in barite $\left(\mathrm{BaSO}_{4}\right)$ and cryptomelane $\left(\mathrm{Km}^{2+} \mathrm{mn}^{4+} 7.25{ }_{16}{ }_{16}, \mathrm{H}_{2} \mathrm{O}\right)$ found in and near some of the ore bodies. The $226 \mathrm{Ra}^{2+}$ occurred in the $\mathrm{Ba}^{2+}$ position in barite and the $\mathrm{m}^{2+}$ position in cryptomelane. The high concentrations of

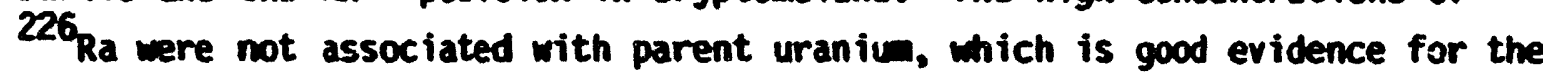
recent aigration of radium. The strongly to meakly radioactive cryptome lane partially replaced andstone that occurred near the ore bodies and was relatively low in uraniun content and emriched in lead. This suggests that the lead is radiogenic and has also migrated with the $226_{\mathrm{Ra}}$. The mechanisa involved in reconcentration of the ${ }^{226} 6_{\mathrm{Ra}}$ is the substitution of ${ }^{226_{\mathrm{Ra}}{ }^{2+}}$ for the chemically very sinilar $\mathrm{Ba}^{2+}$ in barite and $\mathrm{m}^{2+}$ in cryptomelane. Analyses of the outer 5 to $10 \mathrm{col}$ of mustone layers near ore disclosed anomalously high radioactivity coupled with an abnormally high lead content. Within mudstone layers, however, the radioactivity was essentially in balance with the uranium content, and the lead content was low.

Hansen and Huntington (1969) determined radium and thorium distributions in a series of morainal soils in Bench Valley, California. Thorium accumlated imediately beneath horizons containing a high anount of organic material. The thorium apparently migrated as organic complexes. Radiun was distributed with the uranium in the high organic layers. 
The ground and surface water sampling and analyses for radiun given by uruble et al. (1964) and Kaufimam et al. $(1975,1976)$ for waters of the Colorado Basin and Grants area, Mew Mexico, respectively, also illustrate the tendency of the radiu daughter to become separated from uraniun due initially to uraniu wining and willing operations, and to contime aigrating due to inherent geochenical differences between uranium and radium.

\section{Sumary}

Radiun is present as $\mathrm{Ra}^{2+}$ over the normal pH range (4 to 8 ) and shows little tendency to for conplex species. Radium would be expected to suhstitute for other divalent cations during replacement or precipitation reactions. A direct correlation of cation exchange capacity with adsorption and leaching studies with different types of competing cations suggests that on important reaction mechanisa for radiu adsorption is cation exchange. Radiun could be expected to migrate in much the same manner as strontium. 


\section{PUTHEMIL}

\section{Matural Sedinant and Rock Distributions}

Fen data on natural distribution of rutheniu are available. Data available on ruthenium in rock-forwing minerals are listed in Table 8.65. Piatinu grow metals, including ruthenium, are known to be concentrated in chromite; but these are older analytical values and way be much higher than nodern neutron activation rutheniu analyses. There are no rutheniu data on sandstones and limestones. However, the rutheniu contents are probably very 10w. The mager data on rutheniu content of shales are given in Table 8.66. The behavior and distribution of matural rutheniu during weathering processes is largely unknom. Estimates for the ruthenio content of marine sediments are given as 20 to $100 \mathrm{ppg}$.

TABAF 8.65. Nbundances of Rutheniu in Igneous Rocks and Rock-forming Minerals in ppo

\begin{tabular}{|c|c|c|}
\hline Mineral & $\mathrm{Ru}, \mathrm{pob}$ & Reference \\
\hline Dlivine & 10 & Moddack and Moddack, 1931 \\
\hline Chromite, Mormay & 500 & Coldschmidt and Peters, 1932 \\
\hline Chromite, Texas & 500 & Coldschnidt and Peters, 1932 \\
\hline Chromite, Penn. & 500 & Coldschaidt and Peters, 1932 \\
\hline Columbite, Monuy & 10 & Hoddack and Hoddack, 1931 \\
\hline Ilmenite & 4 & Moddack and Moddack, 1931 \\
\hline Rutile & 10 & Moddack and Moddack, 1931 \\
\hline Tantalite & 2 & Moddack and Moddack, 1931 \\
\hline Dunite, Russia & $\begin{array}{l}2 \text { to } 30 \\
\text { ( } 5 \text { average) }\end{array}$ & Razin et al., 1965 \\
\hline Dunite, Russia & $\begin{array}{l}3 \text { to } 6 \\
\text { (4.5 average) }\end{array}$ & Razin et al., 1965 \\
\hline Apodunite, Russia & $\begin{array}{l}0.9 \text { to } 4 \\
(2.2 \text { average })\end{array}$ & Razin et al., 1965 \\
\hline Mica shonkinite & 0.5 & Razin et a1., 1965 \\
\hline
\end{tabular}


TABIE 8.66. Rutheniun Contents of Shales

\begin{tabular}{|c|c|c|}
\hline Shal & $\mathrm{Ru}_{2} \mathrm{PPb}$ & Reference \\
\hline $\begin{array}{l}\text { Kupferschiefer, } \\
\text { Mansfeld, Germany }\end{array}$ & 3 & Moddack, 1936 \\
\hline Black Shale (3) & $\begin{array}{l}60 \\
80 \\
40\end{array}$ & Tischendorf, 1959 \\
\hline Bleached Shale (3) & $\begin{array}{r}40 \\
5 \\
20\end{array}$ & Tischendorf, 1959 \\
\hline
\end{tabular}

\section{Brief Cheaistry}

The 16 isotopes of rutheniu include the radioactive fission products $93_{\mathrm{Ru}},{ }^{9} \mathrm{Ru},{ }^{25},{ }_{\mathrm{Ru}}, 103_{\mathrm{Ru}},{ }^{105_{\mathrm{Ru}}} 106_{\mathrm{Ru}},{ }^{107_{\mathrm{Ru}}}$ and $108_{\mathrm{Ru}}$. The natural stable rutheniu isotopes and their abundance are shown in Table 8.67.

$$
\begin{aligned}
& \text { TABLE 8.67. } \begin{array}{c}
\text { Atomic Percentages of Stable Ruthenium } \\
\text { Isotopes (Heath, 1976) }
\end{array} \\
& \begin{array}{llllllll}
96 & \frac{98}{5.51} & \frac{99}{1.87} & \frac{100}{12.72} & \frac{101}{12.62} & \frac{101}{17.06} & \frac{102}{31.61} & \frac{104}{18.58}
\end{array}
\end{aligned}
$$

Rutheniu-103 with a 39.6-day half-life and ${ }^{106}$ Ru with a 367-day halflife are the only radioisotopes of rutheniun that persist long enough to be of concern in waste disposal.

Rutheniu exhibits several oxidation states varying from Ru(-II) to Ru(VIII), with Ru(III) and Ru(IV) the most camon oxidation states" in aqueous solutions. Pu:(II) is less common. For rutheniun, there is little evidence for simple quo isns. Mearly all aqueous solutions, whatever the anion, wa be considered to contain complex ions (Cotton and Wilkinson, 1962). Ru(II), for example, is knom to form a unique series of nitrosyl complexes, nitric oxide complexes, ansonia and sulrar complexes, carbonyl complexes, etc. 
In an alkaline medium, Ru(IV) forms the insoluble hydrated oxide $\mathrm{RuO}_{2}$. $\mathrm{MH}_{2} \mathrm{O}$ wich does not tend to be reduced to the trivalent state. Rutheniu (III) hydroxide is readily oxidized in air to Ru(IV) (Ginzburg et al., 1975). Rutheniu exists in nitric acid solutions either as the Ru(III) nitrosonitrates $\left[R U M O\left(\mathrm{mO}_{3}\right)_{n}\left(\mathrm{H}_{2} \mathrm{O}\right) \mathrm{B}-3\right]^{3-n}$ or $\left[\mathrm{RuHO}\left(\mathrm{mO}_{3}\right)_{5-n-m}(\mathrm{OH})_{m} \cdot\left(\mathrm{H}_{2} \mathrm{O}\right)_{n}\right]^{\mathrm{p}-}$, or as the polymeric $\mathrm{Ru}(\mathrm{IV})$ aquohydroxo cations $\left[\mathrm{Ru}(\mathrm{OH})_{x}\left(\mathrm{H}_{2} \mathrm{O}\right)_{6-x}\right]\left(\mathrm{MO}_{3}\right)_{4-x}$ (Ginzburg et al., 1975). Thus, from acidic nitrate solutions, which are the isual form of fuel reprocessing astes, rutheniu solutions may be obtained that contain cationic, anionic and neutral comlexes. Hence, the chemical forms of soluble rutheaiu depend heavily on the chemical history of the solution.

\section{Solution Equilibria}

The activity of various solution complexes of ruthenium in equilibrium with $\mathrm{RuO}_{2}$ (amorphous, hydrated) in oxidizing $\left(\mathrm{pO}_{2}=0.68\right.$ ) and other conditions spelled out are given in Figure 8.34. 'The thermodymanic data used to construct Figure 8.34 were selected from several sources including Sillen and Martell (1964) for $\mathrm{RuOH}^{3+}, \mathrm{Ru}^{4+}$ and $\mathrm{Ru}^{3+}$, Baes and Meswer (1976) for $\mathrm{RuO}_{4}(\mathrm{OH})^{-}$. and Hagman et al. (1969) for the remining species. Baes and Mesmer (1976) indicate that the thermodymanic data on ruthenium complexes are either not available or are not very accurate. However, it was decided to construct figure 8.34 using the existing data to estimate the nature of the species that maj be present in solution.

Figure 8.34 indicates that in an oxidizing environent, significant activity of uncomplexed $\mathrm{Ru}^{4+}$ will be present only in very acidic conditions (pH $\leq 2)$. Some of the ruthenium species wich be present in solution are $\mathrm{RuO}_{4}^{-}, \mathrm{RuO}_{4}^{2-}, \mathrm{RuO}_{4}^{\mathrm{O}}, \mathrm{Ru}(\mathrm{OH})_{2}^{2+}, \mathrm{RuO}_{4}(\mathrm{OH})^{-}, \mathrm{RuCl}_{5}(\mathrm{OH})^{2-}, \mathrm{Ru}^{4+}$, and $\mathrm{Ru}^{3+}$. Among these species, $R u^{4+}$ would be predominant in $\mathrm{pH}<2, R u(O H)_{2}^{2+}$ in $\mathrm{pH} 2$ to 5.2 , $\mathrm{RuO}_{4}^{-}$in pH 5.2 to 10.5, and $\mathrm{RuO}_{4}^{2-}$ in $\mathrm{pH}>10.5$. Hith an increase in reducing conditions, the activity of $\mathrm{Ru}^{3+}$ would increase, the activity of Ru $0_{4}^{\circ}$. 


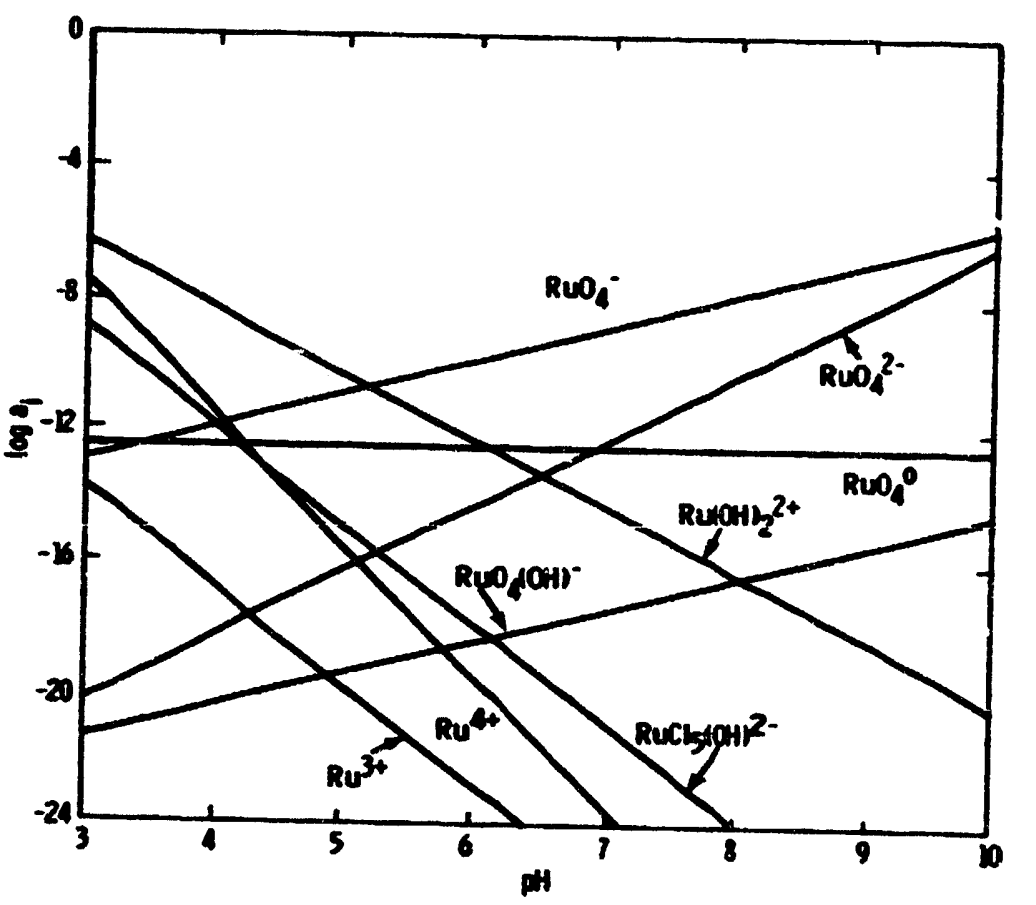

FIGRE 8.34. The Activity of Various Rutheniu Species in Equilibrium with $\mathrm{RuO}$
Other (anditions

$\mathrm{RuO}_{4}^{-}, \mathrm{RuO}_{4}^{2-}$ and $\mathrm{RuO}_{4} \mathrm{OH}^{-}$would decrease and the rest of the species wouid remain unchanged in activity. The nature of the predominant solution species is highly dependent upon the oxidation-reduction conditions, as is the most stable solid compound. The predominant ruthenim species are cationic below PH 5 and anionic above pH 5. Hence, ion exchange on soils and sediments would be of importance only below pH 5 under these conditions.

\section{Laboratory Adsorption Studies}

Aston and Duursma (1973), Darson and Duursma (1974), Duursma (1073), Durursma and Bosch (1970), Duursma and Eisma (1973), and Duursma and Gross (1971) studied the adsorption of ruthenium into marine sedients. The observed $\mathrm{Kd}_{\mathrm{Ru}}$ was not affected by the presence on stable carrier ruthenium over the concentration range 0.005 to $0.1 \mu \mathrm{g} / \mathrm{e}$ [using $\mathrm{Ru}(\mathrm{III}) \mathrm{chloride}$ ]. $\mathrm{Kd}_{\mathrm{Ru}}$ for calcareous sediments was less than $7000 \mathrm{ml} / \mathrm{g}$ and reached values of 50,000 for sediments containing illite clay. In general, the higher the exchange 
capacity of the sediment the larger the observed $\mathrm{Kd}_{\mathrm{Ru}}$. The adsorption of rutheniu follows a Freundlich isotherm. Adsorption versus sediment particle size fraction shows the silt fraction adsorbs nore rutheniu than clay. There appears to be greater adsorption of ruthenium under oxidizing conditions than reducing conditions for a Black Sea sediment. The $K_{\mathrm{Ru}}$ under oxidizing conditions was $5.1 \times 10^{4} \mathrm{~m} / \mathrm{g}$ versus $1.3 \times 10^{4} \mathrm{w} / \mathrm{g}$ for reducing conditions. Durrsa and coworkers admonished that these results using simple cationic tracers might not accurately predict sorption of the complex distribution of rutheniun species in nature.

A sumary of $K d_{R u}$ values and half-periods of sorption for mumerous marine sediments are shown in Table 8.68.

TABLE 8.68. Ru Sorption Data

\begin{tabular}{|c|c|c|c|}
\hline Sediment & $\log x$ & $\begin{array}{c}\text { Kd (est.), } \\
\quad 1 / g \\
\end{array}$ & $\begin{array}{c}t 1 / 2 \text { Sorption, } \\
\text { days }\end{array}$ \\
\hline Atlantic Ocean & $4.4 \pm 0.4$ & $3.5 \times 10^{4}$ & $6.5 \pm 4.6$ \\
\hline Pacific Ocean & $4.3 \pm 0.6$ & $2.9 \times 10^{4}$ & $7.1 \pm 1.6$ \\
\hline Indian Ocean & $4.6 \pm 0.4$ & $8.7 \times 10^{4}$ & $15.2+6.5$ \\
\hline Baltic Sea & $4.5 \pm 0.2$ & $4.7 \times 10^{4}$ & 9.0 \\
\hline North Sea & $4.2 \pm 0.5$ & $2.7 \times 10^{4}$ & 9.0 \\
\hline Mediterranean Sea & $4.3 \pm 0.2$ & $3.0 \times 10^{4}$ & $8.4 \pm 4.3$ \\
\hline Black Sea & $4.2 \pm 0.4$ & $2.6 \times 10^{4}$ & $5.0^{-}$ \\
\hline Red Sea & $4.6 \pm$ & $5.4 \times 10^{4}$ & 5.0 \\
\hline
\end{tabular}

Baranov and Polikarpov $(1966,1968)$ studied the adsorption of ruthenium onto shallow marine sediments and observed the sorption to be poor compared to $\mathrm{Zr}, \mathrm{Cs}, \mathrm{Ce}$. The ruthenium which was adsorbed was readily removed by fresh sea water and $0.2 \mathrm{~N} \mathrm{HCl}$ acid.

Collet et a?. (1968) studied the adsorption of Ru on Rhine River sediments and separated adsorption values for sand, silt and clay fractions. Doshi et al. (1973) found quantitative removal of Ru from sea water during in situ precipitation of manganese dioxide. Gardner and Skulberg (1964) studied the 
adsorption of ruthenium onto sediments from the River Nitelva. Detailed characterization of sediments and river water are given. The sediments were treated with $\mathrm{H}_{2} \mathrm{O}_{2}$ to remove organic matter, dried and ground to $<200$ wh prior to usage. Experiments at 16 to $256 \mathrm{mg} / \ell$ sediment were performed using rutheniu (III) chloride tracer. At $64 \mathrm{mg} / l$ suspended solids rutheniu adsorption was still slowly increasing after 9 days. The effects of sait composition and sediment concentration are shown in Table 8.69 were $\mathrm{Kd}_{\mathrm{Ru}}$ ( $24 \mathrm{hr}$ contact) are show for river water and distilled water. As the authors show sorption contiming beyond 9 days, these values are not equilibrium values.

TABLE 8.69. Ru Sorption in Fresh Water

\begin{tabular}{|c|c|c|}
\hline $\begin{array}{l}\text { Sediment, } \\
\mathrm{mg} / \ell\end{array}$ & $\begin{array}{c}\text { KdRu Distilled Water, } \\
\text { m1/g }\end{array}$ & $\begin{array}{c}\text { KdRu River Mater, } \\
\text { ml/g }\end{array}$ \\
\hline 16 & 11,900 & 1,600 \\
\hline 32 & 9,600 & 1,300 \\
\hline 64 & 8,050 & 1,180 \\
\hline 128 & 6,750 & 910 \\
\hline 256 & 5,300 & 690 \\
\hline
\end{tabular}

Growov (1975) and Gromov and Spitsyn (1974) studied the adsorption and desorption of ruthenium by Pacific Ocean and Indian Ocean sediments. Ruthenium was sorbed readily by the sediments.

Kepak (1966) studied the sorption of ${ }^{106}{ }_{R U}$ as the ruthenium (III)- and nitrosylruthenium (II)-ion on hydrated ferric oxide, containing a small amount of silver oxide under dymanic conditions. The sorption of $106 \mathrm{Ru}$ was also studied under static conditions and it was observed that the absorption of a small quantity of silver oxide in ferric oxide increased its sorption capacity for the ruthenium (III)- and nitrosylruthenium (II)-ion and the sorption was characterized by high values of the distribution coefficient. 
Sorption of Ru from $30.2 \%$ saline water by a sandy sediment from the Skagit River estuary (Washington) has been reported by Schell et al. (1979). Ru appears to be rather insoluble in sea water as 78 to $85 \%$ of the tracer was filterable from blank solutions. Without blank correction the $\mathrm{Kd}_{\mathrm{RH}}$ is 1.7 to $2.9 \times 10^{4} \mathrm{ml} / \mathrm{g}$. With blank correction the $\mathrm{Kd}_{\mathrm{Ru}}$ is 0.8 to $1.1 \times 10^{4}$.

In a dialysis experiment Schell et al. (1979) show that Ru predominates in solut le forms. The portion mich does become bound on particulates shows plankton as stronger sorber than clay or organic detritus. The distributions can be found in Table $\mathbf{8 . 1 0}$ of the americium section.

Schell et al. (1980) report on laboratory determinations of $\mathrm{Kd}_{\mathrm{Ru}}$ in numerous fresh and marine water environments with actual sediments. Table 8.11 sumarizes the resuits. The $K d_{R u}$ values do not appear to be sensitive to salinity effects which suggests Ru sorption is not predominated by ion exchange like processes.

Schell et a1. (1980) determined in the laboratory that the sorption of Ru onto a Clinch River (Tennessee) sediment from fresh water increased fivefold between pH 4 and 6. From pH 6 to 10 there was much scatter in observed $\mathrm{Kd}$ but no clear trend.

Schell et al. (1980) studied the effects of five organics on ruthenium sorption in a fresh water environment. Four organics significantly increased $K_{R u}$ (see Table 8.12). Care must be exercised in interpreting the significance of these results as unnaturally high concentrations of organics were used.

Schell et al. (1980) continued dialysis experiments using a Lake Michigan fresmater system. After 20 days much of the $\mathrm{Ru}$ is found bound to particulates sediments and detritus.

Eichholz et al. (1967) studied the distribution of ruthenium between suspended sediment particles and aqueous solutions. Natural water samples were characterized and used in the adsorption studies as sources of suspended solids, as shom in Table 8.70. A fission product mixture was added to the natural water samples, the system equilibrated and the water and sediments 
separated. The adsorption of ${ }^{106} \mathrm{Ru}$ is shom in Table 8.71. A portion of the ${ }^{106}{ }_{R U}$ was associated with the suspended sediments, though to a lesser extent than the other radionuclides with the exception of ${ }^{131}$ I.

TABLE 8.70. Properties of Matural Hater Samples (Eichholz et al., 1967)

\begin{tabular}{|c|c|c|c|c|c|}
\hline Source & $\begin{array}{l}\text { Suspended } \\
\text { Solids, ppm }\end{array}$ & $\begin{array}{l}\text { Dissolved } \\
\text { Solids, ppm }\end{array}$ & pH & $\begin{array}{c}\text { Conductivity } \\
\text { hos }\end{array}$ & $\begin{array}{l}\text { Solids } \\
\text { Composition }\end{array}$ \\
\hline $\begin{array}{l}\text { Colorado River, } \\
\text { Utah }\end{array}$ & 229 & 350 & 7.5 & 540 & $\begin{array}{l}95 \% \text { quartz, } \\
5 \% \text { calcite, } \\
\text { feldspar, illite, } \\
\text { kaolinite }\end{array}$ \\
\hline $\begin{array}{l}\text { Camp McCoy, } \\
\text { Misconsin }\end{array}$ & 12 & 60 & 6.9 & 80 & $\begin{array}{l}30 \% \text { quartz + } \\
\text { feldspar, } 6 \% \\
\text { kaolinite, } \\
24 \% \text { illite }\end{array}$ \\
\hline $\begin{array}{l}\text { Bayou Anacoco, } \\
\text { Lovisi ana }\end{array}$ & 24 & 63 & 6.2 & 60 & $\begin{array}{l}30 \% \text { quartz, } \\
2 \% \text { kaolinite, } \\
6 \% \text { smectite }\end{array}$ \\
\hline $\begin{array}{l}\text { Lodgepole Creek, } \\
\text { Nebraska }\end{array}$ & 965 & 200 & 6.8 & 300 & $\begin{array}{l}20 \% \text { illite, } \\
80 \% \text { smectite }\end{array}$ \\
\hline $\begin{array}{l}\text { Chattahoochee } \\
\text { River, Georgia }\end{array}$ & 131 & 31 & $\begin{array}{l}7.3 \\
\ldots\end{array}$ & 45 & $\begin{array}{l}33 \% \text { quartz, } \\
44 \% \text { kaolinite } \\
23 \% \text { illite }\end{array}$ \\
\hline $\begin{array}{l}\text { Billy's Lake, } \\
\text { Georgia (swamp) }\end{array}$ & 8 & 68 & 4.2 & 45 & $\begin{array}{l}\text { 2x quartz, } \\
\text { balance was } \\
\text { amorphous } \\
\text { and/or organic }\end{array}$ \\
\hline
\end{tabular}

TABLE 8.71. Adsorption of $106 \mathrm{Ru}$ on Suspended Solids in Matural Waters (Eichholz et al., 1967)

\begin{tabular}{lccc}
\multicolumn{1}{c}{ Source } & pH & 106 Ru Adsorption, X \\
Colorado River & 7.5 & 25.0 \\
Camp McCoy & 6.9 & 5.7 \\
Bayou Anacoco & 6.2 & 0 \\
Chattahoochee River & 7.3 & 10.4 \\
Billy's Lake & 4.2 & 0
\end{tabular}


It is obvious that ruthenium adsorption was a function of Ph of the water. The higher percentages of adsorbed ruthenium are directly correlated with water pH.

Peperstraete et al. (1973) perforwed detailed electrophoretic studies of the distribution of different rutheniu species during their transition from fresh to marine maters. The species distribution was found to be complex with nitroso - (nitrite, chloride, nitrate and hydroxides) all being stable in both fresh and marine environments. With aging the ruthenium complexes appear to form polymers.

The adsorption of trinitratonitrosyl ruthenium on peat as a function of contact time, pH, solids/solution ratio and solution salt content was studied. Ruthenium adsorption was high even above pH 4 where hydrous colloids were present.

Amy (1971) studied the migration rates of different ruthenium forms in calcareous and acidic soil in columns. The nitrodinatrato complexes of ruthenium, RunONO $\mathrm{O}_{2}\left(\mathrm{NO}_{3}\right)_{2}\left(\mathrm{H}_{2} \mathrm{O}\right)_{2}$, were much more mobile than cesium in calcareous soils. From 2 to $33 x$ of this rutheniun form passes through the colum. For comparison, the fraction from $\mathrm{RuCO}_{3}$ that migrates down the entire coluen length varied from 3 to $68 \%$, depending on the soil type. In sumary, in calcareous soils maximum ruthenium mobility was attained when the ruthenium was in the form of an anionic complex in permeable soils with a sandy texture and low in organic material.

Champlin and Eichholz (1976) have shown that finely particulate soil materials, such as kaolinite, can adsorb a variety of trace radionuclides including ${ }^{106} 6_{R u}$ and adhere to the soil matrix surface by Van der Waal's forces (Champlin, 1969). Further, these fine particulates were mobilized by laundry detergents and softening agents, so that they were transported quickly through the soil colum without reaction with contacting soils.

Mishita et al. (1956) leached ruthenium from soils and c? yy minerals with water and a salt solution. The ${ }^{106} 6_{R u}$ was the most readily leached radionuclide from the soils with water. The ${ }^{106} \mathrm{Ru}$ also was the most easily water 
leached from bentonite and kaolinite. The rutheniu tended to be the least exchangeable in both the soils and the bentonite and kaolinite. A persistent fraction of the bentonite and kaolinite adsorbed rutheniu was nonexchangeable.

Nishita and Essington (1967) continued work on $106_{\text {Ru migration in dif- }}$ ferent types of soils, comparing the relative wovenent of ${ }^{65} \mathrm{Zn},{ }^{85} \mathrm{Sr},{ }^{91} \mathrm{Y},{ }^{106} \mathrm{Ru}$, ${ }^{137} \mathrm{Cs},{ }^{144} \mathrm{Ce}$ and ${ }^{147} \mathrm{Pm}$. Irrespective of the soil type, water leaching resulted in the greatest movement for ${ }^{106} \mathrm{Ru}$.

Rhose (1957) reported the variation in ${ }^{106} \mathrm{Ru}$ distribution coefficients with solution pH on a typical Hanford subsoil. The soil had a cation exchange capacity of 5 meq/100 g, 2 wt\% calcium carbonate, with about $2 \%$ clays cf inly montmorillonite and less amounts of chlorite. The $\mathrm{Kd}$ values for ${ }^{106_{\mathrm{Ru}}}$ are presented in Table 8.72. It should be noted that the ${ }^{106}{ }_{R u}$ was obtained from Oak Ridge National Laboratory, probably as $\mathrm{RuCl}_{3}$ in $\mathrm{HCl}$ solution.

The soil adsorption of $\mathrm{Ru}^{+3}$ in a chloride medium cannot be similar to the adsorption of the nitroand nitrato complexes of nitrosylruthenium normally present in acidic nitrate waste solutions. Rhodes and Melson (195i) make this same point when they discuss the soil adsorption of ruthenium present in uranium recovery plant waste. Sampling of ground water beneath a discontinued disposal facility showed that the concentration of ${ }^{106} \mathrm{Ru}$ remained constant for several months. This indicated little adsorption after the initial breakthrough of ${ }^{106_{R u}}$. Klechkovsy (1956) also investigatec ${ }^{106} 6_{R u}$ adsorption on soils but did not specify the type of ruthenium or soils used.

According to Schulz (1965), ruthenius tends to react like manganese, cobalt, zinc, iron and chromium in reactions in a soil environment. They are most soluble in acidic conditions and tend to precipitate as hydroxides as the pH rises. Ruthenium tends to form complexes that are uncharged or negatively charged and would therefore tend to be quite mobile in soils.

Bovard and Saas (1968) reported that the free functional groups (carboxylic, phenolic) mere the cause of organic matter complexing and fixation of radionuclides. For humic acids, the mean order of complexing was Cesfesins Co $\geq R u \geq S r>C s$. In the case of fulvic acids, no universal order existed. Two 
TABLE 8.72. Rutheniu Distribution Coefficients on a Hanford Soil as a Function of pH (Rhodes, 1957)

$\begin{array}{lccc}\mathrm{pH} & \frac{K d_{2} \mathrm{ml} / \mathrm{g}}{0} & \frac{\mathrm{pH}}{\mathrm{K}} & \frac{\mathrm{Kd}}{2} \mathrm{ml} / \mathrm{g} \\ 1.3 & 0 & 9.2 & 40 \\ 2.6 & 26 & 10.1 & 39 \\ 4.7 & 101 & 11.0 & 92 \\ 6.6 & 752 & 11.3 & 27 \\ 7.4 & 460 & 13.0 & 101 \\ 8.5 & 274 & 14.0 & 752\end{array}$

types of soils mere used in the studies, a calcareous alluvial soil and a humoferruginous podzol. Leaching of fission products, particularly ruthenium, by rain wer occurred essentially in the form of fulvates.

Essington et a1. (1965) and Essington and Nishita (1966) determined the leaching effects of water, chelating agents and $\mathrm{HCl}$ on ${ }^{106} \mathrm{Ru}$ adsorbed to soil. Chelating agents (DTPA, CDTA, EDDHA), increased the soluble radionuclides by a small amount as compared to water. The ${ }^{106} \mathrm{Ru}$ tended to remain in the colum. Some ${ }^{103} \mathrm{RU}$ was reported in leachates in CaDPTA-leached soils.

Kuliker (1968) and Kulikov and Holchanova (1972) found EDTA and DTPA could significantly reduce the adsorption of ruthenium by soils.

Wi iding and Rhodes (1963) reported that the addition of 100 ppa citrate to a symthetic waste-cationic ruthen ium solution reduced the $\mathrm{Kd}$ value for ruthenium on Idaho well sediments to $27 \mathrm{ml} / \mathrm{g}$ from $275 \mathrm{ml} / \mathrm{g}$. For the same soiutions, the reduction on the natural zeolite clinoptilolite was to a $\mathrm{Kd}$ value of $4 \mathrm{ml} / \mathrm{g}$ from a $\mathrm{Kd}$ value of $48 \mathrm{~m} \mathrm{l} / \mathrm{g}$ with no citrate present. Addition of 100 ppm EOTA to the synthetic waste (MTR cooling water) lowered the ruthenium Kd value from about $472 \mathrm{ml} / \mathrm{g}$ with no EOTA to $100 \mathrm{ml} / \mathrm{g}$ with EDTA. Kepak (1966) reported the adsorption $\mathrm{Kd}$ for $\mathrm{Ru}(\mathrm{NO})^{+2}$ and $\mathrm{Ru}^{+3}$ on hydrated ferric oxide as $8.4 \times 10^{3}$ and $4.8 \times 10^{3}$, respectively. 


\section{Field Studies}

Numerous articles have been published on the observed migration of ruthenile: from Oak Ridge Natioral Laboratory waste discharges [Carrigan (1968, 1969), Carrigan et al. (1967), Cowser (1963), Couser and Parker (1958), Lamers (1968), Lomenick (1963), Pickering (1969, 1970) and Pickering et a1. (1965, 1966)]. In general, rutheniu reaching the Clinch and Temessee rivers is not retained by botton sediments ( $<1 \%$ retained). The little bit of ruthenium present in the bottom sediments probably already adsorbed on suspended sedivents prior to deposition. Due to the complex and variable pattern of radionuclide distribution in sediments and production, the sediment ruthenium content was not found to correlate with any chenical or physical properties.

Before entering the streams, ruthenium travels through seepage pits and White Oak Lake and Creek. The suspected source is high nitrate waste. Some of the rutheniu is present in the nitrosyl rutheniu hydroxide form Runo( $\mathrm{OH})_{3} \cdot 2 \mathrm{H}_{2} \mathrm{O}$ which is thought to be rather insoluble. Its transport is hypothesized to be as very fine suspended particulates $(<0.7 \mathrm{um})$ at monitoring stations. At the source, mite Oak Dan, rutheniu appears to be predominately in the soluble ohase $(<0.7 \mu)$ and reains largely in solution all the way down the Termessee River for distances greater than 100 miles. At the White Dam only $6 \%$ of the ruthenium is on suspended particulate, downstrean the value fluctuates between 11 and $21 \%$ with the ajority reaining in solution. Surface runoff in water can move 1 arge amounts of suspended radionuclides into thite Oak Lake and the rivers dounstream. L.omenick (1963) found only small amounts $(<15 \%)$ of ruthenium are leached from thite Oak Lake sediments by tap water and dilute acids when the pH is kept above 6.5. Lomenick hypothesized that the waste is a mixture of nitrosylruthenium hydroxide and mononitrate nitrosylruthenium. The hydroxide is believed to be retained by precipitation in the soil wile the nitrato form moves unadsorbed. With time the mononitrato form is slowly converted to the uniobile hydroxide form.

Dey and Pillai (1971) studied the migration of ruthenium from the fuel reprocessing plant at Troebay, India. 
Subsequent to the appearance of radioactivity above background levels in some wells located near the fuel reprocessing plant detailed studies mere undertaken to identify and measure the concentration of radionuclides in the well waters. The measurements indicated that radiorutheniun is the most predominant radionuclide in well waters. Radiorutheniu masurements in sea water, silt, and bottom sediments in the Bombay Harbor Bay indicated low levels in sea water and high concentration in sediments. The radioruthenium in sediments was limited to the discharge locale. Some benthic organisus collected in the bay from areas close to the effluent discharge locations showed high concentration factors for radioruthenium.

6loyma et al. (1966), Gromiec and Gloyma (1973), Reymolds and Gloyna (1963) and Yousef, Kudo and Gloyn (1970) studied the adsorption-desorption of ruthenium in model flumes and field tests. Ruavo and $\mathrm{RuCl}_{3}$ dissolved in waters and injected into fresh water flumes do not become adsorbed to bottom sediments. Upon introducing kaolinite clay suspensions into the water as much as $50 \%$ of the Rumo became associated with suspended sediments wich can ultimately end up in botton deposits.

Jenne and Hahlberg (1968) examined the sediments present in thite Gak Creek, Tennessee, identifying their mineralogy and determining a $\mathrm{Kd}$ for several elements. The $K d$ mas determined by analyzing the radionuclide content of thite Oak Creek water and sediment, and assuming that an equilibrium between the two

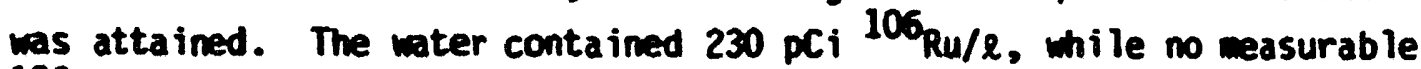
$106_{R u}$ was found in the sediment. It mas concluded that the ${ }^{106_{R u}}$ in thite Oak Creek water was not being adsorbed by the sediment.

Liebscher et al. (1961) studied the fission product contents of rain, spring, tap and surface waters. The residence time of ruthenium is much longer than $\mathrm{Zr}, \mathrm{W}$, and Ce. This as attributed to the ability of ruthenium to form stable soluble anion complexes.

Magno et al. (1970), investigating the radionuclides from the Muclear Fuel Services plant in westem New York that were migrating through the effluent lagconing system, estimated that $70 \%$ of the ${ }^{106}{ }_{\text {Ru }}$ passed through the lagoon system and into nearby surface streans. 
Brow (1967) gave some profiles of $106_{R u}$ at disposal sites. The ${ }^{106} 6_{R u}$ moved at essentially the same velocity as the ground water, with little or no soil adsorption. Radiochemical analyses of the ground water yielded a ruthenium pattern of contamination comarable to the size and shape of the tritiun and technetiun contanination patterns.

Raymond (1964, 1965) investigated the vertical migration and lateral spread of radionuclides beneath three Hanford waste disposal sites by using scintillation logging of nearby monitoring wells over a period of time. Rutheniu traveled at nearly the same velocity as the soil water.

Perkins et al. (1966) and Robertson et al. (1973) studied the speciation of rutheniu emanating from Hanford reactors and within the Columbia River. Downstrean about 50 wi les the rutheniu is observed to be distributed on particulates $(20.3 \mathrm{\mu m})$ suspended in the river and in an apparent non-ionic form. The non-ionic form predominates (60 to 100\%) of the tot.al. In general the percentage of ruthenium on suspended particualtes decriases from the reactor source (32x) to the river wouth (15\%).

In a later study, Robertson and Perkins (1975) measured the speciation of ruthenium on cooling water eanating from $\boldsymbol{N}$ Reactor and in springs fed by the cooling water after percolation through soil. The nixture leaving the reactor is $66 \%$ particulate $(20.3 \mu \mathrm{m}), 16 \%$ cationic, $13 \%$ anionic and $5 \%$ nonionic. At the springs on the bank of the Columia River the distribution is $20.3 \%$ particulate, $23 \%$ cationic, $92 \%$ anionic and $5 \%$ nonionic. More than $90 \%$ of the ruthenium is retained in the soils between the cooling trench and springs.

\section{Sumary}

The fate of rutheniu in the environment is very dependent on the source. Muclear wastes high in nitrates form non-ionic and anionic nitrato complexes wich have been observed to migrate rapidly through soils. Cooling water wastes and tracer experiments with $\mathrm{Ru}$ (III) have shown large $\mathrm{Kd}_{\mathrm{Ru}}$ or a strong tendency to adsorb. Without knowledge of the ruthenium speciation it would be difficult to predict rutheniums aigration potential. Studies by Schell et al. (1980) do not show significant differences in $\mathrm{Kd}_{\mathrm{Ru}}$ with $\mathrm{type}$ of water (fresh versus marine). 


\section{STROA:TIUN}

\section{Matural Sediment and Rock Distribution}

Average strontiu contents of igneous and sedimentary rocks are given in Tables 8.73 and 8.74. Note that the strontiu contents are often high when comared to the trace concentrations of strontiv that may come in contact with then in waste solutions. Vinogradov (1959) reports the average strontiun content of soils as $300 \mathrm{ppm}$. The $300 \mathrm{ppm}$ present as ${ }^{90} \mathrm{Sr}$ in a waste solution would be $12.3 \mathrm{Ci}{ }^{90} \mathrm{Sr} / \mathrm{l}$, for exaple. Limestone and other calciu-rich sediwents and sediventary rocks tend to be the highest in strontiu content due to

jited substitution of strontiun for calciu in calcite. Strontiu carbonate ( ystallizes in an aragonite type structure when present in sufficiently high concentrations.

TABLE 8.73. Average Stront iv Content of Igneous Rocks (Turekian and Vedepchl, 1961) in ppm

\begin{tabular}{|c|c|c|c|c|}
\hline & & \multicolumn{2}{|c|}{ Granitic } & \multirow[b]{2}{*}{ Syenite } \\
\hline Ultrafic & Basaltic & High La & Low Ca & \\
\hline 1.0 & 465 & 4410 & 100 & 200 \\
\hline
\end{tabular}

TABLE 8.74. Average Strontium Content in Sedimentary Rocks and Sediments in ppm

$\frac{\text { Shale }}{300} \frac{\text { Sandstone }}{20} \quad \frac{\text { Limestone }}{610} \frac{\frac{c}{\text { Parbonate }}}{2000} \frac{\text { Clay }}{180}$

Mear Shore Sediments Manganese Modules 250 1000

\section{References}

Turekian and Hedepohl, 1961 Hedepoh 1, 1960

Riley and Senhaseni, 1958

The four naturally-occurring isotopes of strontiv include ${ }^{84} \mathrm{Sr}(0.55 \%)$, ${ }^{86} \mathrm{Sr}(9.75 \%),{ }^{87} \mathrm{Sr}(6.96 \%)$ and ${ }^{88} \mathrm{Sr}(82.74 x)$. The isotope ${ }^{87} \mathrm{Sr}$ can be 
locally variable in abundance because it is a daughter of ${ }^{87} \mathbf{R b}$. The other isotopes of strontium between ${ }^{80} \mathrm{Sr}$ and ${ }^{95} \mathrm{Sr}$ are radioisotopes. Only ${ }^{90} \mathrm{Sr}$ fission product (half-1ife 28.1 years), decaying to 90, , is of sufficiently high yield and long half-life to be of concern in waste disposal operations. The radionuclides ${ }^{88} \mathrm{Sr}$ and ${ }^{89} \mathrm{Sr}$ also are obtained in high yields but the halflives are too short to create a persistent disposal problem. The isotope ${ }^{85} 5_{S r}$ (half-life 64 days) is not a fission product, and is usually not encountered except in laboratory waste solutions.

Strontiv (II) is the only oxidation state to be encountered in environental solutions. According to Ahrens (1952) the ionic radius of $\mathrm{Sr}^{+2}$ is $1.12 \AA$, very close to that of $\mathrm{Ca}^{+2}$ at $0.99 \AA$ and $\mathrm{Ba}^{+2}$ at $1.34 \AA$. Strontium tends to follow calcium in weathering and other geocheinical processes with some exceptions. For example, when present in sufficient concentrations, strontium does form a carbonate that is not isostructural with $\mathrm{CaCO}_{3}$. The other win strontiu ore mineral, celestite $\left(\mathrm{SrSO}_{4}\right)$, is isostructural with its calcium counterpart, anhydrite $\left(\mathrm{CaSO}_{4}\right)$. However, limestone or calcite $\left(\mathrm{CaCO}_{3}\right)$ can allow the substitution of several mundred parts per willion strontiu before there is any tendency for strontianite $\left(\mathrm{SrCO}_{3}\right)$ to form. As the linestone recrystallizes, there is a tendency for the strontiv content to decrease.

There is little, if any, tendency for strontiun to form complexes with inorganic ligands. Izrael and Rovinskiii (1970), for example, studied by electrodialysis the chemical state of strontiu leached by ground water from rubble produced in a muclear explosion. They found that $100 \%$ of the strontiu was $\mathrm{Sr}^{+2}$, with no colloidal or anionic strontiun present in the leachate. Solution Equilioria

Strontiv is an alkaline-earth and forms several salts. Thermodymamic data for various strontiu compounds, $\mathrm{SrO}, \mathrm{Sr}(\mathrm{OH})_{2}, \mathrm{SrF}_{2}, \mathrm{SrCl}_{2}, \mathrm{SrCl}_{2} \cdot \mathrm{ZH}_{2} \mathrm{O}$, $-\mathrm{SrCl}_{2} \cdot \mathrm{HH}_{2} \mathrm{O}, \mathrm{SrCl}_{2} \cdot \mathrm{H}_{2} \mathrm{O}, \mathrm{SrHPO}_{4}, \mathrm{Sr}_{3}\left(\mathrm{PO}_{4}\right)_{2}, \mathrm{SrSO} \mathrm{SO}_{4}, \mathrm{Sr}\left(\mathrm{MO}_{3}\right)_{2}, \mathrm{SrCO}_{3}, \mathrm{SrSiO}_{3}$, $\mathrm{SrSiO}_{4}, \mathrm{SrZrO}_{3}$ mere considered in order to determine their stability. Except for $\mathrm{SrSiO}_{3}, \mathrm{SrtPO}_{4}, \mathrm{Sr}_{3}\left(\mathrm{PO}_{4}\right)_{2}, \mathrm{SrCO}_{3}$, and $\mathrm{SrSO}_{4}$, the strontiu solid phases are too soluble to show in Figure 8.35. The thermodynamic data for all of 
these compounds except $\mathrm{Sr}_{3}\left(\mathrm{PO}_{4}\right)_{2}$ were obtained from Parker et al. (1971). The data for $\mathrm{Sr}_{3}\left(\mathrm{PO}_{4}\right)_{2}$ were selected from Sillen and Martell (1964). In an acidic environment, wost of the strontium solids will be highly soluble, and if the activity of $\mathrm{Sr}^{2+}$ in solution exceeds $10^{-4}$ moles/ $\ell, \mathrm{SrSO}_{4}$ can precipitate and would be a stable phase. However, in alkaline conditions, $\mathrm{SrCO}_{3}$ would be the stable phase and the compound that could mintain strontium activity in the aqueous environment.

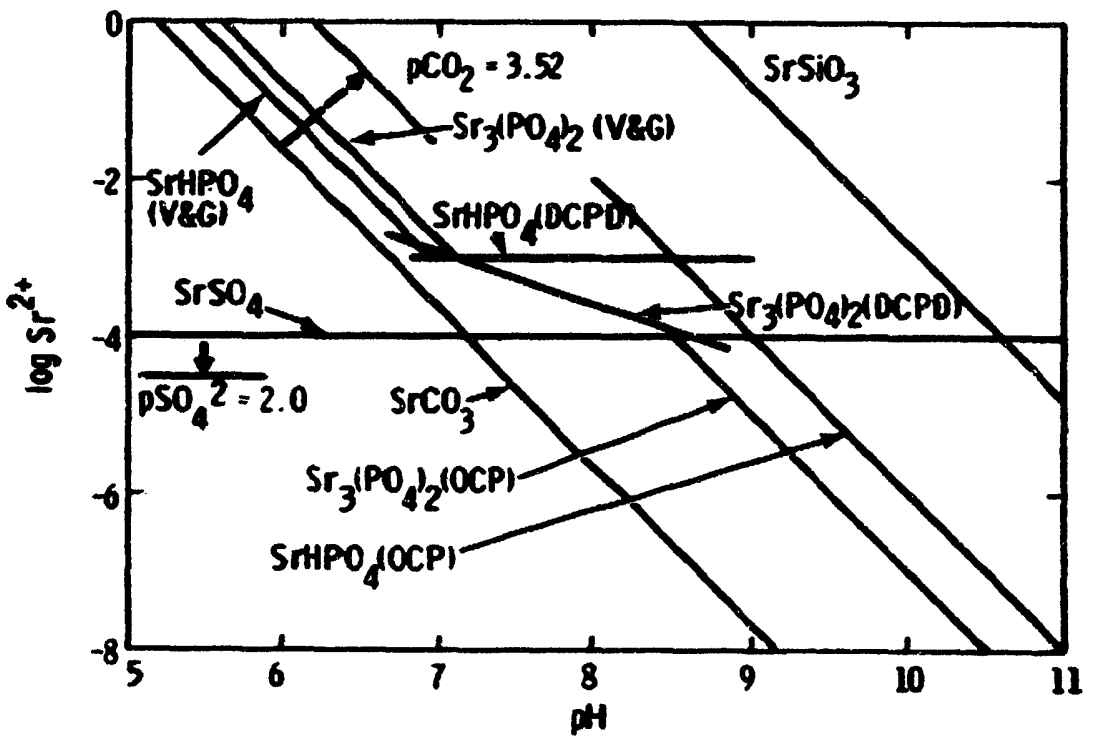

FIGRE 8.35. The Relative Stability of Various Strontium Solids at $\mathrm{PCa}^{2+}$ $=\mathrm{pSO}_{4}=2.5, \mathrm{pH}_{4} \mathrm{SiO}_{4}=3.1$, and $\mathrm{pCO}_{2}(\mathrm{~g})=1.52$ atm in equilíbriun with Variscite and Gibbsite ( $V$ and 6$)$, Dicalcium Phosphate Dihydrate (DCPD) and Octacalcium Phosphate (OCP). Redox potential has little effect on strontium solubilization.

The activity of various solution species in equilibrium with $\mathrm{SrCO}_{3}$ and at anionic activities of $\mathrm{PCl}^{-}=\mathrm{PSO}_{4}^{2-}=2.5, \mathrm{PMO}_{3}^{-}=3.0, \mathrm{pF}^{-}=4.5$, $\mathrm{PH}_{2} \mathrm{PO}_{4}^{-}=5$ and $\mathrm{PCO}_{2}(g)=1.52$ atw are plotted in Figure 8.36. The thermodymaric data for $\mathrm{SrMO}_{3}^{+}$and $\mathrm{SrPO}_{4}^{-}$mere obtained from Sillen and Martell (1564). All the other data mere obtained from Parker et al. (1971). Although strontiun forms complexes with the various anions listed above, the solution complexes do not contribute significantly to the total strontiun activity in 
solution. $\mathrm{Sr}^{2+}$ would be the dominant solution species over the environmental pH range of interest and would be expected to be adsorbed by an ion exchange reaction. Izrael et al. (1970) have indicated that stront iv was lightly to be $100 \%$ cationic and that the principai reaction with soils, sediments and rocks is ion exchange.

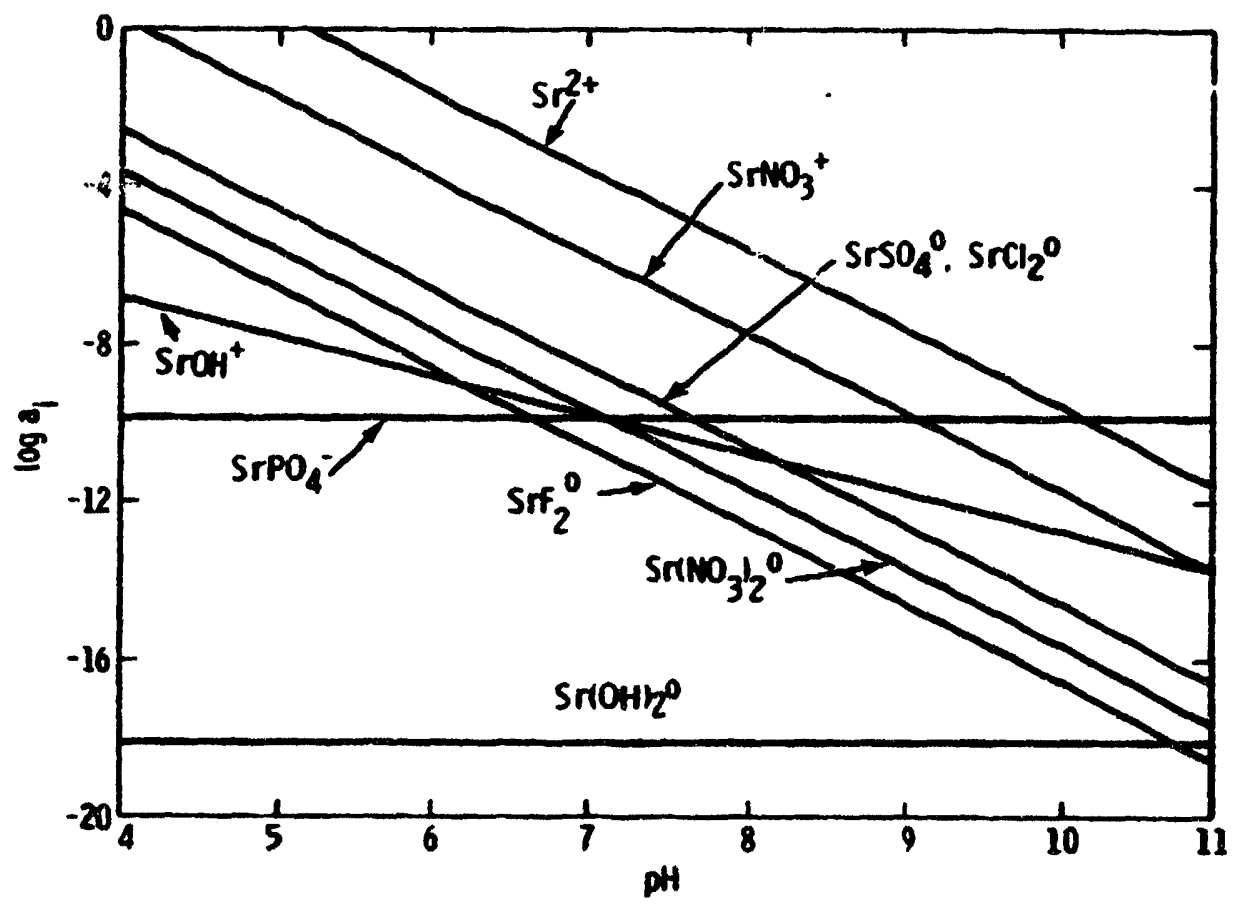

FIERE 8.36. The Activities of Various Strontiu Species in Equilibriu with $\mathrm{SrCO}_{3}(\mathrm{~s})$ in the $\mathrm{SOil}$ at $\mathrm{pCl}=\mathrm{pSO}_{4}^{-}=2.5, \mathrm{PNO}_{3}=$ 3.0, $\mathrm{pf}-=4.5, \mathrm{pCO}_{2}(g)=1.52$ atw and $\mathrm{pH}_{2} \mathrm{PO}_{4}=5.0$

\section{Laboratory Adsorption Studies}

Baker et al. (1964) determined the distribution coefficients for carrierfree strontiu on 17 saples of earth materials collected during July 1961 in the vicinity of Cape Thomson, nortmestern Alaska. High percentage uptake was measured under the test conditions. Strontiv adsorption was found to be a function of the calcium-plus-magnesium concentration and to be independent of the sodiu concentration. In most saples, its equilibrium was reached in less than 1 day. 
Baranov and Polikarpov $(1966,1968)$ studied sorption-desorption of ${ }^{90} \mathrm{Sr}$ in sea water-Black Sea sediments. Among the sediments studied, a large adsorptivity for Sr-90, Zr-95, Ru-106, Cs-137 and Ce-144 was exhibited by shallowwater silts (aleuritic silt with ussel biocoenosis and phaseoline silt). Despite differing mechanical and chemical properties, these silts have similar affinity coefficients for each isotope, an effect for wich the size fraction of particles of less than 90 was responsible. Phaseoline silt and aleuritic silt with mussel biocoenos is most effectively adsorb $Y-91,2 r-95, C s-137$, and Ce-144. Their affinity coefficients for Sr-90 and RU-106 were low.

Collet et al. (1968) determined the distribution coefficient between river silt and river water (the ratio of the absorbed mass of the element studied per gram silt to the concentration of the same element in the water in equilibrium with the silt) in the laboratory for the elements Ce, Cs, I, P, Ru, and Sr. Altogether 756 individual samples were processed. These samples were separated wy a centrifuge method into the three fractions; sand, clay, and organic material; in order to obtain conclusions on the effect of the individual constituents of the silt. The methods were outlined, the resuits were reported, and the fixation capacities found were related to the activity of the individual fallout muclides present in the silt.

Duursma and co-workers [Duursma and Bosch (1970), Duursma (1972), Duursma, Parsi, Stathan (1974), Duursma and Gross (1971), Duursma and Eisma (1973) and Dawson and Duursin (1974)] have performed and collected data on strontium sorption in marine environments. Strontium was usually the least adsorbed nuclide studied in their experiment with a $\mathrm{Kd} \sim 100 \mathrm{ml} / \mathrm{g}$. The adsorption of $\mathrm{Sr}$ on various size fractions of marine sediments is unclear. In one instance all the sorpti in occurred on particles $<4 / \mu$ in diameter. For a secund sediment the adsorption occurred randomily over 5 particle ranges between 64 and $<4$ in. One experiment with a Black Sea sediment showed a 40 -fold increase in $\mathrm{Kd}$ under anoxic conditions than oxygenated conditions. From thermodynamic considerations these resuits would not be expected. They do not observe high correlation between $\mathrm{Kd} S \mathrm{Sr}$ and sediment cation exchange capacity nor with calcium carbonate content. Duursma hypothesized that tracer Sr adsorption is 
controlled by isotopic exchange with stable Sr. Table 8.75 shows average $\mathrm{Kd}_{\mathrm{Sr}}$ and $\mathrm{t}-1 / 2$ of sorption for major oceans and seas.

TABLE 8.75. $\mathrm{Kd}_{\mathrm{Sr}}$ and $\mathrm{t}-1 / 2$ Values

\begin{tabular}{|c|c|c|c|}
\hline Sediment & $\log K$ (unitless) & est. $\mathrm{Kd}=1 / \mathrm{g}$ & $\mathrm{t}-1 / 2$ (days) \\
\hline At lantic Ocean & $2.28 \pm 0.74$ & 290 & $1.8 \pm 1.6$ \\
\hline Pacific Ocean & $2.59 \pm 0.85$ & 580 & $2.5 \pm 2.0$ \\
\hline Indian Ocean & $2.49 \pm 0.82$ & 465 & $0.8 \pm 0.2$ \\
\hline Baltic Sea & $2.37 \pm 1.01$ & 350 & $0.4^{-}$ \\
\hline North Sea & $2.54 \pm 0.76$ & 520 & 3.0 \\
\hline Mediterranean Sea & $2.54 \pm 1.00$ & 520 & $3.8 \pm 1.7$ \\
\hline Black Sea & $2.54 \pm 0.65$ & 520 & 5.0 \\
\hline Red Sea & 2.11 & 190 & 6.0 \\
\hline
\end{tabular}

In leaching experiments of Sr contaminated Mediterranean sediments in (pH 5.4) $\mathrm{HH}_{4}$-acetate and in (pH 2.3) acetic acid both removed $100 \%$ of adsorbed strontium.

Gardner and Skulbert (1964) studied the adsuiption of strontium on a postglacial marine clay from a Morwegian River using low ionic strength p4 6.7 to 7.6 river water. The sediments mere dried and crushed after treatment with hydrogen peroxide. Strontium chloride tracer was added to river water and distilled water and mixed with the dried sediments at various concentrations. The $\mathrm{Kd}_{\mathrm{Sr}}$ after $24 \mathrm{hr}$ contact was dependent on suspended sediment concentration as follows:

\begin{tabular}{|c|c|c|}
\hline Clay Concentration & $\begin{array}{c}\text { Distijiled Water } \\
\mathrm{Kd}\end{array}$ & $\begin{array}{c}\text { River Water } \\
\mathbf{K d}\end{array}$ \\
\hline ppm & $m 1 / g$ & mI/g \\
\hline 16 & 1600 & 950 \\
\hline 32 & 1500 & 800 \\
\hline 64 & 1030 & 800 \\
\hline 128 & 820 & 725 \\
\hline 256 & 660 & 660 \\
\hline
\end{tabular}


At 64 ppo sediment a steady-state adsorption was reached after 40 min; thus, it is doubtful kinetic effects are the cause of the varying $\mathrm{Kd}$.

Ganapathy et al. (1968) studied Sr uptake from seawater by Bombay, India, sediments. The Kd was very small, and they feel the major portions of reactorreleased ${ }^{90_{S r}}$ introduced into coastal waters and the ocean will likely remain in the aqueous phase.

Gawad et al. (1977) report on sorption experiments of Sr using Ismailia Canal (Egypt) sediments. The mass of $\mathrm{Sr} / \mathrm{g}$ on sediment adsorbed was found to ncrease as the particle size distribution of the sediments decreased. For coarse particle sizes $>5$ um changing the pH of the system from 5 to 9 caused little change in sorption. For fines, hand clay ( $<5 \mu$ ) there was an observable increase in sorption as $\mathrm{pH}$ increased. If competing ions $\mathrm{Na}, \mathrm{Mg}, \mathrm{Ca}$ were added to the water $\mathrm{Sr}$ adsorption decreased with the effect being $\mathrm{Ca}>\mathrm{Mg}>\mathrm{Ma}$. Below a $\mathrm{Sr}$ concentration of $10^{-4} \mathrm{M}$, exchange ( $10 \mathrm{~g} \mathrm{Kd}$ versus $\log \mathrm{Sr}$ solution) was linear. Adsorbed strontium was quantitatively removed from sediments by $0.1 \mathrm{~N} \mathrm{CaCl}_{2}$ or $0.1 \mathrm{~N} \mathrm{\textrm {SrCl } _ { 2 }}$ solution after 6 days.

Jenne and Wahlberg (1968) studied whiteoak Creek, TN, seciments in the field and laboratory and found ${ }^{90}$ Sr released from 0ak Ridge Mational Laboratory was controlled by in situ precipitation of carbonates.

Juguet et al. (1966) studied the fixation capacity of muds from various French rivers. Sr sorption was between Ce (totally fixed) and I (slightly fixed).

Kawabata (1967) examined factors affecting the sorption of various radionuclides by a river sediment sample in the fresh or saline water; in adcition, release of radionuclides in the sediments when it was exposed to the sea water was studied. Hater and sediment samples were collected at several places along the Sagami. Uptakes of radionuclides by the sediments were much affected by various competing cations, and the rate of inhibition depends not only on the cationic species but also concentration of cations. The higher the concentration of a competing cation, the more inhibitive to the uptake of radionuclides by river sediments. Release of radionuclides which had been sorbed by the river sediments in the filtered sea water was examined during 12 days storage. 
The release of ${ }^{90} \mathrm{Sr}$, increased for the first 2 days, then gradually decreased, wich wight be due to the re-absorption of the nuclide by sediments in the sea water. In river envirorments $\mathrm{Kd}_{\mathrm{Sr}}$ was $1000 \mathrm{ml} / \mathrm{g}$ wile in estuarine conditions the Kd dropped to 400 .

Meeusen et al. (1975) studied the sorption capacity of Scheldt sediments for $\mathrm{CO}^{2+}, \mathrm{Sr}^{2+}$ and $\mathrm{Cs}^{+}$and the ir distribution coefficients between sediment and Scheldt water. It was found that clay and silt samples show relatively high sorption capacities for ccbalt and cesium, compared with the low fixation rate for strontilim.

The selectivity of the sediments for a particular ion, in competition with other ions, was studied and the sequence found was in accordance with the distribution coefficients. From these experiments it may be concluded that the high salt concentrations, present in normal Scheldt water, will limit the risks of radioactive isotopes accumulation in the sediments.

Magaya and Saiki (1967) and Nakamura and Magaya (1975) collected 19 sanples of sediment from Tokyo Bay and coastal water along Fukush ima Prefecture. The HCl-extraction efficiencies of radionuclides in sediment mere examined. Recoveries of more than $80 \%$ mere obtained for ${ }^{144} \mathrm{Ce},{ }^{106} \mathrm{Ru}$, and ${ }^{137} \mathrm{Cs}$ in fine and collected in Tokyo Bay. The sampling device was designed to collect a large abount of sediment of the surface layer of $2 \mathrm{~cm}$ thickness. ${ }^{90} \mathrm{Sr},{ }^{137} \mathrm{Cs}$, and ${ }^{144} \mathrm{Ce}$ concentrations in fine mod were remarkably higher than those in sandy mud or sand. It was clearly observed that ratios of ${ }^{144} \mathrm{Ce} /{ }^{90} \mathrm{Sr}$ and ${ }^{137} \mathrm{Cs} /{ }^{90} \mathrm{Sr}$ in coastal sediments were substantially higher than those in sea water. Cerium-144 and ${ }^{137}$ Cs were found to be accumulated more effectively in the surface mud on the bottom of the sea, in comparison with ${ }^{90} \mathrm{Sr}$.

The concentrations of fission products ${ }^{90} \mathrm{Sr},{ }^{137} \mathrm{Cs}$ and ${ }^{144} \mathrm{Ce}$ in the marine sediment of Tokyo Bay and of the coastal seas of Ibaraki, Fukushima and Fukui prefectures mere deltermined during 1966 to 1972. The radioactivity ranged 0 to $23.3 \mathrm{pCi} / \mathrm{kg}$-dry for ${ }^{90} \mathrm{Sr}, 5.3$ to $220 \mathrm{pCi} / \mathrm{kg}$-dry for ${ }^{137} \mathrm{Cs}$, and 0 to $12.700 \mathrm{pCi} / \mathrm{kg}$-dry for ${ }^{144} \mathrm{Ce}$. Generally speaking, the ${ }^{90} \mathrm{Sr}$ level is one order of magnitude lower than that of ${ }^{137} \mathrm{Cs}$, and ${ }^{144} \mathrm{Ce}$, concentration is higher than that of ${ }^{90} \mathrm{Sr}$ by almost two orders of magnitude. The degree of the 
radionuclide enrichment in the sediment from sea water is tens for ${ }^{90} \mathrm{Sr}$, $10^{2}$ for ${ }^{137} \mathrm{Cs}$ and apparently horizontal distribution of ${ }^{144} \mathrm{Ce}$ concentration in the sedinent of the areas, but the ${ }^{137}$ Cs concentration shows fairly small horizontal fluctuation.

0 jima et al. (1965) studied the physicochemical behavior of ${ }^{89} \mathrm{Sr},{ }^{90} \mathrm{Sr}$, ${ }^{137} \mathrm{Cs}$, and ${ }^{60} \mathrm{Co}$ ions in relation to $\mathrm{pH}$ of marine water, trace elements dissolved in it, fragments of marine organisus living in it, and sea sediments.

Orlova (1965) found the distribution of ${ }^{90} \mathrm{Sr}$ in a water-bearing stratum is determined to a great extent by the salt content of ground waters. The main cations that may influence the migration of ${ }^{90} \mathrm{Sr}$ are natural strontium, calcium, manganese, and sodium. Investigations, carried out under both static and kinetic conditions, showed that the natural cations in natural water may be class if ied according to their capacity for decreasing the sorption of ${ }^{90} \mathrm{Sr}$ by minerals in the following order: $\mathrm{Sr}^{2+}>\mathrm{Ca}^{2+}>\mathrm{Mg}^{2+}>\mathrm{Ma}^{+}$. The presence in the water of the most common anions $\left(\mathrm{Cl}^{-}, \mathrm{NO}_{3}^{-}, \mathrm{SO}_{4}^{2-}\right)$ had practically no effect on the sorption of ${ }^{90} \mathrm{Sr}$ by the sand. On the other hand, the anions $\left(\mathrm{PO}_{4}^{3-}, \mathrm{CO}_{3}^{2-}\right)$ with which stront ium and calcium form meak $7 y$ soluble compounds increased the sorption of ${ }^{90} \mathrm{Sr}$ by sand and this tended to reduce the migration capacity of the isotope in the water-bearing stratum.

Pus̀chmann (1970) examined fine-grained sediments from the Weser, Donau, and Elbe Rivers for their sorption behavior in respect to ${ }^{85} \mathrm{Sr},{ }^{137} \mathrm{Cs}$, and 131 I. The experiments with closed systems give the course of the sorption and the possible sorption rate after the equilibrium has been established. The sorption rates are converted to grams of the element used per $m^{3}$ sand as used in the laboratory experiment. The results are compared with the sorption rates dealt with by Heisflog (1968), wich mere made with low-terrace sediments from the Rhine River.

Schell et al. (1980) report on laboratory determinations of $\mathrm{Kd}_{\mathrm{Sr}}$ in numerous fresh and marine water environments with sediments. Table 8.11 summarizes the results. The $\mathrm{Kd}_{\mathrm{Sr}}$ for fresh waters is considerably larger than values for seawater wich suggests that ion exchange processes control Sr sorption. Of all elements studied by Schell et al., Sr shows the least affinity for sorption. 
In a dialysis experiment using Lake Michigan sediment and water, $\mathrm{Sr}$ remains predominantly $97 \%$ in the soluble phase in compartments contacting sediment, plankton or organic detritus.

Schneider and Block (1968) and Schneider (1970) performed laboratory experiments on Rhine River sediments and pure minerals. Nuclide sorbability increases in the following order: $I^{-}, \operatorname{Sr}(I I), P U(I V), \operatorname{In}(I I), \operatorname{Cs}(I)$. Saturation was reached by sediments after 24 hours at the latest for all nuclides. The sediment samples were taken from Dehningen (Upper Rhine), Koblenz (Middle Rhine), and Wesel (Lower Rhine). Data were compared with the organic content for each sample. The sorption of ${ }^{137}$ Cs is dependent on grain size but not on organic material. A sudden release by living or dead organic material of radionuclides is not possible, though desorption from mineral suspended material is more rapid, often occurring within a few hours. Less than 1X of transported muclides in the Rhine under any conceivable conditions would be bound to suspended material or sediments.

The sorptive properties of artificial mono-mineralic fine sands of uniform grain size is investigated. Montmorillonite, kaolinite, muscovite, and biotite have a high sorptive power. The sorptive power of quartz oxides and magnet ite and of microcline and albite is low. Hornhlende and augite occupy a medium position. The highest affinity for the minerals show the cations ${ }^{137} \mathrm{Cs},{ }^{90} \mathrm{Sr}$, and ${ }^{65} \mathrm{Zn}$. Phosphorus-32, as complex phosphate anion, is less highly absorbed. The sorption of ${ }^{131}$ I is negligible.

Rhodes (1957) showed the effect of system pH on the adsorption of strontium from a distilled water solution by a fluviatile Hanford soil. A soil paste pH was 8.6, and the calcite content was 2 wt\%. The clay fraction of less than 2 um was 2 wt\%, and consisted of primarily montmorillonite, with some mica and chlorite. The system was $\mathrm{pH}$ adjusted with $\mathrm{NaOH}$ or $\mathrm{HCl}$. The strontium $\mathrm{Kd}$ rose from $5 \mathrm{ml} / \mathrm{g}$ at $\mathrm{pH} 6$ to $30 \mathrm{ml} / \mathrm{g}$ at 8 , and $120 \mathrm{ml} / \mathrm{g}$ at $\mathrm{pH} \mathrm{10.} \mathrm{Above} \mathrm{pH} \mathrm{10,}$ the sodium added in the $\mathrm{NaOH}$ used for pit adjustment began to compete for exchange sites with the strontium, and strontium adsorption began to level off. In $4 \mathrm{M} \mathrm{NaNO}_{3}$, strontium adsorption was much less affected br pH. At pH 8, for example, strontium $\mathrm{Kd}$ was about $5 \mathrm{ml} / \mathrm{g}$ and rose to about $10 \mathrm{ml} / \mathrm{g}$ at $\mathrm{pH} 10$. 
Prout (1958, 1959) showed the effects of $\mathrm{PH}$ and strontium concentration on strontium adsorption by Savannah River soil. This soil was $80 x$ sand and $20 \%$ clay, chiefly kaolinite. The results were very similar to those of Rhodes (1957) in that a maximum was much higher (Kd $=700$ to $800 \mathrm{mi} / \mathrm{g}$ ). The effects of competing cations including several sodiu nitrate concentrations were also given. The $30 \% \mathrm{NaNO}_{3}$ solution is about the same as Rhodes (1957) $4 \mathrm{M} \mathrm{MaNO}$ solution, and the results also are comparable in strontium distribution coefficients. The amount of competing sodium is apparently so high that the soi: differences are of lesser importance.

Spitsyn and Gromov (1958) showed that the adsorption of strontium by montmorillonite was an ion excinange process. Various competing cations were added to the strontium-clay system and the strontium distribution coefficient redetermined. These authors aiso added small amounts of anions such as $\mathrm{ro}_{3}$ and $\mathrm{C}_{2} \mathrm{O}_{4}^{2}$ that were said to form radiocolloids with strontium. They believed the enhanced removal of strontium reported by McHenry (1955), when $3 \times 10^{-5}$ to $3 \times 10^{-4} \mathrm{MPO}_{4}$ was added to wastes contacting calcareous soils, could be attributed to the formation of precipitates as a result of the ratural calcium on soil exchange sites reacting with the added phosphate ions. This may be true at some phosphate concentrations, but later study also demonstrated a replacement reaction (Ames, 1959) where calcite reacted with the phosphate to form an apatite.

Baker and Beetem (1961) studied the distribution coefficients for carrierfree strontium on an Alaskan wind-blown silt with various concentrations of competing cations wich were to be expected at the site. One or two of the Kd values excesd the experimental 1 imits by large amounts, but the remaining values conform to a straight line plot of strontium $\mathrm{Kd}$ versus the inverse sum of the competing calcium and magnesium concentration as required by ion exchange theory (Kaufman, 1963).

Cohen and Gailledreau (1961) investigated strontium adsorption on Saclay soil consisting of $45 \%$ montmorillonite, $45 \%$ kaolinite and $10 \%$ illite. The cation exchange capacity was $210 \mathrm{meg} / 100 \mathrm{~g}$. Graphs were presented of trace strontium-macrocalcium, trace strontium-macrosodium and trace strontiummacropotassium systems. Some work was performed on three-component ion 
exchange systems. It was shown that the $K d$ values plotted versus the strontium concentration for the abo:e Saclay soil yielded a straight line on log scales as required by ion exchange theory.

Kokotov et al. (i2 561,1962$)$ gave Kd values for strontium on six Russian soil types as a function of $\mathrm{pH}$. The replacement series $\mathrm{Sr}>\mathrm{Cs}>\mathrm{Mg}>\mathrm{K} \geq$ $\mathrm{NH}_{4}>\mathrm{Ma}$ was given for strontium competing cation efficiency.

Carlile and Hajek (1967) reported an example of physical transport of strontium. About $0.1 \%$ of the ${ }^{85} \mathrm{Sr}$ was found in the first effluent from $N$-Area soil columns ( $2 \mathrm{~cm}$ diameter by $40 \mathrm{~cm}$ in length). Up to 18 random leakage of strontium was reported until 5 column volumes of Columbia River water had passed through the soil. Then leakage fell to below detection limits $\left(10^{-3} \mathrm{x}\right)$. Columbia Kiver water has an annual mean pH of about 7.8 , a mean $\mathrm{CaCO}_{3}$ hardness of $69 \mathrm{mg} / \mathrm{l}$ and a mean total dissolved solids of $119 \mathrm{mg} / \mathrm{l}$. Effluent samples were centrifuged at high speeds, treated with $\mathrm{H}_{2} \mathrm{O}_{2}$ to destroy organic material and recentrifuged. Fifty to $75 \%$ of the activity in the leaked effluent was removed. Hydrogen peroxide treatment did not affect removal of strontium by centrifugation, indicating that an organic material was not involved. Leaching a soil system with low ionic strength river water containing trace radionuclides had the result of dispersing the soil colloids on wich auch of the ${ }^{85} \mathrm{Sr}$ were adsorbed. Column breakthrough was inmediate until the dispersed colloids were flushed from the column. Preceding the contaminated river water by a preleach of noncontaminated river water flushed the dispersed colloids and prepared the soil for use. Adding other ions to the system could have accomplished the same thing, but would have competed with adsorption of strontium. Several investigators have studied the interactions of strontium and organic matter. Bovard et al. (1968) found low complexing tendency for $S r$ with humic and fulvic acids. The complexing order for humic acids was $\mathrm{Ce}>\mathrm{Fe}>\mathrm{In}_{\mathrm{n}}>\mathrm{Co} \geq \mathrm{Ru} \geq \mathrm{Sr}>\mathrm{Cs}$. Dunigan and Francis (1972) also found the humic acid-strontiu interaction to be weak. Essington and Nishita (1966) and Mishita and Essington (i;67) studied the ability of distilled water, irrigation water and the chelating agents (EOTA, OTPA, EODHA) to leach Sr from soils. Chelating agents did not improve the leaching of $\mathrm{Sr}$ sorbed to soil over the waters suggesting little organic interaction. 
Four soils varying greatly in organic matter content, cation exchange capacity and texture were studied by Juo and Barber (1970) for their strontium retention characteristics. The adsorption of strontium by soils increased with increasing pH within the pH range 4 to 8. Saturating cations had some effect on strontium adsorption, with influence in the order $\mathrm{Na}>\mathrm{K}>\mathrm{Mg}>\mathrm{Ca}>$ $\mathrm{Ba}>\mathrm{H}$. As the $\mathrm{pH}$ increased, an increasing fraction of the adsorbed strnntium became nonexchangeable with ammonium acetate. The nonexchangeable portion of the strontiue is probably tied up by soil organics and is permanently fixed under favorable pH conditions. In a higher pH environment, a larger porticn of the strontium in solution was present as soluble strontium chelates or complexes.

Chelation and movement of strontium in a calcareous soil were evaluated in colums of Mohave sandy loam soil [L'Annunziata and Fuller (1968) and Fuller and L'Annunziata (1969)]. The displacement of ${ }^{89} \mathrm{Sr}$ from the soil colums was 19,38, 44, 47, and $81 \%$ in the order HEEDTA < DCyTA < EDTA < EGTA $\leq$ DTPA. Only $5 \%$ of the ${ }^{89}$ Sr was removed from the soil with no complexing agents in the leaching solution. The radiostrontium existed in the leachate as a negative complex. Any natural organic chelating agents in the soil did not influence radiostrontiun movenent.

Mortensen and Marcusiu (1963) incubated a silty clay loam with $40 \mu \mathrm{Ci}$ ${ }^{90} \mathrm{Sr}$ for 60 days and obtained hot water extractions or hydrolyzed with 6W HCl. The supernatant liquid was electrodialyzed with ${ }^{90} \mathrm{Sr}$ migrating to the anode compartment suggesting negatively charged ${ }^{90}$ Sr-organic matter complexes. Gel filtration showed that ${ }^{90} \mathrm{Sr}$ was complexed or held on exchange sites by high molecular wight polymers. The radioactivity correlated with the presents of polyuronides. Phenols, amino acids and keto acids were separated from the $6 \mathrm{~N} \mathrm{HCl}$ hydrolysate by paper electrophoresis, with no clear correlation between radioactivity and these components.

Mortensen et al. (1963) studied surface organic layers of ten soils for their ability to adsorb strontium. It is apparent that the soils studied, especially those having high exchange capacity and base status, are capable of adsorbing considerable quantities of ${ }^{90} \mathrm{Sr}\left({ }^{90}\right)$. Leaching waters from the 
more acidic soils release strontium more readily into the drainage waters than in the case of less acid soils. The leaching of fallout Sr from acidic organic soils may occur in a relatively short period of time. Fission product ecology in soils of the area is apparently governed largely by pH and cation exchange.

Szalay and Szilagyi (1964) studied the retention of fission products by humic acids present in peat. Strontium is strongly adsorbed by the peat.

\section{Field Studies}

Bowen and others [Bowen (1970), Bowen, Hong and Moshk in (1971), Bowen et al. (1974), Noshkin (1972), Moshk in and Bowen (1973) and Volchok et al. (1971)] have deterwined the concentrations of fallout ${ }^{90} \mathrm{Sr}$ in ocean sediments and wers. There exist on nonuniformity in surface water ${ }^{{ }^{0}}{ }_{S r}$ concentrations wich are not understood. Depth profiles down to $700 \mathrm{~m}$ in the Atlantic and Pacific show regular decreases. Typical surface concentrations range from 0.1 to $1.5 \mathrm{pCi} / e^{90} \mathrm{Sr}$. By 1970 only $1 \%$ of the total ${ }^{90} \mathrm{Sr}$ delivered to the ocean surface by fallout was adsorbed by bottow sediments using the residence-time concept, ${ }^{90} \mathrm{Sr}$ residence time is about $1 \times 10^{3}$ years, wich is at least an order of magnitude less than calculations on stable $\mathrm{Sr}$ in land runoff. A possible mechanism, settling of suspended particulates, needs further study.

Brungs $(1963,1964)$ studied the fate of ${ }^{85} \mathrm{Sr}$ in a 30,000 -gal experimental pond with sand substrate, and containing experimental biota. The conditions were comparable to those in an accidental release of radionuclides to an impoundment. Sampling from the pond continued for 80 days. The quantities of radionuclides were determined with a gama-scintillation spectrometer. Supplemental chemical and biological information on the artificial pond and an adjacent control pond provided a measure of the differences between these two environments.

Of the four radioelements studied, $\mathrm{Sr}, \mathrm{Co}, \mathrm{Cs}, \mathrm{Zn}$, more $\mathrm{Sr}$ remined in solution (23\% versus $<1 \%$ ) after 80 days. The mass balance of $\mathrm{Sr}$ after 80 days was dissolved 23\%, adsorbed in sediment $76.5 \%$, incorporated into tiota $0.40 \%$ and on suspended solids $0.1 \%$. A field Kd for the bottom sediment of 17 to 
$25 \mathrm{ml} / \mathrm{g}$ and for suspended solids $270 \mathrm{ml} / \mathrm{g}$ can be calcuiated from Brung's data. The chemical composition of the pond water was in $\mathrm{mg} / \mathrm{l}: \mathrm{Ca}(24), \mathrm{Hg}(? 2)$, $\mathrm{Fe}(0.12), \mathrm{Mn}(0.06), \mathrm{SO}_{4}(31), \mathrm{Cl}(8)$ and total hardness $(150)$.

Cerrai et al. $(1965,1967,1970)$ measured in fallout conce.stration of ${ }^{90} \mathrm{Sr}$ in marine sediments and performed some laboratory sorption experiments (1969). The ${ }^{90} \mathrm{Sr}$ content of dried sediment decreased with depth from 0.04 to $0.002 \mathrm{pCi} / \mathrm{g}$ between the surface and $40 \mathrm{~cm}$. There was also no large increase in ${ }^{90} \mathrm{Sr}$ concentration on finer size fractions $<100 \mu \mathrm{m}$ versus $>100 \mu \mathrm{m}$.

Laboratory experiments on Ligurian Sea sediments $(200 \mathrm{mg} / 40 \mathrm{~m})$ traced sea water) were performed for contact times of 1 to 15 hours. At a solids to solution ratio of $100 \mathrm{mg} / 40 \mathrm{ml}$ after 1 hour $K d_{S r}=6.3$, after 15 hours $K_{S r}=$ 11.1 -1/9. Distilied water, macro Sr carrier and Ca sorption experiments proved that the low Yd for Sr was caused by ion exchange competition of alkali and alkaline earth ilts.

Dupont (1965) evaluated $89,90 \mathrm{Sr}$ in water at two locations along the Lower Three Runs Creek, which indirectly receives radioactive material discharged during the operation of the $R$ reactor at Savannah River. These data show that the stream bed acted as an ion exchange system.

Flume, field and laboratory studies of strontium migration have been performed by Gloyna and co-workers at University of Texas. [Clanton (1968), Gloyma et al. (1966, 1971), Gromec and 6loyna (1973), Mahmoud et al. (1968, 1973), Purushothaman (1968, 1971), Purushothaman and Gloyna (1968), Reynolds (1963), Reynolds and 6loyna (1963), Shih and Gloyna (1968), and Yousef et al. (1970).]

In a model flume under riverine conditions a $\mathrm{Kd} \mathrm{Sr}_{\mathrm{S}}$ of 85 was obtained for sediment and $600 \mathrm{ml} / \mathrm{g}$ for rooted plants. Typically Sr uptake by sediments follawed a freunchlich sorption isotherm. When $\mathrm{Sr}$ and $\mathrm{Cs}$ soluble spikes were added simultaneously with suspended clays they found $\mathrm{Sr}$ tended to remain in solution wile Cs became much more rapidly bound to the clay. In other experiwents as the river water mixed with the brackish San Antonio Bay water some of the Sr and Cs were transferred from the sediments and suspensoids to the saline 
water. It was also shown that sediments present in marine waters sorbed less $\mathrm{s} . i^{\circ} \mathrm{c}$. tium and cesium than sediments in fresh water. The distribution of ${ }^{90} \mathrm{Sr}$ and. ajiocesium in the lake sediments was ependent upon the grain size. The smaller the grain size the greater the ra. ,onuclide content. This suggests ion exchange is controlling Sr adsorption in the aqueous environment.

lerman (1971), Lerman and Taniguchi (1971, 1972) and Lerman and Lietzke (1975) have constructed models based on field studies and a few experimental sorption studies wich describe the distribution of natural fallout ${ }^{90} \mathrm{Sr}$. Penetration depth of ${ }^{90} \mathrm{Sr}$ in deep-water sediments of Lake Superior and Lake Ontario was 8 to $10 \mathrm{~cm}$ by 1969 . A detailed picture of the ${ }^{90} \mathrm{Sr}$-containing layer indicates that the main mechanisms of transport from lake water into sediment are diffusion of ${ }^{90} \mathrm{Sr}$ in interstitial water, and uptake of ${ }^{90} \mathrm{Sr}$ by solid phases in sediment. A diffusional transport model, with diffusion coefficient $D=2 \times 10^{-6}-6 \times 10^{-6} \mathrm{~cm}^{2}, \mathrm{sec}^{-1}$ and distribution factor $\mathrm{Kd}=30-30$ in favor of solids, gives ${ }^{90} \mathrm{Sr}$ concentrations in sediment comparable with observed values. Intensity of diffusional flux into sediment increases with greater uptake by solids (larger values of $K$ ). In Lake Ontario, flux into sediment has been removing ${ }^{90} \mathrm{Sr}$ from lake water at the rate of 0.2 to $0.5 \%$ per year, during the period 1954 to 1969. The slowness of flux compared with the rate of ${ }^{90} \mathrm{Sr}$ in lake outflow (12\% per $\mathrm{yr}$ ) accounts for the small amount accumulated in sedinents ( 4 to $6 \%$ of $\mathrm{Sr}$ in lake water) and for the lack of noticeable control of concentrations in lake water by floor sediments. Adsorption of the two tracers by sediment particles, supported by experimental data, can be treated as a linear exchange reaction. ${ }^{90} \mathrm{Sr}$ is adsorbed less strongly than ${ }^{137}$ Cs by sediments, and this feature accounts for the greater depths of ${ }^{90} \mathrm{Sr}$ occurrence in lake sediments.

Montgomery et al. (1977) surveyed the transport of ${ }^{90} \mathrm{Sr}$ from the Maxey Flats, KY, nuclear burial ground through surface and strean water. The principal radionuclides detected in off-site surface mater samples were ${ }^{3} \mathrm{H}$ and ${ }^{90} \mathrm{Sr}$. The highest ${ }^{3} \mathrm{H}$ concentration was $179,000 \mathrm{pCi} / \mathrm{l}$ in water from a wash on the west side of the site, outside the exclusion area (i.e., unrestricted area). This corresponds to $6 \%$ of the maximm permissible concentration (MPC) 
for ${ }^{3} \mathrm{H}$ in water discharged to unrestricted areas. The highest ${ }^{90} \mathrm{Sr}$ concentration was $80 \mathrm{pCi}$ / in the Main East Hash, corresponding to $27 \%$ of the MPC for ${ }^{90} \mathrm{Sr}$ in water. The ${ }^{3} \mathrm{H}$ and ${ }^{90} \mathrm{Sr}$ levels in Rock Lick Creek were lower than in the primary drainage pathways; the highest concentrations were $4700 \mathrm{pCi} / \ell$ and $5.8 \mathrm{pCi} / l$, respectively. The major aqueous patmays for radionuclides moving from the site were the Main East Wash and the wash on the west side of the site. The principal vehicle of transport appeared to be precipitation run-off from the surface of the burial site. Contamination of the site surface could have resulted from a number of sources, including lateral migration through the soil zone from the trenches to the land surface, spills during burial and trench pumping operations, and deposition from the evaporator plume. However, the relative contribution from these sources could not be determined. Deposition of radionuclides from the evaporator plume, especially ${ }^{H} \mathrm{H}$, could be a major source of radioactivity observed in surface water, but additional studies would be necessary to evaluate its significance.

Radionuclides detected in stream bed sediment included ${ }^{54} \mathrm{~mm},{ }^{60} \mathrm{Co},{ }^{90} \mathrm{Sr}$, ${ }^{137} \mathrm{Cs},{ }^{238} \mathrm{Pu}$ and ${ }^{239} \mathrm{Pu}$. The highest concentrations were in samples from the Main East Hash wich is the major drainage pathway for the burial site. The sediment data supported the conclusion, based on surface water measurements, that the transfort of radionuclides from the site surface by suspended solids precipitation run-off was a major source of the radioactivity detected in the drainage pathiays.

Mevissi et a1. (1975), Moshkin et al. (1974, 1975) studied the distribution of ${ }^{90} \mathrm{Sr}$ in the Enewetak and Bikini Atolls after bomb testing. Up to $371 \mathrm{pCi} / \mathrm{g}$ soil of ${ }^{90} \mathrm{Sr}$ are reported for surface soils on Bikini Atoll wile well water samples contained from 0.01 to $19 \mathrm{pCi} / \mathrm{l}$, depending on location. Pacific Ocean waters (unfiltered) contained 0.07 to $0.15 \mathrm{PCi} / \ell$. Unfiltered

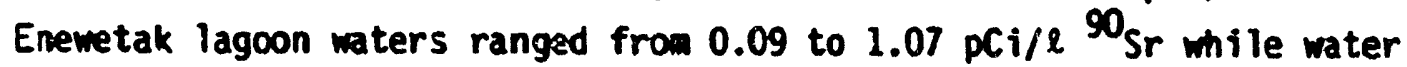
directly in bomb craters ranged from 0.1 to $48 \mathrm{pCi} / \ell$. Filtered $(1 \mu \mathrm{m})$ lagoon and crater water from Bikini Atoll contained 0.3 to $1.7 \mathrm{pCi} / \mathrm{l}{ }^{90} \mathrm{Sr}$. The average concentrations for surface waters are Enewetak 0.3 , Bikini 0.6, and north equatorial Pacific 0.07 pCi/l. 
Ophel, Fraser and Judd (1972) and Ophel (1973) have studiad the cycling of ${ }^{90} \mathrm{Sr}$ in a fresh water lake. The strontium content of bottom secments is strongly correlated with the amount of organic matter they contain. The specific activity of the strontium ( $\mathrm{dpm}{ }^{90} \mathrm{Sr} / \mu \mathrm{g}$ ) appears to be uniform throughout the water and the lake biota, i.e., biological availability of the stable isotope and radioisotope is the same. In the upper $10 \mathrm{~cm}$ of bottom sediments, however, specific activity of the exchangeable strontium and of total strontium is only half that in biota and water indicating incomplete exchange of radionuclide and stable element in this layer even after 15 years of exposure.

Rovinskii (1967) studied the migration of ${ }^{90} \mathrm{Sr}$ in lake waters by determining the content of ${ }^{90} \mathrm{Sr}$, stable $\mathrm{Sr}^{2+}, \mathrm{Na}^{+}, \mathrm{K}^{+}, \mathrm{Mg}^{2+}$, and $\mathrm{Ca}^{2+}$ ions both in waters of 13 lakes and in the lake bed grounds. The migration of ${ }^{90} \mathrm{Sr}$ in stagnant waters is attributed to the ion-exchange reaction between the water and the lake bed ground. The redistribution of ${ }^{90} \mathrm{Sr}$ in the lakes proceeds mainly by ion-exchange reactions with $\mathrm{Ca}^{2+}$. Equations for predicting the level of contamination of lake waters by ${ }^{90} \mathrm{Sr}$ were derived. Comparable results were also obtained under laboratory conditions using synthetic lake water samples.

Ruf (1968) found the artificial radioactivity of frein water in Bavaria differed in the years between 1957 and 1966 within a range of less than $1 \mu \mu \mathrm{Ci} / \ell$ up to $140 \mu \mu \mathrm{Ci} / \ell$. The water activity showed a direct dependence on the activity of rain, and the effects of nuclear power plants. Radioactivity in surface waters was caused by typical fallout products such as: ${ }^{90} \mathrm{Sr},{ }^{89} \mathrm{Sr}$,

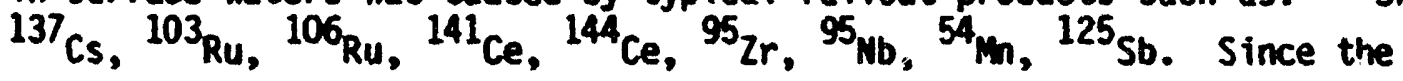
237-mi-KRB-reactor Gundrer...yen reached its full capacity in Novemer 1966, more waste has been passed into the River Oanube. So radioactivity corrosion products ( $\mathrm{Co}, \mathrm{Fe}-, \mathrm{Mr}$ - and $\mathrm{Cr}$-isotopes) of low concentrations could be analyzed besides fission products (especially I-131). Radioactive substances were, to a large extent, concentrated in the sludge of river daws, in consequence of the increased sedimentation of seston particles. In this case the ${ }^{137} \mathrm{Cs}$ and ${ }^{144} \mathrm{Ce}$ activity reached a 12 - to 15,000 fold concentration of the water activit.y. In different fish of the River Isar and Danube a ${ }^{137}$ Cs activity 3,000 times higher than water activity was found. 
Safronova (1974) found a previously proposed diffusion model of the self-purification of natural water as a result of the absorption of ${ }^{90} \mathrm{Sr}$ by the bottom deposits agrees with the experimental data on the kinetics of the change in the concentration of ${ }^{90} \mathrm{Sr}$ in the water of an experimental lake. Together with the diffusion mechanism of self-purification, a factor of selfpurification that can be considered within the framework of the model operates in the lake. Simple computation formulas for the dependence of the concentration of ${ }^{90} \mathrm{Sr}$ in the water on the time were obtained, permitting a long-range prognosis for the experimental lake.

Tritremel et al. (1966) studied the behavior of various radionuclides in surface water by field experiments in the Leitha-Mihl Canal and by complementary experiments in the laboratory. The soundary and profile characteristics of the stream were ascertained and flow rate calculated. Suspensions were examined for size and mineral or organic content in relation to current velocities, and core samples were collected from the bed at selected regions of deposition. Experiments were carried out on dispersion and transport of wastes under varying outlet conditions and the diffusion constant was measured. In the laboratory, sedimentation and uptake experiments were conducted on mineral and organic suspensions in conjunction with nuclides such as ${ }^{90} \mathrm{Sr},{ }^{131} \mathrm{I},{ }^{140} \mathrm{La}$, ${ }^{24} \mathrm{Na}$ and mixed-fission products. Uptake was found to be dependent on mineral species and varied inversely with particle size. Elution experiments were also carried out on accumulated sediments. From chese results it is possible to assess the radioactive content and frequency of batch discharges $f$ effluents that may be released to a river without causing unacceptably high concentrations.

The unitless $K$ sorption of $S r$ versus particle size was:

$\begin{array}{rr}\text { grain size } & K \\ <15 & 500 \\ 30 & 65 \\ 56 & 40 \\ 75 \text { to } 150 & 15 \\ 150 \text { to } 500 & 8\end{array}$


Sorption was complete after 15 minutes whereas desorption of $\mathrm{Sr}$ into c?ean river water contimued longer than 1 hour. Wahlgren and Melson (1973) and Wahlgren and Marshall (1974) measured fallout ${ }^{90} \mathrm{Sr}$ in the water colum of Lake Michigan and bottom sediments during studies on Pu cycling.

Many field studies and a few laboratory studies have been performed to determine the transport of ${ }^{90}$ Sr from Oak Ridge Mational Laboratory disposal grounds to the surface discharges in White Dak Creek, Clinch and Tennessee Rivers.

Duguid (1974a, 1974b, 1975, 1976 and 1977) reports on the groundwater transport of ${ }^{90} \mathrm{Sr}$ from burial ground to white Oak Creek. One to tio curies of ${ }^{90} \mathrm{Sr}$ are leaving the burial trenches with groundwater flow each year.

The $\mathrm{Kd}_{\mathrm{Sr}}$ is very sensitive to $\mathrm{pH}$, leading Duguid to hypothesize sorption by hydrous oxides is important. Contaminated groundwaters with ${ }^{90} \mathrm{Sr}$ concentrations as high as $6.4 \mathrm{pCi} / \mathrm{ml}$ have been recorded. Soils with ${ }^{90} \mathrm{Sr}$ concentrations as high as $810 \mathrm{pCi} / \mathrm{g}$ yield an estimate field $\mathrm{Kd}_{\mathrm{Sr}}$ of 100 to $150 \mathrm{ml} / \mathrm{g}$.

Carrigan (1968, 1969), Carrigan et al. (1967), Morton (1961), Nelson et a1. (1961), Pickering (1969, 1970) and Pickering et al. (1965, 1966) report on the fate of ${ }^{90} \mathrm{Sr}$ once it reaches thite Oak Creek, Clinch and Temressee Rivers. Most all $>99 \%$ of the Sr entering the Clinch River remain soluble and are washed from the area. The sediments contain on the average 1.6 to $3.0 \mathrm{pCi} / \mathrm{g}$ of ${ }^{90} \mathrm{Sr}$. Less than $5 \%$ of the ${ }^{90} \mathrm{Sr}$ in water samples resides on suspended atter. Bottom sediment and standard clay sorption experiments show the $\mathrm{Kd}_{\mathrm{Sr}}$ to be a function of $\mathrm{pH}$ and contact time. The Clinch River sediment contained $60 \%$ illite, $15 \%$ kalinite, 10 to $15 \%$ vermiculite, and 10 to $15 \%$ quartz.

After 7 days the $\mathrm{Kd} \mathrm{Sr}_{\mathrm{f}}$ for the river sediment appears higher than one would expect assuming additive portions based on the mineral distributions. Sorathesn et al. (1960) obtained some strontium distribution coefficients on Clinch River sediments that were in the ten thousands, much higher than for standard clays equilibrated with the same solution. The difference was thought to be due to the organic material in the river sediment. 
Studies of the specific activity $i-1$. 1 ams shows that ${ }^{90} \mathrm{Sr}$ released to a surface water stream moves downstream in solution and there is little or no ionic exchange between the strontium in solution and that in the bottom sediments.

\section{Average Kd of Strontiva- 85 Sorbed by Clays}

\begin{tabular}{|c|c|c|c|c|}
\hline Material & $\begin{array}{l}\text { Contact } \\
\text { Time }\end{array}$ & $\frac{\text { Average }}{\text { pH } 6}$ & $\frac{\mathrm{Kd}}{\mathrm{pH} g}$ & $\begin{array}{c}\text { Ratio of Clay } \\
\text { to } \\
\text { Master Solution }\end{array}$ \\
\hline \multirow{3}{*}{ Illite } & $1 \mathrm{hr}$ & 310 & 320 & \multirow{3}{*}{$0.1 \mathrm{~g} / 100 \mathrm{~m}$} \\
\hline & 3 days & 360 & 700 & \\
\hline & 7 days & 370 & 760 & \\
\hline \multirow{3}{*}{ Kaolinite } & $1 \mathrm{hr}$ & 3400 & 5000 & \multirow{3}{*}{$0.1 \mathrm{~g} / 200 \mathrm{ml}$} \\
\hline & 3 days & 4200 & 4400 & \\
\hline & 7 days & 4000 & 3900 & \\
\hline \multirow{3}{*}{ Montmorillonite } & $1 \mathrm{hr}$ & 2400 & 2600 & \multirow{3}{*}{$0.1 \mathrm{~g} / 100 \mathrm{~m}$} \\
\hline & 3 days & 4200 & 4400 & \\
\hline & 7 days & 2100 & 2200 & \\
\hline \multirow{3}{*}{ Vermiculite } & $1 \mathrm{hr}$ & 170 & 100 & \multirow{3}{*}{$1 \mathrm{~g} / 50 \mathrm{al}$} \\
\hline & 2 days & 1600 & 1400 & \\
\hline & 8 days & 1800 & 3900 & \\
\hline \multirow{3}{*}{ River Sediment } & $1 \mathrm{hr}$ & 540 & 660 & \multirow{3}{*}{$0.1 \mathrm{~g} / 200 \mathrm{ml}$} \\
\hline & 3 days & 1700 & 3500 & \\
\hline & 7 days & 1400 & 4000 & \\
\hline
\end{tabular}

Contaninated bottom sediments release $11 \%$ of the ${ }^{90} \mathrm{Sr}$ when $\mathrm{sog}$ (dry) are contacted with $400 \mathrm{ml}$ of solution for 24 hours. If the water is acidified to $\mathrm{PH} 280$ to $90 \%$ of the $\mathrm{Sr}$ is released. Salt solutions $(0.1$ to $1 \mathrm{M})$ of $\mathrm{Ca}$, $\mathrm{K}$, Ma chloride also remove 40 to $70 \%$ of the absorbed ${ }^{90} \mathrm{Sr}$. Calcium is most effect ive followed by $K$ then $\mathrm{Na}$. 
The migration of ${ }^{90} \mathrm{Sr}$ as seepage from Oak Ridge burial pits was investi gated by Lomenick et al. (1967). They reported that most of the strontius in the side walls and bottom of the pit in Conasauga shaie was tied up in the precipitated calcite (calcium carbonate). Water moved $0.15 \mathrm{~m} /$ day while the ${ }^{90}$ Sr moved $0.24 \mathrm{~m} / \mathrm{yr}$.

Magno et al. (1970) investigated the migration of strontium through the effluent lagooning system of the Nuclear Fuel Services plant in western New York State. They estimated on the basis of analyses that approximately 90\% of the ${ }^{90} \mathrm{Sr}$ passed through the lagoon system and into nearby surface streams. Further, only $12 \%$ of the ${ }^{90} \mathrm{Sr}$ discharged irom the lagoon: system was associated with suspended solids. Thus $78 \%$ of the ${ }^{90} \mathrm{Sr}$ discharged from the lagoon systel was in solution. The low adsorption of ${ }^{90} \mathrm{Sr}$ was apparently due to a combination of $\mathrm{pH}$ and competing cations lower ion exchange loading of solids. For example, when the plant effluent pH was 11 during one sampling period, $75 \%$ of the ${ }^{90} \mathrm{Sr}$ was removed in the lagoon system. At another sampling period, plant effluent was $\mathrm{pH} 7$ and only $10 \%$ of the ${ }^{90} \mathrm{Sr}$ was removed by the lagr i system.

\section{Summary}

Most of the strontium chemical compounds for which data are available are very soluble. Only in highly alkaline environments could $\mathrm{SrCO}_{3}$ control strontium activity in solutions. Strontium in solution is expected to be predominantly present as $\mathrm{Sr}^{2+}$ and to be exchangeable on sediments. Laboratory studies show that ion exchange is the principal mechanism of strontium adsorption by soils and rocks sediments. Strontium $K d$ values are usually directly correlated with cation exchange capacity of the sediment, but not invariably Duursma (1973). A direct correlation between solution pH and strontium Kd has also been reported (Rhodes, 1957; Prout, 1958, 1959; Juo and Barber, 1970), which suggests hydrogen ion competition with $\mathrm{Sr}^{2+}$ for exchange sites. Strontium Kd values fall rapidly from 100 to $200 \mathrm{ml} / \mathrm{g}$ or more in low ionic strength salt solutions to less than $5 \mathrm{ml} / \mathrm{g}$ in high ionic strength salt solutions. Strontium and calcium most readily replace trace strontium (Kokotov et al., 1961, 1962) and cause strontium radioisotopes to migrate rapidiy when present in ground 
water with the strontium. Low $\mathrm{pH}$ a 7 so results in a relatively nigh strontium migration velocity in ground water (Parsons, 1953; Baetsle et al., 1954) with the strontium and ground-water velocity identical at pH 3. Calcium competition is the probable cause of the $90 \%$ soluble strontium migration from the lagoons of the Nuclear Fuel Services plant (Magno et a1., 1970); al though strontiun also migrates on soil particulates (Carlile and Hajek, 1967). The many strontium Kd values determined demonstrate that secondary minerals, such as clays and zeolites, are much better strontium adsorbers, and are more selective for strontium from solutions containing strontium and calcium than are the primary minerals, such as quartz, feldspars and pyroxenes. Another mechanism for strontium removal from solution is its coprecipitation with calcite (Jenne and Wahlberg, 1968). Weak strontium organic complexes are known and result in a measure of strontium fixation (Mortensen and Marcusiu, 1963). The teridency for soluble organic complexation is low. 


\section{TECHNETIUN}

\section{Matura I Sediment and Rock Distributicns}

There are no published values for technetium in aquatic sediments. According to Boya and Larsun (1956), technetium occurs in most abundance in molybdenite $\left(\operatorname{MOS}_{2}\right)$, a common molybdenum ore, as shown in Table 8.76. The technetium content of all materials except pitchblende is of secondary origin, formed by the action of cosmic radiation on molybdenum, ruthenium or niobium. The ${ }^{99} \mathrm{Tc}$ in pitchblende is a product of ${ }^{238} \mathrm{U}$ spontaneous fissioning. Mot everyone accepts the existence of the natural ${ }^{99}$ TC as ha: ing been proven (see Handbook of Chemistry and Physics, 57ti Edition, p. B-50).

TABLE 8.76. Technetium Content of Some Natural Materials (Boyd and Larson, 1956)

\begin{tabular}{|c|c|c|}
\hline Material & Tc, g/kg & Determination Method \\
\hline $\begin{array}{l}\text { Molybdenite, Climax, CO } \\
\text { Molybdenite, NV } \\
\text { Molybdenite, MInomi, AZ } \\
\text { Molybdenite, NV } \\
\text { Osmium-iridium concentrate } \\
\text { Yttrotantalite, West Africa } \\
\text { Iron-nickel Meteorite } \\
\text { KReO4, pure } \\
\text { Pitchblende ( } 50 \text { uranium) }\end{array}$ & $\begin{array}{l}<4 \times 10^{-10} \\
<1.5 \times 10^{-9} \\
<1.8 \times 10^{-7}, 8.3 \times 10^{-11}, \\
1.3 \times 10^{-11} \\
1.3 \times 10^{-10} \\
<1.6 \times 10^{-8} \\
<6 \times 10^{-11} \\
<4.5 \times 10^{-10} \\
<8 \times 10^{-9} \\
2.5 \times 10^{10} 99 \mathrm{Tc}\end{array}$ & $\begin{array}{l}\text { Spectroscopic } \\
\text { Spectroscopic } \\
\text { Activation } \\
\text { Activation } \\
\text { Spectroscopic } \\
\text { Mass Spectr opic } \\
\text { Spectroscopic } \\
\text { Spectroscopic }\end{array}$ \\
\hline
\end{tabular}

\section{Brief Chemistry}

There are 16 isotopes and 6 isomers of technetium presently known (Lavrukhina and Pozdnyakov, 1970). Several technetium isotopes are obtained by the fissioning of nuclear fuels of uranium in the reactor. The fission product technetium isotopes and the ir yields include: ${ }^{99} \mathrm{TC}, 6.06 \%$; ${ }^{101} \mathrm{Tc}$, 5.6\%; ${ }^{102} \mathrm{Tc}, 4.3 \% ;{ }^{103} \mathrm{Tc}, 3.0 \% ;{ }^{104} \mathrm{Tc}, 1.8 \% ;{ }^{105} \mathrm{Tc}, 0.9 \% ;{ }^{107} \mathrm{Tc}, 0.19 \%$ (Katcoff, 1958). According to Boyd (1959), the technetium content of first cycle Purex waste is $41 \mathrm{mg} / \mathrm{l}$. Of the several fission product technetiun isotopes, only ${ }^{99} \mathrm{Tc}$ is long half-lived $1 ? .12 \times 10^{5}$ years), and hence is a potential hazard. 
Technetiun exists in valence states from (VII) to (-I). The most stable state in aqueous solutions is heptavalent, usually corresponding to the $\mathrm{TCO}_{4}^{-}$ (pertechnetate) ion, with other valences encountered chiefly in complex compounds. The ionic radius of $\mathrm{Tc}^{+7}$ is $0.56 \AA$, while its geochemical relative, $\mathrm{Re}^{+7}$, is $0.46 \AA$. The corresponding radius of the solvated $\mathrm{TCO}_{4}^{-}$ion is $4.6 \AA$ (Smith et al., 1953). In weakly acid, neutral and alkaline solutions, TC(IV), the second most stable state of technetium, is oxidized by atmospheric oxygen to TC(VII). The solubility of $\mathrm{KTCO}_{4}$ in water $\mathrm{ai}_{2} 20^{\circ} \mathrm{C}$ is $21.3 \mathrm{~g} / \mathrm{l}$ (Busey and Larson, 1958). Technetium (IV) and TC(V) form halogen complexes such as $\left(\mathrm{TCCl}_{6}\right)^{-2}$, and $\mathrm{TC}(\mathrm{II}),(\mathrm{III})$ and $(V)$ form diarsine complexes and cyanide complexes.

Solution Equilibria

Baes and Mesmer (1976) reported that technetium (VII) forms strong peracids $\left(\mathrm{HMO}_{4}\right)$, and that its oxides are very soluble. No information is available concerning the soluble complexes of technetium or the solubility of its salts (Pourbaix, 1966). Pertechnetate ion, $\mathrm{TCO}_{4}^{-}$, is the most stable species of the element in aqueous soiutions (Boyd, 1959). Under extremely reducing conditions $\mathrm{Tc}^{2+}$ may be the predominant solution species (Pourbaix, 1966).

\section{Laboratory Adsorption Results}

Gromov and Spitsyn (1974) and Gromov (1975) investigate the adsorption of microamounts of ${ }^{99} \mathrm{Tc}$ by Pacific Ocean sediments red clay, carbonates, diatomaceous coze. Technetiu was not absorbed to any significant degree. It appeared that the $\mathrm{TCO}_{4}^{-}$added was stable in sea water. Contaninated sediments were used in desorption experiments in fresh water.

Spitsyn et al. (1969) showed that $2 \mathrm{mg} / \mathrm{e} \mathrm{TCO}_{4}^{-}$could be added to sea water between the $\mathrm{pH}$ 's 2 and 8 without any observable precipitation or colloid formation $>0.1 \mu \mathrm{m}$. Even after 30 days the $\mathrm{TCO}_{4}^{-}$was not filterable.

Hildung et al. (1975) used a batch equilibrium technique to determine pertechnetate ion adsorption on soils. The range of the 22 soil type properties used in the study are given in Table 8.77. The Kd values for pertechnetate 
TABLE 8.77. Range of Properties of 22 Surface Soils Used in the Pertechnetate Adsorption Studies (Wildung et al., 1975)

\begin{tabular}{|c|c|c|c|c|c|c|}
\hline \multirow[b]{2}{*}{$\begin{array}{c}\text { Cation Exchange } \\
\text { Capacity, meq } / 100 \mathrm{~g}\end{array}$} & \multirow[b]{2}{*}{$\begin{array}{c}\text { Soil Paste } \\
\text { pH } \\
\end{array}$} & \multicolumn{5}{|c|}{ Contents, wt: } \\
\hline & & Carbonate & $\begin{array}{l}\text { Organic } \\
\text { Carton }\end{array}$ & Sand & Silt & Clay \\
\hline-90.0 & $3.6-8.9$ & $0-6.5$ & $0.23-28.8$ & $14.1-73.1$ & $17.6-58.0$ & $38-46.6$ \\
\hline
\end{tabular}

ranged from 0.007 to 2.8. The $\mathrm{Kd}$ values were positively correlated with soil organic carbon content and negatively correlated with soil pH. The positive charge on soil organic colloids is probably an important factor in technetium adsorption by soils. The soil carbon-pertechnetate ion removal correlation was the only one significant at the $1 \%$ confidence level. Cation exchange capacity-pertechnetate ion removal also was positively correlated but at a $5 \%$ confidence level. Negatively correlated at the $5 \%$ confidence level was pHpertechnetate ion removal, probably because as pH decreases, positive charge increases with decreased ionization of acidic groups of soil organic colloids and increased protonation of basic groups. A regression equation was given for pertechnetate distribution coefficient determination within the range of significant independent variables. This was $r_{1}=0.08 x_{3}-0.09 x_{4}$, where $r_{1}$ is the pertechnetate distribution coefficient (based on the ranges show in Table 8.77$), x_{3}$ is the soil organic carbon content and $x_{4}$ is the soilsolution pH. The soil silt content $\left(x_{1}\right)$ and clay content $\left(x_{2}\right)$ correlations with Kd were not statistically significant at the $5 \%$ confidence level and did not, therefore, appear in the regression equation.

Gast (1975) studied several Minnesota soils and their abilities to adsorb percetechnetate ions. The soil characteristics are outlined in Table 8.78. From 2 to 5 weeks of contact time between soil and solution were required for equilibrium to be established. Nicollet $C$ and $Z$ imerman soils, both low in organic carbon content, adsorbed very little ${ }^{99}$ TC, wile up to $98 \%$ of the technetium was adsorbed from solution by the remaining soils corresponding to a ${ }^{99} \mathrm{Tc} \mathrm{Kd}$ value of $857.5 \mathrm{ml} / \mathrm{g}$. When the organic carbon was resoved by 
hydrogen peroxide treatment from two soils originally high in carbon content, the adsorption of technetiun was greatly reduced.

TABLE 8.78. Properties of Soils Used in Technet iu Adsorption Studies (Gast, 1975)

\begin{tabular}{|c|c|c|c|c|c|c|c|c|}
\hline Soil & Sand & $\frac{w t x}{1 t}$ & Clay & $\mathrm{pH}, \mathrm{H}_{2} \mathrm{O}$ & $\begin{array}{l}\text { Organic } \\
\text { C, wt\% } \\
\end{array}$ & $\begin{array}{r}\mathrm{CaCO}_{3}, \\
\mathrm{wtz} \\
\end{array}$ & $\mathrm{FFe}_{2} \mathrm{O}_{3}$ & $\begin{array}{c}\text { CEC, } \\
-\mathrm{eg} / 100 \\
\end{array}$ \\
\hline Bearden & 9.1 & 63.7 & 27.2 & 7.68 & 5.39 & 16.29 & 0.09 & 16.9 \\
\hline Hegne & 1.9 & 37.6 & 60.5 & 8.00 & 2.20 & 12.79 & 0.29 & 36.1 \\
\hline Hibbing & 3.3 & 79.5 & 17.2 & 5.48 & 2.29 & $\ldots$ & 1.40 & 11.3 \\
\hline Nicollet A & 24.4 & 42.9 & 29.7 & 5.91 & 2.39 & -- & 0.86 & 19.3 \\
\hline Nicollet C & 23.9 & 48.6 & 27.5 & 8.40 & 0.12 & 15.21 & 1.35 & 15.7 \\
\hline Onega & 61.5 & 30.7 & 7.9 & 7.87 & 1.26 & 1.21 & 1.20 & 6.0 \\
\hline Bergland & 14.0 & 25.1 & 60.9 & 6.35 & 5.67 & $\ldots$ & 2.39 & 32.3 \\
\hline Arveson & 47.1 & 24.6 & 28.3 & 7.70 & 2.80 & 15.58 & 0.21 & 14.9 \\
\hline Mackegan & 10.0 & 69.2 & 20.7 & 6.25 & 2.36 & $\ldots$ & 1.03 & 15.1 \\
\hline Zinmerman & 69.4 & 24.9 & 5.7 & 5.74 & 0.80 & -- & 0.47 & 2.7 \\
\hline Peat & --- & $-\infty$ & -- & 7.83 & 45.95 & 7.58 & 0.40 & 50.9 \\
\hline
\end{tabular}

Gast also mentioned that anaerobic conditions prevailed in the soil-solution environment mich may have led to the precipitation of technetiun heptasulfide, rather than technetium resoval by adsorption processes.

Routson at a1. (1976, 1977) determined distribution coefficients on technetiun with Hashington and South Carolina soils. Soil properties are given in Table 8.79. The organic carbon content was not given. The technetica Kd values obtained were very $10 \mathrm{w}$, as seen in Table $\mathbf{8 . 8 0}$, wen competing bicarbonate ions were present in the system. All Kd values were essentially zero.

TABLE 8.79. Properties of Soil Samples (Routson et al., 1977)

\begin{tabular}{|c|c|c|c|c|c|}
\hline \multirow{2}{*}{ Soil } & \multirow[b]{2}{*}{$\mathrm{CaCO}_{3},=\mathrm{a} / \mathrm{g}$} & \multicolumn{2}{|c|}{ 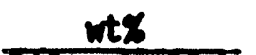 } & \multirow[b]{2}{*}{ CEC, } & \multirow[b]{2}{*}{$\mathrm{pH}, \mathrm{H}-\mathrm{O}$} \\
\hline & & Silt & Clay & & \\
\hline Mashington & 0.8 & 10.1 & 0.5 & 4.9 & 7.0 \\
\hline South Carolina & .0 .2 & 3.6 & 37.2 & 2.5 & 5.1 \\
\hline
\end{tabular}


TABLE 8.80. Technetium $\mathrm{Kd}$ as a function of $\mathrm{MalCO}_{3}$ Concentration for a South Carolina Soil Characterized in Table R.79 (Routson et al., 1977)

\begin{tabular}{|c|c|}
\hline $\mathrm{IathCO}_{3}, \mathrm{M}$ & Average $\mathbf{K d}, \mathrm{ml}$ \\
\hline 0.002 & $0.019 \pm 0.06$ \\
\hline 0.008 & $0.0 \pm 0.01$ \\
\hline 0.020 & $0.0 \pm 0.01$ \\
\hline 0.200 & $0.010 \pm 0.04$ \\
\hline
\end{tabular}

\section{Field Studies}

There are no field studies of technetium migration in rivers, lakes or oceans. Brom (1967) traced the movement of technetium discharged to the ground near the chemical separations plant at Hanford via an extensive network of wonitoring wells. Based on analytical results, a map of the contamination pattern at the surface of the ground water was given for 1966 at limits defined by the $0.01 \mathrm{pCi}{ }^{99} \mathrm{Tc} / \mathrm{cm}^{3}$ isoconcentration contour. The contanination pattern was very similar in shape and size to that for tritium. Technetiu-99 was reported to be moving at essentially the same rate as the ground water, and detectable in the ground water at below public drinking water limits all the way to the Columia River.

Sumary

Pertechnetate ion, $\mathrm{TCO}_{4}^{-}$, is the wost stable species of technetium in aqueous solutions (Boyd, 1959). A major portion of the ion exchange capacity of soils and sediwents is cation exchange capacity at the usual near-neutral pH conditions. Therefore, a negatively charged $\mathrm{TCO}_{4}^{-}$would hardly be exchanged, and hence show little adsorption by soils and rocks (Routson et al., 1976, 1977). Gast (1975) reported high $\mathrm{Kd}$ values (800 to 900 ) for soils with high organic matter. He also reported the presence of $\mathrm{H}_{2} \mathrm{~S}$ in his equilibrating samples, and suggested that the high Kd values were due to precipitation of technetiu as $\mathrm{TC}_{2} \mathrm{~S}_{7}$ in the presence of $\mathrm{H}_{2} \mathrm{~S}$ or another reduced form such as $\mathrm{TCO}_{2}$ (Kotegov, 1968). In conditions where the soil 
contains appreciable organic matter, the Tc(VII) may be reduced to Tc(IV) or Tc(II) and adsorbed (Hildung et al., 1975). TC(IV) can coprecipitate with ferric hydroxide (Anders, 1960). Hence, technetiun Kd values of close to zero would normally be encountered in oxidizing conditions and in sediments that are relatively low in organic matter. More study is required to determine the nature of the organic matter-pertechnetate ion reaction, and the influence of redox conditions on adsorption of technetiun by sediments. 


\section{THORIUA}

\section{Matural Sediment and Rock Distributions}

The content of thorium in rocks and sediments is given in Table 8.81. The thorium in sedimentary rocks may be due either to the selective adsorption of thorium on clays or its retention in heavy resistate minerals such as monazite. Concentrations of thorium in metamphic rocks are highly variable. The thorium content of igneous rocks increases from basalts to granites.

TABLE 8.81. Thor ium Content of Cowmon Rocks and Sediments

\begin{tabular}{|c|c|c|}
\hline Rock & $\begin{array}{l}\text { Thorium Average } \\
\text { or Range, Ppm }\end{array}$ & Reference \\
\hline \multicolumn{3}{|c|}{ Igneous Rocks } \\
\hline Granites & $10-20$ & Rogers, 1964 \\
\hline Intermediate & $2-10$ & Heier and Carter, 1964 \\
\hline Basalt and Gabbros & $0.5-2$ & Heier and Rogers, 1963 \\
\hline \multicolumn{3}{|c|}{ Sedimentary Rocks } \\
\hline Shales, Morth America & $10-15$ & Adaus and Heaver, 1958 \\
\hline Bauxites & 49 & Adans and Richardson, 1960 \\
\hline Bentonites & 24 & Adams and Weaver, 1958 \\
\hline Limestones & 1.1 & Adans and Heaver, 1958 \\
\hline Sandstones & 1.7 & Murray and Adams, 1958 \\
\hline Soils & 6 & Vinogradov, 1959 \\
\hline \multicolumn{3}{|c|}{ Sediments } \\
\hline Pelagic Carbonates & 1 & Turekian and Hedepoh1, 1961 \\
\hline Pelagic Clays & $5-48$ & EI Wakeel and Rilery, 1961 \\
\hline \multicolumn{3}{|c|}{ Metanorphic Rocks } \\
\hline Marble & 0.03 & Pliler, 1956 \\
\hline Slate & 7.5 & Pliler, 1956 \\
\hline Phyllite & 5.5 & Pliler, 1956 \\
\hline Schist & 7.5 & Pliler, 1956 \\
\hline Gneiss & 13.1 & Billings, 1962 \\
\hline
\end{tabular}




\section{Brief Chemistry}

There are 13 isotopes of thorium with six of them found in rature. Of the six natural thoriu isotopes, five are relatively quantitatively unimportant memers of the ${ }^{238} \mathrm{U},{ }^{235} \mathrm{U}$ or ${ }^{232} \mathrm{Th}$ decay series. Thor iv-232 is the major isotope, with a half-life of $1.39 \times 10^{10}$ years (Ryabchikov and Colbraikh, 1969).

Aithough other oxidation states of thorium are knom in the laboratory, only $T h(I V)$ is found in nature. $T h(I V)$ is found as $T^{+4}$. The atomic radius of $\mathrm{Th}^{+4}$ is $0.99 \AA$ (Ahrens, 1952).

Comon insoluble thorium compounds include the hydroxide, fluoride and phosphate. Soluble compounds include the chloride, nitrate and sulfate. Thoriu in solution is a small, highly charged ion that undergoes extensive interaction with water and many anions. The solution chemistry of thorium is largely a stidy of its complex ions. Comon anions that form strong complexes with thoriu include fluoride, chloride, nitrate, phosphate and sulfate. At pH values about 3, thorium undergoes hydrolys is in aqueous solutions. During the sedimentary cycle, thorium usually becomes separated from uranium because the uraniun tends to mobilize in its $U(V I)$ oxidation state until encountering a reducing environment to become insobilized as U(IV). Thorium does not undergo a comparable oxidation state change.

\section{Solution Equilibria}

The relative activity of solution species of thorium in equilibrim with $\mathrm{ThO}_{2}(\mathrm{~s})$ at assumed activities of various ions is plotted in Figure 8.37. The thermodynanic data for all the hydrolysis species except $\mathrm{Th}(\mathrm{OH})_{5}^{-}$were obtained from Sillen and Martell (1964). In general, the total concentration of thorium in solution decreases with an increase of pH from zero to 5. Above 5, pH does not affect thorium concentration in solution due to the formation of $\operatorname{Th}(\mathrm{OH})_{4^{\circ}}^{0}$. The activity of all positively charged species decreases with an increase in pH, wile the activity of the negatively charged species increases with the increase in PH. Under the conditions assumed for Figure 8.37, the total activity of thorium in solution would be expectud to be approximately $10^{-9.6}$ moles/l above ph 5 . 


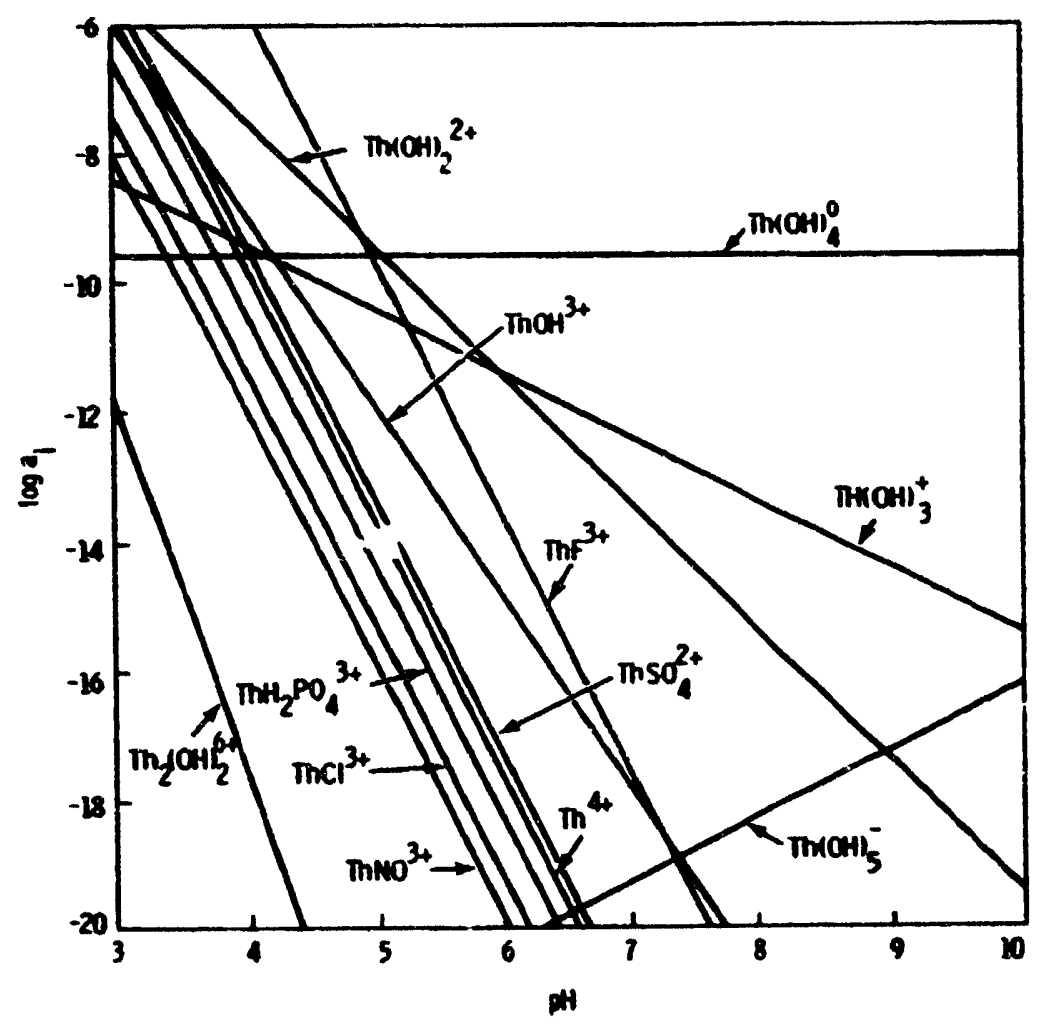

FIGRE 8.37. Activity of Various Thoriu Speçies in Soil in Equilibrium with $\mathrm{ThO}_{2}(\mathrm{~s}), \mathrm{pCl}^{-}=\mathrm{PHO}_{3}=\mathrm{pSO}_{4}^{-}=3.0, \mathrm{pF}^{-}=4.5$ and $\mathrm{PH}_{2} \mathrm{PO} 4=\mathbf{5 . 0}$

In addition to $\mathrm{OH}^{-}$, thoriun forms various complexes with $\mathrm{SO}_{4}^{2-}, \mathrm{PO}_{4}^{3-}$, $\mathrm{Cl}^{-}, \mathrm{MO}_{3}^{-}$, and $\mathrm{F}^{-}$. Various anions in increasing order of the ir importance to forming complexes are: $\mathrm{m}_{3}^{-}, \mathrm{Cl}^{-}, \mathrm{H}_{2} \mathrm{PO}_{4}^{-}$, and $\mathrm{F}^{-}$. Figure 8.37 shows that thorium exists as $\mathrm{Th}^{4+}$ only in very acidic solutions ( $\mathrm{pH}<3$ ). Above pH 3, $\mathrm{Th}^{4+}$ hydrolyzes very rapidly and it does not contribute significantly to the total thorium concentration. Under the conditions assumed for Figure 8.37, $\mathrm{ThF}^{3+}$ would be a dominant solution species at $\mathrm{PH}<5$, and $\mathrm{Th}(\mathrm{OH})_{4}^{0}$ would be a dominant solution species at pH<5. If fluoride ion is absent from the solution, or its concentration is extremely $10 \mathrm{w}, \mathrm{Th}(\mathrm{OH})_{2}^{2+}$ mould mainly control the thoriun concentration in solution at $\mathrm{pH}<5$. 


\section{Laboratory Adsorption Studies}

Antal (1966) found that the acid leachable ${ }^{230}$ Th content of Carribbean Sea sediments decreased with depth in cores. It was suggested that the initially soluble precipitate of ${ }^{230}$ Th is transformed in the sediment to a core acid-resistant state, with an apparent half-life of 24,000 years at $3^{\circ} \mathrm{C}$.

Holland and Kulp (1954) studied the adsorption and base exchange of thorium on deep-sea red clay, globigerina ooze, and green clay. At equilibrium the fraction of radioactivity realining in the seawater solution is independent of the total quantity of tracer added. Extrapolation of the data to actual concentrations of thorium in sea water indicates that the concentrations of thorium in sediments is comparable to that of these experiments. It is concluded that base exchange is the method by wich tho-ium is taken up by the sedirents.

Koczy (1949) described experiments wich show the precipitation of thoriu in sea water. The adsorption of isotopes of radium and thorium on red clay, powdered manganous dioxide, and a powdered manganese nodu le was determined. Radiun ausorbed on a? 1 three ponders, wich is not the case with thorium. The thorium content of a few samples of marine sediments has been measured. They contain about $1 \times 10^{-7} \mathrm{~g} \mathrm{Th} / \mathrm{g}$. One manganese nodule investigated was found to hold as much as $1.3 \times 10^{-6} \mathrm{~g}$ Th/g. The geochemistry of thorium and uranium in sea water is briefly discussed. An attempt is made to estimate the thoriu content of sea water with the aid of the ratio I0:Th in the sediments. The thoriu content of sea water is calculated to be 1 to $10 \times 10^{-9} \mathrm{~g} \mathrm{Th} / \ell$.

Thorium incorporation into sediments by precipitation mechanisas is documented. Koczy (1949) performed experinents in wich thorium directly precipitated in sea water. Pettersson (1949) also hypothesized thoriu precipitation to the sea botton to explain the distribution of thorium and radium.

Nishiwaki et al. (1972) spiked sea water and sea water-distilled water mixtures with $\mathrm{Th}^{+4}$ and measured the adsorption on a mediun sand, very fine 
sand and silt-clay. Twenty grams of soil were contacted with $4 \ell$ of spiked water and mixed until equilibrium was reached. The Kd for thor in increased as the particle size of the soil decreased. Chlorosity of the water did not appear to consistently affect the thoriun kd for the fine sand or silt-clay. The Kd for the mediun sand increased as the chlorosity of the water decreased. The chlorosity effect was compounded by a variable pH of the various salt solutions, so that the exact cause of the trend was not determinable. Kd values for the medium sand, very fine sand and silt-clay were 40 to 130,310 to 470 , and 2700 to $10,000 \mathrm{ml} / \mathrm{g}$, respectively.

Katsurayam (1968) determined the distribution coefficient of thorium $\left(K d_{T h}\right)$ but data are not presented in the available abstract.

Desai and Ganguly (1970) showed humic acids from a coastal marine sediment solubilized $100 \%$ of the thorium added to an anmonia solution (2.5N). Thor in in this solution without humic acid was observed to predominantly precipitate (95\%). The humic acid-thoriu complex was noncationic. In an identical experiment, fulvic acid extract was shown to solubilize $59 \%$ of thorium added to an ania solution. Again, the solubilized organic-thoriu fraction was noncationic.

Sugimura (1964) leached oxean sediments with cold HCl and found 60 to $70 \%$ of the thorium was extracted. Imahashi (1970) observed hytrothermal weathering of rocks in a Japanese hot spring area. Sixty percent of the thorium and $50 \%$ of the uraniun was weathered from the rock. Dementev and Syromyatrukov (1965) concluded that thorium migration in ground waters occurred in both colloidal suspension and anionic complexes probably with organic acids.

Adans et a 1. (1959) suggest that thorium is concentrated cy clay minerals. Schulz (1965) found the thorium in soils wich he studied to be strongly adsorbed by clay particles or present as insoluble oxides and hydroxides. Rubtsov (1966, 1972) found thorium to be associated with the fine-grained particles during soil weathering. Ritchie et al. (1972) found the thorium content of sediments in a fresmwater environment to increase with decreasing particle size distribution. 
Rancon (1973) measured the thoriun Kd for a soil developed on a schist consisting of quartz and clay with no calcite or organic matter, for a mixed quartz-clay-calcite-organic matter soil and for illite with $100 \mathrm{~m} \mathrm{Th} / \ell$ versus solution pH. For the quartz-clay soil, at pH 6 the $\mathrm{Kd}$ was $5 \times 10^{5} \mathrm{ml} / \mathrm{g}$, at pH 4 the $\mathrm{Kd}$ was about $1 \times 10^{3} \mathrm{ml} / \mathrm{g}$, and at pH 2 the $\mathrm{Kd}$ was about $5 \mathrm{ml} / \mathrm{g}$. The wixed quartz-clay-calcite-organic matter soil could not be lowered in pH without removal of soil calcite, but above pH 8, the thoriun Kd dropped from $10^{6} \mathrm{ml} / \mathrm{g}$ to $1000 \mathrm{ml} / \mathrm{g}$ at $\mathrm{pH} 10$. Dissolution of huic acids in the soil frobably resulted in thoriun complexation and a decreased $\mathrm{Kd}$ with rising $\mathrm{pH}$. Illite behaved similarly to the quartz-clay soil, but the thorium Kd at pH 1 was about $500 \mathrm{ml} / \mathrm{g}$ and about $1 \times 10^{5} \mathrm{ml} / \mathrm{g}$ at $\mathrm{pH} \mathrm{6.5}$. For soils without calcite or organic material, the thoriu $\mathrm{Kd}$ decreased as the thoriun concentration in solution initially increased. Calcareous soils neutralized even high strength thoriu solutions to precipitate $\mathrm{Th}(\mathrm{OH})_{4}$. The quartz-clay sOil and illite, for exaple, gave thoriun $\mathrm{kd}$ values of $8 \mathrm{ml} / \mathrm{g}$ and $1000 \mathrm{ml} / \mathrm{g}$, respectively, in a $0.1 \mathrm{~g} \mathrm{Th/l} \mathrm{solution.} \mathrm{The} \mathrm{drop} \mathrm{in} \mathrm{thoriun} \mathrm{Kd}$ was caused by saturation of available exchange sites as a result of increased thorium concentration. There as evidence for the concentration dependence of the thoriun $\mathrm{Kd}$ down to $1 \mathrm{~m} / \mathrm{Th} l$ in the initial contacting solution. In general, three types of soil-thorium adsorption reactions were found: 1) Th(OH) 4 precipitation as a result of soil calcite buffering, 2) strong adsorption on clay-containing soils and silute thoriu $(<1 \mathrm{~g} / \mathrm{l})$ solutions at a pH above 2, and 3 ) strong adsorption on organic-containing soils at the neutral to acid pH range, but diminishing adsorption into the alkaline pH range.

Bondietti (1974) studied the s.tsorption of hydrolyzed thoriun from waters at $\mathrm{pH} 6.5$ by calciu saturated reference clays (montmorillonite and kaolinite) and calcium humate and found $95 \%$ and $99.9+\%$ adsorption, respectively. Desorption studies utilizing calcium citrate rewoved 10 to $30 \%$ of the thorium from the clays but only 1\% from the humate. Stronger complexers (DTPA and EDTA) removed 20 to $30 x$ of the thoriun from the humate. A mixed organic-hydroxy conplex was proposed for the reaction of thoriun with humic substances. 


\section{Field Studies}

Baranov and Khristiansova (1963), Baranov et al. (1962), Baturin et al. (1971), Bernat and 6oldberg (1969), Bonatti et al. (1971), and Kuznetsov et al. $(1964,1968,1969,1971)$ reported on the distribution of thorium in mar ine sediments.

The distribution of the two thorium isotopes, ${ }^{230}$ Th and ${ }^{232} \mathrm{Th}$, are quite different in the marine environment. In suspended particulates and bed sediments ${ }^{230} \mathrm{Th}$ associated with phosphates, hydroxide precipitates, organics and calciu carbonates. Thoriu-232 was associated in sedimentary detrital particles. Thoriu-232 present in the cores is of continental or volcanic origin. Most of the ${ }^{230}$ Th was formed from uranium in the sea water and only $25 \%$ of it is of continental origin. The clay fraction in all types of ocean sediments has a ${ }^{230}$ Th: Th ratio increasing from 30 in terrigenous to 50 in pelitic formations. Increase of the ${ }^{230}$ Th: Th ratio from sands, to silts, and to muds ind $i$ cates that the ${ }^{230}$ Th in sea water is in a form more easily sorbed than thorium. A similar effect was observed with radium; the clayey fractions are 10 times richer in radium than sands. The behavior of uraniun is quite different. Its content in all types of sediments is about the same and does not depend on the granulometric composition of sediment. The Th: $U$ ratio in all types of sediments is $\leqq 1.7$ to 1.8 in clay fractions and $\leqq 0.3$ to 0.7 in sands and silts. The 230 Th: $U$ ratio in all types and all fractions (in silts it is 4 and in claye 7 to 10 ) indicates a distinct radioactive disequilibriu caused by predoninance of ${ }^{230}$ Th over uranium. The Ra:U ratio has the same character as the ${ }^{230}$ Th:U ratio. Thoriu distributions in cores shows no migration occurs during diagenes is but Somayajula and Church (1973) did find thorium $\left({ }^{230} \mathrm{Th}\right.$ and $\left.{ }^{232} \mathrm{Th}\right)$ concentrations in interstitial watsrs of a Pacific Ocean sediment to be higher by a factor of 10 to 1000 over their concentrations in sea water wich suggest migration. Lazarev et al. (1961) and Kimura et al. (1968) studied the fate of thorium in sea water. Both studies show thorium in sea water is bound to colloidal suspended particles. El Madi and Amar (1960) found the thorium content of the Mile River to be $150 \mu \mathrm{g} / \ell$. 
Hikolaev et al. (1969) measured the concentrations of thorium and ion ium $\left({ }^{230} \mathrm{Th}\right)$ in the water and suspensions of the main rivers in the basin of the B Tack and Azov Seas. On the basis of the data obtained, the main elements of balance and the reserves of thorium and ionium in the Black and Azov Seas were determined. The amounts precipitated in deep and shallow water zones in the B lack Sea annually are 143 and 691 tons of thorium and 19,100 and 10,400 $\mathrm{g}$ of ionium. It was calculated that the residence time of thorium in the aqueous phase is 56.5 years for the Black Sea and 160 days in the Azov Sea; for ionium the values are 365 years and 172 days, respectively. Kurokawa (1971) gives the range of thorium content in 40 Japanese soils to be 2.8 to $20 \mathrm{ppm}$ and in ten rivers $2.7 \times 10^{-2} \mathrm{ppb}$. These values yield an apparent $\mathrm{Kd}_{\mathrm{Th}}$ of $10^{3}$ to $10^{4}$.

Sugima (1964) reviews the distribution of natural radioactive elements in sea water and sediment. Sea waters contain $2 \times 10^{-9}$ to $1 \times 10^{-7} \mathrm{~g} \mathrm{Th} / \mathrm{l}$ and $n \times 10^{-11}-n \times 10^{-14} \mathrm{~g}^{230} \mathrm{Th} / \mathrm{l}$. Sea sediments contain 6 to $13 \mathrm{ppm} \mathrm{Th} ; 60$ to $70 \%$ of the thorium is leached with cold $H C l$. Studies were made to determine the sedimentation rate of sediment from the contents of ${ }^{232} \mathrm{Th}$ and ${ }^{230} \mathrm{Th}$ ( Io). Iskra et al. (1969) studied an interior-drained freshwater bas in and determined the main sinks for thorium were the plant detritus and soils. Pashneva et al. (1965) found the thorium content in Tnmsk region Russian soils to increase with increasing humus content. Hansen and Huntington (1969) found a similar correlation with organic atter in Sierra Mountain soils. In contrast, Tyuruykanova and Kalugina (1971) found low thoricm in peats and forest podzol soils compared to alluvial soils.

Two Soviet articles by Yakobenchuck (1968) and Pokidin et al. (1972) found thorium to be associated with the calcium carbonate content of a podzolic soil and Caspian Sea sediment, respectively.

The thorium content of ground water was reported by Dementyev and Syromyatnikov (1965) to be highest in low salinity, low hardness, low pH, high organic content ground waters. These characteristics suggest transport of thorium as colloidal suspensions and anionic complexes involving soil acids. 


\section{Sumary}

Under alkaline conditions, $\mathrm{Th}(\mathrm{OH})_{4}$ and $\mathrm{ThO}_{2}$ manta in low activities in solution and these compounds could form and govern thorium concentration. Thor iu hydrolyzes readily ever: in moderately acidic environments (Figure 8.36) so that $\mathrm{Th}^{4+}$ would be present only in very acidic solutions. Laboratory studies also show that thorium tends to precipitate as thorium hydroxide and hydrated thorium oxide.

An increase in thorium content with increases in $\mathrm{CaCO}_{3}$, phosphate and rumus content of soils and sediments has been reported (Kuznetsov et al., 1968; Pashneva et al., 1965; Menze 1, 1968; Yakobenchuck, 1968; Hansen and Huntington, 1969; Pokidin et al., 197?). Hovever, Tyuryukanova and Kalugina (1971) reported low thorium concentrations in high hums soils (peats and forest podzols) compared with alluvial soils. Thorium adsorption ircreases with increase in pH (Rancon, 1973) and decrease in soil particle size (Hansen and Huntington, 1969; Hanse, 1970; Nishiwaki et al., 1972; Rubtsov, 1966, 1972; Bondietti, 1974). Strong humic and fulvic acid complexes with thorium occur in the neutral to acidic range (Rancon, 1973; Bondietti, 1974) which are noncationic (desai and Ganguly, 1970) and nobile. It has been reported also that thorium migrates primarily in the colloidal form (polymeric) in the natural environment (Baranov et al., 1956; Lazarev et a1., 1961; Kimura et al., 1968). Observed $\mathrm{Kd}_{\mathrm{Th}}$ for fresh and marine environments are typically $10^{3}$ to $10^{5} \mathrm{nl} / \mathrm{g}$. 


\section{TRITIUM}

\section{Matural Sediment and Rock Distributions}

Matural tritiu concentrations vary geographically from about 10 T.U. for northern and southern midlatitude precipitation to 1 T.U. for equatorial precipitation. The background tritium content of deep ocean and ground water is essentially zero (Fairbridge, 1972). Hence, the tritiu content of rocks, minerals and deeper sediments also is nearly zero unless contacted by tritiucontaminated ground water.

\section{Brief Chemistry}

Tritium $\left({ }^{3} \mathrm{H}\right.$ or $\left.\mathrm{T}\right)$ is an isotope of hydrogen with a half-life of $12.16 \mathrm{gr}$. Tritiu occurs naturally in the upper atwosphere, chiefly by the interaction of fast neutrons with nitrogen (Kaufman and Libby, 1954). The amount of natural tritium is about one part in $10^{17}$ parts of normal hydrogen $\left({ }^{1} H\right.$ ) (Cotton and Wilkinson, 1962 ).

It was a fairly recent discovery that tritiun also is a product of uranium fission (Aivenesius, 1959; Albenesius and Ondrejcin, 1960). Several years prior to the identification of tritiu as a uraniu fission product, the Environental Monitoring Group at Savamah River plant recognized tritium as occurring in Purex separations process wastes, and was using it is a groundwater tracer (Horton and Ross, 1960). Tritiun yields of 3.8 to 20.3 curies/ton uranium were obtained for exposures between 300 and 1600 megawatt-days/ton uraniug.

Tritiu oxidizes rapidly to HTO, existing essentially as water, and its distribution in ground and surface waters is controlled by the operation of the hydrological cycle. Iritium is measured in tritiun units, T.U., where $T . U$. $=T / 10^{18_{H}}$, or expressed as picocuries/l. Natural background levels have risen since weapons testing of nuclear devices from 1 to 10 T.U. to several hundred T.U. up to the 1963 atuospheric detonation woratorium. Most of the tritiu added to the hydrological cycle by fusion devices was due to residual tritiun $\left(26.7 \times 10^{6} \mathrm{Ci}^{3} \mathrm{H} /\right.$ megaton fusion device, Stead, 1963$)$. 


\section{Solution Equilibria}

Tritiu $\left(\mathrm{H}^{3}\right)$ is a radioactive isotope of hydrogen. Thus, tritium behavior in the environent would be expected either to be similar to hydrogen or to exist as an ion, gas and liquid (tritiated water). Except for the slight differences in vapor pressure, tritiated water behaves the same as ordinary water (Jacobs, 1974). Although no discrete solid phases of tritium are expected in sediments, it could associate itself with organic components containing hydrogen or with some ninerals as mobile water, water of hydration, or as part of structural hytroxyl groups (Jacobs, 1974; Stewart, 1967).

Tritiu rapidly travels at about the same velocity as the ground water in the form of HTO. Some replacewent of nontritiated water on clays and other hydrated soil constituents occurs, but the reaction is of marginal value as far as tritiun retention is concerned. Tritiun can move in a vapor phase through the soil under certain conditions as well.

\section{Laboratory Adsorption Studies}

Tritiu uitimately exists in aquatic environments as a tritiated water wolecule. Theoretically, tritiun ions are capable of exchanging for hydrogen and other ions. However, the tritium is usually in an aqueous solution before contacting sediment, so that isotopic exchange and replacenent of hydroxyl water wlecules is the wost comm mechanism of tritiu renoval. Little quantitative work on tritiu distribution has been reported. Most of the field studies indicate that tritiun distribution has been reported. Most of the field studies indicate that tritiun distribution coefficients were very low because tritiun migration velocities mere essentially the same as those of the accompanying ground water (Brown and Haney, 1964; Brom, 1967; and Hawkins, 1975). Hawkins (1975) and Hayes (1976) have studied the migration of $3_{H}$ from Savannah River Plant burial grounds and adjacent estuary.

\section{Field Studies:}

Haney, Brom and Reisenaver (1962) and Brom and Haney (1964) estimated by studying the rate and direction of ground-water flon that movenent of tritiv disposed to the ground at the Hanford Purex Plant would require 6 or 
7 years travel tive to the Columbia River, approximately 17 wiles from the Purex Plant. The half-life of tritiun allowed about $70 \%$ of the total tritium discharged to reach the river. The tritilu content of Columia River water was not expected to rise over 50x higher than the present background because of tritiun dispersion during travel and the large dilution represented by the Columbia River $\left(80,000\right.$ to $\left.200,000 \mathrm{ft}^{3} / \mathrm{sec}\right)$.

Brom (1967) reviewed the hydrology and geology of the Hanford area, and showed the 1966 linits of the areas ciefined by $3000 \mathrm{pCi} / \mathrm{cm}^{2}$ abd $10 \mathrm{pCi} / \mathrm{cm}^{3}$ of tritiu based on well water analytical results. The $10 \mathrm{pCi}^{3} \mathrm{H} / \mathrm{Cm}^{3}$ area was $3 \mathrm{~km}$ from the Colubia River in 1966. The concentration of tritiun added at the Purex Plant disposal sites was $10,000 \mathrm{pCi}{ }^{3} \mathrm{H} / \mathrm{cm}^{3}$. Tritium moved at essentially the same rate as the ground water.

Kline and Jordan (1968) reported a field experiment on a Puerto Rican clayey soil mere $1 \ell$ of $20 \mathrm{ci} / \mathrm{l}$ tritiated water was applied to a plot with about $1 \mathrm{~m}^{2}$ area, and sapled via a lysimeter installed horizontally, without disturbing the plot surface soil, $18 \mathrm{~cm}$ below the soil surface. The sampling progran lasted 210 days during time $137 \mathrm{~cm}$ of rain fell on the plot. Runoff surface water was collected as will. The soil remained saturated, or close to saturation for the sampling period. Most of the tritiun passed through the profile as a peak or front 16 days after application, and declined in concentration exponentially curing the rewainder of the experiment. The surface runoff peaked in 1.9 days, with another change in decline of specific activity at 35.6 days. Because of the loss rate curve of tritiv in the free soil water. the authors suggested that tritiun movenent through soils must be nodified to allow for the existence in clay solis of isolated compartinents of inmobile water that does not have free interchange with the wore rapidly woving water.

Jordan et al. (1971) monitored tritiun novement through a soil near Argonne, Illinois. They concluded from the results that a pulse of tritiu noves dommard at a rate deternined by precipitation entering the top of the soil colum. The tritiu peak broadens and flattens from diffusion and will becone imobilized if the upper soil layers dry out. Loss of tritiun occurred 
both by evapotranspiration and deep drainage. Deviation of the field results from a mode: of tritiated water wovement proposed by Sasscer et al. (1971) was explained as due to paraneters that were difficult to quantify such as root holes and hydroxyl exchanges.

Ehalt (1973) pointed out that triated wolecular hydrogen in the atwosphere was oxidized by soil microorganism. He also estimated from the tritim content of $\mathrm{H}_{2}$ of $2 \times 10^{6} \mathrm{~T} . U$. . steady since 1962 , that the $\mathrm{HT}$ input rate was about $5.4 \mathrm{~T}$ atoms/car ${ }^{2}$ sec into the soil from the action of soil microorganisus.

Purtymun (1973) investigated the underground movement of tritiun from solid maste storage shafts in rhyolite tuff at Los Alamos. Levels of $100 \mathrm{pCi}$ $3_{H / m l}$ had moved a distance of $105 \mathrm{ft}$ in 4 years. Core samles of tuff were collected, water was distilled from them and tritium in the water was determined. Asphalt coatings on containers and shaft walls were suggested to control tritiun migration from the shafts.

In contrast, theeler and Marren (1975) reported that a later comparison between asphalted and nonasphalted shafts showed that the asphalt containment techniques used were ineffective in slowing tritiun migration from the shafts. Double containment and complete encapsulation of the 210-l disposal drum in roofing asphalt was suggested to flow tritiun movement from the storage shafts.

Becalise soil water and ground-water systems are similar, it would be expected that tritiun oxide would wove through these systems at essentially the same rate as light water. However, in comparing chloride ions and tritiun breakthrough curves for various soil types, the tritic curve lags behind that for chloride ions in soils contzining clays and silt (Kaufman and Orlob, 1955). This behavior was reported as caused by the tritiated water wolecule entering the clays and replacing nontritiated water adscrbed on clay surfaces or inter layers.

Haney (1963, 1964) reported a laboratory study mere actual ground water containing complexed ${ }^{106} \mathrm{Ru}$ and tritiu was passed through several Hanford proiect soils. In silty solis, the ruthenium breakthrough curve was slightly 
behind that for tritiun, but in sandy soil columns, the breakthrough curres were essentially identical. Several retention mechanisus of tritium on clays are possible. For example: 1) exchange of tritiun ions for hydrogen ions in exchange positions, 2) tritiated w*er molecules exchanged for hydroxyl water or vater of crystallization, 3) exchange of tritium ions for exchangeable cations other than hydrogen, and 4) replacenent of alumimn in lattice sites by tritiun, with the aluimu ions woving into exchangeable cation positions. In the last case, the tritiun ma be wore or less "fixed" in its octahedral position. This "fixation" has been considered to be minimal by some investigations (Higgins, 1959; Halevy, 1964; Corey and Horton, 1968; Teller et al., 1968).

It has been hypothesized by others (Corey and Fenimore, 1968) that the chloride ions are repelled from negatively charged soil particles into the central region of the soil pore where ground-water velocity is greatest (anion exclusion). This would be cost effective in high cation exchange capacity soils which do not retain anions. Also, Corey and fenibore (1968) showed that chloride jons lag far behind tritiu in acid kaolinitic soil due to anion exchange of the chloride ions.

Corey and Horton (1958) reported no appiaciable tritium "fixation" upon investigation of the movement of tritiated and deuterated water through acidic, kaolinitic soil. The work of other investigators, however, indicates that hydrogen isotopes may be se iectively fixed (Rosenqvist, 1963; Koranda, 1965; Clayton et al., 1966; Savin, 1967; Stewart, 1967). The work of Rabinowitz (1969) and Rabinowitz et al. (1973) with forced exchange of tritiated water on clays also supports the yiew that part of the tritium can be "fixed" on clays. The isotopic exchange and fixation was forced with a wild form of electrodialysis $(2 \mathrm{~V} / \mathrm{Cm})$ resulting in an increase in the reaction rate of about five times the rate without electrodialysis. Aluminum and other basing cations were determined after each experiment. The presence of exchangeable $\mathrm{Al}^{+3} \mathrm{cor}-$ related with tritiun loss from the water resulting from tritium "fixation". A mass balance on the tritiun also was determined for each experiment. The anaIytical data for tritiun facilitated the differentiation of isotopic exchange and the "fixation" of tritiun by kaolinite and illite. 
Sugary

Tritium substitutes readily for the hydrogen in water and thus becomes a part of the hydrological cycle (Jacobs, 1974). Migration of tritium in the aquatic environment takes place at the same velocity as the ground ter (Haney 1963, 1964; Haney et al., 1962); Brow and Haney, 1964; Brow, 1967). Some investigators have reported the selective fixation of tritiated water on clays and other hydrated minerals (Rosenqvist, 1963; Koranda, 1965; Clayton et al.. 1966; Savin, 1967; Stewart, 1967; Rabinowitz, 1969; Rabinowitz et al., 1973) wile other investigators have considered tritium fixation to be minimal (Higgins, 1959; Ha levy, 1964; Corey and Horton, 1968; Teller et al., 1968). However, all of the field studies have indicated that tritium movement is synonomous with water movement (Brown, 1967).

8.244 
URNIII

Matural Sediment and Rock Distributions

The range in abundance of uranium in nature is given in Table 8.82 . Vinogradov (1959) reported 1 ppm uranium as the average content of uranium in soils. The oxidation of organic atter in black shales tends to precipitate U(IV). Consequently, the black shales usually contain more uranium than red, green or gray shales.

TABLE 8.82. Abundances of Uranium in Matural Materials

Material

\begin{tabular}{l} 
Material \\
\hline Dunites and Peridotites \\
Gaboro and Diabase \\
Internediate (diorite and \\
quartz dior ite) \\
Sialic (granite, syenite, \\
monazite)
\end{tabular}

Black shales

Red, gray and green shales Orthoquartzite

Limestone and colomite

Bentonite

Bauxite

Halite

Anhydr ite

Pelagic carbonates

Pelagic clays

Mangartese nodule

Beach Sand

Marble

Slate

Phyllite

Schist

Gne iss

Amphibolite

Granulite
$U$ Concentration Range, pom Igneous

0.001-0.8

0.3-3.4 Median 0.5

0.1-11.0 Median 1.7

0.15-21.0 Median 3.9

\section{Sedimentary}

$3.05-25.0$

$1.2-12.0$

$0.2-0.6$

$0.1-9.0$

$1.0-21.0$

3.0-27.0

$0.01-0.02$

$0.25-0.43$

0.1

$0.7-4.3$

3.6-5.0

0.3-0.6

Median 8.9

Median 3.2

Median 0.45

Median 2.2

Median 5.0

Median 8.0

Median 0.013

Median 0.37

Adans et al., 1959

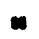

Reference

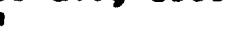

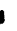

ט

Turekian and Hedepoh 1, 1961

Sugimara and Sugimara, 1962

Tatsunota and Goldberg, 1959 Mahdavi, 1964

Metanorphic

$0.11-0.24$

$1.2-6.1$

1.0-2.7

$1.8-2.9$

4.5-15.0

2.6-4.1

$3.2-7.0$
Clark et al., 1966

a

๓

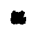

-

n 


\section{Brief Chemistry}

There are 15 known isotopes of uranium from $227_{U}$ to $240 U$ and one uranium isomer $\left({ }^{235} U\right)$ (Fairbridge, 1972). The half-lives of the uranium isotopes vary from a few mimutes to over 4 billion years. Only three of the isotopes occur natura $11 y$, and timo of these $\left({ }^{235} U\right.$ and $\left.238_{U}\right)$ are parents of series that end in lead isotopes. The nuclear data on the three natural uranium isotopes are given in Table 8.83. The common oxidation states of uranium are U(III), U(IV), $U(V)$ and $U(V I)$ (Udaltsova, 1963). U(III) is easily oxidized in air to U(IV). The U(IV) state is fairly stable in aqueous solutions if they are very acidic. Uraniu (V) disproportionates to $U(I V)$ and $U(V I): 2 \mathrm{NO}_{2}^{+}+4 \mathrm{H}_{3} \mathrm{O}^{+} \rightarrow \mathrm{WO}_{2}^{+2}+\mathrm{U}^{+4}+6 \mathrm{H}_{2} \mathrm{O}$ (Udaltsova, 1963). U(VI), as $\mathrm{UO}_{2}^{+2}$ (Uranyl) at $\mathrm{pH} \leq 2.5$, is the most stabie state of uranium in aerated aqueous solutions (Seaborg and Katz, 1954). At higher pH values, hydrolyzed uranyl ions predominate. Approximately 103 uranium minerals have been confirmed. Uraninite (ideally $\mathrm{UO}_{2}$ ) is the primary ore mineral of uraniun, but other secondary minerals include carbonates, sulfates, nolybdates, phosphates, vanadates, silicates and ultiple oxides. Uranyl ions readily form many complexes with anions ordinarily found in water environments such as carbonate, sulfate and fluoride.

TABLE 8.83. Muclear Properties of Matural Uraniun Isotopes (Fairbridge, 1972)

\begin{tabular}{|c|c|c|c|}
\hline Isotopes & I Abundance & $\begin{array}{c}\text { Half-Life, } \\
\frac{y}{y}\end{array}$ & $\begin{array}{c}\text { Decay Series } \\
\text { Parent }\end{array}$ \\
\hline & 0.0056 & $2.48 \times 10^{5}$ & \\
\hline & 0.72 & $7.13 \times 10^{8}$ & $4 N+3$ \\
\hline $238 v$ & 99.27 & $4.51 \times 10^{9}$ & $4 N+2$ \\
\hline
\end{tabular}

\section{Solution Equilibria}

The common oxidation states of uranium are U(III), U(IV), U(V), and U(VI) (Udaltsova, 1963). However, in the geologic environent U(IV) and U(VI) are the most important oxidation states. In an oxidizing environent U(III), 
$U(I V)$, and $U(V)$ species are very low in concentration and do not contribute significantly to the total uranium concentration. U(VI) species entirely control the total uranium concentration in oxidizing environments (Ames and Rai, 1978). $10_{2}^{2+}$ and the $\omega_{2}^{F+}$ are the predominant solution species up to a pH of approximately 6 . The predominant solution species over pH ranges of from 6 to 8 and $>8$ are $\mathrm{NO}_{2}\left(\mathrm{OH}_{2}\right)_{2}$ and $\mathrm{wO}_{2}\left(\mathrm{CO}_{3}\right)_{3}^{4-}$, respectively. In oxidizing and high chloride environment such as sea water the $\mathrm{UO}_{2} \mathrm{Cl}^{+}$will become anong the most predominant solution species below pH 6. In extremely reducing conditions, $\mathrm{WOH}^{3+}$ and to a lesser extent $\mathrm{\omega O}_{2}^{+}$species would be most important.

The thermodynanic data for $\mathrm{CO}_{2} \mathrm{~F}^{+}$and $\mathrm{WO}_{2} \mathrm{H}_{2} \mathrm{PO}_{4}^{+}$were selected from Palei (1970) and selected data from Sillen and Martell (1964) were used for the remaining species in Figure 8.38. All the species except $\omega_{2}^{+}$shown in Figure 8.38 are of $U(Y I)$. Since equilibrium is assumed with $\mathrm{Na}_{2} \mathrm{UO}_{4}$, a $U(V I)$ compound, a change in oxidation-reduction conditions will affect the position of the curves. In an oxidizing environment $\left(\mathrm{pO}_{2}=0.68 \mathrm{~atm}\right)$, the U(IV) species are very $10 w$ in concentration $\left(\log a_{j}<38\right)$ and fall outside of the boundaries of Figure 8.38 .

\section{Laboratory Adsorption Studies}

Bell (1960) and Dall'Aglio and Casentini (1970) found uranium in desiccating salt basins to remain in solution under oxidizing, low organic matter substrate conditions.

Masula and Yamanoto (1971) examined the desorption of uranium from alluvial, sand and volcanic ash soils. The cation exchange capacities were 13.7, 7.7 and 33.0 meq/100 $\mathrm{g}$, respectively, for the alluvial, sand and volcanic ash soils. Strong salt solutions and distilled water were used as leachates. Loads of more than $2000 \mu \mathrm{g} / \mathrm{g}$ of soil were required before desorp-' tion by distilled water was $1 x$ of the uranium on the soiis. The uranium was amended to the soils as uranyl nitrate before the desorption work. Desorption of uranium was higher with $0.5 \mathrm{M}\left(\mathrm{HN}_{4}\right)_{2} \mathrm{SO}_{4}, 1.34 \mathrm{KCl}$ and $1.44 \mathrm{M} \mathrm{K}_{2} \mathrm{HPO}_{4}$ salt solutions, but reached $50 x$ reavol only for the alluvial soil with a high adsorbed uranium content in $1.44 \mathrm{M} \mathrm{K}_{2} \mathrm{HPO}_{4}$ solution. The volcanic asis soil did not attain $5 \%$ uranium desorbed in any of the salt solutions. 


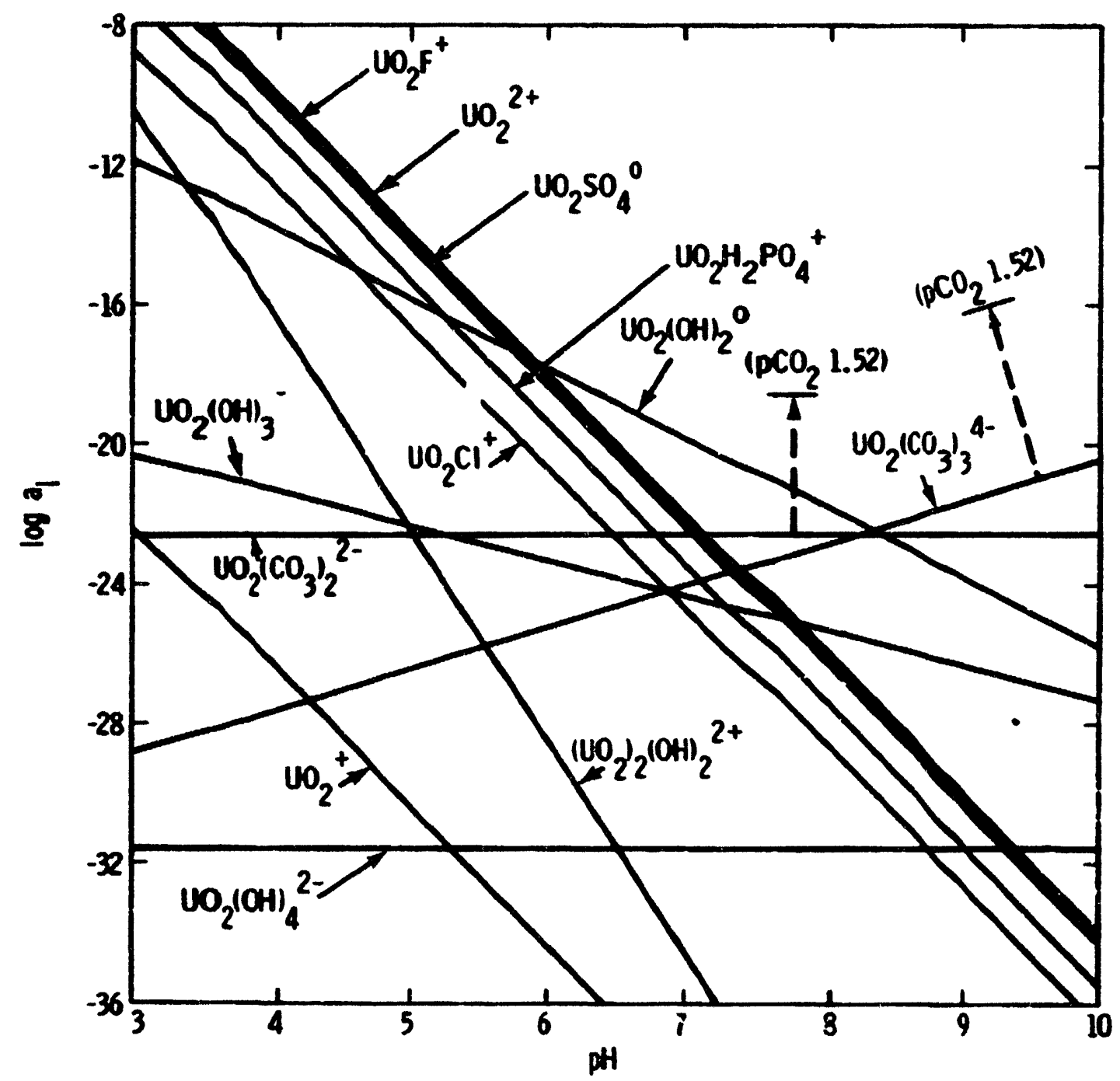

FIGURE 8.38. Activity of Various Uranium Species in Equilibrium with $\mathrm{Ma}_{2} \mathrm{UO}_{4}$ in an Oxidizing Soil Environment $\left[\mathrm{pO}_{2}(\mathrm{~g})=0.68 \mathrm{~atm}\right], \mathrm{pCO}_{2}(\mathrm{~g})=$ $3.52 \mathrm{~atm}, \mathrm{pCl}^{-}=\mathrm{pSO}_{4}^{-}=3.0, \mathrm{pF}^{-}=4.5$ and $\mathrm{pH}_{2} \mathrm{PO}_{3}=5.0$

The effects of carbonate ions on uranium desorption from soils was examined by Yamanoto et a1. (1973). They used an alluvial soil, a volcanic ash soil and a sandy soil containing up to $500 \mathrm{\mu g} \mathrm{U} / \mathrm{g}$ air-dried in their desorption experiments. The desorption of uranium declined as a power function of the anount of uranium on the soil. Desorption results are shown in Table 8.83. Ten grams of soil were magnetically stirred with $100 \mathrm{ml}$ of potassium carbonate solution for 30 min and stood overnight before filtering and fluoremetric 
uranium analysis. As can be seen in Table 8.84, uraniu desorption was very low in the presence of low to moderate environmental carbonate concentrations.

TABLE 8.84. Desorption of Uraniu from Solls with Oistilled Water and Carbonate Solutions (Yamanoto, 1973)

\begin{tabular}{|c|c|c|c|c|}
\hline Soil & $\begin{array}{c}U \text { Content, } \\
\mu \mathrm{g} / \mathrm{g} \\
\end{array}$ & $\begin{array}{l}\text { Distilled } \\
\text { Mater, } 8 \\
\end{array}$ & $\begin{array}{c}\text { Carbonate } \\
4.3 \mathrm{mg} \\
\mathrm{CO}_{3}^{2} / 2\end{array}$ & $\begin{array}{l}\text { Solution, } x \\
43,5 \mathrm{mg} \\
\mathrm{cos}^{2} / 2\end{array}$ \\
\hline Alluvial & $\begin{array}{r}7.1 \\
485.0\end{array}$ & $\begin{array}{l}0.31 \\
0.22\end{array}$ & $\begin{array}{l}0.62 \\
0.25\end{array}$ & $\begin{array}{l}1.20 \\
0.41\end{array}$ \\
\hline Sandy & $\begin{array}{r}10.1 \\
488.2\end{array}$ & $\begin{array}{l}0.14 \\
0.12\end{array}$ & $\begin{array}{l}0.27 \\
0.13\end{array}$ & $\begin{array}{l}0.90 \\
0.46\end{array}$ \\
\hline Volcanic Ash & $\begin{array}{r}8.3 \\
500.0\end{array}$ & $\begin{array}{l}0.18 \\
0.09\end{array}$ & $\begin{array}{l}0.57 \\
0.10\end{array}$ & $\begin{array}{l}1.15 \\
0.20\end{array}$ \\
\hline
\end{tabular}

Rancon (1973) studied the adsorption behavior of uraniun added to soils to simulate nuclear energy discharges as compared to natural weathering events. Rancon chose four soils: a) a river sediment containing a mixture of clay, calcium carbonate and organic matter; b) a highly organic riverine peat; c) a clay-calcium carbonate soil; and d) a clay and pure illite, calcite and quartz. The first two soils were exposed to river water containing uranium wile the latter two solutions were exposed to their respective ground waters both at $10 \mathrm{ppm} \mathrm{U}$. The $\mathrm{Kdy}$ in $\mathrm{ml} / \mathrm{g}$ are shown in Table 8.85 .

An increase in initial uranium concentration above $1 \mathrm{ppo} U$ which causes a subsequent pH decrease in the water causes the $\mathrm{Kd}$ to drop. At 10,000 ppo $U$ (pH 2.5) the $K d_{y}$ is nil for the first two soils. A saturation of the absorbate sites is proposed as a partial cause of the drop in Kd. Rancon also presents data on the variation of $\mathrm{Kd}$ with $\mathrm{pH}$ at $1 \mathrm{ppm} U$. For the clay soil, three peaks were observed; around $\mathrm{PH} 5.5(\mathrm{Kd},=300)$, a larger peak at $\mathrm{pH} 10$ $\left(K d_{U}=2000\right)$, and a peak at $\mathrm{pH} 12\left(K d_{y}=270\right)$. Since soils are of variable composition, Rancon concludes the peaks correspond to sorption maxima corresponding to electrokinetic potential (surface charge) maxima for certain 
TABLE 8.85. Kd Values for Uranium

\begin{tabular}{lr}
\multicolumn{1}{c}{ Adsorbate } & Kd \\
\cline { 1 - 2 } Clay-Carbonate-Organic Mix & 39 \\
Alkaline Peat & 33 \\
Clay-Carbonate & 16 \\
Clay & 270 \\
Pure Quartz & 0 \\
Pure Calcite & 7 \\
Illite & 139
\end{tabular}

const ituents. The uranyl ion $\mathrm{LO}_{2}^{++}$is electrostatically adsorbed at these points. Other explanations for carbonate and humic bearing soils are discussed. The $\mathrm{kd}$ for the alkaline peat is very low compared to the $\mathrm{Kd}$ for acidic peats.

Calvo (1974) reported a short experiment on the metallogenetic aspects of the uraniu-organic matter reported a short experiment on the metallogenetic aspects of the uranium-organic matter association in nature. The author carried out several experiments on uranium fixation by organic matter with different degrees of maturity. Although further studies are considered necessary, the results already obtained lead to the following conclusion: when uraniferous solutions come into contact with humic organic matter, the efficiency and nature of the uranium-organic matter association thus established depends on the degree of carbonization attained by the muic material. At the begiming of the development process, the organic matter has high chemical activity and the uranium tends to occur in stable organic phases. As the process continues, a stage is reached from which uranium tends to form its oen winerals independently of organic atter. From the coalification stage onward the tendency toward uranium-organic matter association becomes increasingly less in any form. Petrographically, the humic constituents to which uraniu is closely and positively related belong to the huminite maceral group. Lastly, it is considered that when the organic matter is present as an accessory constituent in other sedimentary rocks and with quite low maturity indices, there is greater favorability for the formation of uranium deposits. 
result because the pH 6 region is a boundary between anionic and cationic uraniun forms and corresponds to: $\left[\mathrm{LO}_{2}^{+2}\right]+\left[\mathrm{\omega O}_{2} \mathrm{OH}^{+}\right]=\left[\mathrm{UO}_{2}\left(\mathrm{CO}_{3}\right)_{2}^{-2}\right]$, an equality between cation and anion uraniu forms in solution.

Kovalevskit (1967) found the uranium content of noncultivated soils in western Siberia increased with the clay content of the soils. Clay soils contained at least three times as much uranium as sands. Yakobenchuck (1968) correlated the total uranium content in Russian sodpodzilic soils from the Ukraine with other soil constituents. Uranium showed correlation with the oxidizes of silicon, iron, and aluminu suggesting coprecipitation or inclusion.

Erandstaff (1976) arrived at a rate expression for the effects of surface area and uraninite composition, oxygen content of the solution, carbonate conter.t, organics content, $\mathrm{pH}$ and system terperature on uraninite dissolution:

$R$, the rate of uraninite $\left(\mathrm{UO}_{2}\right)$ dissolution $=\frac{-d(\text { uran })}{d t}=10^{20.25}(\mathrm{SS})(\mathrm{RF})^{-1}$ $\left(10^{3.38-20.8 \mathrm{nOC}}\right)\left(\mathrm{arCO}_{2}\right)(0.0).\left(\mathrm{a}_{\mathrm{H}}\right) \exp \left(-7045 / \mathrm{Tday}^{-1}\right)$

where

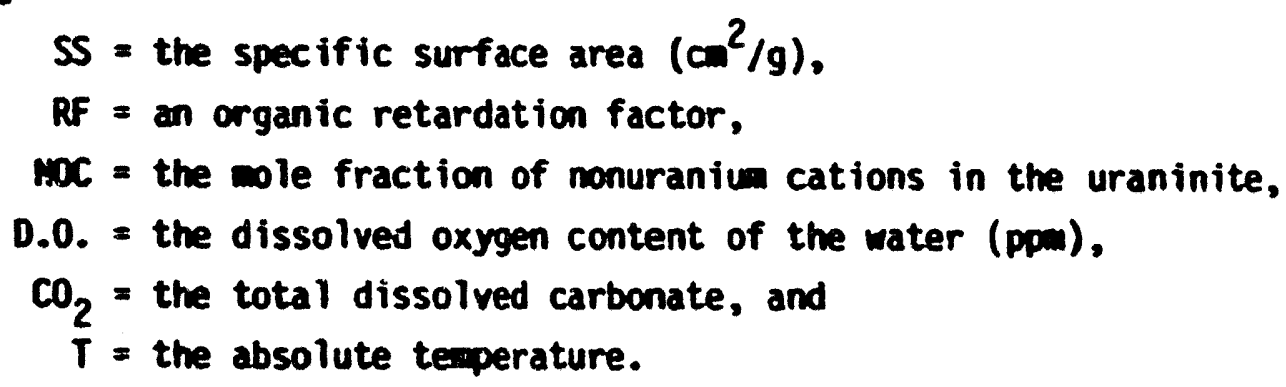

The rate expression was used to predict $\mathrm{wO}_{2}$ dissolution rates under varying conditions in the absence of organics in the contacting water with good results. Dissolved inorganic species in artificial sea water other than hydrogen ion activity (pH), total carbonate and dissolved oxygen did not appreciably affect the $\mathrm{NO}_{2}$ dissolution rate. The organic retardation factor 
must be deterwined experimentally for each organic-containing solution by comparing the calculated $\mathrm{wO}_{2}$ dissolution rate without organics in the environment with the observed dissolution rate, or $R F=R$ calculated/R observed. Retardation values of up to $\mathbf{4 2 0}$ were obtained. The agnitude of the effects of the several factors in the expression on the oxidation rate of $U($ IV) to $U(V I)$ could be of assistance in understanding uranium nobility in matural environments.

Schulz (1965) suggested that uranium may be present in the soil as the divalent uranyl ion, $\mathrm{UO}_{2}^{2+}$, and will be wobile in soils if present as the uranyl ios.

Alberti et a1. (1959) leached uraniva ore deposits with water and found the percentage leached to depend on the acidity of the solution. On the average, $18 \%$ of the total uranium solubilized in water, wile $20 \%$ sulfuric acid leached 606 of the total uranium.

Armands and Landergren (1960) report on a uranium rich peat bog. Leaching experiments on iron ore that contained $0.05 \%$ uran ium showed that 12 to $26 \%$ of the uraniu could be leached by MaHCO $_{3}$ solutions in 4 days; the uraniu in the bog probably cane from leaching the iron ore by ground-water bicarbonate solutions.

Coldszste in and Ros (1963) leached Mediterranean Sea sediments with $2 \mathrm{~m}$ nitric acid and found $60 \%$ of the uranium in continental shelf sediment and $36 \%$ of the uranium in abyssal plain sediments to be leachable.

Imahashi (1970) removed 50\% of the uranica content of hydrotherallyaltered rocks. Leaching performed under acid weather ing conditions is wore rapid than weathering processes under neutral conditions.

Legin, Kuznetsov and Lazarev (1966) leached sulf ide bearing sediments from the Black Sea and sediments from the Azov Sea with $0.7 N$ sodiun bicarbonate. The sulfide rich Black Sea sediment's uraniu quantitatively leached whereas only 4 to $6 \%$ of the uranium in the Azov Sea sediment mobilized. 
Titaeva and Veksler (1969, 1969) found uranium leached from metanorphic gneiss and crystalline schists by ground waters from the Russian permafrost area. The waters, contained high organic loads, oxygen and carbon dioxide contents mich frion a geochemical standpoint all favor uraniu mobilization. Uranium migrated fastest, radium slower and thorium slowest in the extremely cold ground waters. Baturin, Illyina and Popov (1971) found the same order of migration in a marine sedimentary regine.

\section{Field Studies}

There is a large anount of literature on the geochemistry of uranium because of its great value as a fuel for nuclear reactors. The uraniu chemistry in the matural environment has been well studied with the practical objective to better predict the occurrence of ores.

Several imestigators have observed correlation between uraniu content and sediment Eh, organic carbon content, particle size, phosphorous content, and hydrous oxide content. Many of these characteristics are interdependent such that a clear understanding of the controlling mechanisa for uranium adsorption is not possible. For instance one observer will cla in Eh controls uraniu adsorption wile another believes organic carbon is the active adsorbate. Since it is common to find high organic matter and reducing conditions present together the correlation of each parameter with uraniun content is possible.

Anong the imestigators tho have found uranium to be imobilized by reducing conditions in rocks and sedients are Adans et al. (1959), Agairov (1963), Baturin (1966), Baturir et al. (1966), Bonatti et al. (1971), Dorta and Rona (1971), and Veek (1967). Sediments from the Black Sea, Caspian Sea, Cariaco Trench, Pacific Ocean, Eulf of California, a Monwegian Fjord and Terrestrial rocks were studied. Reduced sediments contained 1 to $39 \mathrm{ppm}$ uranium versus oxidized deep sea clay values averaging 3 ppm. Koliadin et al. (1960) based on the observance of $U(V I)$ carbonate complexes in solution just above anoxic Black Sea sediments believed uraniu reduction was not occurring. As mentioned in the section on mechanisas, the Eh of sediments can vary 
rapidly over small distances. It is very likely that $U(V I)$ can exist in solution directly above recucing sediments yet become adsorbed as U(IV) into the sedinents within a reducing film around the sediment particles.

miel et al. (1972), Armands and Landergren (1960), Baranov ard Titaeva (1961), Baturin (1968, 1969, 1971, 1973), Batur in and co-workers (1966, 1967, 1969, 1971, 1973), Calvo (1974), Kochenor et al. (1967), Kolodny and Kaplan (1970) and to et al. (1973) found the total uranium content of sediments to correlate with organic content suggesting organic matter adsorbs significant amounts of uranium. Sediments wich were included are fresh water peat, Lena River (Russia), Baltic Sea, Black Sea, Indian Ocean, Mediterranean Sea, Cuif of Mexico, Saanich Inlet (British Columia), and Pettaquanscutt River (Rhode Island). In one study of sediments offshore of Japan, Mizuno and Mochizuki (1970) found no correlation of uranium content with organic carbon. Instead they found uraniu correlated with fine particle size sediments.

Kochenov and Baturin (1967) found the uranium in Aral Sea sediments to correlate with both organic watter and particle size. Sand and silt ooze contained only 1 to 2 ppo Uranium, ar villaceous (clay sediments and organic rich sediments) contained over 10 ppo uranium.

Baturin (1969), Baturin et al. (1971), Bell (1960), Habashi (1962), Kolodny (1969), Kolodny and Kaplan (1970), Kuznetsor et al.. (1968), Mihalik (1968) and Sakanove (1960) all present field data correlating high uranium contents with high phosphorus suggesting phosphate mineral formation scavenges uraniug.

Haglund (1968), Haglund et a1. (1969), Lambet and Nikolaev (1962), Kuznetsov et al. (1967), Ermolaev et al. (1965) and Pyalling (1970) have studied the uranica content in maters and find soluble carbonate couplexes of $U(V I)$ increase its solubility and mobility in waters.

Baturin (1971, 1973a, 19730) and Baturin and Kochenov (1973) concluded after studies on Atlantic, Pacific, Azov Sea, Black Sea, and various river sediments that all the above mentioned mechanisms (Eh, organic watter, P, carbonate) all play a role in the adsorption affinity of uranium. 
From the several field measurements observed, $\mathrm{Kdy}$ values can be calculated. Typical marine sediments of high organic or reducing potential contain $1 . \% \mathrm{ppm}$ uranium mile the overlying sea waters contain 1 to $10 \mathrm{~g}$ uranium wich yield an average range in $\mathrm{Kdy}$ of $10^{2}$ to $8 \times 10^{4} \mathrm{ml} / \mathrm{g}$ with $10^{3}$ beiny median values [Batur in and Emelanov (1973), Kochenov and Baturin (1967), Suginura (1964)].

Bhat and Krishnaswany (1969) measured Indian River water uranium concentrations at 0.01 to $7 \mu \mathrm{g} / l$ dependent upon the source rock over which the rivers flow. Koczy et al. (1957) report a range of 0.5 to $12.8 \mathrm{\mu g} / \ell$ for rivers entering the Baltic Sea.

Baturin and Kochenov (1969) report that $50 \%$ of the uranium entering the oceans from river runoff is soluble and $50 x$ is adsorbed on suspended matter.

From field measurements kennedy et al. (1977) have calculated Kds for $U$ in the Great Miami River (Ohio) for suspended particles to b? 1.0 to $1.6 \times$ $10^{3}$.

Kurokawa (1971) reports the range of uranium content in 40 Japanese soils as 0.48 to $2.89 \mathrm{ppm}$ wile the average uraniun content in 10 rivers was $0.57 \mathrm{\mu g} / \mathrm{l}_{\text {. The }} \mathrm{Kd}$ for rivers would be above 1 to $6 \times 10^{3} \mathrm{ml} / \mathrm{g}$.

Krylov and Shats (1958) studied the uraniu contents in northwestern Russian mater bodies and concluded that uranium precipitation was controlled by iron hytroxide and muic compounds.

Ritchie, Hawaks, and Mctienry (1972) also found the uranium content of sediments from the Little Tallahatchie River to increase with decreasing particle size.

Yabuki and Shima (1973) measured the metal concentrations of carbonaceous coze and nearty manganese modules and concluded that the 20 times smaller concentration of uraniu in the nodules in comparison with other metals meant that the $\mathrm{UO}_{2}^{\text {tt }}$ ion in sea water rareily coprecipitated with manganese and iron. The uranium present in nodules probably represented surface adsorbed uranyl carbonate complexes. 


\section{Sumary}

The comson oxidation states of uranium are $U(I I I), U(I V), U(V)$ and $U(V I)$. However, in the geologic environment $U(I V)$ and $U(V I)$ are the most important oxidation states. In oxidizing environments $U(V I)$ will predominate. U(IV) would precipitate as $\mathrm{WO}_{2}$ in a reducing environent. $U(V I)$ solution species govern uraniu concentrations and movement in oxidizing environments. Uranium retention by soils and sediments in oxidizing and alkaline conditions is poor because the predominant uranium species at pH 6 in oxidizing environments are either neutral or negatively charged. An increase in $\mathrm{CO}_{2}$ pressure in solutions reduces uranium adsorption and can increase uranium concentration. The cation exchange properties of sediments could contribute to the adsorption of uraniu in the neutral to acidic pH range due to the presence of $\mathrm{wO}_{2}^{2+}$. Oxidation-reduction conditions and PH would be important parzacters of uranium mobilization and imobilization.

The above theoreticaily based predictions are substantiated by experimental results. Uranium has been reported to be solubilized and highly mobile in carbonate-containing wers (Brown and Keller, 1951; Maumov, 1961; Ermolaev et a1., 1965; Legin et a1., 1966; Haglund, 1968, 1369). Soluble uranium [U(VI)] can:

1. precipitate in the presence of phosphorus as evidenced by a direct correlation of uranium and phosphate content in soils and sedisents (Bel1, 1960; Sakanove, 1960; Habashi, 1962; Kuznetsov et al., 1968; Menzel, 1968; Mihalik, 1968), and

2. be adsorbed by the soil organic component and/or reduced to U(IV) followed by precipitation (Breger et al., 1955; Kolodny, 1969; Kolodny and Kaplan, 1970; Baturin, 1971; Dall'Aglio, 1971; Dorta and Rona, 1971; Gabelaan, 1971; Baturin and Kochenov, 1973; Mo et al., 1973).

An increase in uraniu content with a decrease in sediment particle size was reported by several workers (Kovalevskii, 1967; Mizuno and Mochizuki, 1970; Ritchie et al., 1972). 
The uranyl ion can be adsorbed on clay minerals (Eoldsztabu and Hey, 1955; Kovalevskii, 1967; Rubtsov, 1972; Ritchie et a1., 1972; Rancon, 1973) and other adsorbent materials (Masuda and Yamanoto, 1971; Yamanoto et a1., 1973), but also is inclined to form complexes with anions, such as carbonate, that are commonly found in the solution. Uranyl salts also have been shom to substitute for $\mathrm{Ca}^{2+}$ during replacement of calcite by apatite (Ames, 1960), and $\mathrm{Ca}^{2+}$ competes with $\mathrm{UO}_{2}^{2+}$ for available sites during ion exchange reactions on inorganics such as calcite (Rancon, 1973) resulting in low uraniun Kd values. However, uranyl ion adsorption on organic materials and mmic substances is quite high (Szalay, 1954, 1957; Manskaya et a1., 1956; Rozhkova et al., 1959; Rancon, 1973) especially at acid ph values. The most important parameters of uranium aigration and retention are system Eh and pH. 


\section{ZIMC}

\section{Matural Sediment Distribution}

Some average values for zinc in marine and fresh water clays are found in Table 8.86.

TABLE 8.86. Zinc Concentration in Sediments

\begin{tabular}{|c|c|c|}
\hline Type & $\begin{array}{c}\text { Concentration, } \\
\text { pep }\end{array}$ & Reference \\
\hline $\begin{array}{l}\text { General Ocean } \\
\text { Sediment }\end{array}$ & $80-250$ & Duursma, 1974 \\
\hline Pelagic Carbonates & 35 & Turekian and Wedepoh1, 1961 \\
\hline Pelagic Clay & 165 & Turekian and Hedepoh1, 1961 \\
\hline Manganese Module & 6600 & Riley and Sunhaseni, 1958 \\
\hline Freshwater Clays & $80-230$ & Lundeardh, 1947 \\
\hline Soils & 50 & Vinogradov, 1959 \\
\hline
\end{tabular}

\section{Brief Chemistry}

There are five stable isotopes of zinc with the following abundances ${ }^{64} \mathrm{Zm}(48.87 x),{ }^{66} \mathrm{Zm}(27.62 x),{ }^{67} \mathrm{Zn}(4.12 x)$ and ${ }^{68} \mathrm{Zn}(18.71 \%)$. The only radioactive zinc isotope of consequence to nuclear waste disposal ${ }^{65} \mathrm{Zn}$ has a 250-day half-life.

\section{Solution Equilibria}

Zinc exists exclusively in $\mathrm{Zn}$ (II) oxidation state. The predominant zinc species in solution below approximately pH 8 is $2 n^{2+}$, and between pH 8 and 11.5 is $\mathrm{Zn}\left(\mathrm{OH}^{\circ}\right)_{2}$ in both fresh and salt water (Baes and Mesmer, 1976; Lindsay, 1972; Zirino and Healy, 1970; Zirino and Yamanoto, 1972).

\section{Laboratory Adsorption}

Aston and Ourursa (1973), Dawson and Duursma (1974), Duursma and Bosch (1970), Dursima and Eisma (1973), Duursma and Gross (1971) and Duursma et al., (1974) report on sorption-desorption studies on zinc in the marine environment. 
The addition of stable zinc between 50 to $1000 \mathrm{\mu g} / \ell$ did not consistently alter $\mathrm{KdZn}$ for four marine sediments but below $35 \mu \mathrm{g} / \ell$ additional $z$ inc the $K d$ was larger. The natural zinc concentration in sea water is $5 \mu \mathrm{g} / \mathrm{l}$. It was also noted that $25 \%$ of zinc added to sea water was filterable after $50 \mathrm{hr}$ suggesting colloid formation or precipitation. The Kdza was dependent upon sediment concentration below $200 \mathrm{mg} / \ell$ for 3 of 4 sediments studied. Very high $\mathrm{Kd}$ values $(\times 40,000)$ occurred at sediment loads below $200 \mathrm{mg} / \ell$. Above $200 \mathrm{mg} / \mathrm{l}$ KdZ leveled off at about $20,000 \mathrm{ml} / \mathrm{g}$. This suggests nucleation of colloids or precipitates and inflates the sorption. For one sediment, sorption studies were performed as a function of salinity. The adsorption was independent of salinity suggesting ion exchange does not control zinc adsorption. In later experiments on world ocean sediments the $\mathrm{KdZ}$ was shown to correlate with sediment cation-exchange capacity suggesting exchange does play a role in zinc adsorption. For two marine sediments wich were split into six size fractions the KdZn was higher for silt ranges 8 to $16 \mu \mathrm{m}, 4$ to $8 \mu \mathrm{m}, 16$ to $32 \mu \mathrm{m}$ than the clay fraction < 4 suggesting sorption on hydrous oxides wight play a role in zinc adsorption. For a Black Sea sediment the $\mathrm{KdZ}$ under anoxic conditions was 11 times larger than the $K d Z m$ for oxic conditions $\left(4.8 \times 10^{4}\right.$ versus $\left.4.5 \times 10^{3} \mathrm{ml} / \mathrm{g}\right)$. This suggests sulfides present in reducing sediments could imobilize zinc. Table $\mathbf{8 . 8 7}$ lists average values for the zinc distribution coefficient and half period of sorption for sediments studied by Duursma and co-workers.

In one long-term, 7-month experiment $50 \mathrm{~g}$ of Mediterranean Sea sediment was shaken with 10 liters of sea water traced with $1 \mu_{C i / l}{ }^{65} \mathrm{Zm}$. After 7 months the adsorbed zinc was leached with IN acetic acid-annonium acetate (pH 5.4) and 11 acetic acid (pH 2.3). In the first instance 4 to $33 \%$ of the adsorbed zinc was leached, in the latter case 10 to $80 \%$ was rewoved. Strontium wich adsorbs by ion exchange was completely leached in both cases. Thus there is wore than simple ion exchange controlling zinc adsorption. Onishi et al. (1973) found that zinc present in sea water was quantitatively removed by in situ precipitation of manganese dioxide. 
TABLE 8.87. Zinc Sorption in Marine Environments

\begin{tabular}{|c|c|c|c|}
\hline Sediment & $\log K$ & $\begin{array}{l}\text { est. } \\
\text { Kd } \mathbf{m i / g}\end{array}$ & $\begin{array}{c}t^{1 / 2} \begin{array}{l}\text { Sorption, } \\
\text { days }\end{array} \\
\end{array}$ \\
\hline Atlantic Ocean & $3.8+0.9$ & $9.2+10^{3}$ & $2.5+2.7$ \\
\hline Pacific Ocean & $3.6 \pm 0.5$ & $6.3 \pm 10^{3}$ & $1.1 \pm 1.0$ \\
\hline Indian Ocean & $3.6 \pm 0.4$ & $6.6 \pm 10^{3}$ & $2.4 \pm 1.7$ \\
\hline Baltic Sea & $3.6 \pm 0.7$ & $6.7 \pm 10^{3}$ & 5 \\
\hline Morth Sea & $3.8+0.1$ & $9.5+10^{3}$ & 2 \\
\hline Mediterranean Sea & $3.8 \pm 0.8$ & $8.8 \pm 10^{3}$ & $0.9 \pm 0.7$ \\
\hline Black Sea & $4.0 \pm 0.7$ & $1.5 \pm 10^{4}$ & $3-$ \\
\hline Red Sea & 4.3 & $3.0 \pm 10^{4}$ & 2.5 \\
\hline
\end{tabular}

Murray and Murray (1973) adsorbed zinc on river sediments and studied its subsequent rewoval by seawater as a function of $\mathrm{pH}$, time and sediment concentration. Using $800 \mathrm{mg} / \ell$ river sediment, zinc adsorption was observed to reach steady state in from 1 to 3 days. Desorption steady state was reached after one day. In blank experiments without sediment only $3 x$ of the total zinc became particulate $(>0.45 \mathrm{~m})$ in river or sea water, but if $\mathrm{Fe}(\mathrm{OH})_{3}$ was precipitated $50 \%$ of the zinc was rewoved also.

The adsorption and desorption of zinc is rather sensitive to pH changes as shown in Figures 8.39 and 8.40. Between $\mathrm{pH} 7$ and 8 adsorption doubles for the river conditions studied. Between pH 8 and 9.5 the adsorption is constant. Conversely for desorption by sea water the rewoval zinc steadily decreases as pH increases. For the river environment calculated $\mathrm{KdZ}$ is 850 at $\mathrm{pH} 7$ and 5000 at pH 8. The desorption KdZ are 380 at pH 7 and 3750 at pH 8. The values are low because the desorption took place in sea water. The adsorptiondesorption also appeared to be a function of sediment concentration. For adsorption increasing sediment from $200 \mathrm{mg} / \mathrm{l}$ to $800 \mathrm{mg} / \mathrm{l}$ load increased total adsorption but decreased per unit weight adsorption i.e., Kdzn decreased 33\%. For desorption increasing contaninated sediment load leads to proportionally less zinc release/unit wight. 


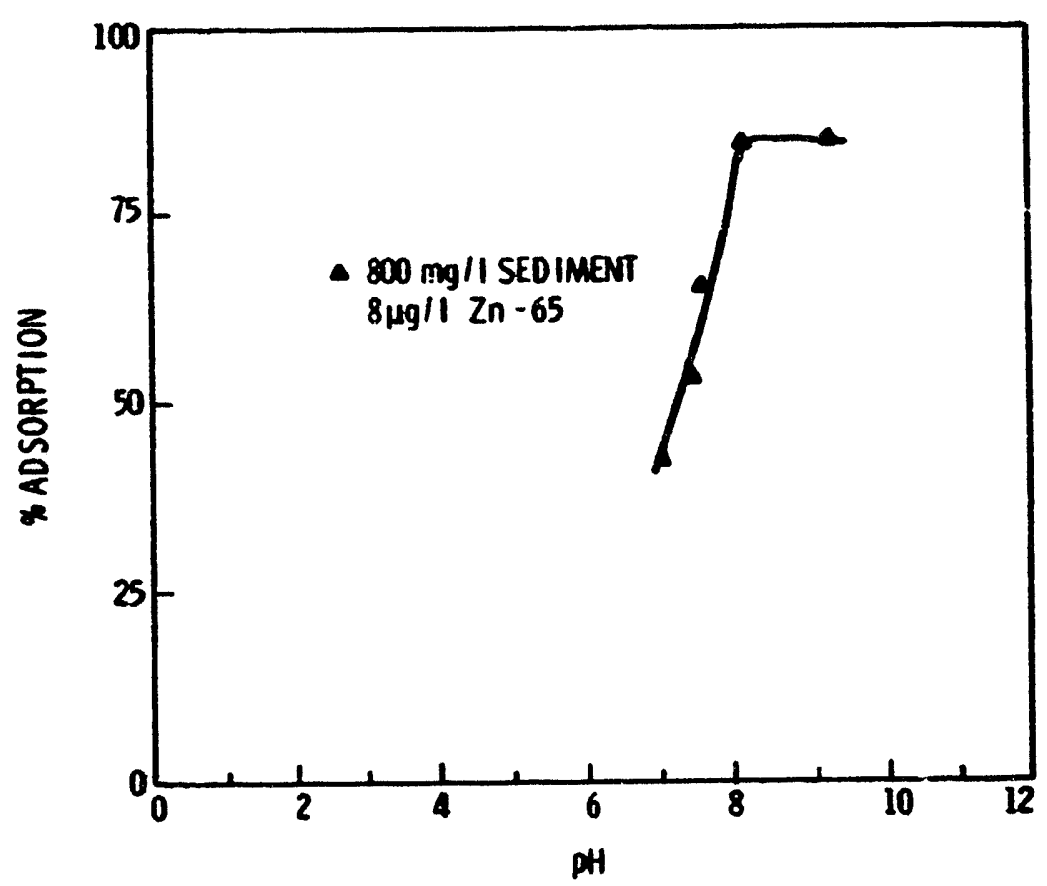

FIGURE 8.39. Adsorption of Zinc at Constant Carrier Concentration and Sediment Lead with Varying pH

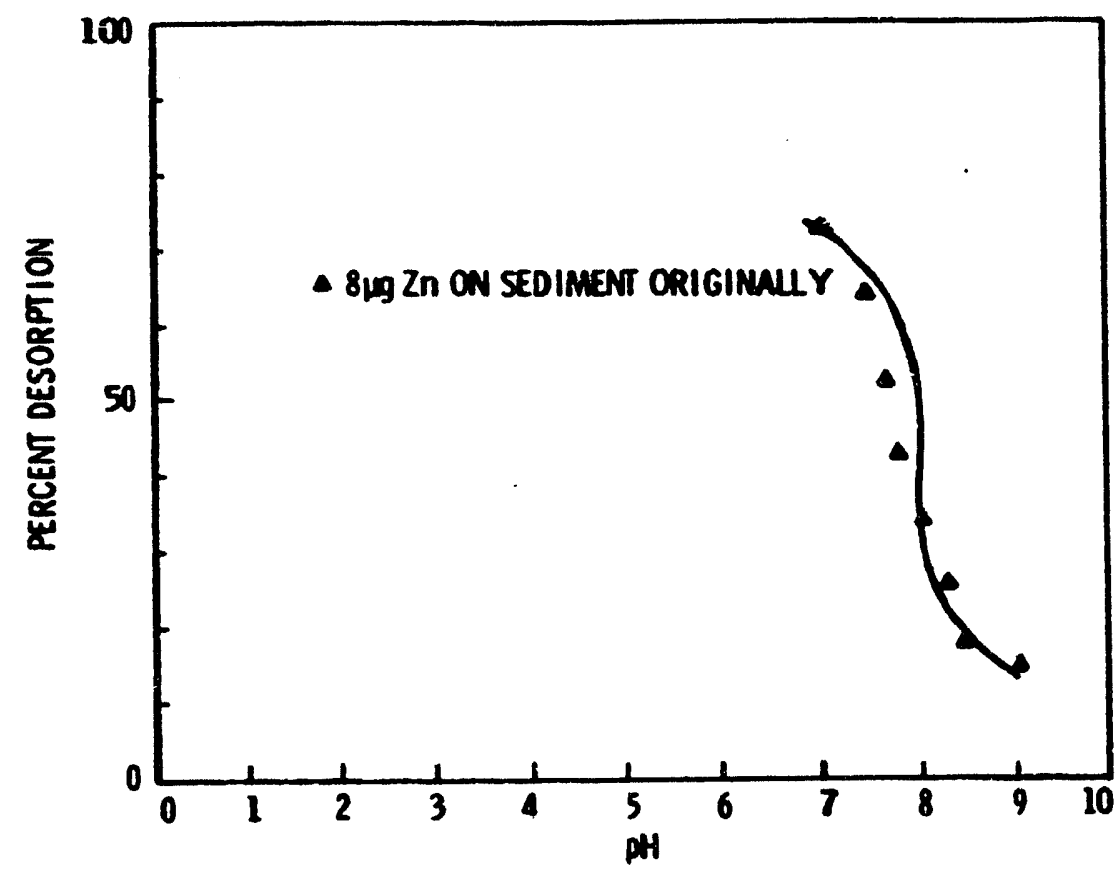

FIGURE 8.40. Desorption of Zinc at Constant Adsorbed Trace Element Concentration and Sediment Load with Varying pH 
The effect of salinity on desorption of zinc from contaminated river sediments is small compared to the pH effect for salinities 25 to $38 \%$ as shom in Figure 8.41.

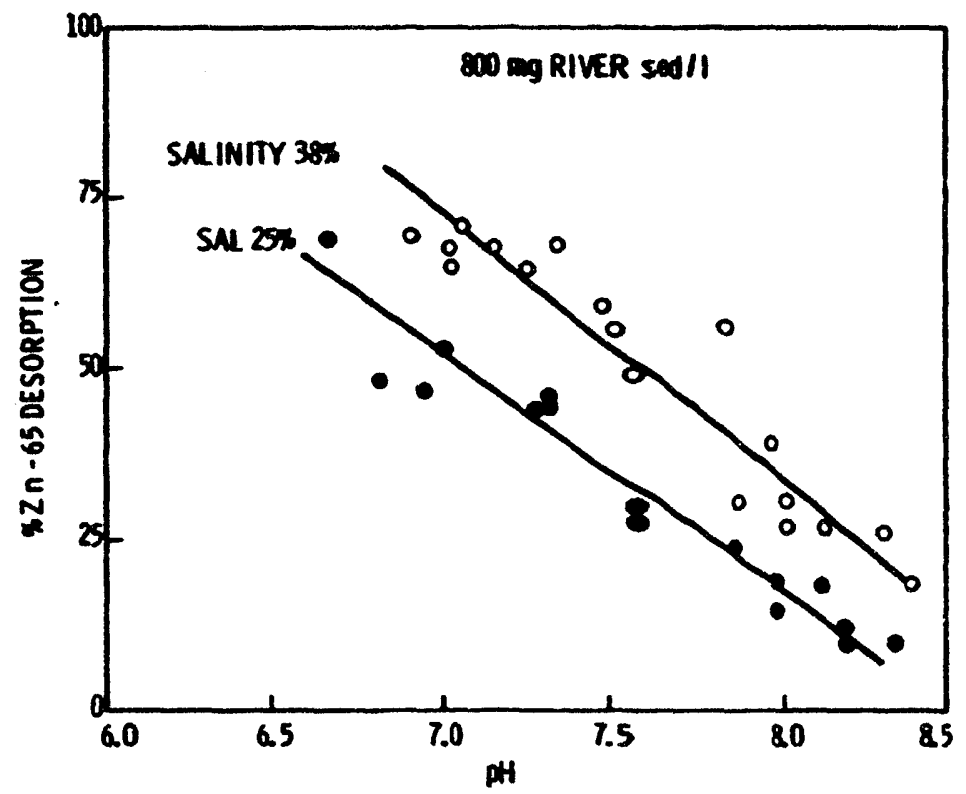

FIGURE 0.41 . Variation of Desorption of Zinc in Sea Hater of Different Salinities at Different $\mathrm{pH}$

Piro et al. (1975) describes an interesting experimental study using anodic stripping voltametry wich permits the simultaneous determination of stable and radioactive ionic zinc in aqueous solution. With this apparatus it is possible to investigate the exchange reactions between stable ionic and complexed zinc and radioactive ionic zinc in NaCl solution and sea water. In $\mathrm{NaCl}(34 \% \mathrm{~S})$, in presence of a complexing agent, after about one hour the ${ }^{65} \mathrm{Zn}$ is distributed between the noncomplexed and complexed fractions in the same way as the stable isotope, indicating a complete exchange reaction. On the other hand, adding ionic ${ }^{65} \mathrm{Zn}$ to sea water, the radioactive isotope is not uniformly distributed in all physico-chemical states present in the sea water but is diluted only in the ionic and particulated fractions. Even one year after the addition of ${ }^{65} 2 n$, the radioactive $z$ inc has not entered the complexed fraction. The consequences of this fractionation for the interpretation of tracer experiments and hazard evaluation are discussed. 
These results raise an important question on the validity of all sorption-desorption experimentation in wich added tracers are used.

Schneider and Block (1968) studied the adsorption of $\operatorname{Zn}($ II) ions onto Rhine River sediments. Steady state adsorption was reached within 1 day.

Seymour et al. (1979) measured the KdZn for three sediments wich had been sterilized by ${ }^{60} C_{0}$ treatment. An anoxic silty marine clay/seawater slurry gave a $\mathrm{KdZn}$ of $1.96 \pm 0.47 \times 10^{3} \mathrm{ml} / \mathrm{g}$. A marine silty sand/seawater slurry gave a value $27.5 \times 10^{2} \mathrm{ml} / \mathrm{g}$. A freshwater clay/lake water slurry gave a value of $5.16 \pm 0.77 \times 10^{3} \mathrm{ml} / \mathrm{g}$.

In two dialysis experiments Schell et al. (1979) studied the distribution of zinc in seawater and its reaction with sediments, plankton and organic detritus. Zinc wich passed through dialysis bags holding sediments and plankton (see Table 8.9, An Section) shors strong sorption tendencies. On the other hand a second dialysis experiment shows zinc remaining predominantly in solution (see Table 8.10, Am Section).

Essington and Nishita (1966), Kulikov (1968) and Salo and Saxen (1974) have investigated the effects of natural organics and chelating agents on the interactions of zinc with soils and sediments. The chelating agents OTPA, EDOHA and EDTA were shown to decrease zinc adsorption. CDTA had no effect on zinc interactions. Natural humic substances with high wolecular weight were strongly associated with zinc in an estuarine environment. Soluble organic compounds of zinc would be expected in coastal waters.

\section{Field Studies}

Brungs $(1963,1964)$ added radiotracers to a 30,000-gal artificial pond and monitored their fate 80 days. Within one day of addition the soluble zinc content was about $10 \%$ of the spike addition and continued to slowly decrease over the 80 day period. Suspended solids accumlated most of the zinc and eventually settled to the bottom where after 80 days $98 \%$ of the zinc resided. After 80 days the observed $\mathrm{KdZn}$ for suspended and botton sediments were $3.1 \times$ $10^{5}$ and 1.0 to $3.9 \times 10^{3} \mathrm{ml} / \mathrm{g}$, respectively. 
Gloyma et al. (1966) and Yousef et al. (1970) report on the fate of ${ }^{65} \mathrm{Zn}$ in model river and estuary flumes. Mumerous investigators have studied the fate of zinc present in the cooling waters of the Hanford reactors as it travels down the Columia River to the Pacific Ocean. To better understand the interactions with sediments several laboratory experiments were also performed. Their results will also be described in this section as they relate specifically to the field studies.

Delaplane et al. (1969) and Glenn (1971) report on a detailed study of ${ }^{65} \mathrm{Zn}$ content of Columbia River sediments versus particle size, cation exchange capacity, C.E.C. and carbon content and mineralogy. As particle size decreases zinc content generally increases with some anomalies explained by valuable C.E.C. and carbon content. On a mass basis through the ubiquitous fine to mediu sand contains $45 \%$ of the adsorbed zinc wile the clay contains $16 \%$.

Haushild et a1. (1971, 1973a, 1973b) and Melson and Haushild (197u, report on the second and spatial variations in ${ }^{65} \mathrm{Zn}$ concentrations in suspended and soluble fractions. During transit from Pasco to Vancouver ( $240 \mathrm{miles}$ ) the soluble fraction of zinc decreases 30 to $50 \%$ depending upon the year. At Pasco the soluble fraction $(<0.3 \mu \mathrm{m})$ accounts for 55 to $70 \%$ of zinc while at Vancouver the value is 18 to 23\%. Gross $(1966,1967,1972)$ and Gross et al. (1963), Carey et al. (1973), Forster and Hanson (1964) and Hanson (1967) studied the deposition of ${ }^{65} \mathrm{Zn}$ along the Columbia River mouth and coast of Washington and Oregon.

Nelson et al. (1966), Perkins et a 1. (1966), Robertson et al. (1973) and Battelle, Pacific Northwest Laboratories (1972) report on the speciation of ${ }^{65} \mathrm{Zn}$ found in the Columbia River water. In general the ${ }^{65} \mathrm{Zn}$ percentage particulate increased downstream from the reactors as shown in Table 8.88 although large variations occur depending on source. Evans (1973), Evans and Cutshall (1973), Johnson et al. (1967), Nelson et al. (1966), Osterberg et al. (1966) and Robertson et al. (1973) performed leaching experiments to determine the fate of adsorbed ${ }^{65} \mathrm{Zn}$ upon contact with sea water. 
TABLE 8.88. Distribution of ${ }^{65} \mathrm{Zn}$ in Columbia River Hater

\begin{tabular}{|c|c|c|c|c|c|c|}
\hline & $\begin{array}{l}\text { Distance } \\
\text { from } \\
\text { Reactor }\end{array}$ & $\begin{array}{c}\mathbf{8} \\
\text { Particulate } \\
>0.3 \text {. } \\
\end{array}$ & $\begin{array}{c}x \\
\text { Cationic }\end{array}$ & $\begin{array}{c}8 \\
\text { Anionic } \\
\end{array}$ & $\stackrel{8}{\text { nonionic }}$ & Source \\
\hline Eff luent & 0 & 16 & 84 & 0 & 0 & weison et al. (1966) \\
\hline (in Reactor) & 0 & 84 & 75 & $<1$ & $<1$ & $\begin{array}{l}\text { Robertson and Perkins } \\
\text { (1975) }\end{array}$ \\
\hline 300 Ares & 25 & 51 & 47 & 0.5 & 1.5 & Weison et al. (1966) \\
\hline Pasco & 50 & 14 & -- & $\cdots$ & - & Perkins et al. (1966) \\
\hline \multirow[t]{2}{*}{ Nenary Da } & 90 & 77 & 22.6 & 0.2 & 0.2 & weison et al. (1966) \\
\hline & & 99 & 0.6 & $<0.1$ & 0.5 & Robertson et al. (1973) \\
\hline Dalles Dan & 175 & 84 & 15.4 & 0.3 & 0.3 & meison et al. (1966) \\
\hline Hood River & 215 & 64 & - & - & -- & Perkins et al. (1966) \\
\hline \multirow[t]{2}{*}{ Var couver } & 275 & 76 & -- & $\cdots$ & -- & \\
\hline & & 80 & 16.6 & 2.4 & 1.0 & velson et a 1. (1966) \\
\hline
\end{tabular}

Robertson et al. loaded Mcllary Dan sediments $(30 \mathrm{~g})$ into a colum and leached with eight liters of sea water. At wost each liter rewoved about $1 x$ of the total adsorbed zinc. Nelson et al. (1966) leached bed sediments with 1N anoniun acetate and rewoved on ly $1.6 \%$ of the adsorbed zinc. Acetic acid (pH 3) removed $19 \%$ of the zinc. Osterberg et al. (1966) found less than $5 \%$ of the ${ }^{65} \mathrm{Zn}$ adsorbed on Columia River sedinents to be ion exchangeable. Johnson et al. (1967) leached nine Columbia River bed sediments with sea water and $0.0 .5 \mathrm{M} \mathrm{Cu} \mathrm{SO} 4$ solution. The sediments were from the Columbia River estuary up to Mcllary Dam (290 miles inland). Sea water leaching $150 \mathrm{ml} / 15 \mathrm{~g}$ sediment released typically less than 18 of the ${ }^{65} \mathrm{Zn}$, wereas greater than $25 \%$ of ${ }^{54} \mathrm{~mm}$ was released. In contrast an equal volume of copper sulfate solution leached 35 to $50 \%$ of the zinc. The other suggest "specific adsorption" as the binding mechanisa for zinc. Specific adsorption was defined as the metal adsorbed and cannot be displaced by alkali, alkaline earth or armonia ions, but can be displaced by other transition metal.

Evans (1973) and Evans and Cutshall (1973) found seawater did not rewove ${ }^{65} \mathrm{Zn}$ from bed sediments even after 11 meeks contact but would remove 15 to 
458 of the zinc adsorbed to suspended solids after $4 \mathrm{hr}$. Three hypotheses were suggested for the differing behavior: 1) the large surface area/volune ratio of the suspended particulates favored surface exchange reasions, 2) possible significant compositional differences between suspended solids and bed sediments, and 3) aging effect allowing surface bound zinc to slowly diffuse into internal lattices of bed sediment.

\section{Sumary}

In water zinc is found in the cationic and at high pH neutral hydrolyzed form. Laboratory experiments suggest colloid formation and precipitation is a dominant adsorption mechanism. Other experiments suggest cation-exchange like mechanises and hydrous oxide sorption play a role in zinc adsorption. In all instances the zinc $\mathrm{Kd}$ in warine environment was quite large, $10^{3}$ to $10^{4}$. In fresh water environments the $\mathrm{KdZm}$ is very sensitive to $\mathrm{pH}$ changes being in one instance 850 at $\mathrm{pH}$ and $5000 \mathrm{ml} / \mathrm{g}$ at pH 8 .

Organic chelation may affect the fate of zinc becacse of highly stable complexes. 


\section{ZIRCOWILA}

Matural Sediment and Rock Distributions

The zirconiun distribution and content in igneous and sedimentary materials are shown in Table 8.89. It should be noted that anch of the zirconiun contained in sedimentary rocks is present as resistate material such as zircon (ZrSiO 4 ), wich is only very slightly soluble in any aqueous solution. The average content of worldwide soils is given by Vinogradov (1959) as $300 \mathrm{ppm}$ zirconivin.

TABUE 8.89. The Average Zirconium Content of Rocks

(Turekian and Hedepohi, 1961)

\begin{tabular}{|c|c|}
\hline Rock Type & $2 r_{2}, P_{2}$ \\
\hline \multicolumn{2}{|c|}{ Igreous Rocks } \\
\hline U1 tranafic & 45 \\
\hline Basaltic & 140 \\
\hline Granitic, high Ca & 140 \\
\hline Granitic, low ca & 175 \\
\hline Syenite & 500 \\
\hline \multicolumn{2}{|c|}{ Sedinentary Material } \\
\hline Shale & 160 \\
\hline Sandstone & 220 \\
\hline Limestone-dolosite & 19 \\
\hline Pelagic clay & 150 to 180 \\
\hline Pelagic carbonates & 20 \\
\hline Manganese nodule & 340 \\
\hline
\end{tabular}

Brief Cheaistry

Eighteen isotopes and two isomers of zirconium are shom. The naturally occurring isotopes are listed in Table 8.90. All are stable except ${ }^{96} \mathrm{Zr}$ mich has a malf-life listed as $3.6 \times 10^{17}$ years (Heast, 1976). For all practical purposes, ${ }^{96} \mathrm{Zr}$ also is a stable isotope. 
The inmediate concern in radioactive waste disposal is for ${ }^{95} \mathrm{Zr}$ with a relatively short half-life of 65 days. Also obtained in much smaller yields as a fission product is the longer-lived ${ }^{93} \mathrm{Zr}$ (half-life $1.5 \times 10^{6}$ years), wich is of long-term interest (Schneider and Platt, 1974). Zirconiu-35 decays by $B^{-}$evission to ${ }^{95} \mathrm{~m}$ which also evits a $B^{-}$and decays to stable 95 ro.

TMBLE 8.90. Matural Isotopes of Zirconium and Their Abundances (Heast, 1976)

$\begin{array}{cc}\text { Isotope } & \text { Abundance, \& } \\ 90_{\mathrm{Zr}} & 51.46 \\ { }^{91} \mathrm{Zr} & 11.23 \\ 92_{\mathrm{Zr}} & 17.11 \\ 94 \mathrm{Zr} & 17.40 \\ { }^{96} \mathrm{Zr} & 2.80\end{array}$

The wost stable and comon form of zirconium in rocks is as the simple orthosilicate zircon, $\mathrm{ZrSiO}_{4}$. The only oxidation state of zirconiun of any importance in aqueous solutions is $\mathrm{Zr}(\mathrm{IV})$, though usually not as $2 r^{+4}$ cations. Dee to the high charge and a small atomic radius $(0.72 \dot{A}$ in six-fold coordination, $0.84 \AA$ in octahedrai coordination (Shannon and Prewitt, 1969), zirconiu ions are readily hydrolyzed in aqueous solutions. When an acid solution is neutralized with a base such as $\mathrm{mH}_{\mathbf{4}} \mathrm{OH}$, hydrous zirconiu oxide is precipitated rather than zirconiu hydroxide. Zirconiu compounds, such as $\mathrm{ZrCl}_{4}$, react violently with water, producing high acjidy solutions. A zirconyl salt $\left(\mathrm{ZrOCCl}_{2} \cdot \mathrm{BH}_{2} \mathrm{O}\right)$ is produced with libnration of hydrogen ions. A solution $0.05 \mathrm{~A}$ in $\mathrm{ZrOCl}_{2} \cdot 8 \mathrm{H}_{2} \mathrm{O}$, for exaple, has a ph of 1 . The equilibriu establisted is $2 r^{+4^{2}}+n_{H_{2}} \mathrm{O} \rightarrow \mathrm{Zr}(\mathrm{OH})_{n}^{4-n^{-}}+\mathrm{nH}^{+}$and depends on the solution acidity.

According to Comick and MeVey (1949), in 2.0 to 0.24 perchloric acid at $25^{\circ} \mathrm{C}$, zirconiun exists as $\mathrm{Zr}^{\text {t4 }}$ and $\mathrm{Zr}(\mathrm{OS})^{+3}$ ions. At concentrations of perchloric acid of less than 0.21, the zirconiu species was probably $2 r(\mathrm{OH})_{2}^{+2}$. At or above $2.0 \mathrm{HCl0} 4$, zirconiun exists exclusively as $\mathrm{Zr}^{\text {th }}$ ions (Larsen and 
Mang, 1954). When zirconiun hytroxides are acidified with HCl, oxo cations $\left(2 \mathrm{rO}^{+2}\right)$ first appear, and not until the solution is $2 \mathrm{Zl}$ in $\mathrm{HCl}$ or higher, do appreciable amounts of $\mathrm{Zr}^{\text {t4 }}$ ions appear (Lister and McDonald, 1951).

Zirconium forms very stable complexes with halogens of the type $M_{2} Z r_{6}$ where $M$ is a univalent metal and $G$ is a halogen. Zirconiu also forms a series of complexes with fluoride phosphate and sulfate ions and many of the organic ligands. Electrolysis of a solution of $\mathrm{Zr}\left(\mathrm{SO}_{4}\right)_{2} \cdot \mathrm{ZH}_{2} \mathrm{O}$, for example, produces hydrogen at the cathode and zirconium sulfate at the anode. Hence,

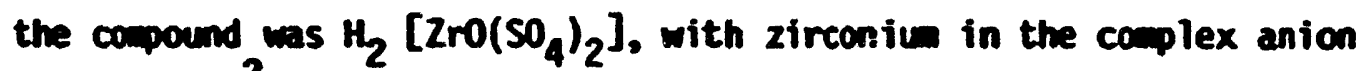
$\left[\mathrm{ZrO}\left(\mathrm{SO}_{4}\right)_{2}{ }^{1-2}\right.$. Since most of the waste solutions containing zirconium are near-neutral solutions, no $\mathrm{Zr}^{+4}$ ion should exist in solution. Only charged to neutral polymers and complexes of zirconium exist in the pH range of most radioactive waste solutions.

\section{Solution Eguilibria}

The activity of various solution species with a change in pH and in equilibriu with zircon $\left(2 \mathrm{rSiO}_{4}\right)$ and $\mathrm{soil}^{\mathrm{SiO}_{2}}$ is given in Figure 8.42. The thennodynamic data for all the hydrolysis species were selected from Baes and Mesmer (1976). Other solution species data were selected from Sillen and Martell (1964). Zirconiun forms complexes with the comon anions $\left(\mathrm{F}^{-}, \mathrm{Cl}^{-}\right.$; $\mathrm{SO}_{4}^{2-}, \mathrm{M}_{3}^{-}$). The significance of complexation of zirconium with these anions decreases in the following order: $\mathrm{F}^{-}, \mathrm{SO}_{4}^{2-}, \mathrm{Cl}^{-}, \mathrm{mO}_{3}^{-}$. Although zirconiu forms complexes with comon anions, Zrf ${ }^{37}$ complex would be the only one wich could contribute significantly in acidic environents (pH 3.5) to the total zirconiu in solution. It can be seen from the diagram that the uncomplexed zirconiun $\left(2 r^{4+}\right)$ would exist in significant anounts only in very acidic solutions $(D H<1)$. The zirconiu ions are hydrolyzed in solutions with pH values of greater than 1.0. The most dominant zirconium solution species with the conditions assumed in figure 8.42 are $2 \mathrm{rf}^{3+}$, $\operatorname{Zr}(\mathrm{CH})_{4}^{0}$, and $\operatorname{Zr}(\mathrm{OH})_{5}^{-}$in pH ranges of $<3.5,3.5$ to 6.25 , and $>6.25$, respectively. 


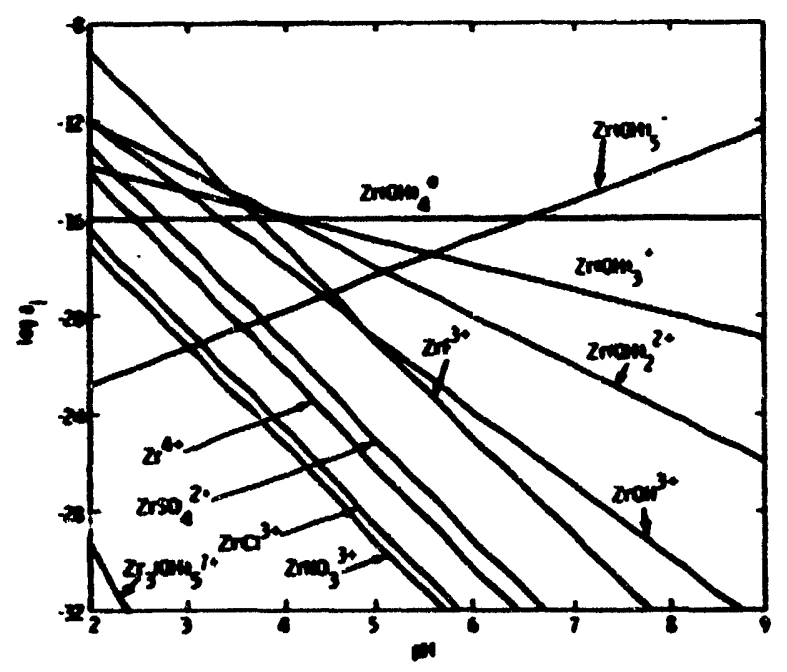

FIGUE 8. 2. The Activity of Various Zirconiv Species in Equilibrium with Zircon [2rSiO 4 (s)] and Soil Solytion Silica (pH4SiO4 $=3.1$ ) at $\mathrm{PC}^{-}=\mathrm{PSO}_{4}^{2}=2.5, \mathrm{PmO}_{3}=3.0$ and $\mathrm{pF}-=4.5$

If a waste solution containing zirconium is assuned to be in equilibriu with zircon and the conditions assumed in Figure 8.42, then the total activity of zirconium in solution would be lower than $10^{-14}$ over a pH range of 3.5 to 8 .

The $\mathrm{Zr}^{4+}$ ion becomes increasingly hydrolyzed above oH 1. The $\mathrm{Zr}^{4+} \mathrm{con}$ tent of the solution falls rapidiy, as does the content of fluoride ccoplex $\mathrm{Zrf}^{3+}$, in favor of hydrolyzed species at higher ph values. Only at relatively low ph values of less than four do positively charged species of zirconiu predominate. Because wost soils and sediments buffer waters contacting then to pH 5 or higher, ion exchange probably plays a relatively minor role in zirconion retention by soils and sediments. Because of the formation of negatively charged complexes in solutions of pH >6.5, zirconium adsorption would be expected to decrease with an increase in pH above 6.5.

\section{Laboratory Adsorption Studies}

Baranova and Polikarpov $(1966,1968)$ studied the adsorption of zirconic on shallow water marine muds. Adsorption was quite large. 
Doshi et al. (1973) found zirconium was quantitatively adsorbed by manganese dioxide formed in situ in sea water.

Dursma and Gross (1971) and Dursia and Eisma (1973) sumarize their work on zirconium adsorption in marine environments. They believe the adsorption is controlled by hydrolysis product $\left[\operatorname{Zr}(\mathrm{OH})_{n}^{4-n]}\right.$ precipitation. Their $\mathrm{KD}_{\mathrm{Zr}}$ values deterwined are for initial concentrations of 1 ppo zirconiu wich is much higher than matural sea water concentrations of $0.03 \mathrm{ppb}$. The values reported in Table 8.91 may thus be overestimated because of precipitation. For Dutch (Hadden) Sea and Mediterranean Sea sediments the fime silt fractions 4 to $10 \mathrm{um}$ adsorb more zirconiu than swaller clay fractions which suggests ion exchange is not the controlling mechanisw. For a Black Sea sediment adsorption under oxidizing conditions was $33 x$ greater than under reducing conditions $\left(\mathrm{Kd}_{\mathrm{Zr}} \sim 1.8 \times 10^{4}\right.$ versus $\left.1.35 \times 10^{4}\right)$.

TABLE 8.91. Zirconium Adsorption on Marine Sediments

\begin{tabular}{|c|c|c|c|}
\hline Sediment & $\log x$ & $\begin{array}{l}\text { est. } \\
\mathrm{Kd}, \mathrm{ni} / \mathrm{g}\end{array}$ & $\begin{array}{c}t_{1 / 2} \begin{array}{l}\text { Sorption, } \\
\text { days }\end{array} \\
\end{array}$ \\
\hline Atlantic Ocean & $4.0 \pm 0.6$ & $1.5 \times 10^{4}$ & $4+2$ \\
\hline Pacific Ocean & $4.2 \pm 0.6$ & $2.1 \times 10^{4}$ & $6 \pm 3$ \\
\hline Indian Ocean & $4.2+0.3$ & $2.6 \times 10^{4}$ & $8+2$ \\
\hline Baltic Sea & $4.9 \pm 0.2$ & $1.1 \times 10^{5}$ & 9.4 \\
\hline North Sea & $4.2+0.4$ & $2.4 \times 10^{4}$ & 5 \\
\hline Mediterranean sea & $4.3 \pm 0.6$ & $2.7 \times 10^{4}$ & $5+3$ \\
\hline Black Sea & $4.0 \div 0.1$ & $1.6 \times 10^{4}$ & $8^{-}$ \\
\hline Red Sea & $4.3^{-}$ & $2.7 \times 10^{4}$ & 6 \\
\hline
\end{tabular}

Garder and Skulberg (1964) studied the adsorption of ${ }^{95} \mathrm{Zr}$ oxalate tracer $(1.2 \mu \mathrm{c} / \mathrm{ml})$ added to distilled water on to glacial clays. Detailed characterization of sediment ater is given. For a sediment concentration of $64 \mathrm{mg} / \mathrm{l}$ it took three days for the percentage $\mathrm{Zr}-\mathrm{lb}$ adsorbed to stabilize. The $\mathrm{Kd} \mathrm{Zr}$ after one day contact was dependent on the sediment concentration. At 16, 32 , 
64, $1: 38$ and $256 \mathrm{~g} / \chi$ sediment concentration, the $K d$ was $5400,4500,3800,2350$ and $2400 \mathrm{ml} / \mathrm{g}$, respectively. In the natural environent zirconium would not be expected to be present as an oxalate complex so the usefulness of these values should be questioned.

Klingeman (1965) and Klingewan and Kaufman (1965) studied the desorption of $\mathrm{Zr}-\mathrm{Nb}$ traced clay-silt suspensions upon mixing of fresh water with sea wier. Zirconium was found to be irreversibly adsorbed on the suspended solids suggesting ion exchange is not controlling zirconium sorption.

Rhodes (1957) determined the effect of pH on the distribution coefficient of zirconiu-niobium on a Hanford soil. The soil was made up of $2 \% \mathrm{CaCO}_{3}$ with $>2$ diameter material, 6\%; 2 to 0.2 diameter material, $67 \% ; 0.02$ to $0.2=$ diameter material, 19\%; 0.02 to 0.002 diameter material, 6x; and <0.002 diameter material, 2\%. The cation exchange capacity was $5 \mathrm{meq} / 100 \mathrm{~g}$ and the water past PH was 8.6. The bulk of the soil consisted of quartz, feldspars, augite, olivine and mica. The clay fraction contained minly montmorillonite. The $\mathrm{Kd}$ values for zirconium as a function of $\mathrm{pH}$ are given in Table 8.92.

TABLE 8.92. Zircon-Miobium Kd Values as a Function of pH (Rhodes, 1957)

\begin{tabular}{|c|c|c|c|}
\hline pH & $\mathrm{Kd}, \mathrm{ml/g}$ & pH & $\mathrm{Kd}, \mathrm{Dl} / \mathrm{g}$ \\
\hline 0 & 82 & 8.3 & 282 \\
\hline 1 & 1028 & 9.6 & 90 \\
\hline 2.6 & 1340 & 10.2 & 104 \\
\hline 4.1 & $>1980$ & 11.0 & 180 \\
\hline 6.4 & $>1980$ & 12.2 & 1980 \\
\hline 7.7 & $>1980$ & 14.0 & 1980 \\
\hline
\end{tabular}

Rhodes considered that the dips in zirconium Kd for pH 8 to 12 were due to a charge alteration of the zirconiun polymer or colloid within this pH range. 
Benson (1960) reported a visible, white precipitate in systems containing $3 \times 10^{-2} \mathrm{H}$ zirconium. The uptake of trace ${ }^{95} \mathrm{Zr}$ was not appreciably different from that noted in the presence of carrier indicating that precipitation also occurred at the trace concentration. Zirconium was not appreciably affected by the presence of other cations unless the pH was below 2. Benson also reported that carbonate, oxalate and citrate ions inhibited zirconium uptake on soil over a wide pH range, probably because of the formation of complex anionic species.

Sorathesn et al. (1960) stated that ${ }^{95} \mathrm{Zr}$ behaved like a colloid at pH 6 to 9. They reported the zirconiu $K d$ on illite at 7 days equilibration time to be $24,470 \mathrm{ml} / \mathrm{g}$.

Prout (1959) reported that tests made at pH 4 with $10^{-3} \mathrm{M}_{2} \mathrm{O}_{4}^{-2}$ showed adsorption of zirconium-niobium on soil to be inhibited, but at $\mathrm{pH} 8$, the oxalate did not seriously affect the removal of zirconium-niobium. Schulz (1965) reported that zirconiug and niobium were two of the elements that were adsorbed by soil in a very imobile form.

Fallout material on soil from an underground nuclear explosion was used by Essington et a1. (1965) to determine the leaching effects of water, HCI and chelating agents. The soil was suspended in $25 \mathrm{ml}$ of solution and equilibrated for up to 106 days. The $10^{-4}$ molar chelating agents in solution included sod ium-diethylenetriaminepentaacetate, sodium-cyclohexane-1,2-dianinetetraacetate, sodiu-ethylenediamine di(0-hydroxyphenylacetate) and $0.1 \mathrm{M} \mathrm{HCI}$. Zirconium-95/Miobium-95 was identified in the original soil. Chelating agents, $\mathrm{HCl}$ and water equilibrations did not appreciably increase ${ }^{95} \mathrm{Zr}$ - ${ }^{95} \mathrm{Nb}$ solubility. In columen studies with Yolo soil (pH 7.9), Sorrento soil (pH 7.8) and Hanford soil (pH 6.6), water and calcium-diethylene-triaminepentaacetate $\left(10^{-4} \mathrm{M}\right)$ leaches of 7 days produced no detectable ${ }^{95} 2 R-95_{\mathrm{Nb}}$ in the effluent solution. The dominant clay minerals in the Hanford, Sorrento and Yolo soils were illite, kaolinite and montmorillonite.

According to Schulz (1965), the zirconium in soils is either very strongly adsorbed by the clay particles or is present as an insoluble oxide or hydroxide. In either case, the zirconium in the soil is immobile. 
Harrison (1969), using nuclear debris contaminated with ${ }^{95} \mathrm{Zr}-{ }^{95} \mathrm{Nb}$ as a source, approached equilibriu from the direction of starting with the radionuclide on the solid. The leaching produced ${ }^{95} \mathrm{Zr}-{ }^{95} \mathrm{Nb}$ Kd values of 5,200 to $17,000 \mathrm{ml} / \mathrm{g}$ in distilled water as a function of particle size range $(<4000$ to $<62 \mu \mathrm{m}), 790$ to $2700 \mathrm{ml} / \mathrm{g}$ in synthetic sea water for the same particlessize range and 270 to $1200 \mathrm{ml} / \mathrm{g}$ in $1 \mathrm{k}$ anonium acetate for that particle size range. An implication of this work is that cation exchange is involved

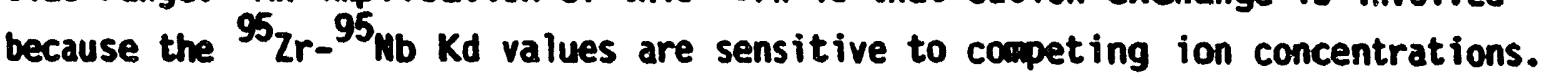

\section{Field Studies}

Eichholz et al. (1967) investigated the partitioning of dissoived radionuclides between suspended sedinent particles and aqueous solutions. Several natural water samples were characterized and used in the adsorption studies as suspended solids sources (see Table 8.93). A fission product mixture was adced to the natural water samples, the system equilibrated and the water recovered and filtered. The adsorption of ${ }^{95} \mathrm{Zr}$ and daughter ${ }^{95} \mathrm{Nb}$ are show in Table 8.92. A large portion of the zirconium was associated with the particulate matter in a highly concentrated form.

Adsorption does not appear to be a direct function of suspended solids content but has to include a consideration of dissolved solids content, pH and solids composition before the adsorption results begin to make any sense. The high ${ }^{95} \mathrm{Zr}$ adsorption on Chattahoochee River suspended solids was due to the low dissolved solids content ( $31 \mathrm{ppm}$ ), which suggests that a positively charged zirconium species was involved.

Magno et al. (1970) investigated radionuclides from the Nuclear Fuel Services Plant in Western New York that were migrating through the plant effluent lagooning system. They estimated that greater than $90 \%$ of the ${ }^{95} \mathrm{Zr}$ discharged from the plant was deposited by sedimentation in the lagoon system. 
TABLE 8.93. Adsorption of $95 \mathrm{Zr}$ and $95 \mathrm{Nb}$ on Suspended Solids in Matural Waters (Eichholz et al., 1967)

\begin{tabular}{|c|c|c|c|}
\hline Source & $\begin{array}{l}\text { Suspended } \\
\text { Solids, mog/l }\end{array}$ & $\begin{array}{c}95 \mathrm{Zr} \text { Adsorption, } \\
\mathrm{x}\end{array}$ & $\begin{array}{l}\text { 95Nb Adsorption, } \\
\mathrm{x}\end{array}$ \\
\hline Colorado River & 229 & 61.1 & 33.3 \\
\hline Camp Mccoy & 12 & 50.0 & 4.7 \\
\hline Bayou Anacoco & 24 & 80.5 & 23.8 \\
\hline Lodgepole Creek & 965 & $8 \mathbf{i} .3$ & -.- \\
\hline Chattahoochee River & 131 & 88.4 & 18.9 \\
\hline Billy's Lake & 8 & 53.9 & 8.9 \\
\hline
\end{tabular}

Perkins et al. (1966) and Melson et al. (1966) found about 70 of the ${ }^{95} \mathrm{Zr}-\mathrm{Mb}$ in the Columbia River at Hanford was on particulate matter $(>0.3 \mu \mathrm{m})$. The percentage did not change downriver all the way to the Pacific Ocean suggesting further significant dissolution-precipitation was not occurring.

Robertson and Perkins (1975) studied the distribution of ${ }^{95} \mathrm{Zr}$ between particulate, cationic, anionic and nonionic species for cooling water leaving N Reactor at Hanford. The zirconium $81 \%$ particulate, $11 \%$ anionic, $6 \%$ cationic and $2 \%$ nonionic. After percolating through alkaline sandy soil less than $10^{-4}$ of the original zirconium was observed in springs along the bank of the Columbia River.

Spitsyn et. al. (1958) used an alkaline solution (4 to $8 \mathrm{~g} \mathrm{MaOH} / \mathrm{l}, 200 \mathrm{~g}$ $\left.\mathrm{NaNO}_{3} / \mathrm{l}\right)$ and an acidic solution [6 to $\left.8 \mathrm{~g} \mathrm{HMO} / / l, 200 \mathrm{~g} \mathrm{Al}\left(\mathrm{MO}_{3}\right)_{3} / l\right]$ in laboratory and field studies of radionuclide migration rates. Zirconium was adsorbed and retained by a sand in field tests mear the point of injection of the waste solutions for both acidic and alkaline solutions. Little movement was indicated even under acidic conditions.

Sumary - -

Trace concentrations of zirconium are strongly adsorbed on sediments. Rhodes (1957) did observe a dip in Kd values between pH 8 to 12, probably due 
to the prevalence of uncharged or anionic zirconium species over this pH range (Figure 8.42). There are some evidence for affects caused by competing cations at near-neutral pH, suggesting at least partial rewoval by an ion exchange wechanism of polymerized or colloidal species (Eichholz et al., 1967; Harrison, 1969). Zirconiu is mell-adsorbed by the sediment over the normal pH range of 6 to 8. Carbonate, oxalate and citrate complexes of zirconium have been reported to migrate rapidly through soil columns (Bensen, 1960), but the concentrations of the hazards used in these experiments were inordinately large and they would not be expected in nature. In general zirconiun can be assuned to be bound strongly to sediments and suspended solids. 


\section{COMCLUSIONS AND EVALUATION}

The solution ions exist in dynamic equilibrium with bed sediment and suspended sediment. Many factors that are inherent to the solid matrix and the solution can influence the concentration of the element and its species in solution. These factors include $\mathrm{pH}$, Eh, CEC, type and amount of soil minerals, solid phases of the element, complexing ligands, and competing ions. In order to deterwine the distribution of the element between solution and solid and its reactions with the solid atrix, the identity and relatiye magnitude of the various factors are required. Such information would help predict the solution concentrations of the element and help extrapolate the results to other situations. However, the data presented in the Element Literature Review section indicate that there is a general lack of systematic evaluation of various factors that determine element-solid matrix interactions, and little information at present is available to quant ify the importance of the various factors. At best, the available data suggest trends for the influence of some of the factors that control solution concentrations and interaction with solid matrices. This type of information would not be very useful for quantitatively predicting the general fate of radionuclides in the environment. Additional research required for general understanding of the behavior of radionuclides is outlired at the end of this section.

\section{Factors Influencing Adsorption of Radionuclides on Geologic Media}

Some of the factors that have been reported to influence the adsorption of elements by geologic edia are listed for the studied elements in Table 8.94. An " $X$ " indicates that a given factor was reported to influence adsorption of that element (present as a radionuclide). The results reported in Table 8.94 are qualitative only. In mose cases, the authors did not definitively show that a specific factor was operative, but hypothesizes that it was. Since these data cannot be used for quantitative predictions, they are mainiy presented for use as guidelines in future experiments or environmental assessments. The probable principal adsorption mechanisms were deduced from an examination of the factors reported for each element. For example, colloid formation is a good indication of precipitation, as pH also may be. An 
TABLE 8.94. Factors Reported to Affect Adsorption of Radioelements over the pH Range of 4 to 9

Factors

\begin{tabular}{|c|c|c|c|c|c|c|c|c|c|}
\hline Elent & Det & En & $\operatorname{CEC}^{(a)}$ & $\begin{array}{c}\text { Cometing } \\
\text { Ions }\end{array}$ & $\begin{array}{l}\text { Selectively } \\
\text { Adsorbed On }\end{array}$ & $\begin{array}{l}\text { Inorgantc } \\
\text { Ligands }\end{array}$ & $\begin{array}{l}\text { Copplex lons } \\
\text { orgutic } \\
\text { const ituents }\end{array}$ & $\begin{array}{l}\text { colloid } \\
\text { formation }\end{array}$ & $\begin{array}{l}\text { Probable Adsorp } \\
\text { tion Mechanisiss (b) }\end{array}$ \\
\hline$m$ & $x$ & & $x$ & $x$ & & $x$ & & & IE, PPT \\
\hline $\mathbf{S}$ & & $x$ & & & Iron Oxides & $x$ & $x$ & $x$ & PPT, ox \\
\hline $\mathbf{C}$ & & & & & an & & $x$ & & B10 \\
\hline Ce & $x$ & & & & & $x$ & $x$ & $x$ & 1E, PPT \\
\hline Cs & & & $x$ & & $\begin{array}{l}\text { Zeolites, } \\
\text { Micas }\end{array}$ & & & & IE \\
\hline Co & $x$ & & & & $\begin{array}{l}\text { Ilifite, } \\
\text { Iran Oxide }\end{array}$ & $x$ & $x$ & $x$ & PPT, ox \\
\hline $\mathbf{\infty}$ & $x$ & & & & & $x$ & & $x$ & PPT \\
\hline Eu & $x$ & & & $x$ & & $x$ & & $x$ & IE, FiT \\
\hline Fe & $x$ & $x$ & & $x$ & & $\mathbf{x}$ & $x$ & PPT, OX & \\
\hline 1 & & & & & an & & $x$ & & on \\
\hline$m$ & & $x$ & $x$ & $x$ & Hydrous oxides & & $x$ & & ox \\
\hline 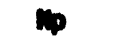 & & & & & & $x$ & & $x$ & $\operatorname{tin}$ \\
\hline$P$ & $x$ & $x$ & & & Hydrous oxides, &, 0.1 .1 & $x$ & & $0 \mathrm{x}, 810$ \\
\hline Pu & $x$ & $x$ & $x$ & & & $x$ & $x$ & $x$ & IE, PPT \\
\hline Pm & $x$ & & & $x$ & & & $x$ & & IE, PPT \\
\hline $\mathbf{R a}$ & & & $x$ & $x$ & $\begin{array}{l}\text { Zeolites, } \\
\text { Buite }\end{array}$ & & & & IE \\
\hline $\mathbf{R u}$ & $x$ & & & & or & $x$ & $x$ & & PPT \\
\hline$s r$ & $x$ & & $x$ & $x$ & $\begin{array}{l}\text { calcite, } \\
\text { Zeolites }\end{array}$ & $x$ & $x$ & & IE \\
\hline Te & & & & & & & $x$ & & $\ln$ \\
\hline $\mathbf{m}$ & $x$ & & $x$ & & an & $x$ & $x$ & $x$ & IE. PPT \\
\hline $\mathbf{3}_{\mathbf{H}}$ & & & & & $\mathrm{H}_{2} \mathrm{O}$ & & & & MOME \\
\hline $\boldsymbol{u}$ & $x$ & $x$ & $x$ & & on & $x$ & $x$ & & PPT, IE \\
\hline$-2 n$ & & & $x$ & & Hydrous Oxide & & $x$ & $x$ & IE, PPT \\
\hline $\mathbf{Z r}$ & $x$ & & & & ar & $x$ & $x$ & $x$ & PPT \\
\hline
\end{tabular}


adsorption sensitivity to cation exchange capacity, competing ions and system pH usually indicates an ion exchange adsorption mechanism. There is, adaittedly, a certain anount of value judgment that ment into the sumation process because in some cases the literature was iguous and vague concerning adsorption-influencing factors, and in other cases, the experimental work has yet to be done.

In addition to concentration, the nature of the solution species would have a tremendous effect on the radionuclide interaction with the geologic aedia and on the mobility of the radionuclides. Yery few data are available in the literature delineating species that have been identified in natural emironments. Thermodynamic data were used to develop solution species diagrass to predict the predominant solution sfecies. There are several linitations and drawbacks to this approach and the author admonishes the reader to place minor emphasis on such projections. The predicted nature of the predominant solution species of various elements are reported in Table 8.95. The environental conditions assumed for Table 8.95 data include a PH range of 4 to 9. $\mathrm{pO}_{2}$ range of 0.68 to $\mathrm{BO}$ atwospheres, $\mathrm{pCO}_{2}$ of 1.52 to 3.52 atmospheres, $\mathrm{pCi}$ of 0.45 to 3.0 and $\mathrm{pmO}_{3}=\mathrm{pSO}^{2-}=3.0, \mathrm{pF}^{-} 4.5$, and $\mathrm{pH}_{2} \mathrm{PO}_{4} 5.0$. It should be pointed out that a change in environmental conditions, in addition to the ligands not considered in the above assumptions, may change the nature of the solution species. Depending upon the given chemicai environment, several species of an element can exist in solution. Cesium, cobalt, promethium, radiu, strontiu, and tritiun would be expected to exist predominantly as uncomplexed solution species as $\mathrm{Cs}^{+}, \mathrm{Co}^{2+}, \mathrm{Pm}^{3+}, \mathrm{Ra}^{2+}, \mathrm{Sr}^{2+}$, and $\mathrm{H}^{+}$. Certain elements such as plutonium, neptunium and uranium can exist in acidic solutions in an oxidizing environment as uncomplexed solution ions $\left(\mathrm{PuO}_{2}^{2+}, \mathrm{PuO}_{2}^{+}\right.$, $\left.\mathrm{NpO}_{2}^{+}, \mathrm{UO}_{2}^{2+}\right)$. Some of the elements such as curium, thorium and zirconium hydrolyze very readily even in acidic environments, so they mainly exist as hydrolyzed species $\mathrm{CmOH}^{2+}, \mathrm{Cm}(\mathrm{OH})_{2}^{+}, \mathrm{Th}(\mathrm{OH})_{3}^{+}, \mathrm{Zr}(\mathrm{OH})_{4}^{0}, \mathrm{Zr}(\mathrm{OH})_{5}^{-}$). Some of the common inorganic ligands $\left(\mathrm{CO}_{3}^{2-}, \mathrm{SO}_{4}^{2-}\right)$ form strong complexes with anericium, curium, europium, neptunium, plutonium and uranium so that these Tigands would influence the concentration of these elenents in solutions. 
TABLE 8.95. Predoninant Solution Species of Elements in a pH 4 to $9, \mathrm{pO}_{2} 0.68$ to $80, \mathrm{PCO}_{2}, 1.52$ to $3.52, \mathrm{PCl}^{-}$ 0.45 to $3 / 0, \mathrm{PMO}_{3}=\mathrm{pSO}^{2-}=3.0$, $\mathrm{pH}^{-} 4.5$ and $\mathrm{PH}_{2} \mathrm{PO}_{4}$ 5.0 Environent Hithout Organic Ligands

\begin{tabular}{|c|c|c|c|}
\hline Ek=ats & 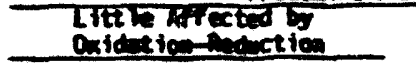 & Onidizien Enotroment & 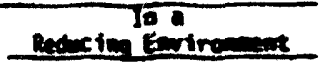 \\
\hline$\infty$ & 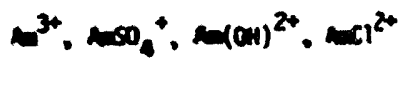 & 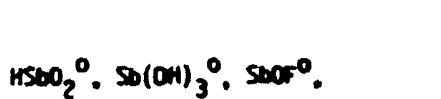 & $520^{\circ}$ \\
\hline c & now. orgic ic atter & $\mathrm{SO}(\mathrm{OH})_{4}$ & \\
\hline ce & $\mathrm{ces}^{3+} \cdot \cos _{4}^{+}$ & & \\
\hline$\sigma$ & & $\mathrm{CrO}_{4}^{2-}, \mathrm{Cr}^{3+}, \mathrm{Cr}(\mathrm{OH})^{2+}, \mathrm{Cr}(\mathrm{OH})_{2}^{+}$ & $\mathrm{Cr}^{3+} \cdot \mathrm{Cr}(\mathrm{OH})^{2+} \cdot \mathrm{Cr}(\mathrm{OH})_{2}$ \\
\hline cs & $\mathrm{cs}^{*}$ & $\sigma_{3}(o+1)_{4}^{s+}$ & $\sigma_{3}\left(\sigma_{1}\right)_{4}^{5+}$ \\
\hline$\infty$ & $\omega^{+} \cdot \operatorname{co}(\theta+1)_{2}^{+}$ & & \\
\hline$\infty$ & $\mathrm{Cos}^{3+} \cdot \mathrm{Cos}^{2+} \cdot \mathrm{Cor}(\mathrm{OH})_{2}^{+}$ & & \\
\hline Ee & $\mathrm{Eu}^{3+} \cdot \mathrm{EuSO}_{4}^{+} \cdot \mathrm{Eu}_{2}^{\mathrm{P}} 2^{0} 7^{2+}$ & $\mathrm{Fe}(\mathrm{OH})_{2,}^{+} \mathrm{Fe}(\mathrm{OH})_{3}^{0}$ & $\mathrm{Fe}^{2+}$ \\
\hline 1 & $\mathrm{I}^{-} \mathrm{10}_{3}^{-}$ & & \\
\hline$m$ & $m^{2+}$ & 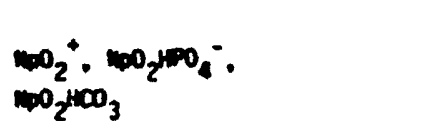 & $\operatorname{lnowar}^{3+} \cdot n^{4+}$ \\
\hline • & $\mathrm{PrO}_{4}^{2-}, \mathrm{H}_{2} \mathrm{PO}_{4}^{3-}, \mathrm{PO}_{4}^{3}$, orgenic & & \\
\hline Pu & & $\begin{array}{l}P_{2}{ }_{2}^{2+} \\
P O_{2}\end{array}$ & 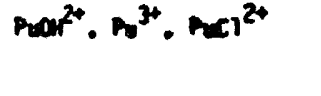 \\
\hline m & $n^{3+}$ & & \\
\hline $\begin{array}{l}\text { Re } \\
\text { in } \\
\text { se }\end{array}$ & $\begin{array}{l}R_{2}^{2+} \\
\mathrm{Sr}^{2+}\end{array}$ & $R u(O H)_{2}^{2+} \cdot R 004_{4}^{-}=R(0)_{4}^{2-}$ & $2=0,-$ \\
\hline TC & & $T=0_{4}^{\circ}$ & $\mathrm{Te}^{2+}$ \\
\hline m & $\pi r^{3+}, \pi(O H)_{3}^{+}$ & & \\
\hline $\begin{array}{l}3 \\
v\end{array}$ & $3_{n-0-n}$ & $\begin{array}{l}w_{2}^{2+} \cdot \omega_{2} E^{*}, w_{2}\left(\omega_{2}\right)^{0} . \\
\left.w_{2}\left(\omega_{3}\right)_{3}^{2}, \omega_{2} C\right)^{*}\end{array}$ & $\begin{array}{l}w_{2}^{2+} \cdot w_{2}^{3+4} \cdot w_{2}^{+} . \\
w_{2}\left(w_{3}\right)_{3}^{2}\end{array}$ \\
\hline 2 & 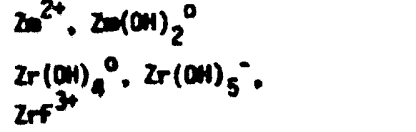 & & \\
\hline
\end{tabular}


Oxidation-reduction conditions would predoninantiy influence the nature of the solution species of antinony, chromiun, iron, neptumium, plutoniun, technetiun and uranium.

Based upon the nature of the predominant solution species, qualitative predictions regarding the adsorption and movement of various elements can be wade. Bed and suspended sediments miniy show cation exchange capacities (since they carry a large net negative charge) and to a liaited extent, anion exchange capacities. Thus, wost cations would react with sediments and transport at speeds slower than the water. Relative to each other, the trivalent cations generally now the slowest, the divalent cations at internediate velocities and the monovalent cations most rapidiy. Tritiun is unique in that it readily substitutes for hydrogen in water and migrates, therefore, ax the same velocity as water. Complicating factors include a higher selectivity of a sediment component for a given cation or a wore successful hydrogen ion canpetition with one cation relative to another. The relative nobilities of strontion and cesium at low on is a good examle of the latter effect. Strontium is much more wobile at low pH than is cesiu.

The simple anions tend to migrate with little reaction because usually a pH of less than 4 is required to activate a significant anion exchange capacity. However, both I and TC wich exist predominantly as anions (I-, $\mathrm{TCO}_{4}^{-}$) undergo other reactions with organic ligands that can greatly slow their migration.

The wigration and retention of inorganic complex species (monomuclear and polymuclear) would also be dependent upon the charge and size of the species. Positively charged species would wove slower than the negative charged species. The highly charged metal ions tend to polymerize or form colloidal size, charged precipitates. The trivalent wal ions ( $\mathrm{Am}, \mathrm{Cm}, \mathrm{Sb}, \mathrm{Ru})$ and quadrivalent or higher charged wetal ions ( $P u, T h, U, Z r)$ are known to form polywers. Initially, at lower pH, the polymers are positively charged and at pH 9 becone increasingly nagatively charged. The result is good adsorption and very slow movement at acidic to neutral pH, and greatly lessened adsorption and rapid migration from pH 9 upuard. 
The behavior of organic complexed species of elenents is difficult to predict because of the lack of knowledge regarding the exact mature of the organic ligands, a wide variation in amounts and types of organic ligands, and the size and solubility of these organics. These organic materials can either reta in the element or complex it in a form that migrates readily. The source of these organic ligands can be the radioactive waste solutions containing the symthetic organic ligands such as TBP and/or the organic ligands produced by flora and fama.

The wetal ions that take part in replacewent reactions fapend upon the size and charge of the species imvolved and the ability of the final nineral product to accept that species into its growing structure. Apatite, for example, accepts into its structure a wide range of wetal ions such as strontiun, uranion and probably anericiu and cerium. Cobalt replaces calcium in calcite, and radiun and strontiu replace barium in barite. These netal ions are buried in the replacenent product crystal structure and are effectively retained unless a changing chemical environment causes instability and dissolution of the crystal.

Adu onumai Research Meeds

The areas that require core work to better understand radionuclide interactions with sediments include:

1. Determination of radionuclide adsorption mechanisus.

Mdditional work is required in the area of radionuclide adsorption, eechanisis (ion exchange, precipitation, coprecipitation, hydrolys is and colloid formation). There are any $K d$ values that include several sediment adsorption mechanises operating simitaneously for a range of elemental species. Definitive experimental data that would allow deduction of probable adsorption mechanises for most elements are lacking in the literature. In addition, the emironent in wich a given adsorption mechaniso predominates should be delineated as well. 
2. Factors that influence radionuclide/geologic media interactions.

The influence of different factors (such as pH, Eh, complexing ligands, competing ions, CEC, type and amount of minerals, solid phases of element) on the magnitude and extent of "sorption of radionuclides by the geologic media needs to be evaluated.

3. An experimental consideration of the effects of redox potential on radionuclide migration.

Stagnant conditions present in bed sediments, especially organic rich lake and estuarine, usually form reducing conditions. There has been little exanination of the effects of radionuclide aigration in the low oxygen environments wich will be encountered under these conditions. It should be mentioned though that suspended sediments and the thin layer in contact with the water colum are very seldow anoxic. The water colvm and sediment interface is the region of biological interest and thus for environmental assessments results for oxidizing environments would be most relevant (although diffusion from anoxic bed sediments can act as a slow release source term).

4. Characterization and influence of organic ligands on radionuclide wigration.

The existing thermodymanic data on species are incomlete in many cases, and of dubious quality in other cases. The thernodymanic data should be confirmed by experimental evidence on radionuclide adsorption and migration. Thermodymaic data on the radionuclide coplexes with natural water organic components are essentially nonexistent. Note in Table 8.95 that radionuclide reaction - with organic material were reported for 17 of the 25 radionuclides reviewed. lence, wat may prove to be a wost important influence on radiomuclide adsorption and migration is one of the least understood. The sources of organic eaterial; in the environment capable of forming complexed species with radionuclides inciude the many industrial wastes from various manufacturing processes disposed to the atmosphere and surface waters, the organics included in muicipal sewage treatuent effluents also disposed to surface mters, the various pesticides and rerbicides used during farming operations 
contained in the atmosphere and irrigation runoff, imic substances and decaying plant and animal reasins already present in the aquatic environent along with the associated living microflora and fauna. With such varied sources and types of organic ligands, a large quantity of work remains to be done in even identifying the aetal ligand species imvolved in radionuclide migration on the land surface. For carbon and phosphorus wich are intimately tied to biological cycling this point is most germane.

5. Therwodynamic data deterninations for several solution species.

Thermodymamic data are badly needed for several complex solution species of different elements. For exaple, the rutheniu complexes Rum $\left(\mathrm{OO}_{2}\right)_{2} \mathrm{OH}_{(\mathrm{H}} \mathrm{H}_{2} \mathrm{O}_{2}$ and Ru:mon $\mathrm{O}_{2}\left(\mathrm{~m}_{3}\right)_{2}\left(\mathrm{H}_{2} \mathrm{O}_{2}\right.$ were reported as very stable and comonly found in nuclear waste solutions by several authors. Yet no firm therwodynaic data for these tio complexes were located in the literature. When the data are determined, they may drastically change the order and specification for ruthenium solution species reported.

6. The generation of $\mathrm{Kd}$ data that can be used in a comparative rode.

The experimental conditions, including sediment and solution characterization, were only sketchily given in wost references, or not given at all in wost cases. Hence, the Kd values reported are the best available, but evaluation of these data by any objective methodology would result in discarding a large number of them. The requirements for determination of a $\mathrm{Kd}$ value that could be used in a comarative mode were listed in the laundry list functional dependency section. A progra to determine such $K d$ values for terrestrial environments is now undersay by the Office of Muclear Waste Isolation (Serne, 1978).

7. Maintenance of a bank of such Xd data.

A bank of the Kd data should be maintained and kept current. The data could be computer-stored and made available to all personnel concerned with waste magement and enviromental assessment upon request. The present systen has resulted in using unevaluated $K d$ values that are often not applicable to the case in point. 
8. Determination of radionuclide adsorption and desorption reaction kinetics with sediments.

Several authors that have equilibrated solutions containing radionuclides with sediments for several weeks have reported that a considerable period of time was required to attain equilibriu. Kinetic studies 1) could indicate radionuclide adsorption mechanisms, 2) could help in separating adsorption rates due to different mechanisus, and 3) would help in increasing the confidence in extrapolating the predicted results into the future. Kinetic or time dependent information is especially imortant in the transport of radionuciides in flowing bodies of water such as streans, rivers, estuaries and near shore or coastal 20nes. The rate of water and suspended solids wovenent in these environents may be quite high compared to the rate of approach to chemical equilibriu for some radionuclides. If one is striving to attain a quantitative transport nodel with a relatively fine spatial grid, the fact that nonequilibriu adsorption may predominate needs to be addressed. A critical assessment is needed to evaluate typical mixing times or contact times between muclear wastes and bed and suspended sediments in the field. As most laboratory determinations of $\mathrm{Kd}$ are performed in a closed batch system at solids to solution ratios much higher than found in nature the rate of approach to equilibriu in the laboratory may differ significantly from the field situation. Actual field verification studies would be quite complicated and expensive; thus, it is suggested that more attention be given to attempts to simulate field conditions in the laboratory. As it is typically soil or earth science chemists wo perform Kd experiments and these disciplines usually are nc I faniliar with hydraulics or sediment transport, some wiltidisciplinary cross talk would be fruitful. If physical oceanographers and hydraulics engineers and the chemists would sit down and familiarize thenselves with the total field system, more relevant experiments would result.

Although it is impossible to generalize and establish one Kd for each nuclide, computer modelers request input values constantly. Thus to sat isfy the needs of modelers the following table was constructed, albeit rather arbitrarily from the literature review in this document. Fresh water and 
marine environments were separated to show the importance of cation competition for those muclides which adsorb by ion exchange reactions. Also marine environments have a very narrow pH range around the mean value of $\mathrm{pH} \mathrm{8.1.} \mathrm{For}$ elewents which adsorb by hydrolysis and colloidal polymer precipitation $\mathrm{Kd}$ values in sea water are often larger than fresh water, wich shows a wider pH range and less tendency to promote coagulation.

Table $\mathbf{8 . 9 6}$ is only for gross generalizations. Median Kd values should be considered to vary \pm an order of magnitude for those values greater than $10^{2}$. 
TABLE 8.96. Gross Average Kd $\mathbf{m l / g}$ for Studied Elements with Empinasis on Oxidizing Conditions

Elements

\begin{tabular}{l} 
Fresh Hater \\
\hline Renoe \\
\hline
\end{tabular}

Sa water

Rance Median

$97-650,000 \quad 10^{4}$

- conflicting data--

- no available data--

$\begin{array}{ll}9,000-10^{7} & 5 \times 10^{4} \\ 0-10^{3} & 10 w \\ 17-10^{4} & 3 \times 10^{2} \\ 7,000-300,000 & 10^{4}\end{array}$

$7,000-300,000$

-no data--

$5,000-130,000$

$10^{4}$

$20,000-450,000$

$5 \times 10^{4}$

$0-100$

$10^{2} \cdot 10^{4}$

10

$10^{3}$

-no data--

$0.2-12710$

$10^{2}-10^{7}$

$10^{3}-10^{4}$

$10^{2} \cdot 10^{3}$

complicated chem istry (witiple species)

High

$5 \times 10^{3}$

$5 \times 10^{2}$

$10^{2}-10^{5}$

$10^{3}-10^{5}$

High

$5 \times 10^{4}$

$10^{4}$

$8-4,000$

$0-10^{2}$

$10^{3}-10^{6}$

0

$16-10^{3}$

$10^{2}-10^{3}$

$10^{3}-10^{4}$ variable

1,000

5

0

0

0

$5 \times 10^{1}$

$5 \times 10^{2}$

$10^{3}$
$10^{1} \cdot 10^{3}$

caeplicated chenistry (aitiple species)

$6-400$

50

$10^{4}-10^{5}$

$10^{2}$

variable

0

$5 \times 10^{4}$

$10^{2}-10^{4}$

$10^{3}-10^{4}$

$10^{3}-10^{5}$
0

$5 \times 10^{2}$

$5 \times 10^{3}$

$10^{4}$

tVery dependent on oxidation - reduction conditions. 


\section{REFERENCES FOR CHAPTER 8}

Aarkrog, A. 19/1. "Radioecological Investigations of Plutonium in an Arctic Marine Environment." Health Physics. 20:31-47.

Aarkrog, A. 1972. "Re-examination of Plutonium at Thule, Greenland, in 1970." EUR-4800. 182:1213-19.

Adans, J. A. S. and C. E. Heaver. 1958. "Thorium-to-Uranium Ratios as Indicators of Sedimentary Processes -- An Example of Geochemical Facies." Bull. An. Petrol. Geol. 42:387.

Adans, J. A. S., J. K. Osmond, and J. J. W. Rogers. 1959. "The Geochemistry of Thorium and Uranium." In: Physics and Chewistry of the Earth. 3.

L. H. Ahrens, F. Press, K. Rankama, and S. K. Runcorn (eds.), pp. 298-348.

Adams, J. A. S. and K. A. Richardson. 1960. "Thoriun, Uranium, and Zirconium Concentrations in Bauxite." Econ. 6eol. 55:1653.

Adans, J. A. S., J. K. Osmond, and J. J. H. Rogers. 1959. "The Geochemistry of Uranium and Thorium." Phys. Chem. Earth. 3:298.

Adars, H. H. 1971. Solubility of Plutoniumn-238 Labeled PuO? in Los Alamos Tap Nater. LADC-12900.

Agamirov, S. S. 1963. "Precipitation of U in Black Sea." Geokhimiya. 1:92-3 (in Russian).

Anlstrom, S. W. and H. P. Foci.s. 1976. Multicomponent Mass Transport Model: Theory and Numerical Implementation (Discrete-Parcel-Random-Malk Versioni: Battelle, Pacific Northwest Laboratories, Richland, WA.

Ahrens, L. H. 1952. "The Use of Ionization Potentials. Part I. Ionic Radii of the Elements." Geochim. et Cosmochim. Acta. 2:155.

Albenesius, E. L. and R. S. Ondrecin. 1960. "Nuclear Fission Produces Tritium. Mucleonics." 18:100.

Albenesius, E. L. 1959. "Tritium as a Product of Fission." Physics Review Letters. $3: 274$.

Alberti, G., C. Bettinali, G. Grassini and F. Silvestro. 1959. "Leaching Tests of Uranium of Canale Monterano." In: Studie Ricerche Della Divisione Geomineraria. 2:129-53.

Alberts, J. J., A. Wahlgren, C. A. Reeve, and P. J. Jehn. 1974a. Sedimentary $239,240 \mathrm{pu}$ Phase Distributions in Lake Michigan Sediments. 
Alberts, J. J., M. A. Mahlgren, P. J. Jehn, D. M. Melsgn and K. A. Or landini. 1974b. Chemical Speciation of $239,240 \mathrm{Pu}$ and $137 \mathrm{Cs}$ in Lake Michigan Waters. All-75-3 (Pt. 3), PP. 89-96.

Ames, L. L. and D. Rai. 1978. Radionuclide Interactions with Soil and Rock Media, Vol. 1: Processes Inf Tuencing Radionuclide Mobility and Retention. Draft Report to Office of Radiation Programs U.S.E.P.A.

Ames, L. L., Jr. 1961a. "Anion Metasomatic Replacement Reactions." Economic Geology. 56:521-532.

Ames, L. L., Jr. 1961b. "The Metasomatic Replacement of Limestones by Alkaline, Fluoride-Bearing Solutions." Economic Geology. 56:730-739.

Ames, L. L., Jr. 1961c. "Cation Metasomatic Replacement Reactions." Economic Geology. 56:1017-1024.

Anes, L. L., Jr. 1960a. Aniun Replacement Reactions for the Rewoval of Strontium from Aqueous Solutions. Hil-66383.

Ames, L. L., Jr. 1960b. "Some Cation Substitutions During the Formation of Phosphorite from Calcite." Economic Geology. 55:354-362.

Ames, L. L., Jr. 1959a. The Removal of the "Bone-Seek ing" Group of Radioisotopes from Solution by a Calcite-Phosphate Reaction. Hi-60412.

Anes, L. L., Jr. 1959b. Zeolite Extraction of Cesium from Aqueous Solutions. HW-62607.

Amiel, A. J., D. S. Miller, and 6. M. Friedman. 1972. Uranium Distribution in Carbonate Sediments of a Hypersaline Pool, Gulf of Elat, Red Sea." Isr. J. Earth Sci. 21:187-91.

Any, J. P. 1971. Contribution to the Study of the Migration of Ruthenium-106 in Soils. RFP-Trans-140.

Andelman, J. B. and T. C. Rozzell. 1970. "plutonium in the Mater Environment. I. Characteristics of Aqueous Plutonium." In: Radionuclides in the Environment. Adv. in Chem. Ser. No. 93. Amer. Chem. SoC., Washington, DC, pp. 118-137.

Anders, E. 1960. The Radiochemistry of Technetium. Nuclear Sci. Ser. Nat. Acad. Sci. - Nat. Res. Council. MAS-NS 3021.

Anonymous. 1960. Summary Report on 1. The Control of Radium and Thorium in the Uranium Milling Industry, II. Radium-226 Analysis Principles, Interference and Practice, III. Current Winchester I aboratory Projects. VIII-112. 
Anonymous. 1968. Radioactivity Transport in Water. Interaction Between Flowing Nater and bed Sediments. 0.R0-490-17. 165 p.

Anonymous. 1973. 241-T-106 Tank Leak Investigat ion. ARH-2874.

Antal, P. S. 1966. "Diagenes is of Thorium Isotopes in Deep Sea Sediments." Limpol. Oceanog. 11:278-92

Armands, 6. and S. Landergren. 1960. "Geochemical Prospecting for Uranium in Northern Sweden: The Enrichment of Uraniua in Peat." Intern. Geol. Congr., Rept. 21st Session, Copenhagen, Part 15:51-66.

Arrustrong, N. E., L. M. Canter, and E. F. Gloyna. 1968. "Transport of Organic and Radioactive Mastes." Hater Mastes Eng. 5:54-6.

Arnold, H. D. and D. J. Crouse. 1971. Radioactive Contanination of Copper Recovered from Ore Fractured with Nuclear Explosions. ORLL-4677.

Arnold, W. D. and D. J. Crouse. 1964. "Radium Resoval from Uranium Mill Effluents with Inorganic Ion Exchangers." I\&EC Process Design and Development. 4:335-337.

Ashizawa, F. T. and P. K. Kuroda. 1957. -The Occurrence of the Short-Lived Iodine Isotopes in Matural and in Depleted Uranium Salts." J. Inorg. Mucl. Chem. 5:12-22.

Astgn, S. R. and E. K. Duursma. 1973. "Concentration Effects on 137Cs, $65 \mathrm{Zn}, 60 \mathrm{Co}$, and $106 \mathrm{Ru}$ Sorption by Marine Sediments with Geochemical Implications." Netherlands Journal of Sea Research. 6:225-240.

Baes, C. F., Jr. and R. E. Mesmer. 1976. The Hydrolys is of Cations. John Wiley and Sons, Mew York.

Baetsle, L. and P. Dejonghe. 1962. "Investigations on the Movement of Radioactive Substances in the Ground. Part III: Practical Aspects of the Program and Physiocochemical Considerations." In: Ground Disposal of Radioactive Wastes. TID-7628, pp. 198-210.

Baetsle, L. H., P. Dejonghe, W. Maes, H. E. Simpson, J. Souffriau, and P. Staner. 1964. Underground Radionuclide Movement. EURAEC-703.

Baker, J. H., H. A. Beetem, and J. S. Hahlberg. 1964. Adsorption Equilibria Between Earth Materials and Radionuclides, Cape Thompson, Alaska. TID-20638.

Balashov, U. A., et al. 1964. "The Effects of $\mathrm{Cl}$ imate and Facies Environment on the Fract ionation of the Rare Earths During Sedimentation." Geochemistry International. 10:951-969. 
Baranov, V. I. and L. A. Khristianova. 1963. "Radioactivity of Ocean Sediments." Khim. Zemnoi Kory, Akad, Mauk SSSR, Tr. Geokhim. Konf. 1:401-8.

Baranov, V. I., A. B. Ronov, and K. G. Kinashova. 1956. "On Geochemistry of Dispersed Thoriun and Uranium in Clays and Carbonate Rocks of Russian Platform." Geokhiniya. Mo. 3:3-8.

Baranov, V. I. and N. I. Titaeva. 1961. "Uranium, Thorium, Radium, and Ionium Content in the Quartenary Deposits of the River Lena." Geokhiniya. No. 2:110-14 (in Russian).

Baranova, D. D. and 6. G. Polikarpov. 1968. "Sorption and Desorption of Radionuclides by Shallow-water Sediments of the Black Sea." Okeanologiya. 8:427-30 (in Russian).

Baranova, D. D. and 6. G. Polikarpov. 1966. Adsorption and Desorption of Radionuclides by Shallow-water Sediments of the Black Sea. Oceanology of the Academy of Sciences of the USSR, PP. 341-344.

Bartlett, R. J. and J. M. Kimble. 1976. "Behavior of Chromium in Soils: I. Trivalent Forms." J. Environ. Qual. $5(4) ; 379-386$.

Baturin, G. N. 1968. "Geochemistry of Uranium in the Baltic Sea." Geokhimiya. 3:377-81 (in Russian).

Baturin, G. N. 1966. "Uranium Content in Caspian Sea Sediments." At. Energ. 21:515-16 (in Russian).

Baturin, 6. N. 1969. "Uranium in the Surface Layer of Sediments in the Morthwestern Part of the Indian Ocean." Okeanologiya. 9:1031-7 (in Russian).

Baturin, G. N. 1971. "Uranium in Solutions of Ooze Deposits in the Southeastern Atlantic." Dok). Akad. Nauk. SSSR. 198:1186-1188 (in Russian).

Baturin, G. N. 1973a. "Uranium in the Contemporaneous Sedimentary Cycle of the Sea." Geokhimiya. 9:1362-1372 (in Russian).

Baturin, G. N. 1973b. "Uranium During Sedimentation in the Black and Azov Seas." Litol. Polez. Iskop. 5:21-32 (in Russian).

Baturin, G. N. and E. M. Emel anov. 1973. "Distribution of Uranium in the Sediments of the Mediterranean Sea." Okeanologiya. 13:814-20 (in Russian).

Baturin, G. M., T. D. Ilyina, and N. I. Popov. 1971. "Soviet Investigations of Matural Radionuclides in Marine and Ocean Sediments." Proc. Roy. Soc. Edinburgh, Section B. 72:183-91. 
Baturin, 6. N. and A. V. Kochenov. 1969. Migration of Uranium in Rivers and the Duration of Its Presence in Haters of the Horld's Oceans, Seas, and Lakes." Ceokhimiya. 6:715-23 (in Russian).

Batur in, 6. N. and A. Y. Kochenov. 1973. "Uranium in Interstitial Waters of Marine and Oceanic Sediments." Geokhimiya. 10:1529-1536 (in Russian).

Batur in, 6. N., A. V. Kochenov, and S. A. Kovaleva. 1966. "Some Aspects of the Distribution of Uranium in Black Sea Waters." Dokl. Akad. Mauk SSSR. 166:698-700 (in Russian).

Batur in, 6. M., A. V. Kochenov, and Y. M. Senin. 1971. "Uranium Concentration in Recent Oceanic Sediments of Hater Uprise Zones." Eeoknimiya. 4:456-62 (in Russian).

Batur in, 6. M., A. V. Kochenov, and K. M. Shimkus. 1967. "Uranium and Minor Metals in Colums of Botton Sediments of the Black and Mediterranean Seas." Geokhimiva. 1:41-50 (in Russian).

Becker, V. J., J. H. Bennett, and 0. K. Manuel. 1972. "Iodine and Uranium in Sed imentary Rocks." Chem. Geol. 9:133.

Becker, V. J. and O. K. Manuel. 1972. "Chlorine, Bromine, Iodine, and Uranium in Tektites, Obsidians and Impact Glasses." J. Geophys. Res. $\underline{77}: 6353$.

Bel1, K. 6. 1960. Deposition of Uranium in Salt-Pan Basins. U.S.G.S. Professional Paper No. 354-6:161-169.

Bell, K. G., C. Goodman and W. L. Whitehead. 1940. "Radioactivity of Sed imentary Rocks and Associated Petroleum." Bull. Am. Assoc. Petroleum Geol. 24:1529.

Belousdva, M. Ya and I. Y. Melikhov. 1972. "Study of the Trapping of Impurities by Hydroxides XV. Two Independent Examples of the Segregation of Cobalt." Sov. Radiochem. 14, 1:7-11.

Benes, P. 1969. "(H73-04126) On the State of Mercury (II) Traces in Aqueous Solutions. Collodial Behavior of Mercury." Journal of Inorganic Nuclear Chemistry, 31:(7)1923-1928.

Bennett, J. H. and 0. K. Manuel. 1968. "Iodine Abundances in Deep-Sea Sed iments." J. Geophys. Res. 73:2302-3.

Bensen, D. W. 1960. Review of Soil Chemistry Research at Hanford. HW-67201.

Bensen, D. H. 1961. Mineral Adsorption of Radionuclides in Reactor Effivent. HH-69225. 
Bernat, M. and E. D. Eoldberg. 1969. "Thoriu Isotopes in the Marine Environment." Earth Planet. Sci. Lett. 5:308-12.

Berner, R. A. 1975. Kinetic Models for the Early Dragenesis of Mitrogen, Sulfur, Phosphorus, and Silicon in Aroxic Rarine Sediments in the Sea. Vclue 5 edited by E. D. Gotdberg, Wiley-Interscience Publications, New York.

Bernorskaya, R. M. and Bogdanov, Yu. A. 1971. "Influence of Iron on the Physic ochemical State of Radicelenents in Sea bater." Soviet Radiocheanistry. $13(1): 158-160$.

Betenekov, M. D., Yu. V. Egorov, V. D. Puzako. 1973. "Radiocolloids in Sorption Systess XI. Mature of Maxim on E-pH Isotherm Relation of Sorption and Colloidal Properties of a Radioisotope in the Formation of True Colloids.- Radiokhimiya. 16(1):20-26.

Beus, A. A. and E. A. Fabrikova. 1961. "Distribution of Cesium in the Granites of the USSR." Geochenistry. 1961-970-976.

Bhat, S. 6. and S. Krishnaswamy. 1969. "Isotopes of Uranivim and Radium in Indian Rivers." Prac. Indian Acad. Sci. Section A, No. 1:1-17.

Bitlings, 6. K. 1362. "A beochemical Investigation of the Valley Spring Gneiss and Packsaddle Schist, Llano Uplift, Texas." Texas J. Sci. 9:328.

Blaine, D. E., R. A. Schwind, H. W. Kirby and E. L. Murphy. 1974. "NewProcess for Removing Plutonium from Waste Water_A Progress Report." Proceedings of the Second AEC Environmental Protection Conference. Albuquerque, New hexico. Apri! 16-19, 1974. UASH-1332-74-V-1: 321-338.

Bonatti, E., D. E. Fisher, O. Joensuu, and H. S. Rydell. 1971. "PostDepositional Mobility of Some Transition Elements, Phosphorus, Uraniun, and Thorium in Deep Sea Sediments." Geochim. et Cosmochim. Acta. 35:189-201.

Bondietti, E. A. 1974. "Adsorption of Pu(IV) and Th(IV) by Soil Colloids." Agronomy Abstracts.

Bond ietti, E. A. and S. A. Reynolds. 1977. Field and Laboratory Observations on Plutonium 0xidation States. BNLL-2117, Pacific Worthwest Laboratory, Richland, WA, Pp. 505-533.

Bondietti, E. A., S. A. Reymoids, and M. H. Shanks. 1975. Interactions of Plutonium with Complexing Substances in Soils and Matural Waters. IAEA-ST-199/51.

Booth, R. A. 1975. "A Systems Analys is Model for Calculating Radionuclide Transport Between Receiving Haters and Sottom Sediments." Chapter 7 of Environmental Toxicity of Aquatic Radionuclides: Models and Mechanisms. Ann Arbor Science, pp. 135-159. 
Bovard, P., A. Grauby and A. Saas. 1968. "Chelating Effect of Organic Matter and Its Influence on the Migration of Fission Products." In: Isotopes and Radiation in Soil Organic Matter Studies. Cow -680275, pp. $471-495$.

Bowen, Y. T. 1971. General Sumary of Progress, 1970-1971. Nro-2174-129.

Bowen, Y. T. 1974a. Plutonium and Americiun Concentration Along F-eshmater Food Chains of the Ereat Lakes, U.S.A. Cu-3568-4.

Boven, Y. T. 1974b. Radice lement Studies in the Oceans. Progress Report, COO-3563-28.

Bomen, Y. T. 1975. Transuranic Elements in Marine Environents. HASL-291.

Bowen, Y. T., H. D. Livingston and J. C. Burke. 1975. Distributions of Transuraniu Muclides in Sedicent and Biota of the Morth Atlantic Ocean. IREA-ST-199/90.

Bowen, Y. T. and V. E. Noshkin. 1973. Plutoniu Concentration Along Fresh Hater Food Chains of the Great Lakes, U.S.A. Eeneral ST ary of Progress, 1972-1973. C00-3568-3.

Bowen, Y. T Y. E. Yoshkin, H. L. Volchok, H. D. Livingston, and K. M. Mong. 1974. -137Cs to Sosr Ratios in the At lantic Ocean, 1966 through 1972." Limol. Oceanogr. 19:670-681.

Bomen, Y. T., K. M. Wong, and Y. E. Moshk in. 1971. "plutoniv-239 in and Over the At lant ic Ocean." Journal Marine Research. 29:1-10.

Bovard, P., A. Grauby, and A. Saas. 1968. "Chelating Effect of Organic Matter and Its Influence on the Migration of Fission Products." In: Isotopes and Radiation in Soil Organic-Matter Studies. COMF-680725, pp. 471-95 (in French).

Boyd, 6. E. 1959. "Technetium and Promethium." J. Chean. Educ. 36:3-14.

Boyd, 6. E. and Q. V. Larson. 1956. "Report on the Occurrence of Technetiua on the Earth's Crust." J. Phys. Chem. 60:707-715.

Boyle, R. H. 1965. Eeology, Geochemistry, and Origin of the Lead-zinc-Silver Deposits of the Keno Hilli-Gatena Hill Area, Yukon Territory. Geol. Surv. Canada Bulletin III.

Breger, 1. A., M. Deul, and S. Rubinstein. 1955. "Geochenistry and Mineralogy of a Uraniferous Lignite." Econ. Geol. 50:206-226.

Brehler, B. and R. Fuge. 1974. "lodine." In: Handbook of Ceochenistry, Vo1. 11/3, Springer-Verlag, New York. p. 53-1. 
Brisbin, I. L., Jr., R. J. Beyers, R. H. Dapson, R. A. Geiger, J. B. Gentry, J. H. Gibbons, M. H. Smith, and S. K. Hoods. 1974. " patterns of Radiocesiu in the Sediments of a Strean Chamel Contaninated by Production Reactor Effluents." Health Phrsics. 27:19-27.

Brown, D. J. 1967. Migration Characteristics of Radionuclides Through Sed tents Underlying the Honford Reservation. ISO-Sh-32.

Brown, R. E., R. E. Franklin, and R. H. Miller. 1969. Meactions of Ceriu-144 in Solution and Suspensions of Soil thuic Acid and Bentonite." Soil Science Society of America, Proceedings. 33:677-681.

Brom, D. J. and H. A. Haney. 1964. Cherical Effluents Technology haste Disposal Investigations July-Dece-ber, I97/3 - The Hovements of Contaminated Ground bater fro the 2u areas to the Cole bia kiver. Hi-80s09.

Brown, J. H. and W. D. Keller. 1952. Uranium in the Clay of a Black Radioactive Shale." Science. 115:632-633.

Brungs, H. A. 1974. Distribution of Cobalt 60, Zinc 65, Strontiv 85, and Cesiur 137 in a Frestwater Pond. U.S. Dept. Fal. Public Health Service. Emironiental Health Series, Radiological Health.

Brungs, H. A. 1963. The Relative Distribution of Multiple Radiomuclides in a Freshater Pond. Thesis. Chio State University, Colvobus, OH.

Burkov, Y. Y. and Ye. K. Podporina. 1966. First Data on Rare Earths in Kibberlite." Dok1. Acad. Sci. USSR. Earth Science Section. 171:215-219.

Burney, 6. A. and R. M. Harbour. 1974. Radiochemistry of Meptuniu. MAS-MRC muciear Sci. Ser. MS-ils-3060.

Busey, R. H. and Q. Y. Larson. 1958. Chemistry Division Anmual Progress Report for Period Ending June 20, 1958. OiRL-258\%.

Butler, J. M. 1964. Ionic Equilibriun. Addison-lesley, Reading, MA. pp. $180-183$.

Calvo, M. M. 1974. "The Role of Humic Natural Organic Matter in Uraniu Concentration." IAEA-SH-183/33. In: Formation of Uraniun Ore Deposits.

Cameron, D. R. and A. Klute. 1977. Convective-Dispersive Solute Transport with a Combined Equilibriu and Kinetic Adsorption Wocel. Water Resources Research, Yol. 13, 10. 1.

Carye, A. 6., Jr. and M. H. Cutshall. 1973. "Zinc-65 Specific Act ivities from Oregon and Hashington Continental Shelf Sedilents and Benthic Invertebrate Fauna." In: Radioactive Contamination of the Marine Environent. IAEA, Vienna, pp. 287-305. 
Car:igan, Jr., P. H. 1968. Radiactive Haste Dilution in the Clinch River Eastern Tennessee. U.S. Geol. Survey Prof. Paper 433-6, Pp. 61-69.

Carrigan, Jr., P. H. 1969. Inventory of Radionuclides in Botton Sediment of the Clinch River Eastern Tennessee. USES-Professional Paper 433-1, 18 p.

Carrigan, P. H., R. J. Pickering, T. Tamura, and R. Forbes. 1967.

Radioactive Materials in Botton Sedicent of Clinch River: Part A, Investigations of Radionuclides in Upper Portion of Sediment. OkiL-3721 (Supp). य).

Carritt, D. E. and S. Goodgal. 1954. "Sorption Reactions and Some Ecological Implications." Deep-Sea Research. 1:224-243.

Cerrai, E., M. 6. Mezzadri, B. Schreiber, and C. Triulzi. 1970. "Some Radioactivity Measurements of Sediment Saples Collected in the Morth Adriatic Sea." Energia Mucleare. 17:(3)176-181.

Cerrai, E., M. 6. Mezzadri and C. Triulzi. 1969. "Sorption Experiments of Strontiu, Cesium. Promethiun, and Europium on Marine Sediment Samples." Energia Mucleare. 16(6) 378-385.

Cerrai, E., M. G. Mezzadri, B. Schreiber, and C. Triulzi. 1970. "Sone Radioactivity Masurements of Sediment Saples Collected in the Morth Adriatic Sea." Energia Mucleare. 17:176-181.

Cerrai, E., B. Schreitrr, and C. Triulzi. 1965. "90Sr in Upper Layers of Coastal Sediments , the Ligurian Sea and Contribution of Some Radionuclides to their Radioactiv. "onergia Nucleare. 12:549-52.

Cerrai, $E_{14}$ 8. Schreiber, $C_{15}$ Triulzi. 1967. "Vertical Distribution of Sosr, $144 \mathrm{Ce}, 14 \mathrm{Pm}_{\mathrm{m}}$, and $155_{\mathrm{Eu}}$ in Coastal Marine Sediments. Energia Muclear. 14:586-92.

Champlin, J. B. F. and 6. G. Eichholz. 1976. "Fixation and Rewobilization of Trace Contaminants in Simulated Subsurface Aquifers." Health Physics. 30:215-219.

Chanplin, J. B. 1970. Transport of Radioisotopes by Fine Particulate Fatter in Aquifers. Thes is, Eeorgia Inst. of Tech., Atlanta, GA.

Champlin, J. B. F. 1969. Transport of Radioisotopes by Fine Particulate Matter in Aquifers. PB-232179.

Char lot, 6. 1957. Qualitative Analys is and Solution Reactions. Fourth Edition. Masson, Paris.

Chase, M. H., J. L. Curnutt, H. Prophet, R. A. McDonald and A. M. Syverud. 1975. "Janaf Thernocheaical Tables, 1975 Supplement." Journ. Phys. and Chem. Ref. Data 1974. (1)4. 
Cheng, H. and H. Hanaguchi. 1968. "Studies on the Adsorption of Radioisotopes on Marine Sediments. I. Role of Exchangeable Cations on the Adsorption of Cesiu and Exchange Equilibria." Health Phys. 14:1353-63.

Cherdyntsev, V. V., V. L. Zverev, V. M. Kuptsov, and 6. T. Kislitsina. 1968. Plutoniv-239 in Mature." Eeochemistry Intermational. 5:355-361.

Christenson, C. H., M. B. Ettinger, 6. 6. Robuck, E. R. Hernan, K. C. Kohr, and F.F. Meveli. 1951. "Rewoval of Plutoniu from Laboratory Masties." Ind. at Eng. Chen. 43:7:1509-15.

Christenson, C. M., E. B. Fowler, 6. L. Johnson, E. H. Rex, and F. A. Virgil. 1958. "Soil Mdsorption of Radioactive Hastes at Los Alanos." Sewage and Industrial Maste. 30:1478-1489.

Christenson, C. H. and P. G. Thomas. 1962. Movement of Plutoniu Through Los Alacos Tuff. TID-7628, Part of Second Ground Uisposal of Radioactive hastes Conference Atomic Energy of Canada Linited Chalk River, Canada, Septenber 26-29, 1961. p. 248-281.

T. M. Church, editor. ACS Symposiu Series 18.

Clanton, U. S. 1968. Sorption and Release of $89 \mathrm{Sr}$ and $137 \mathrm{Cs}$ by Recent Sedinents of the Guadalupe River of Texas. Thesis, University of Texas, hustin, TX.

Clark, S. P., $\quad$ E. Peterman and K. S. Heier. I966. "Abundances of Uraniu, Thorium, and Potassium." In: Handbook of Phrsical Constants. S. P. Clark (ed.). Geol. Soc. An. Men. 97.

Clayton, R. M., I. Friedan, D. L. Graaf, T. K. Mayeda, M. F. Meents and H. F. Shing. 1966. The Origin of Saline Formation Maters. I. Isotopic Composition." J. Geophys. Res., 71, 3869-3882.

Cleveland, J. M. 1970. The Chemistry of Plutonium. Cordon and Breach Science Publishers.

Cline, J. F. 1968. Urtake of 241 An and 239pu by Plants. Bin-714, pp. 8.24-8.25.

Coleman, J. C. 1963. "The Kinetics of the Disproportionation of Americium (V)." Inorg. Chen. 2:53.

Coleman, M. T., R. J. Lewis, and D. Craig. 1963. "Sorption of Cesiur by Soils and Its Displacenent by Salt Solutions." Soil Sci. Soc. Proc.

Collet, M., R. Maushart and P. Spaander. 1968. "Accumlation of Radioactive Materials by River Silt." In: Radiation Protection. Pt-2, W. S. Snyder et al. (eds.). pp. 1343-9. 
Collins, A. 6., J. H. Bennett, and O. K. Manuel. 1971. "Iodine and Algae in Sedimentary Rocks Associated with Iodine-Rich Brines." Bull. Geol. Soc. 스. 르:2607.

Connick, R. E. and W. H. McVey. 1949. "The Aqueous Chemistry of Zirconiun." J. A. Chen. Soc. 71:3182-3192.

Corey, J. C. and A. L. Boni. 1975. Reoval of Plutoniu from Drinking Mater by Commity Mater Treatment Facilities. IAEA-SHAT\%/81.

Corey, J. C. and J. W. Fenicore. 1968. "Tracing Groundwater with Chloride Ions and Tritiu Through Acid Kaolinitic Soil." Int. J. Appl. Rad. Isotopes. 19:741-746.

Corey, J. G and J. H. Horton. 1968. "Wovenent of Hater Tagged with $2 H$, $3 p$ and 180 Through Acidic Kaolinitic Soil." Soil Sci. Soc. Am., Proc. 3k: $471-475$.

Cotton, F. A. and 6. Milkinson. 1962. Advanced Inorganic Cheaistry. Interscience Publishers.

Couser, K. E. 1962. Movenent of Ruthenil in the ORR Maste-Pit System. TID-7628, p. 513-31.

Couser, K. E. and F. L. Parker. 1958. "Soil Disposal of Radioactive Hastes at ORM: Criteria and Techniques of Site Selection and Monitoring." Health Phys. 1:152-63.

Cushing, C. E. and D. 6. Matson. 1974. Aquatic Studies of Gable Mountain Pond. BuL-1884, Pacif ic Northmest Laboratory, Richland, Wh.

Cutsha11, M. H. 1957. $-51 \mathrm{Cr}$ in the Colubia River and Adjacent Pacific Ocean." M0-1750-22 (Vol. 4), Paper 3.

Dall'iglio, M. 1971. "Study of the Circulation of Uraniu in the Supergene Emironent in the Italian Alpine Range." Geochin. et Cosmochim. Acta. 35: 47-59.

Dall'Aglio, M. and E. Casentini. 1970. "Distribution of Uranium Between Precipitates and Brines in the Solar Salt Plant of Margherita Di Savoia. Ceochenical and Geological Considerations." Boll. Soc. Geol. Ital. 89:475-84.

Danes and Hoore. 1976. Developent of Monitorimg Prograns for EROA-Owned Radioactive Low-Level Daste burlal Sites. Thite Plains, NY.

Dases and Moore. 1978. Migration of Radionuclides at Low-Level Haste Burial Grounds. Draft manuscript prepared for Atomic Industrial forv, Inc. 
D'Ans, J. and E. Lax. 1967. Taschenbuch fur Chemiker and Physiker. 3 Aufl.,
Bd. I. Springer.

Davis, 6. L. 1947. "Radiun Content of U1tramafic Igneous Rocks. I. Laboratory Investigation." Am. J. Sci. 245:677.

Davydov, Yu. P. 1972. "Sorption of Hydrolyzed Forms of Pu(IV) by Silica Ge1.- Sov. Radiochem. 14(2):220-224.

Davydov, Yu. P. and I. G. Bogatyreva. 1972. "Sorption Pu(IV) by Ion Exchange Res ins in the Region of Hydrolysis of Plutoniu (IV)." Sov. Radiochea.
$14(2): 209-214$.

Dauson, R. and E. K. Duursma. 1974. Distribution of Radioisotopes Between Phytoplankton, Sediment, and Sea Hater in a Dialysis Compartment System." Neth. J. Sea Res. 8:339-353.

De, S. K., S. S. Rao, C. M. Tripathi, and C. Rai. 1971. "Retention of Iodide by Soil Clays." Indian Journal of Agricultural Chemistry. 4:43-49.

Debortoh, and P. Gaglione. 1970. "Study of the Dispersion of Radioactive Eff luents into a Lake. I. Contamination of the Bottom Sediments." Minerva Fisiconucl. 14:190-6.

De laglane, W.H., M. O. Forster, and H. C. Renfro. 1969. Distribution of $65 \mathrm{Zn}$ and $6 \mathrm{CO}_{0}$ in Fractionated Sediment of the Columbia River Estuary. RLO-1750-54, PP. 92-5.

Dement yev, V. S. and N. 6. Syromatnikov. 1965. "Mode of Occurrence of Thoriu Isotopes in Ground Haters." Geokhiaiya. No. 2:211-218.

Dewent' yev, V. S. and M. 6. Syromyatnikov. 1968. "Conditions of Formation of a Sorption Barrier to the Migration of Uranium in an Oxidizing Environment." Geochemistry International. 5:394-400.

Desai, M. Y. M. and A. K. Ganguly. 1970. Interaction of T-ace Elements with O-ganic Constituents in the Mrine Environment. BRRC-488, P. 102.

Dey, M. M. and K. C. Pillai. 1971. "Radioruthenium in Aquatic Environment of Trombay. In: Proc. of the Mational Syposiue on Radiation Physics. Bombay; Bhabha Atomic Res. Center, Pp. 541-53.

Dorta, C. C. and E. Rona. 1971. "Geochemistry of Uranium in the Cariaco Trench." Bull. Mar. Sci. 21:754-765.

Doshi, 6. R., T. M. Krishnaworthy, V. M. Sastry, and T. P. Sarma. 1973. "Sorption Behavior of Trace Muclides in Sea Mater on Manganese Dioxide." Indian Journal of Cheaistry. 11:158-151. 
Duguid, J. O. 1977. "Hydrologic Transport of Radionuclides from Low-Level Maste Burial Grounds." Cowf-770512-7, presented at Syposiua on the Managewent of Low Level Radioactive Waste at the Ceorgia Inst. of Technology, At lanta, 6A, May 23-27, 1977.

Duguid, J. 0. 1975. Status Report on Radioactivity Movement from Burial Ground in Melton and bethel Valleys. ORh-5017.

Duguid, J. 0. 1976. Anmal Progress Report of Burial Ground Studies at Oak Ridge Mational Laboratory: Period Ending Septemer 30, 1975. ORIL-5141.

Duguid, J. O. 1974a. Groundwater Transport of Radionuclides from Buried Waste: A Case Study at Uak Ridge hational Laboratory. Coif-740406-5.

Duguid, J. O. 1974b. "Grouncwater Transport of Radionuclides from Buried Waste: A Case Study at Oak Ridge Mational Laboratory." In: Proc. of the 2nd AEC Environmental Protection Conference. MASH-1332-74-V-1, Pp. 511-529.

Dunigan, E. P. and C. W. Francis. 1972. "Adsorption and Desorption of Cobait 60, Strontiua 85, and Cesium 137 on Soil Huic Acid." Soil Science. $114: 494-496$.

DuPont. 1965. Sorption of Sr and Cs by Strean Beds. T10-26519.

Dutt, G. R., M. S. Shaffer and H. J. Moore. 1972. Computer Simulation Model of Bio-physic-chemical Processes in Soils. University of Arizona. Agr. Exp. Sta. Tech. Bul. 195.

Duursea, E. K. 1973. "Concentration Effects of ${ }^{137} \mathrm{Cs},{ }^{65} \mathrm{Zn}, 60 \mathrm{Co}$, and 106Ru Sorption by Marine Sediments with Geochemical Inplications." Neth. J. Res. 6:225-240.

Duursma, E. K. 1973. Specific Activity of Radionuclides Sorbed by Marine Sediments in Relation to the Stable Element Composition. IAEA-SW-158/4, pp. 57-71.

Duursea, E. K. 1972. "Geochemical Aspects and Applications of Radionuclides in the Sea." Oceanogr. Mar. Biol. Ann. Rev. 10:137-223.

Duursima, E. K. and C. J. Bosch. 1970. "Theoretical, Experimental, and Field Studies Concerning Diffusion of Radioisotopes in Sediments and Suspended Particles of the Sea. Part B: Methods and Exper iments." Metherlands Journal of Sea Research. 4:395-469.

Duursma, E. K. and D. Eisma. 1973. "Theoretical, Experimental and Field Studies Concerning Reactions of Radioisotopes with Sediments and Suspended Particles of the Sea. Part C: Applications to Field Studies." Metherlands Journal of Sea Research. 6:265-324. 
Dwursma, E. K., ard M. G. Gross. 1971. Marine Sediments and Radioactivity. In: Radioactivity in the Marine Environment. Mational Academy of Sciences, Mashington, OC, PF. 14?-160.

Dursal, E. K. and P. Parsi. 1974. Mistribution Coefficients of Plutonium Between Sediment and Seawater." In: Activities of the International Laboratory of Marine Radioactivity. IAEA-T63, Pp. 94-96.

Duursma, E. K., P. Parsi, and 6. Statham. 1974. Fixation of Radionuclides with Time by Marine Sediments. IAEA-163. Pp. I07-108.

Edgington, D. M., J. J. Alberts, M. A. Mahlgren, J. L. Karttunen and C. A. Reeve. 1975. Plutonium and Americium in Lake Kichigan Sedinents. IAEA-SH-199/47.

Edgington, D. M., C. M. Kennedy, 6. E. Bartelt, and C. M. Bobula. 1977. Plutoniu in the Great Miani River, Ohio - Sumary of an Experiment Conducted in october 1976. ALL-77-5 Part III, Pp. 83-84.

Ehhalt, D. H. 1973. On the Uptake of Tritiun by Soil Mater and Ground Mater." Mater Resources Research. 9:1073-1074.

Eichholz, 6. 6., T. F. Craft, and A. N. Galli. 1967. "Trace Element Fractionation by Suspended Mtter in Mater." Geochim. et Cosmochim. Acta. 31: 737-745.

Eliason, J. R. 1966. Montworillonite Exchange Equilibria with StrontiumSodiu-Cesium." Am. Mineral. 51:324-335.

El Madi, A. F. and M. Mar. 1960. "Thorium Content in Nile Water." Proc. Math. Phys. Soc. (U.A.R.). No. 24:11-16.

Emery, R. M. and D. C. Klopfer. 1975. "The Distributions of Transuranic Elewents in a Freshwater Pond Ecosystem.: Prepared for Eighth Rochester International Conference on Environmental Toxicology: Radioisotopes in the Aquatic Environent, Models and Mechanisms.

Emery, R. M., D. C. Klopfer, T. R. Garland, and H. C. Heimer. 1975. "Ecological Behavior of Plutoniun and Americiun in a Freshwater Pond." BMU-SA-5346, Pacific Northmest Laboratory, Richland, MA.

Emery, R. M., D. C. Klopfer and M. C. McShane. 1977. The Ecological Export of Plutoniu from a Reprocessing Haste Pond.

Emery, R. M., D. C. Klopfer, and H. C. Weimer. 1974a. Ecological Behavior of Plutoniu and Americium in a Freshmer Ecosystem. Phase 1. Linological Characterization and Isotopic Distribution. Bink-1867. 
Emery, R. M. and T. R. Garland. 1974b. The Ecological Behavior of Plutonim and Anericiu in a Freshwater Ecosysten: Phase II. In lications of Differences in Transuranic Isotopic Ratios. Bin-1879, Pacific horthmest Laboratory, Richland, W.

Enfield, C. 6. and B. E. Bledsoe. 1975. Kinetic Model for Orthophosphate Reactions in Mineral Soils. EPA-660/2-75-022.

Ermolaev, M. P., A. P. Zhidikora, and V. A. Zarinski. 1965. "On the Silicate Form of Uraniu Transport in Aqueous Solutions." Geokhimiya. 110. 7:813-826 (in Russian).

Essington, E. H. and H. Nishita. 1966. "Effect of Chelates on the Movement of Fission Products Through Soil Colums." Plant and Soil. 24:1-23.

Essington, E. H. and H. E. Mork. 1969. Radionuclide Contamination Evaluation-Milrow Event. NV0-1229-117.

Essington, E. H., H. Mishita and A. J. Steen. 1965. "Release and Movement of Radionuclides in Soils Contaninated with Fallout Material from an Underground Thermonuclear Detonation." Health Physics. 11:689-698.

Evans, E. J. 1956. Plutoniv Retention in Chalk River Soil. CRHP-660.

Evans, U. H. 1973. Effects of Ocean Water on the Soluble-Suspended Distribution of Colubia River Radionuclides. Thesis, Oregon State University, Corvallis, OR, 56 pp.

Evans, D. H. and N. H. Cutshall. 1973. Effects of Ocean Mater on the Soluble Suspended Distribution of Columia River Radionuclides. IAEA-SH-158/8.

Evans, R. D. and C. Goodman. 1941. "Radioactivity of Rocks." Bull. Geol. Soc. An. 52:459.

Evans, R. D., C. Goodman, and N. B. Keevil. 1942. "Radioactivity: The Earth's Heat and Geological Age Measurements." In: Handbook of Physical Constants. Geol. Soc. An. Special Papers 36, Sec. 18, p. 267.

Eyman, L. D. and N. R. Kevern. 1975. "Cesium-137 and Stable Cesium in a Hypereutrophic Lake." Health Physics. 28:549-555.

Fairbridge, R. H. (ed.). 1972. The Encyclopedia of Geochemistry and Environiental Sciences. Van Nostrand Reintiold Company.

Faure, J., P. Viallef, A. Grauby, and P. Picat. 1972. "Complexing of the Organic Matter of a Sediment and Certain Radioisotopes. Distribution of these Radioisotopes as a Function of the Molecular Meight of the Organic Substances." Compt. Rend. Hebd. Seances Acad. Agr. Fr. 58:377-383 (in French). 
Feldman, I. 1976. "The Colloidal Nature of Radionucl ides in Seawater." In: Environmental Toxicity of Aquatic Radionucl ides: Models and Mechanisms. Edited by M. H. Mitler and J. K. Stannard, Ann Arbor Science Pub., Ann Arbor, MI.

Feldman, M. H. 1961. Sumary Recort, 1959-1961. Hinchester Laboratory, Winchester, Massachusetts and Grand Junction, Colorado. HIN-125.

Fitgera1, 6. P. 1970. "Aerobic Lake Muds for the Rewoval of Phosphorus frum Lake Waters." Lim. and Ocean. Yol. 15, Pp. 550-555.

Fleischer, M. 1966. "Index of New Mineral Names, Discredited Minerals and Changes of Mineralogical Momenclature in Vols. 1-50 of the American Mineralogist." A. Mineral. 51:1248.

Folsom, T. R. and V. F. Hodge. 1975. "Experiments Suggest ing Some First Steps in the Dispersal and Disposal of Plutonium and Other Alpha Emitters in the Ocean." Marine Science Commications. 1:213-247.

Forster, W. O. and P. J. Hanson. 1969. Particulate $65 \mathrm{Zn}$ and $5 l_{\mathrm{Cr}}$ in Columia River Estuary. RL0-1750-54. pp. 55-7.

Foster, R. F. 1963a. Radiological Status of the Hanford Environs for June 1963. HH-76525-6.

Foster, R. F. 1963b. Radiological Status of the Hanford Environs for August 1963. $\mathrm{mW}-76525-8$.

Foster, R. F. 1964. Radiological Status of the Hanford Environs for Augusi 1964. HH-80892-8.

Fowler, E. B. and E. H. Essington. 1974. "Soils Element Activities October 1972 - September 1973." In: The Dynamics of Plutonium in Desert Environments. P. B. Dunnaway and M. G. White (eds.). WVO-142, Pp. 7-16.

Frey, F. A., M. A. Haskin, J. A. Poetz, and L. A. Haskin. 1968. "Rare Earth Abundances in Some Basic Rocks." J. Geophys. Res. 73:6085-6098.

Fried, S., A. M. Friedman, J. Hines, 6. Schmitz, and M. Wheeler. 1977. "Distribution of Plutonium and Americium at an 01d Los Alamos Haste Disposal Site." In: Proc. Sym. on Dynazics of Transuranics in Terrestrial and Aquatic Environment. Gatlinburg, TN, October 1976.

Fried, S., A. M. Friedman, and L. A. Quarterman. 1974a. Annual Report on Project Aw115A, Fiscal Year 1974. ANL-8115.

Fried, S., A. M. Friedman, and R. Heeber. 1974b. Studies of the Behavior of Plutonium and Americium in the Lithosphere. All-8096, pp. 10-11. 
Friend, A. 6. 1963. "The Aqueous Behavior of ${ }^{85} \mathrm{Sr},{ }^{137} \mathrm{Cs},{ }^{65} \mathrm{Zn}$, and ${ }^{60} C_{0}$ as Determined by Laboratory Type Studies." In: Transport of Radionuclides in Fresh Water Systems. TID-7664.

Frissel, M. J. and P. Reiniger. 1974. Simulation of Accumulation and Leaching in Soils. Nageningin Centre for Agricultural Publishing and Documentation.

Frysinger, 6. R. 1962. "Cesium-Sodium Ion Exchange on Clinoptilolite." Nature. 194:351.

Fukai, R. and H. M. Lang. 1968. Studies on the Chemical Behavior of Radionuclides in Seawater. I. General Considerations, and Study of Precipitation of Trace Amounts of Chromium, Manganese, Iron, Cobali, Zinc and Ceriu. IAEA. Radioactivity in the Sea, PubTication Ho. 22 .

Fukai, R. and C. M. Murray. 1973. "Environmental Behavior of Radiocobalt and Radiosilver Released from Nuclear Power Stations into Aquatic Systems." In: Environmental Behavior of Radionuclides Released in the Nuclear Industry. IAEA, Vienna. Pp. 217-242.

Fukai, R. and C. M. Murray. 1974. "Adsorption and Desorption of Plutonium and Americium in Freshwater - Sediment and Seawater - Sediment Systems." In: Activities of the International Laboratory of Marine Radioactivity. IAEA-163, Pp. 96-103.

Fukai, R., C. N. Murray, 6. Statham, and K. Asari. 1974. "Radionuclide Measurements of Nater, Sediments, and Biota, Col lected from the Ligurian Sea: Pu-239, 240, Sr-90, and Cs-137. In: Activities of the International Laboratory of Marine Radioactivity. IAEA-163:134-318.

Gabelman, J. W. 1971. "Sedimentology and Uranium Prospecting." Sediment. Geol. $6: 145-186$.

Gaines, 6. L. and H. C. Thomas. 1953. "Adsorption Studies on Clay Minerals. II. A Formulation of the Thermodynamics of Exchange Adsorption." J. Chem. Phys. 21:714-718.

Garder, K. and 0. Skulberg. 1964. "Sorption Phenomena of Radionuclides to Clay Particles in River Hater." Intern. J. Air Water Pollution. 8:229-41.

Garrels, R. M. and C. L. Christ. 1965. Solutions, Minerals and Equilibria. Harper and Row. New York, pp. 213-216.

Garrels, R. M. and M. E. Thompson. 1962. American J. of Science. Vol. 260, p. 57 .

Gast, R. G. 1975. The Behavior of Technetium-99 in Soils and Plants. Progress Report. TCO-2447-1. 
Giacoletto, C. and C. Triulzi. 1970. Radiochemical Studies for Radioactivity Determinations on Marime Sediment Samples: CS-137, Sb-125, and Co-60. CISE-N-118.

Ginzburg, S. I., N. A. Ezerskaya, I. V. Prokof'eva, M. V. Fedorenko, V. I. Shlenskaya, and M. K. Bel'skii. 1975. Analytical Chemistry of Platim Metals. Translated by N. Kaner, Israel Program for Scientific Transtations.

6lenn, J. L. 1971. Relations Among Radionuclide Content and Physical, Chemical, and Mineral Characteristics of Colvbia River Sediments. TIU-25786.

Glover, P. A., F. J. Miner, and H. L. Polzer. 1977. Plutoniu and Americium Behavior in the Soil/Mater Environent. I. Sorption of PTutoniu and Aericiu by Soils. Bil-2117, Pacific Worthmest Laboratory, Richland, MA, pp. 235-246.

6loyma, E. F., S. K. Bhagat, Y. Yousef, and C. Shih. 1966. Transport of Radionuclides in a Model River. ST1-PUB-126, PP. 11-32.

Gloyna, E. F., Yousef, Y. A. and T. J. Padden. 1971. Redioactivity Transport in Mater: Contimuous Release of Radionuclides in a Small Scale Ecosystem. Technical Report 0.R0-490-21.

Goldberg, E. D., Mikoide, R. A. Schmitt and R. H. Smith. 1963. Rare Earth Distributions in the Marine Environment.

Goldberg, E. D. 1975. Marine Geochemistry Research.. Progress Report. UCSD-34P84X9.

Goldberg, M. C., V. J. Janzer, C. 6. Angelo, and H. A. Beetem. 1962. The Effect of Sodium Ion Concentration on Distribution Coefficients for Tuffs from NiS. U.5.6.5. Technical Letter NTS-16.

Goldschmidt, V. M., T. Barth. G. Lunde, and U. W. Zachariasen. 1926. Geochemische Verteilungsgestze der Elemente. VII. Skrifter Morske Videnskaps Akad. Oslo, I. Mat-Naturv. K1., No. 2.

Goldsztaub, S. and R. Hey. 1955. "Adsorption of Uranyl lons by Clays." Bull. Soc. Franc. Mineral. Crist. 78:242.

Goldsztein, M. and J. Ros. 1963. "On the Uranium Content of Sediments of the Western Basin of the Mediterranean." Bull. Inst. Oceanog. (in French).

Gonzalez, G. F. and A. M. Gomez. 1961. "Geochemistry of Cobalt in Soils of Hestern Andalusia. IV. Cobalt Clays and Correlation Btween Cobalt and Iron, Clay and Manganese Contents." An. Edafol. Agroboil. 23:563-572. 
Grandstaff, D. E. 1976. "A Kinetic S+udy of the Dissolution of Uraninite." Econ. Geol. 71(8):1493-1506.

Granger, H. C. 1963. Radiun Migration and Its Effect on the Apparent Age of Uraniu Deposits at Amrosia Lake, hen hexico. U.S. Geot. Survey Prof. Paper 475-B, pp. 8-60-B-63.

Granger, H. C., E. S. Santos, B. G. Dean and F. B. Moore. 1961. "Sandstone-Type Uranium Deposits at Ambrosia Lake, New Mexico - an Interim Report." Econ. Eeol. 56(7):1179-1209.

Grebenshchikova, V. I., M. B. Chernyavskaya, and M. R. Andreeva. 1972. "Sorption of Tetravalent Elements by Mordenite II. Sorption of Pu(IV)." Radickhimiya. 15(6)761-766.

Grebenshch ikova, V. 1., V. N. Nikonov, A, S. Pershin, and N. R. Andreeva. 1975. "Some Properties of Hydroxo Complexes of Plutoniun (IV)." Soviet Radiochen. 17(3)384-387.

Grebenshchikova, Y. I. and Y. P. Davydov, 1961. "A Study of the State of Pu(IV) in Dilute Solutions of Nitric Acid." Radiokhiniya. $\underline{3}: 155-164$.

Grebenshchikova, Y. I. and Y. P. Davydov. 1965. "State of Pu(IV) in the Region of $\mathrm{pH} 1.0-12.0$ at a Plutonium Concentration of $2.0 \times 10^{-5} \mathrm{M}$." Radiokhimiya. 7:191-195.

Grebenshchikova, V. I., Y. P. Davydov, and A. S. Pershin. 1971. "The Adsorption of Plutoniu (+4) on a Precipitate of Barium Sulfate." Soviet Radiochenistry. 13:457-459.

Green, D. B., T. J. Logan and N. E. Sweck. 1978. "Phosphate AdsorptionDesorption Char acteristics of Suspended Sediments in the Maumee River Basin of Onio." J. of Environ. Qual. I(2):208-212.

Gromiec, M. J. and E. F. 6loyna. 1973. Radioactivity Transport in Water: Fina 1 Report. Technical Report No. 22. ORO-23.

Gromov, V. V. 1975. Investigation of the Behavior of Trace Elements in Ocean Mater by the Desorption Method. BiL-tr-6II.

Gromov, V. V. and V. I. Spitşyn. 1974. "Influence of Photoplankton on the Physi cochemical State of $239 \mathrm{Pu}_{\mathrm{u}}$, $106 \mathrm{Ru},{ }^{99} \mathrm{TC}$ and $60 \mathrm{CO}_{\mathrm{O}}$ in Sea Hater." Transl. Dokl. Akad. Mauk SSSR. 215(2):451-453.

Gromov, Y. V., V. V. Surikov, and YU. A. Bogdanov, 1972. "Adsorption of Yttium-90, Niobium-95, and Cerium-141 by Suspension and Bottom Deposits of the Indian Ocean." Sov. Radiochem. 14:834-8.

Gromv, V. V. and V. I. Spitsyn. 1974. "Sorption of 239pu, 106Ru, and 997c by Bottom Sediments of the Pacific Ocean." Sov. Radiochen. 16:157-162. 
Gross, M. G. 1972. "Sediment-Associated Radionuclides from the Columbia River." In: Columbia River Estuary and Adjacent Ocean Haters.

A. T. Parter (ed.), University of Washington Press, Pp. 736-54.

Gross, M. G. 1967. Distribution and Movement of Radioactive Continental Shelf Sed iment, Northmestern United States. RLO-1725-73.

Gross, M. 6. 1966. "Distribution of Radioactive Marine Sediment Derived from the Columbia River." Journal of Geophysical Research. 71:2017-2021.

Gross, M. 6., D. A. Mckanus, and J. S. Creager. 1963. Preliminary Report on the Sediments and Radioactivity in the Vicinity of the Columbia River Eff Tuent. Brown Bear Cruise, 291 (July 29 - August 12, 1961), 311 (July 23 - August 14, 1962). Tech. Report 10. 84. TID-20200.

Habashi, F. 1962. "Correlation Between the Uranium Content of Marine Phosphates and Other Rock Constituents." Econ. Geol. 57:1081-1084.

Hacquaert, A. L. 1925. "Pink Calcite from Tantara (Katanga)." Matuurw. Tijds. Antwerp. Vol. 7, p. 102.

Haglund, D. S. 1968. The Distribution of Uranium in Recent Carbonate Sediments and Skeletons of Organisins and the Effect of Diagenes is on Uraniun Redistribution. Thesis, Rensselaer Polytechnic Institute, Troy, NY.

Haglund, D. S., G. M. Friedan, and D. S. Miller. 1969. "The Effect of Freshwater on the Redistribution of Uranium in Carbonate Sediments." J. Sediment. Petrol. 39:1283-1296.

Hajek, B. F. 1966. Plutonium and Americium Mobility in Soils. BNHL-CC-925, Pacific Northwest Laboratory, Richland, WA.

Hajek, B. F. and K. C. Knoll. 1966. Disposal Characteristics of Plutonium and Americium in a High Salt Acid Waste. BNLL-CC-649, Pacific Northest Laboratory, Richland, W.

Hakonson, T. E. and F. W. Whicker. 1975. "Cesium Kinetics in a Montane Lake Ecosystem." Health Physics. 28:699-706.

Hakonson, T. E. 1972. Cesiurr Kinetics in a Montane Lake Ecosystem. Thes is. Colorado State University, Fort Collins, CO.

Hakonson, T. E. and L. J. Johnson. 1973. "Distribution of Environmental Plutonium in the Trinity Site Ecosystem After 27 Years." Proceedings of the Third International Congress of the International Radiation Protection Association, Pp. 242-247. 
Hakonson, T. E., L. J. Johnson and H. D. Purtymin. 1973. "The Distribution of Plutoniun in Liquid Waste Disposal Areas at Los Aiamos." In: Proceedings of the Third International Congress of the International Radiation Protection Association, September 9-14, 1973, Washington, DC, Pp. 248-253, COif-730907-P1.

Hakonson, T. E., J. W. Myhan and W. D. Purtymum. 1975. Accumulation and Transport of Soil Plutonium in Liquid Waste Discharge Areas at Los Alamos. IAEA-SIFI99/99.

Hale, V. O. and A. Mailace. 1970. "Effect of Che lates on Uptake of Some Heavy Metal Radionuclides from Soil by Bush Beans." Soil Sci. 109:262-263.

Halevy, E. 1965. "The Exche zqeability of Hydroxly Groups in Kaolinite." Geochim. et Cosmochim. Acta. 28:1139-1145.

Hamaguchi, H. 1941. "Chemical Investigations of Deep-Sea Deposits. VIII. Radium Content of Deep-Sea Deposits." 3 . of the Chem. Soc. Of Japan. 62:836-42.

Hamid, A. and B. P. Warkentim. 1967. "Retention of $131_{\text {I }}$ Used as Tracer in Water Movement Studies." Soil Sci. 104:279-82.

Haney, W. A. 1963. Fission Product Tritium in Fuel Reprocessing Nastes. HW-SA-3303.

Haney, H. A. 1964. "Consequences of Activity Release." Nuclear Safety. 5:399-403.

Haney, H. A. 1967. Final Report on the Effects of Ben Franklin Dam. BMil-412, Pacific Northwest Laboratory, Richland, WA.

Haney, H. A., O. J. Brown, and A. E. Reisenauer. 1962. Fission Product Tritiun in Separations Wastes and in the Ground-Water. HiN-74536.

Haney, H. A. and C. E. Linderoth. 1959. Exploratory Field Study of a Ground Waste Disposal Facility. HW-60115.

Hansen, R. 0. and 6. L. Huntington. 1969. "Thorium Movements in Morainal Soits of the High Sierra, California." Soil Science. 108:257-265.

Hanson, P. J. 1967. Vertical Distribution of Radioactivity in the Columbia Qiver Estuary. RLO-1750-22 (vol. 2), Paper 2.

Harr ison, F. L. 1969. Radioactive Debris from Underground Muc lear Explosions: 1. Physical and Chemical Characteristics, 2. Biological Availability of the Radionuclides to Aquatic Animals. UCRL-50596. 
Harter, R. D. 1968. "Adsorption of Phosphorus by Lake Sediment." Soil Sci. Soc. Aer. Proc. 32:514-518.

Haskin, L. A., et al. 1966. Meteoric, Solar, and Terrestrial Rare Earth Distributions." In: Physics and Chemistry of the Earth. L. H. Ahrens et al. (eds.), Vol. 7, Oxford, Pergamon Press.

Haskin, L. A. and R. A. Schaitt. 1967. "Rare-Earth Distributions." In: Researches in Geochemistry. Vol. 2. P. H. Abelson (ed.), John Wiley \& Sons, Inc., pp. 234-259.

Haury, 6. and H. Schikorski. 1977. "Radioactive Inputs into the Environment, Comparison of Matural and Man-Made Inventories." In: Global Cheaical Cycles and Their Alterations by Man. Edited by H. Struin, PP. 165-188, Bertin.

Haushild, H. L., G. R. Deenpter, Jr., and H. H. Stevens, Jr. 1973a. Distribution of Radionuclides in the Columia River Streamed from the Nuclear Reactors, Hanford Reservation to Longiver, Washington. TID-26531.

Haushild, H. L., H. H. Stevens, Jr., J. L. Melson and G. R. Dempster, Jr. 1973t. Radionuclides in Transport in the Colu bia River from Pasco to Vancouver, Washington. USES Professional Paper 433-N, :P. N1-N43.

Haushild, H. L., H. H. Stevens Jr., J. L. Melson, 6. R. Dempster, Jr. 1971. Radionuclides in Transport in the Columbia River from Pasco to Vancouver Rashington. USES. IIfi-258\%4, $77 \mathrm{p}$.

Havlik, B. 1970. "Radioactive Pollution of Rivers in Czechos lovakia." Heaith Physics. 19:617-625.

Havlik, B., J. Grafova, and B. Mycova. 196ea. "Radiun-226 Liberation from Uranium Ore Processing Mill Haste Solids and Uranium Rocks into Surface Streans - 1." Health Physics. 14:417-422.

Havlik, B., B. Mrcova, and J. Grafova. 1968b. "Radiun-226 Liberation from Uranium Ore Processing Mill Maste Solids and Uranium Rocks into Surface Streans - II." Health Physics. 14:423-430.

Hawkes, H. E. 1954. Geochenical Prospecting Investigations in the Nyeba Lead-Zinc District, Nigeria. USES butet ín I000-B.

Hawkins, D. B. and H. L. Short. 1965. Equations for the Sorption of Cesin and Strontiu on Scil and Clinoptilolite. 100-120\%6.

Hawkins, R. H. 1975. "Migration of Tritiun from a Muclear Maste Burial Site." In: Proc. Third Enviramental Protection Conference. ERDA-92. 2:622-637. 
Hayes, D. W. 1976. Tritium in the Savannah River Estuary and Adjacent Marine Maters. OP-MS-75-122.

Hayes, D. W., J. H. LeRoy and F. A. Cross. 1975. Plutoniun in Atlantic Coastal Estuaries in the Southeastern United States. :4EA-SW-199784.

Heier, K. S. and J. A. S. Adans. 1964. "The Geochemistry of the Alkali Metals." Phys. Chem. Earth. 5:235-380.

Heier, K. S. and J. L. Carter. 1964. Uraniun, Thorium, and Potassium Contents in Basic Rocks and Their Bearing an the Mature of the Upper Mant le." In: The Matural Radiation Environment. p. 75, J. A. S. Adans and M. M. Louder (eds.).

Heier, K. S. and J. J. H. Rogers. 1963. "Radiometric Determination of Thorium, Uraniun, and Potassium in Basalts and in Two Magmatic Differentiation Series." Geochim. et. Cosmochin. Acta. 27:137.

Helgeson, H. C. 1968. "Evaluation of Irreversible Reactions in Geochemical Processes 10lving Minerals and Aqueous Solution--I, Thermodymanic Relations." G 三his. et Cosmochim. Acta. Vol. 32, p. 853.

Helgeson, H. C., T. H. Brown, A. Migrini, and T. A. Jones. 1970. "Calculations of Mass Transfer in Ceochemical Processes Involving Aqueous Solutions." Geochim. et Cosmochim. Acta. Vol. 34, p. 569.

Heigeson, H. C. 1969. "Thermodynamics of Hydrothermal Systems at Elevated Temperatures and Pressures." J. Sci. 267:729-804.

Hew, J. D. 1970. Study and Interpretation of the Chemical Characteristics of Matural Mater. Eeological Survey Kater Supply Paper 1473.

Hetherington, J. A. 1975. "Chapter 5. The Behavior of Plutoniun Muclides ir: the Irish Sea." In: Environmental Toxicity of Aquatic Radionuclides:

Models and Mechanises. Rochester International Conference on Environiental Toxicity, 8th, 1975 .

Hetherington, J. A., D. F. Jefferies, M. J. Mitchell, R. J. Pentreath and D. S. Hoodhead. 1975. Environental and Public Health Consequences of the Controlled Disposal of Transuranic Elements to the Garine Environent. IAER-Si-199/II.

Higgins, 6. H. 1959. "Evaluation of the Ground-Water Contamination Hazard fro Underground Nuclear Explosions." J. Eeophys. Res. 64:1509-1520.

Hirano, S., T. Koyanagi, and M. Saiki. 1973. The Physico-Chenical Behavior of Radioactive Cerlí in Seawater. IAEA-SH-158/3, Pp. 47-55. 
Hirst, D. M. 1962. "The Geochemistry of Modern Sediments from the Gulf of Paria. II. The Location and 'istribution of Trace Elements." Geochim. et Cosmoch im. Acta. 26:1147-1188

Holl and, H. D. and J. L. Kulp. 1954. "The Mechanism of Renoval of Thor ium and Radium from the Oceans." Geochim. et Cosmochim. Acta. 5:214-224.

Horrath, E. 1960. "Investigations of Uranium Adsorption to Peat in Natural Waters Containing U-Traces." Magyar Tudomanyos Akad. Atomag Kutato Intezete, Kozlenenyek. 2:177-183 (in Hungarian).

Horstman, E. L. 1957. "Ine Distribution of Lithium, Rubidium, and Caesium in Igneous and Sed imentary Rocks." Geochim. et Cosmochim. Acta. 12:1-28.

Horton, J. H. and D. I. Koss. 1960. "Use of Tritium from Spent Uranium Fuel Elements as a Ground-Water Tracer." Soil Science. 90:267-271.

Howery, D. G. and H. C. Thomas. 1965. "Ion Exchange on the Mineral Clinoptilolite." J. Phys. Chem. 69:531-537.

Hubbard, J. E. 1968. ${ }^{137} \mathrm{Cs}$ in an Alpine Hatershed. Thesis, Colorado State University, Fort ColTins, CO.

Hubbard, J. E. and H. D. Striffler. 1973. "Cesium-137 in a Mountain Stream Channe 1." Water Resour. Res. 9:1440-1442.

Hubbell, D. H. and J. L. Glenn. 1973. Distribution of Radionuclides in Botton Sedirents of the Columbia River Estuary. Geological Survey Professional Paper 433-L, 63 pp.

IAEA. 1975. "The Oklo Phenomenon." Proc. Sym., International Atomic Energy Agency, Libreville, 23-2?, June 1975.

Imahashi, M. 1970. Uranium and Thorium in Hydrothermally Altered Rocks Under Acid Conditions. As Exemplified by Silicified Rocks from Tateyana Jigokudani, Toyama." Mippon Kagaku Zasshi. 91:668-9 (in Japanese).

Iskra, A. A., M. V. Kulikov, and U. 6. Bakhurov. 1969. "Behavior of Matural Radiozitive Elements in Mon-Running Freshwater Basin." A. Energ. (U.S.S.R.). 27:134-7 (in Russian).

Izrae 1, U. A., V. N. Petrov, A. A. Pressman, F. A. Rovinsky, E. D. Stukin, and A. A. Ter-Saakov. 1959. Radioactive Contamination of the Environment by Underground Nuclear Explosions and Kethods of Forecasting It.

Izrae 1, Yu. A. and F. Ya. Rovinskii. 1970. Hydrological Uses of Isotopes Produced in Undergiound Muclear Explosions for Peaceful Plicposes. TCRL-Trans-10458. 
Jackson, D. D. 1976. Radiochemical Studies for the Nuclear Chemical Mining of Copper. UCRL-52025.

Jacobs, D. C. 1974. Impacts in Groundwater of Effluents Arising in the Nuclear Industry. MP-20456, Pp. vp., Paper 16.

Jacobs, D. G., Y. E. Kim, and 0. M. Sealand. 1966. Application of Mineral Exchange to Reactor Technology. ORNL-4007, Pp. 27-33.

James, R. O. and T. H. Healy. 1972. "Adsorption of Hydrclyzable Metal Ions at the Oxide-Water Interface." J. Colloid Interfac. Sci. 40:65-81.

Jenne, E. A. and J. S. Wahlberg. 1968. Role of Certain Stream-Sediment Components in Radioion Sorption. U.S.6.S. Professional Paper 433-F.

Jenne, E. A., ed. 1979. "Chemical Modeling in Aqueous Systems." ACS Symposium Series 93, American Cheaical Society, Mashington, DC.

Jennings, A. R. and M. C. Schroeder. 1968. "Evaluation of Selected Isotopes as Ground Hater Tracers." Water Resour. Res. 4:829-836.

Johnson, V., M. H. Cutshall and C. Osterberg. 1967. "Retention of ${ }^{65} \mathrm{Zn}$ by Columbia River Sediment Water Resources Research." 3(1):99-i02.

Jones, A. D. and 6. R. Choppin. 1969. "Complexes of Actinide Ions in Aqueous Solutions." Actinide Reviews. 1:311-336.

Jordan, C. F., J. R. Kline, and D. S. Sasscer. 1971. "Tritium Movement in an Old-Field Ecosystem Determined Experimentally." In: Radionuclides in Ecosysters. Conf-710501-P1, pp. 199-203.

Joseph, A. B., P. F. Gustafson, I. R. Russel, E. A. Schuert, H. L. Volchok, A. Tamplin. 1971. "Sources of Radioactivity and Their Characteristics." In: Radiochemistry in the Marine Environent. National Academv of Sciences.

Joshi, L. U. and A. K. Ganguly. 1970. "Disequilibrium Studies in $232 \mathrm{Th} / 228 \mathrm{Th}$ Activity Ratio in Some Sediment Samples of India." Proceedings of the Chemistry Symposium, Bombay. Dept. of Atomic Energy, II:137-48.

Juguet, B., M. Donner, L. Coin, and C. Burg. 1966. importance of Mud and Suspended Matter in the Transport and Elimination of Radionuclides Contained in Surface Haters. IAEA-SH-12/7 (in French).

Kampbel1, D. H. 1964. Cerium, Iron, and Manganese Sorption by Soil Colloid and Uptake by Plants. Thesis, Univ. of hissouri, Colvibia, Mo.

Karttunen, J. O. and D. M. Edgington. 1974. "Distribution of Plutonium in Lake Michigan Sediments." In: Radiological and Environmental Research Division Annual Report, January - December 1974. Ecology. ANL-75-3 (Pt. 3), PP. 113-127. 
Katcoff, S. 1958. "Fission-Product Yield from 6 , Th, and Pu." Mucleonics. $16: 78-85$.

Katsurayana, K. 1968. "Accumulation of Radioactivity in Rice Fields." Annu. Rep. Res. Reactor Inst. Kyoto University. 1:293-97.

Kaufiman, H. J. and P. C. Klingerman. 19--. Nature and Disposition of Sediant Sorbed Radionuclides Entering San Francisco Bay, PP. 149-159.

Kaufmann, R. F., 6. 6. Eadie and C. R. Russe11. 1975. Sumary of Ground Water Quality Impacts of Uranium Mining and Milling in the Grants Mineral Belt, hew Fexico. U.S.E.P.A., Off. Rad. Prog.-Las Tegas Facility. Tech. Note CRPTLV-75-4.71 p.

Kaufmann, R. F., G. G. Eadie and C. R. Russell. 1976. "Effects of Uranium Mining and Milling on Ground Mater in the Grants Mineral Belt, Mew Mexico." Ground Mater. 14(5):296-308.

Kaufman, S. and H. F. Libby. 1954. "The Natural Distribution of Tritium." Phys. Rev. 93:1337.

Kaufman, H. J. and 6. T. Orlob. 1955. "Weasuring Ground Water Movement with Radioactive and Chemical Tracers." Paper presented at the Annual Meeting of the California Section of AlmA, Sacramento.

Kawabata, T. 1967. "Studies on the Sorption and Release of Radionuclides by River Sediments." J. Radiation. Res. 8:20-31.

Keller, C. 1971. The Chenistry of the Transuranium Elewents. Yol. 3. Kernchemie in Einzeldarstellungen. VerTag Chemie/Emb.

Kennedy, C. H., 6. E. Bartelt, and K. A. Orlandini. 1977. Uraniu in Mater and Suspended Sediments of the Great Miani River, Onio. ALL-77-5 Part III, Pp. 86-88.

Kepak, F. 1974. "Separation of Radionuclides in Colloidal Form from Aqueous Solutions." Journal of Radioanalytical Chemistry. 20:159-166.

Kepak, F. 1966. "Sorption of the Radioisotopes ${ }^{35} \mathrm{~S}, 131 \mathrm{I}$ and $106 \mathrm{Ru}$ on Hydrated Gxides in Laboratory Colums." Collection Czechoslov. Chem. Comeun. 31:3500-3511.

Kester, D. R. and R. M. Pytkowicz. 1967. "Determination of the Apparent Dissociation Constants of Phosphoric Acid in Seawater." Lim. and Ocear. 12:243-252. 
Khalid, R. A., H. H. Patrick, Jr. and R. P. Gambrell. 1978. "Effect of Dissolved Oxygen on Chemical Transformations of Heavy Metais, Phosphorus, and Nitrogen in an Estuarine Sediment." Estuarine and Coastal Marine Science. (6): $21-35$.

Kimura, Y., H. Morishuma, T. Koga, H. Kawai and Y. Hionda. 1968. "Studies on the Behavior and Distribution of Radioactive Substances in Coastal and Estuarine Haters." Kinki Daigaku Genshiryaku Kenkyusho Monpo. 7:21-31 (in Japanese).

Klechkovsky, Y. M. 1956. On the Behavior of Radioactive Fission Products in Soil. Their Absorption by Plants and Their Accumlation in Crops. ALC-TR-2867.

Kline, J. R. and C. F. Jordan. 1968. "Tritivin Movenent in Soil of Tropical Rain Forest." Science. 160:550-551.

Klingeaan, P. C. 1965. Transport of Radionuclides in Surface and Estuarine Haters. Thesis, University of California, Berke tey, Ch.

Klingeman, P. C. and H. J. Kaufman. 1965. Transport of Radionuclides with Suspended Sediment in Estuarine Systeas. TIU-24140.

Knaelaann, M. 1970. "Effect of Concentration on the Iodide Sorption by Various Soils." Atcmernenergie. 16:247-52 (in German).

Knoll, K. C. 1965. Reaction of High Salt Aqueous Plus Organic Waste with Soil. Brim-CC-313, Pacific horthest Laboratory, Richland, Wh.

Knoll, K. C. 1969. Reactions of Organic Hastes in Soil. Bim-860, Pacific Northwest Laboratory, Richland, W.

Koczy, F. F. 1949. "Thoriun in Sez Hater and Marine Sediments." Geol. Foren. I Stockhola Forh. 71:238-42.

Koczy, F. F., E. Tonic, and F. Hecht. 1957. "Geochemistry of Uranium in the Baitic Sea Basin." Geochim. et Cosmochim. Acta. 11:86-102 (in German).

Kokotoy, Yu. A., R. F. Popova, I. Tsing-Chih, and M. Shih-tsi. 1962. "Sorption of Long Lived Fission Products by Soils and Argillaceous Minerals. 11. Sorption of Cerilu-144 by Soils." Radiokhinya. 4:227-228.

Kolizdin, L. B., D. S. Nikolaev, S. M. Grashchenko, Y. Y. Kuznetzov, and K. F. Lazarev. 1960. "Staies of Uraniv Detected in Black Sea Haters." Doklady Akad. Mauk S.S.S.R. 132:915-17 (in Russian).

Yolodny, Y. 1969. Studies in Ceochemistry of Uraniu and Phosphorites. University of Caltrornia. Thesis.

Kolodny, Y. and I. R. Kaplan. 1970. Deposition of Uranive in the Sediment and Interstitial Hater of an Anoxic Fjord. $20 \%-700505-1$. 
Koranda, J. J. 1965. "Preliminary Studies of the Persistence of Tritiun and ${ }^{14 C}$ in the Pacific Proving Ground." Health Phys. 11:1445-1457.

Korotkin, Yu. S. 1972. Study of Transplutoniv Element Hydrolysis. 11. Hydroiysis of Americium (III) in the Presence of lons with Positive and Megative Hydration Energy. Jilm-P-6403.

Kotegov, K. V., O. M. Pavlov and V. P. Shredov. 1968. "Technetium." In: Advances in Inorganic Chemistry and Radiochemistry. 11:1-90, Acadenic Press, NY.

Kovalevskii, A. L. 1967. "Deptindence of the Content of Some Trace Elements on the Ciayiness of Soils." Mikroelem. Biosfere Ikh Primer. Scl. Khoz. Med. Sib. Dal'nego Vostoka, DokT. Sib. Knof.. Znd. 1964. 0. V. Makew. Buryat. Khizhn. 12d. Ulan-Ude, USSR.

Krylov, A. Y. and M. M. Shats. 1958. Some Regularities of Uranium Migration in Naters of Morthwestern Districts of USSR. AEC-tr-4474:319-32.

Kubose, D. A., M. 6. Lai, H. A. Goya, and H. I. Cordova. 1968. Radioactivity Release fram Radionuclide Power Sources. VIIa. Dissolution SFudies of Plutonili Dioxide in the Ocean, 5 honths' Exposure. USTRDL-TR-68-74.

Kudo, A. 1969. Radioactivity Transport in Mater. Interaction Between Flowing Water and Bed Sediment. Thesis, University of Taxas, Austin, Texas.

Kudo, A. and E. F. Gloyna. 1971. "Transport of 137 CS, II Interaction with Bed Sediments." Hater Research. Yo1. 5, pp. 71-79.

Kulikov, N. V. 1968. "Influence of Certain Complexons on Radioisotope Sorption by Soil." Tr. Inst. Ekol. Rast. Zknivotn. 61:21-5 (in Russian).

Kulikov, M. V. and I. Y. Molchanova. 1972. Radioijotopes in the Soil Solution System. INIS-MF-887-3-, up. 2-13 (ín Ri ssian).

Kuo, S. and E. 6. Lotse. 1974. "Kinetics of Phosphate Adsorption al 1 Desorption by Lake Sediments." Soil Sci. Soc. Amer. Proc. 38:50-54.

Kurokana, Y. 1971. "Data of Natural Radioactivity in Japan." Hoken Butsuri. 6:192-3 (in Japanese).

Kuznetsov, Y. V. 1969. "On Occurrence Forms of Ionium (230Th) and Thorium (232Th) in the Ocean." Geokhimiya. No. 2:177-84 (in Russian).

Kuznetsov, Y. V., V. K. Legin, A. P. Lisitsyn, and Z. H. Simonyak, 1964. Radioactive Ocean Suspensions. I. Isotopes of Thorium in Ocean Suspensions." Radiokhiniya. 6:242-54 (in Russian). 
Kuznetsov, Y. V., V. K. Legin, A. P. Lisitsyn, and Z. N. Simonyak. 1967. "Radioactivity of Oceanic Suspensions. II. Uranium in Oceanic Suspensions.- Radiokhimiya. 9:489-97 (in Russian).

Kuznetsov, Y. V., E. V. Komarov, A. N. Elizarova, Z. N. Simonyak and A. A. Bochkov. 1973. "Simulation of the Forms of Thorium-230 in Seawater to Study its Sedimentation Mechanism." Sov. Radiochem, Pp. 715-720.

Kuznetsov, Y. V. and V. N. Schebetkovskii. 1971. "Distribution of Radioactive Isotopes Between Sea Haters and Sediments." Geokhimiya. No. 12:1466-72 (in Russian).

Kuznetsov, Y. Y., Z. N, Simonyak, A. P. Lisitsyn, and M. S. Frenklikh. 1968. Thor ium Isotopes (230 Th, 232 Th) in the Surface Layer of the Indian Ocean Sediments." Geochem. Int. 5:169-i77.

Labeyrie, L. D., H. D. Livingston and V. T. Bowen. 1975. Comparison of the Distributions in Marine Sediments of the Fallout Derived Kuclides bsfe and 239,240 Pu: A kew Approach to the Chemistry of Environmental RadionuClides- IAEA-ST-199/115.

Lambet, M. S. and D. S. Nikolaev. 1962. "The Mode of Uranium Occurrence in the Waters of the Azov Sea and in a Number of Estuaries and Rivers of the Azov-B I ack Sea Basin." Doklady Akad. Mauk S.S.S.R. 142:681-2 (in Russian).

Lamers, W. T. 1968. The Distribution of $60 \mathrm{Co}, 106 \mathrm{Ru}$, and $137 \mathrm{Cs}$ Among Suspended and Dissolved Particles in White Oak Lake. K-1758.

L'Annunziata, M. F. and W. H. Fuller. 1968. "The Chelation and Movement of ${ }^{89} \mathrm{Sr}$ - $90 \mathrm{Sr}$ (90\%) in a Calcareous Soil." Soil Sci. 105:311-19.

Latimer, H. M. 1952. The Oxidation States of the Elements and Their Potentials in Aqueous Soluticns. Second Edition. Prentice-Hall, Inc., Englewood CTiffs, NJ.

Lauderdale, R. A. 1951. "Treatment of Radicactive Water by Phosphate Precipitation." Industrial and Engineering Chenistry. 43:1538-1540.

Lavrukhina, A. K. and A. A. Pozdnyakov. 1970. Analytical Chemistry of Technet ium, Promethium, Astatine and Francium. Trans lated by R. Kondor. Ann Arbor - Humphrey Science Publishers.

Lazarev, K. F., D. S. Nikolaev, and S. M. Grashcheriko. 1961. "Concentration of Thor ium Isotopes in Sea Hater." Radiokhimiya. 3:623-35 (in Russian).

Lean, D. R. S. and M. M. Chariton. 1976. A Study of Phosphorous Kinetics in a Lake Ecosystem in Environmental Biogeochemistry. Edited by J. 0. Mriagi, Ann Arbor Science Publishers, Inc., Michigan. 
Legin, V. K., Y. V. Kuznetsov and K. F. Lazarev. 1966. "Uranium Occurrence in Marine Sediments." Geokhimiya. 5:60\%-608 (in Russian).

Lerman, A. 1971. Transport of Radionuclides in Sediments. Corf-710, 5U1-P2, pp. 936-944.

Lerman, A. and T. A. Lietzke. 1975. Muptake and Migration of Tracers in Lake Sed iments." Limol. Oceanogr. 20:497-510.

Lerman, A. and H. Taniguchi. 1971, Stront ium-90 and Cesium-137 in Water and Deep Sediments of the Great Lakes. CONF-710501-P1, pp. 460-464.

Lerman, A. and H. Taniguchi. 1972. "90Sr: Diffusions Transport in Sed iments of the Great Lakes." J. Geophys. Res. 77:474-81.

Lester, D. H., 6. Jansen and H. C. Burkholder. 1975. "Wigration of Radionuclide Chains Through an Adsorbing Medium." In: Adsorption and Ion Exchange, AIChE Symosium Series, 152(71):202-214.

Lewis, R. J. and H. C. Thomas. 1963. "Adsorption Studies on Clay Minerals. VIII. A Consistency Test of Exchange Sorption in the Systems Sodium Ces ium - Barium Montmorillonite." J. Chem. Phys. 67:1781-1783.

Li, H. C., D. E. Armstrong, J. P. H. Milliams, R. F. Harris and J. K. Syers. 1972. "Rate and Extent of Inorganic Phosphate Exchange in Lake Sediments." Soil Sci. Soc. Amer. Proc. 36:279-285.

Liebscher, K., F. Habashi, and T. Schonfeld. 1961. "Observations on the Behavior of Fission Product in Surface Waters." Atompraxis. 7:94-100 (in German).

Lindenbaum, A. and W. Westfall. 1965. "Colloidal Properties of Plutonium in Dilute Aqueous Solution." Inter. J. App. Radiation and Isotopes. 16:545-553.

Lindsay, W. L. 1972. "Inorganic Phase Equi Tibria of Micronutrients in Soils." In: Micronutrients in Agriculture, pp. 41-57. Soil Sci. Soc. Amer. Inc., Madison VI.

Lisitsyn, A. P. and M. S. Frenklikh. 1968. "Uranium and Radium in the Surface Layer of Oceanic Sediments." Geokhimiya. No. 3:323-33 (in Russian).

Lister, B. and L. McDonald. 1951. Some Aspects of the Solution Chemistry or ZirCOnium. AERE-C/R-801.

Lamenick, T. F. 1963. "Movement of Ruthenium in the Bed of White Oak Lake." Health Phys. 9:835-45. 
Lomenick, T. F. and T. Tamura. 1965. "Naturally Occurring Fixation of 137 Cs on Sediments of Lacustrine Origin." Soil Sci. Soc. Amer., Proc. 29:383-7.

Magno, P., T. Reavey, and J. Apidianakis. 1970. Liquid Waste Effluents from a Muclear Fuel Reprocessing Plant. BRH-NERHL-70-2.

Mahmoud, K. A., Y. A. Yousef, N. I. Abdel-Kerim, and W. E. Y. Abde I-:ilik. 1968. "Affinity of Ismaii ia Canal Bottom Sediments for Certain Radionuclides." Isotope Radiat. Res. 1:9-18.

Mahmoud, K. A., Y. A. Yousef, M. M. Ishak, H. E. Y. Abdel-Malik, S. R. Khalil, A. Shafik, and R. M. K. El-Shinawy. 1973. "Transfer Mechanism and Concentrating Processes of Certain Radionuclides in the Aquatic Ecology of the I smailia Canal." In: Envirormental Behavior of Radionuclides Released in the Nuclear Industry. IAEA, Vienna. Pp. 205-215.

Manskaya, S. M., 6. V. Drozdora, and M. P. Yemel'yanova. 1956. "Fixation of Uranium by Humic Acids and Me?anoidins." Geokhimiya. No. 4.

Marshall, J. S., D. N. Edgington and M. A. Wahlgren. 1973. Great Lakes Radioecology Program: Introduction. AML-8060, Part 3, pp. 1-5.

Marter, H. L. 1974. Radioactivity from SRP Operations in a Downstream Savannah River Swamp. OP-1370.

Martin, J. M., Jednacak and V. Pravdic. 1971. "The Physico-Chernical Aspects of ace Element Behavior in Estuarine Environments." Thalassia, Ugos lavica. $\underline{7}(2): 619-637$.

Masuda, K. and T. Yamamoto. 1971. "Studies on Environmental Contamination by Uranium. II. Adsorption of Uranium on Soil and Its Desorption." J. Radiat. Res. 12:94-99.

Means, J. L., D. A. Crerar, and J. 0. Duguid. 1976. Chemical Mechanisms of 60 Co Transport in Ground Hater from Intermediate - Level Liquid Waste Irench 7: Progress Report for Period Ending June 30, 1975. ORNL/Th-5348.

Meeusen, M. A., G. J. Willems and C. J. DeRanter. 1975. "Sorption Capacity Studies of Scheldt Sediments for $60 \mathrm{Co},{ }^{85} \mathrm{Sr}$, and $137 \mathrm{Cs} . " \mathrm{~J}$. Pharm. Belg. 30(1):82-90.

Menzel, R. 6. 1968. "Uranium, Radium, and Thorium Content in Phosphate Rocks and The ir Possible Radiation Hazard." J. Agr. Fogd Chem. 16:231-34.

Mercer, B. W. 1966. Adsorption of Trace Ions from Intermediate Level Radioactive Wastes by Ion Exchange. BWWL-180, Pacific Northwest Laboratory, Richland, WA. 
Mercer, B. W. 1967. "Icn Exchange Equilibria of Trace Cesium-137 and Strontium-85 in Multicomponent Systems." BNLL-SA-1173, Pacific Northwest Laboratory, Richland, WA.

Merrian, C. N., Jr. and H. C. Thomas. 1956. "Absorption Studies on Clay Minerals. IV Alkali Ions on Attapulgite." J. Chem. Phys. 24:993.

Meyer, 6. L. 1975. Preliminary Data on the Occurrence of Transuranium Nuclides in the Erivironment at the Radioactive Waste Burial Site. Maxey Flats, KY.

Mihalik, P. 1968. Uranium Compounds in the Dominion Peefs, and Their Association with Phosphorus Compounds. NIM-415.

Miner, F. J., P. A. Glover, and H. H. Miller. 1973. Plutonism Behavior in the Soil/Water Environment. RFP-2004-A, Pp. 1-3.

Miner, F. J., P. A. Glover, and W. L. Polzer. "Plutonium Behavior in the Soil/Water Environment. I. Sorption of Plutonium. by Soils." Agronomy Abstracts, D. 35.

Miyake, Y. and Y. Sugimura. 1975. The Plutonium Content in the Pacif is: Ocean Waters. IAEA-SM-199/22.

Mizunn. A. and T. Mochizuki. 1970. "Distribution of Uranium in the Sediments froa uan' in Off-Shore, Southwestern Japan." Chishitsu Chosasno Geppo. 21:287-292 (in Japanese).

Mo, T. and F. G. Lomman. 1975. Laboratory Experiments on the Transfer Dynamics of Plutonium from Marine Sediments to Seawater and to Marine Organisms. CoNf-750503-5, $35 \mathrm{p}$.

Mo, T., A. D. Suttle, and W. M. Sackett. 1973. "Uranium Concentrations in Marine Sediments." Geochim. et Cosmochim. Acta. 37:35-51.

Molchanova, I. V. 1968. "Behavior of Cerium-144, in Various Types of Soil." Ir. Inst. Ekol. Rast. Zhivotn. 61:4-11.

Montgomery, D. M., H. E. Kolde, and R. L. Blanchard. 1977. Radiological Measurements at the Maxey Flats Radioactive Waste Burial Site 1974-75. EPA-520/5-76/020.

Moore, L. R. 1964. "The Microbiology, Mineraiogy and Genes is of a Tonstein." Prac. Yorkshire Geol. Soc. 34:235-292.

More 1, F. and J. Morgan. 1972. "A Mumerical Method for Computing Equilitria in Aqueous Chemical Systems." In: Envirommental Science and Technology. o(1):58. 
Mortensen, J. L. and E. C. Marcusiu. 1963. "Fission Product Soil Organic Matter Camplexes. I. Strontium-90 (Yttrium-90) in Hater Extracts and $\mathrm{HCl}$ Hydrolys is of Soil." Soil Sci. Soc. An. Proc. 27:653-6.

Mortensen, J. L., E. C. Marcusiu, and N. Holowaychuk. 1963. "Strontium Exchange Characteristics of Soils from the Ogctoruk Creek Watershed in Alaska." Ohio J. Sci. 63:225-31.

Mortimer, C. H. 1941. "The Exchange of Dissolved Substances Between Mud and Water on Lakes." J. Ecology. 29:280-329.

Moskin, A. I. 1969. "Complex Formation of the Actinides with Anions of Acids in Aqueous Solutions." Soviet Radiochemistry. 11:447.

Mumer, C. H., D. L. Roukhust, and D. R. Kosiur. 1975. MIX2: A Computer Program for Modeling Chemical Reactions in Matural Maters. F8-251668, National Technical Information Service.

Mun, A. I. and I. A. Basilevich. 1964. "Some Characteristics of the Distribution of Iodine in Lake Muds." Geokhimiya. No. 5:468-476.

Murray, E. G. and J. A. S. Adams. 1958. "Amount and Distribution of Thorium, Urani_m, and Potassium in Sandstones." Geochim. et. Cosmochim. Acta. 13:260.

Murray, C. N. and H. Kaursky. 1975. Plutoniun and Americium Values in the North Sea and German Coastal Regions. IAEA-SM-199!26.

Murray, C. N. and L. Murray. 1973. Adsorption-Desorption Equilibria of Some Radionuclides in Sediment-Fresh-Water and Sediment-Seawater Systems. IAEA-S/A-158/7.

Nagaya, Y. and M. Saiki. 1967. "Accumulation of Radionuclides in Coastal Sed iment of Japari. I. Fallout Radionuclides in Some Coastal Sediments in ¿554-1965." J. Radiat. Res. 8:37-43.

Nakamura, K. and Y. Nagaya. 1975. "Accumslation of Radionuclides in Coastal Sediment of Japan, (2). Contents of Fission Products in Some Coastal Sediments Collected in 1966-1972." J. Radiat. Res. 1E: 184-192.

Naumov, G. 5. 1961. "Scme Physico-Chemical Peculiarities of Uranium Behavior in Hydrotherma] Solutions." Geokhimiya. No. 2:115-132 (in Russian).

Neison, D. J., R. L. Herman Et al. 1961. Clinch River Studies. ORNL-3189, pp. $129-39$.

Nelson, D. M., and M. B. Lovett. 1977. The Oxidation State of Plutonium in the Irish Sea. ANL-77-5 Part III, p. 99. 
Melson, J. L. and H. L. Haushild. 1970. "Accumulation of Radionuclides in Bed Sediments of the Colubia River Between Hanford Reactors and Michary Daw." Mater Resour. Res. 6:130-7.

Melson, J. L., R. W. Perkins, J. M. Mielsen, and H. L. Haushild. 1966. Reactions of Radionuclides from the Hanford Reactors with Columbia River Sediments. IAEA-ST-72/8, pp. 139-61.

Mevissi, A. and H. R. Shel1. 1975. "Distribution of Plutonium and Americium in Bikini Atoll Lagoon." Health Physics. 28:539-547.

Niggli, P. 1952. Rocks and Mineral Deposits. Volume 2.

Nikolaev, D. S., Y. M. Drozhzhin, K. F. Lazarev, and O. P. Korn. 1969. "The Geochemical Balance of Radioactive Elements in the Bas in of the Black and Azov Seas. II. Reserves of Thorium Isotopes." Radiokhiniya. 11:688-98 (in Russian),

Nikolskii, B. P., L. I. Krylov, B. B. Zakhuataev. 1974. "Sorption of Ions of Some Polyvalent Actinide and Rare-Earth Elements by a Cationite with a Ehthalic Functional Group." Radiokhimiya. 16(2):162-166.

Mishita, H. and E. H. Essington. 1967. "Effect of Chelating Agents on the Movement of Fission Products in Soils." Soil Science. 103(3):168-176.

Nishita, H., M. Hamilton, and A. J. Steen. 1976. "Extractability of 238pu and $242 \mathrm{Ca}$ from a Contaminated Soil as a Function of pH and Certain Soil Components." Presented at Meeting of Soil Science Society of America, Novemer 28-Decenber 3, Houston, Texas.

Mishita H., M. Hamilton and A. J. Steen. 1976. "Extractability of 238pu and $242 \mathrm{Cm}$ from a Contaninated Soil as a Function of pH and Certain Soil Components. $\mathrm{HMO}_{3}$ - $\mathrm{MaOH}$ System." Presented at Annual Meeting of Soil Science Society of America, Houston, Texas.

Nishita, H., B. H. Kowalewsky, A. J. Steen, and K. H. Larson. 1956. "Fixation and Extractability of Fission Products Contaminating Various Soils and Clays 1. Strontive-90, Rutheniu-106, Cesium-137, and Cerium-144." Soil Science. 81:317-326.

Nishiwaki, Y., Y. Honda, Y. Kimura, H. Morishima, T. Koga, Y. Miyaguchi, and H. Kawai. 1972. "Behavior and Distribution of Radioactive Substances in Coastal and Estuarine Haters." In: Radioactive Contamination of the Marine Environent. IAEA-SH-158/11, PD. 177-193.

Moshkin, V. E. 1972. "Ecological Aspects of Plutonium Dissenination in Aquatic Environments." Health Physics. 22:537-549. 
Moshkin, Y. E. and V. T. Bowen. 1973. "Concentrations and Distributions of Long-Lived Fallout Radionuclides in Open Ocean Sadiments." In: Radioactive Contanination of the Marine Environment. IAEA-SH-158/45, 671-686.

Moshkin, V. E., K. M. Hong, R. J. Eagle, and C. Gatrousis. 1971.

Transuranics at Pacific Atolls. 1. Concentrations in the Haters at Enewetak and Bikini. UCRL-5I6I2.

Noshkin, Y. E., K. M. Hong, K. Marsh, R. Eagle, G. Holladay, and R. H. Buddeweier. 1975. Plutoniu Radionuclides in the Ground Maters at Enevetak Ato 11. IAEA-SH-199/33.

Ojima, T., H. Yoratani, and H. Fujimoto. 1965. "Behavior of Radioactive Strontium, Ces:un, and Cobalt in Marine Mater." Ann. Rep. Radiat. Center Osaka Prefect. 6:93-7.

ORIL. 1970. Siting of Tuel Reprocessing Plants and Maste Management Facilities. ORIL-4451.

Ophe1, I. L. 1973. Environmental Capacity of Fresh-waters for Maste Radionuc lides. Environiental Behavior of Radionuclides Released in the huclear Industry. IAEA, Viema, pp. 613-624.

Ophe1, I. L. and C. D. Fraser. 1971. Fate of Cobalt-60 in a Matural Freshmater Ecosysten. Comf-710501-P1. pp. 323-327.

Ophel, I. L., C. C. Fraser, and J. M. Judd. 1972. Strontiu Concentration Factors in Biota and Bottom Sediments of a Fresmater Lake. ELR-485J (Vols. 1 and 2), pp. 509-30.

Orcutt, R. 6., M. M. E. Rifai, 6. Klein, and H. J. Kaufman. 1957. "Underground Movement of Radioactive Wastes." Presented at Muclear Engineering and Science Congress, Philadelphia, Pennsylvania, March 11, 1957.

Or lova, E. I. 1965. Migration of $\mathrm{MOSr}_{\mathrm{Sr}}$ in the Ground Waters of Various Salt Compositions." Gig. Sanit. No. 7:46-50 (in Russian).

Osterberg, C., N. Cutshall, V. Johnson, J. Cronin, D. Jennings, and L. Frederick. 1966. "Some Non-Biological Aspects of Collubia River Radioactivity." In: Disposal of Radioactive Hastes into Seas, Oceans and Surface Haters. IAEA-ST-727I8\%, Pp. 321-335.

Palei, P. M. (comp.). 1962. Analytical Chemistry of Uranium. Trans. by N. Kaner. 1963. Israel Program for Scientific Translations Ltd., 121 p.

Parker, M. 1966. Studies on the Distribution of Cobalt in Lakes. C00-1281-5.

Parker, V. B., D. D. Magman, and H. H. Evans. 1971. Selected Values of Chemical Thermodymanic Properties. U.S. Department of Comerce. 18.5 Technical ivte 270-6. 
Pashneva, G. E., T. P. Slavnina, and V. V. Serebrennikov. 1965. "Rare Earth and Thoriu Content in Solls of Tomsk Region." IzV. Sibirsk. Otd. Akad. Mauk SSSR, Mo. 4 Ser. Biol. Med. Mauk. Mo. 1:58-52 (in Kussian).

Patterson, J. H., G. M. Matlack and 6. B. Melson. 1974a. The Interaction of $23 \mathrm{PuO}_{2}$ Heat Sources with Simulated Terrestrial Environments." Am. muclear Society Transactions. 19:33-34.

Patterson, J. H., G. B. Melson and G. M. Matlack. 1974b. The Dissolution of $230 \mathrm{Pu}$ in Environmentol and Biological Systems. LA-5624.

Peperstraete, H., J. Yos, S. Pan Puymbroeck and 0. Banderborght. 1973. Phusico-chemical Characteristics of Five Rutheniun Salts During Freshwater to harine Transition. INEA-Si-158/52.

Perkins, R. M., J. L. Melson, and H. L. Haushild. 1966. "Behavior and Transport of Radionuclides in the Columbia River Between Hanford and Vancouver, Hashington." Liminl. Oceanog. 11:235-48.

Pettersson, H. 1949. "Exploring the Bed of the Ocean." Mature. 164:468-70.

Phillips, J. H., J. Gruhlke and 6. A. Gaul. 1977. Sumary of Radioactivity Released in Effluents from Muclear Power Plants from 1972 through 1975. EPh-520,3-77-006.

Pickering, R. J. 1969. Distribution of Radionuclides in Bottan Sediment of the Clinch River Eastern Tennessee. US65 Prof. Paper 433-H. PP. HI-H25.

Pickering, R. J. 1970. Composition of Hater in Clinch River, Tennessee River, and Writeoak Creek as Related to Disposal of Low-Level Radioactive Liquid Wastes. IS65 Professional Paper 433-0, $15 \mathrm{p}$.

Pickering, R. J., P. H. Carrigan, Jr., and F. L. Parker. 1965. The Clinch River Study - An Investigation of the Fate of Radionuclides Released to a Surface Strean. Geological Survey Circular 497.

Pickering, R. J., P. H. Carrigan, T. Tamura, H. H. Abee, J. H. Beverage, and R. H. Andrew. 1966. Radioactivity in Botton Sediments of the ClinchTennessee Rivers. IAEA-SHFT2/4.

Pillai, K. C. and E. Mathew. 1975. Plutonium in Aquatic Environment -. Its Behavior, Distribution and Significance. IAEA-SH-199/27.

Pirn, A., M. Bernhard, M. Branica, and M. Verzi. 1975. Incomplete Exchange Reaction Between Radioactive Ionic Zinc and Stable Natural Zinc in Seawater. IAEA-ST-158/2, Pp. 29-44.

Pirs, M. 1974. "Sorption-Desorption of Radioactive Caesium, Strontium, and Ceriu on Earth Components." In: Population Dose Evaluation and Standards for ton and His Environment. IAEA, Vienna, Pp. 539-551. 
Pliler, R. 1956. The Distribution of Thorium and Uraniv in Sedicentary Rocks and the Oxpen content of the Prece orian Atiosphere. Thesis, Rice Institute, louston, Texas.

Polzer, H. L. 1971. Solubility of Plutonic in SoilMater Environments. COWf-710401, pp. 411-430.

Polzer, W. L. and F. J. Miner. 1974. "Plutonium Behavior in the Soillater Environment. II. Mechanisus of Plutoniun Sorption by Soils." Agronomy Abstracts, p. 37.

Polzer, H. L. and F. J. Miner. 1977. Plutoniun and Americium Behavior in the Soil/Mater Envirorment. 11. The Effect of Selected chenical and Pirisical Characteristics of Arveous plutonion and hericiu on their sorption by Solls. BIIL-2117, Pacific horthest Laboratory, Richland, W. Pp. 255-286.

Pokidin, V. K., Y. V. Kuznetov, E. A. Prozorovich, and F. A. Asadullaeva. 1972. "Radioactivity and Rate of Sediment Formation in the Caspian Sea." Geokhimiye. Mo. 7:834-43 (in Russian).

Pourbaix, M. 1966. At las of Electrocheaical Equilibria in Agreous Solutions. Pergaun Press, Oxford, England.

Prout, M. E. 1958. "Adsorption of Radioactive Mastes by Savannah River Plant Soil." Soil Science. 86:13-17.

Prout, H. E. 1959. Adsorption of Fission Products by Savannah River Plant Soi1. DP-394.

Purtymum, H. D. 1971. Plutonium in Strean Channel Alluvium in the Los Alanos Area, Men Mexico. LA-4561.

Purtymun, H. D. 1973. Underground Movement of Tritiun from Solid-Haste Storage Shafts. LA-5285-ivs.

Purtymun, M. D. 1974. Storm Runoff and Transport of Radionuclides in DP Canyon, Los Alamos County, hew Wexico. LA-5744, Pp. 1-7.

Purushothaman, K. 1568. Transport of $25 \mathrm{Sr}$ and 137 Cs Under Induced Clay Suspensions. Thesis, University of Texas, hustin, Texas.

Purushothaman, K. 1971. "Radionuclide Transport in an Aquatic Model System." in: Trace Substances in Environental Health. IV. D. D. Hemphill (ed.), Colimbia, F, Univ. of Tid, pp. 174-85.

Purushothaman, $K_{8}$ and E. $F$ Gloyna. 1968. Radioactivity Transport in Water: Transport of $85 \mathrm{Sr}$ and $137 \mathrm{Cs}$ Under Induced Clay Suspensions. Gro-490-13. 
Puschang, H. 1970. Research on Sorption of the Radiosuic lides 85 sr, 137Cs, and $\mathrm{ZII}_{\mathrm{I}}$ by Unconsolidated Sediments. Sands from the Low-Terraces of the Rivers Heser, Donau, Elbe/Germany." Deut. Gearamesserk. Mitt. 14:63-72 (in Cerman).

Pyaliing, A. 0. 1970. "Effect of Physiochemical Conditions of the Rediun on the Leaching of Uraniu fro Matural Dahllite." Probl. Regional Ceol. Petrogr. Sibiri Metedy Geokhin. Geofiz. Issled. Ko. 2:88-91 (In Russian).

Rabinowitz, D. D. 1969. Forced Exchange of Tritiated Mater with Matural Clay. Master's Thesis, M. Wex. Inst. of Win. and Tech., Socorro, W.

Rabinowitz, D. D., C. R. Holmes and 6. W. Eross. 1973. Forced Exchance of Tritiated Mater with Clays." In: Tritiu, Messenger Graphics Pub., Phoenix and Las Vegas, 471-485.

Radosavljevic, R. and T. Tasovac. 1970. "Capture of 60Co by Suspended Particles in the Canube." In: Symosiun International de Radioecologie. Vol. I. Fontenay-aux-Roses, France, Pp. 83-92.

Rai, D. and W. T. Franklin. 1973. Progra for Computing Equilibriu Solution Composition in $\mathrm{CaCO}_{3}$ and $\mathrm{CaSO}_{4}$ Systems fro Irrigation hater Compositions. Colorado State University, Mater Managenent Technical Report Bo. 29.

Rai, Dhanpat and R. J. Serne. 1978. "Solid Phases and Solution Species of Different Elements in Geologic Environments." PM-2651. Stum, $U$. and J. J. Morgan, Aquatic Chemistry. Miley-Interscience, Mew York.

Rai, Ohanpat and R. J. Serne. 1973. "Plutoniu Activities in Soil Solutions and the Stability and Formation of Selected Plutoniu Metals." Journal Environmental Quality. 6:89-95.

Rancon, D. 1973. The Behavior in Underground Environments of Uraniun and Thor iu Discharged by the Muclear Industry." In: Environmental Behavior of Radionuclides Released in the Muclear Industry. IAEA-SI/172/55, pp. 333-376 (in French).

Raymond, J. R. 1964. Investigation of the Disposition and Migration of Gross Gama Enitters Beneath Liquid haste Disposal Sites. Rif81746, Pp. $4.32-4.36$.

Raymond, J. R. 1965. Cesiun and Strontiun Distribution Beneath Liquid Haste Disposal Sites. Biniz-235.

Renfro, H. C. 1971. Seasonal Radionuclide Inventories in Alder Slough, an Ecosyste in the Colo bia River Estuary. Cow-110501, P. 2, Pp. 738-146.

Reymolds, T. D. 1963. Transport of Strontiv and Cesium by Strean and Estuar ine Sediments. Thesis, Liviversity of Texas, wustin, Texas. 
Reynolds, T. D. and E. F. Gloyna. 1963. Radioactivity Transport in MaterTransport of Strontiv and Cesiu by Strea and Estuarime Sedrents. Tech. R.t. io. 1. TIV-IS559.

Rhodes, D. H. 1952. Preliminary Studies of Plutonium Adsorption Hanford Soil. Het-24548.

Rhodes, D. H. 1957a. "The Adsorption of Plutoniun by Soil." Soil Science. 84: $465-471$.

Rhodes, D. H. 1957b. "The Effect of pH on the Uptake of Radioactive Isotopes from Solution by a Soil." Soil Science Society of Merica, Proceedings. 21:389-392.

Rhodes, D. W. and J. L. MeIson. 1957. Disposal of Radioactive Liguid Hastes fro the Uraniu Reiovery Plant. W-547ZI.

Richmond, C. R. and E. M. Sullivan. 1974. Ammul Report of Bionedical and Environental Research Progra of the LAST haath Ufvision, JamiaryDece-ber 1973. LA-5633-PiR.

Riley, J. P. and P. Sinkaseni. 1958. J. Mar. Res. 17:466.

Ritchie, J. C., P. H. Hanks, and J. R. Mctlemry. 1972. "Thoriun, Uranium, and Potassium in Upper Cretaceous, Pateocene, and Eocene Sediments of the Little Tallahatchie River Matershed in Morthern Mississippi." Southeast Geol. 14:221-231.

Robertson, D. E. 1974. Physicochenical Characterization of N-Reactor Effluent Radionuclides in Soll and Wter Systeis. Bi-1950, Pacific horthmest Laboratory, Richland, Wh, Pt. 2, Dp. 82-85.

Robertson, D. E. and R. H. Perkins. 1974. "Radioisotope Ratios in Characterizing the Movement of Different Physical and Chemical Species Through Matural Soils." BMm-SA-5024, Pacific Morthwest Laboratory. Richland, wh.

Robertson, D. E. and R. W. Perkins. 1975. Radioisotope Ratios in Characterizing the Hovement of Different Physical and Chemical Species Through Matural Soils." In: Isotope Ratios as Pollutant Source and

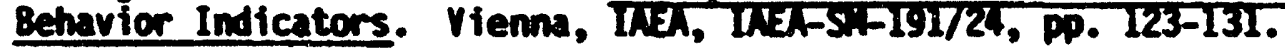

Robertson, D. E., H. B. Silker, J. C. Langford, M. R. Petersen and R. W. Perkins. 1973. "Transport and Depletion of Radionuclides in the Columbia River." In: Radiaactive Contapination of the Marine Emvironment. IAEA-SM-158/9, Pp. 141-158.

Robie, R. A., and D. R. Halcbay. 1968. "Thermodynaric Properties of Minerals and Related Substances at $298.15^{\circ} \mathrm{K}\left(25^{\circ} \mathrm{C}\right)$ and One Atrosphere (1.013 bars) Pressure and at Higher Temperatures." Geol. Surr. Bull. 1259. 
Rogers, J. J. H. 1964. "Statistical Test of the Homogeneity of the Radioactive Components of Granite Rocks." In: The Matural Radiation Environent, J. A. S. Mdans and U. M. Louder (eds.), p. S1.

Rogers, J. J. M. and J. A. S. Adans. 1974. "Thoriu Solubilities in Mater." Handbook of Ceochemistry, K. H. Wedepohi, ed., Vol. II-4, P. SO-H-1, Springer-Yerlag, ivew York.

Ronov, A. B., Yu. A. Balashov, and A. A. Migdisov. 1967. "Geochemistry of the Rare Earths in the Sedimentary Cycle." Geochemistry International. 4:1-17.

Rosenquist, I. T. 1963. "Studies in Position and Mobility of the H Atoms in Hydrous Micas." In: Clays and Clay Minerals. Monograph No. 13, Pp. 11-135, Macaill lan Co., N.

Routson, R. C. 6. Jansen, and A. V. Robinson. 1975. Sorption of 99TC, 237 $\mathrm{Ng}$, and $24 \mathrm{~h}_{\mathrm{h}}$ on $\mathrm{Tw}$ Subsoils from Differing Mathering Intensity hreas. Bim-18\%9, Pacific horthest Laboratory, kichland, Wh.

Routson, R. C., 6. Jansen, and A. V. Robinson. 1976a. 99TC, 237 $\mathrm{WP}$, and $241 \mathrm{~h}$ Sorption on Two Subsoils from Differing Weathering intensity Areas. EXil-2000, Pacific Northmest Laboratory, Richland, KA, Pt. 2, Pp. 50-52.

Routson, R. C., G. Jansen and A. V. Robinson. 1976b, 241/R, 237 $\mathrm{m}$, and 99tc Sorption on Two United States Subsoils from Differing Weatherimg Intensity Areas. BinL-1889, Pactfic Northwest Laboratory, Richland, MA.

Routson, R. C. and R. J. Serne. 1972a. One Dimensional Model of the Movenent of Trace Radioactive Solute Through Soll Colvens: The PERCO Thodel. Ein-1718, Pacffic Morthwest Laboratory, Richland, Wh.

Routson, R, C. and R. J. Serne. 1972b. Experimental Support Studies for the PERici and Transport Models. Biml-1719, Paciflc horthmest Laboratory, Richland, W.

Rovinskii, f. Ya. 1967. "Migration of 905r in Stagnant Haters." Radiokhiniva. 9:80-4 (in Russian).

Rozhkova, Ye. Y., Ye. 6. Razumaya, M. B. Serebryakova and 0. Y. Schebak. 1959. "Role of Sorption in Concentration of Uraniu in Sedimentary Rocks." Tr. II. Mezhdunar, knof. po miro ny ispol'z. atom. energii. 3.

Rozzell, T. C. and J. B. Andelman. 1971. "Plutonim in ths Mater Environment. II. Sorption of Mqueous Plutonium on Silica Surfaces." Advances in Chemistry Series. 106:280-98.

Rubtsor, D. M. 1966. "Distribution of Thoriun in Various Solls." Pochvoredente. Mo. 3:55-67 (in Russian). 
Rubtsov, D. M. 1972. "Thorium and Uranium Content in the Clay Fraction of Podzolic Mountain Soils of Thin Forests." Radioekol. Issled Prir. Biogeotsenozakh, pp. 53-66 (in Russian).

Rubtsov, D. M. 1972. "Thoriun and Radiu Content in the Silt Fraction of the Podzolic Mounta in Soils of Thin Forests. Radioekologicheskie Issledavaniya Prirodnykh Biogeotsenozakh." In: Izdatel'stov Mauka, Yerkhovskaya (ed.), Pp. $42-53$.

Ruf, M. 1968. "Contanination of Fresh Hater with Radioactive Material with Special Attention to Sludge of River Dams." Hasserwirtschaft. 58:16-22 (in Cerman).

Ryabchikov, D. I. and E. K. Eolbraikh. 1969. Analytical Cheaistry of Thoriu. Translated by A. Aladjem. Am Arbor thphrey Science PobTishers.

Saas, A. and A. Grauby. 1973. Mechanisus for the Transfer to Cultivated Solls of Radinnuclides Discharged by Muclear Pover Stations into the System: River-Irrigated Soil--Ground Mater.- In: Environental Behavior of Ravionuclides Released in the Auclear Industry. INEA-SiFI72/56, Pp. 255-259.

Safronova, M. G. 1974. "Kinetics of the Self-Purification of a Body of Water Containing Strontiu-90 as a Result of Absorption of the Radionuclide by the Botton Deposits." Sor. J. Ecol. 4:101-105.

Sakanoure, M. 1960. "Geochemical Studies on the Radioactive Sediments. III. Uranium, Phosphorus, and Arsenic in the Sedimentary Bed at Mingyo Pass." Mippon Kagaku Zasshi. 81:898-902.

Sakanoue, M. 1960. "Geochenical Studies on the Radioactive Sediments. II. Uraniu Content of Matural Haters from the Mingyo-Pass Mining Area." Mippon Kagakii Zasshi. 81:896-898.

Salo, A. and R. Saxen. 1974. Role of Humic Substances in the Transport of Radionuclides. SFL-A-20.

Sanchez, A. L. 1977. Disiribution Coefficients of Pu-237 and A-241 in Aquatic Environents. Mon-thesis Wisters Research, Departinent of Oceanography.

Sanchez, A. L. and H. R. Schell. 1977. Distribution Coefficients for Transuranic Elements in Aquatic Environiments.

Savin, A. M. 1967. Oxygen and Hydrogen Isotope Ratios in Sedimentary Rocks and Minerals. Ph.D. Uissertation, Callf. Inst. of Tech. Pasadena, $C$.

Sasscer, D. S., C. F. Jordan, and J. R. Kline. 1971. MMathematical Model of Tritiated and Stable Mater Hovement in an 01d-Field Ecosystem." In: Radionuclides in Ecosysters. Cow-710501-P1, pp. 915-923. 
Schebetkovskii, Y. M. and Yu. Y. Kuzketsov. 1971. -(W73-04324) Behavior of Cs-137 and Ce-144 in the Sorption System Sea Hater-Sediment." Trans. from Radiokhiniya. 13(6):911-913.

Schell, H. R. and R. L. Malters. 1975. "plutonium in Aqueous Systems. Heaith Phrsics. 29:589-597.

Schell, H. R., T. H. Sibley, A. Mevissi and A. Sanchez. 1979. Distribution Coefficients for Radionuclides in Aquatic Environments. II. Studies on Farine and Frestwater sedinent Systens Includim the kadomiclides 100-ku,

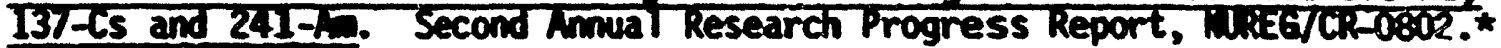

Schell, H. R., T. H. Sibley, A. Sanchez and J. R. Clayton, Jr. 1980. Distribution Coefficients for Radionuclides in Mguatif Environments. III.

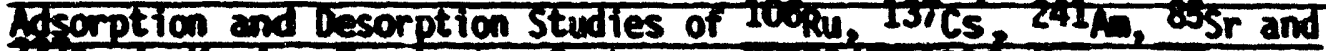
zsypu in har ine freshater Systems. Wliet/CR-0803.:

Schmal2, B. L. 1972. Radionuclide Distribution in Soil Mantle of the Lithosphere as a consequence of haste Uisposal at the hational Reactor Testing Station. Iov-looil9.

Schneider, H. 1970. "To the Question of the Lording Capacity of the Rhine for Radioactive uclides. 6. Sorption of Radionuclides on Selected Minerals." Gas-Hasserfach, Hasser-Abmasser. 111:21-6 (in German).

Schneider, H. and H. Block. 1968. "On the Question of the Capacity of the Rhine for Radioactive Muclides. Sorption of Radionuclides by Sedinents of the Rhine." Gas-Wasserfach. 109:1410-15 (in Eerman).

Schneider, K. J. and A. H. Platt (eds). 1974. High-Level Haste Management Alternatives. BMmL-1900, Pacific Morthwest Laboratory, Richland, th, Volume 1, Append ix 2.0, Pp. 2.0.7-2.0.8.

Schubert, A. J., E. R. Russell, and L. S. Myers. 1950. "Dissociation Constants of Radiv Inorganic Acid Complexes Measured by Ion Exchange." J. Biol. Chem. 185:387-398.

Schultz, R. K. 1965. "Soil Chemistry of Radionuclides." Health Physics. 11:1317-1324.

Schum, R. H., D. D. Hagman, S. M. Bailey, H. H. Evans, and V. B. Parker. 1973. Selected Values of Chemical Thermodmanic Properties. Tables for the Lanthanide (kare Earth) Elements (Elements 62 throurh 76) in the Standard order of Arrangement. Tis Technical hote $270-7$.

Schwille, F., H. Lippok and D. Heisflog. 1967. Model Experiments on Fluid Flow in the Transition Zone fro Unsaturated to Saturated soll. Ind-ST-93/11, Pp. 151-159. 
Seaborg, 6. T. and J. J. Katz (ed.). 1954. The Actinide Elements. McGraw Hill Book Company, Inc.

Sedlet, J. and M. M. 6olchert. 1977. "Environental Monitoring for Some Transuranium Elements." Presented at 4th International Congress of the International Radiation Profection Association, Paris, France, April 24-30, 1977 (CONF 770409-5).

Senftle, F. E. and N. B. Keevil. 1947. "Thorium-Uraniu Ratios in the Theory of Genes is of Lead Ores." Trans. Am. Geophys. Union. 28:732.

Serne, R. J. 1978. Waste Isolation Safety Assessment Progran Task 4 Contractor Information Meeting Proceedings." PNL-SA-6957, Pacific Northmest Laboratory, Richland, $M$.

Serne, R. J. and Dhanpat Rai. 1976. "Adsorption-Precipitation Behevior of Eu in Soils and Standard Clays." Agronomy Abstracts, p. 132.

Serne, R. J., R. C. Routson and D. A. Cochran. 1974. Experimental Methods for Obtaining PERCOL Model Impact and Verification Data. BimL-1721, Pacif ic Northest Laboratory, Richland, Wh.

Seymour, A. H. 1977. 1976-77 Annual Progress Report Distribution Coefficients for Transuranic Elements in Aquatic Environments. Laboratory of Radiation Ecology College of Fisheries, University of Washington.

Seymour, A. H., A. Mevissi, W. R. Schell and A. Sanchez. 1979. Distribution Coefficients for Radionuclides in Aquatic Environments. I. Development of Fethods and Results for Plutonium and Aericium in Fresh and Tarine Rater-Sediment Systews. First Annual Research Progress Report, RIREGTCR-0801.*

Shade, J. H. 1974. Reaction of Hanford Sediments with Synthetic Naste, A Reconna is sance Study. ARH-CD-176.

Shalinets, A. B. and A. V. Stepanov. 1972. "Investigation of Complex Formation of the Trivalen: Actinide and Lanthanide Elements by the Method of Electromigration. XVII. Hydrolys is." Radiokhimiya. 14:280-282.

Shannon, R. D. and C. T. Prewitt. 1969. "Effective Ionic Radii in Oxides and Fluorides." Act.a. Cryst., B. 25:925.

Shearer, S. D., Jr. 1962. The Leachability of Radium-226 from Uranius Miii Solids and River Sediments. Thesis, University of Misconsin, Madison, MI.

Shearer, S. D., Jr. and G. F. Lee. 1954. "Leachability of Radium-226 from Uraniva Mill Solids and River Sediments." Health Physics. 10:217-227. 
Sheidina, L. D. and E. N. Kovarskaya. 1970. "Colloidal State of Pu(IV) in Aqueous Solutions." Sor. Radio. Chea. 12:229-233.

Sheppard, J. C., J. A. Kittrick, and T. L. Hart. 1976. Determination of Distribution Ratios and Diffusion Coefficients of Meptunium, Americium and Curiu in Soil-Aquatic Environents. RLO-2221-T-12-2.

Shih, C. S. and E. F. 6loyna. 1968. Influence of Sediments on the Transport of Solutes. OR0-490-12a.

Shukla, S. S., J. K. Syers, J. D. H. Milliams, D. R. Armstrong and R. F. Harris. 1971. "Sorption of Inorganic Phosphate by Lake Sediments So i1." Sci. Soc. Amer. Proceed. Vol. 35, p. 244-245.

Sillen, L. 6. and A. E. Martell. 1964. Stability Constants of Metal-Ion Complexes. Special Publication Ho. 17, Second Edition. The Chemical Society, London.

Simpson, H. J., D. E. Hawiond, B. L. Deck and S. C. Hilliams. 1975. Nutrient Budgets in the Hanford River Estuary in Marine Chemistry in the Coastal Environient.

Simpson, H. J., R. M. Trier, C. R. Olsen, D. E. Hameond, A. Ege, L. Miller, J. M. Melack. 1980. "Fallout Plutonium in an Alkaline, Sal ine Lake." Science. 207:1071-73.

Smith, W. T., J. W. Cobble, and G. E. Boyd. 1953. "Thermodynamic Properties of Technetiu and Rhenium Compounds. I. Vapor Pressures of Technet ium Heptoxide, Pertechnic Acid and Aqueous jolution of Pertechnic Acid." J. Am. Chem. Soc. 75:5773-5776.

Somayajulu, B. L. K. and T. M. Church. 1973. "Radium, Thorium, and Uranium Isotopes in the Interstitial Mater from the Pacific Ocean Sedimer ." J. Geophy. Res. 78:4529-31.

Sorathesn, A., 6. Bruscia, T. Tamura, and E. 6. Struxness. 1960. Mineral and Sed iment Affinity for Radionuclides. CF-60-6-93.

Spitsyn, V. I., R. N. Bernovskaya, Yu. A. Bogdanov, V. V. Gromov, and V. N. Tikhoairov. 1969. "The State of Microquantities of Niobium-95 and Technetium-99 in Sea Nater." Radiokhimiya. 11:607-709.

Spitsyn, V. I., R. N. Bernovskaya, V. V. Gormov, and Yu. A. Bogdanov. 1973. "Trapping of Cerium-144 and Yttium-91 by Ocean Sediments." Oceanology. $12(4): 586-589$.

Spitsyn, V. I., V. D. Balukova, A. F. Maumova, V. V. Gronov, F. M. Spiridonov, E. M. Vetrov, and G. 1. Gravfov. 1958. "A Study of the Migration of Rad ice lements in Soils." In: Proc. Second Annual U.M. Conf. Peaceful Uses of Atomic Energy. 18:439-448. 
Sprugel, D. G., R. N. Muller, G. E. Barte 1t, C. W. Mayman and C. M. Bobula. 1975. Dispersal of Plutonium from an Efflient Pulse in the Great Miami River. ANL-75-60 Part III, pp. 28-31.

Sreekumaran, C., K. C. Pillai, and T. R. Folsom. 1968. "The Concentrations of Lithium, Potassium, Rubidium and Cesium in Some Hestern American Rivers and Marine Sediments." Geochim. et Cosmochim. Acta. 32:1229-1234.

Starik, I. E., N. I. Ampelogova, F. L. Ginzburg, M. S. Lambert, I. A. Skulskii, and V. N. Shchebetkorskii. 1959. "On the Molecular State of Uitra-Smal! Quant ities of Radioelements in Solutions." Radiokhimiya. $1=370-378$ (in Russian).

Starik, I. E., Y. V. Kuznetsov, E. P. Petryaev and V. K. Legin. 1963. "Geochemistry of Radioactive Elements." Khim. Zemmoi Kory, Akad. Mauk SSSR Tr. Geokhim. Knof. 1:375-89.

Starik, I. E. and M. S. Lambert. 1958. "State of Microquantities of Promethium in Aqueous Solutions." ZhNKh. 3:136.

Starik, I. E. and K. F. Lazarev. 1960. "Effect of Crushing of Minerals on the Extraction of Radioactive Elements." Radiokhimiya. II:749-752.

Starik, 1. E., O. S. Nikolaev, Y. V. Kuznetsov and V. K. Legin, 1961. "Radioactivity of Black Sea Deposits." Doklady Akad. Nauk. SSSR. 139:1456-9 (in Russian).

Star ik, I. E. and M. I. Polevaya. 1958. The Leachability of ThX and Rd Th from Minerals. NEC-tr-4208, p. 108.

Starik, 1. Ye., F. Ye Starik and A. N. Apollonova. 1958. "Adsorption of Traces of Uranium on Iron Hydroxide and Its Desorption by the Carbonate Method." Zh. Meorgan. Khimii. 3(1).

Stead, F. H. 1963. "Tritium Distribution in Ground Hater Around Large Underground Fusion Explosions." Science. 142:1163-1165.

Stead, F. W. 1964. "Distribution in Groundwater of Radionuclides from Underground Nuclear Explosions." In: Proc. Third Plowshare Symp. Engineering with Nuclear Explosives. Apr il 21-23, 1964. T10-7695, pp. 127-138.

Stewart, G. L. 1967. "Fractionation of Tritium and Deuterium in Soil Water. In: Isotope Techniques in the Hydrologic Cycle, Geophys. Monügraph No. 1i, 159-168.

Stum, W. and J. J. Morgan. 1970. Aquatic Chemistry. Wiley-Interscience, New York, pp. 407-412.

Sugimura, Y. 1964. "Natural Radioactive Elements in the Ocean." Kahaku No Ryoiki. 18:89-101 (in Japanese). 
Szabova, T. 1976. "Effect of pH Value of Applied Solution on Radioiodine Sorption by Soils." Poi nohos-podarstro. 22:196-201.

Szalay, A. 1957. "The Role of thums in the Geochemical Enrichment of $v$ in Coal and Other Bioliths." Acta "hys. Acad. Sci. Hungary. 8:25-35.

Szalay, A. 1954. "The Enrichment of Lranive in Some Brown Coals in Hungary." Acta Geol. Acad. Sci. Hungary. 2:299-311.

Szalay, S. and M. Szilagyi. 1964. "Retention. of Fission Products by the Humic Acids of Peat - A Mew Hethod for the Treatment of Effluents." Fiz. Szemle. 15:388-91 (in Hungarian).

Tamers, M. A. and H. C. Thomas. 1960. "Ion-Exchange Properties of Kaolinite Slurries." J. Chem. Phy. 64:29-32.

Tamura, T. 1972. "Sorption Phenomena Significant in Radioactive - Maste Disposal. In: Underground Naste Management and Environmental Implications, T. D. Cook (ed.), An. Assoc. Petrol. Geol., pp. 318-330.

Tanji, K. K., 6. R. Dutt, J. L. Paul and L. D. Doneen. 1967a. "Quality of Percolating Haters. II. A Cosputer Method for Predicting Salt Concentrations in Soils at Variable Moisture Cotents." Hilgardia. 38(9).

Tanji, K. K., L. D. Doneen and J. L. Paul. 1967b. "Quality of Percolating Haters. III. The Quality of Haters Percolating Through Stratified Substrata, as Predicted by Computer Analyses." Hilgardia. 38(9).

Tanji, K. K. and L. D. Doneen. 1966. "A Caputer Technique for Prediction of $\mathrm{CaCO}_{3}$ Precipitation in $\mathrm{HCO}_{3} \mathrm{Salt}$ Solution." Soil SCi. SoC. Amer. Proc. 30:53-55.

Tarutani, T. and S. Misumi. 1962. Adsorption of Ceriun Ion by Various Solid Substances in Aqueous Solution." Men. Fac. Sci. Kyushu Univ., Ser. C. $\underline{5}: 21-6$.

Taylor, S. R. 1964. "Abundance of Chemical Elements in the Continental Crust: A New Table." Geochim. et Coswochim. Acta. 28:1273-1285.

Taylor, S. R. 1964. "Trace Element Abundances and the Chondritic Earth Model." Eeochim. et Cosmochim. Acta. 28:1989-1998.

Taylor, S. R. and A. J. R. White. 1966. "Trace Element Abundances in Andesites." Bull. Yolcanol. 29:177-194.

Teller, E., M. K. Talley and 6. H. Higgins. 1968. The Constructive Uses of Muclear Explosives. McGraw-Hill, Mew York.

Templeton, H. L. and A. Preston. 1966. "Disposal of Radioactive Haters into Seas, Oceans and Surface Haters." In: IASA Pub ication, pp. 267-289. 
Tewari, P. H., A. B. Campbell, and H. Lee. 1972. "Adsorption of Cobalt (+2) by Oxides from Aqueous Solution." Can. J. Chem. 50:1642-1648.

Texas University. 1968. Radioactivity Transport in Water. Interaction Between Floring Hater and bed Sediments. 0,R0-49-17.

Thomas, H. C. 1967. The Thermodmanics of Ion Exchange on Colloidal Materials with Applications to Silicate Finerals. Thesis, University of Worth Carolina, Crapel Hill, it.

Thomas, U. A. and D. G. Jacobs. 1969. "Curium Behavior in Plants and Soil. Soit Science. 108:305-307.

Thorburn, R. C. 1950. Absorption on Hanford Soil and Related Soil Properties. hin-15655.

Tiller, K. 6., J. F. Hodgsen, and M. Peech. 1963. "Specific Sorption of Cobalt by Soil Clays." Soil Science. 95:392-399.

Titaeva, M. A. 1967. "On the Character of Radium and Uranium Bond in Peat." Geokhiniya. No. 12:1493-99.

Titaeva, M. A. and T. I. Yeksler. 1969. Uranium and Thoriu During Heathering of Yakutia Rocks." Geokhiniya. No. 6:740-4 (in Russian).

Trayis, C. C. 1978. Matheatical Descriptions of Adsorption and Transport of Reactive Solutes in Soil: A Review of Selected Literature. Cin -5403.

Tritremal, Ch., G. Knollwayer, E. Handerer, H. G. Heintschel, and P. Stipanits. 1966. Behavior of Radioisotopes Released to a Strean. STI PUB-126, pp. 89-105.

Trotman-Dickinson, A. F. (Executive Ed.). 1973. Comprehensive inorganic Chemistry. Pergamon Press, Mew York.

Turekian, K. K. and K. H. Medepoh1. 1961. "Distribution of the Elements in Some Major Units of the Earth's Crust." Bull. Geol. Soc. America. 72:175.

Tyuryukanova, E. B. and V. A. Kalugnia. 1971. "The Behavior of Thoriun in Soils." Soviet Journal of Ecology. 2:467-469.

Udaltsova, N. I. 1963. "General Information on Uranium." In: Analytical Chemistry of Uranica. Israel Program for Scientific Translations, Pp. 3-7.

United States Environmental Protection Agency. 1973. Environmental Analysis of Uraniu Fuel Cycle. Part III. Muclear Fuel Reprocessing. EPA-520/9-73-0030. 
United States Muclear Regulatory Comission. 1976. Proceedinos of Muclear Requlatory Comission Morkshop on the Management of Radioactive Haste: Taste Partitioning as an Alternative, Ni-Cow-001, D. 45.

Van Dalen, A., F. Dellitte, and J. Niskstra. 1975. "Distribution Coefficients for Some Radionuclides Between Saline Water and Clays, Sandstones and Other Samples from the Dutch Subsoil." Reactor Centru Mederland, Pp. 75-109.

Van Genuchten, M. Th. and P. J. Hierenga. 1974. Simulation of OneDimensional Solute Transfer in Porous Media.

Vdovenko, Y. M. and Yu. Y. Dubasov. 197s. Anaiytical Chenistry of Radiu. Israei Progran for Scientific Translations.

Veeh, H. H. 1967. "Deposition of Uranium from the Ocean." Earth Planet. Sci. Lett. 3:145-50.

Vickery, R. C. 1953. Chemistry of the Lanthanons. Buttenworths Sci. Publ. London.

Vinogradov, A. P. 1959. The Geochemistry of Rare and Dispersed Chenical Elements in Soils. Consultants bureau, Inc.

Magaan, D. D., H. H. Evans, V. B. Parker, I. Halow, S. M. Bailey, R. H. Schum, and K. L. Churney. 1971. Selected Values of Chemical Thermodymanic Properties. Tables for Elements 54 throwe 61 in the Standard order of Arrangevent. Tis Technical hote 270-5.

Wagman, D. D., H. H. Evans, V. B. Parker, I. Halow, S. M. Bailey and R. H. Schw. 1969. Selected Values of Chemical Thernodymaic Properties. Tables for Elements 35 through 53 in the Standard order of Arrangenent. hat. Bur. Stds. Technical hote $270-4$.

Maganan, D. D., M. H. Evans, V. B. Parker, I. Halon, S. M. Bailey, and R. H. Schim. 1:58. Selected Volumes of Cheaical Thenodynabic Properties. U.S. Department of Comerce.

Mahlberg, J. S. and M. J. Fishman. 1962. Adsorption of Cs on Clay Minerals. USES Bulletin 1140-A.

Hahlberg, J. S., J. H. Baker, R. H. Vernon, and R. S. Dewar. 1965. Exchange misorption of Strontiu on Clay Minerals. USGS Bullet in 1140-C.

Wahlberg, J. S. and R. S. Dewar. 1365. Comparison of Distribution Coefficients for Strontium Exchange from Solutions Containing one and Two Competing Cations. usts 8 utetin IIt0-0.

Wahlgren, M. A. and D. M. Melson. 1972. "Plutonium in Lake Michigan Mater." In: Radiological and Environmental Research Division Ammal Report. Ecology, January - Decewer 19/2, NL-7960, Part III, Pp. T-14. 
Wahlgren, M. A. and D. M. Nelson. 1973a. Evidence of an Anmual Plutonium Crele in the Mear-Surface Haters of Lake Fichigan. ANL-8060 (Pt. 3), pp. 90-92.

Wah ]gren, M. A. and D. M. Melson. 19730. Residence Times for 239pu and $137 \mathrm{Cs}$ in Lake Mich igan Mater. All-8060 (Pt. 3) Pp. 85-89.

Wahlgren, M. A. and D. W. Melson. 1973c. Plutoniu in the Five Great Lakes: Compar ison of Surface Haters. ANL-8060 (Pt. 3), pp. 93-98.

Mahlgren, M. A. and J. S. Marshall. 1974. "Distribution Studies of Plutonium in the Ereat Lakes." In: Proc. Second International Conference on Muclear Methods in Environmental Research. Cow -740701, PP. 267-275.

Wahlgren, M. A. and D. M. Melson. 1974. -Studies of Plutoniun Cycling and Sed imentation in Lake Michigan." In: Proc. Seventeenth Conference on Great Lakes Research. Cow -740813-P1, Pp. 212-218.

Wahlgren, M. A., J. J. Alberts, D. M. Melson, K. A. Orlandini. 1976. Study of the Behavior of Transuranics and Possible Chenical Homologues in Lake Fichigan later and Biota. IAEA-Si-199/44, pp. 9-24.

Mahlgren, M. A., and D. M. Melson. 1976. A Comparison of the Distribution Coefficients of Plutonium and Other Radionuclides in Lake Fichigan to those in other Systems. Ar-76-88 Part III, Pp. 56-60.

Wahlgren, M. A., D. M. Melson and E. T. Kucera. 1977a. Seasonal Creling of Piutoniu in the Mater Colum of Lake Michigan: 1975-1977. AM-77-5 part III, Pp. 89-91.

Mahlgren, M. A., J. J. Alberts, K. A. Orlandini and E. T. Kucera. 19770. A Comarison of the Concentrations of Fallout-Derived Plutoniu in a Series of reshmeter Lakes. $\mathrm{NL}-77-5$ part II, Pp. 92-94.

Wahlgren, M. A., J. J. Alberts, D. M. Melson, and K. A. Orlandini. 1977c. Study of the Occurrence of Multiple Oxidation of Plutonium in Matural Waters. Nim-77-5 Part III, pp. 95-98.

Walker, J. B., and 6. R. Choppin. 1967. Thermodymanic Parameters of Fluoride Complexes of the Lanthanides. Advances in cheaistry Series 10.71 , the Anerican Chemical society, Mashington DC, pp. 127-140.

Hallace, A. 1969. Behavior of Certain Symthetic Chelating Agents in Soil and Biological Systens. TCLA-34-p-51-26, $92 \mathrm{pp}$.

Hard, F. M. and H. H. Lakin. 1954. "Determination of Traces of Antinony in Soils and Rocks." Analytical Chemistry. 26:1168-1173.

Heast, R. C. 1976. Handbook of Chemistry and Physics. The Chemical Rubber Co. 
Medepoh1, K. H. 1969. Handbook of Ceochemistry. Springer-Ver lag Publishers, new York.

Wheeler, M. L. and J. L. Harren. 1975. "Tritiu Containnent After Burial of Contaminated Solid Maste." Trans. M. Mucl. Soc. 22:741.

Whee Iwright, E. J. 1973. Promethiun Technology. Am. Mucl. Soc. Publications.

Inituan, A. and E. S. Porter. 1958. Cheaical Strea Pollution from Hraniv nills. UIN-99.

Mildewan, T. R. and L. Hask in. 1965. Mare-Earth Elements in Ocean Sediments." Jour. Eeophrs. Res. 70:2905-2910.

Wilding, M. W. and D. W. Rodes. 1963. Renoval of Radioisotopes a Solution by Earth Materials from Eastern Idwo. Ili-16b24.

Wildung, R. E. R. C. Routson, R. J. Serme, and T. R. Garland. 1975. Pertechnetate, Iodide and Methyl Iodide Retention by Surface Soils. Bin-ISjo, Pt. 2, DP. 37-10.

Millians, J. D. H., J. R. Syers, D. E. Arustrong and R. F. Harris. 1971. "Characteristics of Inorganic Phosphate in Moncalcerous Lake Sedinents." Soil Sci. Soc. Nmer. Proc. Vo J. 35, Dp. 556-561.

Ui 1son, C. 8. and T. H. Essig. 19?9. Envirosmental Status of the Hanford Reservation for Jasuary-dume, 1969. Biclic-2478.

Wong, K. M., V. E. Moshkin, L. Surprenant and V. T. Bowen. 1970. Plutonitu-239 in Some Marine Organisos and Sedinents. MSL-227, Pp. 1-25 Ehrough 1-33.

Uren, M. E. and S. J. Jinks. 1976. The Dosimetric Implications of Release to the Aquatic Environnent from Muclear Power Industry." In: Emvironental Toxicity of Aouatic Radionuclides Models and Mechanises, M. H. Filter and 1. H. Stannard, eds., thin Arbor Science Podisters, $/ 5 n$ Arbor, MI.

Wreqa, M. E., S. M. Jinks, M. Cohen, and L. H. Hairr. 1974. 137Cs and 3ics Distribution in Sediment, Hater, and Biota of the Loner hedsori River

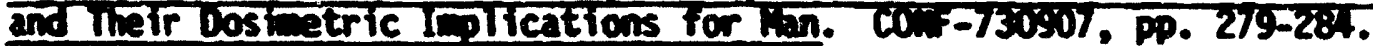

Uren, M. E., J. W. Lentsch, M. Eisenbud, 6. J. Laver, and 6. P. Howells. 1971. Radiocesiu Distribution in Matur, Sedinent, and Biota in Hudson

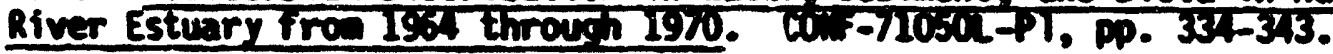

Uruble, D. T., S. D. Shearer, D. E. Rushing and C. E. Sponagle. 1964. Radioactivity in laters and Sediments of the Colorado River Basin, 1950-1953." Rad. Health Data. 5(11):557-567. 
Yabuki, H. and M. Shima. 1973. "Uranium and Other Heavy Elenents in Deep-Sea Sediments Crexisting with Manganese Modules." Sci. Pap. Inst. Phys. Chen. Ris. 67:155-6 (in Japanese).

Yakobenchuk, V. 6. 1968. MRadioactivity and Chemical Properties of Sod-Podzolic Soils in the Ukrainian thestern Polesie." Visn. Sill's' Korosped. Maki. 11:45-50 ('n Ukranian).

Yanomoto, T., E. Yunoki, M. Yamakawa, and M. Shinizu. 1973. "Studies on Environental contamination by Uranium. 3. Effects of Carbonate Ion on Uraniu Adsorption to and Desorption from Soils." J. Radiat. Res. 14:219-224.

Young, R. S. 1957. "The Geochemistry of Cobalt." Geochin. et. Coswochim. Acta. 13:28-41.

Yousef, Y. A., A. Kudo, and E. F. 6loyna. 1970. Radioactivity Transport in Heter: Si Aary Report. ORO-490-20.

Zirino, A. and S. Yamanoto. 1972. "A pH-Dependent Model for the Chemical Speciation of Copper, Zinc, Camiun and Lead in Seawater." Lim. and Ocean. 17(5):661-67i.

Zirino, A. and M. L. Healy. 1970. "Inorganic Zinc complexes in Seawa'er." Lifi. and Ocean. 15(6):956-958.

Whatiable for purchiase from the MRC/GPO Sales Program, U.S. Muclear Regulatory Comission, Mashington, DC 20555, and the Mational Technical Information Service, Springfield, VA 22161. 
11
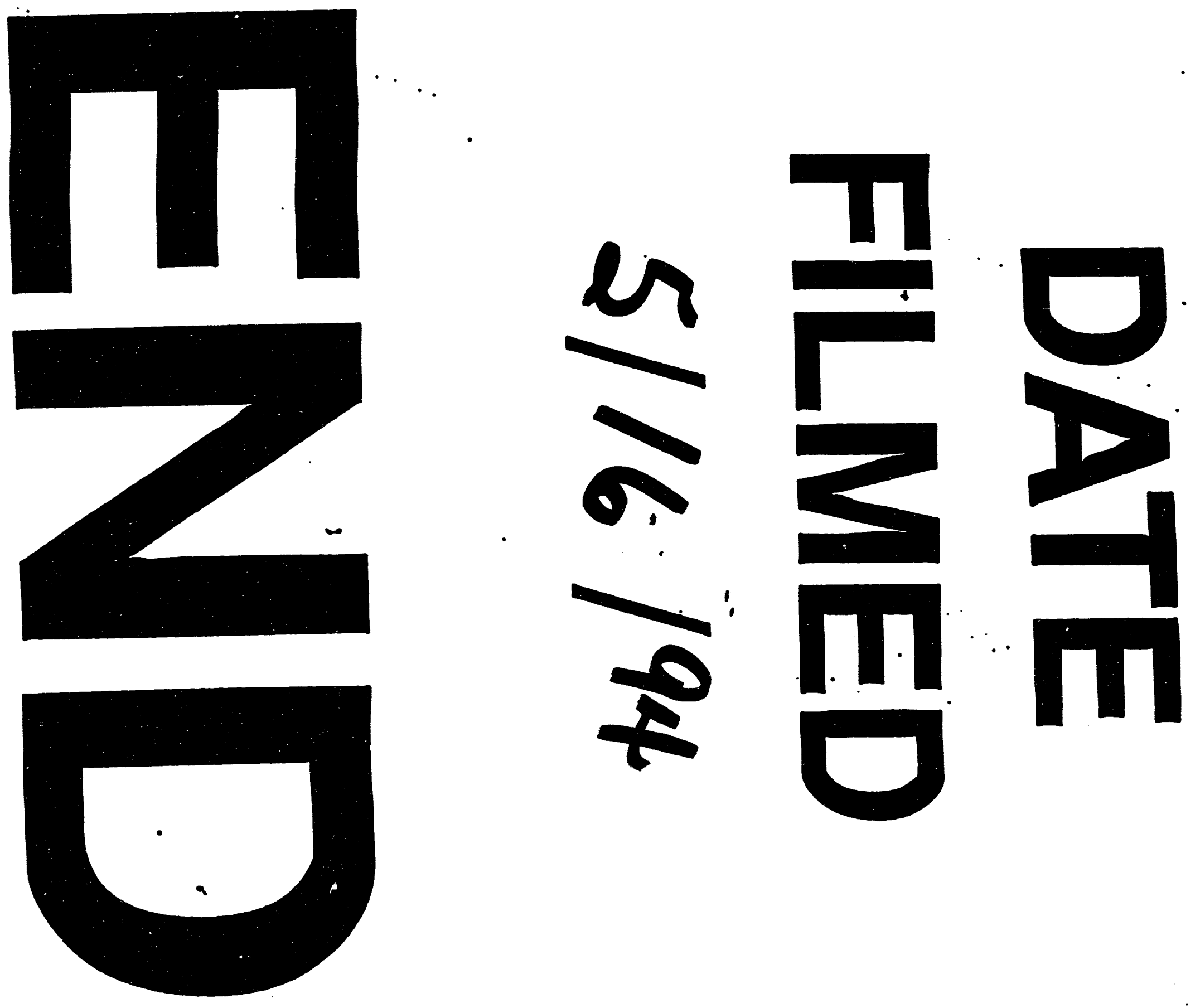


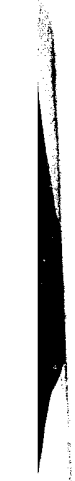

